Universidad Politécnica de Cartagena

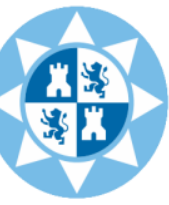

Universidad Politécnica de Cartagena
Campus

de Excelencia Internacional
Avances en baterías de Zinc:

Desarrollo de nuevos geles poliméricos y caracterización y evaluación de electrodos de $\mathrm{Zinc} / \mathrm{Bi}_{2} \mathrm{O}_{3}$.

Programa de Doctorado: Energías Renovables y Eficiencia Energética

SurE's BATrRRx.-Each cell consists of two plates of Fo. 215. zinc and one of silver suspended between them. They aro elamped together with screws and hung in a glass jar filled with diluto sulphuric acid. Since bubbles of hydrogen gas tend to collect on the smooth surface of the silver and interrupt the action, it is roughened with fincly-divided platinum.

Grove's BAxtrRX is a "two-fluid battery." The outer or glass jar contains dilute sulphuric acid, in which is placed a hollow zine cylinder with a slit at the side to allow a free eireulation of the liquid. The inner cup is of porous earthenware, and filled with strong nitric acid (aqua fortis), in which is suspended a thin strip of platinum.*

Fto. 210.

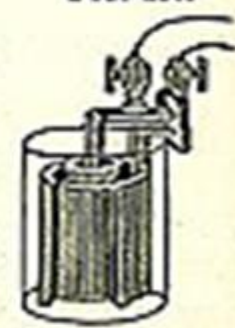

BuAsex's Batrery differs from Grove's in substituting a carbon rod for the platinum strip in the inner cup. This, being an excellent conductor, answers the same purpose and is cheaper. 



\section{Aniversidad | Campus \\ (3) Politécnica de Excelencia de Cartagena Internacional \\ UNIVERSIDAD POLITÉCNICA DE CARTAGENA}

\section{DEPARTAMENTO DE INGENIERIA QUÍMICA Y AMBIENTAL}

Programa de doctorado en

Eficiencia Energética y Energías Renovables

Avances en baterías de Zinc: Desarrollo de nuevos geles poliméricos y caracterización y evaluación de electrodos de $\mathrm{Zinc} / \mathrm{Bi}_{2} \mathrm{O}_{3}$.

\section{Tesis Doctoral}

Presentada por

Florencio Santos

Licenciado en Ciencias Químicas por la Universidad de Murcia

para obtener el título de Doctor

por la

Universidad Politécnica de Cartagena

Director de tesis

Antonio J. Fernández Romero

Prof. Dr. Ingeniería Química y Ambiental

Cartagena, Murcia, Octubre de 2019 


\section{Prólogo}

Florencio Santos Cutillas

COMITÉ DE 
Prólogo

Florencio Santos Cutillas

COMITÉ DE D: 


\section{Prólogo}
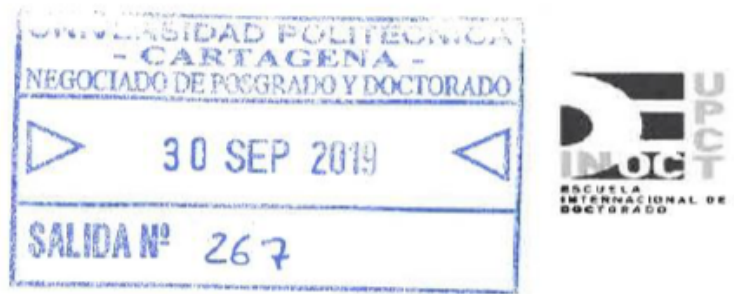

Sr. D. Florencio Santos Cutillas

Visto el informe favorable del Director de Tesis y el $\mathrm{V}^{\circ} \mathbf{B}^{\circ}$ de la Comisión Académica del Programa de Doctorado "Energías Renovables y Eficiencia Energética" para la presentación de la Tesis Doctoral titulada: "Avances en baterías de Zinc: desarrollo de nuevos geles poliméricos y caracterización y evaluación de electrodos de Zinc/Bio ${ }_{2} \mathrm{O}_{3}$ " solicitada por D. FlORENCIO SANTOS CUTILlaS, el Comité de Dirección de la Escuela Internacional de Doctorado de la Universidad Politécnica de Cartagena, en reunión celebrada el 30 de septiembre de 2019, considerando lo dispuesto en el artículo 23 del Reglamento de Estudios Oficiales de Doctorado de la UPCT, aprobado en Consejo de Gobierno el 17 de diciembre de 2015,

\section{$A C U E R D A$}

Autorizar la presentación de la Tesis Doctoral a D. Florencio Santos Cutillas en la modalidad de "compendio de publicaciones".

Contra el presente acuerdo, que no agota la vía administrativa, podrá formular recurso de alzada ante el Sr. Rector-Magnífico de la Universidad Politécnica de Cartagena, en el plazo de un mes a partir de la notificación de la presente.

Cartagena, 30 de septiembre de 2019

EL DIRECTOR DE LA ESCUELA INTERNACIONA $\angle$ DE DOCTORADO

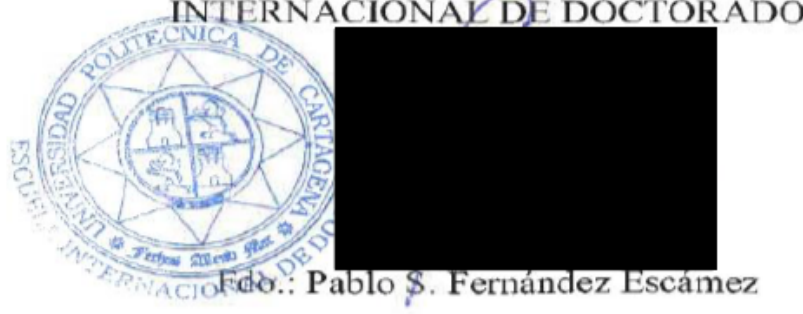


A mis padres, Carmen y Julián

Toda la sabiduría humana se resume en dos palabras: espera y esperanza. All human wisdom is summed up in two words: wait and hope.

Alexandre Dumas 


\section{Prólogo}

Florencio Santos Cutillas

\section{Preámbulo y agradecimientos.}

La realización de esta tesis ha sido un trabajo arduo y difícil. Las constantes adaptaciones a los diferentes enfoques durante su desarrollo, visitas a otros grupos de investigación o instalaciones científicas, congresos, charlas, etc., me han servido, en estos años, no sólo para profundizar en temas científicos, sino también para mantener presente la importancia del esfuerzo y la perseverancia para lograr tanto metas importantes como pequeños objetivos del día a día. Todo se ha logrado con la participación y el apoyo de muchas personas, de ahí, la importancia de estas palabras de gratitud.

El trabajo realizado en esta tesis ha contado con el apoyo financiero del proyecto español MINECO y AEI/FEDER/UE (Ref. ENE2013-48816-C5-3-R y ENE201679282-C5-5-R). También se agradece la provisión de tiempo de haz por parte del ESRF y el ICMM-CSIC. Gracias a la F. Séneca (Región de Murcia, España; Ref: 19882GERM-15 y 20985/PI/18) .

El autor desea agradecer al Dr. Antonio Fernández Romero por su trabajo de mentor, guía y notable apoyo durante el tiempo que duró este trabajo. No hay palabras para expresar cómo aprecio el esfuerzo que el Dr. Fernández ha puesto en este trabajo.

Al Dr. Antonio Urbina de Yeregui por transmitirme el deseo de ampliar y retener el conocimiento científico y al resto del grupo de Materiales Avanzados para la Producción y Almacenamiento de Energía (MAPAE): José Abad por iluminarme la "oscuridad científica" a la que a veces sucumbí, Javier Padilla por su larga amistad y cooperación, Rodo y Carlos por su compañía durante esta "travesía del desierto". Al Dr. Juan P. Tafur por permitirme tomar el relevo en esta línea de investigación y al Dr. Javier López por los pequeños e importantes detalles científicos que, a lo largo de los años, me ha revelado y que de otra manera habrían sido difíciles de adquirir.

El autor agradece también al Departamento de Ingeniería Química y Ambiental de la Universidad Politécnica de Cartagena y al Servicio de Apoyo a la Investigación 
Tecnológica del SAIT por la disponibilidad encontrada en todo momento para realizar los diferentes análisis.

Además, el autor desea recordar al Dr. Toribio Fernández Otero por la oportunidad que me dio, hace unos años, de iniciar mi viaje personal en el mundo electroquímico.

A Juan Albaladejo por la fabricación de los diferentes dispositivos electroquímicos y su valiosa ayuda para resolver problemas triviales pero molestos.

Por último, quiero expresar también mi sincero agradecimiento a todas las personas que, en mayor o menor medida, han colaborado conmigo a lo largo de los años de diferentes maneras, pero en todo caso importante para mí.

Un agradecimiento especial a mí querida familia por su apoyo incondicional, aliento y amor, que he recibido de ellos.

A todos vosotros, gracias de nuevo. 


\section{Prólogo}

\section{Declaración del autor.}

Por la presente declaro que soy el único autor de esta tesis. Ésta, es una copia fiel de la tesis, incluyendo la revisión final requerida tal y como ha sido aceptada por mi director.

Entiendo que mi tesis puede estar disponible electrónicamente para el público y que no he utilizado más que las fuentes y/o recursos declarados, y que he marcado o citado explícitamente todo el material utilizado, ya sea literalmente o por el contenido de la fuente utilizada. 
Dedicación.

Me gustaría dedicar este trabajo a los siete magníficos: Vicente, Cáelán, Óscar, Iobhar, Mariche, Éire y Áedán y por supuesto a mis padres, Carmen y Julián. 


\section{Prólogo}

Florencio Santos Cutillas

\section{RESUMEN.}

Las baterías recargables han estado en el centro de atención de los investigadores en la búsqueda de fuentes de energía renovables, sostenibles, baratas y cómodas. Hasta la fecha, la batería de iones de litio son las más comercializadas hasta el momento y se han utilizado para alimentar dispositivos electrónicos y vehículos híbridos y eléctricos. Sin embargo, en la actualidad, las baterías de iones de litio no satisfacen las expectativas de energía y los requisitos de energía, junto con los problemas de seguridad en los que están involucrados, limita su uso en servicios críticos. Las baterías de metal y aire se han convertido en sistemas alternativos o complementarios por sus altas densidades de energía y una configuración de celda simple.

Por otro lado, el óxido de bismuto es un semimetal con enlace covalente. El $\mathrm{Bi}_{2} \mathrm{O}_{3}$ manifiesta una capacidad práctica comparable al valor teórico, capacidad de descarga excepcional y buena "ciclabilidad". Sin embargo, excepto como aditivo en los ánodos de baterías alcalinas para suprimir la evolución del hidrógeno, la aplicación de bismuto y sus óxidos en baterías se ha ignorado durante décadas. En este trabajo ánodos de zinc con distintas cantidades de óxido de bismuto han sido estudiados espectroscópica y electroquímicamente. En este sentido, además, últimamente se ha abierto una nueva línea de investigación utilizando $\mathrm{Bi}_{2} \mathrm{O}_{3}$ como material activo en los ánodos de zinc-aire.

Los electrolitos poliméricos gelificados para sistemas electroquímicos (GPEs) se desarrollaron para reemplazar los electrolitos líquidos con el fin de evitar fugas y problemas de seguridad, entre otros, durante su funcionamiento. Los GPEs de PVA dopados con $\mathrm{KOH}$ se han estudiado y probado exhaustivamente en baterías, pero apenas se han probado en baterías de zinc-aire. En este trabajo se ha utilizado un amplio espectro de técnicas experimentales en la caracterización de los GPEs. Es de destacar el cambio en los valores de conductividad obtenidos en geles de PVA-KOH cuando han sido sumergidos en disolución de $\mathrm{KOH}$ concentrada (12M). A partir de los resultados experimentales posteriores, este trabajo examina, basándose en el 
mecanismo de Grotthus, los buenos valores de conductividad para estos GPEs y el rendimiento de éstos en baterías de zinc-aire.

En la misma línea, se han investigado GPEs de PVdF-HFP en baterías de Zn $\mathrm{MnO}_{2}$ con distintos líquidos iónicos y diferentes cantidades en sal de triflato. Los ánodos de zinc de estas baterías fueron analizados en distintos estados de cargadescarga, por medio de espectroscopia fotoelectrónica de rayos de $\mathrm{X}$ de alta energía, difracción de rayos X y XPS convencional. Se evidenció la presencia de $\mathrm{Zn}(\mathrm{OH})_{2}$ previamente a la formación de la capa pasivante de $\mathrm{ZnO}$, durante la descarga, y antes de la formación del Zn metal, durante la recarga. Este hecho nos permitió proponer un mecanismo de reacción en el electrodo, y al mismo tiempo, mediante ATR-FTIR confirmar la migración del anión triflato.

Además, en este documento, se establecerá una descripción detallada de las baterías metal-aire, específicamente para las baterías zinc-aire, incluidos los principios básicos de funcionamiento y los últimos avances en su desarrollo. 


\section{Prólogo}

Florencio Santos Cutillas

\section{ABSTRACT.}

Rechargeable batteries have attracted much attention from the researchers in the search for renewable, sustainable, cheap and convenient energy sources. Up to date, lithium-ion battery is the most marketable so far and has been used to power electronic devices and hybrid and electric vehicles. Lithium-ion batteries, however, do not, nowadays, satisfy the expectations of energy and power requirements, together with the encompassing safety issues in which they have been involved limits their use in critical services. Thus, metal-air batteries have become an alternative or complementary battery systems for its high energy densities and a simple cell configuration.

On the other hand bismuth oxide Bismuth is a semimetal with covalent bonding. The $\mathrm{Bi}_{2} \mathrm{O}_{3}$ manifests a high practical capacity comparable to the theoretical value, outstanding rate capability and good performance. Nevertheless, except as an additive in alkaline battery anodes to suppress hydrogen evolution, the application of bismuth and its oxides in batteries has been ignored for decades. In this sense a new research line has been followed using $\mathrm{Bi}_{2} \mathrm{O}_{3}$ as active material in zinc-air anodes.

Polymer electrolytes for electrochemical systems were developed to replace liquid electrolytes to prevent leakages and safety concerns during operation, among others. PVA-KOH doped GPEs has been extensively studied and tested in batteries but have rarely been tested on zinc-air batteries. A wide range of experimental techniques have been used in this work in order to characterize PVA-KOH GPEs. Conductivity values increased when PVA-KOH GPEs were soaked in concentrated $\mathrm{KOH}$ solutions (12M). The latest was examined, based on the Grotthus mechanism. The good conductivity values obtained for this GPEs gave out real interesting performance in a zinc-air battery.

In line with the foregoing on GPEs, PVdF-HFP based GPEs were investigated in $\mathrm{Zn} / \mathrm{MnO}_{2}$ batteries using several ionic liquids and different zinc triflate contents. The study of zinc anodes at different states of charge and discharge, on the same type of batteries, PVdF-HFP based GPEs wit IL and $\mathrm{Zn}(\mathrm{TF})_{2}$, by hard x-ray photoelectron 
spectroscopy (HAXPES) and X-ray diffraction using synchrotron radiation as werl as conventional XPS, showed the presence of $\operatorname{Zinc}(\mathrm{OH})_{2}$ previously to the formation of a passivizing $\mathrm{ZnO}$ layer, what allowed us to propose a mechanism where it is clear that $\mathrm{Zn}-\mathrm{ZnO}$ conversion through $\mathrm{Zn}(\mathrm{OH})_{2}$ formation exists. Besides, ATR-FTIR spectroscopy showed triflate migration during the discharge and charge processes.

In addition, herein, detailed description of metal-air battery system, specifically for zinc-air battery, will be established including basic principles of operation and latest advances in its development. 


\section{Prólogo}

Florencio Santos Cutillas

\section{MOTIVACIÓN.}

El objetivo principal de cualquier investigador que trabaje en el sistema zincaire es obtener una batería recargable que, posteriormente, se pueda usar comercialmente en vehículos eléctricos u otros dispositivos electrónicos ${ }^{11}$. Las ventajas del uso de la batería de zinc-aire se derivan de la disponibilidad de materias primas, de la alta densidad energética teórica, así como de la seguridad e inocuidad medioambiental. Este objetivo principal puede abarcar varios objetivos parciales, cada uno relacionado con los componentes principales de la batería de zinc-aire, a saber: ánodo, electrolito, electrodo de aire o relacionado con una cuestión específica que podría mejorar el rendimiento de una batería de zinc-aire. Por lo tanto, el propósito de esta tesis es mejorar aún más el rendimiento de las baterías de metal-aire actuando sobre el ánodo, el electrolito y/o el electrodo de aire.

En la actualidad, el sistema zinc-aire sigue siendo un campo de investigación de gran interés. Este tipo de baterías tiene muchos puntos fuertes, como ya se ha mencionado, pero para que su total despliegue comercial sea posible en el futuro, es necesario realizar más mejoras en este campo. Uno de los objetivos es estabilizar la morfología del electrodo de zinc durante los procesos electroquímicos, ciclos de carga y descarga, la cual es modificada durante el funcionamiento de la batería. El óxido de bismuto ha sido estudiado como aditivo, en este tipo de baterías, extensamente, tanto en el electrolito como en el ánodo. En nuestro caso, hemos mezclado óxido de bismuto y zinc, en diferentes proporciones, y hemos estudiado cómo el óxido de bismuto dentro del electrodo, afecta al comportamiento del ánodo.

Para realizar el estudio del ánodo se ha diseñado y fabricado una celda electroquímica con las características necesarias para ser utilizada en un difractómetro de rayos X utilizando la técnica de "gracing incidence difraction" disminuyendo de esta manera la cantidad de electrolito que debe atravesar el haz antes y después de incidir sobre el electrodo metálico. La celda fue utilizada exitosamente bajo condiciones reales de funcionamiento, o “in-operando”, en baterías de zinc-aire con electrolito líquido. 


\section{Prólogo}

Florencio Santos Cutillas

Por otra parte, la obtención de baterías recargables de zinc-aire con aplicabilidad real necesitan de la solución de diferentes problemas, que están descritos en la bibliografía. Entre ellos destaca que las baterías de zinc-aire, como sistema abierto, tienen interacciones estrechas con el entorno circundante. Una humedad demasiado baja puede provocar el secado gradual del electrolito o una humedad demasiado alta puede inundar el electrodo de aire, lo cual es perjudicial para el rendimiento de la batería. Además, se ha observado frecuentemente el crecimiento de las dendritas. Al mismo tiempo, se pretende que sean fácilmente procesables, sin problemas de fugas, sin problemas de seguridad y tengan una amplia estabilidad electroquímica.

Con el fin de aportar algunas mejoras a estos inconvenientes, se han explorado el uso de electrolitos poliméricos en fase gel "Gel Polymer Electrolytes" GPEs. Se han preparado dos tipos de GPEs, por una parte, los GPEs basados en PVA dopados con $\mathrm{KOH}$ que fueron probados en baterías de Zinc-aire y por otro lado se han sintetizado también GPEs basados en PVdF-HFP con diversas concentraciones de ZnTf 2 y diferentes líquidos iónicos ("ionics liquids", ILs), con lo que se pretendía disminuir la influencia del vapor de agua sobre el funcionamiento de la batería.

La reacción de reducción de oxígeno (ORR) es probablemente la reacción más importante en procesos vitales como la respiración celular, y en sistemas de conversión de energía como las pilas de combustible y las baterías de metal-aire. Este es el motivo por el que en un futuro, aunque ya hemos realizado algún trabajo preliminar con $\mathrm{Cr}_{2} \mathrm{O}_{3}$, nos centraremos en el desarrollo de electro-catalizadores para la reacción de reducción de oxígeno (ORR). Estos electrocatalizadores se utilizan en el electrodo de aire de las baterías de zinc-aire. El estudio de la reacción de evolución del oxígeno (OER), sería también de mucho interés, ya que ésta es necesaria que ocurra en electrodos de aire bifuncionales en baterías secundarias o recargables de zinc-aire.

Con esto último se cierra el círculo de los componentes clave, además de los separadores, sobre los que se puede realizar investigación básica volviendo a la motivación principal mencionada al inicio de este epígrafe. 
Florencio Santos Cutillas

\section{ORGANIZACIÓN DE TESIS.}

Esta tesis se ha organizado en tres bloques. El primero comprende una visión general, parte teórica y metodología experimental, Capítulos I-III; el segundo muestra todos los resultados experimentales obtenidos durante la investigación, Capítulos IVVII y el tercero incorpora las conclusiones y perspectivas futuras, Capítulo VIII.

El CAPÍTULO I, Introducción y Panorama General, presenta una introducción general y un breve repaso histórico del desarrollo del sistema zinc-aire. También se esbozan los objetivos y el alcance de la presente investigación.

El CAPÍTULO II, Revisión Teórica y Bibliográfica, traza un cuadro del “estado del arte” o tecnología de vanguardia, así como establece el marco teórico en el que se llevará a cabo esta investigación.

El CAPÍTULO III, Metodología Experimental, trata de la preparación de electrolitos por el método "solutión casting method" y de los detalles de los instrumentos y metodología utilizados para las distintas caracterizaciones. Describe en profundidad aspectos experimentales relacionados con esta investigación.

El CAPÍTULO IV, "Influence of the Ionic Liquid Type on the Gel Polymer Electrolytes Properties", resume el estudio comparativo de los GPEs basados en PVdF-HFP/ZnTf2 con tres IL diferentes. Se obtienen diferentes comportamientos estructurales y eléctricos de los GPEs cuando no se añade sal o se añade una baja concentración dela misma a la membrana de PVdF- HFP. Una vez que se alcanza una cantidad mínima umbral de $\mathrm{Tf}_{2}$, el comportamiento de los GPEs no cambia, independientemente del tipo de IL añadido.

CAPÍTULO V, “A synchrotron $X$-ray diffraction and hard $X$-ray photoelectron spectroscopy study of $\mathrm{Zn}$ negative electrodes at different charge and discharge states of $\mathrm{Zn} / \mathrm{MnO}_{2}$ batteries using an ionic liquidbased gel polymer electrolyte" .Este estudio de difracción de rayos X y espectroscopia de fotoelectrones de rayos $\mathrm{X}$ usando radiación sincrotrón de electrodos negativos de $\mathrm{Zn}$ a diferentes estados de carga y descarga de baterías de $\mathrm{Zn} / \mathrm{GPE} / \mathrm{MnO}_{2}$ 


\section{Prólogo}

Florencio Santos Cutillas

utilizando un electrolito de gel polimérico de PVdF-HFP con BMIM-TFSI y ZnTf2 , dilucida el mecanismo químico que ocurre en el ánodo durante el proceso de carga y descarga utilizando espectroscopia fotoelectronica de rayos X (HAXPES) y espectroscopía XRD. La espectroscopia XPS convencional y ATR-FTIR también se han utilizado para completar el estudio. Se comentarán los resultados proponiendo un mecanismo de reacción durante los procesos de carga y descarga, el cual incluye la formación de $\mathrm{Zn}(\mathrm{OH})_{2}$ además de $\mathrm{ZnO}$.

CAPÍTULO VI, "In situ synchrotron x-ray diffraction study of $\mathrm{Zn}$ / $\mathrm{Bi}_{2} \mathrm{O}_{3}$ electrodes prior to and during discharge of $\mathrm{Zn}$-air batteries: Influence on ZnO deposition". Este estudio de difracción de rayos $\mathrm{X}$ con radiación sincrotrón de los electrodos de $\mathrm{Zn} / \mathrm{Bi}_{2} \mathrm{O}_{3}$ antes y durante la descarga de las baterías de Zn-air, revela que se genera un depósito de Bi metálico en el electrodo negativo de los electrodos de $\mathrm{Zn} / \mathrm{Bi}_{2} \mathrm{O}_{3}$ mediante el uso de análisis de difracción XRD y otras mediciones electroquímicas y espectroscópicas. La reducción espontánea, dentro del electrodo, de $\mathrm{Bi}^{3+}$ a Bi metálico ocurre antes de la descarga. Además, la formación de Bi metálico continúa durante la descarga de la batería. El uso de pequeñas cantidades de $\mathrm{Bi}_{2} \mathrm{O}_{3}$ en electrodos negativos forma un depósito metálico inestable de $\mathrm{Bi}$ junto con una capa de $\mathrm{ZnO}$. Sin embargo, el uso de cantidades mayores de $\mathrm{Bi}_{2} \mathrm{O}_{3}$ en los electrodos negativos iniciales proporciona un depósito masivo de Bi metálico estable.

CAPÍTULO VII, "Structural modifications and ionic transport of PVA-KOH Hydrogels applied in Zn/air batteries”. Conocimiento más profundo sobre la configuración estructural y las propiedades de transporte iónico de los hidrogeles PVA-KOH para su aplicación en baterías de Zn/aire, muestra la utilidad de las membranas de PVA-KOH, sintetizadas por un sencillo método, como GPE en baterías de Zn/PVA-KOH/aire. Las técnicas XRD, ATR-FTIR y TGA han confirmado la reestructuración de las cadenas de PVA cuando se incluyó una solución acuosa de $\mathrm{KOH}$ en la membrana. Además, cuando estas membranas se sumergen en una solución acuosa de $\mathrm{KOH} 12 \mathrm{M}$, se incorporan a la membrana una mayor cantidad de moléculas de $\mathrm{KOH}$ y $\mathrm{H}_{2} \mathrm{O}$, lo que mejora los cambios en la estructura del polímero y sus 


\section{Prólogo}

capacidades, cuando se emplean en descargas de baterías de zinc-aire. Finalmente se explica el aumento de la conductividad teniendo en cuenta el mecanismo Grotthus.

En el CAPÍtulo VIII, Conclusiones y trabajos futuros, se revisa brevemente el resumen de todos los resultados presentados en esta investigación, junto con las conclusiónes y futuras perspectivas. 


\section{CONTENIDO}

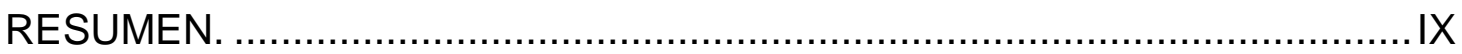

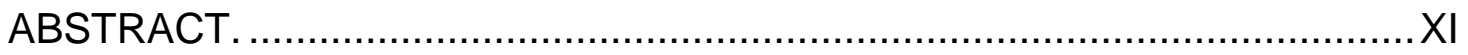

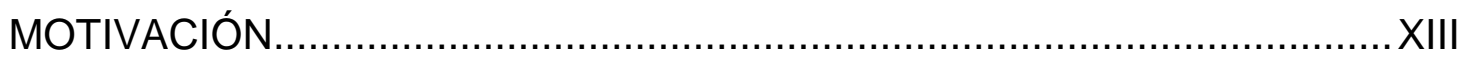

ORGANIZACIÓN DE TESIS. ............................................................ XV

\section{CAPÍTULO I. Introducción y Panorama General.}

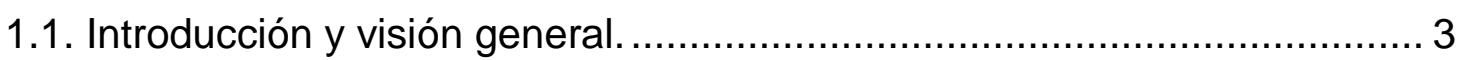

1.2. Breve historia del sistema zinc-aire............................................. 11

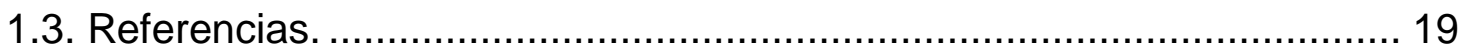

CAPÍTULO II. Revisión Teórica y Bibliográfica.

2.1. La batería de zinc-aire.................................................................. 25

2.1.1.Clasificación de las baterías de zinc-aire ..................................... 25

2.1.2.Ventajas y desventajas de una batería de zinc-aire. ...................... 26

2.1.3.Construcción de una batería de zinc-aire. .................................... 27

2.1.3.1.El ánodo de zinc............................................................... 27

2.1.3.2.El electrolito................................................................. 30

2.1.3.3.El separador........................................................... 30

2.1.3.4.El cátodo (electrodo de aire). ........................................ 31

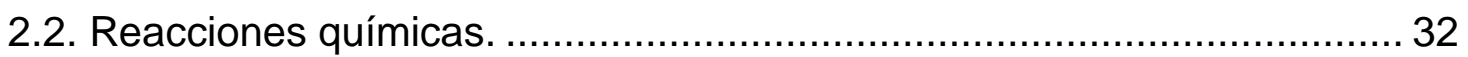

2.3. Electrolitos de geles poliméricos. ............................................ 36

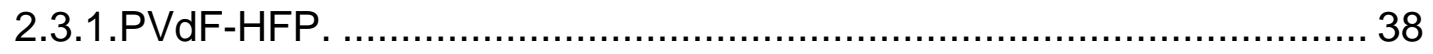

2.3.2.Líquidos iónicos. .............................................................. 45

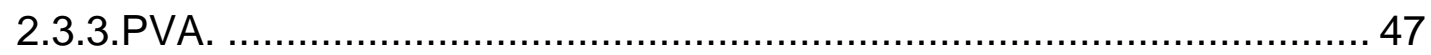

2.3.3.1. Hidrogeles de PVA. ........................................................ 48 


\section{Prólogo}

Florencio Santos Cutillas

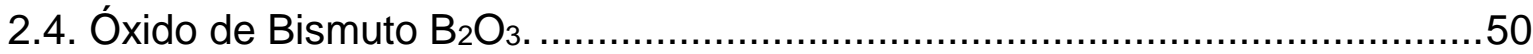

2.5. Reacción de reducción de oxígeno (ORR) ................................................52

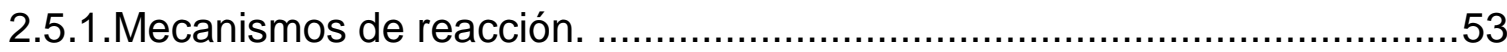

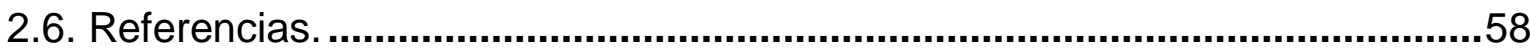

\section{CAPÍTULO III. Metodología Experimental.}

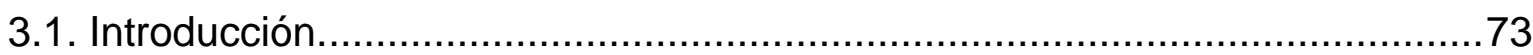

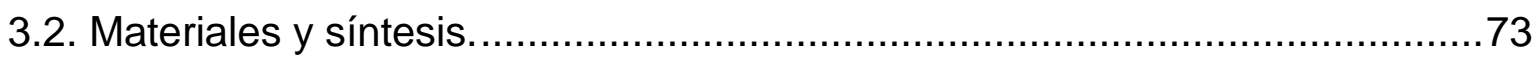

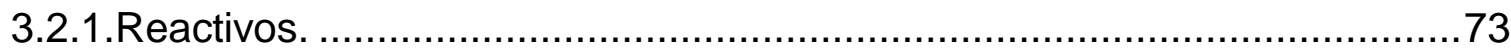

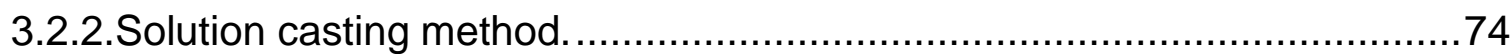

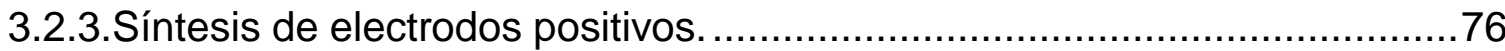

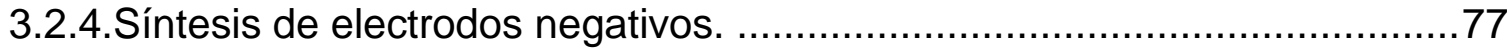

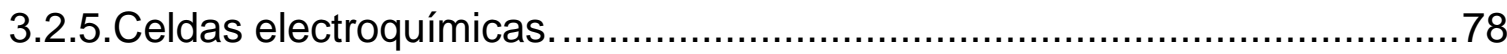

3.3. Técnicas de caracterización físico-química.................................................79

3.3.1.Microscopía Electrónica de Barrido...........................................................79

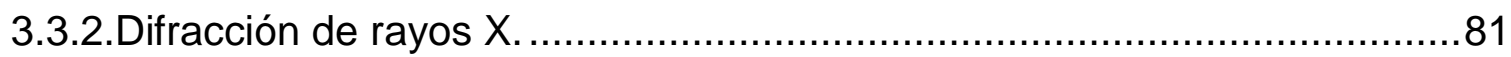

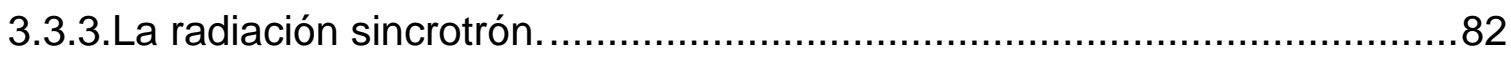

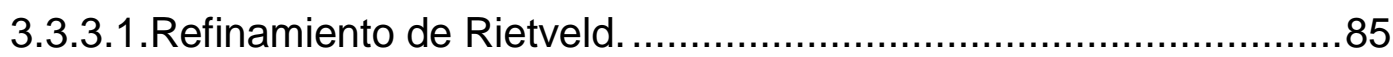

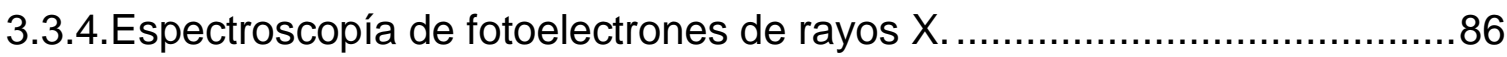

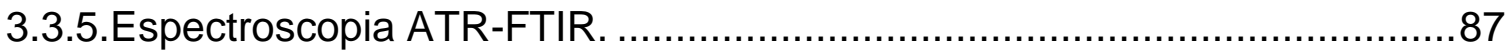

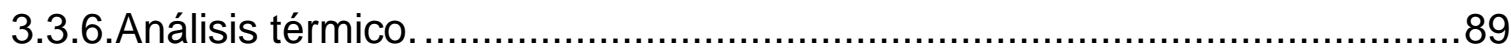

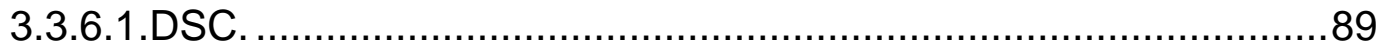

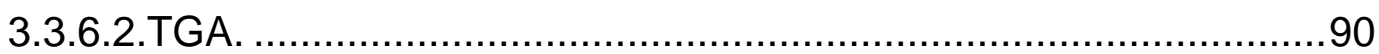

3.4. Técnicas de caracterización electroquímica.............................................91

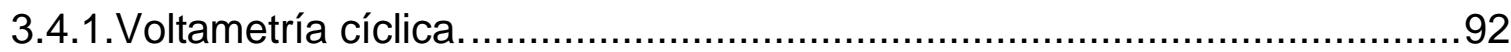

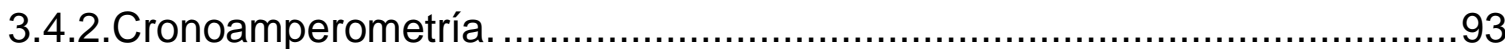




\section{Prólogo}

Florencio Santos Cutillas

3.4.3.Espectroscopía de impedancia. .......................................... 94

3.4.4.Carga y descarga galvanostática........................................96 96

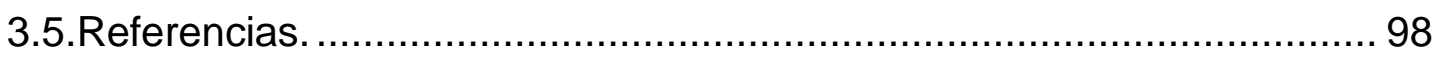

CAPÍTULO IV. Influence of the Ionic Liquid Type on the Gel Polymer Electrolytes Properties.

CAPÍTULO V. A Synchrotron X-Ray Diffraction and Hard X-Ray Photoelectron Spectroscopy Study of Zn Negative Electrodes at Different Charge and Discharge States of $\mathrm{Zn} / \mathrm{MnO}_{2}$ Batteries Using an Ionic LiquidBased Gel Polymer Electrolyte.

CAPÍTULO VI. In Situ Synchrotron X-Ray Diffraction Study of $\mathrm{Zn} / \mathrm{Bi}_{2} \mathrm{O}_{3}$ Electrodes Prior to and during Discharge of Zn-Air Batteries: Influence on ZnO Deposition. 135

CAPÍTULO VII. Structural Modifications and Ionic Transport of PVA-KOH Hydrogels Applied in Zn/Air Batteries.

CAPÍTULO VIII. Conclusiones y Perspectivas Futuras. .171

Anexo I. Lista de Tablas.

Anexo II. Lista de Figuras.

Anexo III. Publicaciones.

201

Anexo IV. Abreviaturas. 209

Anexo V. Índice de Impactos.

Anexo VI. Notificaciones de Aceptación. 219

Anexo VII. Artículos Impresos. .225 



\section{Introducción y Panorama General.}

"If your experiment needs statistics, you ought to have done a better experiment." 



\subsection{Introducción y visión general.}

Tal y como afirmó Javier Solana, primer alto representante de la Unión Europea para la Política Exterior y de Seguridad Común, en el Foro Nueva Murcia en 2013¹, la nueva población que se incorpore al nivel y modo de vida occidental ejercerá tal presión sobre los recursos de la Tierra que esto supondrá una amenaza para la Tierra tal y como la conocemos hoy en día. En consecuencia, la demanda de energía aumentaría enormemente, lo que fomentaría el agravamiento del calentamiento global. Es un deber de las generaciones actuales satisfacer las necesidades del presente sin poner en peligro la capacidad de las generaciones venideras de satisfacer sus propias necesidades. Teniendo en cuenta este punto de vista, los recursos no renovables se han de limitar en su uso, mientras que los renovables deben tomar el relevo en un futuro próximo, lo que dependerá en gran medida de la tasa de puesta en marcha de nuevas instalaciones que utilicen estos recursos renovables².

El objetivo del Acuerdo de París de que el calentamiento global se mantenga muy por debajo de los $2{ }^{\circ} \mathrm{C}$ de la media preindustrial y se alcance cuanto antes el nivel máximo de GEI (gases de efecto invernadero), así como que se logre la emisión cero en la segunda mitad de este siglo ${ }^{3}$, no parece factible.

La investigación básica y aplicada debe aportar tecnologías que permitan la reducción de la dependencia de los recursos agotables y no renovables, siendo el almacenamiento de energía uno de los retos en curso para alcanzar el "enorme objetivo" de cumplir con el acuerdo de París y, lo que es más importante, proteger nuestra propia existencia como especie en la Tierra. Es un tren que no se puede perder.

La emisión total de gases de efecto invernadero en EE.UU. en 2016, representada en la Figura 1.1-1, muestra que la generación de electricidad y la industria del transporte representan alrededor del $56 \%$ de la cantidad total de GEI. Este hecho indica el enorme impacto que el transporte y la generación de electricidad tienen en las emisiones de GEI y, por consiguiente, en el calentamiento global ${ }^{4}$. El calentamiento global se ha convertido en el mayor desafío al que se enfrenta la humanidad, por lo que es evidente que se tendrá que actuar en estos sectores económicos para reducir o eliminar los GEI. 


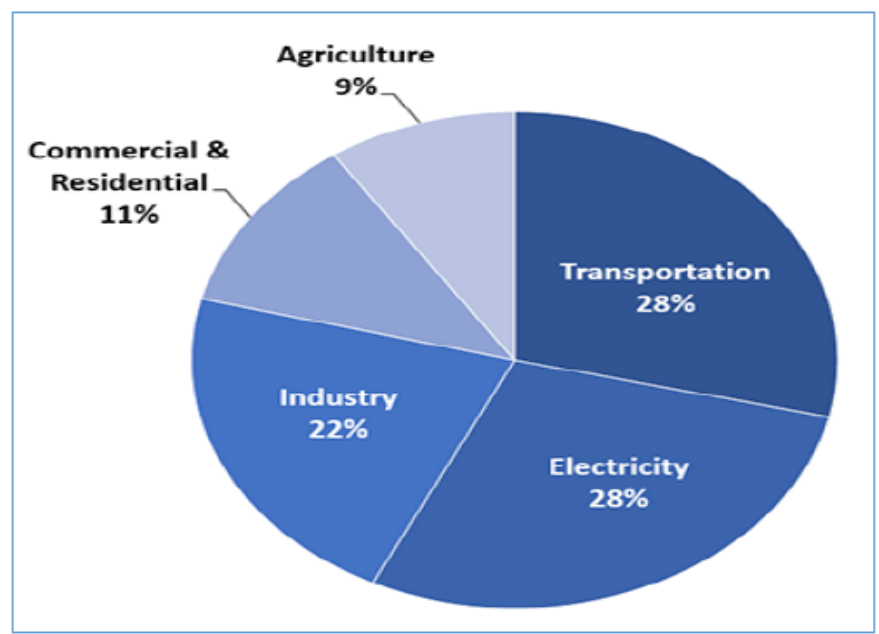

Figura 1.1-1: Emisión total de gases de efecto invernadero en EE.UU. en 2016.

El crecimiento del sector del transporte como resultado de las crecientes actividades económicas en los países en desarrollo, es un factor clave que dará cuenta de la demanda de energía. En consecuencia, se estima que esta aumentará en más de un 11 por ciento por año en promedio en los próximos 20 años, como se muestra en la Figura 1.1-2.5.

Por otra parte, la Figura 1.1-3 se muestra la previsión de la participación de la generación de electricidad renovable por regiones y cómo se generará la electricidad para cumplir con la propuesta 2DS establecida en el acuerdo de París contra el calentamiento global ${ }^{2}$.

En el análisis de las previsiones de generación de energía en el futuro destaca claramente el aumento del uso de fuentes de generación de energía solar y eólica. La base tecnológica de estas fuentes de energía hace que su uso esté unido a factores relacionados con el tiempo meteorológico o atmosférico. Por tanto, la utilidad de estas fuentes alternativas hará imprescindible el desarrollo de nuevos sistemas de almacenamiento de electricidad, que jugarán un papel importante en un futuro sistema eléctrico de bajas emisiones, los cuales, además tendrán que adaptarse a la fluctuante disponibilidad de energía de las tecnologías solar y eólica ${ }^{6}$.En el escenario de 2DS, se estima que se necesitarían $320 \mathrm{GW}$ de almacenamiento en las cuatro regiones consideradas ${ }^{2}$. 


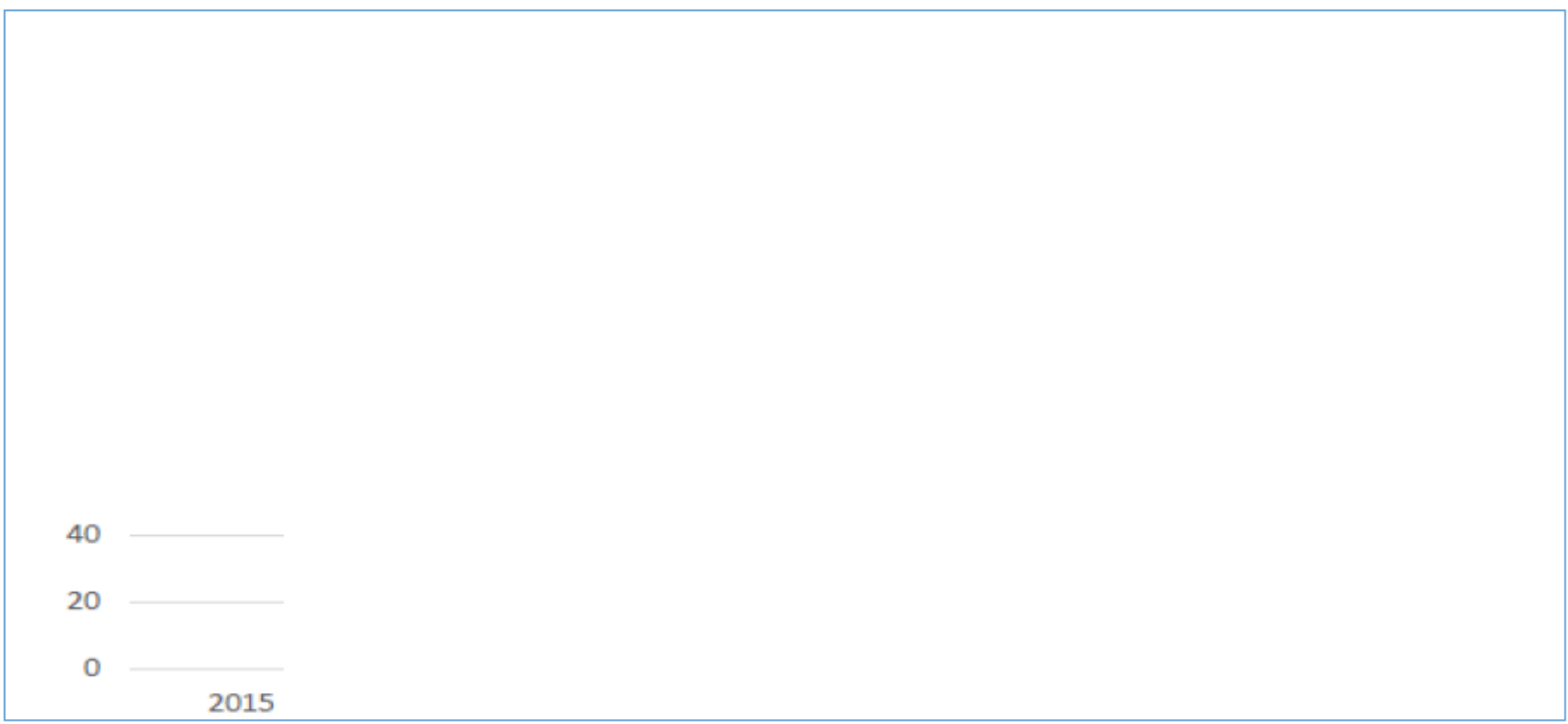

Figura 1.1-2: Aumento previsto del consumo de energía en el sector del transporte. Tomado de la referencia 3.

El almacenamiento mediante saltos de agua, hidroeléctrica, es el método preferible de almacenamiento de energía eléctrica, pero su viabilidad se resiente debido a su naturaleza específica y a los altos costes de capital para su funcionamiento a gran escala7 . El aire comprimido es también una tecnología madura, pero adolece también de la necesidad de una inversión inicial elevada, así como de una geografía favorable, como cavernas, por lo que sólo es económicamente viable para las centrales eléctricas que tienen minas de roca cercanas, cavernas de sal, acuíferos o yacimientos de gas agotados ${ }^{8,9}$. El coste del almacenamiento de aire en tanques artificiales es dos órdenes de magnitud superior al que puede conseguirse con el almacenamiento subterráneo ${ }^{8}$. Estos dos últimos métodos de almacenamiento de energía son muy adecuados como apoyo para la gestión de energía en redes de distribucion ${ }^{6}$.

Las tecnologías de almacenamiento de energía tienen diferentes propiedades intrínsecas que determinan su idoneidad técnica para determinadas aplicaciones. Los tiempos de descarga de los sistemas de almacenamiento en función de los requisitos de potencia asociados, desde $\mathrm{kW}$ hasta $\mathrm{GW}$, ofrece una buena visión general de estas tecnologías en función de los requisitos necesarios. Este gráfico típico se muestra en la Figura 1.1-4 (reimpreso de la referencia 10). 
El diseño futuro de las redes eléctricas debe incluir los sistemas de almacenamiento como un componente importante para la seguridad de la estabilidad del suministro ${ }^{10}$.

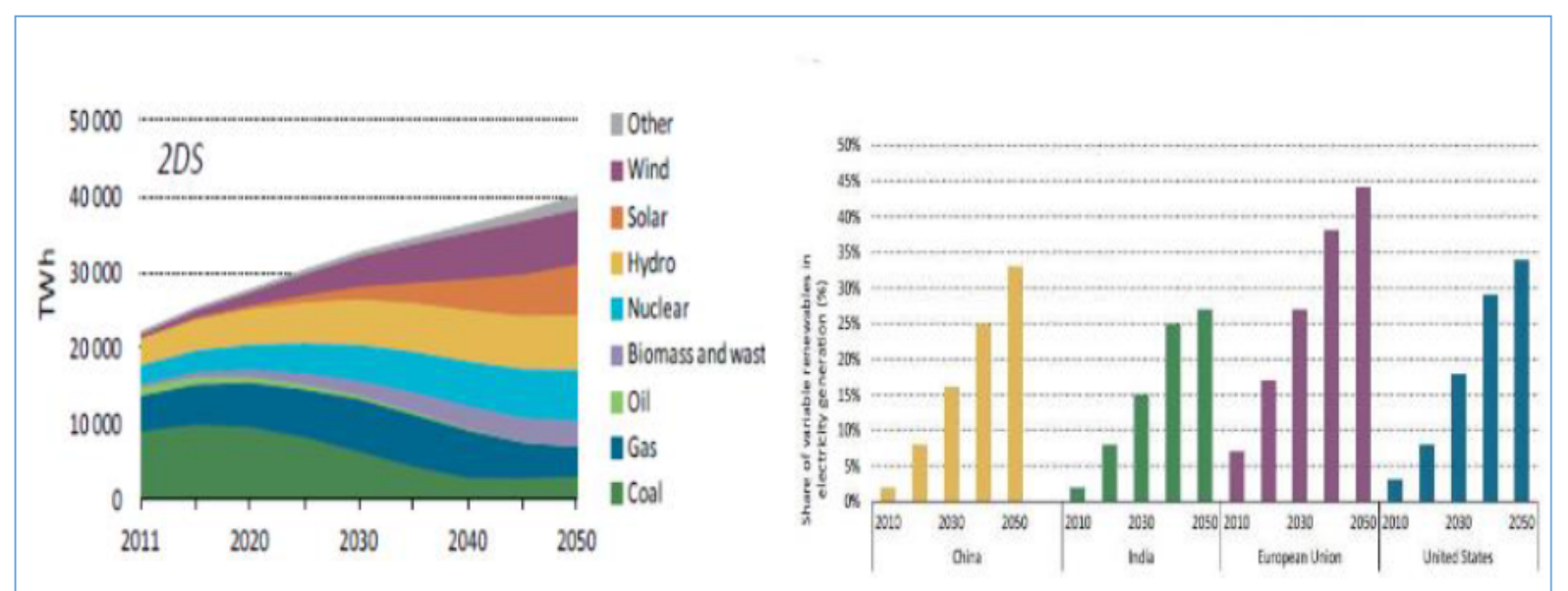

Figura 1.1-3: Generación global de electricidad en la propuesta 2DS, izquierda. \% de energía renovable en la generación de electricidad por regiones, derecha.

Como método alternativo y complementario a los anteriores, el sistema de conversión de energía electroquímica ofrece características atractivas ${ }^{11}$. Las tecnologías de conversión electroquímica -baterías- son una tecnología prometedora que ofrece eliminación y/o reducción de emisiones de GEI, alta eficiencia y sostenibilidad ${ }^{11}$.

También es casi obligatorio mencionar el enorme aumento del tamaño del mercado de los dispositivos microelectrónicos, que exigirá una mayor densidad de energía, fuentes de energía seguras, baratas y fiables ${ }^{12}$, como puede verse en la Figura 1.1-5. Los ingresos han aumentado constantemente desde 1996 y no hay razón para pensar que esta tendencia se vaya a romper a corto plazo. La creciente popularidad de los dispositivos electrónicos portátiles junto con un aumento en los niveles de ingresos del consumidor, especialmente en los países en desarrollo, impulsará aún más el crecimiento de las baterías para el mercado de semiconductores ${ }^{13}$.

Existe una extensa gama de sistemas electroquímicos aplicados en baterías. Dependiendo del material activo de los electrodos y del electrolito usado, se consiguen diferentes tensiones y son capaces de suministrar mayores o menores intensidades de corriente. 
Entre estos sistemas, las baterías de metal-aire han llamado mucho la atención como alternativa a las baterías de iones de litio debido a su alta densidad energética y a la reducción, en teoría, del impacto medioambiental ${ }^{14}$. Son numerosos los metales que se han empleado como ánodos de baterías metal-aire, lo que permite ajustar sus características a una amplia gama de aplicaciones ${ }^{15}$, sin embargo, son las baterías de zinc-aire y litio-aire las que han alcanzado un mayor interés. La primera, aunque tiene una menor densidad energética teórica, $1090 \mathrm{Whkg}^{-1}$ tiene mayor interés por su aplicabilidad, es la única batería metal-aire realmente comercial en la actualidad. Por otra parte, la batería litio-aire tiene una mayor densidad energética teórica, 5200 Whkg-1, pero esta batería sigue teniendo problemas críticos que deben ser abordados para que sea comercialmente viable. Por ejemplo, su capacidad práctica, y su vida útil son algunos de los factores que deben mejorarse ${ }^{16}$.

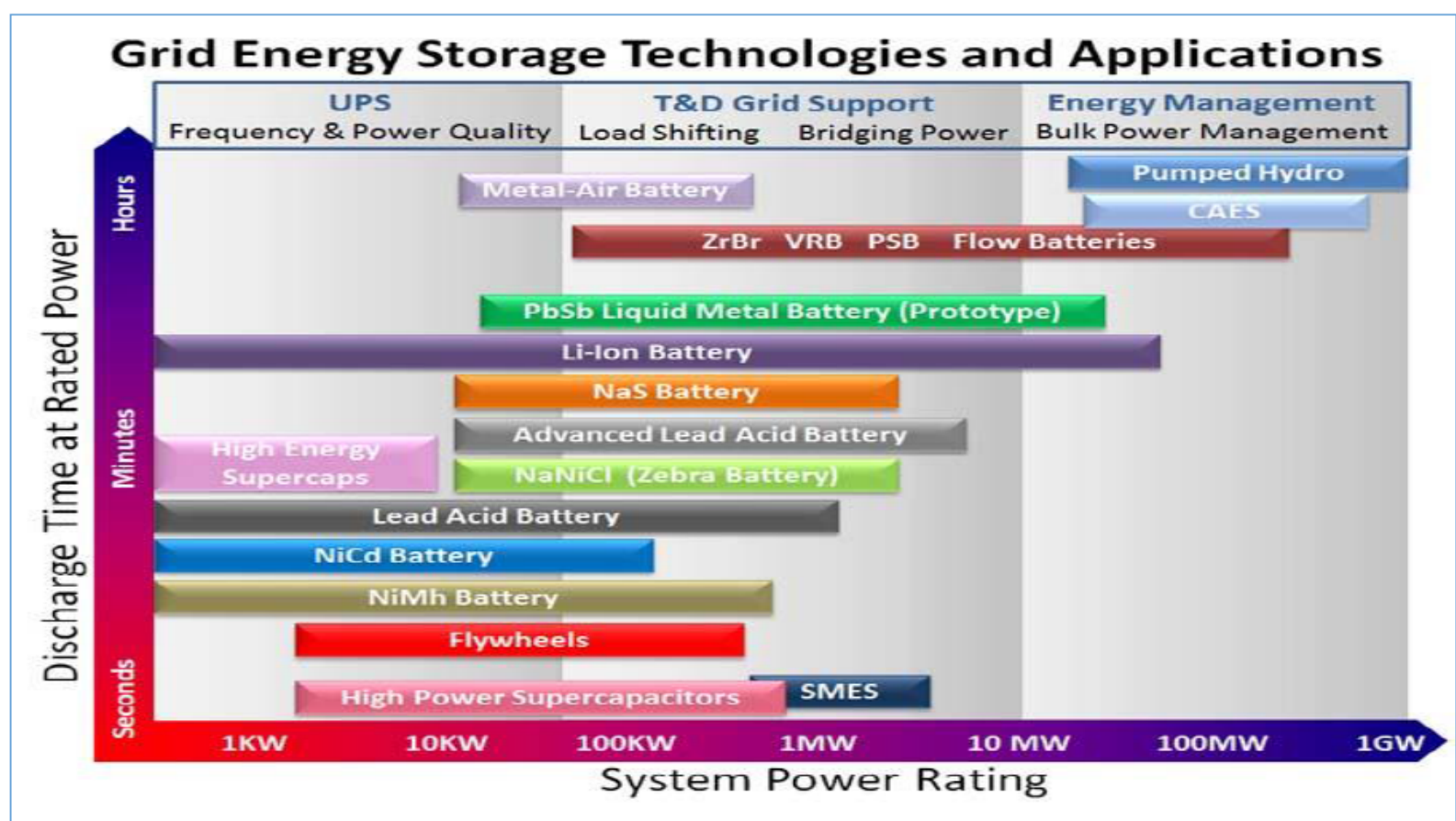

Figura 1.1-4: Posicionamiento de diversas tecnologías de almacenamiento de energía segúm su potencia nominal y tiempos de descarga.

Por otra parte, la tecnología de baterías de metal-aire, independientemente de la selección del electrodo de ánodo, se enfrenta a retos en el electrodo de aire, específicamente no existe todavía un electrodo bifuncional fiable, y se están llevando a 
cabo enormes esfuerzos y asignando enormes recursos para mejorar la reacción de reducción del oxígeno del aire ORR ${ }^{17-19}$.

La pila primaria de zinc-aire está disponible en el mercado desde 1932. Otros sistemas, como las baterías de hierro, magnesio y de aluminio se desarrollaron en los años 60 y, más recientemente, las de sodio, potasio y litio ${ }^{14}$.

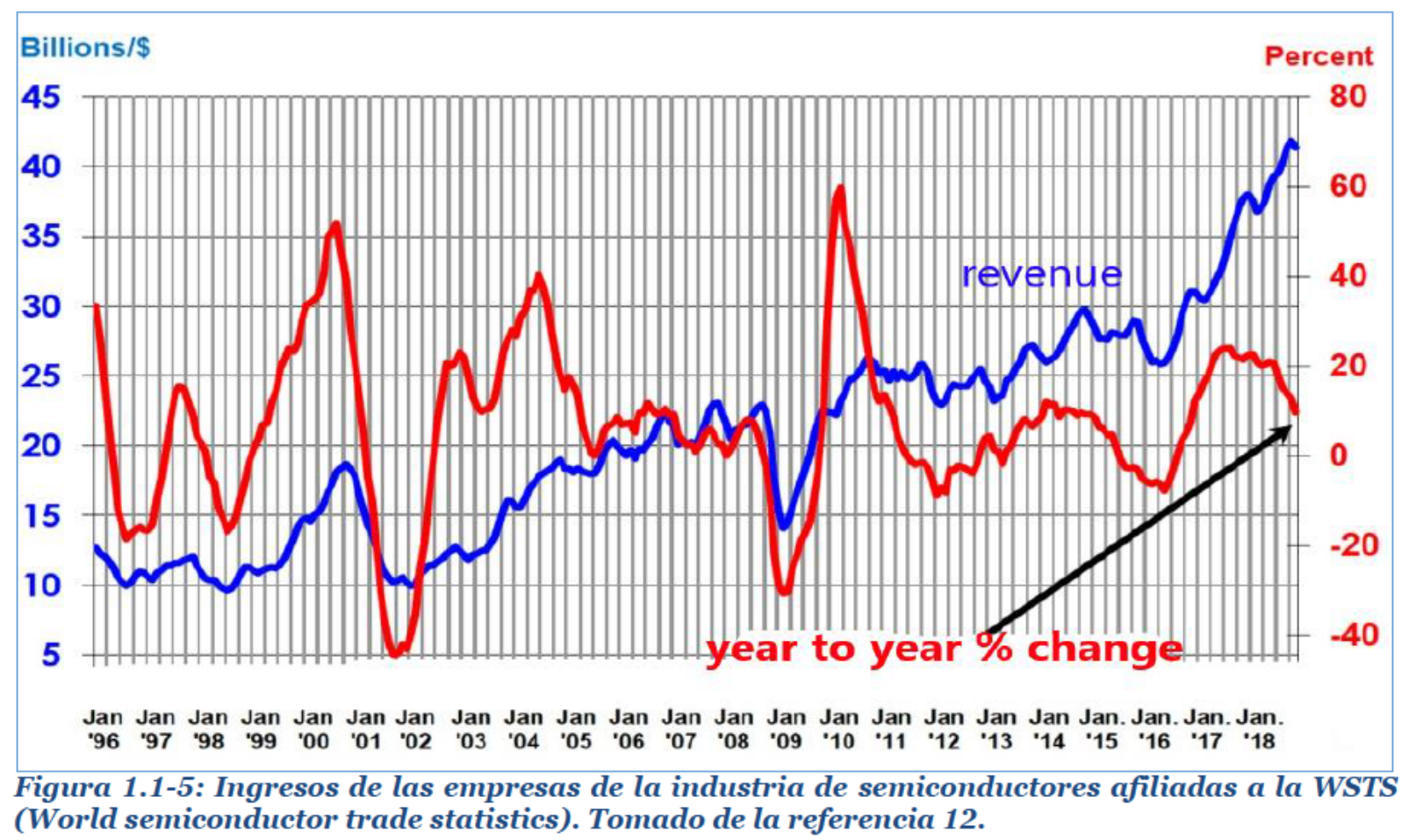

Incluso algunos grupos de investigación están trabajando en baterías de silicioaire $^{20}$. El berilio se ha descartado, por su toxicidad, pero se ha investigado su uso en baterías de aire ${ }^{21}$. En la Figura 1.1-6 se aprecia que la batería de metal-aire muestra claramente densidades de energía mucho más altas en comparación con otras baterías. Esta tremenda densidad de energía de las baterías de metal-aire se debe a que el oxígeno está disponible libremente y no añade peso o volumen adicional al dispositivo. Específicamente, el sistema de baterías litio-aire muestra una densidad energética excepcional cercana a los $12.000^{1} \mathrm{Whkg}^{-1}$, en el mismo rango de la gasolina, como se

\footnotetext{
${ }^{1}$ Excluyendo oxígeno. Incluyendo oxígeno el valor pasa a ser de $5200 \mathrm{Whkg}^{-1}$.
} 
muestra en la Figura 1.1-6. Adicionalmente, este tipo de baterías puede alcanzar un bajo coste de fabricación, un buen ciclo de vida, además de ser respetuosa con el medio ambiente ${ }^{14,22}$.

La densidad de energía específica y la tensión de funcionamiento de la batería de metal-aire varían en función de la elección del ánodo metálico, como se muestra en la Tabla 1.1-1. Como se acaba de mencionar, la batería de litio-aire demuestra la mayor densidad de energía teórica y práctica, sin embargo, la oxidación espontánea del litio con el aire atmosférico, formando hidróxido de litio ( $\mathrm{LiOH})$, es un contratiempo difícil de resolver. Esta es una de las causas principales por la que la comercialización de baterías de litio-aire aún no es posible y este sistema sigue enfrentándose a retos relacionados con los costes operativos y la seguridad durante la operación ${ }^{23,24}$, a pesar de su alta energía específica.

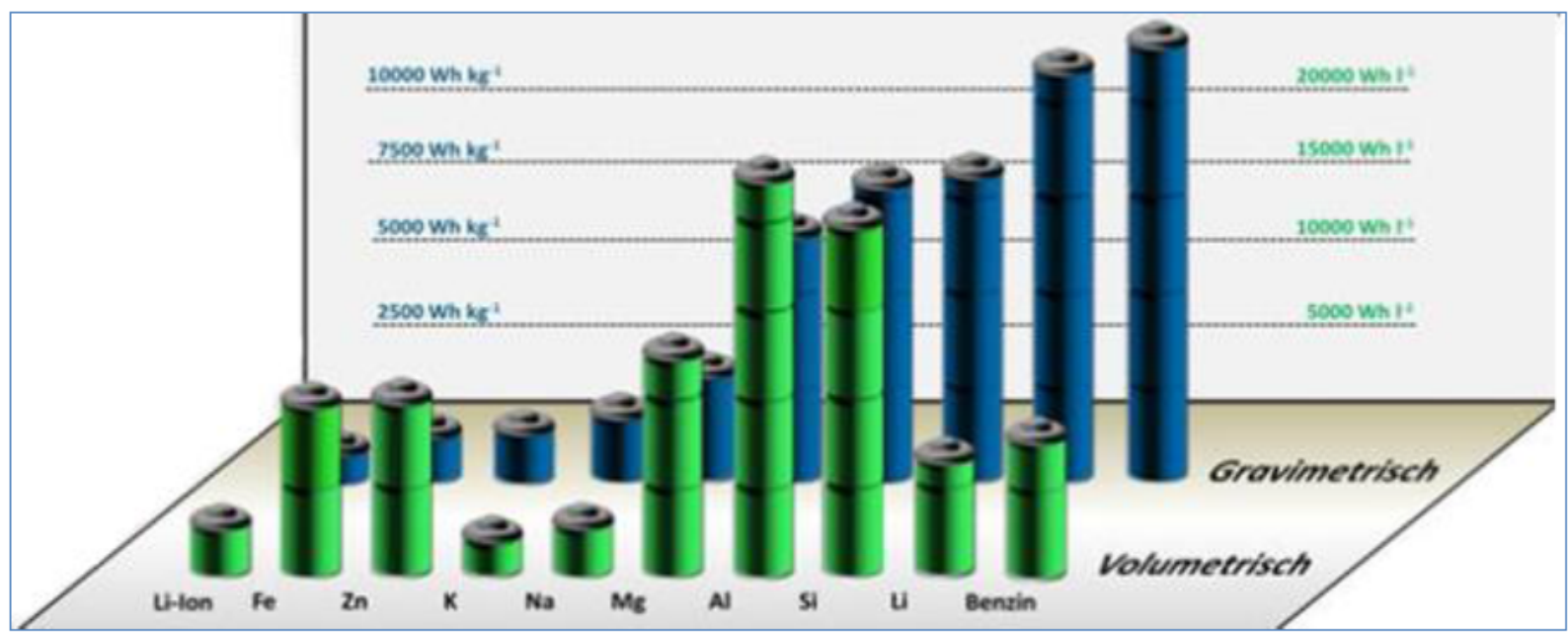

Figura 1.1-6: Densidad de energía específica teórica de varios sistemas de baterías, incluyendo los tipos representativos de sistemas de baterías metal-aire, litio-aire y zinc-aire. Tomado de Jïlich Forchung Zentrum.

En general, las baterías de metal-aire funcionan con electrolitos alcalinos o neutros, $\mathrm{Zn}, \mathrm{Fe}, \mathrm{Al}$, y Mg, pero también se utilizan electrolitos no acuosos para baterías metal aire de Li, K y Na ya que son muy reactivas en electrolitos acuosos aunque podrían ser usados en estos medios debidamente protegidos por membranas conductoras iónicas como el NASICON ${ }^{14}$. Recientemente, tetraetilenglicol dimetil éter (TEGDME), dimetoxietano (DME) dimetilsulfoxido (DMSO) y acetonitrilo están siendo muy estudiados como electrolitos apróticos en baterías de litio-aire.16,25.En 
baterías de zinc se han usado también electrolitos de geles poliméricos, PVA, PEO, PAA, etc., con $\mathrm{KOH}$ en medio acuoso alcanzando resultados similares a los electrolitos acuosos ${ }^{25}$.

Se espera que a corto plazo la tecnología metal-aire sustituya a la tecnología de iones de litio en los sistemas de tracción eléctrico, "powertrain", e instaladas en los vehículos eléctricos. Véase la Figura 1.1-7 26.

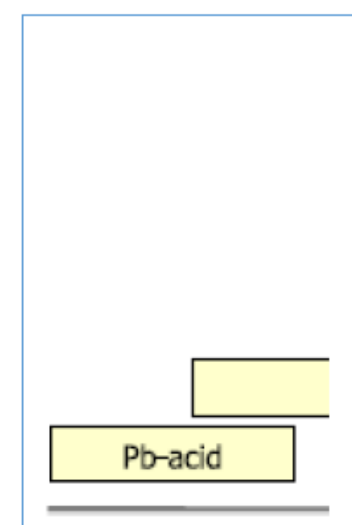

Fïgura 1.1-7: Baterías para sistemas de tracción de vehículos eléctricos. Tomado de la referencia 24.

\begin{tabular}{cccccc}
\hline $\begin{array}{c}\text { Metal } \\
\text { ánodo }\end{array}$ & $\begin{array}{c}\text { Equivalente } \\
\text { electroquímico del } \\
\text { metal (mAhg-1) }\end{array}$ & $\begin{array}{c}\text { Tensión } \\
\text { teórica de } \\
\text { celda (V) }\end{array}$ & $\begin{array}{c}\text { Electrones } \\
\text { Transferidos }\end{array}$ & $\begin{array}{c}\text { Energía teórica } \\
\text { específica (Whkg-1) }\end{array}$ & $\begin{array}{c}\text { Tensión } \\
\text { práctica de } \\
\text { trabajo (V) }\end{array}$ \\
\hline $\mathrm{Li}$ & 386 & 3.4 & 1 & 13.0 & 2.4 \\
$\mathrm{Ca}$ & 134 & 3.4 & 2 & 4.6 & 6.8 \\
$\mathrm{Mg}$ & 220 & 3.1 & 2 & 8.1 & $1.2-1.4$ \\
$\mathrm{Al}$ & 298 & 2.7 & 3 & 1.3 & $1.1-1.4$ \\
$\mathrm{Zn}$ & 820 & 1.6 & 2 & 1.2 & $1.0-1.2$ \\
$\mathrm{Fe}$ & 960 & 1.3 & 2 & 1.0 \\
\hline
\end{tabular}

Tabla 1.1-1: Características de las baterías metal-aire.

El zinc metal ofrece una gran ventaja en comparación con otros metales en una batería metal-aire, por ejemplo: coste de producción, disponibilidad, estabilidad en medios acuosos alcalinos, manipulación y eliminación o reciclaje seguros. Por lo tanto, se prevé que la batería zinc-aire sea la batería metal-aire más prometedora para tener éxito en múltiples nichos de mercado. Aunque este tipo de batería se comercializa 
desde hace décadas para algunas aplicaciones específicas, para su aplicación en dispositivos portátiles (teléfonos celulares y computadoras portátiles) y de gran tamaño (vehículos y transporte), es necesario abordar los problemas de formación no deseada de dendritas, disolución desigual y rendimiento insuficiente de los electrodos de aire.

Creemos firmemente que el zinc será la opción elegida para convertirse en el próximo material que impulsará estos sistemas eléctricos de tamaño medio por razones de disponibilidad, medio ambiente, coste de producción, seguridad y reciclabilidad

\subsection{Breve historia del sistema zinc-aire.}

El principio de la batería zinc-aire $\left(\mathrm{Zn} / \mathrm{O}_{2}\right)$ ya era conocido por Thomas Edison, que ya había experimentado con ella. El primer diseño de una batería de zinc-aire data del año $1878^{14}$. Sin embargo, la producción comercial comienza en 1932, cuando George W. Heise y Erwin A. Schumacher construyeron celdas en la National Carbon Co. Los electrodos de carbono, usados como cátodos, estaban tratados con cera para aislarlos del exterior y evitar que puedan producirse fugas de electrolito.

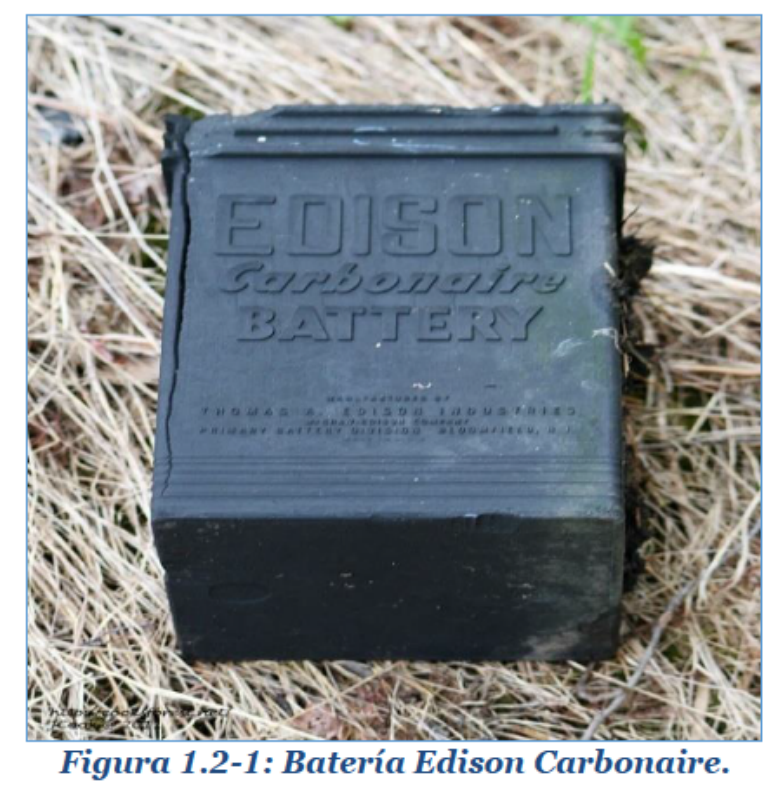


Grandes baterías primarias, no recargables, como la "Carbonaire Battery" de Thomas A. Edison Industries, se utilizan para las señales ferroviarias, lugares con comunicación remota y boyas de navegación a partir de 1954 (Figura 1.2-1).

En la década de 1970 se comprueba la idoneidad de estos sistemas en vehículos eléctricos, por ejemplo, Gulf General Atomic desarrolla una batería de 20 kW y la prueba en un Jeep, mientras que General Motors, con una batería de $35 \mathrm{~kW}$, que también es recargable mecánicamente, alimenta un vehículo de $1.350 \mathrm{~kg}$. Sin embargo, ninguno de los experimentos lo convierten en un producto comercial ${ }^{27}$. Experiencias similares son realizadas por la empresa japonesa Sanyo, que instala circuitos reforzados de aire y electrolito y prueba una batería de $124 \mathrm{~V} / 560 \mathrm{Ah}$ en un vehículo grande.

La Compagnie Générale d'Electricité (CGE) ${ }^{28}$ desarrolló entre 1970 y 1980 un sistema completo de $300 \mathrm{~kg}$ de peso que alcanzo una energía especifica $84 \mathrm{Wh} / \mathrm{kg}$. En realidad este sistema se debería de llamar una pila de combustible más que una batería de zinc-aire ya que el "slurry" de zinc es recirculado a través de un espacio entre dos tubos concéntricos que actúan como electrodos.

Después de estos intentos, el panorama investigador permanecerá bastante estático durante casi dos décadas, hasta que a principios de la década de 1990 se vuelve a retomar la investigación relacionada con este tipo de baterías, principalmente en EE.UU. y en Alemania.

El desarrollo de una nueva pila de combustible de zinc-aire mecánicamente recargable (ZAFC) comenzó en 1991 en el Laboratorio Nacional Lawrence Livermore (LLNL) en California. En el mismo laboratorio se lanzó un programa de investigación sobre baterías de aluminio-aire. Entre 1992 y 1997, la LLNL desarrolló un sistema de 6V/300W para operar en un autobús en Santa Bárbara (Figura 1.2-2).

En el Informe Final del Grupo de Asesoramiento Técnico sobre el Rendimiento y Fiabilidad de las Baterías de los Vehículos Eléctricos, publicado en diciembre de 1995, la batería zinc-aire, con su energía específica teórica de $1.085 \mathrm{Wh} / \mathrm{kg}$, se considera la única fuente de energía viable para los vehículos eléctricos ${ }^{29}$. 
Además, en 1995 Lawrence Berkeley Laboratories lanzaron la idea de en lugar de cargar mecánicamente o reemplazar baterías agotadas, reemplazar el electrolito liquido agotado por un electrolito nuevo y el ánodo se regenera en una celda similar de lecho fluidificado ${ }^{28}$.

En 1997, se fundó Power Air Tech Inc. (PAT) con sede en Livermore, California, para comercializar los dispositivos desarrollados en LLNL. PAT se asoció con un fondo de energía australiano, Power Air Dynamics Ltd., para recaudar capital adicional y hacer avanzar la tecnología de zinc-aire para su comercialización.

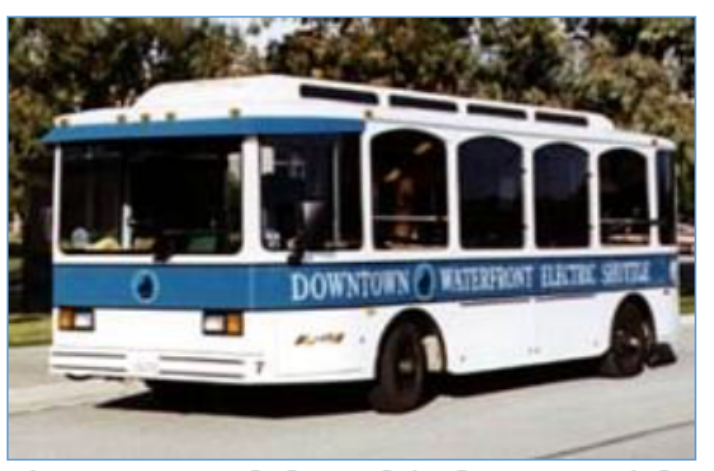

Figura 1.2-2: El electrobús de Santa Bárbara.

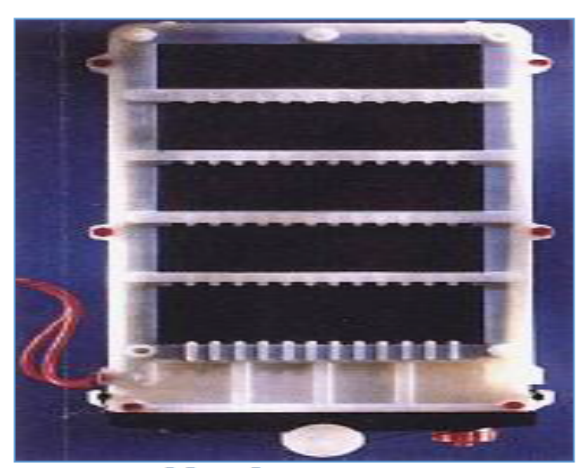

Figura 1.2-3: Celdas de Zoxy Energy System AG.

En Alemania, la empresa ChemTEK GmbH nace en 1992 por iniciativa de las empresas energéticas EnBW Energie Baden Württemberg AG y Stadtwerke Karlsruhe GmbH para el desarrollo de una nueva batería zinc-aire. En 1997, el resultado se presentó en Karlsruhe: La nueva batería ZOXY (para Zinc-Oxígeno) tiene una densidad de energía de $150 \mathrm{Wh} / \mathrm{kg}$ y es un $80 \%$ más ligera que las baterías convencionales de plomo-ácido con el mismo contenido energético. Un vehículo de prueba alcanza un récord de $760 \mathrm{~km}$ en Utah, EE.UU en 1996. En el mismo año, un coche eléctrico recorre en pleno calor de California una distancia de unos $1.650 \mathrm{~km}$. El proceso de carga, sin embargo, tiene un problema, ya que se forman finas agujas de zinc en el electrodo negativo, que tarde o temprano producen cortocircuitos. La batería sólo se puede cargar diez veces antes de que los electrodos de zinc tengan que ser regenerados ${ }^{28}$.

En el año 2000, se fundó cerca de Karlsruhe, ZOXY Energy Systems AG, como continuación de ChemTEK Gmbh, para fabricar y comercializar baterías de zinc-aire, 
que tienen una capacidad significativamente mayor que las baterías de plomo disponibles en el mercado.

Las potentes y hasta 300 veces recargables celdas ZOXY se utilizan principalmente para accionar scooters, sillas de ruedas o unidades móviles de limpieza, sistemas de alimentación ininterrumpida y fuentes de alimentación fuera de la red para uso en exteriores (Figura 1.2-3).

El problema de las dendritas durante la carga es abordado por la empresa israelí Electric Fuel Ltd. (EFL), con sede en Jerusalén y fundada en 1994. Los electrodos de zinc oxidado se regeneran mediante un complejo proceso mecánico-químico para que la batería vuelva a estar lista para su uso. Sin embargo, el sistema sólo es adecuado para flotas de empresa con taller propio, ya que las baterías deben cambiarse completamente después del uso. El sistema entero consta de zona de cambio de baterías, zona de recarga mecánica de casetes y zona de regeneración de zinc ${ }^{30}$ (Figura $1.2-5)$.

En el tipo de batería de EFL, el zinc en forma de "slurry" mezclado con KOH se compacta sobre un colector de corriente envuelto en separadores con dos electrodos de aire, uno a cada lado ${ }^{31}$. La utilidad de la tecnología se probó en 1995 en un parque de vehículos eléctricos de la Oficina Federal de Correos de Bremen consiguiendo una densidad de energía practica de $200 \mathrm{Wh} / \mathrm{kg}$. El óxido de zinc obtenido en la descarga es disuelto en $\mathrm{KOH}$ obteniendo disoluciones concentradas de zincato a partir de las cuales, el zinc se regenera electrolíticamente en una planta de regeneración ${ }^{30}$.

En 2003, Electric Fuel recibió un contrato millonario para suministrar baterías zinc-aire al Ejército de los Estados Unidos. La empresa cambia su nombre por el de Arotech Corporation. Otra parte de Arotech, Epsilor Industries Ltd., también desarrolló baterías de zinc-aire de gran formato y alta densidad energética en respuesta a las necesidades del Ejército de los EE.UU. de sistemas energéticos ligeros, de bajo coste y adecuados para el campo de batalla ${ }^{32}$.

En California, la empresa estadounidense Metallic Power Inc, se asoció en 1999 con la empresa energética ABB para construir un prototipo de un sistema de respaldo 
o reserva para telecomunicaciones de $48 \mathrm{~V} / 4 \mathrm{~kW}$. A medio plazo también produjeron versiones más grandes para equipos eléctricos de hasta 50 kW³3.

La celda electroquímica, Figura 1.2-6, puede ser vaciada del producto de reacción en aproximadamente diez minutos, así como ser realimentada con zinc nuevo. Las mejoras de los productos en 2001 reducen el tiempo de carga de combustible a sólo 3-5 minutos. La versión comercial del sistema está diseñada para disponer una manguera con boquerel de fácil manejo, similar al sistema de reabastecimiento de gasolina de hoy en día. Finalmente la empresa cesó operaciones en 2004.

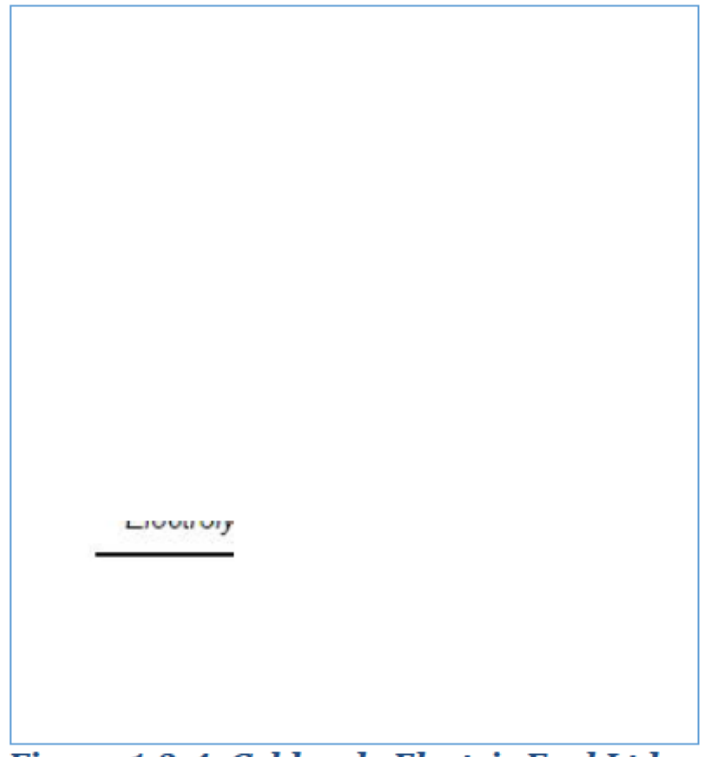

Fïgura 1.2-4: Celdas de Electric Fuel Ltd.

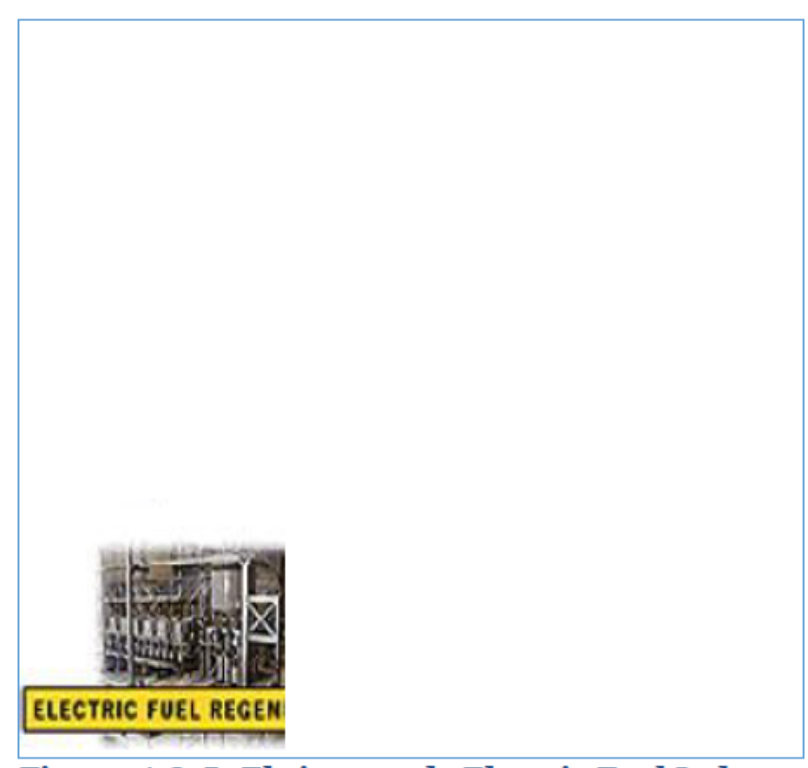

Figura 1.2-5: El sistema de Electric Fuel Ltd.

En 1999 se funda Powerzinc y comienza la fabricación de su serie Dynamic Quick-Refuel Fuel Cell (DQFC) para fabricantes de bicicletas eléctricas, scooters, coches y autobuses. El modelo DQFC-12/11-070 (12V/70Ah), por ejemplo, es adecuado para vehículos de dos ruedas, otros modelos más grandes están destinados a vehículos más pesados. Además, se ofrece un modelo PE2815 (28V/15Ah) para aplicaciones militares.

Powerzinc firma múltiples acuerdos de distribución con los principales fabricantes de bicicletas eléctricas de Shanghai y Suzhou. En cooperación con una universidad de China, se desarrolló un coche eléctrico que funcionó con éxito con una batería zinc-aire y, junto con uno de los mayores fabricantes de autobuses de China, 
trabajó en un autobús eléctrico con pila de combustible DQFC, que estaría listo para funcionar en los Juegos Olímpicos de Pekín de $2008^{34}$.

La empresa ReVolt Technology AS fue fundada en 2004, como una spin-off de la empresa noruega (SINTEF) en Trondheim, uno de los mayores institutos independientes de investigación industrial de Europa, con el fin de comercializar una batería recargable zinc-aire.

Mientras que el diseño típico de las baterías tenía dos electrodos planos de tamaño comparable, uno de los electrodos de las nuevas baterías será líquido compuesto de "slurry" de zinc, mientras que los electrodos de aire tendrán la forma de tubos, ver Figura 1.2-7. Para generar electricidad, el "slurry" de zinc almacenado en un recipiente anejo a la batería es bombeado a través de los tubos, donde se oxida. El óxido de zinc se recoge en otro recipiente. Durante el proceso de carga, el óxido de zinc vuelve a fluir a través del electrodo de aire, donde libera el oxígeno para formar zinc de nuevo. Se estima que estas baterías podrían soportar entre 2.000 y 10.000 ciclos de carga ${ }^{35}$.

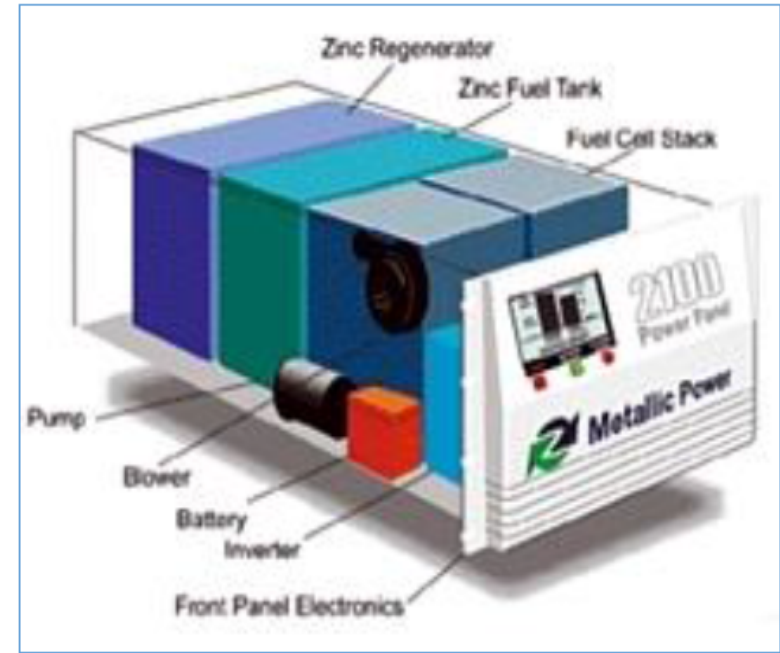

Figura 1.2-6: Metallic Power Inc. Design.

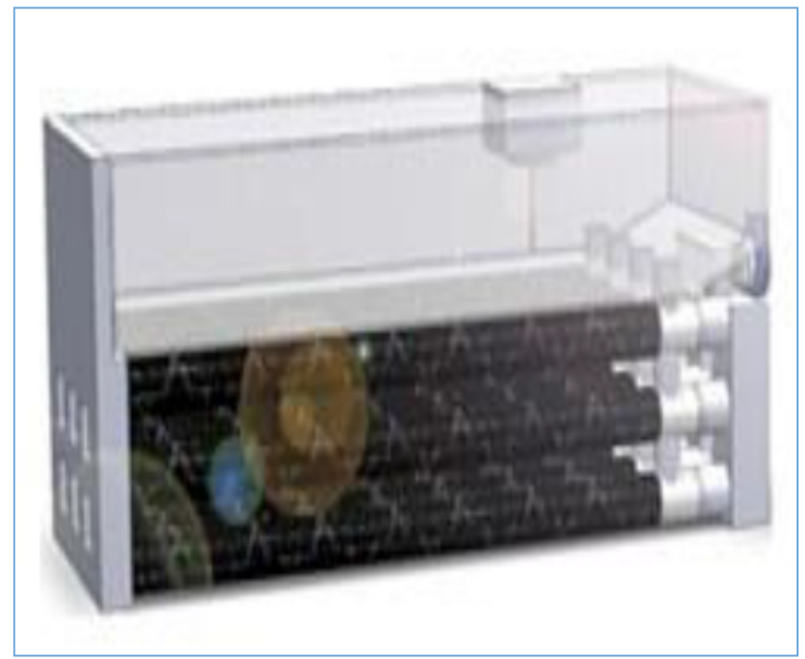

Figura 1.2-7: Diseño ReVolt Zinc-Air.

QuantumSphere Inc. fundada en 2002 en Santa Ana, California, es un fabricante líder de nanometales y aleaciones. En octubre de 2006 anunció la presentación de dos patentes sobre la composición de un electrodo delgado en papel basado en nanomateriales. Bajo el nombre de MetAir Ranger, ofrece una batería de zinc-aire para sistemas de emergencia. El sistema de baterías de $3.5 \mathrm{kWh}$ pesa unos $12 \mathrm{~kg}$ y tiene una 
densidad energética de $352 \mathrm{Wh} / \mathrm{kg}$. Esto corresponde aproximadamente a la mitad del peso de una batería de plomo-ácido, con once veces la energía por kilogramo.

Esencialmente, la serie MetAir Ranger es una caja portátil de potencia "plugand-play" que contiene un ensamblaje con hasta 36 celdas de zinc-aire desechables (12 en serie con 3 filas en paralelo) en una sola batería. Una vez activado con aire, el sistema proporciona energía continua y fiable durante 192 horas u ocho días ${ }^{36}$.

La empresa Fluidic Energy, con sede en Scottsdale, Arizona, fue fundada en 2007 para transformar una batería recargable zinc-aire, desarrollada en la Universidad Estatal de Arizona, en un producto comercial. La nueva empresa, que continúa con el desarrollo técnico, quiere desarrollar y construir una batería de metal-aire con líquidos iónicos, similar a una batería de litio, pero que tiene una densidad de energía de hasta 11 veces mayor y cuesta menos de un tercio ${ }^{37}$.

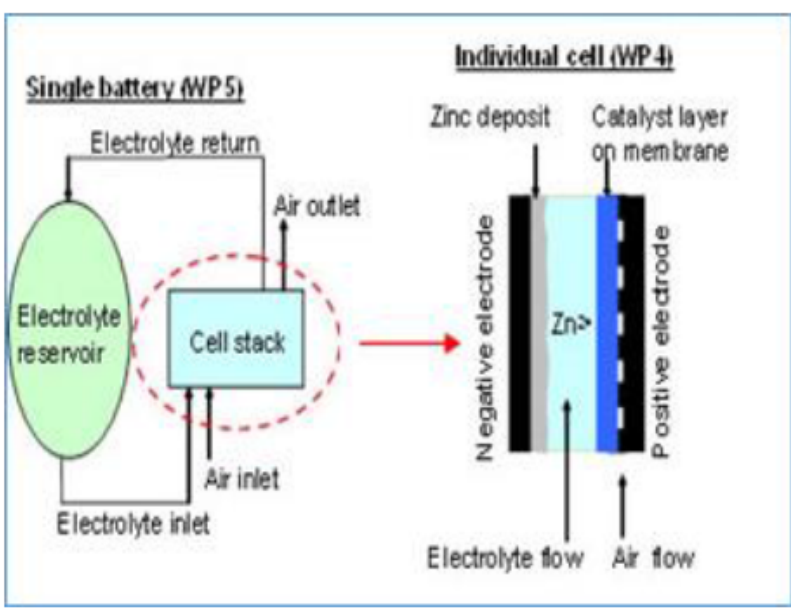

Figura 1.2-8: Esquema del sistema del consorcio POWAIR.

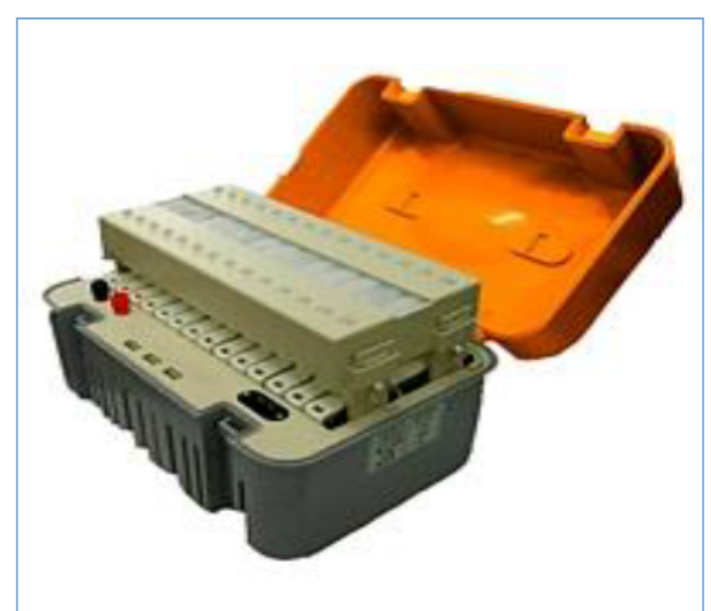

Figura 1.2-9: Batería Zinc-air de AVICChangli.

Eos Energy Storage LLC, que lleva el nombre de Eos, la diosa griega del amanecer, creó y comercializó una tecnología de baterías de zinc-aire, bajo el nombre de Znyth, como la "primera batería acuosa de bajo coste y larga duración inherentemente segura, de alta energía y alta eficiencia". La característica especial de esta batería, que está en desarrollo desde 2004, es un nuevo electrolito acuoso que ayuda a resolver muchos de los problemas de las baterías de zinc-aire. Además, hay un cátodo de aire bifuncional, que podría sobrevivir a 10.000 ciclos de carga ${ }^{38}$. 
En 2010, el proyecto Powair - Zinc-Air Flow Batteries for Electrical Power Distribution Networks, financiado por la UE, puso en marcha un consorcio de ocho socios de cinco países, entre los que se incluyen las universidades de SouthHampton y Sevilla y tres grandes empresas europeas, para desarrollar un sistema de almacenamiento de energía eléctrica rentable, modular y sostenible desde el punto de vista medioambiental, con una alta densidad energética y un tiempo de respuesta rápido ${ }^{39}$ (Figura 1.2-8).

La empresa china AVIC-Changli Energy Science and Technology Co.Ltd. en Pekín comercializa el modelo XKZB60Ah, un sistema de $7 \mathrm{~kg}$ con 15V/60Ah, que puede suministrar una cantidad de energía de $840 \mathrm{Wh}$ (Figura 1.2-9).

Incluso, el Instituto de Química Física de la Academia Polaca de Ciencias en Varsovia, usaron un 'biocátodo' implantable hecho de una enzima biológica que está embebida en nanotubos de carbono, recubierta con gel de sílice y luego recubierta con una membrana permeable al oxígeno. Esto elimina la, a menudo pesada y voluminosa, carcasa en la que debe ser envuelta otras baterías implantables ${ }^{40}$.

Recientemente NantEnergy ha presentado una batería recargable de zinc-aire con un costo de almacenamiento de energía tan bajo como $\$ 100$ por kWh. Ésta, es la cifra limite que algunos expertos de la industria consideran realista para crear una red eléctrica libre de carbono que funcione incluso cuando el sol no está disponible y el viento amaina ${ }^{41}$. 


\subsection{Referencias.}

(1) 08/07/2013 FORO NUEVA MURCIA, JAVIER SOLANA - YouTube https://www.youtube.com/watch?v=NOExWoMXdgo (accessed Aug 1, 2019).

(2) González, I. H.; Ruiz, P.; Sgobbi, A.; Nijs, W.; Quoilin, S.; Zucker, A.; Heinrichs, H. U.; Silva, V.; Koljonen, T.; Kober, T.; et al. Addressing Flexibility in Energy System Models; 2015. https://doi.org/10.2790/925.

(3) Streck, C. The Paris Agreement. Summary. Brief. Note III 2015, No. December, 1. https://doi.org/l.

(4) Vinet, L.; Zhedanov, A. A “missing” Family of Classical Orthogonal Polynomials. EPA 2011, 44 (8), 1323-1330. https://doi.org/10.1088/1751$8113 / 44 / 8 / 085201$.

(5) EIA. Global Transportation Energy Consumption: Examination of Scenarios to 2040 Using ITEDD. 2017, No. September, 1-38.

(6) IRENA. Electricity Storage and Renewables: Costs and Markets to 2030; 2017. https://doi.org/ISBN 978-92-9260-038-9 (PDF).

(7) Rehman, S.; Al-Hadhrami, L. M.; Alam, M. M. Pumped Hydro Energy Storage System: A Technological Review. Renew. Sustain. Energy Rev. 2015, 44, 586598. https://doi.org/10.1016/j.rser.2014.12.040.

(8) Garvey, S. D.; Pimm, A. Compressed Air Energy Storage. In Storing Energy: With Special Reference to Renewable Energy Sources; 2016; pp 87-111. https://doi.org/10.1016/B978-0-12-803440-8.00005-1.

(9) Perkins, D. Compressed Air Energy Storage (CAES). Encycl. Energy Eng. Technol. - 3 Vol. Set (Print Version) 2010, 214-218. https://doi.org/10.1201/9780849338960.ch28.

(10) Moseley, P. T.; Garche, J. Electrochemical Energy Storage for Renewable Sources and Grid Balancing; 2014. https://doi.org/10.1016/C2012-0-012537. 
(11) Dunn, B.; Kamath, H.; Tarascon, J. M. Electrical Energy Storage for the Grid: A Battery of Choices. Science (80-. ). 2011, 334 (6058), 928-935. https://doi.org/10.1126/science.1212741.

(12) Rosso, D. Semiconductor Industry Association - Global Semiconductor Sales Up 16.5

Percent

Year-to-Year

https://www.semiconductors.org/news/2017/04/03/global_sales_report_20 17/global_semiconductor_sales_up_16.5_percent_year_to_year/.

(13) Global Market for Semiconductor Batteries https://www.prnewswire.com/news-releases/global-market-forsemiconductor-batteries-300777528.html (accessed Aug 8, 2019).

(14) Li, Y.; Lu, J. Metal-Air Batteries: Will They Be the Future Electrochemical Energy Storage Device of Choice? ACS Energy Lett. 2017, 2 (6), 1370-1377. https://doi.org/10.1021/acsenergylett.7b00119.

(15) Dromantien, R. E.; Tripolskaja, L. European Association for Storage Energy. 2009, 2 (2), 97-110.

(16) Tan, P.; Jiang, H. R.; Zhu, X. B.; An, L.; Jung, C. Y.; Wu, M. C.; Shi, L.; Shyy, W.; Zhao, T. S. Advances and Challenges in Lithium-Air Batteries. Appl. Energy 2017, 204, 780-806. https://doi.org/10.1016/j.apenergy.2017.07.054.

(17) Zhang, S.; Wen, Z.; Rui, K.; Shen, C.; Lu, Y.; Yang, J. Graphene Nanosheets Loaded with Pt Nanoparticles with Enhanced Electrochemical Performance for Sodium-Oxygen Batteries. J. Mater. Chem. A 2015, 3 (6), 2568-2571. https://doi.org/10.1039/c4ta05427j.

(18) Zhang, X.; Wang, X. G.; Xie, Z.; Zhou, Z. Recent Progress in Rechargeable Alkali Metal-air Batteries. Green Energy Environ. 2016, 1 (1), 4-17. https://doi.org/10.1016/j.gee.2016.04.004.

(19) Luntz, A. C.; McCloskey, B. D. Nonaqueous Li-Air Batteries: A Status Report. Chem. Rev. 2014, 114 (23), 11721-11750. https://doi.org/10.1021/cr500054y. 
(20) Cohn, G.; Starosvetsky, D.; Hagiwara, R.; Macdonald, D. D.; Ein-Eli, Y. SiliconAir Batteries; 2009; Vol. 11. https://doi.org/10.1016/j.elecom.2009.08.015.

(21) Hartwig, A. SCOEL / REC / 175 Beryllium and Inorganic Beryllium Compounds Recommendation from The; 2017. https://doi.org/10.2767/958699.

(22) Li, Y.; Dai, H. Recent Advances in Zinc-Air Batteries. Chem. Soc. Rev. 2014, 43 (15), 5257-5275. https://doi.org/10.1039/c4cs00015c.

(23) Fu, J.; Cano, Z. P.; Park, M. G.; Yu, A.; Fowler, M.; Chen, Z. Electrically Rechargeable Zinc-Air Batteries: Progress, Challenges, and Perspectives. Advanced Materials. 2017. https://doi.org/10.1002/adma.201604685.

(24) Gu, P.; Zheng, M.; Zhao, Q.; Xiao, X.; Xue, H.; Pang, H. Rechargeable Zinc-Air Batteries: A Promising Way to Green Energy. Journal of Materials Chemistry A. 2017, pp 7651-7666. https://doi.org/10.1039/c7ta01693j.

(25) Li, Y.; Dai, H. Recent Advances in Zinc-Air Batteries. Chem. Soc. Rev. 2014, 43 (15), 5257-5275. https://doi.org/10.1039/c4cs00015c.

(26) Catenacci, M.; Verdolini, E.; Bosetti, V.; Fiorese, G. Going Electric: Expert Survey on the Future of Battery Technologies for Electric Vehicles. Energy Policy 2013, 61, 403-413. https://doi.org/10.1016/j.enpol.2013.06.078.

(27) Pletcher, D. Environmental Oriented Electrochemistry; Elsevier, 2003; Vol. 379. https://doi.org/10.1016/0022-0728(94)87191-4.

(28) Haas, O.; Holzer, F.; Müller, K.; Müller, S. Metal/Air Batteries: The Zinc/Air Case; 2010. https://doi.org/10.1002/9780470974001.f104022.

(29) Powerzinc https://www.powerzinc.com/en/index-3-x2.html (accessed Apr 6, 2019).

(30) Koretz, B.; Goldstein, J. R. Regeneration of Zinc Anodes for the Electric Fuel(R) Zinc-Air Refuelable EV Battery System. 2002, 877-882 vol.2. https://doi.org/10.1109/iecec.1997.661884. 
(31) Goldstein, J.; Brown, I.; Koretz, B. New Developments in the Electric Fuel Ltd. Zinc/Air System. J. Power Sources 1999, 80 (1), 171-179. https://doi.org/10.1016/S0378-7753(98)00260-2.

(32) High Capacity Zinc Air Military Batteries - Epsilor https://www.epsilor.com/sections/military/Zinc-Air-Batteries/ (accessed Apr 6, 2019).

(33) Cathy Swirbul. Metallic Power takes fuel cell technology into new frontier https://www.poweronline.com/doc/metallic-power-takes-fuel-cell-technologyint-0001 (accessed Aug 5, 2019).

(34) Powerzinc https://www.powerzinc.com/en/index-2-c1-4.html (accessed Apr 6, 2019).

(35) REVOLT, T. Rechargeable Zinc-Air Battery.

(36) Quantum Sphere. White Paper MetAir TM Ranger Portable Power Systems : Meeting Needs for Mission Critical and Emergency Applications July, 2012. 2012.

(37) ARPA-E.ZINC-AIR GRID ENERGY STORAGE. US DEPARTMENT OF ENERGY. FluidicEnergy_GRIDS_ExternalImpactSheet_FINAL.Pdf. 2016, 24-26.

(38) Bouchard, P.; Development, B. CEC EPIC Symposium; 2015.

(39) Collins, J. POWAIR Zinc-Air flow batteries for electrical power distribution http://www.powair.eu/ (accessed Apr 8, 2019).

(40) Zloczewska, A.; Jönsson-Niedziolka, M. Efficient Air-Breathing Biocathodes for Zinc/Oxygen Batteries. J. Power Sources 2013, 228, 104-111. https://doi.org/10.1016/j.jpowsour.2012.11.081.

(41) NantEnergy - Air Breathing Zinc Rechargeable Storage Cell https://nantenergy.com/ (accessed Apr 6, 2019). 


\section{Revisión Teórica y Bibliográfica.}

"Science, to give young people nourishment, to give comfort to the elderly; she makes the happy life icing on the cake, she protects you at an unfortunate moment". 



\subsection{La batería de zinc-aire.}

\subsubsection{Clasificación de las baterías de zinc-aire.}

El sistema de zinc-aire se presenta en tres tipos distintos: baterías primarias, secundarias y mecánicamente recargables ${ }^{1}$.

Baterías primarias. Las baterías de zinc-aire primarias se han desarrollado para un solo uso, como ejemplo podemos citar las pilas botón en audífonos. Las ventajas de estas baterías son bajo costo, alta densidad de energía y bajo o ningún mantenimiento. Además este tipo de baterías es considerada una tecnología madura1,2.

Baterías recargables mecánicamente. Este tipo de batería es en realidad una batería primaria, en la que una vez descargada, se reemplaza el ánodo mecánicamente, es decir, se puede reemplazar el zinc en la celda por medio de un cartucho reemplazable, varillas u otra forma geométrica Por otra parte, el electrolito también se puede reemplazar de manera similar a como un coche actual de combustión interna se reabastece de combustible en una gasolinera. La vida útil depende por lo tanto del cátodo puesto que el ánodo se sustituye con regularidad. Esta forma de proceder, evita los problemas de cambio en la morfología del ánodo que tiene lugar durante el proceso de carga y descarga en baterías secundarias con recarga electroquímica ${ }^{3}$.

Baterías secundarias (batería recargable eléctricamente). Las baterías secundarias, son capaces de ser recargadas eléctricamente una vez descargadas, mediante la aplicación de una corriente positiva. Sin embargo, optimizaciones adicionales son necesarias para esta aplicación. En primer lugar se necesita desarrollar ánodos de zinc reversibles que eviten la formación de dendritas durante la carga, mejorar el proceso de formación de la película de $\mathrm{ZnO}$, durante la descarga y el proceso de reducción de $\mathrm{ZnO}$ a $\mathrm{Zn}$ metal, durante la recarga. Por otra parte, es necesario desarrollar nuevos electrodos de aire con catalizadores bifuncionales que reduzcan la sobretensión durante la carga y por lo tanto puedan prevenirse daños al cátodo 2 . 


\subsubsection{Ventajas y desventajas de una batería de zinc-aire.}

El sistema de zinc-aire con una densidad de energía específica de $1084 \mathrm{Wh} / \mathrm{kg}^{4}$ tiene uno de los contenidos de energía más altos (la batería de plomo tiene 30-40 $\mathrm{Wh} / \mathrm{kg}$ ). Este alto valor es debido al hecho de que sólo el material activo del ánodo está incluido en la celda y el material activo del cátodo se extrae del aire circundante durante el proceso de descarga ${ }^{2}$. Otra ventaja es la descarga plana, que resulta de la alta polarización de oxígeno ${ }^{5}$. La inocuidad para el medio ambiente de los sistemas de zinc-aire y la alta disponibilidad del zinc hace que la mejora en este sistema sea muy interesante desde el punto de vista científico-tecnológico.

En comparación con otros sistemas de baterías recargables, tales como la batería de Li-Ion, la seguridad es también una gran ventaja. Por último, la posibilidad de usar electrolitos de base acuosa es realmente interesante, con respecto a otras baterías que necesitan electrolitos con disolvente orgánicos, que tienen una menor conductividad, son más caros y más perjudiciales para el medio ambiente.

En el desarrollo técnico de los sistemas de zinc-aire eléctricamente recargables, sin embargo, hay varios problemas que suponen desventajas claras en relación con otros tipos de baterías. Debido a la buena solubilidad del zincato en el electrolito alcalino, el electrodo de zinc sufre cambios en su estructura y forma geométrica durante repetidos ciclos de carga y descarga (cambios en la morfología). También el crecimiento de dendritas es el resultado de esta buena solubilidad ${ }^{6}$. Otra desventaja es el diseño semi-abierto ${ }^{7}$ de la batería, ya que es dependiente del aire ambiente. En este sentido, el dióxido de carbono del aire conduce a la carbonatación del electrolito7 ${ }^{7}$, ésto, se traduce en que el rendimiento de la batería se reduce y por la misma el razón, el almacenamiento y "ciclabilidad" del sistema pueden verse afectados. Otros factores limitantes son la difusión del oxígeno y la oxidación del material carbonoso del cátodo en la etapa de carga. 


\subsubsection{Construcción de una batería de zinc-aire.}

Como se mencionó en la introducción, las baterías de zinc-aire están disponibles comercialmente desde hace muchos años y los fundamentos del sistema básicamente no han cambiado.

Las baterías de zinc-aire utilizan zinc y aire para producir energía electroquímica. La aplicación más conocida de una batería primaria de zinc-aire es la pila botón como se muestra en la Figura 2.1-1. El aire entra por los orificios creados a tal efecto, justo debajo se encuentra el conjunto del electrodo de aire el cual está en contacto con el ánodo impregnado en electrolito. La carcasa de metal sirve como contenedor de toda la celda y colector de corriente. Se debe añadir un aislante para separar la carcasa en dos partes y así evitar cortocircuitos².

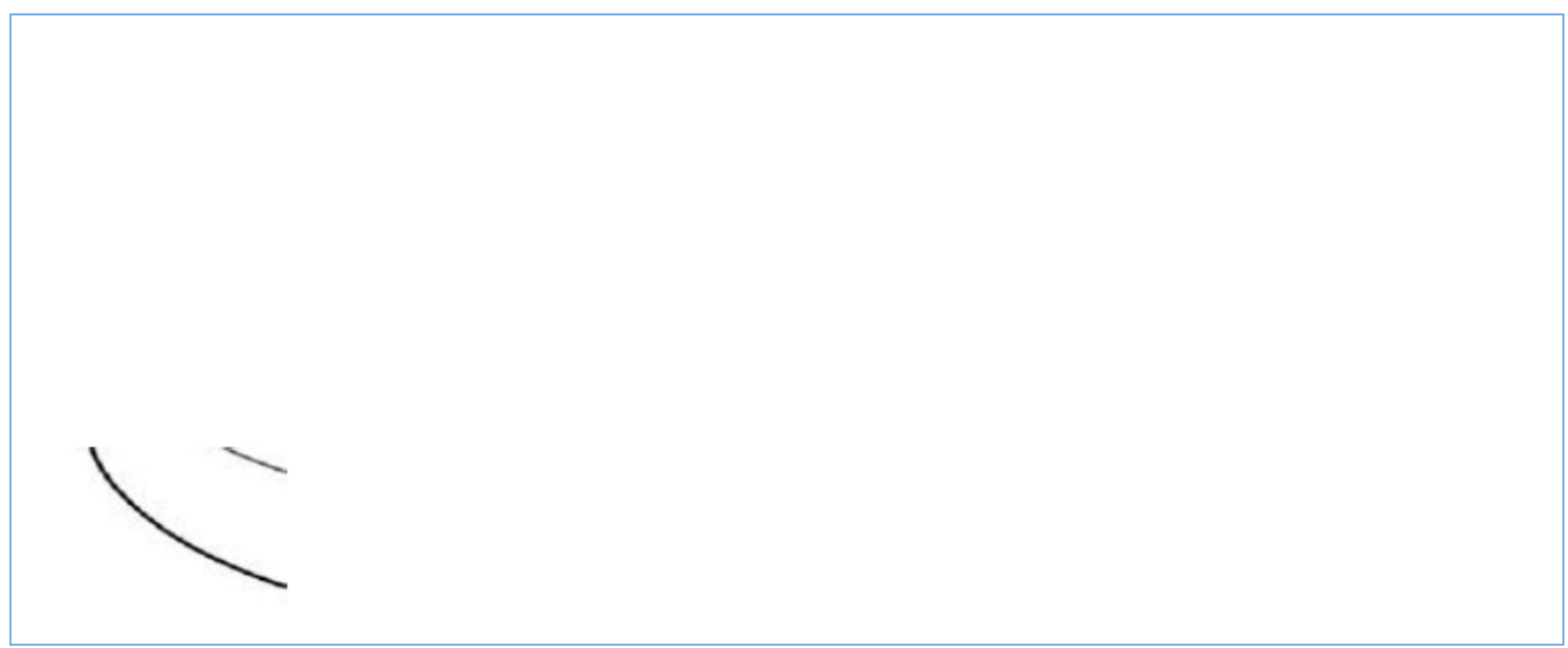

Figura 2.1-1: Esquema de uma pila de botón de zinc-aire comercial. Tomado de la referencia 2.

\subsubsection{El ánodo de zinc.}

El material activo del ánodo de las baterías de Zinc-aire es simplemente zinc, que puede presentarse en diferentes formas, y algún aditivo. Algunas propiedades interesantes del zinc, relevantes para aplicaciones de baterías (a temperatura ambiente) se enumeran en la Tabla 2.1-1. 
El material anódico usado en una pila de botón comercial es una forma granular de zinc, impregnado con el electrolito. La forma y la morfología de los granos de zinc juegan un papel importante en asegurar el contacto óptimo entre las partículas manteniendo, de esta manera, baja la resistencia eléctrica. Al usar zinc granulado se consigue alto rendimiento ya que se aumenta el área de contacto del ánodo. Sin embargo, también se han empleado otras morfologías, tales como: fibras, dendritas, “whiskers”, espumas, etc. La Figura 2.1-2 muestra las diferentes formas en las que el zinc se ha empleado en ánodos tanto en baterías de zinc-aire primarias como secundarias $^{8}$. Zhang et al. ${ }^{9}$ describe con detalle las ventajas y desventajas que presentan estas distintas morfologías de zinc. Entre ellas, el uso de lámina de zinc presenta un inconveniente fundamental, reduce el rendimiento de la celda electroquímica debido a la baja área superficial.

\begin{tabular}{l|l|c}
\hline \multicolumn{1}{|c|}{ PROPIEDAD } & VALOR \\
\hline Zn & Peso atómico & 65.38 \\
& Estructura cristalina & hexagonal empaquetada cerrada \\
& Densidad & $7.14 \mathrm{~g} / \mathrm{cm}^{3}$ \\
& Temperatura de fusión & $419.51 \mathrm{C}^{\circ}$ \\
& Resistividad & $5.96 \mu \Omega \mathrm{cm}$ \\
& Valencia iónica & 2 \\
& Radio iónico & $0.074-0.083 \mathrm{~nm}$ \\
& Forma disuelta estable en KOH & $\mathrm{Zn}(\mathrm{OH}) 4^{2-}$ \\
& Potencial estándar & $-0.763 \mathrm{vs.} \mathrm{SHE}$ \\
& & \\
& Densidad & \\
& Razón molar ZnO/Zn & $1 \Omega \mathrm{cm}$ \\
\hline
\end{tabular}

Tabla 2.1-1: Principales propiedades del zinc utilizado en aplicaciones de baterías.

El material del ánodo no sólo puede ser usado en forma de zinc metálico. Haas et al. ${ }^{10}$ reportó en 2009 sobre la producción de electrodos negativos en baterías de zinc 
usando óxido de zinc como material activo, el cual es reducido a zinc metálico en una etapa de acondicionamiento inicial.

Cast

Figura 2.1-2: Diferentes morfologías de zinc producidos por diferentes métodos. Reproducido de 11.

A fin de aumentar la superficie de los ánodos de zinc varias estrategias se han explorado lo que resulta en una mejora del rendimiento de la batería. Ya XG Zhang reporta en 2006 que el uso de zinc en fibras conduce a una mejora en la estabilidad, la porosidad y mayor capacidad de descarga ${ }^{11}$.

S. Muller et al. ${ }^{12}$ reportan que los cambios de morfología en el ánodo se pueden reducir mediante el uso de fibras de celulosa. Además, el uso de fibras de celulosa 
mejora la humectabilidad. C.W. Lee et al. reportan que el uso de fibras de celulosa puede sustituir la adición de $\mathrm{PbO}$, que es perjudicial para el medio ambiente ${ }^{13}$.

Con el fin de usar el zinc tan uniformemente como sea posible, tiene sentido producir estructuras de zinc lo más porosas posible con una gran área de superficie. Pero el zinc fino o atomizado tiene baja porosidad alrededor del $50 \%$, por este motivo se añaden agentes gelificantes al ánodo para tratar de aumentar la porosidad ${ }^{14,15}$.

\subsubsection{El electrolito.}

Las baterías de zinc-aire usan como electrolito soluciones de hidróxido de potasio, aunque otras opciones son posibles como los GPEs (electrolito de tipo gel polimérico). Además, otras soluciones alcalinas, tales como hidróxido de litio o de sodio pueden ser utilizadas, sin embargo, es el hidróxido de potasio el preferido debido a la mayor conductividad iónica del $\mathrm{K}^{+}\left(73.50 \Omega^{-1} \mathrm{~cm}^{2} /\right.$ equiv.) en comparación con el $\mathrm{Na}^{+}\left(50.11 \Omega^{-1} \mathrm{~cm}^{2} /\right.$ equiv. $){ }^{16}$.

Para el KOH en solución acuosa se consigue la conductividad máxima para concentraciones de $\mathrm{KOH} 6-8 \mathrm{M}$, que se corresponde a un $\approx 28-30 \%$ en peso de $\mathrm{KOH}^{16}$. En la Tabla 2.1-2 se pueden ver algunas propiedades relevantes de una disolución de $\mathrm{KOH}$ al 35\%. Del mismo modo, en la Figura 2.1-3 se muestra la conductividad de disoluciones de $\mathrm{KOH}$ con distintas concentraciones y la solubilidad del $\mathrm{ZnO}$ en esas mismas disoluciones.

\subsubsection{El separador.}

En las baterías, la función básica de un separador es actuar como una barrera física, permitiendo el flujo iónico y evitando el contacto físico de los dos electrodos. A pesar de ser una parte integral de una batería de zinc-aire, el separador no ha recibido merecida atención en comparación con otras partes de la batería. Hasta ahora, la mayoría de los separadores en uso no están diseñados específicamente para la batería de zinc-aire; comúnmente se toman de baterías a base de litio. La función principal del separador en las baterías recargables de zinc-aire es evitar cortocircuitos por la penetración de las dendritas de zinc durante proceso de ciclado. 
Además de la inhibición dendrítica, el separador debe ser electroquímicamente estable dentro de una amplia ventana de potencial de trabajo, ser estable en electrolitos alcalinos fuertes $(\mathrm{pH} \geq 13)$, tener una baja resistencia eléctrica. Idealmente, el separador también debe tener una estructura fina porosa que permita el paso de iones $\mathrm{OH}^{-}$mientras bloquea el anión zincato soluble ${ }^{17}$.

\begin{tabular}{l|l}
\hline \multicolumn{1}{c|}{ PROPIEDAD } & VALOR \\
\hline KOH & \\
Densidad $35 \% \mathrm{KOH}, 8.2 \mathrm{~mol} / 1$ & $1.34 \mathrm{~g} \mathrm{~cm}^{-3}$ \\
Resistividad & $2.3 \Omega \mathrm{cm}$ \\
Solubilidad del ZnO en $35 \% \mathrm{KOH}$ & $0.8 \mathrm{M}$ \\
Supersaturacion de zincato en & $2-3$ veces \\
KOH & solubilidad \\
\hline
\end{tabular}

Tabla 2.1-2: Propiedades relevantes de una disolución de $\mathrm{KOH} 35 \%$ en peso de $\mathrm{KOH}$.

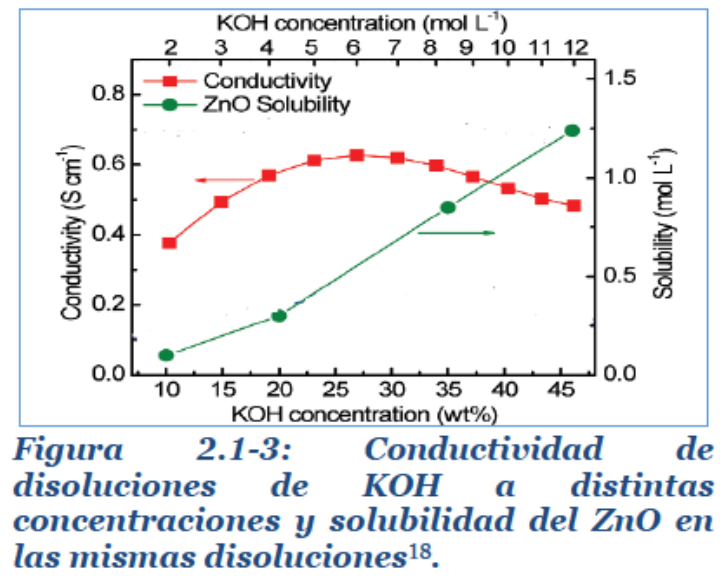

las mismas disoluciones ${ }^{18}$.

Por lo tanto, los separadores deben tener un tamaño de poro adecuado, tienen que ser estables en solución alcalina, aislante para evitar cortocircuitos y permitir la migración de los iones hidróxido. Los separadores están hechos de materiales tales como polietileno, alcohol de polivinilo y polipropileno ${ }^{19}$.

\subsubsection{El cátodo (electrodo de aire).}

En las baterías de zinc-aire, se emplean los llamados electrodos de difusión de gas (GDE) o electrodos de aire. La Figura 2.1-4 muestra gráficamente una estructura de un electrodo de aire y sus componentes. Esta estructura hace posible que una fase líquida y una fase gaseosa coexistan en el electrodo, permitiendo que la reacción química se lleve a cabo, pues el aire puede fluir a través del electrodo sin producirse fugas de electrolito. Además, dentro del GDE se dispone una rejilla de metal que actúa como colector de corriente, proporcionando los electrones necesarios para la reducción del oxígeno. Finalmente, el lado interior del electrodo de aire está equipado con un separador. 
Típicamente, el GDE consiste en una estructura hidrófoba, a base de carbono. Sin embargo, dado que la reducción del oxígeno requiere una alta energía de activación y procede de forma relativamente lenta, la estructura de carbono se mezcla con un catalizador para acelerar la reacción de reducción del oxígeno ${ }^{20}$. Hasta ahora, el catalizador más utilizado son los óxidos de metal no noble, tales como, por ejemplo, dióxido de manganeso. Sin embargo, también se están investigando otros catalizadores. Además, se intenta compensar la lenta velocidad de la reacción ORR por medio de una superficie más grande. Con el fin de preservar la ventaja de la alta densidad de energía de la celda, se buscan por lo tanto materiales porosos, manteniendo el volumen total y la masa del cátodo tan pequeños como sea posible.

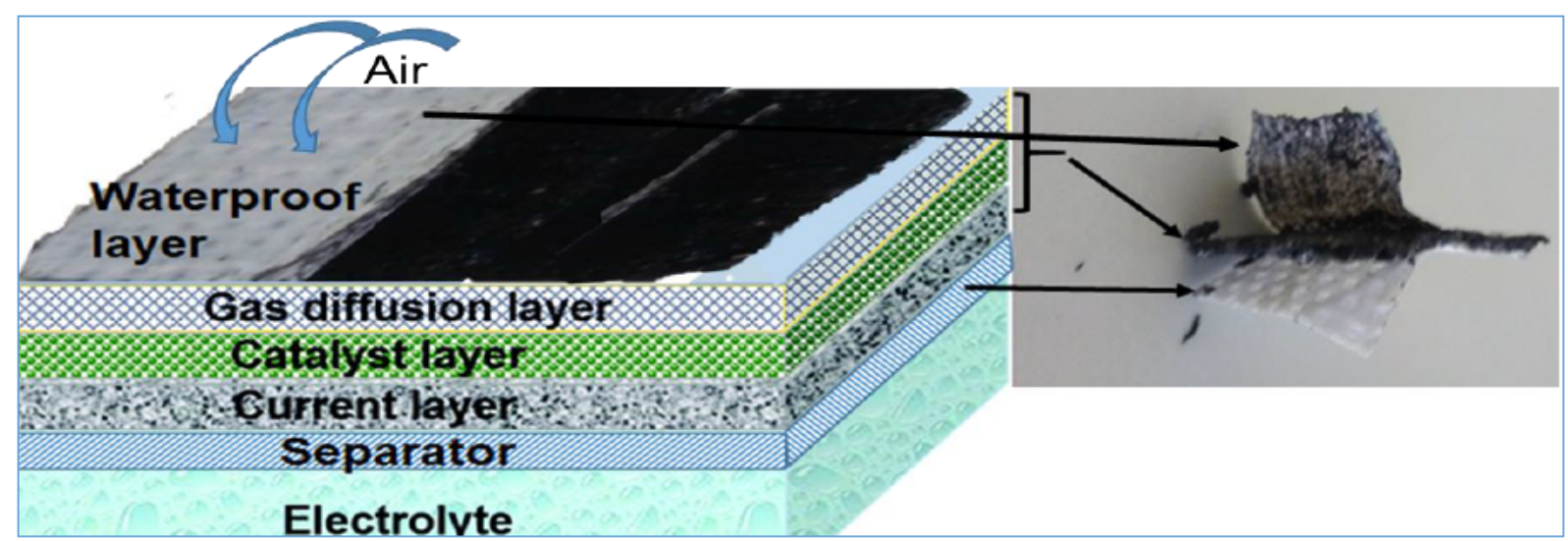

Figura 2.1-4: Vista esquemática de un electrodo de difusión de gas, a la izquierda. Componentes de um Electrodo de aire E4B suministrado por Electric Fuel Ltd., a la derecha.

El cátodo de aire es uno de los componentes más caros de una batería zinc-aire y es, en gran parte, responsable de determinar el rendimiento de la batería. La demanda de cátodos de aire con catalizadores de metales no nobles ha aumentado la actividad investigadora con el fin de obtener nuevos catalizadores ORR que sean activos y duraderos en electrolitos alcalinos ${ }^{20}$.

\subsection{Reacciones químicas.}

En este subcapitulo se va a revisar más de cerca las reacciones químicas que tienen lugar en la celda electroquímica. En la Figura 2.2-1, éstas se muestran esquemáticamente. En el ánodo, el zinc se oxida cuando la batería es descargada. En teoría, diferentes zincatos de la forma $\mathrm{Zn}(\mathrm{OH})_{x}^{y-}$ pueden surgir, de acuerdo con Pessine 
et al. ${ }^{21}$. Sin embargo, se suele aceptar que, principalmente es el $\mathrm{Zn}(\mathrm{OH})_{4}^{2-}$ el que está presente. La oxidación puede entonces ser considerada como:

$$
\mathrm{Zn}+4 \mathrm{OH}^{-} \leftrightarrows \mathrm{Zn}(\mathrm{OH})_{4}^{=}+2 \mathrm{e}^{-}
$$

La reacción global se puede dividir en sucesivas etapas simples con cinéticas de primer orden. Por ejemplo, Bockris et al. ${ }^{22}$ han propuesto el siguiente mecanismo de cuatro pasos:

$$
\begin{aligned}
& \mathrm{Zn}+\mathrm{OH}^{-} \leftrightarrows \mathrm{Zn}(\mathrm{OH})+\mathrm{e}^{-} \\
& \mathrm{Zn}(\mathrm{OH})+\mathrm{OH}^{-} \leftrightarrows \mathrm{Zn}(\mathrm{OH})_{2}^{-} \\
& \mathrm{Zn}(\mathrm{OH})_{2}^{-}+\mathrm{OH}^{-} \leftrightarrows \mathrm{Zn}(\mathrm{OH})_{3}^{-}+\mathrm{e}^{-} \\
& \mathrm{Zn}(\mathrm{OH})_{3}^{-}+\mathrm{OH}^{-} \leftrightarrows \mathrm{Zn}(\mathrm{OH})_{4}^{=}
\end{aligned}
$$

La velocidad de reacción de la etapa (4) es significativamente más lenta que la de las otras etapas, y por tanto, determina la velocidad de la reacción global. La formación del anión zincato también ha sido reportada por Chang et al. ${ }^{23}$ y Prentice et al. ${ }^{24}$ a partir de un mecanismo de tres etapas, respecto al proceso de disolución anódica del zinc.

Cuando el electrolito es saturado con zincato, $\mathrm{ZnO}$ precipitará formando una capa pasiva blanca y porosa de óxido de zinc, $\mathrm{ZnO}$ de Tipo $\mathrm{I}^{25}$, siguiendo la siguiente reacción:

$$
\mathrm{Zn}(\mathrm{OH})_{4}^{=} \leftrightarrows \mathrm{ZnO}+\mathrm{H}_{2} \mathrm{O}+2 \mathrm{OH}^{-}
$$

Por lo tanto, la reacción global para la disolución de Zn se expresa según la siguiente reacción:

$$
\mathrm{Zn}+2 \mathrm{OH}^{-} \leftrightarrows \mathrm{ZnO}+\mathrm{H}_{2} \mathbf{O}+2 \mathrm{e}^{-}
$$

Esta reacción se produce principalmente en la superficie del ánodo de zinc y forma una capa porosa de óxido de zinc, $\mathrm{ZnO}$ de tipo $\mathrm{I}^{26}$, que poco a poco pasiva el ánodo. Para que la oxidación pueda continuar, los iones hidroxilo primero deben ser transportados a través de la capa de óxido de zinc mencionada hasta alcanzar el 
electrodo. Como la capa de óxido crece, el anión hidroxilo se difunde a una velocidad más lenta. Por lo tanto, la concentración de hidroxilo en la superficie de zinc disminuye y la reacción es inhibida, disminuyendo el voltaje de la celda. Si el voltaje de la celda cae, óxido de zinc $\mathrm{ZnO}$ de Tipo II precipita. Éste, forma una capa de óxido de zinc compacto, que pasiva inmediatamente el ánodo donde se deposita ${ }^{26}$. El óxido de zinc de tipo II, sin embargo, sólo se produce a voltajes de celda por debajo de 0.9 voltios, mientras que la tensión nominal de una celda de zinc-aire es de aproximadamente 1.4 voltios. Por lo tanto, este efecto sólo se produce cuando la celda está casi descargada.

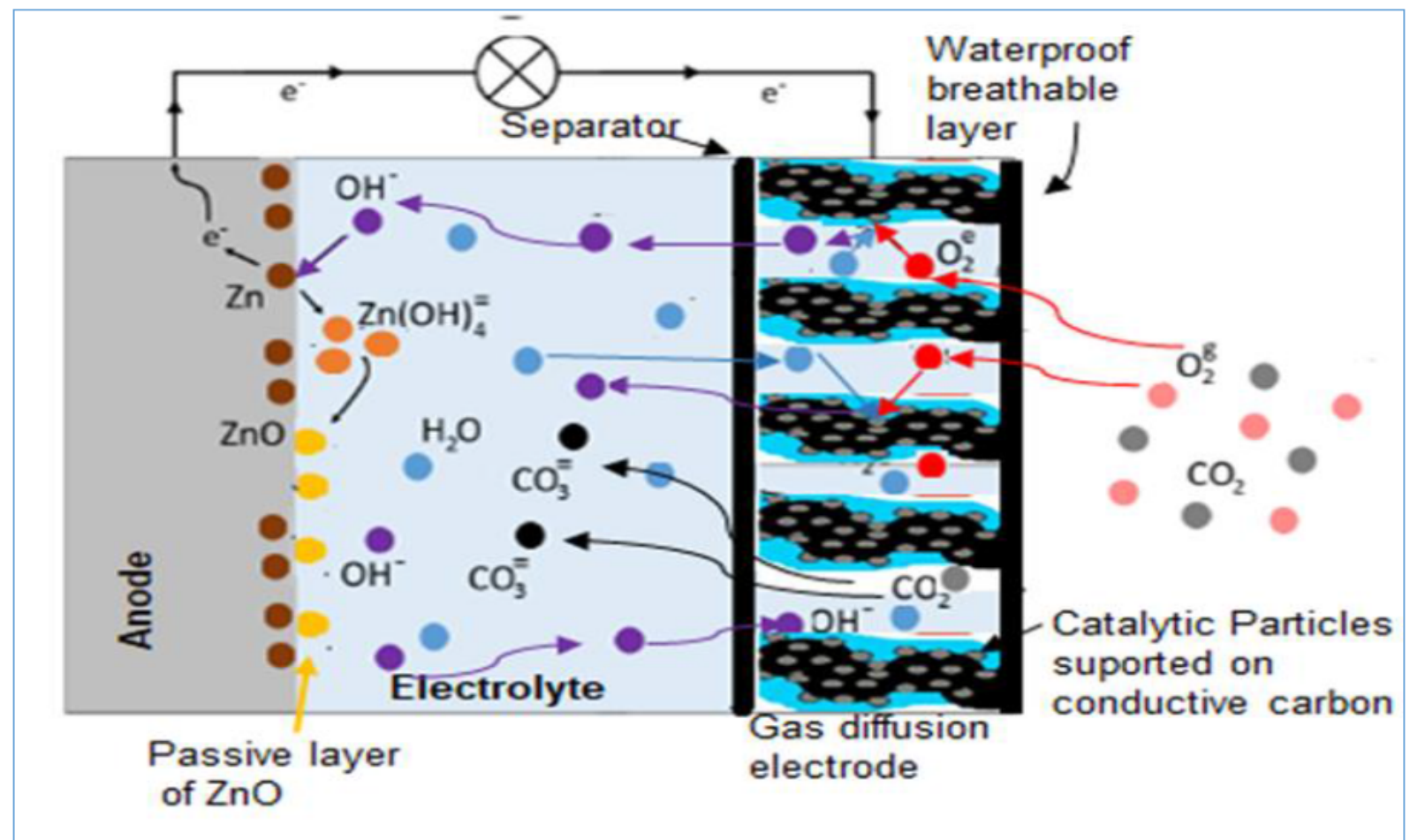

Figura 2.2-1: Vista esquemática de las reacciónes químicas implicadas en uma batería de zincaire. El zinc se oxida en el ámodo para formar $\mathrm{ZnO}$ vía zincato. El oxígeno permea a través del electrodo de aire y se reduce para formar aniones hidroxilo. $\mathrm{El} \mathrm{CO}_{2}$ presente en el aire también se disuelve en el electrolito para formar carbonato.

Las reacciones (1) y (2) se producen hasta que la solubilidad del anión zincato alcanza el punto de saturación, momento en el cual $\mathrm{ZnO}$ es depositado sobre el electrodo formando una capa poco conductora que provoca la pasivación del electrodo y el cambio en la morfología del mismo. Sin embargo, el proceso de formación del ZnO no está definido claramente y varios autores han propuesto mecanismos donde $\mathrm{Zn}(\mathrm{OH})_{2}$ 
$\mathrm{u}$ otros compuestos del tipo $\mathrm{Zn}-\mathrm{OH}$ se forman previamente a la deposición del $\mathrm{ZnO}^{6,16,27-29}$.

De acuerdo a varios autores, una película de $\mathrm{Zn}(\mathrm{OH})_{2}$ se pueden formar a potenciales altos, la cual se convierte en una película o capa pasivante de $\mathrm{ZnO}$ cuando se alcanzan potenciales más catódicos. Así, en baterías totalmente descargadas solo se encuentra $\mathrm{ZnO}$.

Cai et al. ${ }^{27}$ concluyeron a partir de estudios espectroelectroquímicos que la película prepasiva formada antes de la completa pasivación del electrodo está compuesta de $\mathrm{ZnO}$ y $\mathrm{Zn}(\mathrm{OH})_{2}$. Mainar et al. ${ }^{6}$ lleva acabo una profunda revisión del proceso de disolución anódica del zinc así como de la pasivación del mismo siguiendo un diagrama de Pourbaix. En él, se detallan todas las especies posibles en función del $\mathrm{pH}$, el cual afecta a la diversidad de las especies posibles.

En el cátodo, el oxígeno del aire permeará a través de la membrana exterior del cátodo hasta alcanzar los centros activos donde a continuación, se reducirá para formar el anión hidroxilo. Para ello, en los sitios activos deben coexistir las tres fases, centros activos de carbón con catalizador, electrolito liquido donde se disolverá el hidroxilo y el oxígeno gaseoso para ser reducido ${ }^{30,31}$ tal y como se muestra en la Figura 2.2-2; y de acuerdo a la reacción siguiente:

$$
\mathrm{O}_{2}+\mathrm{H}_{2} \mathrm{O}+2 e^{-} \leftrightarrows 2 \mathrm{OH}^{-}
$$

Por otro lado, hay algunas reacciones secundarias que son importantes de mencionar. Primero de todo, el dióxido de carbono del aire ambiente se difunde también a través de la capa externa de PTFE y reacciona con los grupos hidroxilo en el medio acuoso para formar carbonatos. Está ampliamente aceptado que estos carbonatos tienen efectos perjudiciales sobre todo para el rendimiento de la celda. Por un lado, $\mathrm{KOH}$ se consume (reacción 9), lo que perjudica la conductividad eléctrica del electrolito y acelera la pasivación a través de la capa de óxido de zinc. Por otro lado, disminuye la solubilidad de zincato y oxígeno e inhibe las dos semireacciones 6 y 8 . Además, se produce la obstrucción de poros en el electrodo de difusión de gas cuando 
los carbonatos precipitan ${ }^{16,32}$. Por ultimo las baterías secundarias también tienen el problema de que la reacción 9 no se revierte cuando se recarga la celda.

$$
\mathrm{CO}_{2}+2 \mathrm{OH}^{-} \leftrightarrows \mathrm{CO}_{3}^{\overline{-}}
$$

En paralelo con la reacción de oxidación en el electrodo negativo, se produce una reacción parásita no deseada entre el zinc y el agua resultando en la generación de gas hidrógeno (reacción 10). Ésto provoca una “auto-corrosión” del zinc reduciendo la eficiencia electroquímica del material activo ${ }^{32}$.

$$
\mathrm{Zn}+2 \mathrm{H}_{2} \mathrm{O} \leftrightarrows \mathrm{Zn}(\mathrm{OH})_{2}+\mathrm{H}_{2} \uparrow
$$

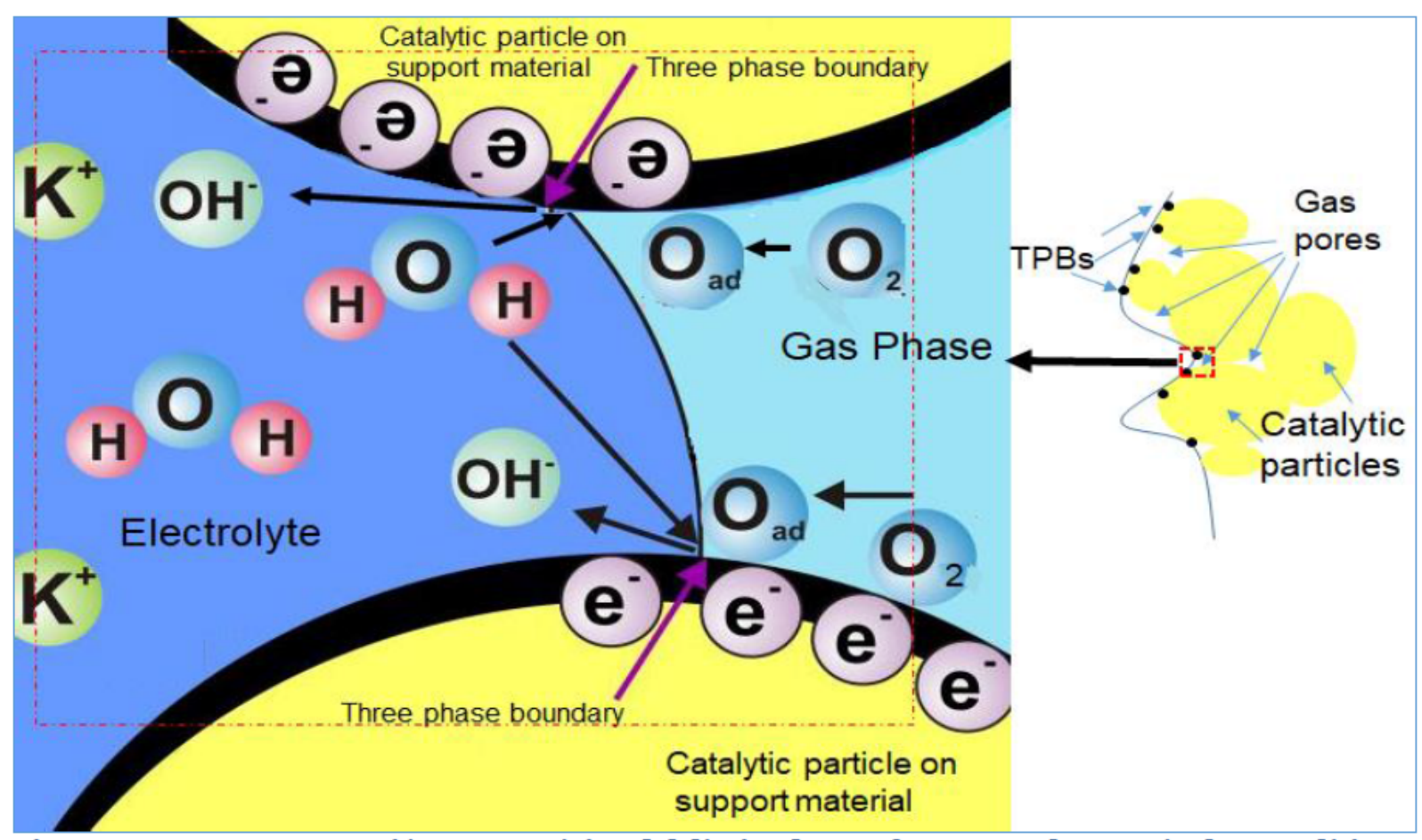

Figura 2.2-2: Representación esquemática del límite de tres fases entre las partículas catalíticas.

\subsection{Electrolitos de geles poliméricos.}

El estudio de los electrolitos de geles poliméricos comenzó con Wright et al. ${ }^{33} \mathrm{en}$ 1973, pero su importancia tecnológica no se puso de relieve hasta que la investigación realizada por Armand et al. ${ }^{34}$ demostró que la fase semicristalina formada en geles a partir de sales de metales alcalinos y de poli (óxido de etileno) (PEO) eran capaces de 
tener conductividad iónica significativa; y señaló su posible aplicación como electrolitos en baterías. Desde entonces, se han hecho grandes avances en este campo dando lugar a un gran número de documentos técnicos ${ }^{35,36}$.

Típicamente, en un GPE se utiliza un polímero como "material anfitrión o soporte", "host material" en inglés, proporcionando integridad y estabilidad mecánica. Son varios los criterios que el polímero debe cumplir para ser considerado como buen "material anfitrión":

- rápido movimiento de los segmentos de la cadena de polímero.

- grupos funcionales que promuevan la disolución de sales.

- baja temperatura de transición vítrea $(\mathrm{Tg})$.

- alto peso molecular.

- amplia ventana electroquímica.

- alta temperatura de degradación.

Dentro de la matriz polimérica, las sales en los GPEs sirven como portadores de carga, que generalmente se requiere que tengan baja energía de disociación con el fin de disociar éstas en los iones móviles ${ }^{37}$ que serán responsable del transporte de carga y por tanto de la conductividad.

Se han preparado y caracterizado un gran número electrolitos poliméricos, sin embargo, pueden ser agrupados en tres categorías generales: electrolitos poliméricos sólidos (SPE), electrolitos poliméricos gelatinizados o gelificados (GPE) y polielectrolitos ${ }^{38}$. Mencionar los hidrogeles, utilizados profusamente en este trabajo, cuando el gel polimérico se ha fabricado en medio acuoso.

En los SPE se disuelva una sal, por ejemplo de litio $\left(\mathrm{LiCIO}_{4}, \mathrm{LiBF}_{4}, \mathrm{LiPF}_{6}\right.$, $\mathrm{LiCF}_{3} \mathrm{SO}_{3}$, $\left.\mathrm{LiC}\left(\mathrm{CF}_{3} \mathrm{SO}_{2}\right)_{3}\right)$, en polímeros de alto peso molecular, como pueden ser, PEO y PPO, los cuales actúan como disolventes sólidos ${ }^{39}$. La segunda categoría consiste en electrolitos que contienen, además del polímero "anfitrión” y una sal, una proporción significativa de disolventes líquidos, pudiendo ser estos de naturaleza acuosa $\mathrm{u}$ orgánica ${ }^{40}$. Por último, los polielectrolitos están constituidos por cadenas poliméricas que contienen grupos eléctricamente cargados en cada unidad monómerica, los cuales 
son compensados por iones libres, que serán responsables de la conductividad ${ }^{41}$ (Figura 2.3-1).

\subsubsection{PVdF-HFP.}

En las últimas décadas se han sintetizado una gran variedad de electrolitos poliméricos y co-polímeros, tratando de mejorar su estabilidad electroquímica, mecánica, así como su flexibilidad. Desde entonces, se han obtenido GPEs utilizando polímeros o copolímeros estructuralmente similares ${ }^{42-45}$. La Tabla 2.3-1 recoge en una lista, no exclusiva, los polímeros más comunes utilizados para la fabricación de SPEs y GPEs.

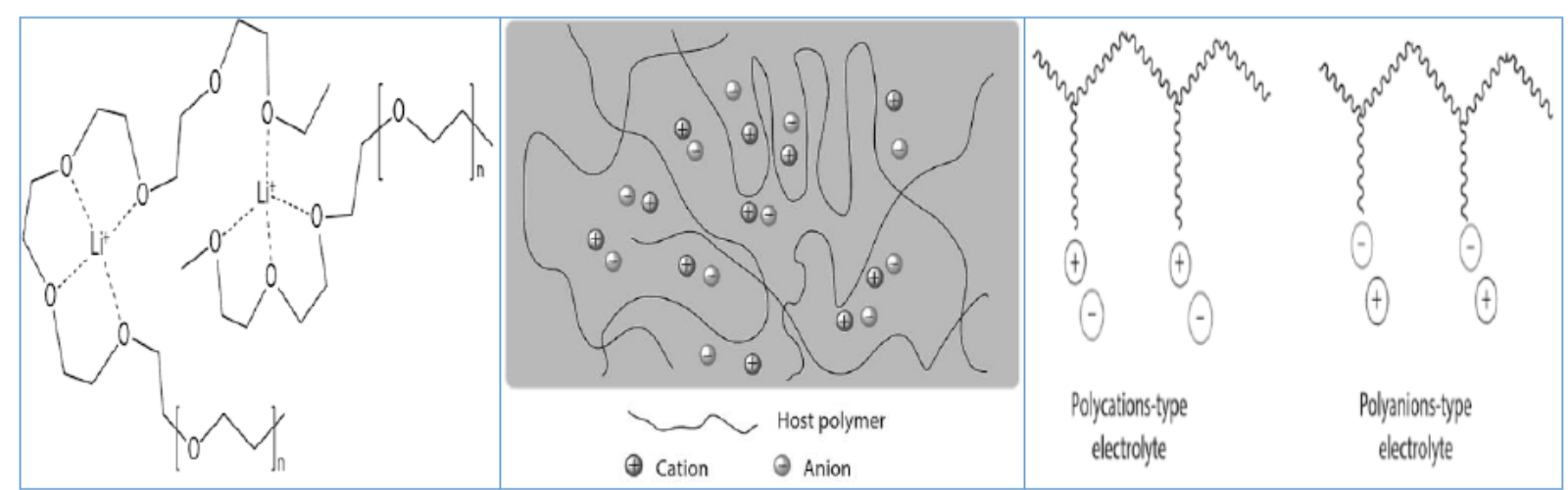

Figura 2.3-1: SPE, electrolito polimérico sólido, izquierda, GPE, gel polimérico, centro, polielectrolito, derecha.

El fluoruro de polivinilideno (PVdF) es un termoplástico industrial de la familia de los fluoropolímeros, semicristalino con tres fases cristalinas, $\alpha, \beta$ y $\gamma$. Las dos primera prevalecen a temperatura ambiente, siendo la última responsable de las características piezoeléctricas en el PVdF, debido a la orientación de los átomos en su estructura molecular ${ }^{46}$.

El PVdF tiene un punto de fusión relativamente bajo de alrededor de $177^{\circ} \mathrm{C}$. Tiene baja densidad, su estructura molecular y alta cristalinidad le proporciona una alta estabilidad mecánica, incluso a altas temperaturas. Su excelente resistencia a los productos químicos hace que sea un material ideal para un gran número de aplicaciones, por lo general en aplicaciones que requieren resistencia a disolventes, ácidos, bases, calor y baja emisión de humos durante un hipotético incendio. 
CAPITULO II. Revisión Teórica y Bibliográfica.

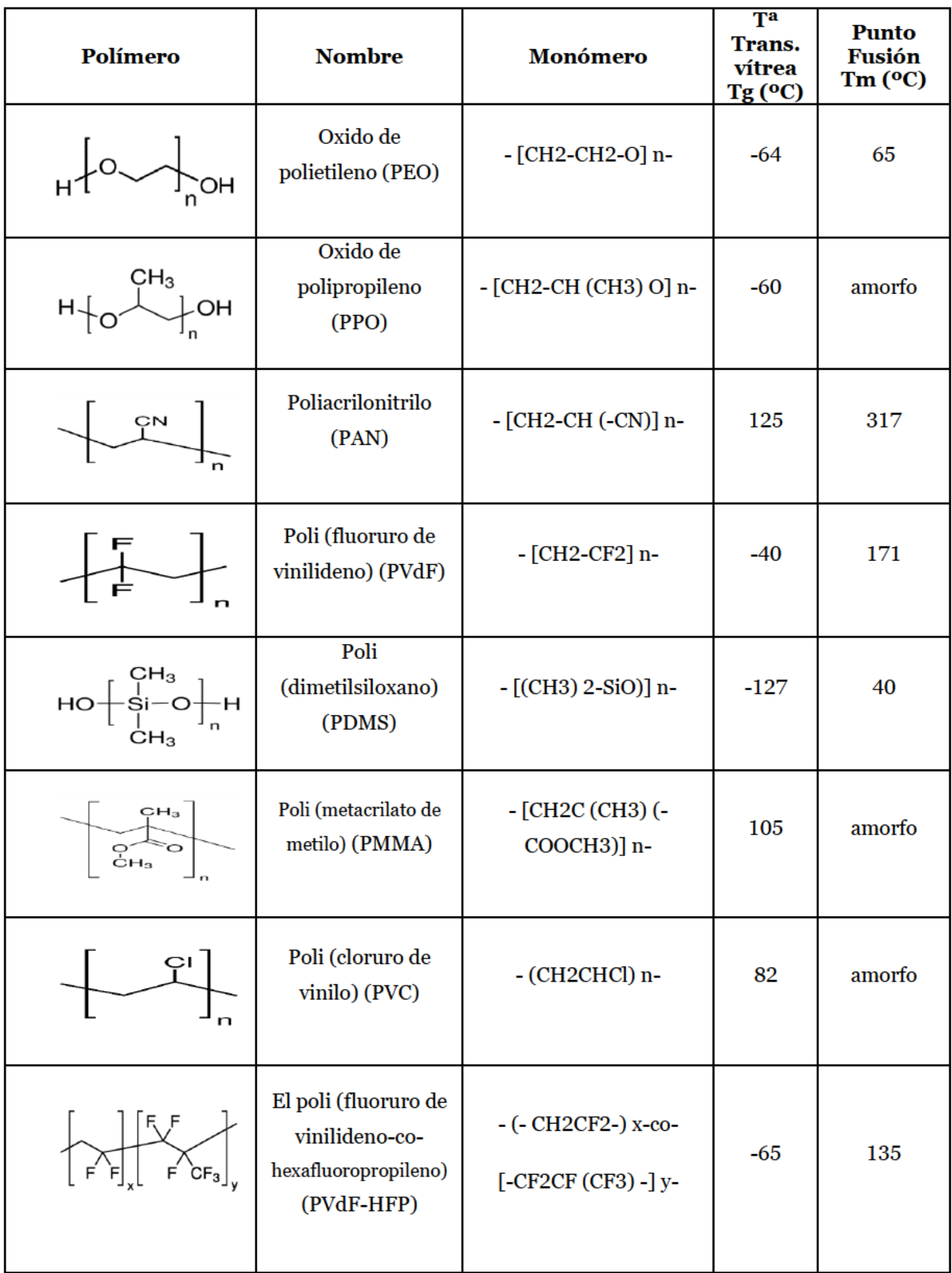

Tabla 2.3-1: Polímeros más comumes utilizado para fabricar GPEs y SPEs. 
La introducción en la cadena de PVdF de grupos funcionales con grupos electronegativos fuertes $\left(-\mathrm{CF}_{3}\right)$ le confiere una alta constante dieléctrica $(\varepsilon=8.4)$, lo cual es beneficioso para la disolución de sales y mantiene una alta concentración de portadores de carga dentro de la matriz favoreciendo así la conductividad ${ }^{38}$.

De esta manera, al copolimerizar VDF y HFP se obtiene el PVdF-HFP, el cual presenta una baja cristalinidad en comparación con PVdF. Como resultado, en el PVdF-HFP se presentan dominios más cristalinos alternados con otros más amorfos, estos últimos capaces de contener grandes cantidades de sales y electrolitos líquidos ${ }^{47}$.

Se considera también que el aumento de los dominios amorfos dentro de una matriz polimérica proporciona una mejor conductividad, ya que los iones son más libres para moverse. Por lo tanto, el PVdF-HFP es considerado como una de las matrices más prometedora como material "anfitrión" en geles poliméricos. Las principales propiedades del PVdF-HFP se muestran en la Tabla 2.3-2 y una lista más extensa de propiedades se puede encontrar en "Handbook of Polymers"48.

Los primeros trabajos sobre PVdF fueron publicados por Tsuchida et al.49. Estos autores estudiaron los sistemas de PVdF plastificados con $30 \mathrm{~mol} \% \mathrm{LiClO}_{4}$ y diferentes plastificantes, observando un incremento de la conductividad en el siguiente orden: DMF $>$ butirolactona $>$ EC $>$ PC $>$ PEG 400 > PPG 1000.

Tsunemi et al.50 advirtieron que el problema más crítico del electrolito polimérico basado en PVdF es su incompatibilidad con el metal de litio. De hecho, los polímeros fluorados no son químicamente estables frente al litio, lo que resulta en la formación de LiF y hace que los electrolitos basados en PVdF no sean aptos para baterías que contengan este metal.

Tarascon et al. ${ }^{51}$ reemplazaron el PVdF por el copolímero PVdF-HFP. Como ya se ha apuntado, las películas de electrolito de PVdF sufrían de diversas deficiencias. Sus propiedades mecánicas eran a menudo muy pobres y las películas tuvieron que ser endurecidas por medio de reticulación química o física. Al usar PVdF-HFP, se superaron con éxito estas dificultades y desarrollaron electrolitos fiables y prácticos en baterías de ion-litio. Estos polímeros contenían dominios amorfos capaces de atrapar 
grandes cantidades de electrolitos líquidos; y regiones cristalinas que proporcionaron suficiente integridad mecánica, eliminando, de este modo, la necesidad de cualquier reticulación u otros procesos para el endurecimiento o la mejora de sus propiedades mecánicas. Identificaron en el GPE al menos cuatro fases: una fase semicristalina con un grado relativamente bajo de cristalinidad (20-30\%), una fase amorfa que contenía el disolvente o plastificante, una fase con gran volumen de poros y, finalmente, zonas donde los "filler" añadidos se encontraban rodeados de electrolito líquido.

Jiang et al. ${ }^{52}$ prepararon membranas de electrolito polimérico compuesto de PVdF, carbonato de etileno (EC), carbonato de propileno (PC) y una sal de Li (LiX = $\mathrm{LiCF}_{3} \mathrm{SO}_{3}, \mathrm{LiPF}_{6}$ o LiN $\left.\left(\mathrm{SO}_{2} \mathrm{CF}_{3}\right)_{2}\right)$ usando un método de extrusión. Los electrolitos que contenían el copolímero de PVdF-HFP y LiN $\left(\mathrm{SO}_{2} \mathrm{CF}_{3}\right)_{2}$ tenían el rango de composición más amplio para sintetizar películas de electrólitos dimensionalmente estables. Se caracterizaron la resistencia, la ventana de estabilidad electroquímica y la estabilidad de la interfaz Li/electrolito. Se encontró que la plastificación de PVdF con la solución EC/PC/LiX alteró significativamente su estructura cristalina y la resistencia mecánica de las películas de electrolito de polímero varió ampliamente dependiendo del contenido en PVdF. La conductividad de los electrolitos se vio influenciada por la viscosidad del medio y la concentración de los portadores de carga, que están directamente relacionados con la proporción en peso de $\mathrm{PVdF} /(\mathrm{EC} / \mathrm{PC})$ y el tipo y la concentración de la sal de litio. Se observó que las conductividades a temperatura ambiente eran de $2.2 \times 10^{-3} \mathrm{Scm}^{-1}$ para electrolitos que contenían $\mathrm{LiN}\left(\mathrm{SO}_{2} \mathrm{CF}_{3}\right)_{2}$.

Jacob et al. ${ }^{53}$ prepararon y caracterizaron las membranas de electrolito polimérico con PVdF, PEO, y LiClO4. La miscibilidad entre el PVdF y PEO fue estudiada por XRD y DTA con el fin de entender la compatibilidad química entre ellos. La caracterización estructural se llevó a cabo en películas finas utilizando XRD. La conductividad y la integridad mecánica del sistema PVdF: $\mathrm{LiClO}_{4}$ polimérico fue estudiada en función de la concentración de PEO. La adición de PEO al sistema PVdF: $\mathrm{LiClO}_{4}$ mejoró la conductividad a temperatura ambiente y la estabilidad mecánica. Encontraron que la conductividad máxima a $30^{\circ} \mathrm{C}$ era $\approx 10^{-5} \mathrm{Scm}^{-1}$ para $\left(\mathrm{PVdF}^{-\mathrm{LiClO}_{4}}\right.$ ): PEO(80:20). 


\begin{tabular}{|c|c|c|}
\hline PARÁMETRO & UNIDAD & VALOR \\
\hline Densidad a $20^{\circ} \mathrm{c}$ & $\mathrm{g} / \mathrm{cm}^{3}$ & $1.77-1.86$ \\
\hline Color & - & gris plata y ámbar \\
\hline Índice de refracción, $2^{\circ} \mathrm{c}$ & - & 1.41 \\
\hline Olor & - & inodoro \\
\hline Temperatura de fusión, & ${ }^{\mathbf{o}} \mathbf{C}$ & 125-164 \\
\hline Temperatura de descomposición, DSC. & ${ }^{\circ} \mathbf{C}$ & > 204; > 330; 330-370 \\
\hline Coef. Exp.Térmica, 23-80 ${ }^{\circ} \mathrm{C}$ & $10^{-4} \mathbf{o}^{-1}$ & 1.5-1.7 \\
\hline Ángulo de contacto del agua, $20^{\circ} \mathrm{C}$ & grados & 152 \\
\hline Conductividad térmica, $2^{\circ} \mathrm{C}$ & $\mathbf{W} \mathbf{m}^{-1} \mathbf{K}^{-1}$ & 0.18 \\
\hline Temperatura de transición vítrea & ${ }^{\circ} \mathbf{C}$ & $-5--40$ \\
\hline Capacidad calorífica específica & $\mathbf{J} \mathbf{K}^{-1} \mathbf{k g}^{-1}$ & 1.2 \\
\hline Calor de fusión & $\mathbf{k J} \mathbf{~ m o l}^{-1}$ & 39 \\
\hline Temperatura máxima de servicio & ${ }^{\circ} \mathbf{C}$ & $>\mathbf{2 0 0}$ \\
\hline Entalpía de fusión & $\mathbf{J ~ g}^{-1}$ & $36.0-65.0$ \\
\hline
\end{tabular}

Tabla 2.3-2: Propiedades más relevantes del copolimero PVdF-HFP.

Jacob et al. ${ }^{54}$ llevaron a cabo estudios de FTIR de PVdF, plastificados con DMF, y sus mezclas con $\mathrm{LiBF}_{4}$. Los espectros de $\mathrm{LiBF}_{4}$-DMF para diversas concentraciones de sal mostraron el desplazamiento de la banda del grupo $\mathrm{O}=\mathrm{C}-\mathrm{N}$ del DMF desde 659 $\mathrm{cm}^{-1}$ a $680 \mathrm{~cm}^{-1}$. La división de la banda "stretching" simétrica del grupo $\mathrm{CN}$ del plastificante en un doblete a 860 y $880 \mathrm{~cm}^{-1}$ es una evidencia de la interacción plastificante-polímero.

Zhaohui Li et al. ${ }^{55}$ examinaron el efecto de nanopartículas de $\mathrm{Al}_{2} \mathrm{O}_{3}$ sobre las propiedades electroquímicas de los electrolitos poliméricos basados en PVdF-HFP. Los autores aseguran que la adición de partículas de alúmina disminuye el grado de 
cristalización del polímero y aumenta la fase amorfa del electrolito polimérico. Este resultado sugiere que las partículas de relleno desempeñan el papel de plastificante para la matriz polimérica.

Ataollahi et al. ${ }^{56}$ prepararon PVdF-HFP/MG49 dopado con $\mathrm{LiBF}_{4}$ mediante "solution casting method". La conductividad iónica mejoró significativamente de 10-9 a $10^{-4} \mathrm{~S} \mathrm{~cm}^{-1}$ con el aumento en porcentaje de sal $\mathrm{LiBF}_{4}$. La conductividad iónica más alta era de aproximadamente $\approx 2.8 \times 10^{-4} \mathrm{~S} \mathrm{~cm}^{-1}$ para la muestra con $30 \%$ en peso de $\mathrm{LiBF}_{4}$. Los Análisis FTIR confirmaron la interacción entre los iones Li y el polímero y por difracción de rayos $\mathrm{X}$ se confirmó que la sal, produjo una disminución de la cristalinidad.

Stephan et al. ${ }^{57}$ prepararon electrolitos poliméricos compuestos de PVdF-HFP con oxihidróxido de aluminio como "filler" inerte y $\mathrm{LiN}\left(\mathrm{CF}_{3} \mathrm{SO}_{2}\right)_{2}$ como sal de litio. La incorporación del "filler" inerte reduce la cristalinidad del polímero "anfitrión” y actúa como "plastificante sólido" capaz de mejorar las propiedades de transporte. Además, proporcionó mejores propiedades interfaciales entre el ánodo metálico de litio y el electrolito polimérico

En 2010, Yu et al. ${ }^{58}$ sintetizaron un electrolito hidrófobo compuesto de un líquido iónico, sílice y PVdF-HFP, el cual fue empleado en baterías de Li-aire por primera vez. El electrolito polimérico fabricado ofreció una alta conductividad iónica de $\approx 1.83 \times 10^{-3} \mathrm{Scm}^{-1}$ a temperatura ambiente. El perfil de descarga plano y gran capacidad de descarga indican que la membrana de electrolito hidrófoba protegió eficazmente al litio de la humedad.

Liao et al. ${ }^{59}$ prepararon un gel polimérico mezclando PVdF-HFP y acetato de celulosa (CA), en la que el CA mejora la humectabilidad y la conductividad iónica de las membranas. La batería de Li-oxigeno fabricada con la membrana sintetizada presenta buena absorción de electrolito y alta conductividad iónica, así como una excelente estabilidad térmica y electroquímica y una mayor retención de la capacidad de ciclado. 
Tafur et al. ${ }^{60}$ estudiaron GPEs sintetizados con diferentes líquidos iónicos y PVdF-HFP, con y sin sal de ZnTf 2 . La incorporación de IL o IL + ZnTf 2 al polímero produjo membranas más amorfas y polares en comparación con la película de PVdFHFP pura, como se deduce de los datos de ATR-FTIR y XRD. La conductividad iónica y las mediciones de impedancia y de voltametría indicaron que las propiedades eléctricas de los GPEs dependen claramente del catión del IL utilizado. De los resultados de impedancia, se demostró que el electrolito con [P6,6,6,14]TFSI era más resistivo que los electrolitos basados en EMIMTFSI y EPYTFSI, lo cual se puede atribuir al mayor volumen del catión [P6,6,6,14]. La inclusión de la sal ZnTf 2 produjo un aumento en la conductividad iónica y una disminución en la energía de activación, que se relaciona con la existencia de aniones triflato libres, como se dedujo a partir de los análisis de ATR-FTIR.

Pandey et al. ${ }^{61}$ sintetizaron geles poliméricos con sal de $\mathrm{MgTf}_{2}$ en un líquido iónico, EMIMTf, inmovilizados en PVdF-HFP y fue comparado con una mezcla de PVdF-HFP y líquido iónico. Atendiendo a los resultados de varios estudios estructurales, térmicos, eléctricos y electroquímicos, consiguieron películas flexibles con una conductividad $\approx 10^{-3} \mathrm{~S} \mathrm{~cm}^{-1}$. Debido a la inmovilización del líquido iónico y la sal de Mg en el GPE se produjeron cambios conformacionales sustanciales en la textura cristalina del polímero "anfitrión" PVdF-HFP.

El tipo del disolvente, así como las cantidades durante el proceso de "solution casting method" es también de gran importancia y fue objeto de estudió por Kumar et al62. Cantidades más altas de disolventes dentro de la matriz polimérica mejoran la movilidad iónica, por tanto, la conductividad. Sin embargo, éstos deben tener un punto de ebullición alto como para evitar la evaporación durante el funcionamiento del gel que podría causar la pérdida de conductividad. Una forma de superar tal problema es la adición de líquidos iónicos a los GPEs. Actualmente un enfoque para aumentar la conductividad iónica en los GPEs parece ser la incorporación de líquidos iónicos en ellos $^{63}$. En la Tabla 2.3-3 se muestran los disolventes orgánicos más utilizados para la preparación de GPEs. 


\subsubsection{Líquidos iónicos.}

En 1914, Paul Walden sintetiza una sustancia llamada nitrato de etilamonio ${ }^{64}$. Esta sal tiene la propiedad especial de que es líquido a temperatura ambiente, ya que su punto de fusión es de sólo $12{ }^{\circ} \mathrm{C}$. Sin ser consciente de ello, Walden descubrió una nueva clase de material que más tarde se conocerán como "líquidos iónicos". Aunque Walden había descubierto el primer líquido iónico a temperatura ambiente (RTIL por sus siglas en inglés) hace casi un siglo, pasarían décadas antes de que los científicos se interesaran más de cerca en esta clase de sustancias. Sólo unos pocos trabajos sobre los "líquidos iónicos" se publicaron en la década de los noventa, aumentando continuamente desde entonces y hasta la fecha.

Los líquidos iónicos son sales que tienen un punto de fusión muy bajo. Peter Wasserscheid las definió como: las sales con un punto de fusión por debajo de $100{ }^{\circ} \mathrm{C}$ se definen como un líquido iónico, mientras que las sales con un punto de fusión por debajo de la temperatura ambiente (por debajo de $25^{\circ} \mathrm{C}$ ) se conocen como líquidos iónicos a temperatura ambiente ${ }^{65}$. Ésta, es una definición muy abierta y no es obligatorio su uso estrictamente, ya que a veces sustancias liquidas por encima de 100 ${ }^{\circ} \mathrm{C}$ fueron llamados también IL.

Un líquido iónico se compone de un catión y un anión. Como cationes, generalmente un catión orgánico, se utilizan frecuentemente imidazolio, piridinio, tetra-alquilamonio y tetra-alquilo de fosfonio. Como aniones, sin embargo, se usan haluros, nitratos, pero también aniones orgánicos más grandes. Los líquidos iónicos se pueden modificar para adaptarse a una aplicación determinada variando los tamaños y las interacciones entre los aniones y cationes. En la Figura 2.3-2 se muestran los cationes y aniones más utilizados en líquidos iónicos.

Vale la pena mencionar algunos aspectos de interés de estos productos para la investigación científica, tales como una gran ventana electroquímica, alta conductividad, líquido sobre un amplio rango de temperaturas y baja presión de vapor que los hacen de interés industrial en procesos químicos donde la evaporación es un inconveniente. 


\begin{tabular}{|c|c|c|c|c|}
\hline Disolvente & $\begin{array}{l}\text { Fórmula } \\
\text { química }\end{array}$ & $\begin{array}{c}\text { Punto de } \\
\text { ebullición }\left({ }^{\circ} \mathrm{C}\right)\end{array}$ & $\begin{array}{c}\text { Constante } \\
\text { dieléctrica- } \mathrm{T}^{\mathrm{a}}\left({ }^{\circ} \mathrm{C}\right) \\
\end{array}$ & $\begin{array}{c}\text { Densidad } \\
\mathrm{g} / \mathrm{cm}^{3} \\
\end{array}$ \\
\hline $\begin{array}{l}\text { Carbonato de } \\
\text { etileno }\end{array}$ & & 261 & $89.8-40$ & 1.321 \\
\hline $\begin{array}{l}\text { Carbonato de } \\
\text { propileno }\end{array}$ & & 240 & $66.1-20$ & 1.205 \\
\hline Dimetilsulfóxido & & 189 & $47.2-20$ & 1.092 \\
\hline$\gamma$-butirolactona & & 204 & $39.0-20$ & 1.128 \\
\hline Dimetilformamida & & 153 & $38.2-20$ & 0.944 \\
\hline $\begin{array}{c}\mathrm{N}, \mathrm{N}- \\
\text { dimetilacetamida }\end{array}$ & & 164 & $39,8-21$ & 0.940 \\
\hline Acetonitrilo & & 82 & $36.6-20$ & 0.786 \\
\hline N- metil-2- & & 202 & $32.2-25$ & 1.028 \\
\hline Tetrahidrofurano & & 66 & $7.5-22$ & 0.889 \\
\hline $\begin{array}{l}\text { Carbonato de } \\
\text { dimetilo }\end{array}$ & & 90 & $3.1-25$ & 1.060 \\
\hline
\end{tabular}

Tabla 2.3-3. Algunas de las propiedades físicas de los disolventes orgánicos más utilizados en el campo de investigación de los GPEs. 


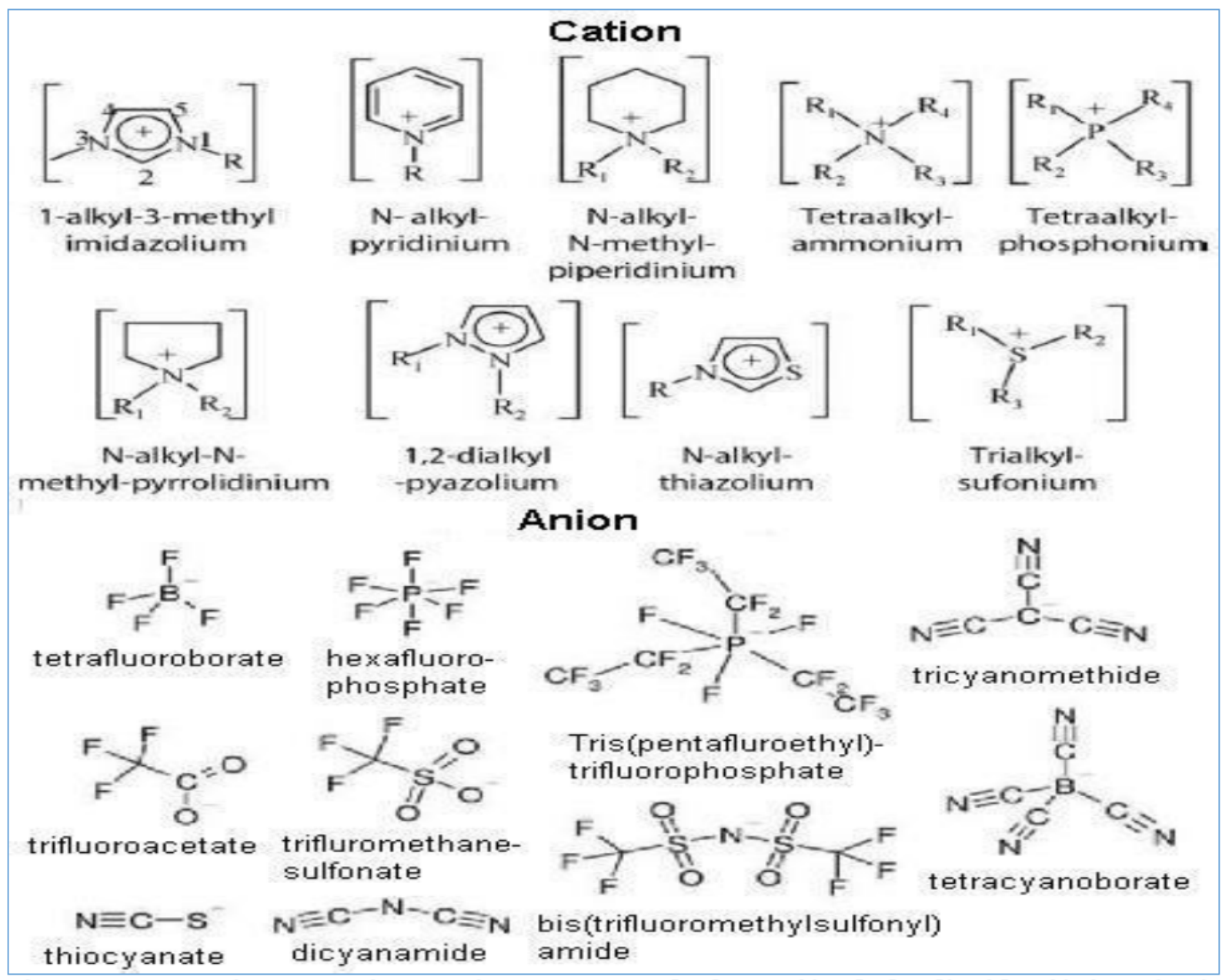

Figura 2.3-2: Cationes y aniones más commes en la formación de los líquidos iónicos (ILs). Tomado de la referencia $66^{66}$.

\subsubsection{PVA.}

El PVA es un polímero de cadena lineal principal de carbono con grupos hidroxilo unidos a los de metileno. El PVA es un polímero semi-cristalino, de bajo coste con buenas propiedades mecánicas. Es muy hidrófilo, no tóxico y presenta una buena estabilidad térmica y química. Tiene excelentes propiedades formadoras de películas ${ }^{67}$. Posee propiedades ópticas sorprendentes, gran resistencia dieléctrica, y excelente capacidad de almacenamiento de carga ${ }^{68}$. Sus atributos mecánicos, ópticos y eléctricos pueden ser fácilmente adaptados por adición de nanomateriales como "fillers". El PVA está disponible en el mercado en diferentes grados en función de la viscosidad y su grado de hidrólisis ${ }^{69}$. El PVA es biocompatible, no tóxico y exhibe adhesión celular y absorción de proteínas. Se utiliza en muchas aplicaciones de relevancia incluso se 
utiliza en el campo biomédico como estructura base para la ingeniería de tejidos, donde el cultivo celular se lleva a cabo ${ }^{70}$.

Por otra parte, los grupos hidroxilo del PVA forman enlaces de hidrógeno inter e intra-molecular ${ }^{71}$. En la Tabla 2.3-4, se puede encontrar una revisión exhaustiva de las propiedades más relevantes del PVA.

\subsubsection{Hidrogeles de PVA.}

Un hidrogel es una red tridimensional de polímeros hidrófilos que pueden, por absorción, contener una gran cantidad de agua mientras se mantiene la estructura debido a la reticulación química o física de las cadenas poliméricas que lo forman. Esta absorción de agua produce aumento de volumen, "hinchazón", de toda la estructura, confiriéndole un grado de flexibilidad muy similar al tejido natural72. Los hidrogeles fueron reportados por primera vez por Wichterle y Lim en 196073. Por definición, el agua debe constituir al menos el $10 \%$ del peso total (o volumen) para que un material pueda ser considerado un hidrogel. El carácter hidrófilo de la red se debe a la presencia de grupos hidrófilos tales como $-\mathrm{NH}_{2},-\mathrm{COOH},-\mathrm{OH},-\mathrm{CONH}_{2},-\mathrm{CONH}$ - y - $\mathrm{SO}_{3} \mathrm{H}$.

Los hidrogeles se pueden clasificar en función de diferentes propiedades o atributos. De este modo, podemos encontrar hidrogeles naturales o sintéticos, dependiendo de sus fuentes de obtención; pueden ser catiónicos, aniónicos o neutros dependiendo de las cargas iónicas; físicos o químicos dependiendo de los métodos de reticulación y basado en los métodos de preparación, se pueden dividir en homopolímero y copolímero de red interpenetrante,etc.74,75.

Hidrogeles de PVA dopados con $\mathrm{KOH}$ se han estudiado ampliamente, aunque parece que el interés de éstos no ha decaído, prueba de ello es la investigación llevada a cabo últimamente ${ }^{76-80}$.

Los iones $\mathrm{OH}^{-}$y $\mathrm{H}^{+}$son las especies iónicas con mayores valores de movilidad iónica. Muestran anómalas movilidades ${ }^{81}\left(3.62 \times 10^{-3} \mathrm{~cm}^{2} \mathrm{~V}^{-1} \mathrm{~s}^{-1}\right.$ para $\mathrm{H}^{+}$y $1.98 \times 10^{-3}$ $\mathrm{cm}^{2} \mathrm{~V}^{-1} \mathrm{~s}^{-1}$ para $\mathrm{OH}^{-}$). Las disoluciones alcalinas liquidas de $\mathrm{NaOH}$ y $\mathrm{KOH}$ exhiben conductividades máximas iónicas de 0.37 y $0.54 \mathrm{Scm}^{-1}$ en 15 y $30 \%$ en peso respectivamente ${ }^{82}$. Los electrolitos alcalinos han sido estudiados en menor 
profundidad que los electrolitos ácidos. De ahí el interés en el uso de geles poliméricos alcalinos para ampliar su uso en aplicaciones electroquímicas y entender la conducción del anión $\mathrm{OH}^{-}$en estos sistemas poliméricos alcalinos.

Lewandowski et al. ${ }^{83}$ mostraron que geles de $\mathrm{PVA} / \mathrm{KOH} / \mathrm{H}_{2} \mathrm{O}$ tienen una conductividad iónica de $\approx 10^{-3} \mathrm{Scm}^{-1}$. Mohamad et al. ${ }^{84}$ confirmaron este valor en sistemas de $\mathrm{PVA} / \mathrm{KOH}$ obteniendo una conductividad iónica de $\approx 8.5 \times 10^{-4} \mathrm{Scm}^{-1}$. Además, reportaron que por encima del $40 \%$ en peso en $\mathrm{KOH}$, la cristalinidad del gel polimérico aumentó y se volvió mecánicamente inestable. En el sistema alcalino, la conductividad iónica aumenta con la presencia de agua, lo que evita la cristalización. Sin embargo, la resistencia mecánica de PVA disminuye con el aumento en contenido de agua y una solución de compromiso tiene que ser alcanzada.

Yang et al. ${ }^{85}$ estudiaron un electrolito hibrido de polímero $\mathrm{KOH} / \mathrm{PEO} / \mathrm{PVA} / \mathrm{H}_{2} \mathrm{O}$ para los sistemas de baterías de Ni-MH y mostró una conductividad iónica notable de $3.8 \times 10^{-2} \mathrm{Scm}^{-1}$ a temperatura ambiente.

Wu et al. ${ }^{86}$ usaron "fillers" tales como $\mathrm{TiO}_{2}$ en geles poliméricos $\mathrm{PVA} / \mathrm{KOH} / \mathrm{H}_{2} \mathrm{O}$ para baterías secundarias de Zn-Ni.

Yuan et al. ${ }^{87}$ estudiaron el efecto de aditivos tales como CMC (carbometilcelulosa) en hidrogeles de PVA/KOH. La adición de CMC al sistema de PVA-KOH hizo que éste fuera capaz de acomodar más KOH y, por lo tanto, que aumentara la conductividad iónica. Los resultados experimentales de la batería de $\mathrm{Ni} / \mathrm{MH}$ con $\mathrm{PVA} / \mathrm{CMC} / \mathrm{KOH} / \mathrm{H}_{2} \mathrm{O}$ demostraron que el gel polimérico se podría aplicar a las baterías de $\mathrm{Ni} / \mathrm{MH}$, especialmente bajo regímenes de descarga bajos.

Li et al. ${ }^{88}$ sintetizaron las membranas de material compuesto PVA-PAA por un método sol-gel. La conductividad iónica podía mantenerse alrededor de $0.019 \mathrm{Scm}^{-1}$ a temperatura ambiente, y el valor aumenta con la temperatura. La membrana presentó una excelente estabilidad alcalina después de la inmersión en solución $6 \mathrm{molL}^{-1} \mathrm{de}$ KOH durante $360 \mathrm{~h}$. Se usó este compuesto en una batería Ni-MH con capacidad de descarga excelente, demostrando la viabilidad de PVA-PAA-KOH como electrólito en una batería de Ni-MH. 


\begin{tabular}{|c|c|}
\hline $\begin{array}{l}\text { Parámetro o propiedad } \\
\text { Física / química }\end{array}$ & DESCRIPCIÓN / VALOR \\
\hline Peso molecular & 20.000 a $400.000 \mathrm{~g} / \mathrm{mol}$ \\
\hline Fórmula estructural & $-(\mathrm{CH} 2 \mathrm{CHOH}) \mathrm{n}-(\mathrm{CH} 2 \mathrm{CHOCOCH} 3 \mathrm{~A}) \mathrm{m}-$ \\
\hline Formula empírica & $(\mathrm{C} 2 \mathrm{H} 4 \mathrm{O}) \mathrm{n}(\mathrm{C} 4 \mathrm{H} 6 \mathrm{O} 2) \mathrm{m}$ \\
\hline Estructura química & 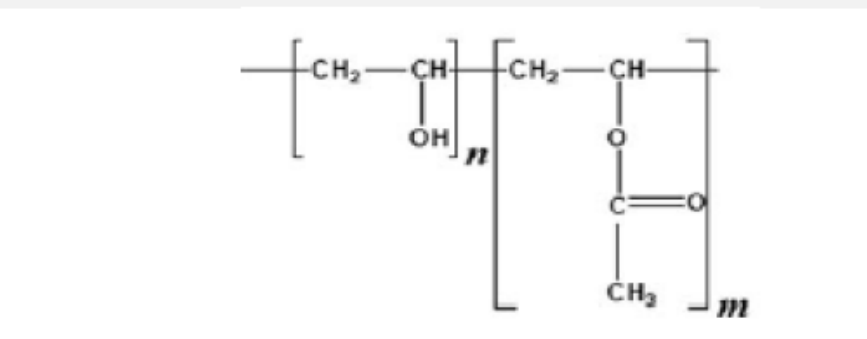 \\
\hline Punto de fusión & $\begin{array}{c}230^{\circ} \mathrm{C} \text { para completamente hidrolizado, } 180^{\circ} \mathrm{C}-190^{\circ} \mathrm{C} \\
\text { para parcialmente hidrolizado }\end{array}$ \\
\hline Punto de ebullición & $228^{\circ} \mathrm{C}$ \\
\hline Densidad aparente & $641 \mathrm{~kg} / \mathrm{m}^{3}$ \\
\hline Densidad & 1.19 a $1.31 \mathrm{~g} / \mathrm{cm}^{3}$ \\
\hline Estabilidad térmica & $\begin{array}{c}\text { La decoloración } \mathrm{a} \approx 100^{\circ} \mathrm{C} \text {, se oscurece por encima de } \\
150^{\circ} \mathrm{C} \text {, descomposición } \mathrm{a} \approx 200^{\circ} \mathrm{C}\end{array}$ \\
\hline Temperatura de transición vítrea & $75^{\circ} \mathrm{C}-85^{\circ} \mathrm{C}$ \\
\hline PVA parcialmente hidrolizado & $84.2 \%-89 \%$ \\
\hline PVA moderadamente hidrolizada & $92.2 \%-96.5 \%$ \\
\hline PVA completamente hidrolizado & $98 \%-99 \%$ \\
\hline Estabilidad a la luz solar & Excelente \\
\hline Calor especifico & $1.5 \mathrm{~J} /(\mathrm{g} \mathrm{K})$ \\
\hline Solubilidad & $\begin{array}{c}\text { Soluble en agua. Insoluble en hidrocarburos alifáticos y } \\
\text { aromáticos, aceites, cetonas, y ésteres }\end{array}$ \\
\hline
\end{tabular}

Tabla 2.3-4: Propiedades fisicas y químicas más relevantes del PVA.

Por ultimo hay también numerosos artículos dedicados a la mezcla de PVA con biopolímeros 40,89-91. GPEs hechos de biopolímeros se ha convertido en una nueva perspectiva dentro la investigación en almacenamiento de energía electroquímica92.

\section{4. Óxido de Bismuto $\mathrm{B}_{2} \mathrm{O}_{3}$.}

Bismuto, se cree que deriva de la palabra alemana "wismuth" (masa blanca), es un elemento relativamente raro y es el menos abundante de los grupo del nitrógeno o 
elementos del Grupo $15^{93}$. Desde una perspectiva ambiental es el sustituto natural de plomo93. El bismuto semimetal tiene una banda de conducción baja y alta movilidad de electrones. Cuando el tamaño de los cristalitos se reduce a la nano-escala, el bismuto semimetal se convierte en un semiconductor debido a fenómenos cuánticos, y esto, hace que las nanopartículas de bismuto sean especialmente útiles para aplicaciones optoelectrónicas ${ }^{94}$.

$\mathrm{Bi}_{2} \mathrm{O}_{3}$ tiene seis polimorfos $\left(\alpha-, \beta-, \gamma-, \delta-, \varepsilon-, y \omega-\mathrm{Bi}_{2} \mathrm{O}_{3}\right)$ con estructuras cristalinas: $\alpha-\mathrm{Bi}_{2} \mathrm{O}_{3}$ (monoclínico), $\beta-\mathrm{Bi}_{2} \mathrm{O}_{3}$ (tetragonal), $\gamma-\mathrm{Bi}_{2} \mathrm{O}_{3}$ ( cúbico, bcc), $\delta-\mathrm{Bi}_{2} \mathrm{O}_{3}$ (cúbico, fcc) $\varepsilon-\mathrm{Bi}_{2} \mathrm{O}_{3}$ (ortorrómbica), $\omega-\mathrm{Bi}_{2} \mathrm{O}_{3}$ (triclínico). Entre ellos, $\alpha-\mathrm{Bi}_{2} \mathrm{O}_{3}$ (monoclínico) es la más estable a temperatura ambiente ${ }^{95}$.

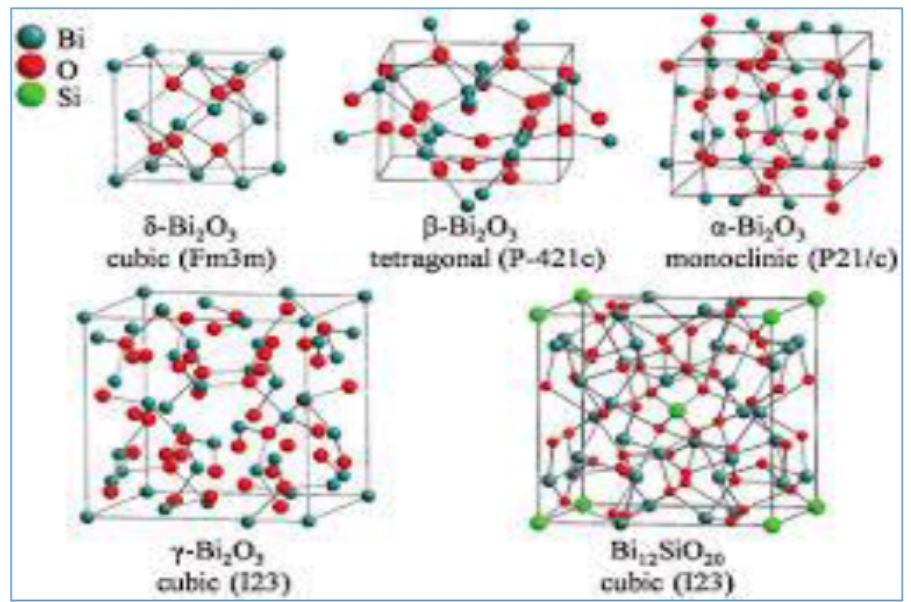

Figura 2.4-1: Estructuras polimorfas del $\mathrm{Bi}_{2} \mathrm{O}_{3}$.

El $\mathrm{Bi}_{2} \mathrm{O}_{3}$ manifiesta una capacidad electroquímica práctica alta comparable al valor teórico, razón de descarga alta y buen ciclo de vida. Es uno de los materiales más investigados para aplicaciones industriales y fotocatalíticas. Sin embargo, salvo como aditivo en los ánodos de las baterías alcalinas para suprimir el desprendimiento de hidrógeno, la aplicación de bismuto y sus óxidos en las baterías ha sido ignorada durante décadas.

Sólo unos pocos artículos se han dedicado a este material en sistemas electroquímicos de almacenamiento de energía, como se mencionó anteriormente, la mayoría de ellos como aditivo para aplicaciones de sensores. 
La reacción de reducción del $\mathrm{Bi}_{2} \mathrm{O}_{3}$ a bismuto metálico de acuerdo a la reacción (11) ha sido propuesta con anterioridad ${ }^{96-98:}$

$$
\mathrm{Bi}_{2} \mathrm{O}_{3}+3 \mathrm{H}_{2} \mathrm{O}+6 \mathrm{e}^{-} \rightarrow 2 \mathrm{Bi}^{\mathrm{O}}+6 \mathrm{OH}^{-} \quad \mathrm{E}^{0}=-0,46 \mathrm{~V}
$$

Además, en esta última reacción se pueden formar especies intermedias de complejos de bismuto hidrosolubles tales como $\mathrm{Bi}(\mathrm{OH})^{2+} \mathrm{o} \mathrm{Bi}(\mathrm{OH})_{2}^{+}$, antes de la reducción del $\mathrm{Bi}_{2} \mathrm{O}_{3}$ a Bi metálico99,100.

Moser et al.96 mostraron la potencialidad de las mediciones simultáneas de XRD y la respuesta electroquímica de un batería secundaria de $\mathrm{Ni}-\mathrm{Zn}$ con $\mathrm{KOH}$ como electrolito. Además, reseñaron el papel del $\mathrm{Bi}_{2} \mathrm{O}_{3}$ en la creación de una red conductora de bismuto metálico.

McBreen et al. ${ }^{101}$ usaron pequeñas cantidades de $\mathrm{Bi}_{2} \mathrm{O}_{3}$ como aditivo en electrodos negativos de zinc el cual fue reducido cuantitativamente formando un deposito activo de Bi metálico y Gallaway et al. ${ }^{102}$ consiguieron obtener superficies más planas durante la deposición, añadiendo $\mathrm{Bi}_{2} \mathrm{O}_{3}(3 \mathrm{ppm})$ a una disolución de zincato.

Shin et al. ${ }^{103}$ revelaron que tras la oxidación del zinc, los iones zincato se forman y se depositan en la superficie de la especies de bismuto. En segundo lugar, los iones zincato se convierten en $\mathrm{ZnO}$ sobre las especies químicas de bismuto. El electrodo es completamente recargable debido a que la conexión eléctrica nunca se pierde para el $\mathrm{ZnO}$. Confirmaron el papel vital del $\mathrm{Bi}_{2} \mathrm{O}_{3}$ en la provisión de superficies para el que el $\mathrm{ZnO}$ se deposite

\subsection{Reacción de reducción de oxígeno (ORR).}

El diseño del electrodo de aire tiene que tener una cantidad suficiente de un catalizador adecuado para las reacciones de reducción del oxígeno, así como garantizar una estructura altamente porosa con puntos de contacto para la formación del sistema de tres fases. ${ }^{31}$. Puesto que el oxígeno es tomado desde el aire ambiente, el electrodo de oxígeno, siempre y cuando no haya ningún daño físico, se puede utilizar, en principio, de forma indefinida. El electrodo de oxígeno normalmente consiste en una GDL y una capa activa catalítica, y ambas están laminadas junto con una rejilla de 
metal como colector de corriente para formar el GDE. La capa de difusión de gas consiste en un material de carbono tal como partículas de carbón activado o nanotubos de carbono (CNT) ${ }^{104}$, que juntos forman una estructura porosa, y un aglutinante hidrófobo tal como politetrafluoroetileno (PTFE), lo que asegura la hidrofobicidad, así como la permeabilidad al aire. El PTFE es casi el único aglutinante adecuado en el caso de baterías de zinc-aire debido a su alta resistencia a la corrosión en medios fuertemente básicos ${ }^{105}$.

El catalizador se aplica finamente a este sustrato y la ORR o OER tiene lugar en esta capa activa catalítica ${ }^{16}$. En el caso de baterías de zinc-aire secundarias, la oxidación del catalizador y el sustrato de carbono también debe tenerse en cuenta debido a que, durante la carga, la gran superficie del sustrato de carbono puede ser severamente atacado por el oxígeno altamente reactivo que se genera en la OER ${ }^{106,107 .}$

La cinética de las reacciones de reducción de oxígeno limita la eficiencia de toda la celda ${ }^{108}$. Es por eso que es importante entender el mecanismo de reacción implicada. El electrolito, los catalizadores en el cátodo, el envejecimiento del electrodo y su estructura tienen una gran influencia sobre el mecanismo de reducción de oxígeno.

Desde 1960, la reacción de reducción de oxígeno comenzó a llamar la atención, motivado por el interés de las pilas de combustible a baja temperatura, incluso entonces, se utilizaron celdas de combustible alcalinas en el programa espacial Apolo ${ }^{109}$.

La reducción del oxígeno sigue siendo un campo fundamental de investigación. Sin embargo, la complejidad de la cinética solo ha hecho posible, hasta el momento, dibujar un panorama parcial de la materia.

\subsubsection{Mecanismos de reacción.}

La reducción del oxígeno en soluciones acuosas se produce principalmente a través de dos vías diferentes: o bien una vía de reducción $\mathrm{O}_{2}$ a $\mathrm{H}_{2} \mathrm{O}$ en la que intervienen cuatro electrones o una vía bielectrónica de $\mathrm{O}_{2}$ a $\mathrm{H}_{2} \mathrm{O}_{2}$. Los primeros intentos para explicar el mecanismo por el que ocurre esta reacción, fueron propuestos por Damjanovic et al. ${ }^{110}$ y Wroblowa et al. ${ }^{111}$. 
En la Tabla 2.5-1, se muestran las vías de reducción de 1, 2, y 4 electrones, dependiendo de las aplicaciones. En la celda de combustible y los procesos de baterías de metal-aire, la vía directa de 4-electrónes es la preferida. La vía de reducción de 2 electrones se utiliza en la industria para la producción de $\mathrm{H}_{2} \mathrm{O}_{2}$, mientras que la reducción mono electrónica es de importancia solo para el estudio del mecanismo de la ORR ${ }^{112}$.

Para que la reducción del oxígeno se produzca, el oxígeno molecular debe primero unirse a la superficie. . El modo en el que el oxígeno molecular se adsorbe sobre el catalizador determinará el mecanismo de reducción que tendrá lugar.

Yeager et al. ${ }^{113,114}$ han propuesto tres tipos diferentes de adsorción de oxígeno en una superficie y de la vía de reducción preferencial posterior. La Figura 2.5-1 distingue entre estas tres posibilidades de adsorción del oxígeno.

\begin{tabular}{|c|c|c|}
\hline Electrólito & Reacciones ORR & $\begin{array}{c}\text { Potencial de electrodo termodinámico } \\
\text { en condiciones estándar, } \mathrm{V}\end{array}$ \\
\hline \multirow{3}{*}{$\begin{array}{l}\text { Solución acuosa } \\
\text { ácida }\end{array}$} & $\mathrm{O}_{2}+4 \mathrm{H}^{+}+4 \mathrm{e}^{-} \rightarrow \mathrm{H}_{2} \mathrm{O}$ & 1.229 \\
\hline & $\mathrm{O}_{2}+2 \mathrm{H}^{+}+2 \mathrm{e}^{-} \rightarrow \mathrm{H}_{2} \mathrm{O}_{2}$ & 0.70 \\
\hline & $\mathrm{H}_{2} \mathrm{O}_{2}+2 \mathrm{H}^{+}+2 \mathrm{e}^{-} \rightarrow \mathrm{H}_{2} \mathrm{O}$ & 1.76 \\
\hline \multirow{3}{*}{$\begin{array}{l}\text { Solución acuosa } \\
\text { alcalina }\end{array}$} & $\mathrm{O}_{2}+\mathrm{H}_{2} \mathrm{O}+4 \mathrm{e}^{-} \rightarrow 4 O \mathrm{H}^{-}$ & 0.401 \\
\hline & $\mathrm{O}_{2}+\mathrm{H}_{2} \mathrm{O}+2 \mathrm{e}^{-} \rightarrow+\mathrm{HO}_{2}^{-} \mathrm{OH}^{-}$ & -0.065 \\
\hline & $\mathrm{HO}_{2}^{-}+\mathrm{H}_{2} \mathrm{O}+2 \mathrm{e}^{-} \rightarrow 3 \mathrm{OH}^{-}$ & 0.867 \\
\hline \multirow{2}{*}{$\begin{array}{c}\text { Disolventes } \\
\text { apróticos no } \\
\text { acuosos }\end{array}$} & $\mathrm{O}_{2}+\mathrm{e}^{-} \rightarrow \mathrm{O}_{2}^{-}$ & \multirow{2}{*}{ Dependiente del electrólito ${ }^{112}$} \\
\hline & $O_{2}^{-}+\mathrm{e}^{-} \rightarrow O_{2}^{2-}$ & \\
\hline
\end{tabular}

Tabla 2.5-1: Potenciales de electrodo termodinámicos de reducción electroquímica del $\mathrm{O}_{2}$.

Estos modelos han sido desarrollados para los metales de transición, pero también se puede aplicar a otros tipos de catalizadores. Por otra parte, también son válidos en solución. 


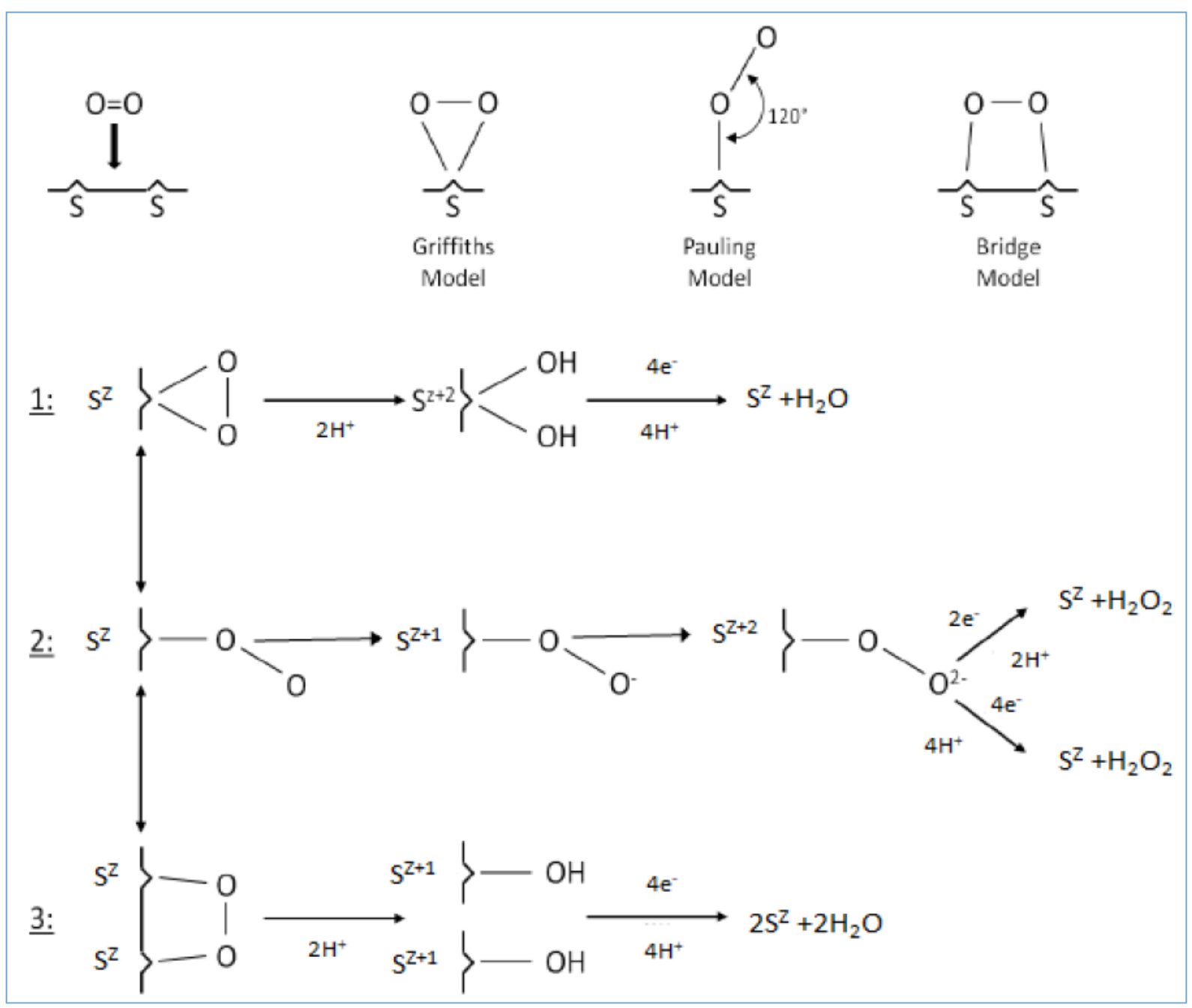

Figura 2.5-1: Modelos para la adsorción de oxígeno en una superficie de metal y mecanismos de reacción relacionados de acuerdo con Yeager et al. ${ }^{113}$.

El oxígeno puede adsorberse a la superficie de acuerdo con el modelo Griffiths, Pauling o el llamado de puente. En los tres modelos la unión entre el oxígeno y el metal de transición se produce a través de los orbitales del oxígeno y el orbital d del metal de transición y, además, el doble enlace de la molécula de oxígeno se rompe y se forma un enlace sencillo. En el caso de los modelos Griffiths y de puente, le disociación del oxígeno es más probable que suceda por la debilidad del enlace. Si el enlace entre el metal de transición y los átomos de oxígeno es suficientemente fuerte, es incluso posible que una adsorción disociativa tenga lugar con la transferencia simultánea de dos protones. En total, dos electrones se transfieren desde el metal a las especie en la superficie en los modelos de puente y Griffith. La principal diferencia entre estos dos 
últimos modelos es el número de sitios de la superficie, donde la molécula de oxígeno se une. El modelo de puente adsorbe oxígeno en dos sitios de superficie libre, mientras que el modelo de Griffith los hace solo por un sitio.

El modelo de Pauling, por otra parte, describe la adsorción de un solo átomo de oxígeno en una superficie libre del metal de transición. El enlace entre los dos átomos de oxígeno está por lo tanto relativamente intacto. Debido a la transferencia de carga incompleta primero se forma una especie de superóxido y posteriormente, se forma un peróxido. La reducción puede entonces ser completa o incompleta. Sin embargo, debido a la unión relativamente no debilitada entre los dos átomos de oxígeno, se prefiere el camino de dos electrones. Así, con una reducción incompleta en la que intervienen sólo dos electrones, se forma peróxido de hidrógeno mientras una reducción completa con cuatro electrones producirá dos moléculas de agua.

Según Yeager, la manera en que el oxígeno se une a la superficie decide el tipo de reacción preferente. Aunque, el tipo de reacción estará además influenciado por otros factores. Si la superficie del catalizador está, contaminada con sustancias extrañas, la reacción vía dos electrones tiene lugar preferentemente, ya que la vía de cuatro electrones se ve impedida en gran medida, especialmente cuando se producen enlaces tipo puente. Por supuesto, el material del catalizador usado juega un papel importante.

La actividad de la ORR para catalizadores metálicos se puede predecir teóricamente, en cierta medida, lo que reduce el tiempo y el coste de desarrollo del catalizador. De ahí, el conocido grafico volcán de Norskov et al..115donde un perfil "volcánico" se obtiene mediante la representación de la energía de enlace de oxígeno sobre la superficie metálica en función la actividad del catalizador, Figura 2.5-2. En la parte superior se encuentra el platino, próximo al punto óptimo donde el oxígeno no está enlazado ni demasiado fuertemente ni demasiado débilmente a la superficie. Los catalizadores de metales nobles tales como platino, paladio o plata por lo tanto tienen una alta actividad para la ORR. Sin embargo, debido a su precio y su escasez, tales catalizadores no se utilizan comercialmente, excepto para aplicaciones específicas. En las baterías de zinc-aire los catalizadores no se limitan exclusivamente a metales nobles 
puros, ya que la ORR, tiene lugar aquí en medio alcalino. Es por esta razón, por la que se ha extendido el uso de los óxidos de metales de transición típicos, perovskitas, espinelas, óxidos singulares y sus mezclas así como materiales carbonosos en el electrodo de aire ${ }^{106}$.

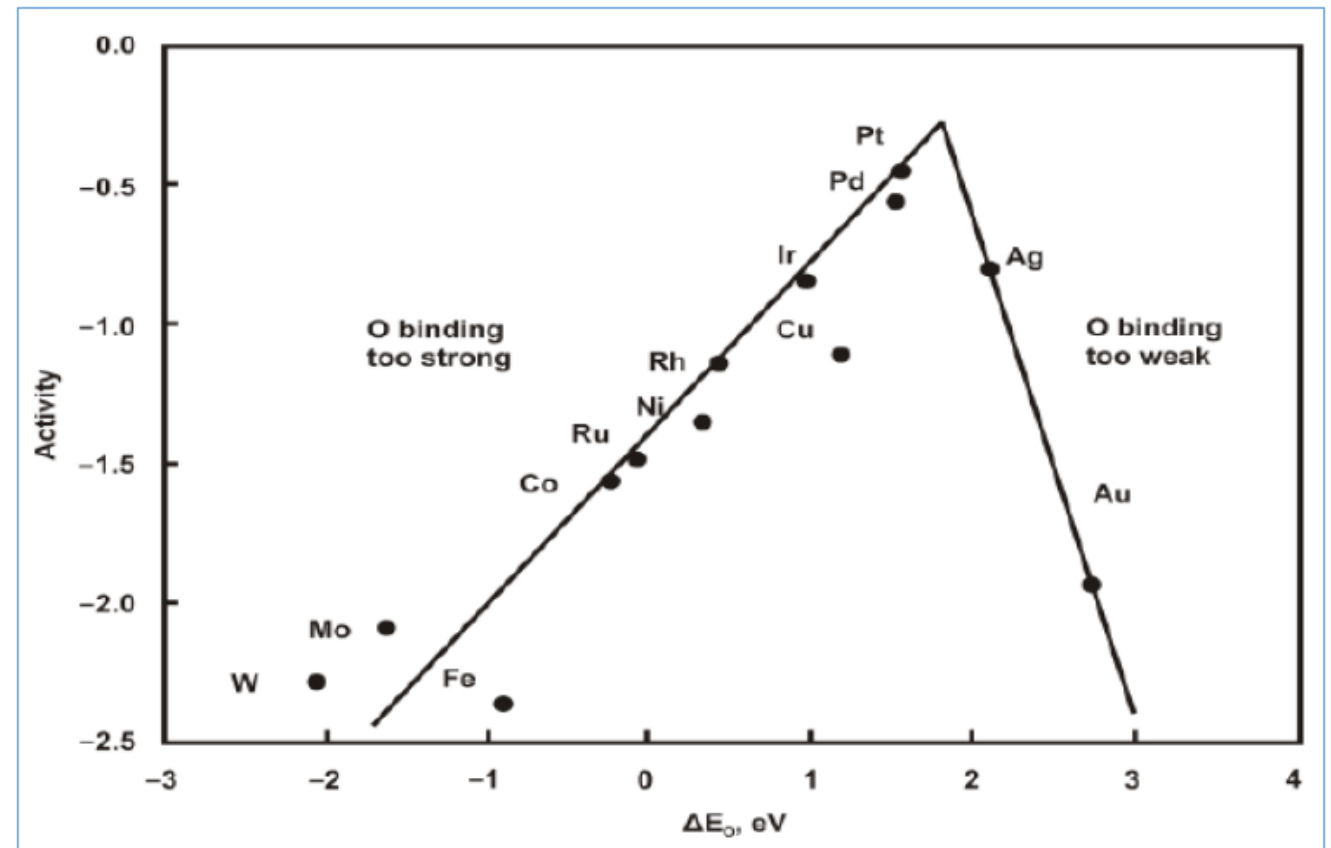

Figura 2.5-2: Actividad de catalizadores metálicos en función de la energía de enlace.

Finalmente, aunque queda fuera del ámbito de este trabajo, reseñar la importancia de los catalizadores bifuncionales de manera breve. La principal función de un catalizador bifuncional es facilitar las reacciones ORR y OER en una única estructura física contenida en el cátodo lo que permite que una batería de zinc-aire sea recargable electroquímicamente. 


\subsection{Referencias.}

(1) Chakkaravarthy, C.; Waheed, A. K. A.; Udupa, H. V. K. Zinc-Air Alkaline Batteries - A Review. J. Power Sources 1981, 6 (3), 203-228. https://doi.org/10.1016/0378-7753(81)80027-4.

(2) COLLINS, D. Handbook of Batteries and Fuel Cells By David Linden, Published by McGraw-Hill Book Company GmbH., Hamburg, F.R.G., 1984; 1024 Pp.; Price DM 258.80.; 1986; Vol. 17. https://doi.org/10.1016/03787753(86)80059-3.

(3) Koretz, B.; Goldstein, J. R. Regeneration of Zinc Anodes for the Electric Fuel(R) Zinc-Air Refuelable EV Battery System. 2002, 877-882 vol.2. https://doi.org/10.1109/iecec.1997.661884.

(4) Toussaint, G.; Stevens, P.; Akrour, L.; Rouget, R.; Fourgeot, F. Development of a Rechargeable Zinc-Air Battery; 2010; pp 25-34. https://doi.org/10.1149/1.3507924.

(5) Chen, J.; Cheng, F. Combination of Lightweight Elements and Nanostructured Materials for Batteries. Acc. Chem. Res. 2009, 42 (6), 713-723. https://doi.org/10.1021/ar800229g.

(6) R. Mainar, A.; Leonet, O.; Bengoechea, M.; Boyano, I.; De Meatza, I.; Kvasha, A.; Guerfi, A.; Alberto Blázquez, J. Alkaline Aqueous Electrolytes for Secondary Zinc-Air Batteries: An Overview. International Journal of Energy Research. 2016, pp 1032-1049. https://doi.org/10.1002/er.3499.

(7) Cheng, F.; Chen, J. Metal-Air Batteries: From Oxygen Reduction Electrochemistry to Cathode Catalysts. Chemical Society Reviews. 2012, pp 2172-2192. https://doi.org/10.1039/c1cs15228a.

(8) Caramia, V.; Bozzini, B. Materials Science Aspects of Zinc-Air Batteries: A Review. Mater. Renew. Sustain. Energy 2014, $3 \quad$ (2). https://doi.org/10.1007/s40243-014-0028-3.

(9) Zhang, X. G. SECONDARY BATTERIES - ZINC SYSTEMS | Zinc Electrodes: Overview. Encycl. Electrochem. Power Sources 2009, 454-468. https://doi.org/10.1016/b978-044452745-5.00166-0.

(10) O. Haas, J. V. W. Zinc-Air: Electrical Recharge. Encyclopedia of 
Electrochemical Power Sources; 2009.

(11) Zhang, X. . Secondary Batteries-zinc System. Zinc Electrodes: Overview. Encyclopedia of Electrochemical Power Sources; G., J., Ed.; Elsevier B.V.: Amsterdam.

(12) Müller, S.; Holzer, F.; Haas, O. Optimized Zinc Electrode for the Rechargeable Zinc-Air Battery. J. Appl. Electrochem. 1998, 28 (9), 895-898. https://doi.org/10.1023/A:1003464011815.

(13) Lee, C. W.; Sathiyanarayanan, K.; Eom, S. W.; Yun, M. S. Novel Alloys to Improve the Electrochemical Behavior of Zinc Anodes for Zinc/Air Battery. J. Power Sources 2006, $160 \quad$ (2 SPEC. ISS.), 1436-1441. https://doi.org/10.1016/j.jpowsour.2006.02.019.

(14) Lee, C. W.; Eom, S. W.; Sathiyanarayanan, K.; Yun, M. S. Preliminary Comparative Studies of Zinc and Zinc Oxide Electrodes on Corrosion Reaction and Reversible Reaction for Zinc/Air Fuel Cells. Electrochim. Acta 2006, 52 (4), 1588-1591. https://doi.org/10.1016/j.electacta.2006.02.063.

(15) Wu, G. M.; Lin, S. J.; Yang, C. C. Alkaline Zn-Air and Al-Air Cells Based on Novel Solid PVA/PAA Polymer Electrolyte Membranes. J. Memb. Sci. 2006, 280 (12), 802-808. https://doi.org/10.1016/j.memsci.2006.02.037.

(16) Lee, J. S.; Kim, S. T.; Cao, R.; Choi, N. S.; Liu, M.; Lee, K. T.; Cho, J. Metal-Air Batteries with High Energy Density: Li-Air versus Zn-Air. Advanced Energy Materials. 2011, pp 34-50. https://doi.org/10.1002/aenm.201000010.

(17) Arora, P.; Zhang, Z. J.; Lakes, S.; Carolina, N. A Review, Battery Separator, Pankaj Arora, Chem. Rev. 2004, 104, 4419-4462.Pdf. 2004.

(18) Fu, J.; Cano, Z. P.; Park, M. G.; Yu, A.; Fowler, M.; Chen, Z. Electrically Rechargeable Zinc-Air Batteries: Progress, Challenges, and Perspectives. Advanced Materials. 2017. https://doi.org/10.1002/adma.201604685.

(19) Merle, G.; Wessling, M.; Nijmeijer, K. Anion Exchange Membranes for Alkaline Fuel Cells: A Review. J. Memb. Sci. 2011, 377 (1-2), 1-35. https://doi.org/10.1016/j.memsci.2011.04.043.

(20) Neburchilov, V.; Wang, H.; Martin, J. J.; Qu, W. A Review on Air Cathodes for Zinc-Air Fuel Cells. Journal of Power Sources. 2010, pp 1271-1291. https://doi.org/10.1016/j.jpowsour.2009.08.100. 
(21) Pessine, E. J.; Agostinho, S. M. L.; Chagas, H. C. Evaluation of the Diffusion Coefficient of the Zincate Ion Using a Rotating Disk Electrode. Can. J. Chem. 2006, 64 (3), 523-527. https://doi.org/10.1139/v86-083.

(22) Bockris, J. O.; Nagy, Z.; Damjanovic, A. On the Deposition and Dissolution of Zinc in Alkaline Solutions. J. Electrochem. Soc. 2007, 119 (3), 285. https://doi.org/10.1149/1.2404188.

(23) Chang, Y.-C. A Model for the Anodic Dissolution of Zinc in Alkaline Electrolyte. J. Electrochem. Soc. 2006, 131 (7), 1465. https://doi.org/10.1149/1.2115875.

(24) Prentice, G. A Model for the Passivation of the Zinc Electrode in Alkaline Electrolyte. J. Electrochem. Soc. $\mathbf{2 0 0 6 ,} 138 \quad$ (4), 890. https://doi.org/10.1149/1.2085742.

(25) Liu, M.-B. Passivation of Zinc Anodes in KOH Electrolytes. J. Electrochem. Soc. 2006, 128 (8), 1663. https://doi.org/10.1149/1.2127707.

(26) Mainar, A. R.; Iruin, E.; Colmenares, L. C.; Kvasha, A.; de Meatza, I.; Bengoechea, M.; Leonet, O.; Boyano, I.; Zhang, Z.; Blazquez, J. A. An Overview of Progress in Electrolytes for Secondary Zinc-Air Batteries and Other Storage Systems Based on Zinc. J. Energy Storage 2018, 15, 304-328. https://doi.org/10.1016/j.est.2017.12.004.

(27) Cai, M.; Park, S. M. Spectroelectrochemical Studies on Dissolution and Passivation of Zinc Electrodes in Alkaline Solutions. J. Electrochem. Soc. 1996, 143 (7), 2125-2131. https://doi.org/10.1149/1.1836970.

(28) Mohamad, A. A. Zn/Gelled 6 M KOH/O2 Zinc-Air Battery. J. Power Sources 2006. https://doi.org/10.1016/j.jpowsour.2005.10.110.

(29) Shivkumar, R.; Paruthimal Kalaignan, G.; Vasudevan, T. Studies with Porous Zinc Electrodes with Additives for Secondary Alkaline Batteries. J. Power Sources 1998. https://doi.org/10.1016/S0378-7753(98)00096-2.

(30) Xie, F.; Tian, Z.; Meng, H.; Shen, P. K. Increasing the Three-Phase Boundary by a Novel Three-Dimensional Electrode. J. Power Sources 2005, 141 (2), 211215. https://doi.org/10.1016/j.jpowsour.2004.10.002.

(31) Fang, Z. qian; Hu, M.; Liu, W. xi; Chen, Y. ru; Li, Z. ya; Liu, G. yuan. Preparation and Electrochemical Property of Three-Phase Gas-Diffusion Oxygen Electrodes for Metal Air Battery. Electrochim. Acta 2006, 51 (26), 5654-5659. 
https://doi.org/10.1016/j.electacta.2006.01.056.

(32) Li, Y.; Dai, H. Recent Advances in Zinc-Air Batteries. Chem. Soc. Rev. 2014, 43 (15), 5257-5275. https://doi.org/10.1039/c4cs00015c.

(33) Fenton, D. E.; Parker, J. M.; Wright, P. V. Complexes of Alkali Metal Ions with Poly(Ethylene Oxide). Polymer (Guildf). 1973, 14 (11), 589. https://doi.org/10.1016/0032-3861(73)90146-8.

(34) Armand, M. B.; Chabagno, J. M.; Duclot, M. J. Poly-Ethers as Solid Electrolytes. In Proceedings of the International Conference on Fast Ion Transport in Solids: Electrodes and Electrolytes; 1979; pp 131-136.

(35) Vincent, C. A. Applications of Electroactive Polymers. Edited by B. Scrosati. Chapman and Hall, London, 1993. Pp. 354 Price £40.00. ISBN 0-412-41430-9. Polym. Int. 2005, $33 \quad$ (3), $343-343$. https://doi.org/10.1002/pi.1994.210330323.

(36) Cameron, G. G. Solid Polymer Electrolytes: Fundamentals and Technological Applications. Fiona M. Gray. VCH Publishers Inc., New York 1991. Pp. x + 245, Price £44.00. ISBN 0-89573-772-8. Polym. Int. 2007, 32 (4), 436-436. https://doi.org/10.1002/pi.4990320421.

(37) Cheng, X.; Pan, J.; Zhao, Y.; Liao, M.; Peng, H. Gel Polymer Electrolytes for Electrochemical Energy Storage. Adv. Energy Mater. 2018, 8 (7), 1-16. https://doi.org/10.1002/aenm.201702184.

(38) Ye, L.; Feng, Z. Polymer Electrolytes as Solid Solvents and Their Applications. Polym. Electrolytes Fundam. Appl. 2010, 550-582. https://doi.org/10.1533/9781845699772.2.550.

(39) Jiang, Y.; Yan, X.; Ma, Z.; Mei, P.; Xiao, W.; You, Q.; Zhang, Y. Development of the PEO Based Solid Polymer Electrolytes for All-Solid State Lithium Ion $\begin{array}{llllll}\text { Batteries. } & \text { Polymers } & \text { (Basel). 2018, } 10 & \text { (11), } 1237 .\end{array}$ https://doi.org/10.3390/polym10111237.

(40) Masri, M. N.; Nazeri, M. F. M.; Mohamad, A. A. Sago Gel Polymer Electrolyte for Zinc-Air Battery. Adv. Sci. Technol. 2010, 72 (January), 305-308. https://doi.org/10.4028/www.scientific.net/ast.72.305.

(41) Quartarone, E.; Mustarelli, P. Encyclopedia of Polymeric Nanomaterials. Encycl. Polym. Nanomater. 2014, 1-10. https://doi.org/10.1007/978-3-642-36199- 
9.

(42) He, C.; Liu, J.; Cui, J.; Li, J.; Wu, X. A Gel Polymer Electrolyte Based on Polyacrylonitrile/Organic Montmorillonite Membrane Exhibiting Dense Structure for Lithium Ion Battery. Solid State Ionics 2018, 315 (November 2017), 102-110. https://doi.org/10.1016/j.ssi.2017.12.014.

(43) Tsao, C. H.; Kuo, P. L. Poly(Dimethylsiloxane) Hybrid Gel Polymer Electrolytes of a Porous Structure for Lithium Ion Battery; 2015; Vol. 489. https://doi.org/10.1016/j.memsci.2015.03.087.

(44) Jahn, M.; Sedla ikova, M.; Vondrak, J.; Pa izek, L. PMMA-Based Electrolytes for Li-Ion Batteries. ECS Trans. 2016, 74 (1), 159-164. https://doi.org/10.1149/07401.0159ecst.

(45) Rani, M. A. A.; Hwang, J.; Matsumoto, K.; Hagiwara, R. Poly(Vinyl Chloride) Ionic Liquid Polymer Electrolyte Based on Bis(Fluorosulfonyl)Amide for Sodium Secondary Batteries. J. Electrochem. Soc. 2017, 164 (8), H5031-H5035. https://doi.org/10.1149/2.0221708jes.

(46) Ruan, L.; Yao, X.; Chang, Y.; Zhou, L.; Qin, G.; Zhang, X. Properties and Applications of the $\beta$ Phase Poly(Vinylidene Fluoride). Polymers. 2018. https://doi.org/10.3390/polym10030228.

(47) Liu, W.; Zhang, X. K.; Wu, F.; Xiang, Y. A Study on PVDF-HFP Gel Polymer Electrolyte for Lithium-Ion Batteries. IOP Conf. Ser. Mater. Sci. Eng. 2017, 213 (1). https://doi.org/10.1088/1757-899X/213/1/012036.

(48) Wypych, G. Handbook of Polymers; 2016. https://doi.org/10.1016/c2011-004631-8.

(49) Tsuchida, E.; Ohno, H.; Tsunemi, K. Conduction of Lithium Ions in Polyvinylidene Fluoride and Its Derivatives-I. Electrochim. Acta 1983, 28 (5), 591-595. https://doi.org/10.1016/0013-4686(83)85049-X.

(50) Tsunemi, K.; Ohno, H.; Tsuchida, E. A Mechanism of Ionic Conduction of Poly (Vinylidene Fluoride)-Lithium Perchlorate Hybrid Films. Electrochim. Acta 1983, 28 (6), 833-837. https://doi.org/10.1016/0013-4686(83)85155-X.

(51) Tarascon, J. M.; Gozdz, A. S.; Schmutz, C.; Shokoohi, F.; Warren, P. C. Performance of Bellcore's Plastic Rechargeable Li-Ion Batteries. Solid State Ionics 1996, 86-88 (PART 1), 49-54. https://doi.org/10.1016/0167- 
2738(96)00330-X.

(52) Jiang, Z.; Carroll, B.; Abraham, K. M. Studies of Some Poly(Vinylidene Fluoride) Electrolytes. Electrochim. Acta 1997, 42 (17), 2667-2677. https://doi.org/10.1016/S0013-4686(97)00005-4.

(53) Jacob, M. Effect of PEO Addition on the Electrolytic and Thermal Properties of PVDF-LiClO4 Polymer Electrolytes. Solid State Ionics 1997, 104 (3-4), 267276. https://doi.org/10.1016/s0167-2738(97)00422-0.

(54) Jacob, M. M. E.; Arof, A. K. FTIR Studies of DMF Plasticized Polyvinyledene Fluoride Based Polymer Electrolytes. Electrochim. Acta 2000, 45 (10), 17011706. https://doi.org/10.1016/S0013-4686(99)00316-3.

(55) Li, Z.; Su, G.; Gao, D.; Wang, X.; Li, X. Effect of Al2O3 Nanoparticles on the Electrochemical Characteristics of P(VDF-HFP)-Based Polymer Electrolyte. Electrochim. Acta $\mathbf{2 0 0 4}, \quad 49 \quad$ (26), $4633-4639$. https://doi.org/10.1016/j.electacta.2004.05.018.

(56) Ataollahi, N.; Ahmad, A.; Hamzah, H.; Rahman, M. Y. A.; Mohamed, N. S. Preparation and Characterization of PVDF-HFP/MG49 Based Polymer Blend Electrolyte. Int. J. Electrochem. Sci. 2012, 7 (8), 6693-6703. https://doi.org/10.1007/s11581-009-0415-4.

(57) Stephan, A. M.; Nahm, K. S.; Anbu Kulandainathan, M.; Ravi, G.; Wilson, J. Poly(Vinylidene Fluoride-Hexafluoropropylene) (PVdF-HFP) Based Composite Electrolytes for Lithium Batteries. Eur. Polym. J. 2006, 42 (8), 1728-1734. https://doi.org/10.1016/j.eurpolymj.2006.02.006.

(58) Zhang, D.; Li, R.; Huang, T.; Yu, A. Novel Composite Polymer Electrolyte for Lithium Air Batteries. J. Power Sources 2010, 195 (4), 1202-1206. https://doi.org/10.1016/j.jpowsour.2009.08.063.

(59) Leng, L.; Zeng, X.; Chen, P.; Shu, T.; Song, H.; Fu, Z.; Wang, H.; Liao, S. A Novel Stability-Enhanced Lithium-Oxygen Battery with Cellulose-Based Composite Polymer Gel as the Electrolyte. Electrochim. Acta 2015, 176, 1108-1115. https://doi.org/10.1016/j.electacta.2015.07.111.

(60) Guisao, J. P. T.; Romero, A. J. F. Interaction between $\mathrm{Zn}^{2+}$ Cations and n-Methyl2-Pyrrolidone in Ionic Liquid-Based Gel Polymer Electrolytes for Zn Batteries. Electrochim. Acta 2015, 176 (January), 1447-1453. 
https://doi.org/10.1016/j.electacta.2015.07.132.

(61) Pandey, G. P.; Hashmi, S. A. Experimental Investigations of an Ionic-LiquidBased, Magnesium Ion Conducting, Polymer Gel Electrolyte. J. Power Sources 2009, 187 (2), 627-634. https://doi.org/10.1016/j.jpowsour.2008.10.112.

(62) Kumar, R.; Singh, B.; Sekhon, S. S. Effect of Dielectric Constant of Solvent on the Conductivity Behavior of Polymer Gel Electrolytes. J. Mater. Sci. 2005, 40 (5), 1273-1275. https://doi.org/10.1007/s10853-005-6950-0.

(63) Ye, L.; Feng, Z. Polymer Electrolytes as Solid Solvents and Their Applications. In Polymer Electrolytes: Fundamentals and Applications; Elsevier, 2010; pp 550-582. https://doi.org/10.1533/9781845699772.2.550.

(64) Plechkova, N. V.; Seddon, K. R. Applications of Ionic Liquids in the Chemical Industry. Chem. Soc. Rev. 2008, 37 (1), 123-150. https://doi.org/10.1039/b006677j.

(65) Wasserscheid, P. Ionic Liquids in Synthesis, 2003 WILEY.; 2002. https://doi.org/10.5772/14646.

(66) Liu, T. Electrodéposition de Couches Minces Métalliques à Partir de Solutions de Liquides Ioniques Pour Des Applications Électroniques . To Cite This Version : HAL Id : Tel-01142699 DOCTEUR DE L' UNIVERSITÉ DE BORDEAUX ET DE L' UNIVERSIT É DE LISBONNE. 2015, No. July 2014.

(67) Aslam, M.; Kalyar, M. A.; Raza, Z. A. Polyvinyl Alcohol: A Review of Research Status and Use of Polyvinyl Alcohol Based Nanocomposites. Polym. Eng. Sci. 2018, 58 (12), 2119-2132. https://doi.org/10.1002/pen.24855.

(68) Saini, I.; Sharma, A.; Dhiman, R.; Aggarwal, S.; Ram, S.; Sharma, P. K. Grafted SiC Nanocrystals: For Enhanced Optical, Electrical and Mechanical Properties of Polyvinyl Alcohol. J. Alloys Compd. 2017, 714, 172-180. https://doi.org/10.1016/j.jallcom.2017.04.183.

(69) Alcohol, P. Mowiol Polyvinyl Alcohol. 1999, 105.

(70) Dattola, E.; Parrotta, E. I.; Scalise, S.; Perozziello, G.; Limongi, T.; Candeloro, P.; Coluccio, M. L.; Maletta, C.; Bruno, L.; De Angelis, M. T.; et al. Development of 3D PVA Scaffolds for Cardiac Tissue Engineering and Cell Screening Applications. RSC Adv. 2019, $9 \quad$ (8), $4246-4257$. https://doi.org/10.1039/C8RA08187E. 
(71) Abdullah, Z. W.; Dong, Y.; Davies, I. J.; Barbhuiya, S. PVA, PVA Blends, and Their Nanocomposites for Biodegradable Packaging Application. Polymer Plastics Technology and Engineering. 2017, pp 1307-1344. https://doi.org/10.1080/03602559.2016.1275684.

(72) Ahmed, E. M. Hydrogel: Preparation, Characterization, and Applications: A Review. J. Adv. Res. 2015, 6 (2), 105-121. https://doi.org/10.1016/j.jare.2013.07.006.

(73) Wichterle, O.; Lím, D. Hydrophilic Gels for Biological Use. Nature 1960, 185 (4706), 117-118. https://doi.org/10.1038/185117a0.

(74) Bahram, M.; Mohseni, N.; Moghtader, M. An Introduction to Hydrogels and Some Recent Applications. In Emerging Concepts in Analysis and Applications of Hydrogels; 2016. https://doi.org/10.5772/64301.

(75) Inoue, H. Hydrogel Electrolyte. In Encyclopedia of Applied Electrochemistry; Springer New York: New York, NY, 2014; pp 1035-1039. https://doi.org/10.1007/978-1-4419-6996-5_515.

(76) Fan, L.; Wang, M.; Zhang, Z.; Qin, G.; Hu, X.; Chen, Q. Preparation and Characterization of PVA Alkaline Solid Polymer Electrolyte with Addition of Bamboo Charcoal. Materials (Basel). 2018, $11 \quad$ (5). https://doi.org/10.3390/ma11050679.

(77) Liao, G. M.; Yang, C. C.; Hu, C. C.; Pai, Y. L.; Lue, S. J. Novel Quaternized Polyvinyl Alcohol/Quaternized Chitosan Nano-Composite as an Effective Hydroxide-Conducting Electrolyte. J. Memb. Sci. 2015, 485, 17-29. https://doi.org/10.1016/j.memsci.2015.02.043.

(78) Jiang, M.; Zhu, J.; Chen, C.; Lu, Y.; Ge, Y.; Zhang, X. Poly(Vinyl Alcohol) Borate Gel Polymer Electrolytes Prepared by Electrodeposition and Their Application in Electrochemical Supercapacitors. ACS Appl. Mater. Interfaces 2016, 8 (5), 3473-3481. https://doi.org/10.1021/acsami.5b11984.

(79) Fan, L.; Chen, J.; Qin, G.; Wang, L.; Hu, X.; Shen, Z. Preparation of PVA-KOHHalloysite Nanotube Alkaline Solid Polymer Electrolyte and Its Application in Ni-MH Battery. Int. J. Electrochem. Sci. 2017, 12 (6), 5142-5156. https://doi.org/10.20964/2017.06.65.

(80) Padwal, N.; Prakash, S. S.; Thakkar, S.; Deshpande, T. Supported Liquid 
Membrane Technology: Advances and Review of Its Applications. Indian J. Adv. Chem. Sci. 2018, 6 (3), 2018. https://doi.org/10.22607/IJACS.2018.601003.

(81) Agmon, N.; Bakker, H. J.; Campen, R. K.; Henchman, R. H.; Pohl, P.; Roke, S.; Thämer, M.; Hassanali, A. Protons and Hydroxide Ions in Aqueous Systems. Chem. Rev. 2016, $116 \quad$ (13), $7642-7672$. https://doi.org/10.1021/acs.chemrev.5b00736.

(82) Li, J. Alkaline Polymer Electrolytes for Electrochemical Capacitors Alkaline Polymer Electrolytes for Electrochemical Capacitors. 2015.

(83) Lewandowski, A.; Skorupska, K.; Malinska, J. Novel Poly(Vinyl Alcohol)-KOHH2O Alkaline Polymer Electrolyte. Solid State Ionics 2000, 133 (3), 265-271. https://doi.org/10.1016/S0167-2738(00)00733-5.

(84) Mohamad, A. A.; Mohamed, N. S.; Yahya, M. Z. A.; Othman, R.; Ramesh, S.; Alias, Y.; Arof, A. K. Ionic Conductivity Studies of Poly(Vinyl Alcohol) Alkaline Solid Polymer Electrolyte and Its Use in Nickel-Zinc Cells. Solid State Ionics 2003, 156 (1-2), 171-177. https://doi.org/10.1016/S0167-2738(02)00617-3.

(85) Yang, C. C.; Lin, S. J. Alkaline Composite PEO-PVA-Glass-Fibre-Mat Polymer Electrolyte for Zn-Air Battery. J. Power Sources 2002, 112 (2), 497-503. https://doi.org/10.1016/S0378-7753(02)00438-X.

(86) Wu, Q.; Zhang, J.; Sang, S. Preparation of Alkaline Solid Polymer Electrolyte Based on PVA-TiO 2-KOH-H2O and Its Performance in Zn-Ni Battery. J. Phys. Chem. Solids 2008, 69 (11), 2691-2695. https://doi.org/10.1016/j.jpcs.2008.06.132.

(87) Yuan, A.; Zhao, J. Composite Alkaline Polymer Electrolytes and Its Application to Nickel-Metal Hydride Batteries. Electrochim. Acta 2006, 51 (12), $2454-$ 2462. https://doi.org/10.1016/j.electacta.2005.07.027.

(88) Li, B.; Lu, X.; Yuan, J.; Zhu, Y.; Li, L. Alkaline Poly(Vinyl Alcohol)/Poly(Acrylic Acid) Polymer Electrolyte Membrane for Ni-MH Battery Application. Ionics (Kiel). 2014, 21 (1), 141-148. https://doi.org/10.1007/s11581-014-1145-9.

(89) Caldeira, I.; Lüdtke, A.; Tavares, F.; Cholant, C.; Balboni, R.; Flores, W. H.; Galio, A.; Pawlicka, A.; Avellaneda, C. O. Ecologically Friendly Xanthan Gum-PVA Matrix for Solid Polymeric Electrolytes. Ionics (Kiel). 2018, 24 (2), 413-420. https://doi.org/10.1007/s11581-017-2223-6. 
(90) Zhang, S.; Yu, N.; Zeng, S.; Zhou, S.; Chen, M.; Di, J.; Li, Q. An Adaptive and Stable Bio-Electrolyte for Rechargeable Zn-Ion Batteries. J. Mater. Chem. A 2018, 6 (26), 12237-12243. https://doi.org/10.1039/c8ta04298e.

(91) Mokhtar, M.; Majlan, E. H.; Talib, M. Z. M.; Ahmad, A.; Tasirin, S. M.; Daud, W. R. W. A Short Review on Alkaline Solid Polymer Electrolyte Based on Polyvinyl Alcohol (PVA) as Polymer Electrolyte for Electrochemical Devices Applications. Int. J. Appl. Eng. Res. 2016, 11 (19), 10009-10015.

(92) Armelin, E.; Pérez-Madrigal, M. M.; Alemán, C.; Díaz, D. D. Current Status and Challenges of Biohydrogels for Applications as Supercapacitors and Secondary Batteries. Journal of Materials Chemistry A. 2016, pp 8952-8968. https://doi.org/10.1039/c6ta01846g.

(93) Singerling, S. A. Bismuth. S. Geological Survey, Mineral Commodity Summaries; 2019.

(94) Condurache-Bota, S. Bismuth Oxide Thin Films for Optoelectronic and Humidity Sensing Applications. In Bismuth - Advanced Applications and Defects Characterization; InTech, 2018. https://doi.org/10.5772/intechopen.75107.

(95) Yilmaz, S.; Turkoglu, O.; Ari, M.; Belenli, I. Electrical Conductivity of the Ionic Conductor Tetragonal (Bi2O3)1-x(Eu2O3)X. Cerâmica 2012, 57 (342), 185192. https://doi.org/10.1590/s0366-69132011000200009.

(96) Moser, F.; Fourgeot, F.; Rouget, R.; Crosnier, O.; Brousse, T. In Situ X-Ray Diffraction Investigation of Zinc Based Electrode in Ni-Znsecondary Batteries. Electrochim. Acta $\quad \mathbf{2 0 1 3}, \quad 109, \quad 110-116$. https://doi.org/10.1016/j.electacta.2013.07.023.

(97) Yuan, Y. F.; Li, Y.; Tao, S.; Ye, F. C.; Yang, J. L.; Guo, S. Y.; Tu, J. P. Preparation and Electrochemical Performance of Nanosized Bi Compounds-Modified ZnO for Zn/Ni Secondary Cell. Electrochim. Acta 2009, 54 (26), 6617-6621. https://doi.org/10.1016/j.electacta.2009.06.063.

(98) Pyper, O.; Hahn, B.; Schöllhorn, R. Electrochemical Solid-Solid Conversion of Bismuth Oxide to Bismuth Metal. J. Mater. Chem. 1997. https://doi.org/10.1039/a605939b.

(99) Svancara, I.; Kotzian, P.; Bartos, M.; Vytras, K. Groove Electrodes: A New 
Alternative of Using Carbon Pastes in Electroanalysis. Electrochem. commun. 2005, 7 (7), 657-662. https://doi.org/10.1016/j.elecom.2005.04.017.

(100) Gujar, T. P.; Shinde, V. R.; Lokhande, C. D.; Han, S. H. Electrosynthesis of Bi2O3 Thin Films and Their Use in Electrochemical Supercapacitors. J. Power Sources 2006, 161 (2), 1479-1485. https://doi.org/10.1016/j.jpowsour.2006.05.036.

(101) McBreen, J.; Gannon, E. Bismuth Oxide as an Additive in Pasted Zinc Electrodes. J. Power Sources 1985. https://doi.org/10.1016/0378-7753(85)80070-7.

(102) Gallaway, J. W.; Gaikwad, A. M.; Hertzberg, B.; Erdonmez, C. K.; Chen-Wiegart, Y. C. K.; Sviridov, L. A.; Evans-Lutterodt, K.; Wang, J.; Banerjee, S.; Steingartb, D. A. An In Situ Synchrotron Study of Zinc Anode Planarization by a Bismuth $\begin{array}{lllll}\text { Additive. } \quad J . & \text { Electrochem. } & \text { Soc. 2014, } & 161\end{array}$ (3). https://doi.org/10.1149/2.037403jes.

(103) Shin, J.; You, J. M.; Lee, J. Z.; Kumar, R.; Yin, L.; Wang, J.; Shirley Meng, Y. Deposition of $\mathrm{ZnO}$ on Bismuth Species towards a Rechargeable Zn-Based Aqueous Battery. Phys. Chem. Chem. Phys. 2016, 18 (38), 26376-26382. https://doi.org/10.1039/c6cp04566a.

(104) Huang, H.; Zhang, W.; Li, M.; Gan, Y.; Chen, J.; Kuang, Y. Carbon Nanotubes as a Secondary Support of a Catalyst Layer in a Gas Diffusion Electrode for Metal Air Batteries. J. Colloid Interface Sci. 2005, 284 (2), 593-599. https://doi.org/10.1016/j.jcis.2004.10.067.

(105) Bresser, D.; Buchholz, D.; Moretti, A.; Varzi, A.; Passerini, S. Alternative Binders for Sustainable Electrochemical Energy Storage-the Transition to Aqueous Electrode Processing and Bio-Derived Polymers. Energy Environ. Sci. 2018, 11 (11), 3096-3127. https://doi.org/10.1039/c8ee00640g.

(106) Cheng, F.; Chen, J. Metal-Air Batteries: From Oxygen Reduction Electrochemistry to Cathode Catalysts; 2012; Vol. 41. https://doi.org/10.1039/c1cs15228a.

(107) Davari, E.; Ivey, D. G. Bifunctional Electrocatalysts for Zn-Air Batteries. Sustain. Energy Fuels 2018, 2 (1), 39-67. https://doi.org/10.1039/c7se00413c.

(108) Keith, J. A.; Jacob, T. Computational Simulations on the Oxygen Reduction Reaction in Electrochemical Systems; 2010; pp 89-132. https://doi.org/10.1007/978-1-4419-5594-4_3. 
(109) HALPERT, G.; FRANK, H.; SURAMPUDI, S. Batteries and Fuel Cells in Space. Electrochem. Soc. interface 1999, 8 (3), 25-30.

(110) Damjanovic, A.; Genshaw, M. A. The Mechanism of Oxygen Reduction at Platinum in Alkaline Solutions with Special Reference to $\mathrm{H}_{2} \mathrm{O}_{2}$. 1968, 114 (11).

(111) Wroblowa, H. S.; Yen-Chi-Pan; Razumney, G. Electroreduction of Oxygen. $J$. Electroanal. Chem. Interfacial Electrochem. 1976, 69 (2), 195-201. https://doi.org/10.1016/s0022-0728(76)80250-1.

(112) Song, C.; Zhang, J. Electrocatalytic Oxygen Reduction Reaction. PEM Fuel Cell Electrocatal. Catal. Layers Fundam. Appl. 2008, 89-134. https://doi.org/10.1007/978-1-84800-936-3_2.

(113) Vielstich, W. B. E. Conway, J. O’M. Bockris, E. Yeager, S. U. M. Khan, R. E. White: Kinetics and Mechanisms of Electrode Processes, Vol. 7 Aus Der Reihe: Comprehensive Treatise of Electrochemistry, Plenum Press New York and London 1983. 788 Seiten, Preis: \$ 95,- (+ 20\%. Berichte der Bunsengesellschaft für Phys. Chemie 1984, $88 \quad$ (8), 777-778. https://doi.org/10.1002/bbpc.19840880820.

(114) YEAGER, E. ChemInform Abstract: RECENT ADVANCES IN THE SCIENCE OF ELECTROCATALYSIS. Chem. Informationsd. 1981, 12 (31), 160-171. https://doi.org/10.1002/chin.198131337.

(115) Nørskov, J. K.; Rossmeisl, J.; Logadottir, A.; Lindqvist, L.; Kitchin, J. R.; Bligaard, T.; Jónsson, H. Origin of the Overpotential for Oxygen Reduction at a Fuel-Cell Cathode. J. Phys. Chem. B 2004, 108 (46), 17886-17892. https://doi.org/10.1021/jp047349j. 



\section{Metodología Experimental.}

"A young man passes from our public schools to the universities, ignorant almost of the elements of every branch of useful knowledge."

CHARLES BABBAGE 



\subsection{Introducción.}

En este capítulo se recogen, por una parte, los reactivos y materiales usados en el trabajo experimental, así como la metodología empleada en la realización de dichos experimentos, incluyendo la fabricación de electrodos, geles poliméricos y celdas electroquímicas. Posteriormente, se lleva a cabo una pequeña introducción de las distintas técnicas experimentales, tanto espectroscópicas como electroquímicas y de imagen, que se han utilizado para caracterizar los materiales de los que están compuestos las baterías. Además, se explican también las técnicas empleadas en las descargas de dichas baterías.

\subsection{Materiales y síntesis.}

\subsubsection{Reactivos.}

Los diversos reactivos químicos utilizados en los experimentos se detallan en la Tabla 3.2-1 con su grado y/o pureza junto con el fabricante.

\begin{tabular}{|c|c|c|c|}
\hline S. $\mathrm{N}^{\mathbf{0}}$ & $\begin{array}{c}\text { NOMBRE DEL } \\
\text { REACTIVO QUÍMICO }\end{array}$ & FABRICANTE & ENSAYO \\
\hline $\mathbf{1}$ & EMIM TFSI & IOLITEC GmbH & $99 \%$ \\
\hline 2 & BMIM Tf & IOLITEC GmbH & $99 \%$ \\
\hline 3 & EMIM Tf & IOLITEC GmbH & $99 \%$ \\
\hline 4 & PVdF-HFP & Sigma-Aldrich & MW 400.000 \\
\hline 5 & THF & Sigma-Aldrich & $99.9 \%$ \\
\hline 6 & $\mathrm{Bi}_{2} \mathrm{O}_{3}$ & Alfa-Aesar & $99.5 \%$ \\
\hline 7 & $\mathrm{KOH}$ & Sigma-Aldrich & $85 \%$ \\
\hline 8 & PVA Mowiol 18-88 & Sigma-Aldrich & MW 130.000 \\
\hline 9 & PVA Mowiol 20-98 & Sigma-Aldrich & MW 125.000 \\
\hline 10 & Zinc powder & Goodfellow & $>98.7 \%$ \\
\hline 11 & NMP & Sigma-Aldrich & $99,5 \%$ \\
\hline 12 & $\mathrm{Zn}(\mathrm{Tf})_{2}$ & Sigma-Aldrich & $98 \%$ \\
\hline 13 & Zinc Plate & Española del Zinc S.A. & $>99.9$ \\
\hline 14 & Malla de Niquel & Goodfellow & No aplicable \\
\hline
\end{tabular}




\begin{tabular}{c|ccc}
$\mathbf{1 4}$ & Prolene $^{\mathrm{TM}}$ & Chemplex & No aplicable \\
$\mathbf{1 5}$ & $\mathrm{NaOH}$ & Sigma-Aldrich & $>97 \%$ \\
$\mathbf{1 6}$ & $\mathrm{KCl}$ & Sigma-Aldrich & $>99 \%$ \\
$\mathbf{1 7}$ & Agua bidestilada & SAIT & $>18 \mathrm{M} \Omega \mathrm{cm}$ \\
$\mathbf{1 8}$ & Cátodo E4B & Electric Fuel LTD. & No aplicable \\
\hline \multicolumn{2}{l}{ Tabla 3.2-1: Materiales utilizados en este trabajo. }
\end{tabular}

\subsubsection{Solution casting method.}

Los electrolitos de gel polimérico (GPEs) se obtienen por el procedimiento "solution casting method". El polímero es el "anfitrión" y las sales inorgánicas se disuelven en las proporciones pertinentes en disolventes adecuados (por ejemplo, AN, NMP, THF, DMF, metanol, agua destilada, etc.). El disolvente se deja entonces evaporar a temperatura ambiente o por medio de vacío y calor. El espesor de las membranas depende de la cantidad de solución añadida a la placa de Petri en el proceso de síntesis. Un esquema del procedimiento de preparación de películas o membranas de geles poliméricos se muestra en la Fig. 3.2-1.

La síntesis de GPEs mediante "solution casting method" de soluciones de polímeros y sales permite, entre otras ventajas, el procesamiento a bajas temperaturas, simplificar la adición de aditivos, mejorar la uniformidad de las películas y el uso de una amplia gama de disolventes, orgánicos, líquidos iónicos o agua.

En esta investigación, se han fabricado por medio de esta técnica GPEs hechos de PVA y PVdF-HFP, como polímero anfitrión. Como disolventes, se ha utilizado agua desionizada y NMP para membranas de PVA y PVdF-HFP respectivamente. Debido a que el punto de ebullición del NMP es $202^{\circ} \mathrm{C}$ se ha utilizado un desecador termostático, como el que se muestra en la Figura 3.2-1B, conectado a una bomba de vacío para acelerar el proceso de evaporación del disolvente.

Para las membranas sintetizadas con PVdF-HFP, 0.5g del copolímero se disuelven en 3.6g de NMP añadiendo posteriormente el líquido iónico y la sal de $\mathrm{ZnTf}_{2}$. La mezcla se mantuvo en agitación durante $12 \mathrm{~h}$ siendo, finalmente, transferida al 
desecador termostático y conectado a una bomba de vacío hasta obtener la membrana. Las cantidades utilizadas en las diferentes membranas se detallan en la siguiente tabla.

\begin{tabular}{|c|c|c|c|}
\hline GPE & PVdF-HFP/g & IL/g & $\mathrm{ZnTf}_{2} / \mathrm{g}$ \\
\hline PVdF-HFP & 0.5 & 0 & 0 \\
\hline IL-GPE & 0.5 & 0.445 & 0 \\
\hline $\mathrm{ZnTf}_{2} \mathrm{GPE}$ & 0.5 & 0 & 0.255 \\
\hline $\mathrm{IL} \mathrm{ZnTf}_{2}$ GPE 1 & 0.5 & 0.445 & 0.127 \\
\hline IL-ZnTf ${ }_{2}$ GPE 2 & 0.5 & 0.445 & 0.255 \\
\hline IL-ZnTf ${ }_{2}$ GPE 3 & 0.5 & 0.445 & 0.382 \\
\hline IL-ZnTf ${ }_{2}$ GPE 4 & 0.5 & 0.445 & 0.509 \\
\hline IL-ZnTf ${ }_{2}$ GPE 5 & 0.5 & 0.445 & 0.636 \\
\hline IL-ZnTf ${ }_{2}$ GPE 6 & 0.5 & 0.445 & 0.763 \\
\hline
\end{tabular}

Tabla 3.2-2: Composición de todos los GPEs sintetizados y nomenclaturas utilizadas. IL representa los diferentes líquidos iónicos: EMIM TFSI (ET), BMIM Tf (BTf) y EMIM Tf (ETf). En todos los casos se emplearon $3,6 \mathrm{~g}$ de NMP. También se incluye el polímero PVdF. HFP.

Para las membranas sintetizadas con PVA se utilizaron siempre 4g de PVA en $60 \mathrm{ml}$ de agua destilada a la que se le añadieron diversos volúmenes de disolución acuosa de KOH 6M una vez que el PVA fue disuelto completamente. Es necesario aplicar calor $\left(80-90^{\circ} \mathrm{C}\right)$ y agitación vigorosa durante dos horas para disolver el PVA completamente. Posteriormente se vertió la disolución en una placa Petri y se dejó evaporar el disolvente hasta obtener las membranas.

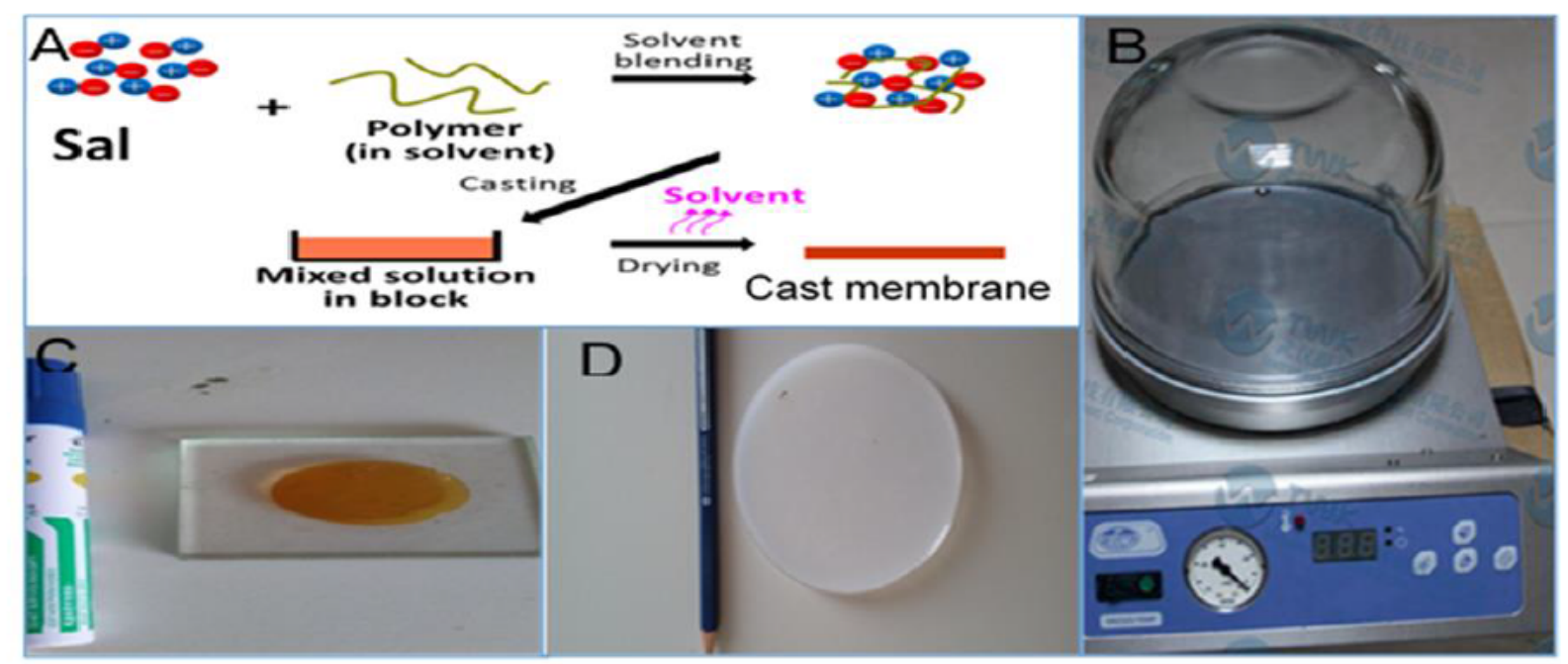

Figura 3.2-1: A) Proceso esquemático para la fabricación de membranas usando el método "solution casting method". B) desecador termostático. C) y D) Membranas de PVdF-HFP-ZnTf y PVA-KOH, respectivamente, sintetizadas en el laboratorio. 
En el Capitulo II, se da una visión general de los denominados líquidos iónicos sin detallar los utilizados en esta investigación. En la Figura 3.2-2, se muestran específicamente los líquidos iónicos con los que se ha trabajado para la fabricación de los geles poliméricos de PVdF-HFP de esta investigación.

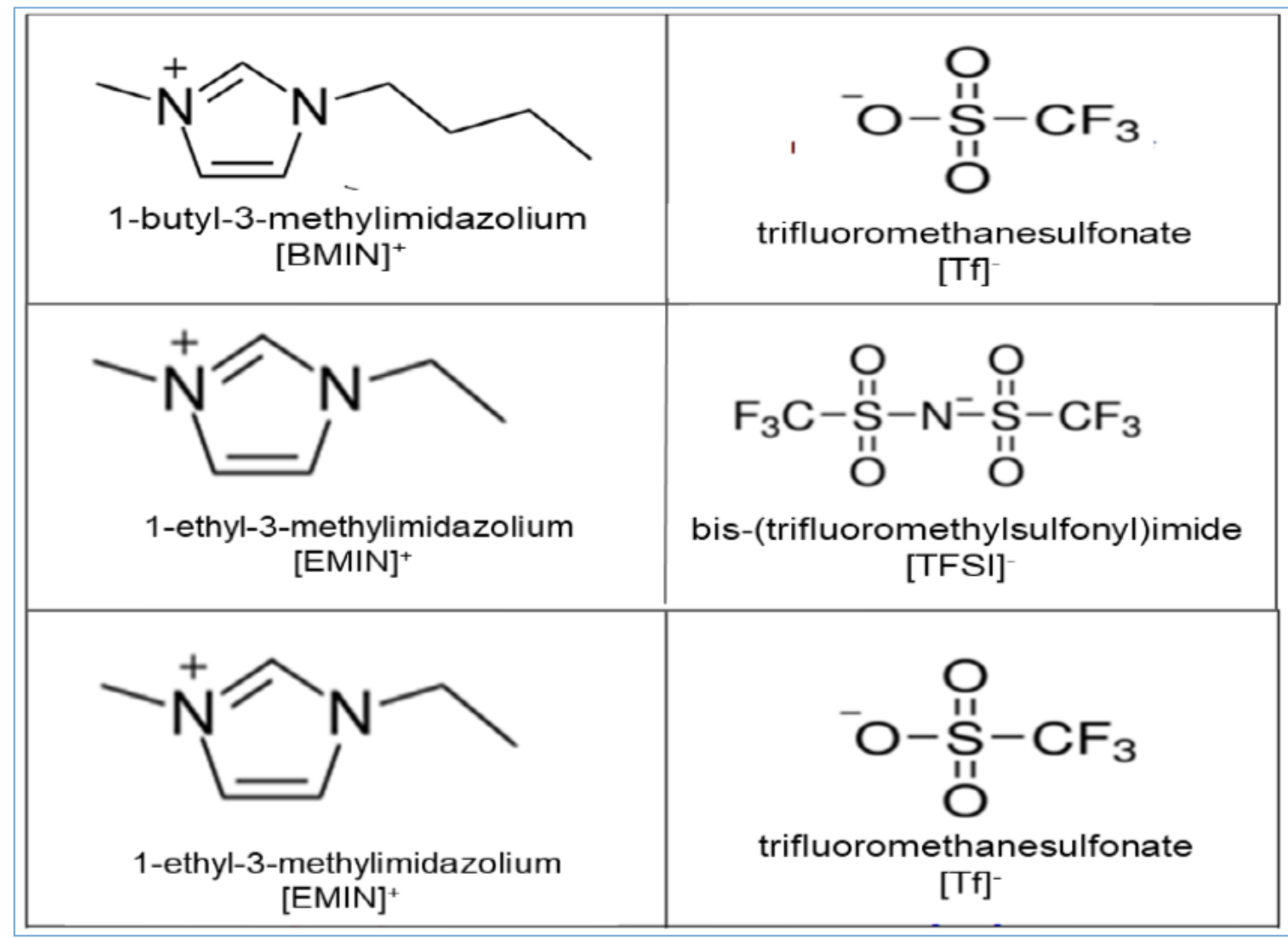

Figura 3.2-2: ILs utilizados en esta investigación.

\subsubsection{Síntesis de electrodos positivos.}

Para las baterías que usan como electrolito una membrana polimérica se utilizaron dos tipos de electrodo de aire. El electrodo E4B comercial suministrado por Electric Fuel Ltd.(Israel) ${ }^{1}$ y electrodos de $\mathrm{MnO}_{2}$ y negro de carbón fabricados por nosotros siguiendo el procedimiento representado en la Figura 3.2-2. Las cantidades apropiadas de negro de carbono, $\mathrm{MnO}_{2}$ y aglutinante (PVdF) se mezclan en THF. Posteriormente se permite que se evapore el THF en una estufa antes de pasarlo a una prensa hidráulica manual aplicando una presión de 250 bares durante 1 min para formar el cátodo por compresión mecánica. 
El electrodo de aire comercial suministrado por Electric Fuel Ltd. es concretamente el modelo E4B que dispone de separador interior y capa externa de PTFE que actúa como barrera. Según las especificaciones del fabricante, este electrodo contiene un $25 \%$ en peso de $\mathrm{MnO}_{2}$ como catalizador.

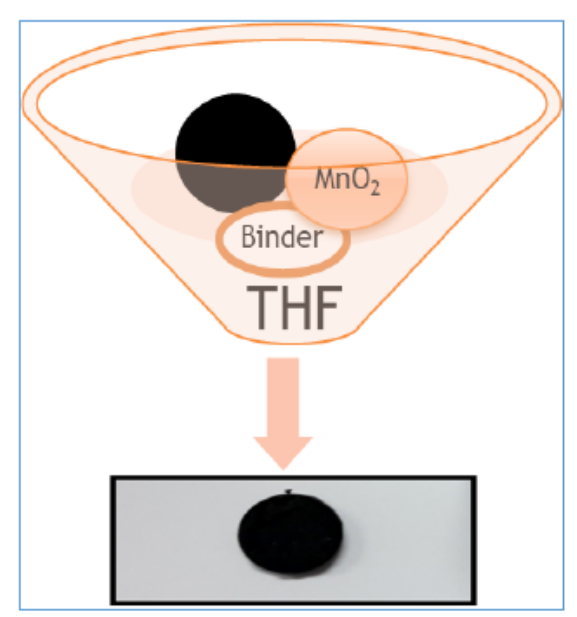

Figura 3.2-3: Esquema del proceso de fabricación de un electrodo de aire a escala de laboratorio con catalizador de $\mathrm{MnO}_{2}$, parte superior. Imagen de un electrodo de aire fabricado en el laboratorio, parte inferior.

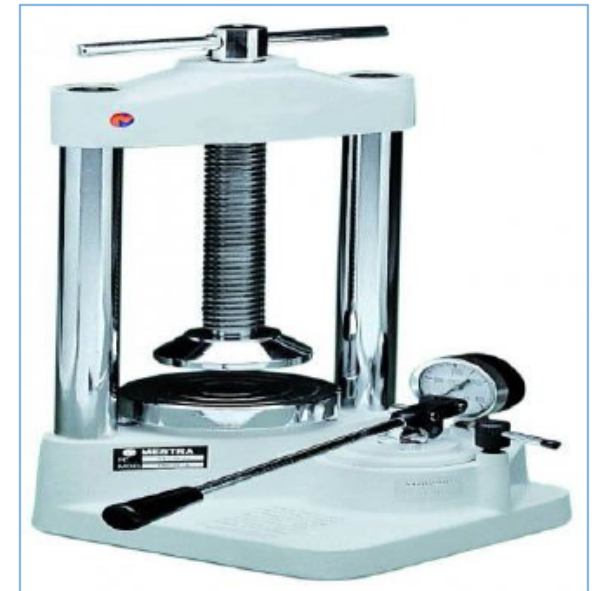

Figura 3.2-4: Prensa hidráulica donde se realizaron los cátodos por prensado de la mezcla de los componentes.

\subsubsection{Síntesis de electrodos negativos.}

En cuanto a los electrodos negativos, se ha usado zinc en polvo contenido en una capsula para las pruebas de capacidad de las baterías. En las baterías liquidas es imposible el uso de zinc en polvo debido a la configuración de la celda, por lo que en estos casos, el zinc en polvo fue prensado a 250 bares durante $1 \mathrm{~min}$ hasta obtener pastillas o discos de zinc, los cuales encajaban perfectamente en el "anode holder" de la misma, ver Figura 3.2-6.

Los electrodos negativos compuestos por $\mathrm{Zn} \mathrm{y} \mathrm{Bi}_{2} \mathrm{O}_{3}$, se usaron siempre en forma de pastilla o disco. A diferencia de las pastillas de zinc puro, las mezclas de $\mathrm{Zn} / \mathrm{Bi}_{2} \mathrm{O}_{3}$ se llevaron a un mortero donde se homogeneizaron antes de llevarlas a la prensa manual. 
También se ha usado lámina de zinc, la cual se pulió con lijas de diferente tamaño de grano hasta alcanzar una superficie libre de suciedad y restos de óxido de zinc.

\subsubsection{Celdas electroquímicas.}

Dependiendo del electrolito usado, se diseñaron y fabricaron dos tipos de celdas experimentales que fueron utilizadas para caracterizar los componentes de las baterías, así como para analizar las propiedades de las mismas baterías (Figuras 3.2-4 y 3.2-5).

Cuando usamos una membrana polimérica como electrolito se usó la celda que aparece en la Figura3.2-5, en ésta se pueden observar los componentes necesarios; ánodo, cátodo, electrolito y conectores, por separado (derecha); y una vez montados para realizar el ensayo (izquierda). Como se muestra en la Figura, el prototipo consta de dos piezas de Teflón ${ }^{\mathrm{TM}}$ entre las que se colocan los distintos componentes de la batería, los cuales quedan sujetos usando dos tornillos dispuestos en los extremos de la celda. Cuando se trata de una batería zinc-aire, la pieza superior de Teflón ${ }^{\mathrm{TM}}$ dispone de un orificio que permite la entrada de $\mathrm{O}_{2}$ desde el aire.

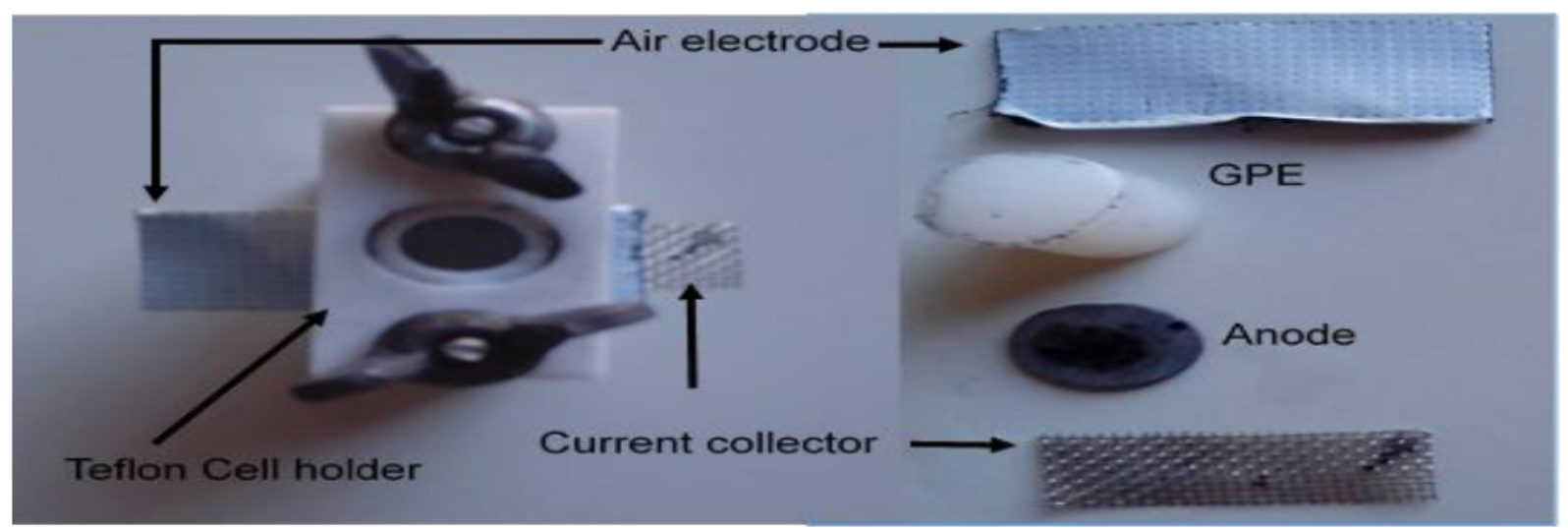

Figura 3.2-5: Batería con GPE completamente montada (izquierda). Los componentes de la misma batería (derecha).

En caso de utilizar electrolitos líquidos se usa otro tipo de celda electroquímica representada en la Figura 3.2-6. Esta celda fue construida específicamente ad hoc para el análisis in-situ o in-operando mediante técnicas que usan radiación sincrotrón. Su característica principal es una ventana de Prolene ${ }^{\mathrm{TM}}$ que permite a los rayos $\mathrm{X}$ alcanzar 
el material en estudio, en este caso el electrodo negativo de la celda electroquímica, y al mismo tiempo retiene el electrolito líquido dentro de la celda. Esta celda se ha utilizado con éxito en la línea SpLine Rama B del ESRF en Francia².

Otra característica de esta celda electroquímica es la posibilidad de ajustar la superficie del electrodo negativo en altura por medio de un tornillo regulable. Esta característica fue fundamental para la nivelación del electrodo cuando se utilizó la técnica de difracción de rayos $\mathrm{X}$ con ángulo de incidencia rasante.

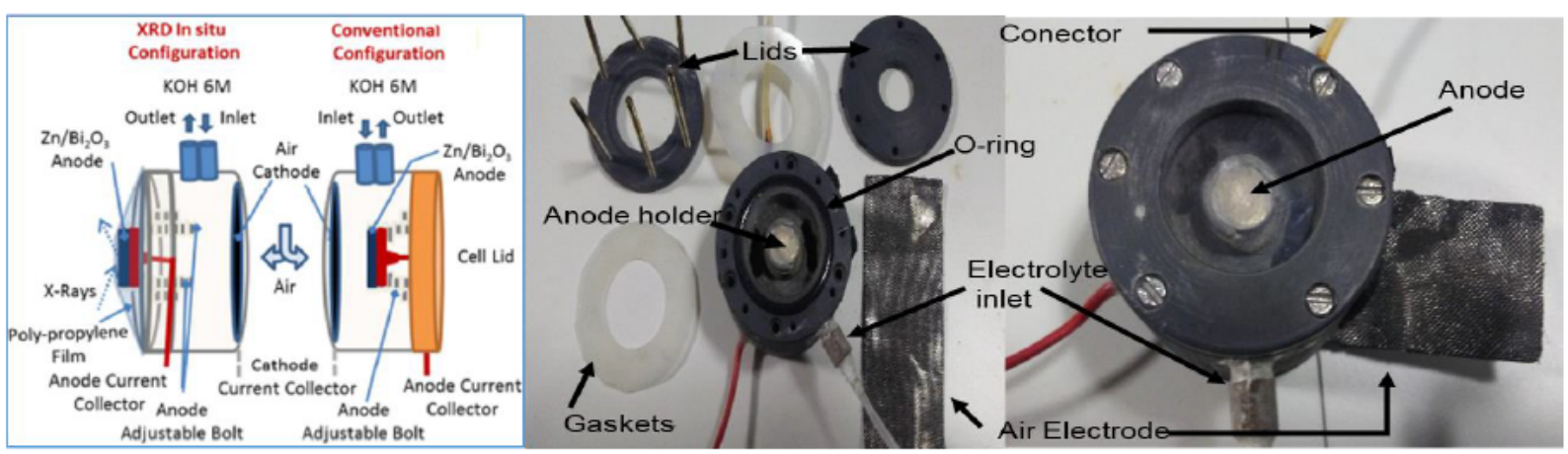

Figura 3.2-6: Vista esquemática de la celda electroquímica utilizada para electrolitos líquidos (izquierda). Componentes de la celda (centro). Batería completamente montada (derecha).

\subsection{Técnicas de caracterización físico-química.}

\subsubsection{Microscopía Electrónica de Barrido.}

La microscopía electrónica de barrido (SEM) es una técnica utilizada para estudiar la morfología de la superficie de los materiales ${ }^{3}$.

La fuente de iluminación no es una luz ordinaria sino un haz de electrones. Mientras que la lente condensadora controla la intensidad del haz de electrones, y de esta manera, el brillo, la resolución es controlada por la lente del objetivo, permitiendo que los electrones fluyan a través de la lente de enfoque la cual está compuesta de bobinas. Estas bobinas desvían el haz de electrones lo cual permite el enfoque. El principal inconveniente de la microscopía electrónica de barrido es la condición inherente de funcionamiento en vacío.

La Figura 3.3-2 muestra las varias señales generadas por la interacción del haz de electrones con la muestra en el microscopio electrónico de barrido y las regiones en 
las que se pueden detectar las señales. Los electrones secundarios y retrodispersados, que se producen a través de interacciones entre los átomos de la muestra y los electrones incidentes son detectados y cuantificados por los distintos detectores.

Aproximadamente el 30\% de los electrones incidentes escapan de la muestra por la retrodispersión. Estos electrones son conocidos como electrones retrodispersados, y proporcionan una señal útil para obtener imágenes de SEM. La fracción de electrones retrodispersados emitidos desde una muestra depende del número atómico de los elementos que la componen. Una muestra con un alto número atómico emite una mayor fracción de electrones retrodispersados que una muestra que contiene elementos con bajo número atómico.

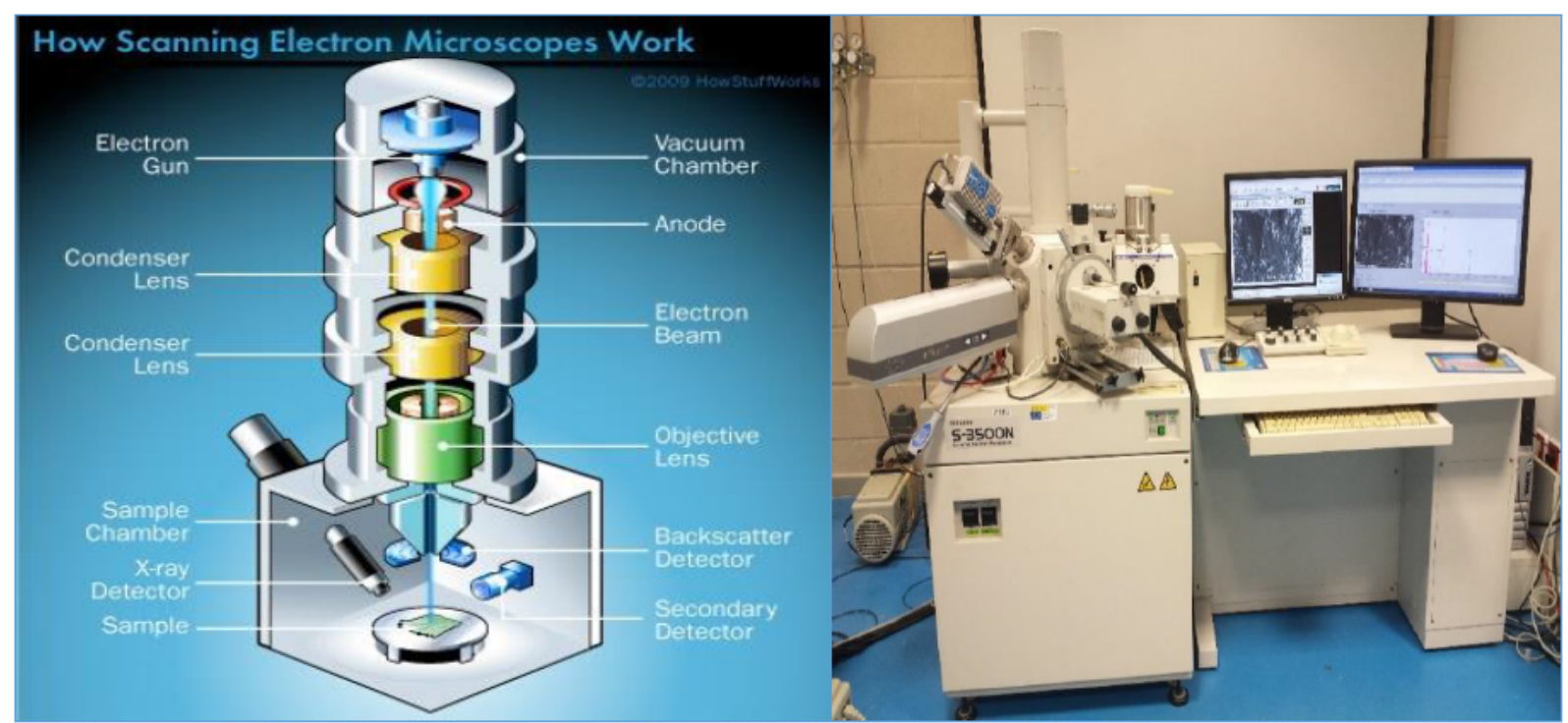

Figura 3.3-1: Configuración básica SEM ${ }^{4}$ (izquierda) y equipo de microscopia electrónico de barrido en el Servicio de Apoyo a la Investigación Tecnológica utilizada en esta investigación (SAIT-UPCT), derecha.

Las imágenes obtenidas a través de esta microscopía se recogen en colores grises. A posteriori, la imagen SEM se construye mediante la creación de un mapa de intensidades desde el detector de interés, con respecto a la ubicación xy del haz de electrones.

Además, con esta técnica, también se puede estimar la composición elemental de la materia objeto de estudio. Los electrones son dirigidos hacia la muestra utilizando el cañón de electrones (véase la Figura 3.3-1).Generalmente, el SEM viene equipado con un espectrómetro de energía dispersiva (EDAX o EDX) que analiza la radiación de 
rayos X emitida (líneas características Ka y K $\beta$ ) de la muestra cuando los haces de electrones interactúan con el espécimen ${ }^{5}$. Este fenómeno físico se denomina fluorescencia y produce líneas características de longitud de onda fija. Las intensidades de los picos se pueden comparar con los picos de una muestra estándar para obtener las cantidades relativas de cada elemento, con lo que la composición exacta de la muestra se puede determinar.

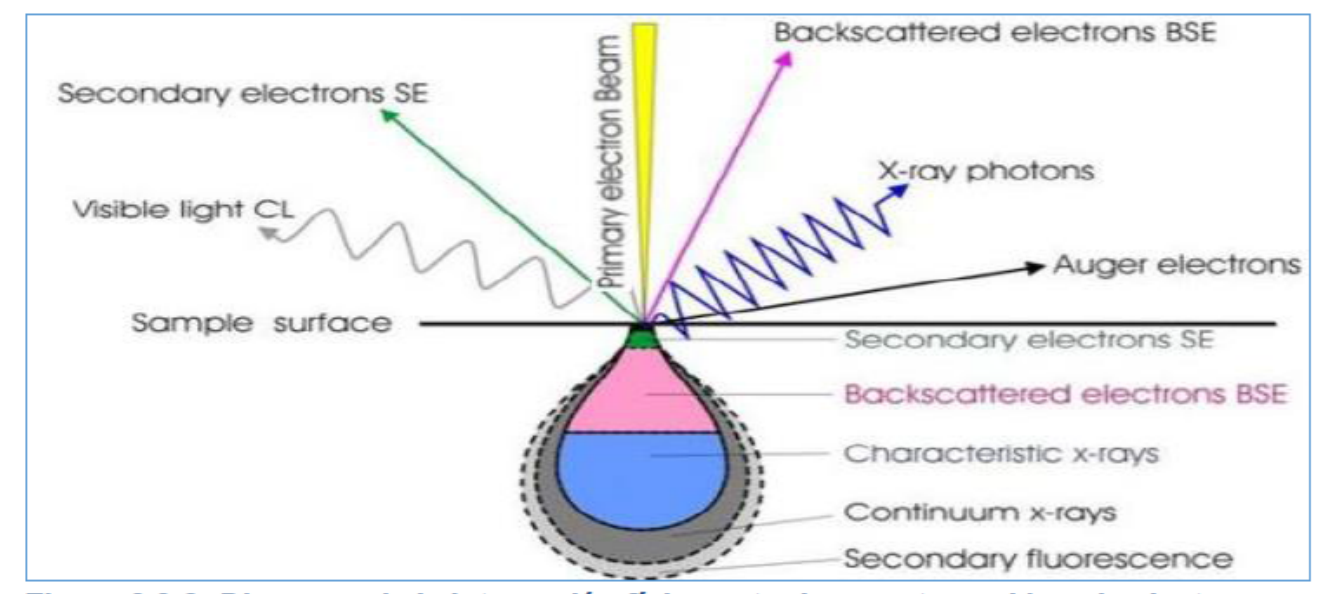

Figura 3.3-2: Diagrama de la interacción física entre la muestra y el haz de electrones. Tomado del Helmholtz-Zentrum Dresden-Rossendor.

En esta investigación se ha utilizado un equipo SEM, modelo HITACHI S$3500 \mathrm{~N}$. Este equipo está configurado para obtener imágenes tanto en alto vacío como en presión variable y está acoplado a un analizador por dispersión de energía de Rayos X, XFlash 5010 de Bruker con una resolución de 129eV.

\subsubsection{Difracción de rayos $X$.}

La difracción de rayos X (XRD) es una poderosa herramienta que se utiliza para estudiar las estructuras cristalinas mediante la medición de la difracción que experimentan los rayos $\mathrm{X}$ incidentes con los planos de átomos que forman dicha estructura cristalina. Dependiendo de los ángulos de incidencia, existirá una interferencia constructiva entre las radiaciones dispersadas y registrando los ángulos a los que esta interferencia constructiva tiene lugar, es posible estudiar la ordenación geométrica de los átomos dentro de los materiales cristalinos. 
Los patrones de difracción XRD nos proporcionan información geométrica sobre la estructura cristalina y de la celda unidad, según viene definido por la ley de Bragg ${ }^{6}$, como se describe en la Figura 3.3-3. La muestra se monta sobre un goniómetro que gira, mientras se hacen incidir rayos $\mathrm{X}$ monocromáticos a distintos ángulos de incidencia. De esta forma se obtiene un difractograma en el que se representa la intensidad de los picos a cada ángulo de incidencia.

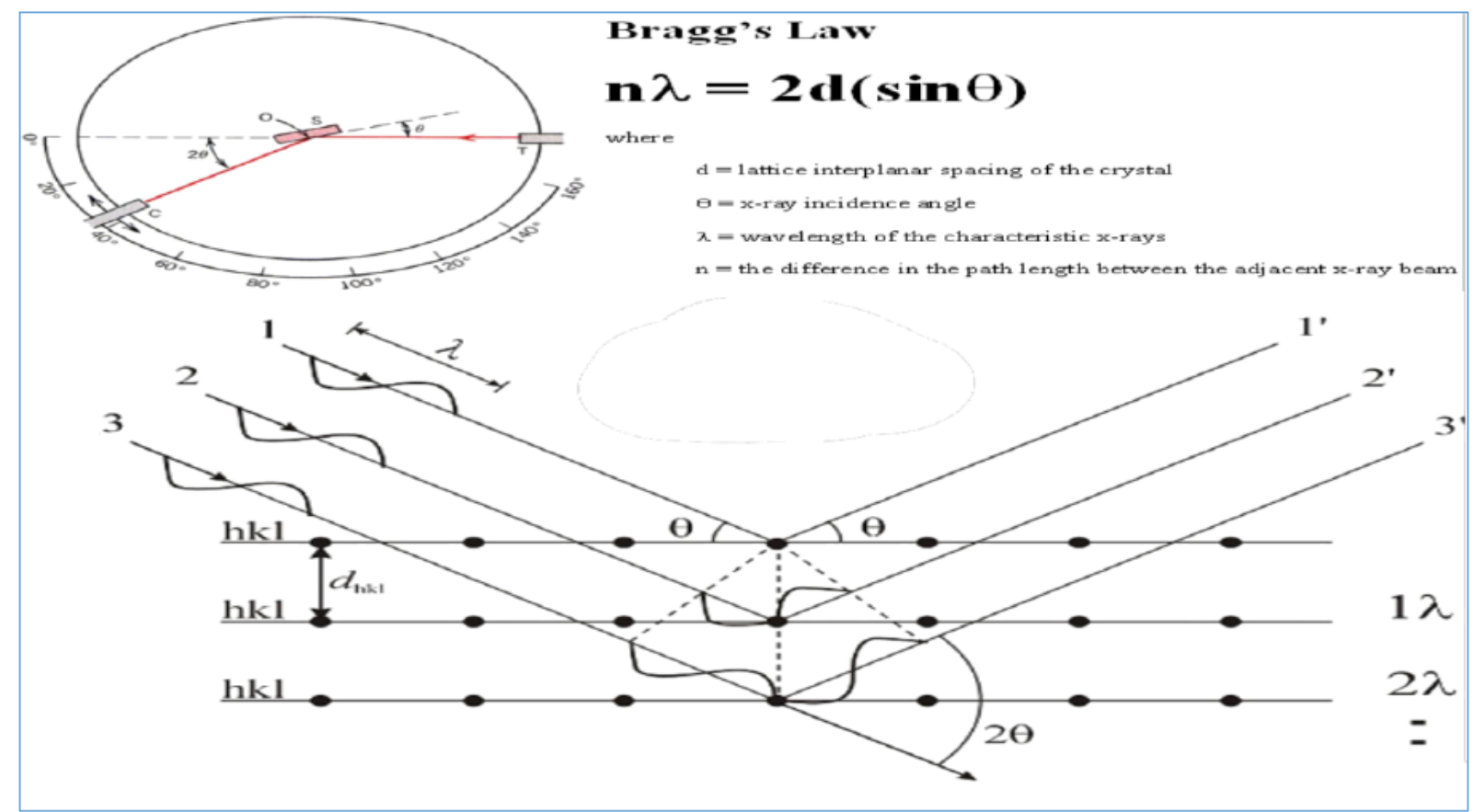

Figura 3.3-3: Esquema de funcionamiento XRD; Ecuación de Bragg y explicación geométrica para la difracción de la radiación $X$.

En este trabajo, se utilizó un difractometro Bruker D8 Advance (Bruker AXS $\mathrm{GmbH}$ ) de rayos X generados por un tubo de cerámica (2.2kW) de Cu K- $\alpha$. Figura 3.34. Se utilizó radiación de rayos X con longitud de onda de 1.54 Angstrom. Las muestras fueron escaneadas en $2 \theta$ entre 10 y $50^{\circ}$, en saltos de $0.05^{\circ}$ y $1 \mathrm{~s}$ por paso y a una velocidad de rotación de $30 \mathrm{rpm}$. Para el análisis de datos y con fines de identificación se utilizaron, el paquete de software DIFRAC.EVA y la base de datos ICCD respectivamente.

\subsubsection{La radiación sincrotrón.}

Un sincrotrón es una fuente extremadamente potente de rayos $\mathrm{X}^{7}$. Los rayos $\mathrm{X}$ son producidos por electrones de alta energía que se ven obligados a cambiar de 
dirección mientras circulan alrededor del anillo de almacenamiento del sincrotrón. Cuando un electrón que se mueve cambia de dirección, emite energía si se está moviendo lo suficientemente rápido. La energía emitida se encuentra dentro del rango de energía perteneciente a los rayos $\mathrm{X}^{8}$.

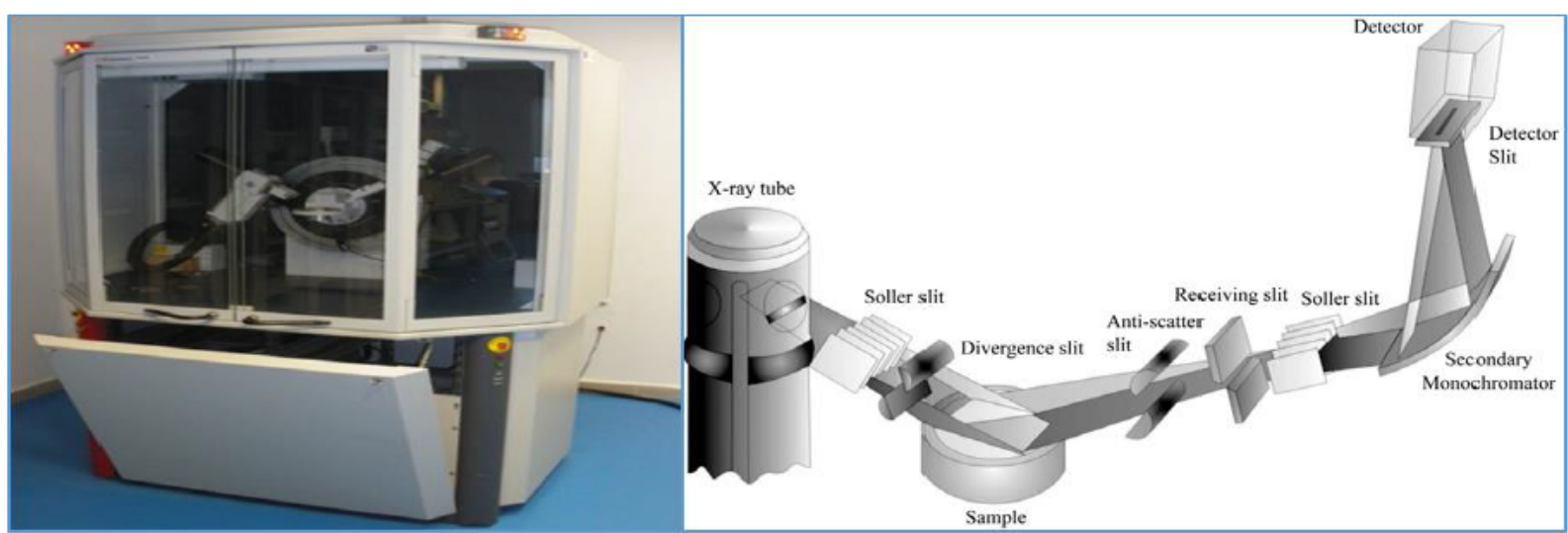

Figura 3.3-4: Bruker D8 Advance ,Bruker AXS GmbH, (izquierda) y el esquema básico de un difractómetro de rayos $X$ (derecha).

Una instalación de sincrotrón comprende algunos elementos clave que son importantes de mencionar. En la Figura 3.3-5 se pueden observar las partes principales de una instalación de radiación de sincrotrón. Estos son los siguientes:

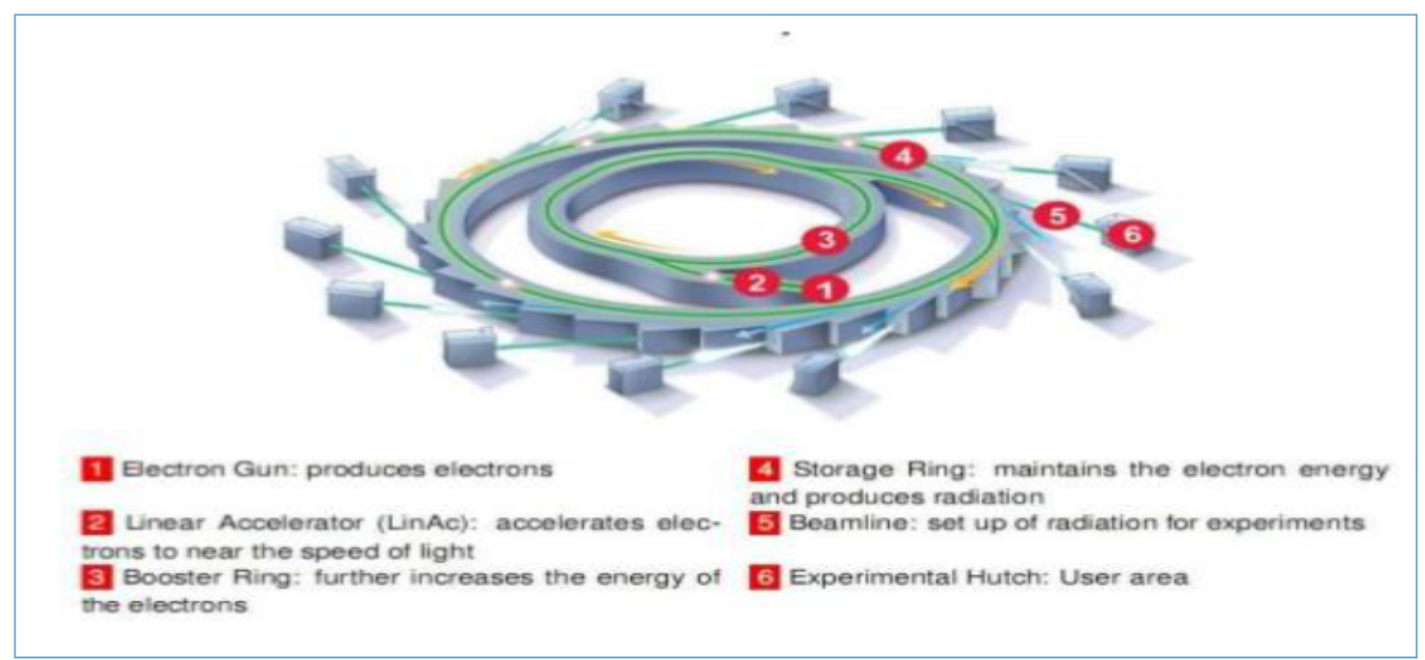

Figura 3.3-5: Componentes básicos de una instalación de radiación de sincrotrón. Tomado del sitio web del ESRF.

- Acelerador lineal/Linac. Los electrones se producen en un cañón de electrones, un dispositivo similar a los tubos de rayos catódicos. Estos 
electrones se aceleran a 200 millones de eVs y, posteriormente, se inyectan en el impulsor.

- Impulsor/Booster. Este es un pre-acelerador donde los electrones se aceleran a una energía de alrededor de $6 \mathrm{GeV}$ antes de ser pasados al anillo de almacenamiento. Este "sincrotrón de refuerzo" sólo trabaja un par de veces al día durante unos minutos, cuando se vuelve a rellenar el anillo de almacenamiento.

- Anillo de almacenamiento/Storage Ring. El anillo de almacenamiento es un tubo de varios cientos de metros de circunferencia donde los electrones viajan casi a la velocidad de la luz, pasando a través de diferentes tipos de imanes (Figura 3.3-6) donde se producen los rayos $\mathrm{X}$. El tubo se mantiene a una presión muy baja (alrededor de $10^{-9} \mathrm{mbar}$ ).

- Líneas de haz/Beam Lines. Los haces de rayos X emitidos por los electrones se dirigen hacia las líneas de haz que rodean el anillo de almacenamiento. Cada línea de haz está diseñada para utilizar técnicas específicas o para un tipo específico de investigación. Dentro de las líneas de haz se encuentran las estaciones experimentales.

- Imanes y dispositivos de inserción (Magnets and insertion devices). El anillo de almacenamiento incluye secciones rectas y curvas en orden alterno. En cada sección curva, grandes imanes fuerzan a los electrones a seguir en el anillo de almacenamiento de forma que al hacerlo, los electrones emiten rayos $\mathrm{X}$ tangencialmente. Sin embargo, esto rayos $\mathrm{X}$ son menos brillantes que los emitidos por los dispositivos de inserción. Las secciones rectas acomodan estos dispositivos de inserción. Estas estructuras magnéticas, compuestas de una serie de imanes, fuerzan a que los electrones sigan una trayectoria ondulada. La radiación emitida interfiere constructivamente para generar un haz mucho más brillante que el generado por un solo imán.

- Estaciones de trabajo/Experimental hutches. Éstas, son los denominadas "front-end" del sincrotrón y donde realmente los 
experimentos se llevan a cabo. Cada estación experimental está diseñada de acuerdo a la investigación específica que se ha planeado.
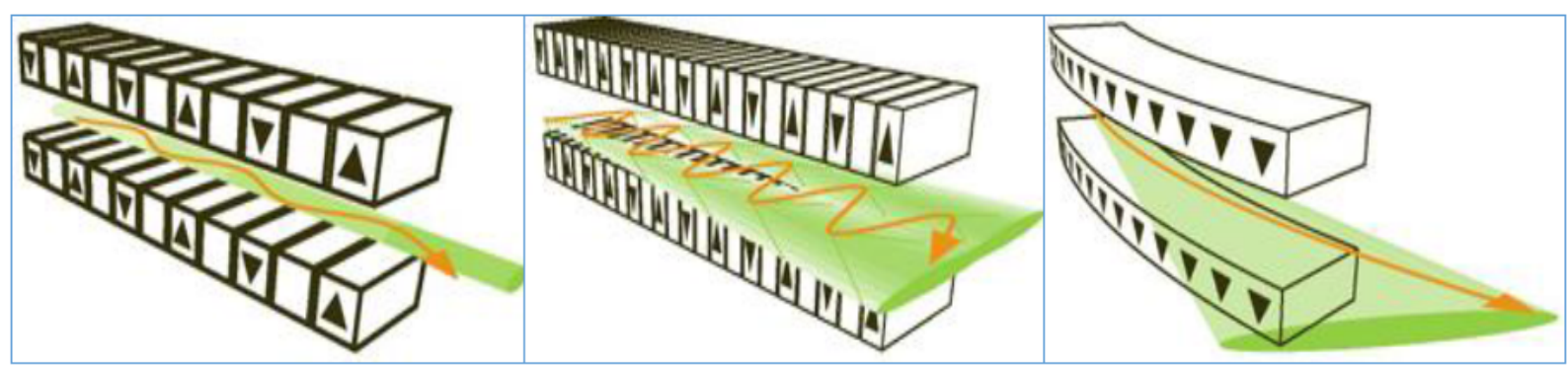

Figura 3.3-6: Dispositivo de inserción tipo ondulador (izquierda), "tipo de lombriz" (centro) e imán de flexión (derecha).

Los experimentos en los que se utilizó la radiación sincrotrón, se llevaron a cabo en el SpLine Rama B situado en el European Synchrotron Radiation Facility (GrenobleFrancia).

La línea española en el sincrotrón de Grenoble, SpLine, se divide en la rama A y B. Cada rama tiene asignadas distintas técnicas. La rama A se dedica a la Difracción de Polvo de alta resolución de (HRDP) y espectroscopía de absorción de rayos X (XAS). La rama B está dedicada a espectroscopia de fotoelectrones de rayos $\mathrm{X}$ de alta energía (HAXPES), desde unos pocos eV hasta $15 \mathrm{keV}$ de electrones de energía cinética y la técnica de difracción de rayos $\mathrm{X}$ tanto de monocristales como de superficies e interfaces, SXRD9.

\subsubsection{Refinamiento de Rietveld.}

En las medidas de XRD llevadas a cabo en el SpLine del ESRF, una vez que se identificaron las fases del difractograma de XRD, se realizó el refinamiento Rietveld a fin de extraer información más precisa para los parámetros de la red cristalina. Este refinamiento se realiza para minimizar la diferencia entre el patrón experimental y la estructura cristalina teórica por el método de mínimos cuadrados.

Este tratamiento fue establecido por Hugo Rietveld a finales de 1960. La difracción de rayos $\mathrm{X}$ en combinación con el análisis de Rietveld, da información detallada de los parámetros de red, longitudes de enlace, ángulos de enlace, etc., de las distintas fases presentes en la muestra. El método de Rietveld consiste en ajustar 
teóricamente los parámetros estructurales o parámetros de red, deslizamientos atómicos, anisotropía, tensiones de la red, etc., así como experimentales, al perfil completo del difractograma en polvo suponiendo que el difractograma es la suma de un número de reflexiones de Bragg centradas en sus posiciones angulares respectivas. Luego, los parámetros escogidos van siendo ajustados en un proceso iterativo hasta que se alcanza una condición de convergencia con los valores de las intensidades experimentales y el modelo teórico ${ }^{10}$.

El método de Rietveld es una técnica de refinamiento para minimizar la diferencia Sy entre $y_{i o}$ intensidad observada e yic la intensidad calculada por el mejor ajuste de mínimos cuadrados, según la expresión:

$$
s_{y}=\sum_{i} \frac{\left(y_{i o}-y_{i c}\right)^{2}}{y_{i o}}=\sum_{i} \omega_{i}\left(y_{i o}-y_{i c}\right)^{2}
$$

donde $\omega_{\mathrm{i}}$ es el peso estadístico asignado a cada punto e yic es la intensidad de cada paso.

\subsubsection{Espectroscopía de fotoelectrones de rayos $\mathrm{X}$.}

La espectroscopia de fotoelectrones de rayos X (XPS) proporciona información química de la superficie de una muestra que incluye sus estados electrónicos, configuración de enlace en la superficie, valencia, desplazamientos químicos y la composición elemental de una muestra. La espectroscopia XPS es una técnica muy sensible y se usa para estudiar solo las capas más superficiales, ya que sólo los electrones de estas capas más superficiales (recorrido libre medio de $\sim 1.5 \mathrm{~nm}$ ) pueden escapar sin pérdida de energía debido a una nueva colisión ${ }^{11}$. Los espectros XPS se obtienen mediante la detección de las energías cinéticas de los electrones emitidos desde la superficie del material de muestra cuando ésta es irradiada con un haz de rayos $\mathrm{X}$ utilizando un analizador de energía dispersiva ${ }^{11}$.

La energía cinética de los electrones arrancados por el haz de rayos-X y enviados al analizador se puede obtener siguiendo la ecuación:

$$
E_{k i n}=h v-E_{B, \text { Fermi }}-\Phi_{s p}
$$


donde h es la constante de Planck y v es la frecuencia del fotón de rayos X, Ekin es la energía medida por el analizador de energía durante el barrido del espectro de energía cinética, Eв,Fermi representa la energía de enlace del nivel i-ésimo correspondiente a los electrones de energía más alta del sistema en estado fundamental a 0 Kelvin, que es el nivel de Fermi y $\Phi_{\text {sp }}$ es la función de trabajo del espectrómetro. La función de trabajo es muy pequeña (2-5 eV) en comparación con los valores del rango de la energía cinética Ekin en XPS (50-1500eV).

En el presente estudio, el análisis de XPS se llevó a cabo usando dos modos, XPS convencional, así como XPS utilizando radiación sincrotrón (HAXPES). Las fuentes de radiación sincrotrón han permitido hacer estudios de alta resolución con rango de energía, para la energía cinética de los electrodos arrancados, más amplio (5-5000 eV). Con la técnica HAXPES incidimos la muestra con fotones más energéticos con lo que conseguimos penetrar más en la muestra $(5-10 \mathrm{~nm})$ y, por tanto, podemos examinar capas más profundas de la muestra.

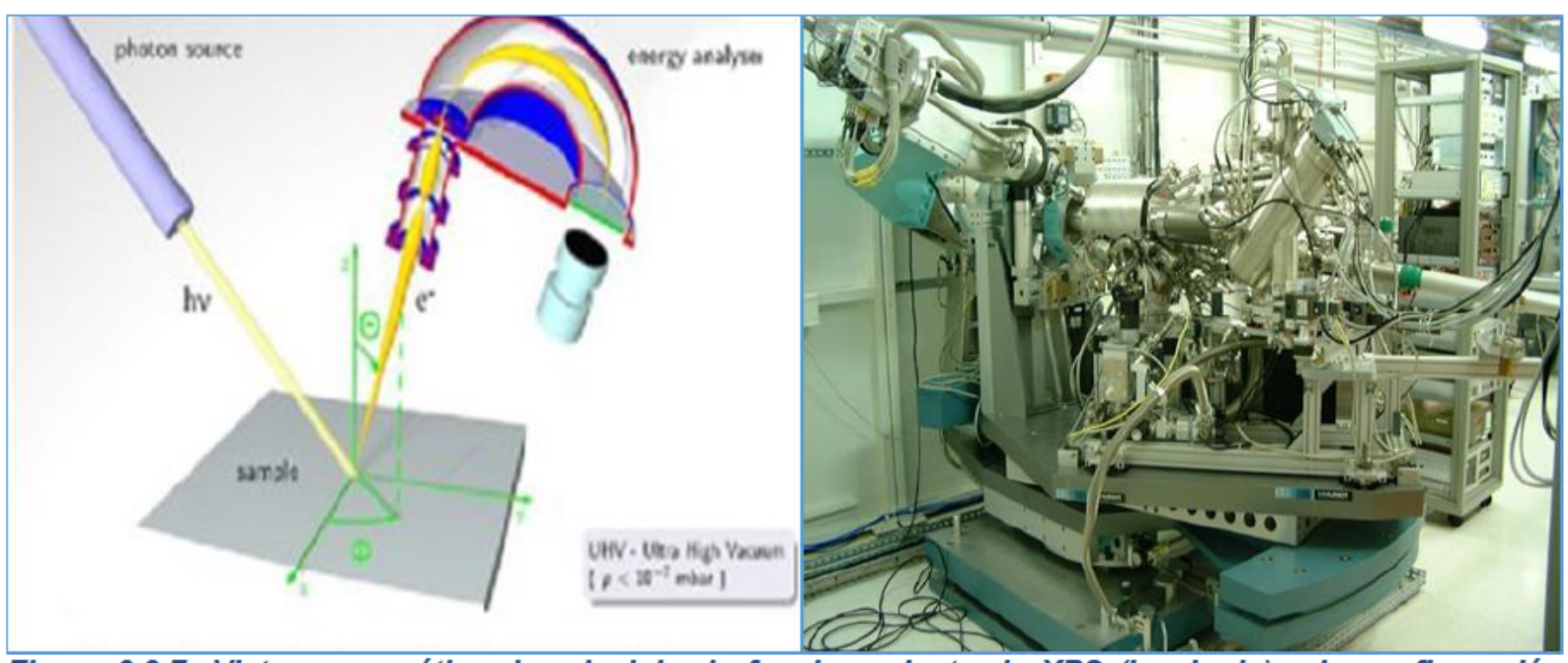

Figura 3.3-7: Vista esquemática de principio de funcionamiento de XPS (izquierda) y la configuración HAXPES utilizado en SpLine rama B (derecha).

\subsubsection{Espectroscopia ATR-FTIR.}

La espectroscopia de infrarrojos (IR) es un método espectroscópico de absorción en la que las muestras se irradian con radiación infrarroja en longitudes de onda de $1 \mu \mathrm{m}-1 \mathrm{~mm}$. La absorción de radiación infrarroja conduce a la excitación 
vibracional de las moléculas, pero sólo aquellos modos de vibración activos, i.e. aquellos en el que el momento dipolar de la molécula cambia durante la oscilación ${ }^{12}$.

La espectroscopia IR con transformada de Fourier (FT) se basa en el uso de un interferómetro de Michelson, en lugar de elementos dispersivos tales como rejillas o prismas para generar información espectral (Figura 3.3-8A). Un interferómetro de Michelson consiste en un divisor de haz, así como espejos, uno fijo y otro móvil. La radiación IR de la fuente es dividida en el divisor de haz en dos haces, uno de los cuales es fijo y el otro se refleja en el espejo móvil (Figura 3.3-8B). Ambos haces son de nuevo reunidos, interfieren entre sí y pasan a través de la muestra al detector.
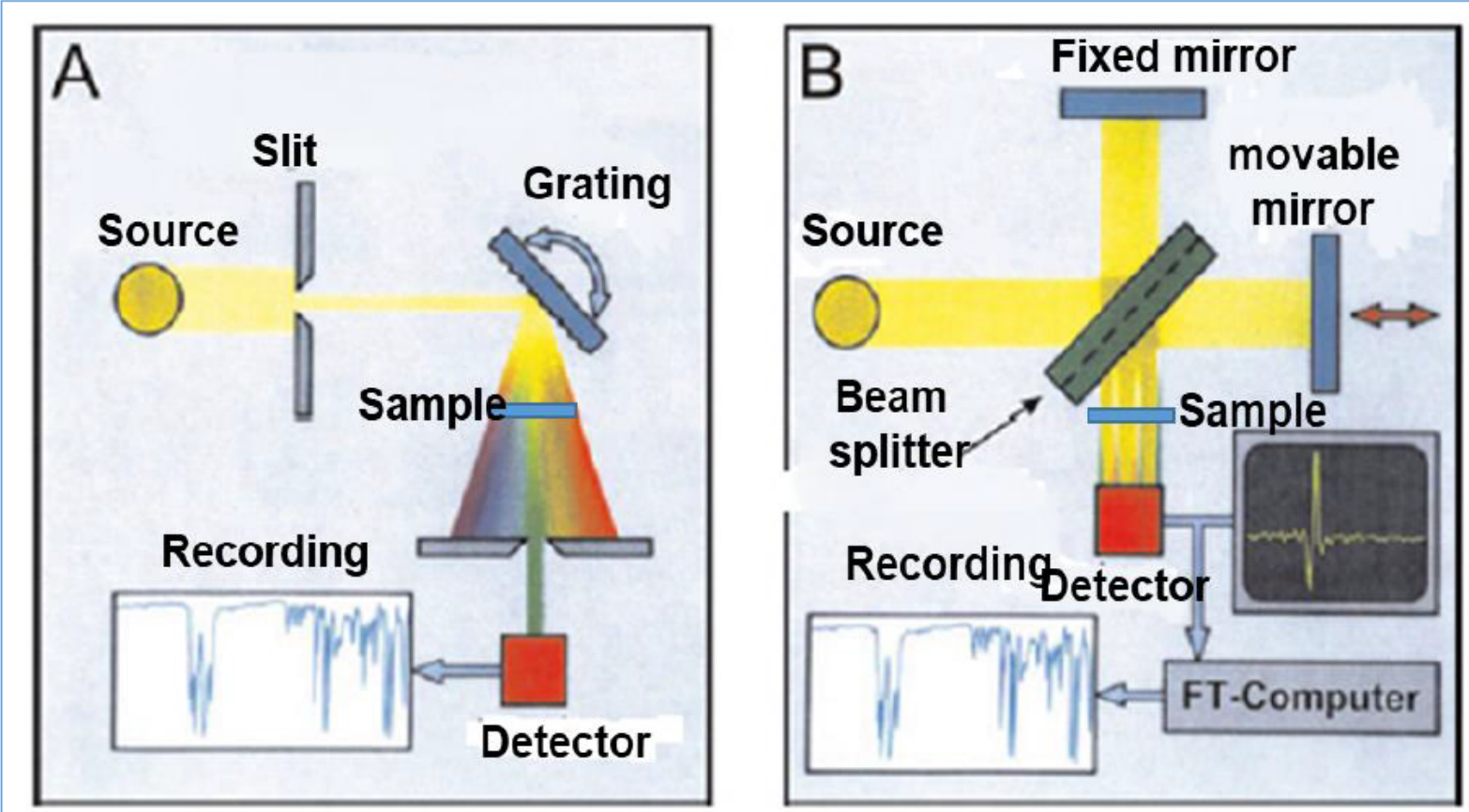

Figura 3.3-8: Estructura esquemática de los espectrómetros de IR. A: espectrómetro dispersivo, la resolución espectral se logra por una rejilla como elemento dispersivo. B: espectrómetro de FT-IR: la información espectral se genera por el interferómetro Michelson, registrado como un interferograma y convertido en un espectro por transformación de Fourier.

La interferencia de los dos rayos parciales depende de la desviación del espejo móvil, por consiguiente, la información espectral está contenida en la señal dependiente de la posición del espejo, el llamado interferograma.

En la técnica "Attenuated Total Reflectance" (ATR), se coloca la muestra en estrecho contacto con un cristal de alto índice de refracción (IRE) y buenas 
propiedades de transmisión de la radiación IR. De este modo, cuando se hace pasar radiación IR por este cristal con un ángulo de incidencia igual a superior al crítico, la radiación experimentará una reflexión total en la interfaz muestra-cristal ${ }^{13}$. En la muestra se crea lo que se llama una onda evanescente cuya profundidad de penetración $(2-15 \mu \mathrm{m})$, se determina por los índices de refracción de la IRE $\left(\mathrm{n}_{1}\right)$ y el medio $\left(\mathrm{n}_{3}\right)$, el ángulo del haz y la longitud de onda. La muestra absorberá esta onda evanescente en las regiones del espectro en las que es activa.

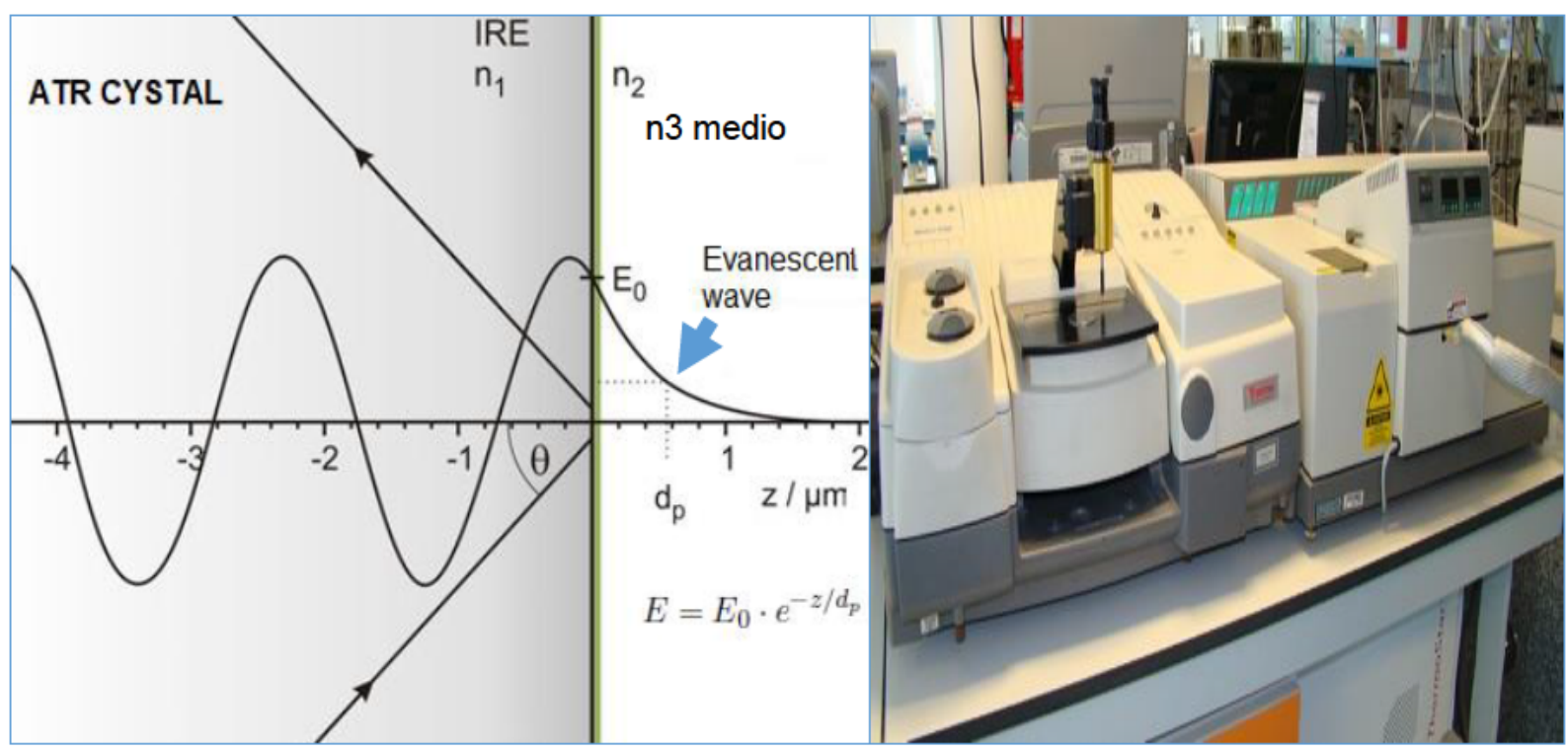

Figura 3.3-9: Representación esquemática del campo evanescente (izquierda). La intensidad del campo disminuye exponencialmente al aumentar la distancia desde la superficie. Equipo FTIR-ATR utilizado en esta investigación (SAIT-UPCT) derecha..

En este trabajo se utilizó un THERMO Nicolet 5700. Este equipo está equipado con un interferómetro de Michelson con las siguientes características principales: precisión en longitudes de onda mejor que 0.01 , la resolución mejor que $0.5 \mathrm{~cm}^{-1}$, alineación asistida por láser automático, divisor de haz de $\mathrm{Ge} / \mathrm{KBr}\left(7400-350 \mathrm{~cm}^{-1}\right)$ y software para la evaluación y manipulación de los espectros.

\subsubsection{Análisis térmico.}

\subsubsection{DSC.}

La calorimetría diferencial de barrido (DSC) es una técnica para la medición de la energía necesaria para establecer una diferencia de temperatura neta de cero entre 
una sustancia y un material de referencia. Las dos muestras son sometidas a mismas condiciones de temperatura en un espacio cerrado ${ }^{14}$.

En "heat flux-DSC" la muestra y la referencia se introducen en crisoles y estos se introducen en el horno (Figura 3.3-10). Por lo general, el crisol de referencia está vacío. El calor fluye a través de un sensor, diseñado como una resistencia térmica del horno, a la muestra y la referencia. Si la temperatura en la muestra cambia debido a un efecto térmico, habrá una diferencia de temperatura entre la muestra y la sustancia de referencia. A partir de esta diferencia se determina el cambio de flujo de calor ya que éste es directamente proporcional a la diferencia de temperatura medida.

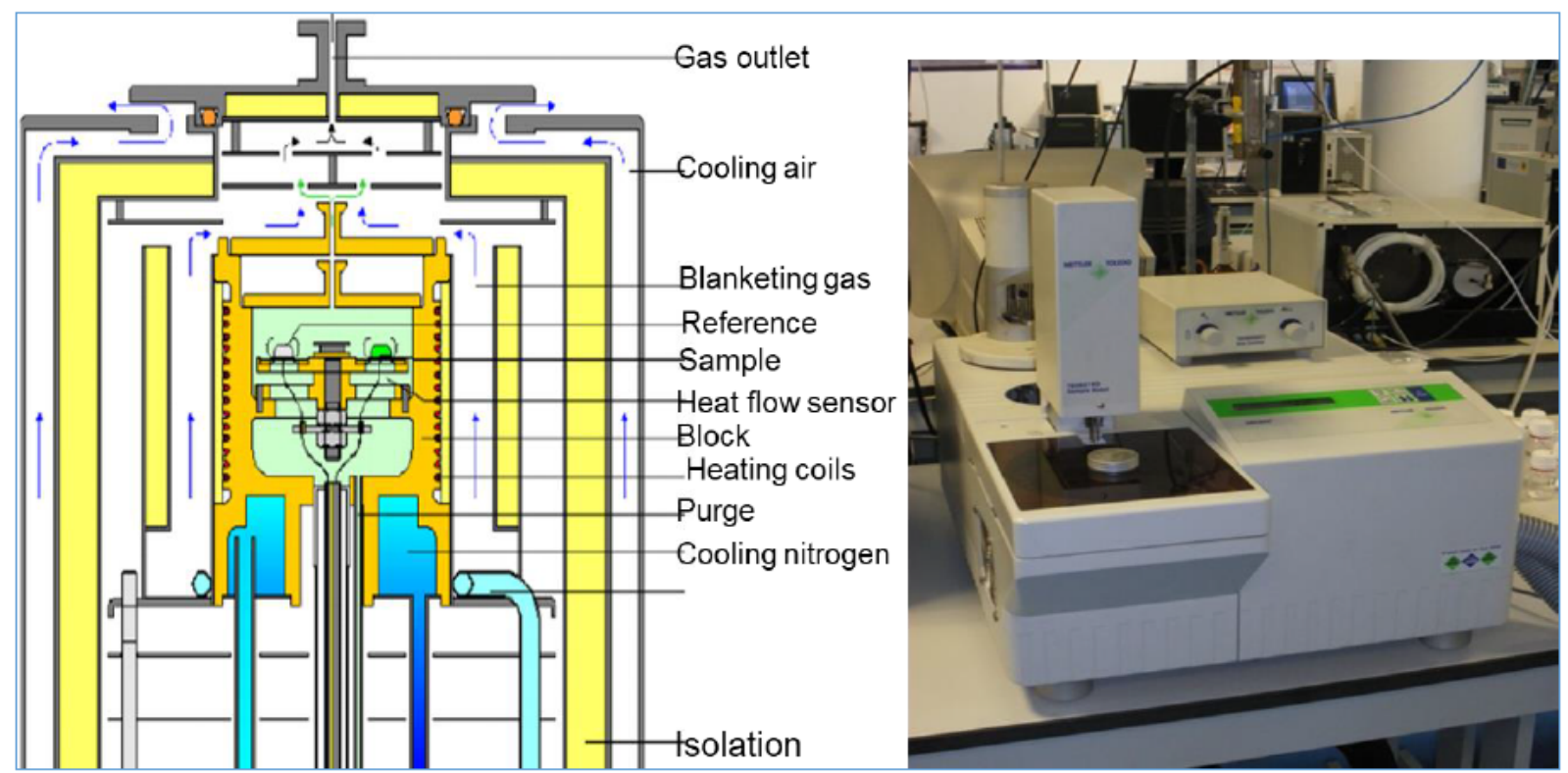

Figura 3.3-10: Vista esquemática de un "heat flux" DSC (izquierda). Equipo de DSC utilizado en esta investigación (derecha).

En este trabajo se utilizó un Mettler-Toledo DSC 822e bajo un principio de flujo de calor (heat flux-DSC). Este equipo trabaja entre 150 y $700^{\circ} \mathrm{C}$ con precisión de \pm $0.2^{\circ} \mathrm{C}$ y una velocidad de calentamiento de 0 a $200^{\circ} \mathrm{C}$ en incrementos de $0.01^{\circ} \mathrm{C}$.

\subsubsection{TGA.}

La Termogravimetría se utiliza para medir la masa o el cambio de masa en una muestra en función de la temperatura y/o tiempo. Los cambios de masa podrían ocurrir en procesos tales como evaporación, descomposición, reacciones químicas, de 
cambio de fase, etc. Se utilizan gases inertes, tales como nitrógeno, helio, argón, y gases oxidantes de purga, como el oxígeno o el aire para disponer de una atmosfera controlada $^{15,16}$. Otro factor a tener en cuenta es la velocidad de flujo de los gases de purga, que afecta a la transferencia de calor a la muestra.

Se utiliza la compensación electromagnética o electromecánica de peso para medir la pérdida de masa. A partir de la resultante de la señal de compensación, la masa de la muestra se determina en función de la temperatura y del tiempo con una sensibilidad de varios $\mu$ g. La Figura 3.3-11 muestra la estructura esquemática de un sistema TGA horizontal; estructuras verticales también se utilizan en la práctica.

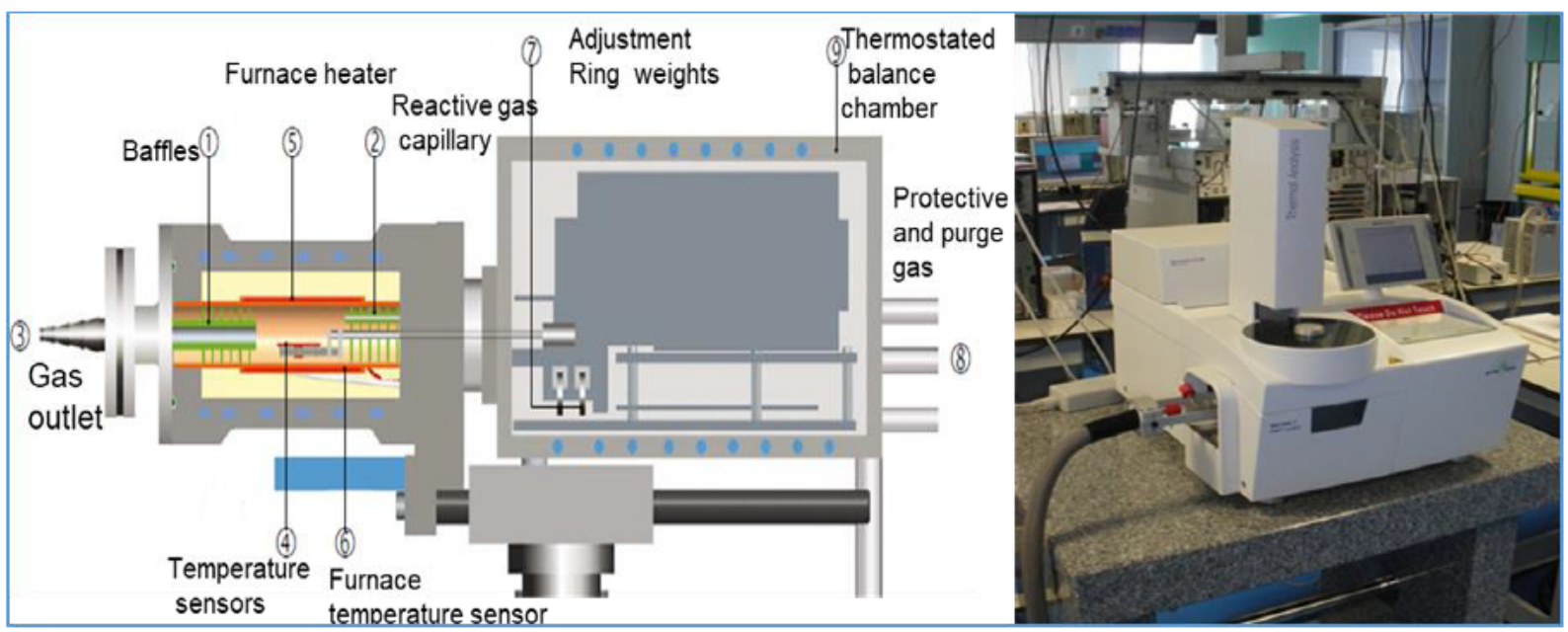

Figura 3.3-11: Estructura esquemática de un sistema horizontal (izquierda). Equipo de TGA utilizado en esta investigación (SAIT-UPCT) derecha.

La indicación de la variación de la masa de una muestra es, o bien absoluta en $\mathrm{mg}$, o relativa en \%, referida a la masa de partida y representado frente el tiempo o la temperatura. La curva obtenida en un análisis termogravimétrico se llama termograma (TG), o espectro térmico, o una curva de la descomposición térmica y la primera derivada se suele usar para obtener puntos de inflexión con mayor claridad.

En este trabajo se utilizó un Mettler-Toledo TGA/DSC 1HT. Este equipo es capaz de establecer la temperatura hasta $1600^{\circ} \mathrm{C}$ y una exactitud de $0.5^{\circ} \mathrm{C}$. 


\subsection{Técnicas de caracterización electroquímica.}

Todas las pruebas electroquímicas se realizaron con un potenciostato/galvanostato multicanal (Biologic VSP, Science Instrument) bajo la configuración de dos o tres electrodos dependiendo de los requisitos del ensayo.

En el modo de configuratcion estándar de tres electrodos utilizado típicamente en electroquímica o en experimentos de corrosión, el electrodo de trabajo está conectado a REF1+CA2 ("current amplfier"). El contra-electrodo está conectado a REF3+CA1 y el electrodo de referencia está conectado a REF2. Sin embrago, en la configuracion de dos electrodos, por ejemplo en la conexión a una batería, el electrodo positivo de la batería está conectado a REF1+CA2 mientras que el negativo se une a REF2+REF3+CA1. En la Figura 3.4-1 se puede ver un esquema con la configuracion de los electrodos junto con el potenciostato utilizado en este trabajo.
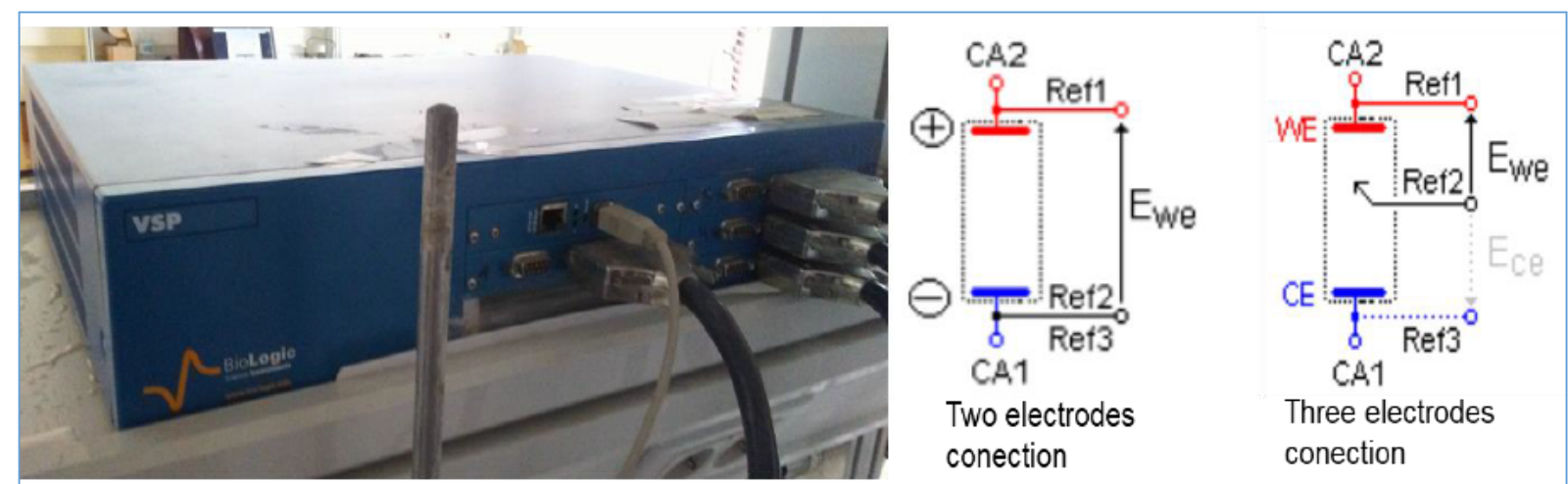

Figura 3.4-1: Potenciostato VSP de cinco canales usado en este trabajo (izquierda). Esquemas de configuración de electrodos (derecha).

Este potenciostato trabaja en un rango de corriente que varía de 0 a 400mA. En los ensayos con radiación sincrotrón se ha usado un potenciostato de las mismas características pero equipado únicamente con un canal.

\subsubsection{Voltametría cíclica.}

En las mediciones de voltametría cíclica, una tensión triangular se aplica al electrodo de interés, el electrodo de trabajo. La corriente I, que es necesaria para mantener esta tensión U (o potencial $\varphi$ ), se registra y se representa frente a la tensión 
predeterminada. Si las reacciones electroquímicas tienen lugar en el rango de potencial seleccionado, se observan picos de corriente ${ }^{17}$.

Esta técnica nos da información cualitativa y cuantitativa acerca de una reacción electroquímica o una sustancia electroquímicamente activa de forma rápida y fácil. Por ejemplo, podemos conocer los datos termodinámicos del proceso, las constantes cinéticas de las reacciones químicas heterogéneas y la caracterización de una sustancia, si la reacción es irreversible o reversible, etc.

El potencial de partida $\left(\mathrm{E}_{\mathrm{a}}\right)$ es normalmente el potencial a circuito abierto (OCP u OCV), que no provoca la oxidación o reducción del material activo. El potencial $\mathrm{E}_{\mathrm{a}}$ aplicado se aumenta entonces con una velocidad de barrido determinado $(\mathrm{mV} / \mathrm{s})$ hasta un potencial máximo $\left(\mathrm{E}_{1}\right)$. Posteriormente, el voltaje aplicado es de nuevo disminuido a la misma velocidad de barrido hasta el potencial inverso $\left(\mathrm{E}_{2}\right)$, y finalmente, vuelve al potencial final (Eb), que podría ser el mismo valor del potencial inicial (Figura.3.4-2).

Uno o más ciclos se pueden realizar dependiendo de la información que se pretenda extraer de un experimento. La corriente depende de la tensión aplicada y de la velocidad de barrido usada. Los gráficos representan la intensidad de corriente, I, frente al potencial, E, como se muestran en la Figura 3.4-2. En los voltagramas se observarán picos anódicos, en los que se produce un proceso de oxidación, y picos catódicos, en los que se produce una reducción. En el recuadro se representa la señal de entrada al sistema.

\subsubsection{Cronoamperometría.}

Otro método de medición electroanalítico importante es la cronoamperometría (CA). En contraste con la CV, el potencial no se cambia linealmente, sino que se realiza un salto directo de un potencial inicial a otro final.

La medición cronoamperométrica se inicia en un potencial ( $\left.V_{1}\right)$ en el que no hay, proceso redox. Posteriormente, se produce el salto de potencial hasta $\mathrm{V}_{2}$, donde se obtendrá una corriente debido a la existencia de una reacción redox. La corriente I que fluye a través del electrodo de trabajo se mide como una función del tiempo t, mientras que el potencial aplicado se mantiene constante. Esta técnica se utiliza para sistemas 
estacionarios y cuando el transporte de masa tiene lugar solo por difusión. En esta situación, el sistema puede ser descrito por la ecuación de Cottrell , que describe la corriente observada para electrodos planos en cualquier momento después de un gran salto de potencial directo en un sistema redox reversible ${ }^{17}$. Esta ecuación puede ser derivada para para otras geometrías y la corriente observada depende de la velocidad con la que la especie activa difunda hacia el electrodo.

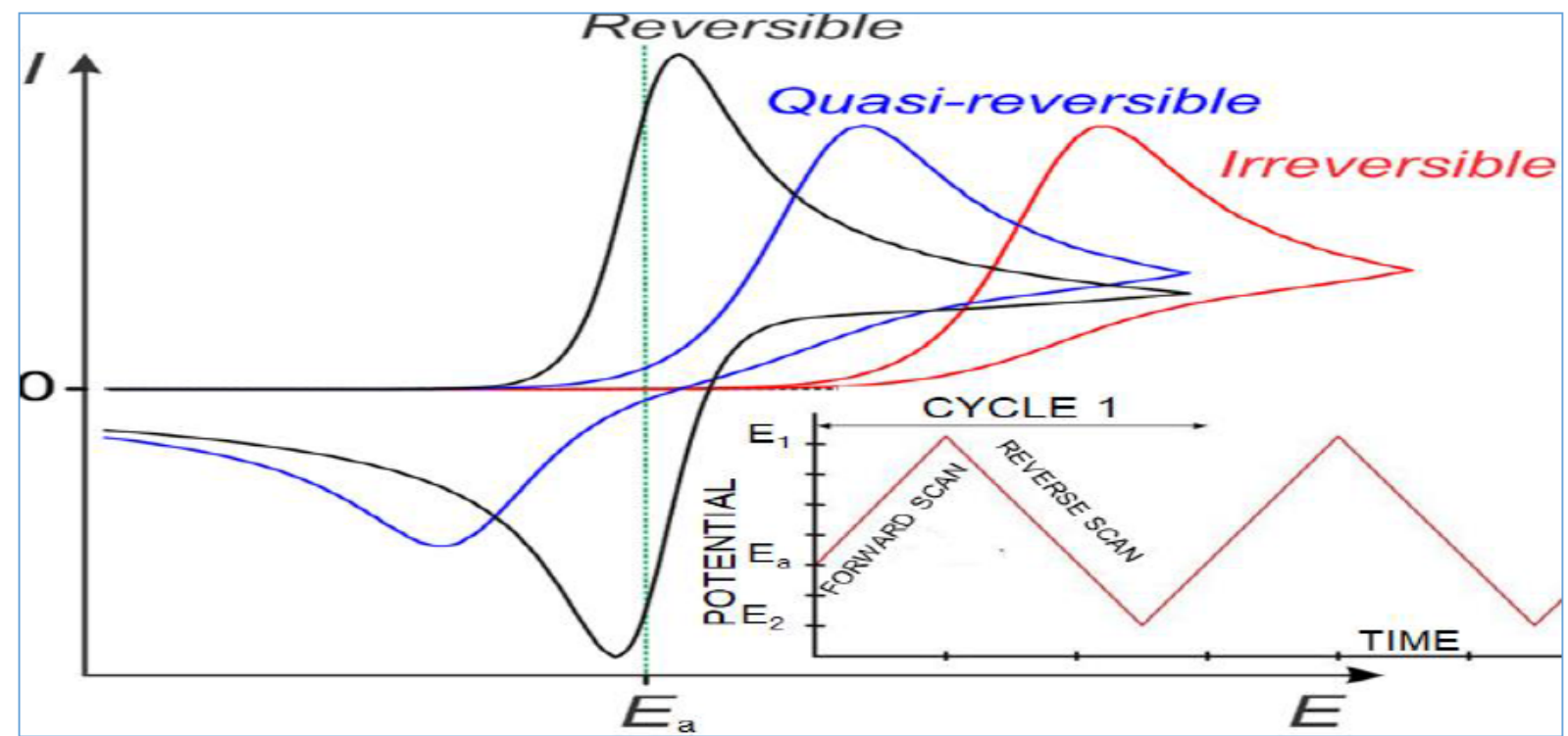

Figura 3.4-2: Forma gráfica típica de CV para diferentes sistemas electroquímicos y señal de entrada (recuadro).

$$
i_{t}=\frac{n F A C_{0} D_{0}^{1 / 2}}{\pi^{1 / 2} t^{1 / 2}}
$$

donde $\mathrm{n}$ es el número estequiométrico de los electrones implicados en la reacción; F la constante de Faraday (96.485 C/equivalente), A el área del electrodo $\left(\mathrm{cm}^{2}\right), \mathrm{C}_{0}$ la concentración de especies electroactivas $\left(\mathrm{mol} / \mathrm{cm}^{3}\right), \mathrm{y}$ Do la constante de difusión de especies electroactivas $\left(\mathrm{cm}^{2} / \mathrm{s}\right)$.

Esta técnica se utiliza para obtener información; el área de la superficie , la medición del coeficiente de difusión, la determinación de la constante de velocidad heterogénea, la determinación del espesor de la capa de difusión, evaluación de los mecanismos de $\mathrm{ECE}^{17}$,etc. 


\subsubsection{Espectroscopía de impedancia.}

La espectroscopía de impedancia es una poderosa herramienta ampliamente utilizada en electroquímica. Puede revelar mecanismos de las reacciones electroquímicas, propiedades dieléctricas y de transporte de reactivos, propiedades de electrodos porosos o superficies pasivas, etc.

La impedancia $(\mathrm{Z})$ se define de forma similar a la resistencia eléctrica, una medida de la capacidad de un circuito para resistir al flujo de corriente eléctrica. Pero en este caso, su alcance es más amplio y no limitado solamente a una resistencia ideal ${ }^{18}$.

La espectroscopia de impedancia electroquímica se realiza aplicando una pequeña señal de excitación (3-10 mV) al sistema electroquímico. De esta manera, la respuesta del sistema es pseudo-lineal y la respuesta de corriente a un potencial sinusoidal será una sinusoide en la misma frecuencia pero desplazada en fase. La señal de excitación de una sola frecuencia $\omega=2 \pi f$ es aplicada a una celda y se mide la corriente de estado estacionario resultante repitiendo el mismo proceso para el rango de frecuencias deseado. La relación entre la señal de entrada al sistema y la respuesta en corriente del mismo es una magnitud compleja en el dominio del tiempo. Afortunadamente, el uso de la transformada de Fourier nos permite simplificar el tratamiento matemático de este sistema ${ }^{19}$.

El resultado son representaciones en el plano complejo; $\mathrm{Z}$ se compone de una parte real y una parte imaginaria (Figura 3.4-3). Si la parte real se representa en el eje $\mathrm{X}$ y la parte imaginaria en el eje $\mathrm{Y}$ de un gráfico, se obtiene lo que se conoce como "diagrama de Nyquist". Otra forma, y muy popular también, de presentar la impedancia compleja se realiza trazando el $\log (\omega)$ en el eje X y el valor absoluto de la impedancia $|Z|$ en el eje Y. Esta representación se conoce como diagrama de Bode. Ambos tipos de gráficos se representan en la Figura 3.4-4. 


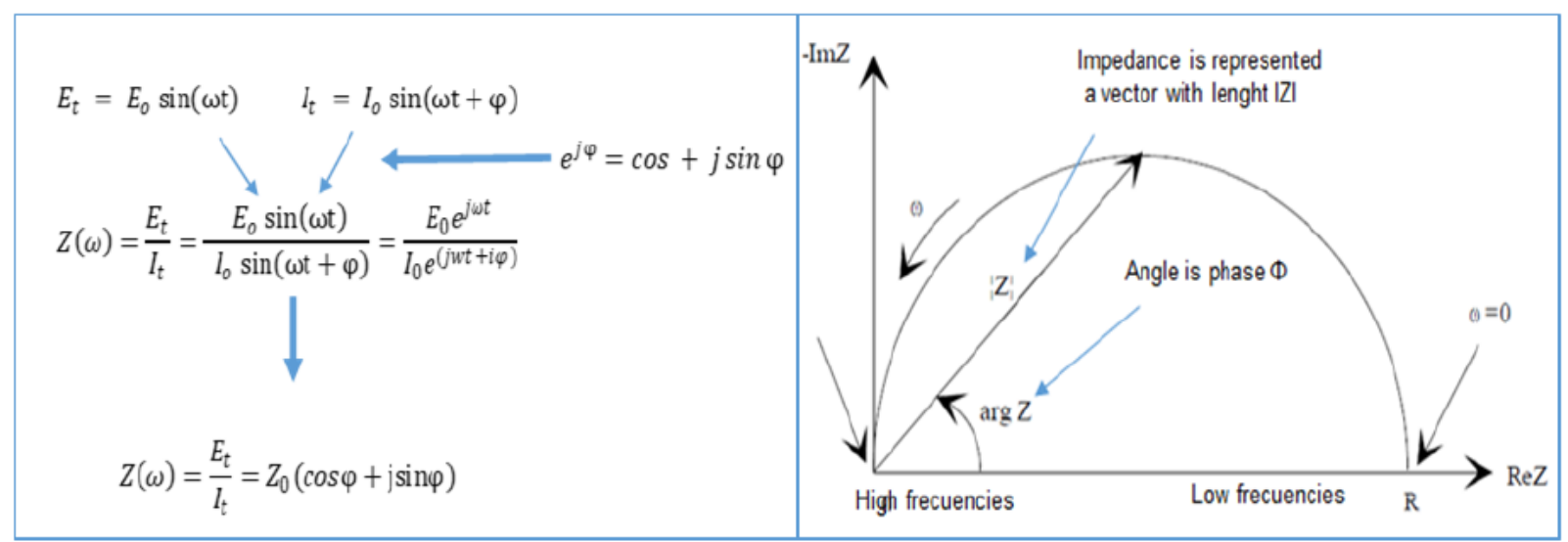

Figura 3.4-3: Fórmulas espectroscopia de impedancia (izquierda). Representación en plano complejo de la impedancia (derecha).

\subsubsection{Carga y descarga galvanostática.}

El análisis del comportamiento de la carga/descarga galvanostática es probablemente la técnica de caracterización principal para analizar el rendimiento electroquímico de baterías. Esta técnica nos suministra información importante de las características de una batería, como son la capacidad y la energía entregada, perfiles de carga y descarga, ciclo de vida, y la eficiencia culómbica ${ }^{20}$.
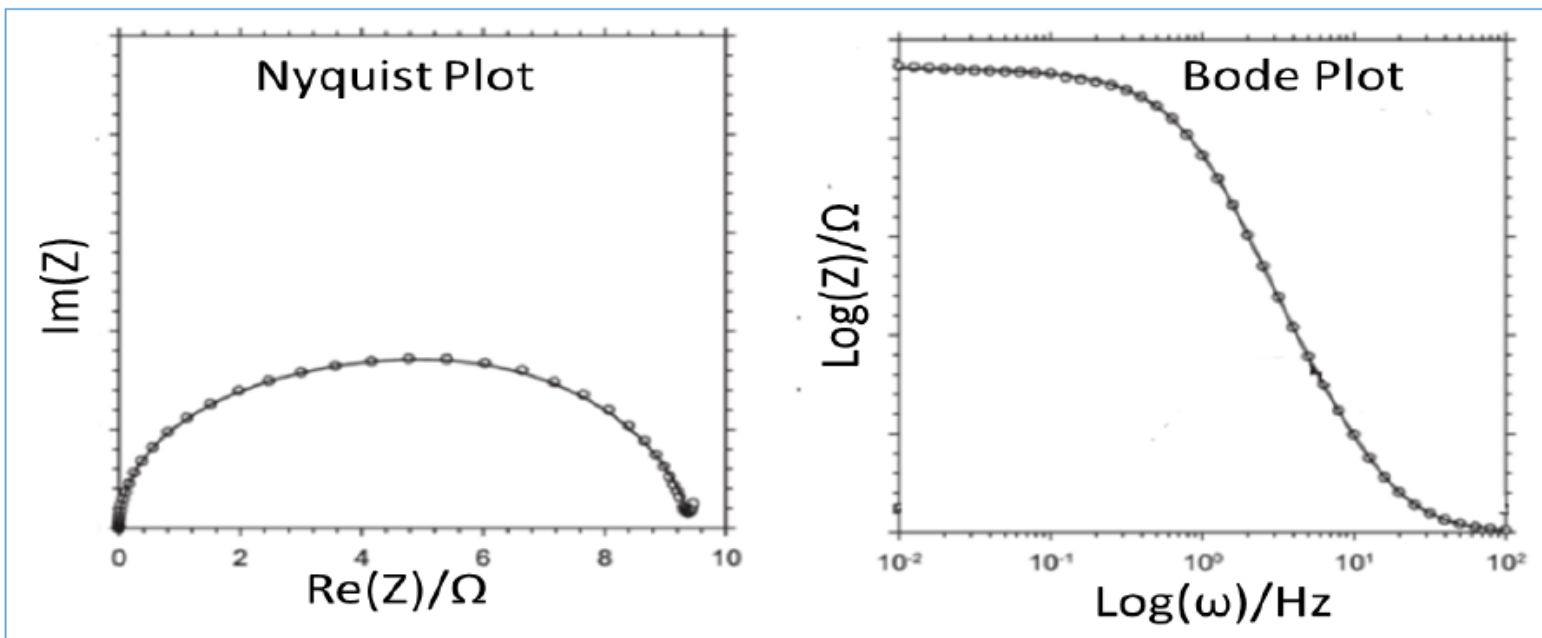

Figura 3.4-4: Gráfico típico de Nyquist (izquierda). Diagrama de Bode (derecha).

La carga y descarga galvanostática es una técnica de laboratorio ampliamente utilizada para evaluar la capacidad electroquímica de las baterías en condiciones de corriente controlada (Figura 3.4-5). Sin embargo, la vida de una batería recargable se 
puede aumentar de manera significativa usando el método de carga adecuado. Algunas baterías no toleran la sobrecarga, mientras que otras necesitan ser descargada al máximo para evitar el efecto de memoria. Las baterías comerciales pueden estar compuestas de diferentes materiales que actúan de forma diferente, por lo tanto, se deben cargar de acuerdo con las instrucciones del fabricante y con el cargador adecuado para ello ya que éstos disponen de fábrica el método de carga más adecuado para el cuidado óptimo de la batería en cuestión.

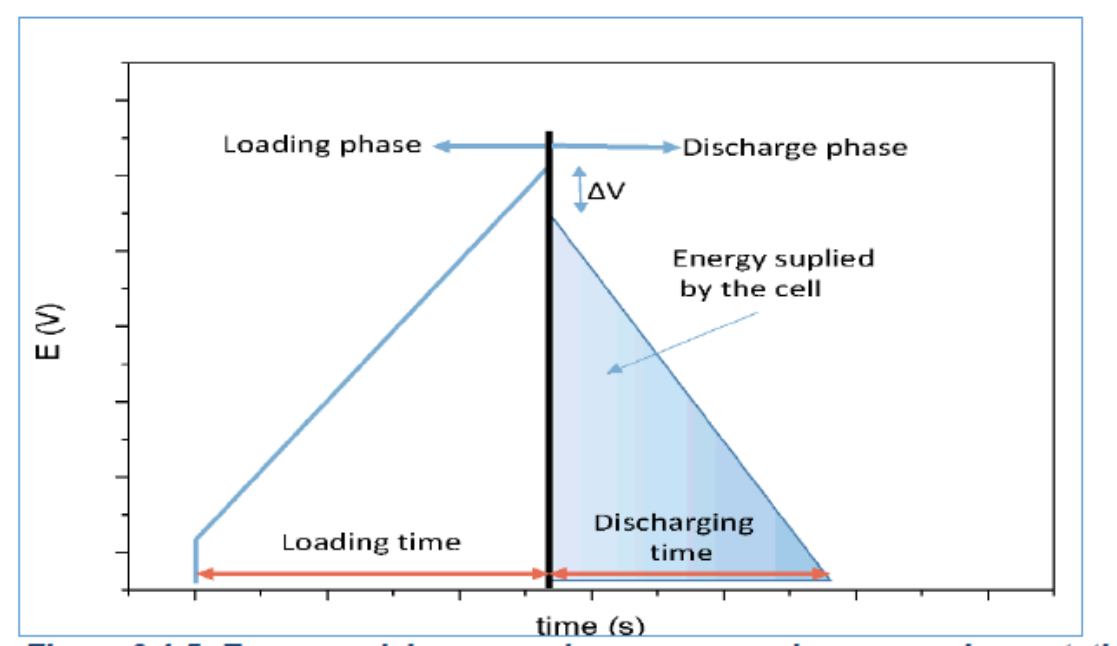

Figura 3.4-5: Esquema del proceso de una carga y descarga galvanostatica.

Usualmente al describir las baterías, la corriente de descarga, a menudo, se expresa como la "C-rate" o "razón C" para normalizarse frente a la capacidad teórica de la batería. C-rate es una medida de la velocidad a la que se descarga una batería en relación con su capacidad máxima teórica. En este estudio se han realizado descargas y cargas galvanostáticas a corriente constante sin llegar a calcular la C-rate. 


\subsection{Referencias.}

(1) Air Electrode - Electric Fuel https://electric-fuel.com/rd/zinc-air/air-electrode/ (accessed Apr 9, 2019).

(2) Santos, F.; Abad, J.; Vila, M.; Castro, G. R.; Urbina, A.; Fernández Romero, A. J. In Situ Synchrotron X-Ray Diffraction Study of Zn/Bi2O3 Electrodes Prior to and during Discharge of Zn-Air Batteries: Influence on ZnO Deposition. Electrochim. $\quad$ Acta $2018, \quad$ 133-141. https://doi.org/10.1016/j.electacta.2018.05.138.

(3) Khursheed, A. Scanning Electron Microscope Optics and Spectrometers; WORLD SCIENTIFIC, 2011. https://doi.org/10.1142/9789812836687.

(4) Eberle, A. L.; Mikula, S.; Schalek, R.; Lichtman, J.; Knothe Tate, M. L.; Zeidler, D. High-Resolution, High-Throughput Imaging with a Multibeam Scanning Electron Microscope. J. Microsc. 2015. https://doi.org/10.1111/jmi.12224.

(5) Hafner, B. Energy Dispersive Spectroscopy on the SEM: A Primer. Charact. Facil. Univ. Minnesota 2006, 7-10.

(6) W.L., B. W. . and B. The Crisytalline State. A General Survey. A Clear Survey of $x$-Ray Diffraction and Its Use for Crystal Structure Determination.; MacMillan: New York, NY, 1934; Vol. Vol.1.

(7) Gavaghan, H. What is a synchrotron? https://www.esrf.eu/about/synchrotronscience/synchrotron $\quad$ (accessed $\quad$ Apr 2019 ). https://doi.org/10.1038/35070715.

(8) Mobilio, S.; Boscherini, F.; Meneghini, C. Synchrotron Radiation: Basics, Methods and Applications; 2015. https://doi.org/10.1007/978-3-642-55315-8.

(9) $\mathrm{EH} 2$ Branch B HAXPES http://www.esrf.eu/UsersAndScience/Experiments/CRG/BM25/BeamLine/ex perimentalstations/HAXPES (accessed Apr 4, 2019).

(10) Petrick Casagrande, S.; Castillo Blanco, R. Método de Rietveld Para El Estudio 
de Estructuras Cristalinas.

(11) Aziz, M.; Ismail, A. F. X-Ray Photoelectron Spectroscopy (XPS). Membr. Charact. 2017, 81-93. https://doi.org/10.1016/B978-0-444-63776-5.00005$\mathrm{X}$.

(12) Smith, B. C. Fundamentals of Fourier Transform Infrared Spectroscopy; CRC Press, 2011. https://doi.org/10.1201/b10777.

(13) Ramer, G.; Lendl, B. Attenuated Total Reflection Fourier Transform Infrared Spectroscopy. In Encyclopedia of Analytical Chemistry; John Wiley \& Sons, Ltd: Chichester, UK, 2013. https://doi.org/10.1002/9780470027318.a9287.

(14) Radfern, j p. For Better Thermal Analysis III Edition. Int. Confed. Therm. Anal. New Castle, Aust. 1991, 5-36.

(15) Gooch, J. W. Thermal Gravimetric Analysis; 2011. https://doi.org/10.1007/978-1-4419-6247-8_11752.

(16) Mohomed, K. Thermogravimetric Analysis (TGA) Theory and Applications. TA Instruments 2016, 4-235.

(17) Aikens, D. A. Electrochemical Methods, Fundamentals and Applications; Wiley, 2009; Vol. 60. https://doi.org/10.1021/ed060pa25.1.

(18) Lasia, A. Electrochemical Impedance Spectroscopy and Its Applications.Modern Aspects of Electrochemistry.; Academic/Plenum: New York, 1999.

(19) Breitkopf, C. Impedance Spectroscopy Old Technique - New Applications. Ppt 2012.

(20) Talaie, E.; Bonnick, P.; Sun, X.; Pang, Q.; Liang, X.; Nazar, L. F. Methods and Protocols for Electrochemical Energy Storage Materials Research. Chem. Mater. 2017, 29 (1), 90-105. https://doi.org/10.1021/acs.chemmater.6b02726. 



\section{Influence of the Ionic Liquid Type on the Gel Polymer Electrolytes Properties. \\ Tafur, J. P.; Santos, F.; Fernández Romero, A. J.. Membranes. 2015, 5, (4), 752-771. https://doi.org/10.3390/membranes5040752.}

"Science is a bit like the joke about the drunk who is looking under a lamppost for a key that he has lost on the other side of the street, because that's where the light is. It has no other choice." 



\section{RESUMEN}

En este artículo electrolitos de geles poliméricos (GPEs) compuestos por diferentes concentraciones de sal $\mathrm{ZnTf}_{2}$, poli(fluoruro de vinilideno-cohexafluoropropileno) (PVdF-HFP) y diferentes líquidos iónicos se sintetizaron usando n-metil-2-pirrolidona (NMP) como solvente. Se han explorado tres líquidos iónicos diferentes a base de imidazolio que contienen diversos cationes y aniones. Los IL-GPEs sin sal de triflato presentan un comportamiento distinto ya que están influenciados por los diferentes cationes y aniones del IL usado. Sin embargo, la inclusión de la sal de $\mathrm{ZnTf}_{2}$ dentro de los polímeros proporciona a los GPEs características muy similares, señalando que las propiedades de transporte iónico son causadas principalmente por el movimiento del catión $\mathrm{Zn}^{2+}$ y triflato. Además, la presencia de disolvente NMP dentro de la matriz del polímero resulta ser un factor clave para mejorar el transporte de $\mathrm{Zn}^{2+}$ dentro del GPE debido a la interacción entre los cationes $\mathrm{Zn}^{2+} \mathrm{y}$ los grupos carbonilos del NMP. Los altos valores de conductividad iónica, los bajos valores de energía de activación y la buena reversibilidad voltamperométrica obtenida, independientemente del líquido iónico utilizado, demuestran la aplicabilidad estos GPEs en baterías de Zn.

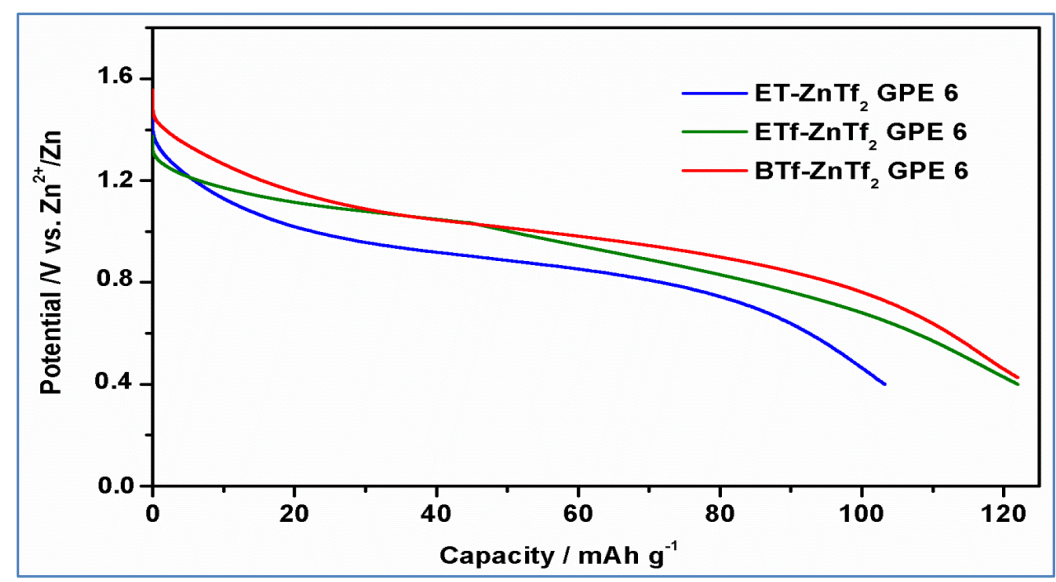

Primeros ciclos de descarga de una celda Zn/GPE/MnO2 a 1 $\mathrm{mAcm}^{-2}$ para BTf- ZnTf 2 GPE 6, ETf-ZnTf 2 GPE 6 y ET- ZnTf 2 GPE 6. 


\subsection{Introducción.}

Los electrolitos de geles poliméricos (GPEs) son materiales que no son $\mathrm{ni}$ sólidos ni líquidos, pero que mantienen tanto las propiedades cohesivas de los sólidos como el carácter difusivo de los líquidos. Por lo tanto, estos electrolitos se han vuelto relevantes debido a su uso como excelentes sustitutos de los electrolitos líquidos o como separadores en dispositivos electrónicos incluyendo baterías, supercondensadores, celdas de combustible, etc. Los GPEs pueden prepararse atrapando electrolitos líquidos en diferentes polímeros "anfitriones". En este caso, la sal proporciona iones libres móviles que participan en el proceso de conducción, el disolvente actúa como plastificante y el polímero proporciona estabilidad mecánica. Diferentes plastificantes de solventes orgánicos, como el carbonato de dimetilo (DMC), el carbonato de propileno (PC) y el carbonato de etileno (EC), han sido ampliamente utilizados. Por lo tanto, la morfología y propiedades de los GPEs dependerán del tipo y cantidad de polímero huésped, sal y solvente presente en la matriz del polímero. Entre los materiales huéspedes utilizados en los GPEs, el PVdF-HFP ha sido ampliamente utilizado porque es un polímero con suficiente cristalinidad para mantener una estabilidad mecánica y es lo suficientemente amorfo como para contener electrolitos líquidos. Además, debido a su alta constante dieléctrica, $\varepsilon=8.4$, el PVdF-HFP podría ser el huésped adecuado para disolver más sal, contribuyendo a mejorar la conductividad eléctrica del electrolito polimérico.

Los grupos carbonilos del NMP, son capaces de reducir la coordinación de $\mathrm{Zn}^{2+}$ con los aniones en el GPE, evitando o reduciendo la formación de agregados. De esta manera, se favorece el transporte catiónico y, por lo tanto, los valores de conductividad catiónica serán más altos.

En este trabajo hemos estudiado la influencia de los ILs, que contienen diferentes tipos de cationes y aniones, sobre las propiedades eléctricas y estructurales de estos GPEs. Se han sintetizado GPEs basados en PVdF-HFP y ZnTf 2 utilizando tres líquidos iónicos diferentes (Tabla 4.1-1). El análisis de los distintos GPEs utilizando varias técnicas espectroscópicas y electroquímicas nos ha permitido estudiar el transporte iónico que ocurre en dichas membranas. 


\begin{tabular}{cccc}
\hline GPE & PVdF-HFP/g & IL/g & ZnTf2/g \\
\hline PVdF-HFP & 0.5 & 0 & 0 \\
IL-GPE & 0.5 & 0.445 & 0 \\
ZnTf2 GPE & 0.5 & 0 & 0.255 \\
IL-ZnTf2 GPE 1 & 0.5 & 0.445 & 0.127 \\
IL-ZnTf2 GPE 2 & 0.5 & 0.445 & 0.255 \\
IL-ZnTf2 GPE 3 & 0.5 & 0.445 & 0.382 \\
IL-ZnTf2 GPE 4 & 0.5 & 0.445 & 0.509 \\
IL-ZnTf2 GPE 5 & 0.5 & 0.445 & 0.636 \\
IL-ZnTf2 GPE 6 & 0.5 & 0.445 & 0.763 \\
\hline
\end{tabular}

Tabla 4.1-1: Composición de todos los GPEs sintetizados y nomenclaturas utilizadas. IL representa los diferentes líquidos iónicos: EMIM TFSI (ET), BMIM Tf (BTf) y EMIM Tf (ETf). En todos los casos se emplearon 3.6 g de NMP. También se incluye el polímero PVdF-HFP.

\subsection{Resultados.}

Por medio de difracción de rayos X (XRD) se han podido identificar las diferentes fases cristalinas del PVdF-HFP. Todas las fases muestran un gran pico a, aproximadamente, $20^{\circ}$. Tanto la fase $\alpha$ como la fase $\gamma$ tienen un segundo pico a $\sim 18^{\circ}$, de distinta intensidad, mientras que la fase $\beta$ tiene una sola línea más amplia también a $20^{\circ}$. Sin embargo, hay un cambio claro en el difractograma del PVdF-HFP cuando éste se sintetiza usando THF o NMP. Mientras la película sintetizada con THF muestra una estructura $\alpha$, la estructura obtenida cuando la película es sintetizada con NMP es la $\beta$. Este resultado indica que el NMP modifica la estructura del PVdF-HFP, lo que puede estar relacionado con las interacciones entre las moléculas de NMP y las cadenas de PVdF-HFP. La retención de las moléculas de NMP dentro del polímero ha sido confirmada con diferentes técnicas, como se describe a continuación. Además, la incorporación de sal IL y ZnTf 2 en el GPE produjo picos aún más amplios y de menor intensidad, lo que indica una estructura más amorfa, que puede ser causada por los ILs y ZnTf 2 dentro de la matriz de polímero PVdF-HFP.

La Figura 4.2-1 muestra el difractograma XRD de la membrana de PVdF-HFP con BMIM Tf, a diferentes concentraciones de $\mathrm{ZnTf}_{2}$, que es muy similar a los encontrados para los GPEs basados en EMIM Tf y a los reportados previamente para los GPEs basados en EMIM TFSI. 


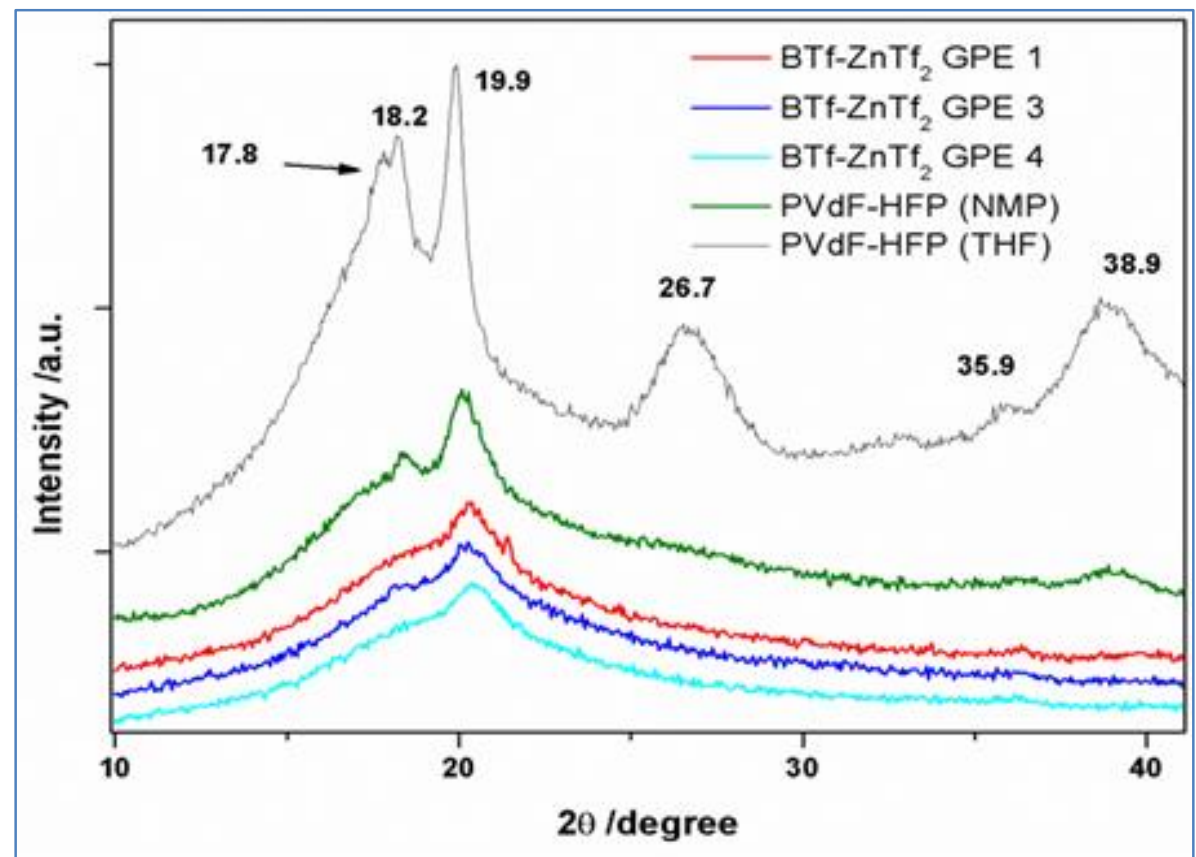

Figura 4.2-1: Difiactogramas XRD de PVdF-HFP (THF), PVdF-HFP (NMP) y BTf-ZnTf2 GPEs 1, 3 y 4.

Por otra parte, se han registrado los espectros ATR-FTIR de películas de PVdF-HFP preparadas utilizando THF y NMP como disolventes. Una vez más hay una clara variación en los espectros. El espectro de la película de PVdF-HFP sintetizada utilizando THF muestra bandas asignadas a la formación de una fase tipo a Sin embargo, cuando se utiliza NMP como disolvente, se obtiene una estructura diferente con bandas atribuidas a una fase $\beta$ de PVdF-HFP.

Las bandas características de NMP pueden observarse en el espectro ATR-FTIR del PVdF-HFP (NMP), entre ellas hay una banda intensa a $\sim 1667 \mathrm{~cm}^{-1}$. que ha sido atribuida al grupo carbonilo (Figura 4.2-2).

La banda del grupo carbonilo del NMP que aparece a $\sim 1667 \mathrm{~cm}^{-1}$ se desplaza a valores menores de número de onda, $\sim 1637 \mathrm{~cm}^{-1}$, una vez que la sal $\mathrm{ZnTf}_{2}$ se incorpora a la membrana. Adicionalmente, se ha observado un aumento de la intensidad con la concentración de ZnTf2.

Este proceso se observa también para los GPEs basados en ETf y BTf, coincidiendo con el comportamiento reportado previamente para los GPEs basados en 
ET. Además, como puede verse en al recuadro de la Figura 4.2-2, no se observaron estos cambios cuando sólo se incorporaron ILs dentro del polímero PVdF-HFP. Este hecho sugiere que los cambios se deben a la interacción entre los cationes $\mathrm{Zn}^{2+}$ y los grupos $\mathrm{C}=\mathrm{O}$ del NMP. La intensidad de la banda de $\sim 1637 \mathrm{~cm}^{-1}$ aumentó con la concentración de sal, indicando que una mayor cantidad de cationes $\mathrm{Zn}^{2+}$ interactúan con los grupos $\mathrm{C}=\mathrm{O}$ del NMP hasta alcanzar un valor máximo (Figura 4.2-2).

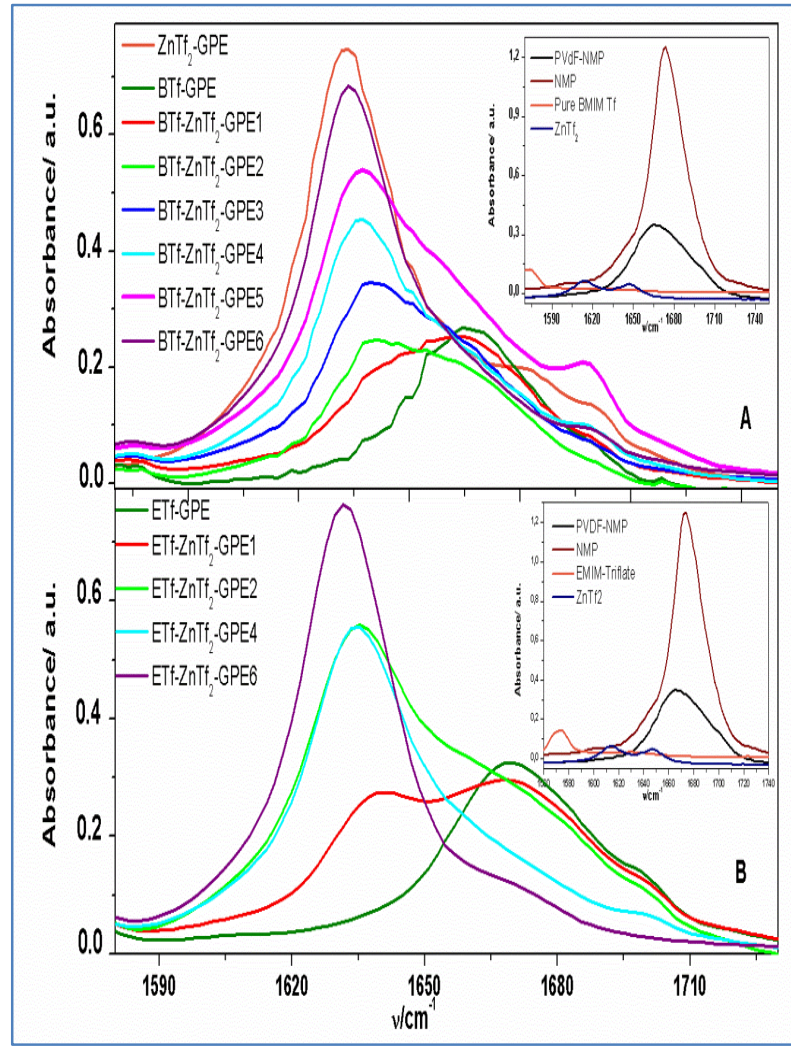

Figura 4.2-2: Espectros ATR-FTIR de GPEs analizados en el rango de frecuencia de 1580$1730 \mathrm{~cm}^{-1}$ para (A) BTf-ZnTf2-GPEs; y (B) ETfZnTf 2 -GPEs. Insertos: Espectros ATR-FTIR de disolvente NMP, IL puro, ZnTf $f_{2}$ GPE y PVdF-HFP (NMP).

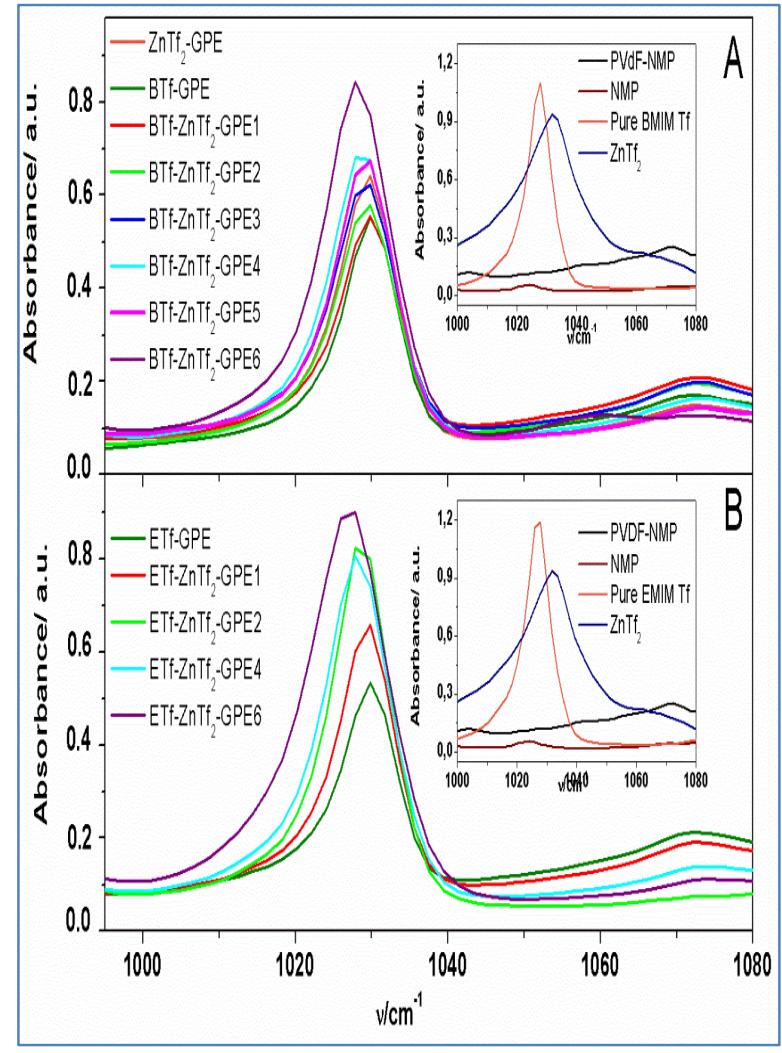

Figura 4.2-3. Espectros ATR-FTIR de GPEs analizados en el rango de frecuencia de 1000$1080 \mathrm{~cm}^{-1}$ para (A) BTf-ZnTf2-GPEs; y (B) ETfZnTf2-GPEs. Insertos: Espectros ATR-FTIR de disolvente NMP, IL puro, ZnTf2 GPE y PVdFHFP (NMP).

$\mathrm{El} \mathrm{ZnTf}$ tiene una alta capacidad de disociación debido a los grupos $\mathrm{SO}_{2} \mathrm{CF}_{3}$, con fuerte carácter electro-retirador y con una baja tendencia a formar pares de iones. Además, la alta constante dieléctrica del PVdF-HFP $(\varepsilon=8.4)$ ayuda a disociar la sal y, por lo tanto, favorece una alta concentración de iones libres en el gel. Este hecho, junto con una interacción $\mathbf{Z n}^{2+-N M P}$, debería producir una fuerte disociación del $\mathrm{ZnTf}_{2}$, resultando en una gran cantidad de aniones Tf libres. Con el objetivo de confirmar si 
los aniones Tf están libres o formando pares de iones dentro del GPE, hemos analizado el rango de frecuencia de 1000-1080 $\mathrm{cm}^{-1}$ donde se han reportado previamente bandas asociadas con aniones triflato libres $\left(1030 \mathrm{~cm}^{-1}\right)$, pares de iones $\left(\sim 1042 \mathrm{~cm}^{-1}\right)$, y agregados superiores $\left(\sim 1055 \mathrm{~cm}^{-1}\right)$ formados por estos aniones triflato.

La Figura 4.2-3 muestra este rango del espectro ATR-FTIR obtenido para los GPEs basados en ETf y BTf. Como se puede ver, sólo se obtiene una banda intensa a $\sim 1030 \mathrm{~cm}^{-1}$, lo que indica que los aniones triflato libres están presentes para todos los GPEs basados en ILs. Además, la intensidad máxima aumenta con la cantidad de sal añadida, que nos indica que la cantidad de aniones triflatos libres aumenta con la concentración de sal. No se han observado pares iónicos o agregados superiores según los datos obtenidos.

Se ha llevado a cabo un estudio DSC de los tres diferentes GPEs basados en IL. El análisis DSC proporciona información sobre parámetros importantes como la temperatura de transición vítrea, el punto de fusión y la estabilidad térmica de los GPEs. Los valores obtenidos de estos parámetros se recogen en la Tabla 4.2-1.

La temperatura de transición vítrea (Tg) cuando sólo se agregó IL al PVdF-HFP, produjeron películas con valores de Tg más bajos, $\sim-80^{\circ} \mathrm{C}$, para los tres IL-GPE estudiados. Sin embargo, la inclusión de $\mathrm{ZnTf}_{2}$, sin IL, dentro de las GPEs proporcionó el valor de Tg más alto, $\sim-30^{\circ} \mathrm{C}$. La incorporación de IL y ZnTf 2 juntos en los GPEs mostró valores intermedios, que oscilaron entre -67 y $-50{ }^{\circ} \mathrm{C}$, desplazándose desde una temperatura más baja a una más alta con el aumento de la concentración de sal. Este resultado puede explicarse por el hecho de que los movimientos de las cadenas poliméricas se ven obstaculizados por la inclusión de una mayor cantidad de sal. Además, los valores de Tg son muy similares para todos los GPEs analizados, lo que indica que el grado de impedimento debe ser similar independientemente del tipo de IL incluido en el GPE. Esto, nos lleva a pensar que la interacción entre la matriz polimérica y los ILs es similar cuando se añade suficiente cantidad de sal.

Además, se han observado picos endotérmicos (Figura 4.2-4) relacionados con las temperaturas de fusión (Tm) en las mediciones de DSC. Para GPEs de BTf$\mathrm{ZnTf}_{2}$, los valores de $\mathrm{Tm}$ obtenidos se encuentran en torno a $110^{\circ} \mathrm{C}$ con una pequeña 
tendencia a temperaturas más bajas con el aumento de la concentración de sal. Un comportamiento similar se observa para los GPEs ET-ZnTf2, con valores de Tm también alrededor a $110^{\circ} \mathrm{C}$ y la misma tendencia a temperaturas más bajas.

\begin{tabular}{|c|c|c|c|c|c|c|}
\hline Nombre GPE & TFSI EMIM & EMIM Tf & BMIM Tf & TFSI EMIM & EMIM Tf & BMIM Tf \\
\hline Muestra & \multicolumn{3}{|c|}{$\mathrm{Tg}^{\circ} \mathrm{C}$} & \multicolumn{3}{|c|}{$\sigma\left(S \mathrm{~cm}^{-1}\right) \cdot 10^{-3}$} \\
\hline IL-GPE & -81.6 & -79.3 & -78.8 & 1.98 & 7.07 & 5.20 \\
\hline IL-ZnTf ${ }_{2}$ GPE 1 & -67.5 & -64.8 & -56.3 & 3.82 & 7.05 & 1.93 \\
\hline IL-ZnTf ${ }_{2}$ GPE 2 & -58.5 & -63.2 & -56.3 & 3.73 & 4.62 & 2.68 \\
\hline IL-ZnTf ${ }_{2}$ GPE 3 & -57.3 & - & -55.3 & 3.05 & - & 2.99 \\
\hline IL-ZnTf ${ }_{2}$ GPE 4 & -56.9 & -61.1 & -54.5 & 2.2 & 1.96 & 2.21 \\
\hline IL-ZnTf $f_{2}$ GPE 5 & -53.3 & - & -53.8 & 1.54 & - & 2.57 \\
\hline IL-ZnTf ${ }_{2}$ GPE 6 & -49.4 & -51.3 & -51.1 & 1.88 & 1.09 & 1.88 \\
\hline Nombre GPE & TFSI EMIM & EMIM Tf & BMIM Tf & TFSI EMIM & EMIM Tf & BMIM Tf \\
\hline Muestra & \multicolumn{3}{|c|}{$t+$} & \multicolumn{3}{|c|}{$\mathrm{Ea}(\mathrm{eV})$} \\
\hline IL-GPE & 0.098 & 0.42 & 0.19 & 0.041 & 0.024 & 0.030 \\
\hline IL-ZnTf ${ }_{2}$ GPE 1 & 0.296 & - & 0.42 & 0.027 & 0.026 & 0.026 \\
\hline IL-ZnTf $f_{2}$ GPE 2 & 0.42 & 0.53 & 0.56 & 0.026 & 0.028 & 0.025 \\
\hline IL-ZnTf ${ }_{2}$ GPE 3 & 0.428 & - & 0.52 & 0.028 & - & 0.028 \\
\hline IL-ZnTf ${ }_{2}$ GPE 4 & 0.578 & 0.52 & 0.56 & 0.03 & 0.037 & 0.033 \\
\hline IL-ZnTf ${ }_{2}$ GPE 5 & 0.544 & - & - & 0.032 & - & 0.033 \\
\hline IL-ZnTf ${ }_{2}$ GPE 6 & 0.575 & 0.52 & 0.48 & 0.027 & 0.038 & 0.031 \\
\hline
\end{tabular}

Tabla 4.2-1: Temperatura de transición vítrea, Tg, conductividad iónica, $\sigma$, energía de activación, $E, y$ números de transporte catiónico, $t_{+}$, para los electrolitos poliméricos estudiados. $\sigma$ y valores $\boldsymbol{t}_{+}$obtenidos a $30^{\circ} \mathrm{C}$.

Del análisis DSC podemos deducir que el tipo de anión o catión del IL no induce cambios importantes en las propiedades de la matriz del polímero. Por lo tanto, el comportamiento del GPE se debe principalmente a las interacciones de la matriz del polímero, la sal y el solvente. Además, las curvas DSC demuestran un comportamiento térmico estable en un amplio rango de temperaturas, por encima de $\operatorname{los} 130^{\circ} \mathrm{C}$, que es lo suficientemente amplio como para aplicar estos GPEs en baterías.

La Figura 4.2-5 muestra la variación de la conductividad iónica con la temperatura para los GPEs basados en ETf y BTf con diferente concentración de $\mathrm{ZnTf}_{2}$. Todos los gráficos obedecen al comportamiento de Vogel-Tammen-Fulcher (VTF) en todo el rango de temperatura estudiado, tal y como se ha observado frecuentemente en los GPEs basados en IL, y se ajustan a la ecuación: 


$$
\sigma=A \mathbf{T}^{-1 / 2} \exp \left(-\frac{E_{a}}{\mathrm{k}_{\mathrm{B}}\left(\mathrm{T}-\mathrm{T}_{0}\right)}\right)
$$

donde $A$ es el factor preexponencial; $\boldsymbol{E}_{\boldsymbol{a}}$, la energía de activación; $k_{B}$ la constante de Boltzmann; $T$ la temperatura de ensayo y $T_{0}$ la temperatura de transición vítrea de equilibrio.

De las pendientes de la Figura 4.2-5 se pueden obtener los valores de energía de activación, que se presentan junto con los valores de conductividad para todos los GPEs basados en ETf, BTf y ET en la Tabla 4.2-1. Los valores de Ea para todos los GPEs oscilaron entre 0.024 y $0.038 \mathrm{eV}$, y no se observaron cambios relevantes para todos los GPEs, excepto para el GPE libre de IL que tiene un valor máximo de $0.041 \mathrm{eV}$, indicando la importancia de la inclusión del líquido iónico en la membrana.

La Tabla 4.2-1 muestra también que todas las conductividades iónicas obtenidas a $30^{\circ} \mathrm{C}$ para los GPEs estudiados tienen valores similares, que oscilan entre $1.09 \times 10^{-3}$ y $7.07 \times 10^{-3} \mathrm{Scm}^{-1}$.

A partir de IL-ZnTf 2 GPE 3 en adelante hemos obtenido valores de conductividad muy similares para cada IL bajo la misma concentración de sal, indicando claramente ninguna variación o influencia significativa ejercida por los aniones o cationes del IL usado.

El número de transporte iónico total (tion) fue evaluado por la técnica de polarización, y siempre se obtuvieron valores $>0.98$ para los tres GPEs bajo estudio, lo que indica que la conductividad total fue predominantemente iónica. También hemos determinado los números de transporte catiónico $\left(\mathrm{t}_{+}\right)$utilizando el método de Evans, ya que son un factor clave en la optimización de los electrolitos para las baterías de ion-zinc (ZIB). La Figura 4.2-6 y la Tabla 4.2-1 muestran los valores $t+$ para los GPE estudiados.

Hemos analizado cómo los valores del número de transporte catiónico se ven afectados por la variación de la cantidad de sal dentro de la membrana. Una tendencia similar se ha obtenido para los tres IL-GPE. Como se puede ver en la Figura 4.2-6 y la Tabla 4.2-1, a bajas concentraciones de sal en los GPEs los valores de t- son siempre 
más altos que $t_{+}$. Sin embargo, $t_{+}$aumenta con la concentración de sal dentro de la membrana para todos los GPEs, haciendo $t_{+}$más alto que $t$ - para los GPEs de mayor concentración de sal.

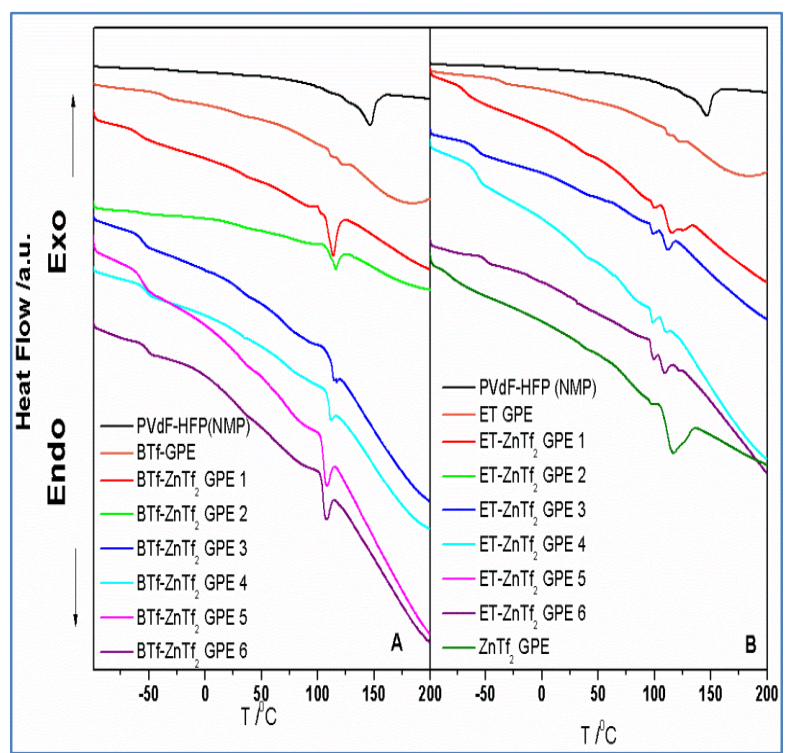

Figura 4.2-4: Gráficos DSC de (A) BTf-ZnTf, GPEs; (B) ET-ZnTf 2 -GPEs.

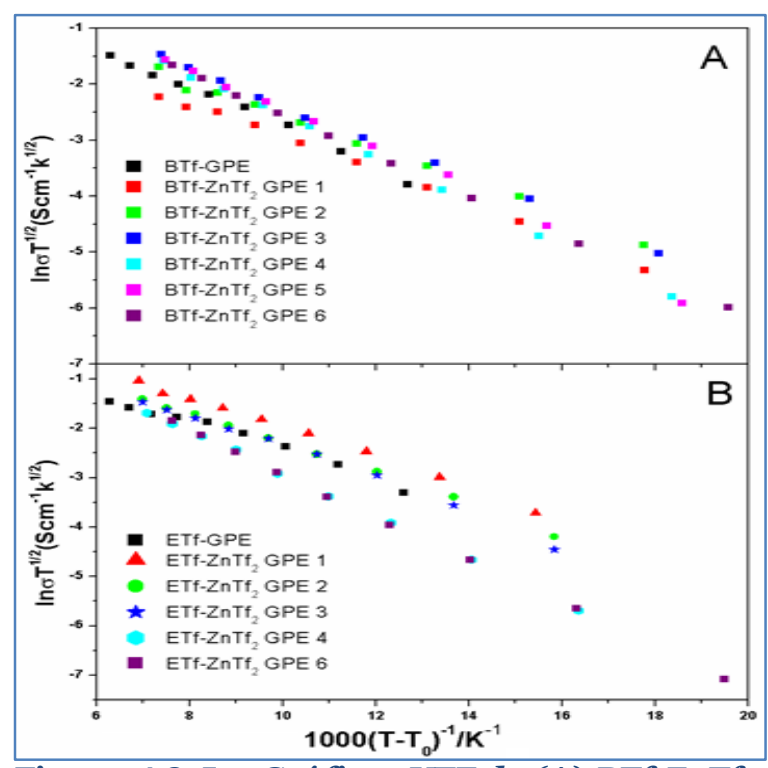

Figura 4.2-5: : Gráficos VTF de (A) BTf-ZnTf 2 GPEs; y (B) ET-ZnTf $f_{2}$ GPEs.

Dado que $\mathrm{EMIM}^{+}$y $^{\mathrm{BMIM}^{+}}$son cationes voluminosos, la movilidad debe ser muy baja, y por lo tanto la conductividad en estas películas será predominantemente aniónica cuando aún no se haya añadido sal al sistema. La adición de sal $\mathrm{ZnTf}_{2}$ dentro de los GPEs proporcionó valores $t_{+}$más altos hasta alcanzar un valor máximo de $c a$. $0.55 \pm 0.05$ para los tres GPEs. Estos valores de $t_{+}$indican que la movilidad catiónica aumentó cuando se incorporó la sal de $\mathrm{ZnTf}_{2}$ al GPE, debida principalmente por los cationes $\mathrm{Zn}^{2+}$, ya que las movilidades del $\mathrm{EMIM}^{+} \mathrm{y} \mathrm{BMIM}^{+}$, tiene que ser muy baja debido a sus grandes volúmenes.

En este punto, tenemos que considerar la interacción entre los cationes $\mathrm{Zn}^{2+} \mathrm{y}$ los grupos carbonilos de las moléculas NMP, como se dedujo de las mediciones ATRFTIR. Así, podemos deducir que los mayores números de transporte catiónico obtenidos para los GPE con mayores concentraciones de sal son también consecuencia de que los cationes $\mathrm{Zn}^{2+}$ son disueltos por el disolvente NMP, favoreciendo el transporte catiónico dentro del GPE independientemente del IL incluido. 


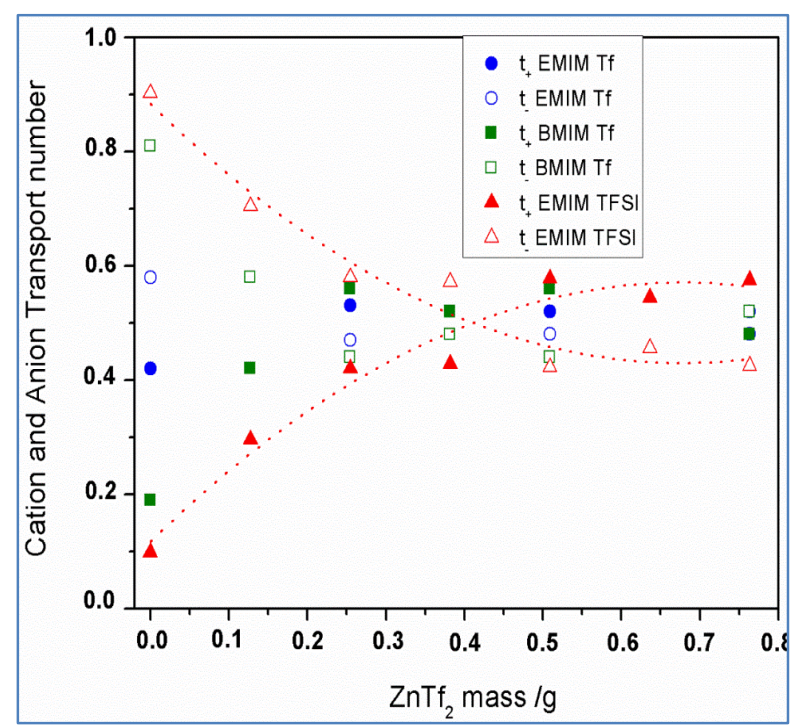

Figura 4.2-6: Numero de transporte catiónico y aniónico para IL-ZnTf 2 GPEs vs masa de ZnTf.

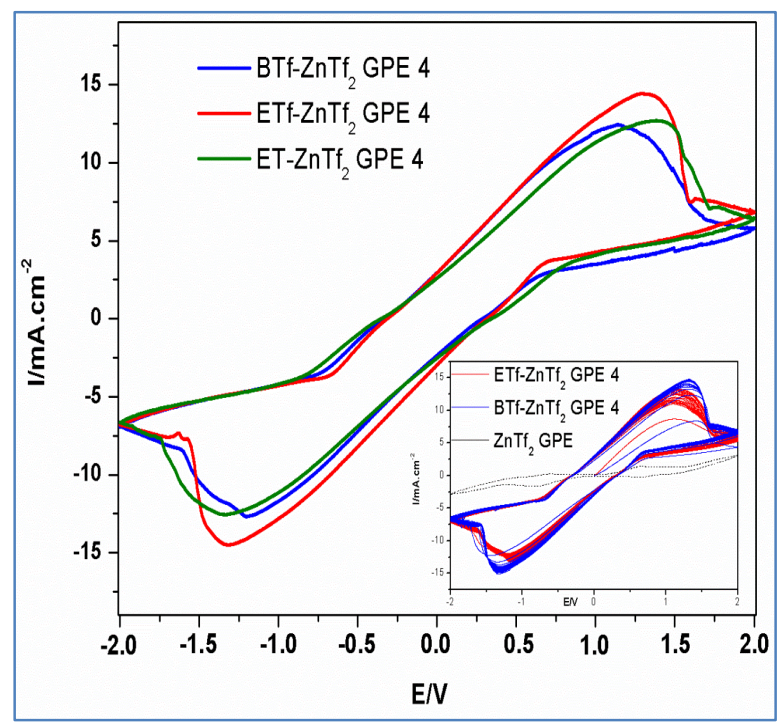

Figura 4.2-7: Voltametría cíclica de las celdas Zn/GPE/Zn para BTf-ZnTf2 GPE 4, ETf-ZnTf2 GPE 4 y ET-ZnTf2 GPE 4. Recuadro: 20 ciclos consecutivos de ETf-ZnTf2 GPE 4 y BTf-ZnTf2 GPE 4 comparado con ZnTf2 GPE 4. Velocidad de barrido $=20 \mathrm{mV} / \mathrm{s}$.

Para confirmar la conducción de $\mathbf{Z n}^{2+}$ en los GPEs, se realizó un estudio por voltametría cíclica utilizando una celda simétrica de Zn/GPE/Zn. La Figura 4.2-7 muestra la comparación de los registros para tres tipos de IL-ZnTf 2 GPEs 4. No se observaron diferencias relevantes lo que indica que los tipos de catión y anión no afectan el comportamiento voltamperométrico en general. Se obtuvieron valores de densidad de corriente, ca. $15 \mathrm{mAcm}^{-2}$, y $\Delta \mathrm{E}$ similares. Además, los voltamperogramas correspondientes a las membranas basadas en IL y libres de $\mathrm{ZnTf}_{2}$, muestran que esencialmente no hay corriente para estos GPEs. Tampoco se obtuvo ninguna corriente para los registros voltamperométricos de membrana sin IL, lo que confirma que sólo $\mathrm{ZnTf}_{2}$ dentro del polímero no fue suficiente para producir buenos resultados de transporte. Finalmente, estos resultados indican que los iones $\mathrm{Zn}^{2+}$ son efectivamente móviles en los GPEs y que el Zn es capaz de disolverse y depositarse, lo cual es esencial para su posible aplicación en baterías de zinc. Por lo tanto, estos resultados demuestran que estas membranas compuestas por PVdF-HFP, ZnTf 2, y diferentes ILs, como EMIM Tf, BMIM Tf, o EMIM TFSI, pueden ser utilizadas en baterías basadas en Zinc como GPEs. 
Finalmente, se han probado tres $\mathrm{ZnTf}_{2}$-GPE que contienen diferentes ILs en una

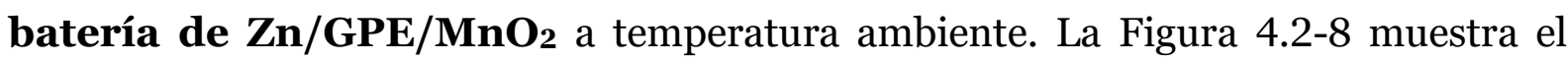
primer ciclo de descarga realizada a $-1 \mathrm{mAcm}^{-2}$ con potencial de corte $0.4 \mathrm{~V}$, obteniendo capacidades de descarga similares de 110-120 mAhg-1 ${ }^{-1}$ Una vez más, no se encontraron cambios significativos para los diferentes GPEs, confirmando que el tipo de IL no influye en el comportamiento de los GPEs.

Los tres tipos de GPEs muestran, cuando se incluye una cantidad suficiente de sal $\mathrm{ZnTf}_{2}$ valores de conductividad iónica, energías de activación, número de transporte y de Tg similares. Además, los voltamogramas y curvas de descarga obtenidos para los GPEs sintetizados con la misma cantidad de $\mathrm{ZnTf}_{2}$ pero cambiando el líquido iónico, presentan un comportamiento muy parecido. En este sentido, nos preguntamos por qué los diferentes cationes y aniones de los líquidos iónicos utilizados no han afectado al comportamiento general de los GPEs.

Con el fin de aclarar este punto, hemos prestado atención a los valores de conductividad obtenidos para los tres GPEs libres de sal (Figura 4.2-9). Como se puede ver, se obtienen diferentes valores de conductividad dependiendo del IL añadido, se obtiene una conductividad más alta siguiendo el orden ETf-GPE $>$ BTf-GPE $>$ ET-GPE. La conductividad iónica es muy baja para el ET-GPE, que contiene aniones TFSI; sin embargo, es mayor para el ETf-GPE y el BTf-GPE, ambos incluyendo aniones Tf-. Este comportamiento parece indicar que el anión TFSI afecta claramente la conductividad iónica del ET-GPE, probablemente debido a la interacción entre TFSI- y EMIM $^{+}$, que será muy diferente a la resultante entre $\mathrm{BMIM}^{+} \mathrm{o} \mathrm{EMIM}^{+}$con Tf-.

La conductividad, $\sigma$, puede ser expresada por:

$$
\sigma=e\left(n^{+} \mu^{+}+n^{-} \mu^{-}\right)
$$

De esta ecuación y considerando el número de transporte medido para estos GPEs, podemos obtener las conductividades aniónicas, $\sigma_{-}$, y catiónicas, $\sigma_{+}$:

$$
\begin{aligned}
& \sigma_{+}=\sigma t_{+} \\
& \sigma_{-}=\sigma t_{-}
\end{aligned}
$$




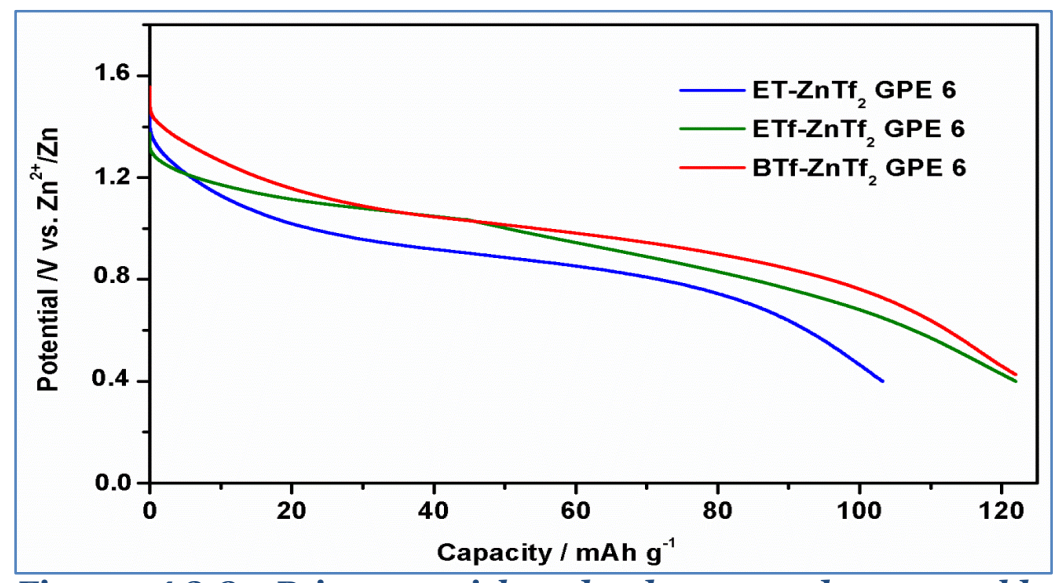

Figura 4.2-8: Primeros ciclos de descarga de una celda $\mathrm{Zn/GPE} / \mathrm{MnO} 2$ a $1 \mathrm{mAcm}^{-2}$ para BTf-ZnTf 2 GPE 6, ETf-ZnTf 2 GPE 6 y ET- ZnTf 2 GPE 6. El voltaje de corte a $0.4 \mathrm{~V}$.

Desafortunadamente, cuando más de dos tipos de iones están incluidos dentro de los GPEs, este modelo no puede ser aplicado. La Figura 4.2-9 muestra la conductividad total, aniónica y catiónica de los tres GPEs libres de sal. Como puede verse para todos los GPEs, $\sigma_{-}$es siempre superior a $\sigma_{+}$, lo que indica que el transporte de iones es principalmente aniónico. Este resultado está de acuerdo con el gráfico $t_{+}$ y t-, que se muestra en la Figura 4.2-6. Además, la conductividad de TFSI es inferior a la conductividad de Tf- observada para los GPEs de ETf y BTf.

Este comportamiento puede explicarse en base a las diferentes interacciones catiónicas-aniónicas que se producen en cada GPE. En este sentido, dado que los tres ILs utilizados en este trabajo tienen un catión imidazolio, se ha analizado la región 3000-3240 $\mathrm{cm}^{-1}$ obtenida por ATR-FTIR, donde se presentan las bandas de C-H imidazolio.

En la Figura 4.2-11, se muestra el rango 3000-3240 $\mathrm{cm}^{-1}$ ATR-FTIR para los tres GPEs. Se incluyen los tres GPEs sin sal y los obtenidos para los que se añade ZnTf2 , IL-ZnTf 2 GPE 4. Además, se incluyen los espectros ATR-FTIR de los ILs puros como referencia. 


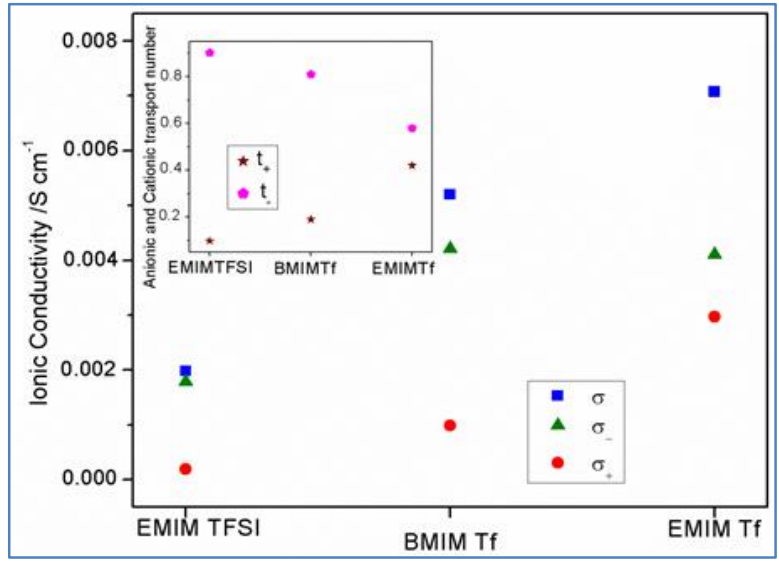

Figura 4.2-9: $\sigma$ total, aniónico, $\sigma$ - y catiónico, o+ para los tres IL-GPEs sin sal. Recuadro: Número de transporte aniónico y catiónico para el mismo IL-GPE libre de sal.

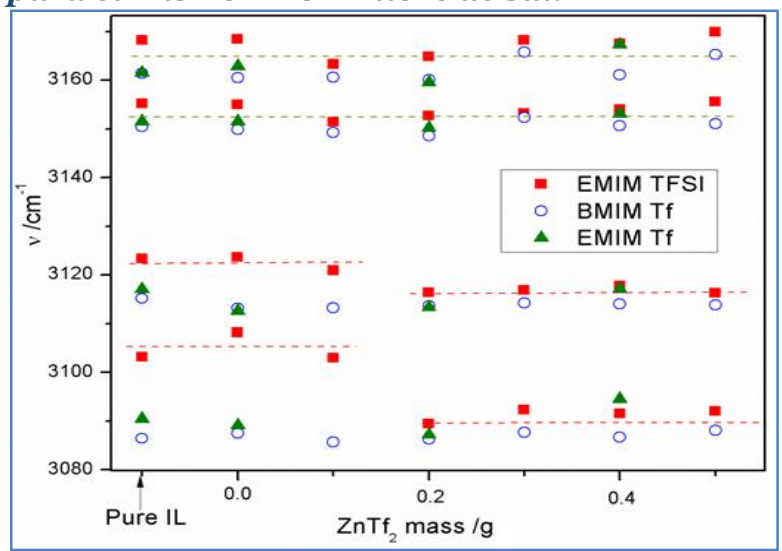

Figura 4.2-10: Deconvolución de picos ATRFTIR en el rango 3000-3240 frente a la masa de ZnTf2. La leyenda indica ILs.

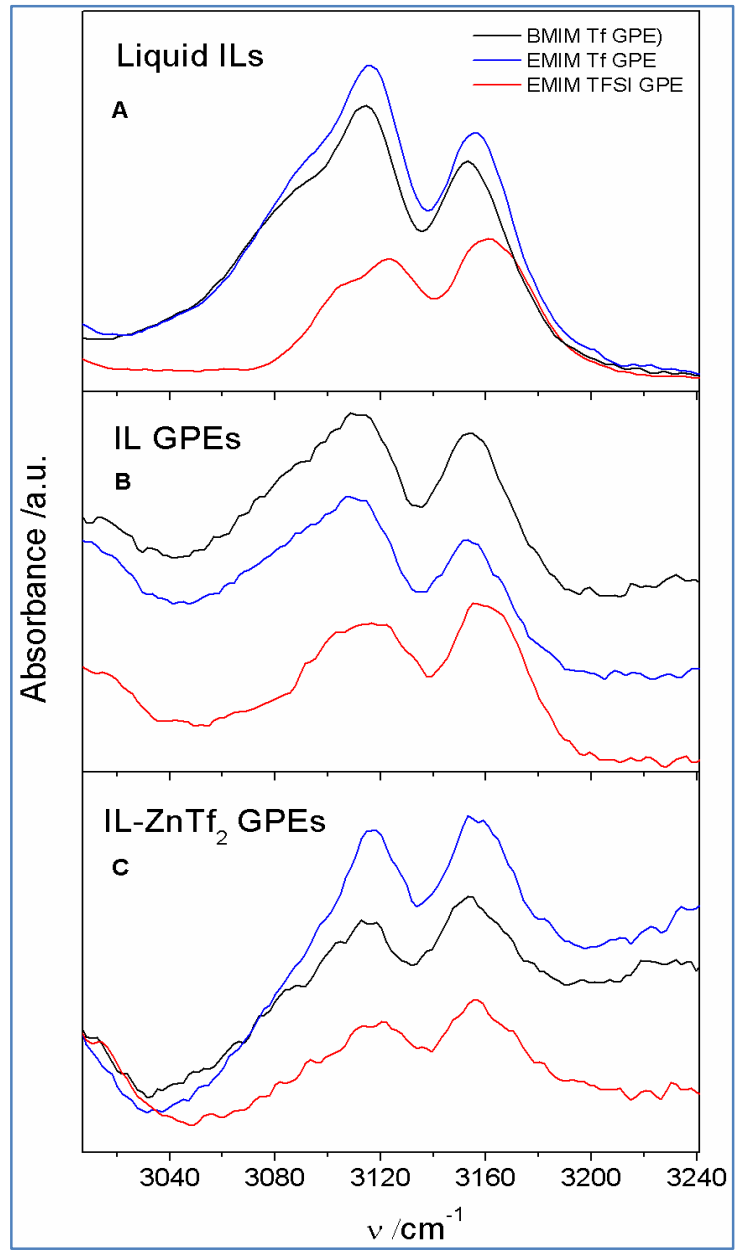

Figura 4.2-11: Espectros ATR-FTIR en el rango 3000-3240 $\mathrm{cm}^{-1}$ para (A) ILs puras; (B) IL-GPEs sin sal; y (C) IL-ZnTf2 GPEs 4. La leyenda indica los nombres de IL.

La Figura 4.2-11A muestra que las bandas del TFSI EMIM puro tienen un desplazamiento con respecto a las otros ILs puros. Este cambio también se observa para el ET-GPE libre de sal (Figura 4.2-11B). Sin embargo, una vez que se incluye la sal en los GPEs este desplazamiento desaparece (Figura 4.2-11C). El último resultado indica que en estos GPEs, los cationes de los ILs presentarán una interacción muy similar con los aniones correspondientes al añadir suficiente cantidad de $\mathrm{ZnTf}_{2}$.

Con el fin de destacar la magnitud de este cambio, hemos llevado a cabo la deconvolución de las bandas ATR-FTIR y se obtuvieron cuatro picos para todos los GPEs y los ILs puros. La Figura 4.2-10 muestra las frecuencias de las cuatro bandas ATR-FTIR para los ILs puros y para todos los GPEs sintetizados. Esta figura muestra que no se observa ningún desplazamiento apreciable en las dos bandas de frecuencias 
más altas ( $\left.\sim 3165 \mathrm{y} \sim 3155 \mathrm{~cm}^{-1}\right)$ tanto para los IL-GPE, IL-ZnTf 2 -GPE como para los ILs puros. Además, ambas bandas muestran valores similares y estables para todos los GPEs a lo largo de todo el rango de concentración de sal. Sin embargo, las otras dos bandas ( $\left.\sim 3115 \mathrm{y} \sim 3090 \mathrm{~cm}^{-1}\right)$ se desplazan a frecuencias más altas para el EMIM TFSI IL puro y para el ET-GPE con baja concentración de sal. Sin embargo, el aumento de sal dentro de los GPEs produce que los GPEs basados en ET muestren picos de frecuencias similares a las obtenidas para los GPEs basados en ETf y BTf. Este resultado confirma que las interacciones catiónicas son similares cuando se añade suficiente concentración de $\mathrm{ZnTf}_{2}$ al GPE.

\subsection{Conclusiones.}

A la vista de los resultados presentados, podemos concluir que se obtiene un comportamiento estructural y eléctrico diferente, dependiente del tipo de IL, cuando no se incluya sal o la concentración de ésta sea baja en la membrana.

Sin embargo, cuando se introduce una cantidad suficiente de sal de $\mathrm{ZnTf}_{2}$ en el GPE, se produce un comportamiento muy similar independientemente del IL utilizado. Este resultado indica que el transporte de iones $\mathrm{Zn}^{2+} \mathrm{y}$ Tf- es predominante a altas concentraciones de sal dentro de los GPEs. Adicionalmente, cuando se incluye suficiente cantidad de $\mathrm{ZnTf}_{2}$ en los GPEs se obtuvieron valores de número de transporte catiónico alto, lo que tiene que estar relacionado con la interacción NMP$\mathrm{Zn}^{2+}$. Este hecho hace que $\mathrm{Zn}^{2+}$ sea el portador de carga más importante en todas los GPEs, independientemente del IL utilizado. A pesar de ello, la inclusión de los ILs dentro de las membranas es necesaria para obtener GPEs con buenas características eléctricas, como lo demuestran los malos resultados obtenidos para los GPEs sin ILs. En consecuencia, los ILs tienen un papel importante en el proceso de conductividad dentro de los GPE. Así, aunque la inclusión de NMP es fundamental para aumentar el número de transporte de cationes, sólo se obtuvieron GPEs de alta calidad cuando NMP, IL y ZnTf 2 se incluyeron en la matriz de polímero. 


\section{A Synchrotron X-Ray Diffraction And Hard X-Ray Photoelectron Spectroscopy Study Of Zn Negative Electrodes At Different Charge And Discharge States Of $\mathrm{Zn} / \mathrm{MnO}_{2}$ Batteries Using An Ionic Liquid-Based Gel Polymer Electrolyte. \\ Abad, J.; Santos, F.; Tafur, J. P.; Urbina, A.; Román, E.; González-Martínez, J. F.; Rubio-Zuazo, J.; Castro, G. R.; Fernández Romero, A. J. J. Power Sources 2017, 363, 199-208. https://doi.org/10.1016/j.jpowsour.2017.07.082}

"Science never solves a problem without creating ten more." 



\section{RESUMEN}

Baterías de $\mathbf{Z n / I L - G P E / M n O}$, han sido descargadas o descargadas y luego recargadas alcanzando diferentes estados de carga. Los electrodos de Zn utilizados en estas baterías de $\mathrm{Zn} / \mathrm{IL}-\mathrm{GPE} / \mathrm{MnO}_{2}$ han sido estudiados mediante técnicas HAXPES y XRD con radiación sincrotrón. Además, las mediciones HAXPES se comparan con los resultados obtenidos por XPS convencional. La formación de $\mathrm{Zn}(\mathrm{OH})_{2}$ y $\mathrm{ZnO}$ se ha observado en estados intermedios de carga durante las cargas y descargas. Sin embargo, sólo se observa $\mathrm{ZnO}$ en el ánodo cuando se realizó una descarga completa. Por el contrario, un proceso de carga completa provoca una reducción completa de todas las especies de $\mathrm{Zn}^{2+}$ a $\mathrm{Zn}$ metálico. Además, varias técnicas han confirmado la entrada de aniones Triflato y moléculas de disolvente NMP en el electrodo, acompañando el movimiento de los cationes $\mathrm{Zn}^{2+}$ durante la carga.

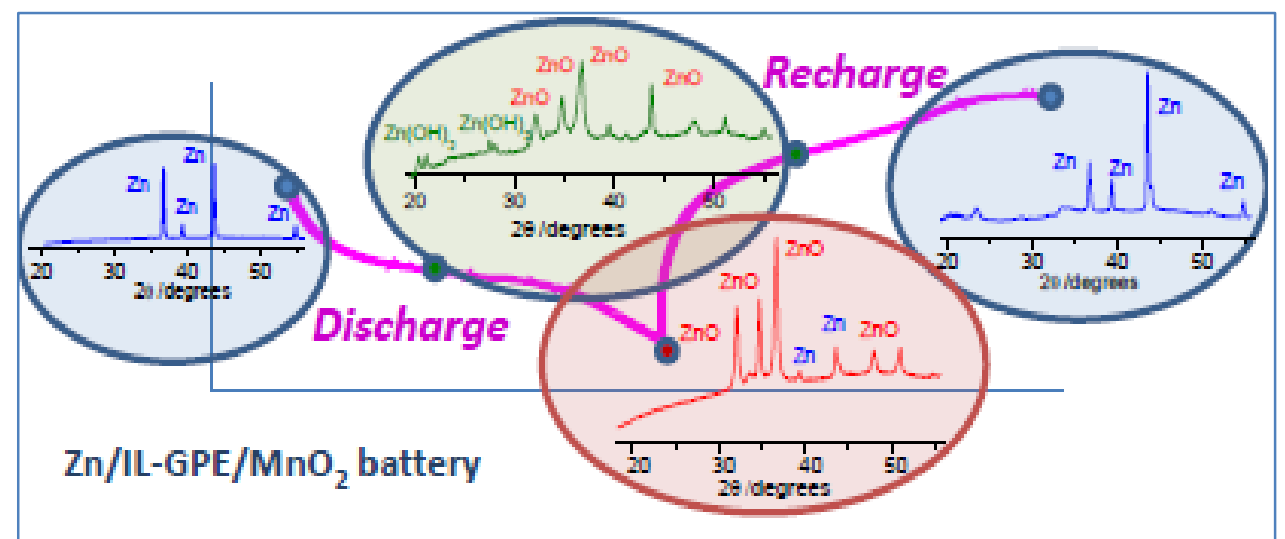

Zn anodes at different states of charge were analysed by Synchrotron XRD and HAXPES. 


\subsection{Introducción.}

Es sabido que los electrodos de zinc presentan algunos problemas como la pasivación del ánodo, el crecimiento dendrítico o la evolución del $\mathrm{H}_{2}$, los cuales impiden la comercialización de baterías recargables basadas en $\mathrm{Zn}$.

En este sentido, el uso de Líquidos Iónicos (ILs) puede prevenir la formación dendrítica durante la deposición de Zn y disminuir la evolución de $\mathrm{H}_{2}$, así como otros efectos negativos. Por lo tanto, los electrolitos de gel polimérico (IL-GPE) con líquidos iónicos en baterías de $\mathrm{Zn}$ han atraído mucha atención durante la última década para mejorar este tipo de baterías.

Se acepta ampliamente que en baterías alcalinas acuosas, el $\mathrm{Zn}$ se oxida a $\mathrm{Zn}^{2+}$ por el siguiente mecanismo:

$$
\begin{aligned}
& \mathrm{Zn} \rightarrow \mathrm{Zn}^{2+}+2 \mathrm{e}^{-} \\
& \mathrm{Zn}^{2+}+4 \mathrm{OH}^{-} \leftrightarrows \mathrm{Zn}(\mathrm{OH})_{4}^{\bar{y}}+2 e^{-} \\
& \mathrm{Zn}(\mathrm{OH})_{4}^{\bar{\leftrightarrows}} \leftrightarrows \mathrm{ZnO}+\mathrm{H}_{2} \mathrm{O}+2 \mathrm{OH}^{-}
\end{aligned}
$$

Las reacciones ( 1 y 2 ) proceden hasta que la solubilidad del ion zincato, $\mathrm{Zn}(\mathrm{OH})_{4}^{2-}$, alcanza el punto de saturación en el electrolito alcalino. A continuación, el $\mathrm{ZnO}$ se deposita en el electrodo formando una película poco conductora, lo que provoca cambios de forma y la pasivación del electrodo negativo. Sin embargo, el proceso de formación del $\mathrm{ZnO}$ no está claro, y hay varios autores que han propuesto un mecanismo en el que interviene el $\mathrm{Zn}(\mathrm{OH})_{2}$.

Obviamente, cuando se utilizan electrolitos puros a base de IL, no se pueden formar $\mathrm{ZnO}$ y $\mathrm{Zn}(\mathrm{OH})_{2}$ porque no hay agua en el medio. Sin embargo, pequeñas adiciones de agua en el electrolito pueden provocar la formación de una película de óxido metálico, mejorar la reversibilidad redox del par $\mathrm{Zn}^{2+} / \mathrm{Zn}$, el coeficiente de difusión de las especies de $\mathrm{Zn}$ y la conductividad iónica de los electrolitos. La clarificación de los procesos que se producen en el electrodo de $\mathrm{Zn}$ durante la carga y descarga es esencial para hacer que este tipo de baterías sean reversibles. 
En este trabajo hemos utilizado el XRD y HAXPES con radiación sincrotrón, así como la técnica XPS convencional, para analizar la reestructuración del electrodo de $\mathrm{Zn}$ que se produce durante los procesos de descarga y recarga de una batería de $\mathrm{Zn} / \mathrm{IL}-\mathrm{GPE} / \mathrm{MnO}_{2}$. Se han analizado varias láminas de $\mathrm{Zn}$ utilizadas como electrodos negativos en estas baterías los cuales se han llevado a diferentes estados de carga. La Figura 5.1-1. A muestran las curvas de descarga obtenidas hasta una tensión de corte de $1.1 \mathrm{~V}$ (azul), $0.8 \mathrm{~V}$ (verde) y $0.4 \mathrm{~V}$ (azul); mientras que en la Figura 5.1-1.B aparecen las curvas de carga hasta alcanzar la misma capacidad que se alcanzó durante la descargas con potenciales de corte de $1.1 \mathrm{~V}, 0.8 \mathrm{~V}$ y $0.4 \mathrm{~V}$.

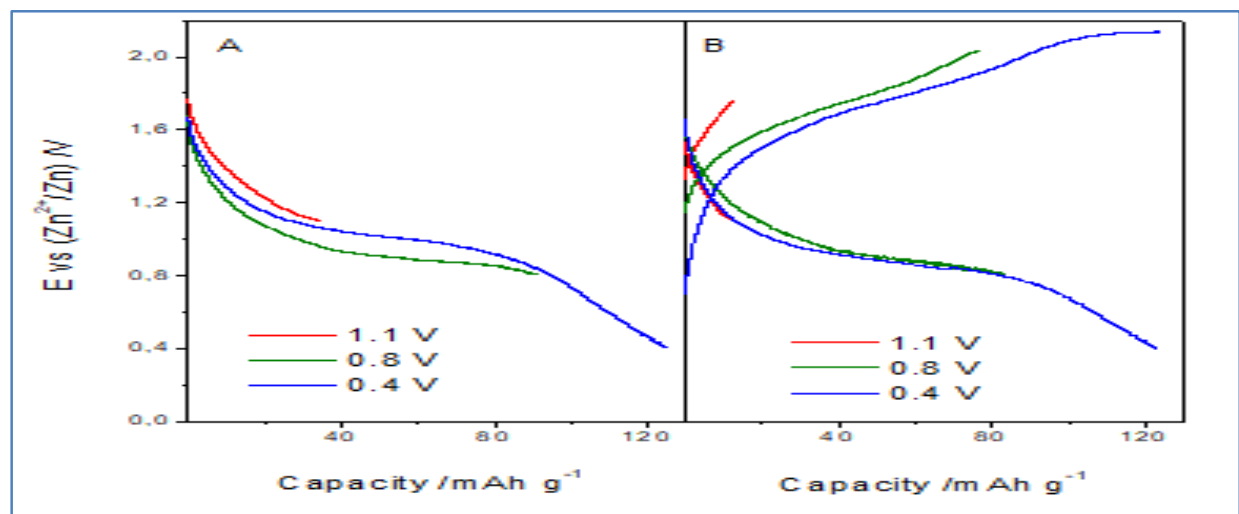

Figura 5.1-1: Curvas de descarga (A) y carga (B) obtenidas para baterías $\mathrm{Zn} / \mathrm{IL}-\mathrm{GPE} / \mathrm{MnO}_{2}$. Se muestran las tensiones de corte alcanzadas durante los procesos de descargas y las cargas se realizaron hasta alcanzar la misma capacidad de carga que se descargó previamente.

\subsection{Resultados.}

La Figura 5.2-1 muestra los espectros HAXPES de Zn $2 p_{3 / 2}$ (Figura 5.2-1A) y Zn 1s (Figura 5.2-1C) de los electrodos de Zn en varios estados de carga: i) placa de Zn no utilizada, ii) descargada hasta $0.4 \mathrm{~V}$ y iii) recargada completamente. La energía de enlace de los electrones (BE) de $\mathrm{Zn} 2 p_{3 / 2}$, pico a $1022.2 \mathrm{eV}$, para la placa no utilizada, se asigna a la presencia de Zn metálico. Desafortunadamente, las líneas Zn 2p no son muy sensibles al ambiente químico por lo que no es posible distinguir claramente el estado químico del $\mathrm{Zn}$ entre el $\mathrm{ZnO}$ y el Zn metálico, ya que las diferencias son de unos pocos cientos de meV. 
Curiosamente, después del proceso de descarga (línea roja), este pico se divide en dos componentes (1022.2 eV y 1026.8 eV). La aparición del segundo pico en 1026.8 $\mathrm{eV}$ puede atribuirse a $\mathrm{Zn}^{2+}$. Aunque el desplazamiento observado de $4.6 \mathrm{eV}$ es grande para la línea $\mathrm{Zn}^{2+} 2 p_{3 / 2}$, este desplazamiento se debe a la acumulación de una cantidad significativa de carga positiva en las regiones no conductoras de la superficie, aumentando así la BE de los fotoelectrones. Además, este segundo pico no se observa después de una recarga completa (línea azul). Sólo queda el pico de $1022.2 \mathrm{eV}$, que coincide con el estado inicial e indica que las especies de $\mathrm{Zn}^{2+}$ se redujeron a $\mathrm{Zn}$ metálico. Otra evidencia que apunta a la asignación de este pico a la línea $\mathrm{Zn}^{2+} 2 p_{3 / 2} \mathrm{es}$ el valor $4 \mathrm{eV}$ obtenido para la anchura de pico a media altura (FWHM), que es mayor que el FWHM del Zn metálico de $3.5 \mathrm{eV}$.

Usando fuentes convencionales de XPS, el flujo de rayos X es menor que el producido en una fuente de sincrotrón, los problemas de carga son menores y la alineación de los picos es más sencilla. La profundidad de análisis de una fuente convencional XPS es menor que la de la HAXPES, por lo que el XPS es más sensible a los procesos que se producen en la superficie. Los picos obtenidos para la placa de $\mathrm{Zn}$ sin usar y los correspondientes a los electrodos recargados están centrados en 1022.2 $\mathrm{eV}$, mientras que el pico del electrodo descargado está situado en $1022.1 \mathrm{eV}$ (Figura 5.2-1B). El hombro que parece ha sido previamente reportado como aglomerados $\mathrm{Zn}$ $\mathrm{O}-\mathrm{C}$.

La alta energía fotónica de $11 \mathrm{keV}$ utilizada en HAXPES nos permite medir el nivel de núcleo de Zn 1s situado a 9659.8 eV (Figura 5.2-1C). Es interesante notar que después del proceso de descarga (línea roja) se observa un hombro con energía aproximadamente $4.6 \mathrm{eV}$ más alta, lo que puede deberse a los efectos de la carga. Este hallazgo concuerda con los resultados de HAXPES Zn $2 p_{3 / 2}$, indicando que algunas especies de $\mathrm{Zn}$ han sido oxidadas durante la descarga. Además, este hombro desaparece para el electrodo cargado recuperando el estado de oxidación de la lámina de $\mathrm{Zn}$ sin usar o prístina.

Por otra parte, las líneas Auger de Zn LMM y Zn KLL han sido estudiadas con el fin de identificar los estados de oxidación del Zn. En la Figura 5.2-2A se muestra la 
línea LMM de Zn para $11 \mathrm{keV}$ de energía fotónica para los tres estados de carga. Espectros similares se obtienen para la placa de Zn no utilizada (línea negra) y la recargada (línea verde). Sin embargo, el Zn descargado (línea roja) muestra un hombro a $986.4 \mathrm{eV}$, lo que podría ser una indicación de la formación de cationes $\mathrm{Zn}^{2+}$.

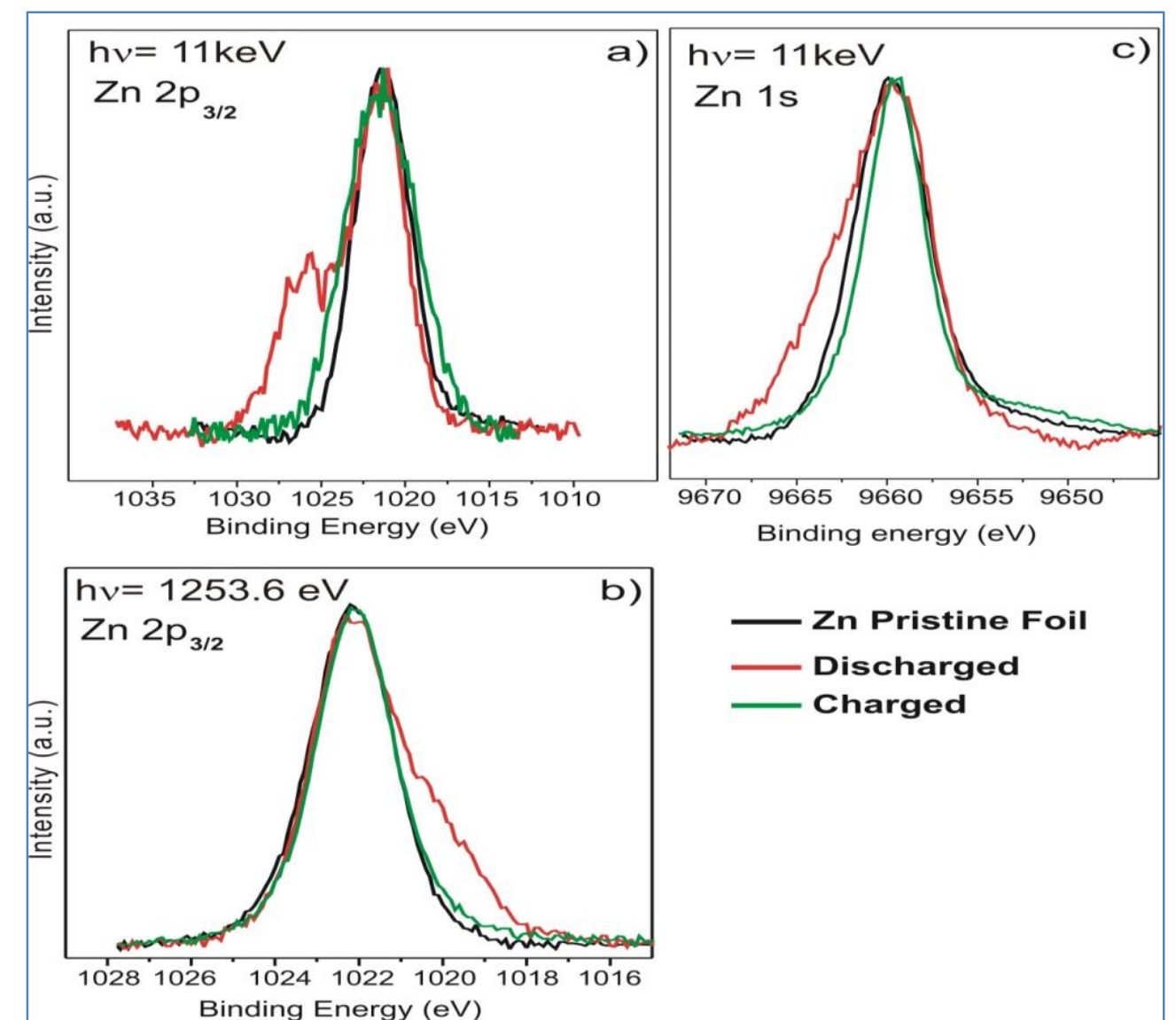

Figura 5.2-1: A) Espectros HAXPES Zn $2 p_{3 / 2}$, B) Espectros XPS Zn 2p $p_{3 / 2}$ de una fuente convencional y C) Espectros HAXPES Zn 1 s. La línea negra corresponde a la lámina prístina de $\mathrm{Zn}$, la línea roja al ánodo de $\mathrm{Zn}$ descargado y la línea verde al electrodo de Zn recargado.

A modo de comparación, en la Figura 5.2-2B se muestra la línea LMM de Zn medido con una fuente de rayos X convencional. La forma del pico de Zn LMM para la placa de Zn y el electrodo recargado de Zn son bastante similares, sin embargo su KE $987.3 \mathrm{eV}$ y $986.6 \mathrm{eV}$, respectivamente, son mucho menores que los valores reportados en la literatura para el Zn metálico (992-993 eV KE). La línea Zn LMM para el Zn descargado (línea roja) presenta una forma de línea diferente y el pico principal se encuentra en $986.9 \mathrm{eV}$ de $\mathrm{KE}$. Este valor es consistente con la presencia de cationes $\mathrm{Zn}^{2+}(987-989 \mathrm{eV} \mathrm{KE})$. 
La alta energía fotónica obtenida con radiación sincrotrón, nos permite estudiar además, la región de Zn KLL Auger, que hasta donde sabemos no ha sido publicada anteriormente. La Figura 5.2-2C muestra la región Zn KLL para las tres muestras. El espectro de la placa de $\mathrm{Zn}$ no utilizada muestra un pico de $7526.4 \mathrm{eV}$ con un hombro de $7532.5 \mathrm{eV}$. Para el ánodo descargado se observaron cambios notables, el hombro a $7532.5 \mathrm{eV}$ desapareció y un nuevo hombro apareció a valores inferiores de KE, 7521.1 $\mathrm{eV}$. Este comportamiento podría estar asociado con la oxidación de $\mathrm{Zn}$ a $\mathrm{Zn}^{2+}$. Además, al recargar el electrodo de $\mathrm{Zn}$, el hombro a $7521.1 \mathrm{eV}$ desapareció mientras que el hombro a $7532.5 \mathrm{eV}$ volvió a ser visible, lo que indica que el electrodo recupera el estado inicial.

Así, a partir del estudio de las líneas de $\mathrm{Zn}$, hemos demostrado experimentalmente que durante el proceso de descarga el $\mathrm{Zn}$ se oxidó a $\mathrm{Zn}^{2+}$ y este se redujo durante la recarga. Sin embargo, no podemos saber qué especies de $\mathrm{Zn}^{2+}$ se formaron y destruyeron durante los procesos de descarga y carga. En este sentido, el análisis de la región $\mathrm{O}$ 1s es más sensible al ambiente químico y puede ayudarnos a determinar las especies formadas y destruidas.

La Figura 5.2-3 muestra el pico de O 1s para la técnica HAXPES (Figura 5.2-3A) y para XPS convencional (Figura 5.2-3B). En la Figura 5.2-3A, la placa Zn no utilizada (línea negra) muestra un pico de $532 \mathrm{eV}$, correspondiente a los productos adsorbidos en la placa provenientes del aire. Cuando se descarga el Zn (línea roja), se observa el pico de $\mathrm{O} 1 \mathrm{~s}$ con una energía de enlace más baja, $530 \mathrm{eV}$. Este pico se asigna a la presencia de aglomerados metal-O, señalando la formación de aglomerados Zn-O durante la descarga.Además, se observó un componente a $535 \mathrm{eV}$.

Sin embargo, para el electrodo de $\mathrm{Zn}$ recargado (línea verde), el pico correspondiente a la unión de $\mathrm{Zn}-\mathrm{O}$ desaparece, indicando que $\mathrm{Zn}^{2+}$ se redujo a $\mathrm{Zn}$ metal. Este espectro muestra también un pico de alta intensidad a $535 \mathrm{eV}$ con un hombro de $531 \mathrm{eV}$. El pico más intenso a $535 \mathrm{eV}$ podría asignarse a enlaces $\mathrm{S}=\mathrm{O}$ y $\mathrm{C}=\mathrm{O}$ correspondientes a aniones Triflato y moléculas de NMP. Este pico es más intenso para el electrodo recargado de $\mathrm{Zn}$ que el observado para el ánodo descargado, lo que podría indicar que las moléculas de Triflato y de solvente entran masivamente en el ánodo 
acompañando el movimiento de los cationes de $\mathrm{Zn}^{2+}$ hacia el electrodo durante el proceso de recarga.

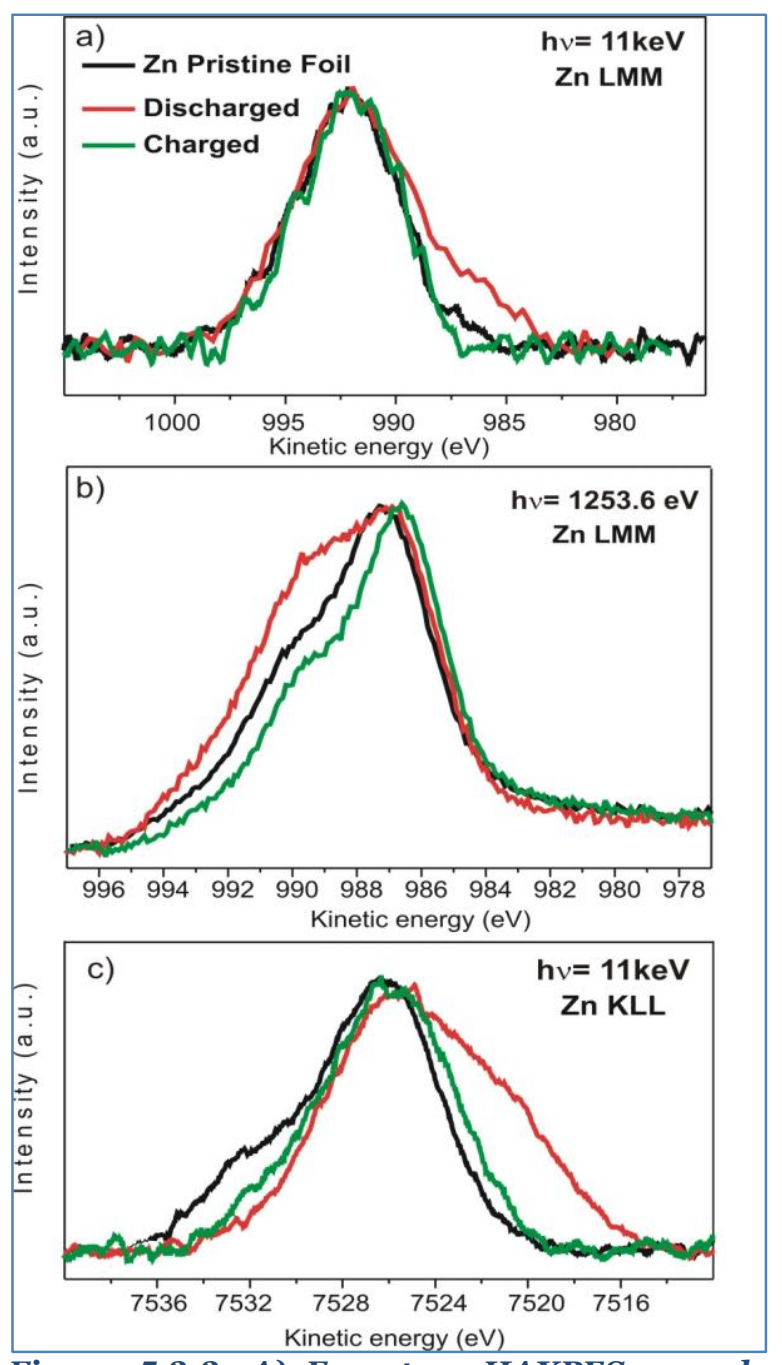

Figura 5.2-2: A) Espectros HAXPES para la línea Zn LMM, B) Espectros XPS para la línea Zn LMM y c) Espectros HAXPES para la línea Zn KLL. La línea negra corresponde a la lámina prístina de Zn, la línea roja al ánodo de Zn descargado y la línea verde al electrodo de $\mathrm{Zn}$ recargado.

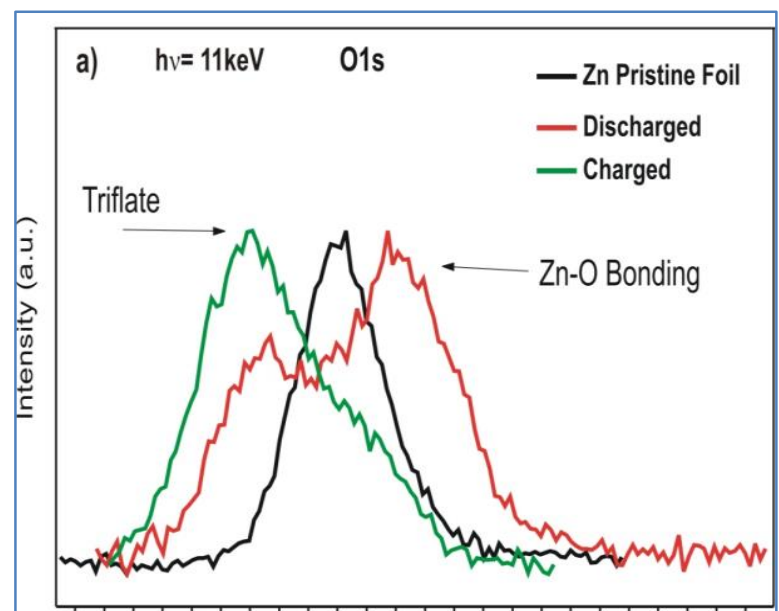

$\begin{array}{llllllllllll}540 & 538 & 536 & 534 & 532 & 530 & 528 & 526 & 524 & 522 & 520 & 518\end{array}$ Binding Energy (eV)

b) $h_{v}=1253.6 \mathrm{eV} \quad 01 \mathrm{~s}$

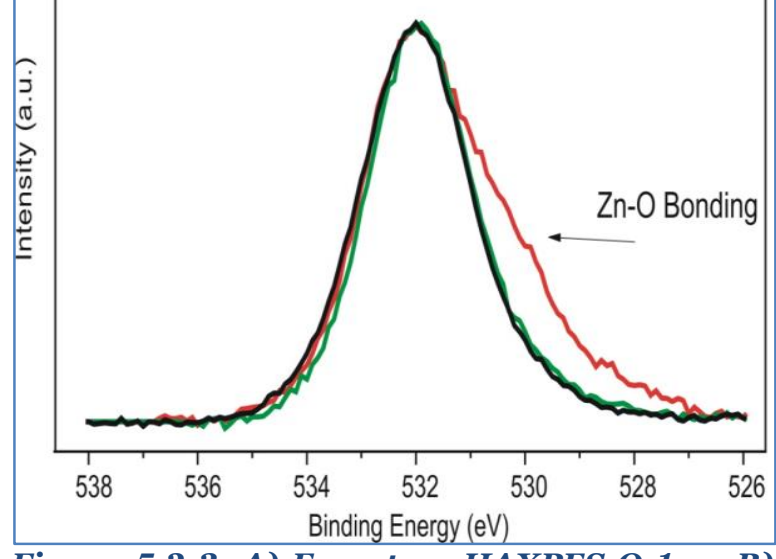

Figura 5.2-3: A) Espectros HAXPES O 1 s y B) Espectros XPS $O$ is de una fuente de laboratorio. La línea negra corresponde a la lámina prístina de $\mathrm{Zn}$, la línea roja al ánodo de Zn descargado y la línea verde al electrodo de Zn recargado.

La Figura 5.2-3B muestra la región O 1s medida con XPS convencional. La placa de $\mathrm{Zn}$ sin usar (línea negra) presenta un pico situado a $532 \mathrm{eV}$, similar al observado en HAXPES, relacionado con la contaminación de la superficie de Zn. Para el ánodo Zn descargado (línea roja) aparece un hombro a 530 eV, correspondiente a la unión ZnO. Después del proceso de recarga (línea verde), el hombro desaparece y sólo 
permanece en el pico a $532 \mathrm{eV}$, lo que indica claramente que las especies de óxido de Zn se han reducido después del proceso de recarga.

La existencia de aniones Triflato dentro del electrodo negativo se demuestra analizando las regiones F 1s y S 1s. En la Figura 5.2-4A la región F 1s muestra un pico de $684 \mathrm{eV}$ tanto para electrodos negativos descargados como recargados; se ha encontrado un pico tres veces más intenso para el electrodo recargado que para el descargado. Se observó un resultado similar cuando se midió el S 1s, como se muestra en la Figura 5.2-4B, resultando en un pico tres veces más intenso para el electrodo recargado que para el descargado.

Estos resultados apoyan la existencia de aniones Triflato dentro del electrodo negativo, y una entrada de aniones Triflato que acompañan la entrada de $\mathrm{Zn}^{2+}$ en el ánodo durante el proceso de recarga.

Aunque las medidas de la región $\mathrm{O}$ 1s, nos informan de la formación de compuestos que incluyen enlaces $\mathrm{Zn}-\mathrm{O}$, aún no podemos diferenciar entre $\mathrm{ZnO}$, $\mathrm{Zn}(\mathrm{OH})_{2}$, u otros tipos de compuestos que incluyan $\mathrm{Zn}$ y O. Es por esto, y con el fin de dilucidar qué especies de $\mathrm{Zn}$ se forman durante la descarga y recarga, que se han realizado mediciones XRD simultáneamente a las de HAXPES.

La Figura 5.2-5 muestra los difractogramas de rayos $\mathbf{X}$ registrados para una lámina de Zn sin usar, y los ánodos de Zn descargados hasta 1.1 V, $0.8 \mathrm{~V}$ y $0.4 \mathrm{~V}$. El difractograma de lámina de $\mathrm{Zn}$ muestra cuatro picos a $36.77^{\circ}, 39.41^{\circ}, 43.68^{\circ}$ y $54.86^{\circ}$ que se atribuyen a los planos cristalográficos (002), (100), (101) y (102) característicos del Zn metálico. Los difractogramas observados para los ánodos descargados son más complejos, ya que aparecen nuevos picos junto a los asignados al Zn metálico. Los picos de $32^{\circ} .12^{\circ}, 34.79^{\circ}$ y $47.98^{\circ}$ pueden atribuirse a los planos cristalográficos (100), (002) y (102) del ZnO. Además, se encuentra un pico a $36.4^{\circ}$, que corresponde al plano (101) del $\mathrm{ZnO}$, pero puede solaparse con el pico metálico de $\mathrm{Zn}$ observado a $36.7^{\circ}$. Finalmente, se observa un pico de $51.1^{\circ}$ debido a la película de $\mathrm{Cu}$ adhesiva utilizada para soportar las muestras. 


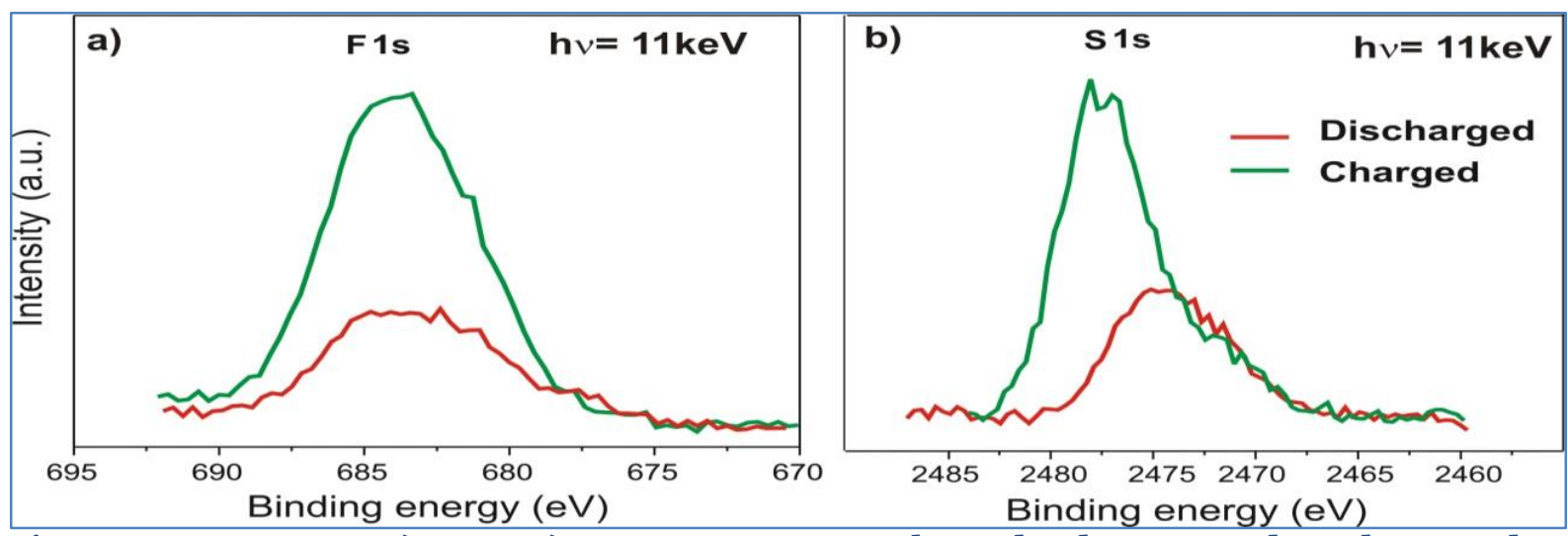

Figura 5.2-4: HAXPES A) F 1 s y B) Espectros $S$ is para electrodos de Zn cargados y descargados. Las líneas roja y verde corresponden a los electrodos de $\mathrm{Zn}$ descargados y recargados, respectivamente.

Los tamaños de los cristalitos de partículas nanométricas de $\mathrm{ZnO}$ han sido estimados para diferentes electrodos a partir del pico de difracción de ZnO (002), de acuerdo con la ecuación de Scherrer:

$$
\mathbf{d}_{\mathbf{c}}=\frac{\mathrm{K} \lambda}{\beta \cos \theta}
$$

donde $\mathrm{d}_{\mathrm{c}}$ es el tamaño del cristalito, K(0.89) es el factor de forma, $\lambda$ la longitud de onda de rayos X, $\beta$ el FWHM del pico (002), y $\theta$ es el ángulo de difracción. El recuadro de la Figura 5.2-5 muestra los tamaños de cristalito medidos para D-1.1, D0.8 y D-0.4. Se observó un aumento de los tamaños de cristalito con el incremento de la profundidad de descarga, de $33.7 \mathrm{~nm}$ para D-1.1 a $42.5 \mathrm{~nm}$ para D-0.4.

En cuanto al proceso de carga, en la Figura 5.2-6 se muestran los difractogramas obtenidos para los ánodos descargados hasta 1.1 , 0.8 y $0.4 \mathrm{~V}$ y luego recargados para alcanzar una capacidad similar a la descargada, que se denominan C-1.1, C-0.8 y C0.4. Como se puede ver, los difractogramas C-1.1 y C-0.8 muestran los picos correspondientes al $\mathrm{ZnO}$, aunque todos los picos de $\mathrm{ZnO}$ disminuyen para el C-0.8 con respecto al C-1.1. Sin embargo, los picos correspondientes al $\mathrm{ZnO}$ desaparecieron totalmente cuando la batería se recargó completamente, por lo que la curva C-0.4 muestra sólo los picos correspondientes al Zn metálico.

Estos resultados parecen indicar que se forma una película de ZnO directamente durante la descarga y se elimina cuando se recarga el electrodo de Zn. Sin 
embargo, se debe prestar atención a las curvas C-0.8 y C-1.1, que muestran cuatro picos adicionales a $20.4^{\circ}, 21.2^{\circ}, 27.5^{\circ}$ y $28.1^{\circ}$. Estos picos pueden asignarse a la formación de $\mathrm{Zn}(\mathrm{OH})_{2}$, según la base de datos de la ICDD (PDF-04-012-2300). Sin embargo, estos picos no estaban presentes en la curva C-0.4, lo que indica que la película de $\mathrm{Zn}(\mathrm{OH})_{2}$ fue destruida, como la película de $\mathrm{ZnO}$, cuando se realizó una recarga completa.

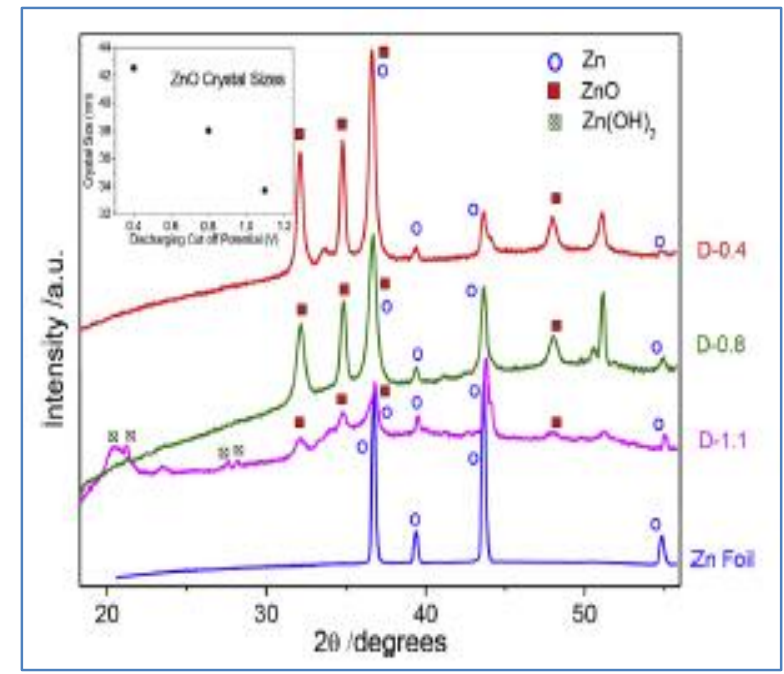

Figura 5.2-5: Difractogramas de rayos $X$ de lámina prístina de Zn (azul), y los ánodos de Zn descargados hasta 1.1 (magenta), 0.8 (verde) y $0.4 \mathrm{~V}$ (rojo), denominados como $D-1.1, D-0.8 y$ D-0.4, respectivamente. Los picos se asignan a $\mathrm{Zn}, \mathrm{ZnO}$ y $\mathrm{Zn}(\mathrm{OH})_{2}$ con los símbolos que se identifican en la leyenda. El recuadro muestra el tamaño de cristalito del $\mathrm{ZnO}$ en los tres estados de descarga.

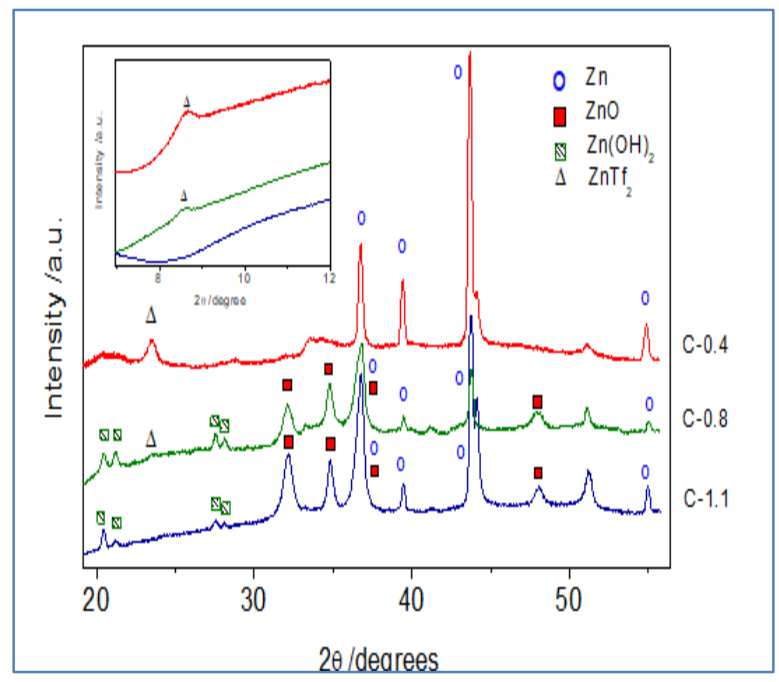

Figura 5.2-6: Difractogramas de rayos $X$ de los electrodos de Zn descargados hasta 1.1, $0.8 \mathrm{y}$ $0.4 \mathrm{~V}$ y luego recargados hasta obtener la misma capacidad descargada, denominada $C$ 1.1 (azul marino), C-0.8 (verde) y C-0.4 (rojo), respectivamente. Los picos se asignan a $\mathrm{Zn}$, $\mathrm{ZnO}, \mathrm{Zn}(\mathrm{OH})_{2}$ y ZnTf2 con los símbolos que se identifican en la leyenda. El recuadro muestra los tres difractogramas de rayos $X$ en la región de 4-12 grados.

Estos picos también se han observado durante la descarga en la curva D-1.1, lo que indica que también se formó $\mathrm{Zn}(\mathrm{OH})_{2}$ durante el proceso de descarga. Sin embargo, la película de $\mathrm{Zn}(\mathrm{OH})_{2}$ desapareció cuando se alcanzaron los potenciales de corte de $0.8 \mathrm{~V}$ y $0.4 \mathrm{~V}$. Los difractogramas de D-0.8 y D-0.4 sólo presentan los picos correspondientes al $\mathrm{ZnO}$ y al Zn metálico.

Con el objetivo de cuantificar las cantidades relativas de cada fase formadas durante los procesos de descarga y carga, se ha llevado a cabo un refinamiento de Rietveld, Figura 5.2-7. Se obtuvo un área máxima de pico no identificada del $0.3 \%$ para todos los ajustes que se han realizado. La Tabla 5.2-1 
muestra las cantidades relativas de cada especie para todos los electrodos negativos descargados y cargados.

\begin{tabular}{ccccccc}
\hline Fase & D-1.1 \% & D-0.8 \% & D-0.4 \% & C-1.1 \% & C-0.8 \% & C-0.4 \% \\
\hline $\mathrm{Zn}$ & 48.8 & 23.2 & 9.6 & 35.4 & 15.7 & 73.7 \\
$\mathrm{ZnO}$ & 23.0 & 67.3 & 85.0 & 40.4 & 47.3 & 0 \\
$\mathrm{Zn}(\mathrm{OH})_{2}$ & 11.5 & 0 & 0 & 8.4 & 21.1 & 0 \\
$\mathrm{ZnTF}_{2}$ & 0 & 0 & 0 & 0 & 9.4 & 18.2 \\
$\mathrm{Cu}$ & 16.8 & 9.4 & 5.4 & 15.9 & 6.6 & 8.0 \\
\hline
\end{tabular}

Tabla 5.2-1: Cantidades relativas de diferentes especies en los electrodos negativos analizados obtenidas por el ajuste de datos de Rietveld.

De la Tabla 5.2-1 se pueden extraer diferentes datos: i) se demuestra que una descarga total produce sólo $\mathrm{ZnO}$, aunque apareció una cantidad baja de Zn no oxidado; ii) al finalizar el proceso de recarga, sólo se observó $Z n$, con una pequeña cantidad de $\mathrm{ZnTf}_{2}$; y iii) $\mathrm{Zn}(\mathrm{OH})_{2}$ aparece sólo en estados intermedios de carga y descarga, siempre junto al $\mathrm{ZnO}$.

La aparición de picos de $\mathrm{Zn}(\mathrm{OH})_{2}$ en los estados intermedios de carga tanto en el proceso de carga como en el de descarga, y su eliminación cuando la descarga y la carga se llevaron a cabo por completo, puede asociarse a la formación de una película pre-pasiva de $\mathrm{Zn}(\mathrm{OH})_{2}$. Según varios investigadores durante la descarga se podría formar una película pre-pasiva de $\mathrm{Zn}(\mathrm{OH})_{2}$ a potenciales más altos, que se convierte en una película pasiva de $\mathrm{ZnO}$ a potenciales más catódicos. Así, en el electrodo totalmente descargado sólo se encontraron especies de $\mathrm{ZnO}$.

Durante la recarga, este proceso se invierte ya que en la recarga temprana, la película pasiva de $\mathrm{ZnO}$ se convierte en $\mathrm{Zn}(\mathrm{OH})_{2}$, antes de la reducción de $\mathrm{Zn}^{2+}$ a $\mathrm{Zn}$. Por lo tanto, en estados de recarga altos, tanto las películas de $\mathrm{ZnO}$ como las de $\mathrm{Zn}(\mathrm{OH})_{2}$ se eliminan completamente y sólo se obtiene $\mathrm{Zn}$ metálico. Aunque se ha encontrado la formación de $\mathrm{Zn}(\mathrm{OH})_{2}$ como especie intermedia, no puede descartarse la formación directa de $\mathrm{ZnO}$ durante la descarga y su reducción a Zn durante la recarga. 


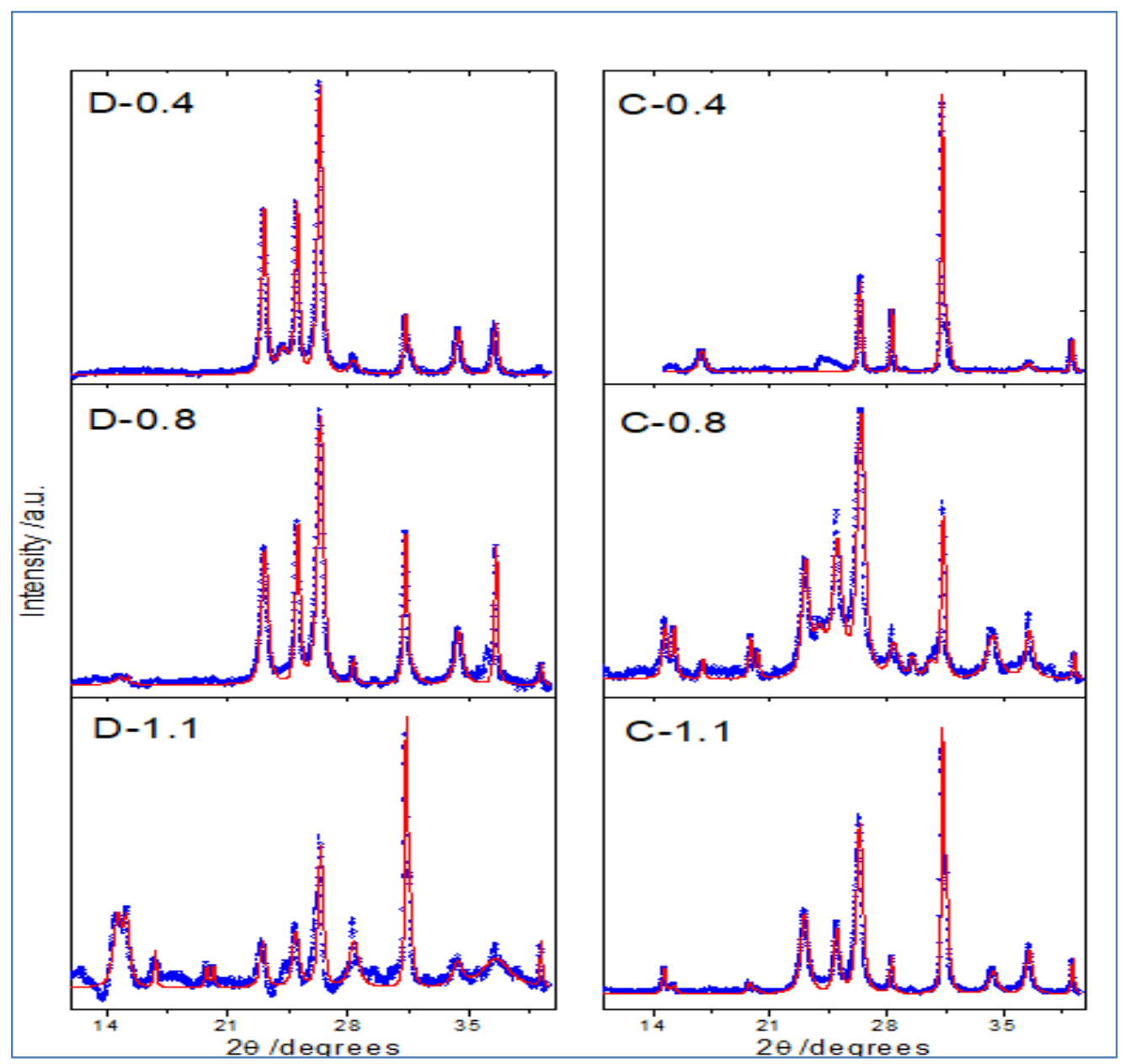

Figura 5.2-7: Comparación entre espectros de rayos $X$ experimentales (puntos azules) y los obtenidos por los refinamientos de Rietveld (líneas rojas). $\lambda=1.12701$ $\AA$.

En este punto, debemos recordar que las mediciones HAXPES señalaron una entrada masiva de aniones Triflato durante el proceso de recarga. En este sentido, hay que prestar atención a los dos picos observados en el difractograma C- 0.4 a valores $2 \theta$ de 8.5 y $24.5^{\circ}$. Estos picos pueden asignarse a la presencia de $\mathrm{ZnTf}_{2}$ dentro del electrodo negativo recargado, de acuerdo con la base de datos del ICDD (PDF-04-0140963). Por lo tanto, este resultado confirma la entrada de $\mathrm{ZnTf}_{2}$, probablemente disuelto con NMP dentro del electrodo de Zn durante el proceso de recarga. A partir del ajuste de datos de Rietveld, ZnTf 2 apareció para C-0.8 (9.4\%) y C-0.4 (18.2\%), indicando que si el proceso de recarga es más largo, la cantidad de ZnTf 2 que penetra en el electrodo negativo es mayor. 
La entrada de ZnTf2 y NMP durante el proceso de recarga se demuestra también con la espectroscopía ATR-FTIR. En la región 995-1055 cm-1 (Figura 5.2-8A) se observa una banda de $\sim 1027 \mathrm{~cm}^{-1}$, que corresponde al grupo $\mathrm{SO}_{3}$ de los aniones triflato. Una vez más, el pico correspondiente al electrodo totalmente cargado (C-0.4) es casi cuatro veces más intenso que el pico correspondiente al descargado (D-0.4). Este hecho indica una mayor cantidad de Triflato en el electrodo de $\mathrm{Zn}$ recargado, de acuerdo con una entrada masiva de $\mathrm{ZnTf}_{2}$ durante el proceso de carga. Además, un pico de $~ 1027$ $\mathrm{cm}^{-1}$ para C-0.8 (estado medio de carga) muestra una intensidad intermedia, mientras que este pico para D-0.8 es muy similar al obtenido para D-0.4, indicando que para cualquier capacidad de descarga una cantidad análoga de aniones Triflato entra en el electrodo negativo.

Además, se observa una banda correspondiente al grupo $\mathbf{C}=\mathbf{O}$ de NMP en la región 1530-1810 $\mathrm{cm}^{-1}$ (Figura 5.2-8B). Como se puede ver, esta banda se desplaza a frecuencias más bajas con respecto al NMP puro, lo que indica una interacción de este grupo con cationes $\mathrm{Zn}^{2+}$, tal y como fue reportado por nuestro grupo en trabajos anteriores. Una vez más, el electrodo C-0.4 muestra la intensidad máxima, seguido de C-0.8, y ambos tienen intensidades más altas que los observados para D-0.4 y D-0.8. Este hecho apunta a una alta absorción de moléculas de NMP dentro del electrodo negativo que acompaña a los aniones Triflato durante los procesos de recarga.

En este tipo de baterías se ha utilizado un electrolito basado en IL. Sin embargo, la formación de $\mathrm{ZnO}$ y $\mathrm{Zn}(\mathrm{OH})_{2}$ necesita una fuente de hidrógeno y oxígeno. Sabiendo que los experimentos se realizaron en atmósfera ambiente, la fuente más razonable de moléculas de agua presentes en el medio deben ser las absorbidas desde el aire por los GPE.

En este sentido, es importante señalar que el líquido iónico BMIMTf es miscible con agua. Aunque el contenido de agua del BMIMTf comercial es de $\approx 450$ ppm, según el proveedor, puede absorber agua en torno al 5\% del peso. 
Con el objetivo de aclarar la existencia de agua dentro del GPE, se han realizado dos experimentos adicionales. En primer lugar, hemos registrado un espectro ATRFTIR del GPE basado en BMIMTf, Figura 5.2-8C. En este espectro, el pico correspondiente a los grupos $\mathrm{OH}^{-}$se puede ver en la región 3200-3700 $\mathrm{cm}^{-1}$. De esta manera, se confirma la presencia de agua en este tipo de GPE. Otros picos se asignan a cadenas alifáticas $\left(\sim 2900 \mathrm{~cm}^{1}\right)$ y grupos de imidazolio $(\sim 3100 \mathrm{~cm} \cdot 1)$, como puede verse en el espectro del líquido iónico BMIMTf.

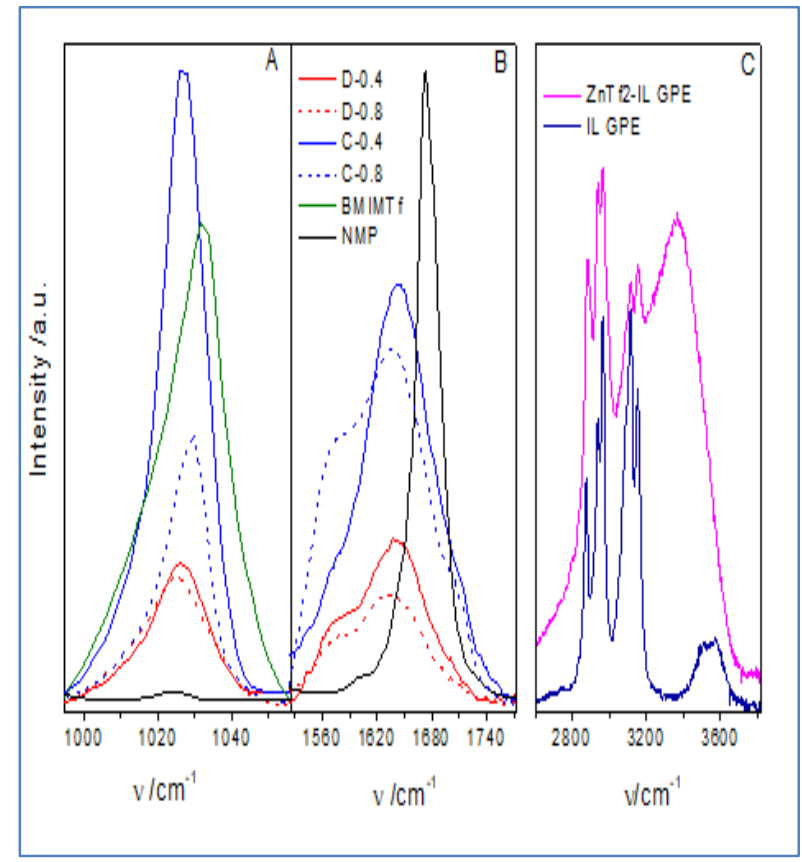

Figura 5.2-8: Espectros ATR-FTIR de A) SO3 y B) $C=O$ regiones del grupo de electrodos negativos de $\mathrm{Zn}$ cargados y descargados. Se han incluido como referencia los espectros BMIMTF y NMP. C) Espectros ATR-FTIR de la región del grupo $\mathrm{OH}$ del GPE basado en BMIMTf. El líquido iónico BMIMTf se muestra como referencia.

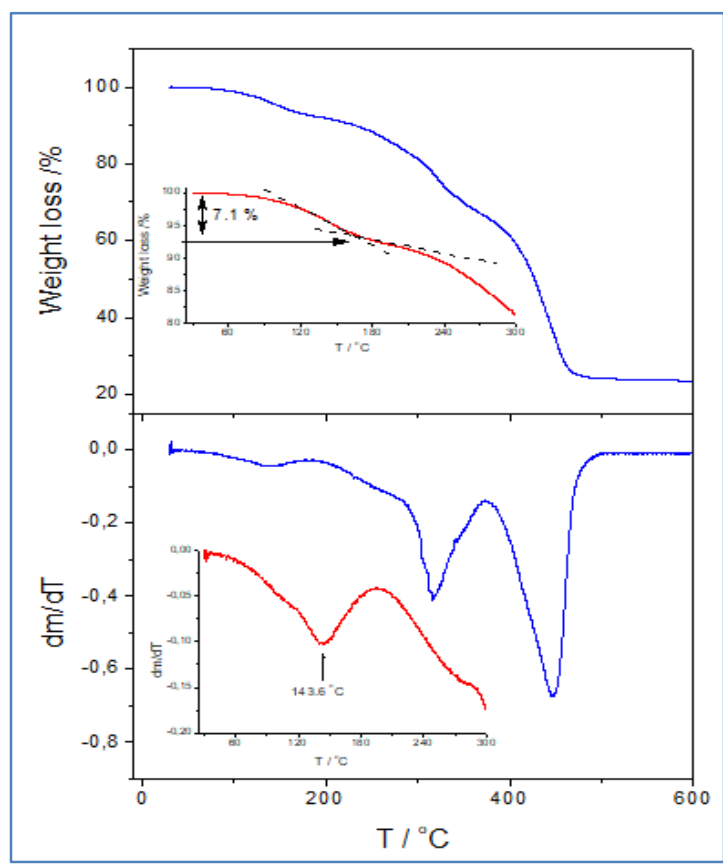

Figura 5.2-9: A) Curva TGA de GPE basado en BMIMTF. B) Curva derivada del análisis de TGA. Los recuadros muestran la región de temperatura donde se evapora el agua.

La Figura 5.2-9 muestra la curva TGA obtenida para un GPE basado en BMIMTf, donde se observa una pérdida de peso inicial de $50^{\circ} \mathrm{C}$ a $171^{\circ} \mathrm{C}$, señalada por la inflexión en la curva. Así, a $171^{\circ} \mathrm{C}$ se pierde un $7.1 \%$ del peso total, lo que corresponde a la cantidad de agua evaporada.

La derivada de la curva para el GPE también se muestra en la Figura 5.2-9B. En este caso, se observa un pico de $143.6^{\circ} \mathrm{C}$, que está asociado a la pérdida de agua. La 
integración de este pico proporciona un área total del 6.9\%, que es muy cercana a la obtenida a partir de la curva TGA de la Figura 5.2-9A.

Con el fin de determinar si esta cantidad de agua es suficiente para formar el total de especies de $\mathrm{ZnO}$ y $\mathrm{Zn}(\mathrm{OH})_{2}$ obtenidas durante los procesos de descarga, hemos realizado una estimación teórica de la cantidad de agua necesaria y concluido que, la cantidad de agua disponible en el GPE, 6.9\%, es suficiente para formar todas las especies $\mathrm{ZnO}$ y $\mathrm{Zn}(\mathrm{OH})_{2}$ detectadas en este estudio.

\subsection{Conclusiones.}

Los electrodos negativos descargados y recargados en una batería de $\mathrm{Zn} / \mathrm{IL}$ GPE/ $\mathrm{MnO}_{2}$ han sido estudiados por HAXPES, Sincrotrón XRD y XPS convencional. Durante el proceso de descarga, la formación de $\mathrm{Zn}(\mathrm{OH})_{2}$ en estados intermedios de carga se ha evidenciado previamente a la formación de la película de ZnO. Durante la carga, la película pasiva de $\mathrm{ZnO}$ se transforma para formar una película de $\mathrm{Zn}(\mathrm{OH})_{2}$, que se destruirá al mismo tiempo que $\mathrm{Zn}^{2+}$ se reduce a $\mathrm{Zn}$ metálico. Aunque en este tipo de baterías se ha utilizado un electrolito basado en IL libre de agua, las moléculas de vapor de $\mathrm{H}_{2} \mathrm{O}$ tienen que penetrar en el interior del electrolito durante los procesos de descarga y recarga, haciendo posible la formación de especies de $\mathrm{ZnO}$ y $\mathrm{Zn}(\mathrm{OH})_{2}$. $\mathrm{La}$ existencia de moléculas de agua dentro del GPE ha sido demostrada por mediciones de TGA y ATR-FTIR.

Además, las mediciones HAXPES, XRD y ATR-FTIR demuestran que el movimiento de los cationes $\mathrm{Zn}^{2+}$ hacia el electrodo negativo está acompañado por aniones Triflato y moléculas NMP del electrolito durante el proceso de carga. En consecuencia, proponemos el siguiente mecanismo para los procesos de descarga y carga, Figura 5.3-1.

Durante la descarga, se formó una película pasiva de $\mathrm{ZnO}$ directamente o formando una película pre-pasiva de $\mathrm{Zn}(\mathrm{OH})_{2}$. Por el contrario, durante el proceso de carga, la película pasiva de $\mathrm{ZnO}$ se destruía formando $\mathrm{Zn}$ metálico directamente, o formando previamente una película de $\mathrm{Zn}(\mathrm{OH})_{2}$. Además, la entrada de aniones Triflato y moléculas NMP ocurrirá durante el proceso de carga. 


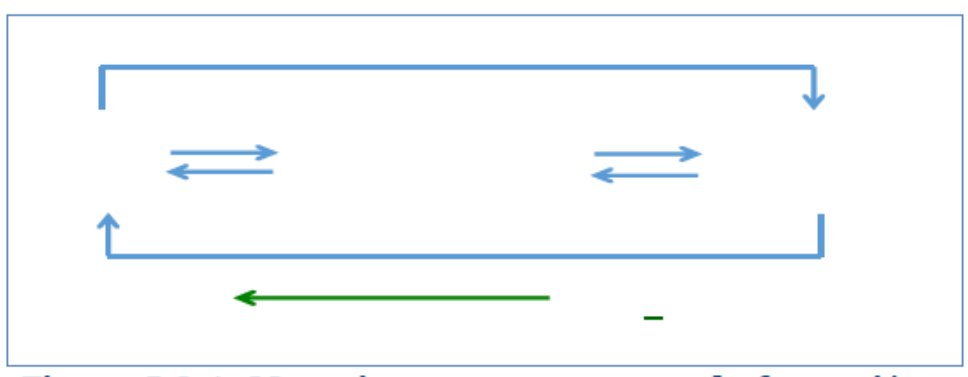

Figura 5.3-1: Mecanismo propuesto para la formación y destrucción de especies de $\mathrm{Zn}$ en el electrodo negativo durante los procesos de descarga y carga.

Las dos vías reversibles propuestas en el esquema son obligatorias porque hemos observado especies de $\mathrm{ZnO}$ y $\mathrm{Zn}(\mathrm{OH})_{2}$ en estados intermedios, pero sólo se obtuvo ZnO durante una descarga completa y sólo Zn apareció en una recarga total. Por lo tanto, está claro que existe una conversión de $\mathrm{Zn}-\mathrm{ZnO}$ mediante la formación de $\mathrm{Zn}(\mathrm{OH})_{2}$, sin embargo no podemos descartar una conversión directa de $\mathrm{Zn}-\mathrm{ZnO}$. Para resolver esta cuestión se debe realizar un estudio de XRD "in-operando" durante los procesos de descarga y recarga. 


\section{In Situ Synchrotron X-Ray Diffraction Study of $\mathrm{Zn} / \mathrm{Bi}_{2} \mathrm{O}_{3}$ Electrodes Prior to and during Discharge of Zn-Air Batteries: Influence on ZnO Deposition.}

Santos, F.; Abad, J.; Vila, M.; Castro, G. R.; Urbina, A.; Fernández Romero, A. J. Electrochim. Acta 2018, 281, 133-141. https://doi.org/10.1016/i.electacta.2018.05.138.

"Chemistry ought to be not for chemists alone." 



\section{RESUMEN}

Electrodos basados en $\mathrm{Zn}$ con diferentes cantidades de $\mathrm{Bi}_{2} \mathrm{O}_{3}$ han sido analizados mediante XRD con radiación sincrotrón durante el proceso de descarga de una batería real de $\mathrm{Zn}$-aire. $\mathrm{Bi}_{2} \mathrm{O}_{3}$ se detecta claramente para electrodos prístinos basados en $\mathrm{Zn}-\mathrm{Bi}_{2} \mathrm{O}_{3}$. Sin embargo, la inmersión de los electrodos de $\mathrm{Zn}-\mathrm{Bi}_{2} \mathrm{O}_{3}$ en solución de $6 \mathrm{M} \mathrm{KOH}$ antes de iniciar la descarga provoca la desaparición de la señal XRD debida al $\mathrm{Bi}_{2} \mathrm{O}_{3}$ en el difractograma y la aparición de nuevos picos que indican la presencia de Bi metálico. Este comportamiento, junto con las mediciones de tensión a circuito abierto, apunta a una reducción espontánea de $\mathrm{Bi}^{3+}$ a $\mathbf{B i}$ metálico por la oxidación de $\mathrm{Zn}$ a $\mathrm{Zn}^{2+}$. Independientemente de la cantidad de $\mathrm{Bi}_{2} \mathrm{O}_{3}$ presente en los electrodos negativos, los picos de Zn XRD disminuyen a medida que avanza la descarga. Sin embargo, la cantidad inicial de $\mathrm{Bi}_{2} \mathrm{O}_{3}$ afecta claramente a los picos de $\mathrm{ZnO}$ y Bi metal. Los picos de $\mathrm{ZnO}$ se observan sólo para los electrodos $\sin \mathrm{Bi}_{2} \mathrm{O}_{3}$ o aquellos que contienen $6 \%$ de $\mathrm{Bi}_{2} \mathrm{O}_{3}$. Por el contrario, los picos de $\mathrm{ZnO}$ no aparecen en los difractogramas XRD obtenidos para mayores cantidades de electrodos de $\mathrm{Bi}_{2} \mathrm{O}_{3}$. Además, en este caso se observan picos de Bi metálico durante todos los procesos de descarga, lo que indica que el Bi permaneció en el electrodo. Por último, los estudios SEM y EDX apoyan estas conclusiones.

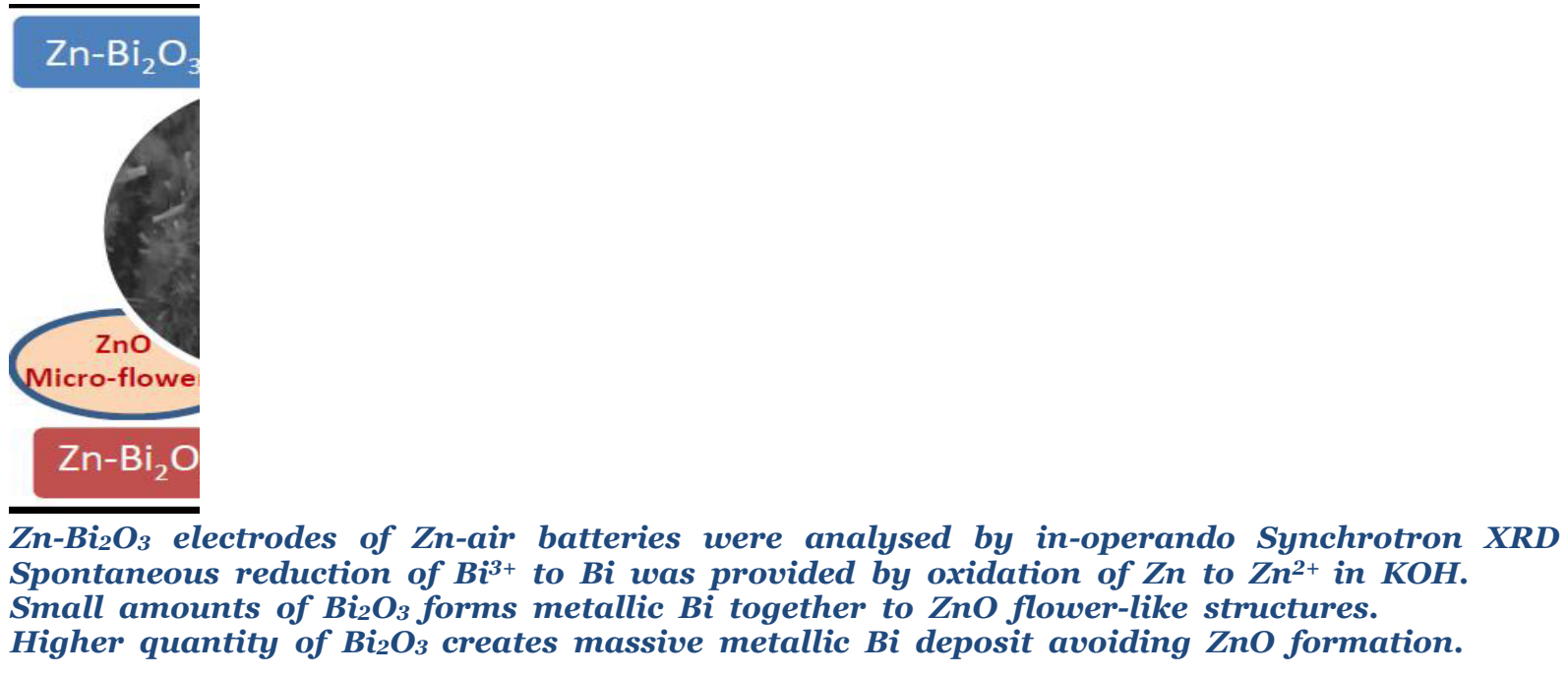




\subsection{Introducción.}

Como se ha comentado en capítulos anteriores, los electrodos de zinc tienen varios problemas como la pasivación del ánodo, el crecimiento dendrítico, la evolución de $\mathrm{H}_{2}$, etc. Estos hechos no han permitido la fabricación de baterías recargables a base de $\mathrm{Zn}$ con propiedades aceptables para ser comercializadas.

Con el objetivo de resolver estos inconvenientes, se han propuesto diferentes soluciones, como el uso de electrolitos poliméricos, líquidos iónicos, el aumento de la superficie del electrodo de zinc, o el empleo de diferentes aditivos incorporados tanto al electrodo negativo como al electrolito. En este sentido, diferentes metales puros, óxidos e hidróxidos metálicos o compuestos orgánicos, como los tensioactivos, han sido probados como aditivos para mejorar el rendimiento de las baterías a base de $\mathrm{Zn}$.

Entre los aditivos utilizados en las baterías a base de Zn, las especies de bismuto han llamado mucho la atención en las últimas décadas. $\mathrm{Bi}_{2} \mathrm{O}_{3} \mathrm{u}$ otros compuestos basados en Bi se han incorporado directamente al electrodo negativo o se han añadido al electrolito para mejorar la estabilidad cíclica, suprimir el crecimiento dendrítico, disminuir la evolución del hidrógeno y mejorar la capacidad de descarga de los electrodos basados en zinc. Además, Bi metálico ha sido incluido en los electrodos de zinc mejorando la conductividad electrónica, el rendimiento en la utilización del zinc así como disminuyendo la evolución del $\mathrm{H}_{2}$ y la corrosión de los electrodos

Hasta ahora, las mediciones in-operando apenas se han utilizado para analizar el mecanismo de reacción que se produce en los electrodos basados en $\mathrm{Zn}$

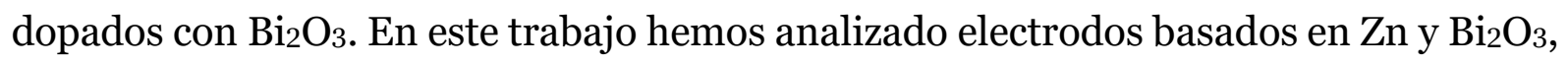
mediante XRD con radiación sincrotrón durante la descarga de una batería de Zn-aire real en condiciones in-operando. Además, hemos estudiado la reducción espontánea de $\mathrm{Bi}_{2} \mathrm{O}_{3}$ a Bi metálico. En consecuencia, hemos observado Bi metálico depositado en el interior del electrodo de $\mathrm{Zn}$ antes del inicio del proceso de descarga, sin que la corriente fluya. Por último, mediciones adicionales, como tensión en circuito abierto (OCV), XRD ex situ, espectroscopía Raman y la microscopía electrónica de barrido (SEM) con análisis EDX, han confirmado la formación espontánea de Bi metálico antes de la descarga. 


\subsection{Resultados.}

En este trabajo se utilizó una celda electroquímica "casera" para realizar las mediciones XRD in-operando con radiación sincrotrón. La Figura 6.2-1 muestra la celda situada en el portamuestras XRD de la línea de haz BM25 del sincrotrón ESRF así como una esquema de dicha celda.

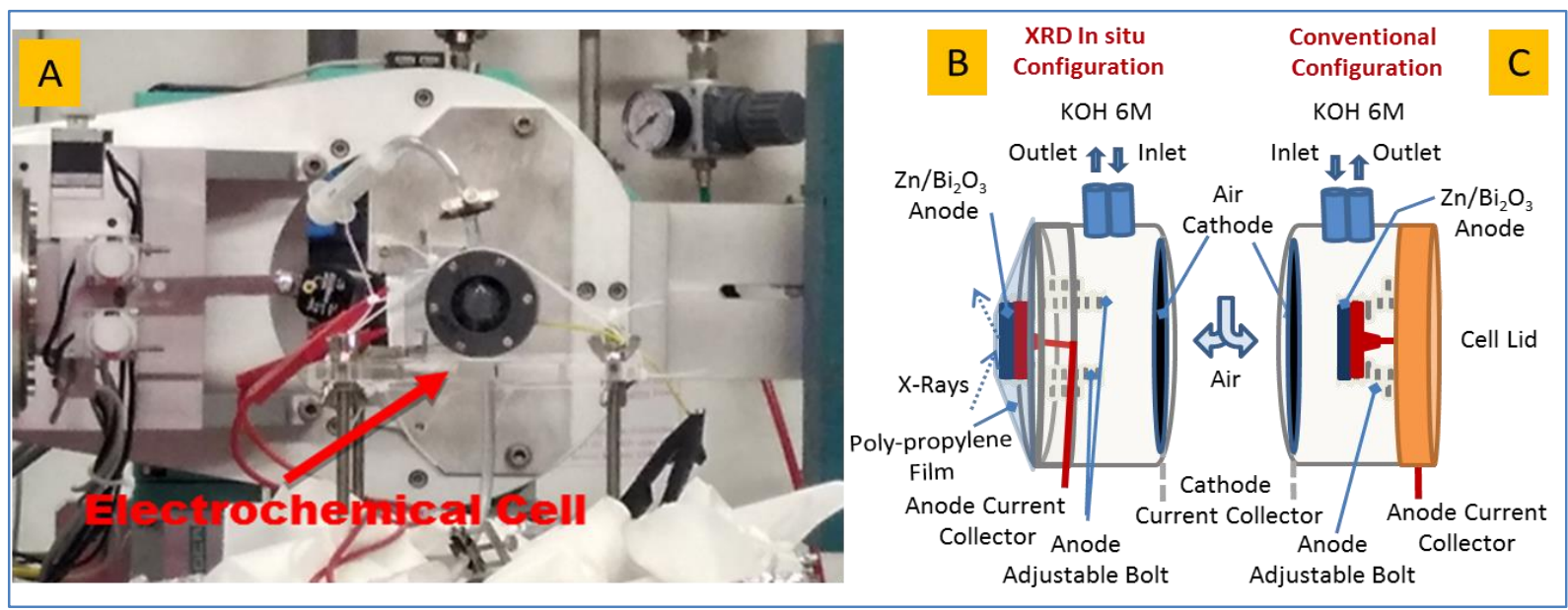

Figura 6.2-1: Celda Electroquímica situada en el portamuestras del difractómetro de rayos $X$ en la línea de haz BM-25 del sincrotrón ESRF. B) Esquema de la celda electroquímica utilizada en las mediciones de XRD del sincrotrón. C) Configuración de la misma celda electroquímica donde ambos electrodos estaban orientados el uno hacia el otro para realizar descargas convencionales y mediciones de OCV.

Se han obtenido difractogramas in-operando de diferentes electrodos negativos antes de iniciar la descarga de la batería de Zn-aire. La Figura 6.2-2 compara los difractogramas obtenidos para las muestras de referencia puras de $\mathrm{Bi}_{2} \mathrm{O}_{3}$ y $\mathrm{Zn}-\mathrm{Bi}_{2} \mathrm{O}_{3}$, realizadas al aire, con muestras de $\mathrm{Zn}-\mathrm{Bi}_{2} \mathrm{O}_{3}$ que contienen $6 \%, 12 \%$ y $25 \%$ de $\mathrm{Bi}_{2} \mathrm{O}_{3}$, las cuales fueron sumergidas en electrolitos de KOH 6M (sin aplicar ninguna tensión).

Como se puede ver, el difractograma de $\mathrm{Bi}_{2} \mathrm{O}_{3}$ está de acuerdo con los datos de la referencia PDF-04-015-6851 del International Center for Diffraction Data (ICDD) (líneas negras). Además, la muestra de $\mathrm{Zn}-\mathrm{Bi}_{2} \mathrm{O}_{3}$ al aire mantiene las bandas relacionadas con $\mathrm{Bi}_{2} \mathrm{O}_{3}$ junto con las debidas al $\mathrm{Zn}$ metálico (las líneas azules corresponden a Zn, PDF-00-004-0831). Por el contrario, cuando una muestra de Zn$\mathrm{Bi}_{2} \mathrm{O}_{3}(6 \%)$ se sumergió en una solución de $6 \mathrm{M} \mathrm{KOH}$, se observaron cambios evidentes. Los picos de $\mathrm{Bi}_{2} \mathrm{O}_{3}$ a $27.9^{\circ}, 31.7^{\circ}, 32.7^{\circ}$ y $46.1^{\circ}$ desaparecen y aparecen nuevas bandas 
a $27.2^{\circ}, 38.0^{\circ}, 39.6^{\circ}, 44.6^{\circ}, 46.0^{\circ}$ y $48.7^{\circ}$. Estas nuevas bandas pueden ser asignadas a Bi metálico, de acuerdo con PDF-04-006-7762 (líneas rojas). Además, las bandas a $31.7^{\circ}, 34.4^{\circ}$ y $47.6^{\circ}$ se atribuyen a la formación de $\mathrm{ZnO}$ (las líneas verdes representan la referencia PDF-00-036-1451, confirmando que parte de $\mathrm{Zn}$ ha sido oxidada a $\mathrm{Zn}^{2+}$ ).

Sin embargo, debemos destacar que, en nuestro caso, hemos observado picos de Bi metálico sin aplicar voltaje alguno aunque nuestros electrodos están compuestos de $\mathrm{Bi}_{2} \mathrm{O}_{3}$ y $\mathrm{Zn}$ metálico. Por lo tanto, este resultado sugiere que la reducción de $\mathrm{Bi}^{3+}$ tiene que ser debida a la oxidación simultánea de $\mathrm{Zn}$ a $\mathrm{Zn}^{2+}$. El potencial redox normal de $\mathrm{Zn}^{2+} / \mathrm{Zn}$ es lo suficientemente negativo como para reducir $\mathrm{Bi}^{3+}$ a $\mathrm{Bi}$, y por lo tanto, este resultado puede indicar un proceso redox espontáneo. Se puede proponer la siguiente reacción global:

$$
\mathrm{Bi}_{2} \mathrm{O}_{3}+3 \mathrm{Zn}+3 \mathrm{H}_{2} \mathrm{O} \rightarrow 2 \mathrm{Bi}+3 \mathrm{Zn}^{2+}+6 \mathrm{H}^{-}
$$

Por otro lado, cuando los electrodos de $\mathrm{Zn}-\mathrm{Bi}_{2} \mathrm{O}_{3}$ con mayor cantidad de $\mathrm{Bi}_{2} \mathrm{O}_{3}$ (12\% y 25\%) se sumergen en la solución 6M KOH, vuelven a aparecer picos de $\mathrm{Bi}$ metálicos mientras que los de $\mathrm{Bi}_{2} \mathrm{O}_{3}$ desaparecen. Sin embargo, se observa un cambio claro con respecto al $\mathrm{Zn}-\mathrm{Bi}_{2} \mathrm{O}_{3} 6 \%$ (Figura 6.2-2B): Los picos de $\mathrm{ZnO}$ nunca se observan en los difractogramas XRD de los electrodos con $12 \%$ y $25 \%$ de $\mathrm{Bi}_{2} \mathrm{O}_{3}$.

Con el objetivo de investigar la evolución de los electrodos de $\mathrm{Zn}-\mathrm{Bi}_{2} \mathrm{O}_{3}$ cuando se sumergen en una solución de $6 \mathrm{M} \mathrm{KOH}$, hemos realizado una serie de mediciones de tensión en circuito abierto (OCV). Para ello, hemos utilizado la celda electroquímica de la Figura 1C, pero comenzamos a registrar el voltaje antes de añadir la solución de $\mathrm{KOH}$. Como consecuencia, podemos observar la evolución del voltaje desde el principio, como se muestra en la Figura 6.2-3.

Las mediciones de OCV se registraron durante 24 horas para los electrodos de $\mathrm{Zn}$ puro y los tres de composición $\mathrm{Zn}-\mathrm{Bi}_{2} \mathrm{O}_{3}$. Para todos los experimentos, se observan aumentos bruscos de potencial, inmediatamente después de la incorporación de la solución a la celda, hasta que se alcanza un potencial estable cercano a $1.5 \mathrm{~V}$ que se mantiene hasta el final de la medición (Figura 6.2-3C). Sin embargo, prestando 
atención al cambio de potencial, un aumento instantáneo real es claro sólo para el electrodo de Zn puro.

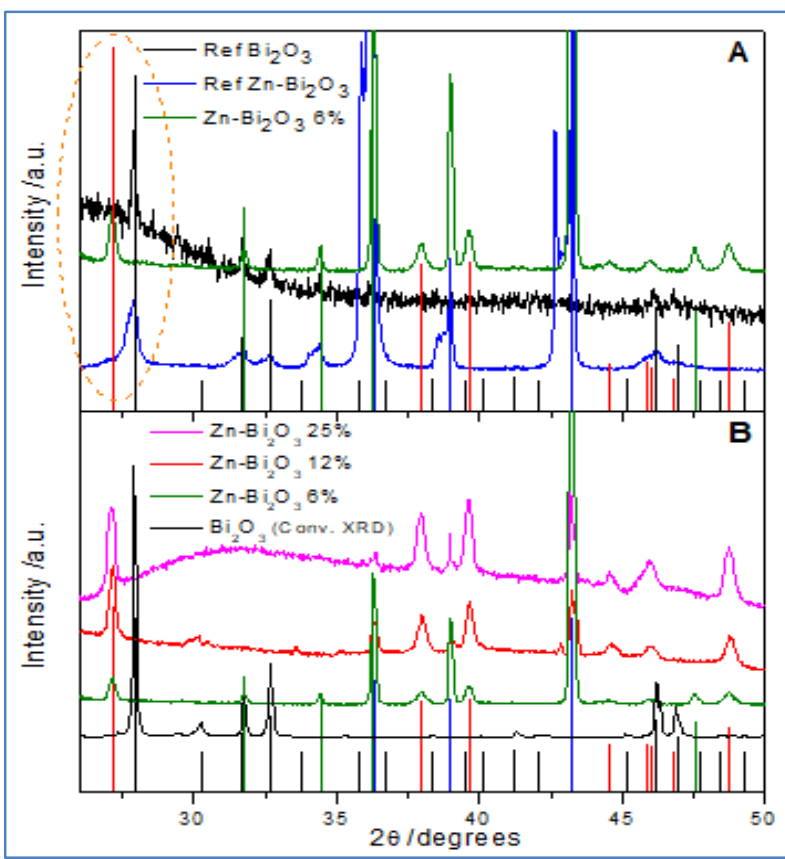

Figura 6.2-2: A) Difractogramas XRD de sincrotrón de muestras de referencia de $\mathrm{Bi}_{2} \mathrm{O}_{3} y$ $\mathrm{Zn}-\mathrm{Bi}_{2} \mathrm{O}_{3}$ comparados con un $\mathrm{Zn}-\mathrm{Bi}_{2} \mathrm{O}_{3} \quad 6 \%$ sumergido en solución de $\mathrm{KOH}$ antes de iniciar la descarga de la batería. B) Difractogramas $X R D$ de sincrotrón de muestras de $\mathrm{Zn}-\mathrm{Bi}_{2} \mathrm{O}_{3}$ con diferentes cantidades de $\mathrm{Bi}_{2} \mathrm{O}_{3}(6 \%, 12 \%$ y 25\%) sumergidas en solución de $\mathrm{KOH}$ antes de iniciar la descarga de la batería.

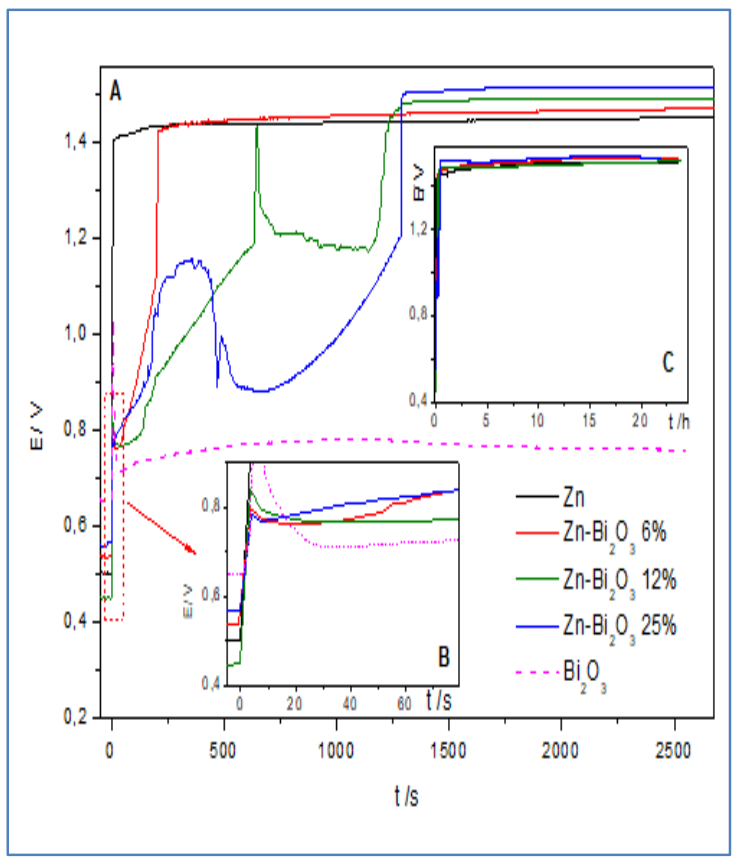

Figura 6.2-3: Evolución del voltaje a circuito abierto (OCV) registradas para los electrodos negativos $\mathrm{Zn}-\mathrm{Bi}_{2} \mathrm{O}_{3}$ en tres rangos de tiempo diferentes. Se ha incluido la curva $\mathrm{OCV}$ de $\mathrm{Bi}_{2} \mathrm{O}_{3}$ puro para comparar. Electrolito: 6M КОН en agua.

Por el contrario, para todas las muestras que contienen $\mathrm{Bi}_{2} \mathrm{O}_{3}$, después del aumento inicial, el potencial disminuye y aparece un pico bien definido, como puede observarse en la Figura 6.2-3B. Posteriormente a la formación de este pico, el potencial aumentó lentamente, a veces con un comportamiento errático, hasta alcanzar un potencial estable cercano a $1.5 \mathrm{~V}$. Además, como puede verse en la Figura 6.2-3A, el tiempo necesario para alcanzar el potencial estable es mayor cuanto mayor es la cantidad de $\mathrm{Bi}_{2} \mathrm{O}_{3}$ dentro del electrodo negativo.

Estas mediciones de OCV están de acuerdo con la reacción redox global (1). Cuando se utiliza un electrodo negativo de $\mathrm{Zn}$ puro, el potencial estable se alcanza inmediatamente, sin embargo la presencia de $\mathrm{Bi}_{2} \mathrm{O}_{3}$ ralentiza este proceso debido a la 
oxidación de $\mathrm{Zn}$ metálico a $\mathrm{Zn}^{2+}$, reduciendo así $\mathrm{Bi}^{3+}$ a Bi metálico. Mientras ocurre este proceso espontáneo, no hay una superficie de Zn estable en contacto con el electrolito y, por lo tanto, no se alcanza un potencial estable del par Zn-aire manteniendo las condiciones OCV. Además, este proceso redox será más largo cuando se incluya una mayor cantidad de $\mathrm{Bi}^{3+}$ en el electrodo.

Por otro lado, para verificar la presencia de Bi metálico después del OCV, hemos realizado mediciones adicionales mediante espectroscopía Raman. Los espectros Raman de una muestra de $\mathrm{Bi}_{2} \mathrm{O}_{3}$ y de una de $\mathrm{Zn}-\mathrm{Bi}_{2} \mathrm{O}_{3}$ al $25 \%$, después de 24 horas de proceso OCV, se muestran en el recuadro de la Figura 6.2-4. El espectro de la muestra de $\mathrm{Bi}_{2} \mathrm{O}_{3}$, muestra las bandas típicas asignadas a $\mathrm{Bi}_{2} \mathrm{O}_{3}$. Sin embargo, después de OCV, el espectro Raman de $\mathrm{Zn}-\mathrm{Bi}_{2} \mathrm{O}_{3}$ muestra dos picos de alta intensidad a 67 y $94 \mathrm{~cm}^{-1}$, que han sido asignados frecuentemente al Bi metálico.

Además, hemos realizado una serie de mediciones ex-situ de XRD en un difractómetro XRD convencional. Los difractogramas XRD de los electrodos recién preparados de $\mathrm{Zn}, \mathrm{Zn}-\mathrm{Bi}_{2} \mathrm{O}_{3} 6 \%$ y Zn- $\mathrm{Bi}_{2} \mathrm{O}_{3} 25 \%$ se muestran en la Figura 6.2-4, donde se comparan con los difractogramas de $\mathrm{Zn}-\mathrm{Bi}_{2} \mathrm{O}_{3} 6 \%$ y $25 \%$ de los electrodos sometidos a pruebas de OCV durante $24 \mathrm{~h}$ en solución de $6 \mathrm{M} \mathrm{KOH}$.

Como se puede ver, los difractogramas de todos los electrodos sin sumergir en $\mathrm{KOH}$ muestran picos de $\mathrm{Zn}$ y $\mathrm{ZnO}$, mientras que los que incluyen $\mathrm{Bi}_{2} \mathrm{O}_{3}$ muestran también los picos asignados a $\mathrm{Bi}_{2} \mathrm{O}_{3}$, pero ninguno de los atribuidos a Bi metálico. Por lo tanto, este resultado es coherente con los obtenidos por el sincrotrón XRD para los electrodos de referencia $\mathrm{Zn}$ y $\mathrm{Zn}-\mathrm{Bi}_{2} \mathrm{O}_{3}$.

Con respecto a los electrodos de $\mathrm{Zn}-\mathrm{Bi}_{2} \mathrm{O}_{3}$ sometidos a procesos $\mathrm{OCV}$, se observa una vez más un comportamiento diferente para el electrodo que contiene $\mathrm{Bi}_{2} \mathrm{O}_{3}$ del $6 \%$ con respecto al que contiene el 25\% (Figura 6.2-4A). El difractograma $\mathrm{Zn}-\mathrm{Bi}_{2} \mathrm{O}_{3} 6 \%$ presenta sólo los picos de $\mathrm{ZnO}$, pero no se observan picos debidos a $\mathrm{Zn}, \mathrm{Bi}_{2} \mathrm{O}_{3}$ o $\mathrm{Bi}$ metálico. En cuanto al $\mathrm{Zn}-\mathrm{Bi}_{2} \mathrm{O}_{3} 25 \%$, el difractograma muestra principalmente picos correspondientes a $\mathrm{Bi}$ metálico y algunos picos pequeños correspondientes a $\mathrm{Bi}_{2} \mathrm{O}_{3}$, en cambio los picos de $\mathrm{ZnO}$ no aparecen en este difractograma. 


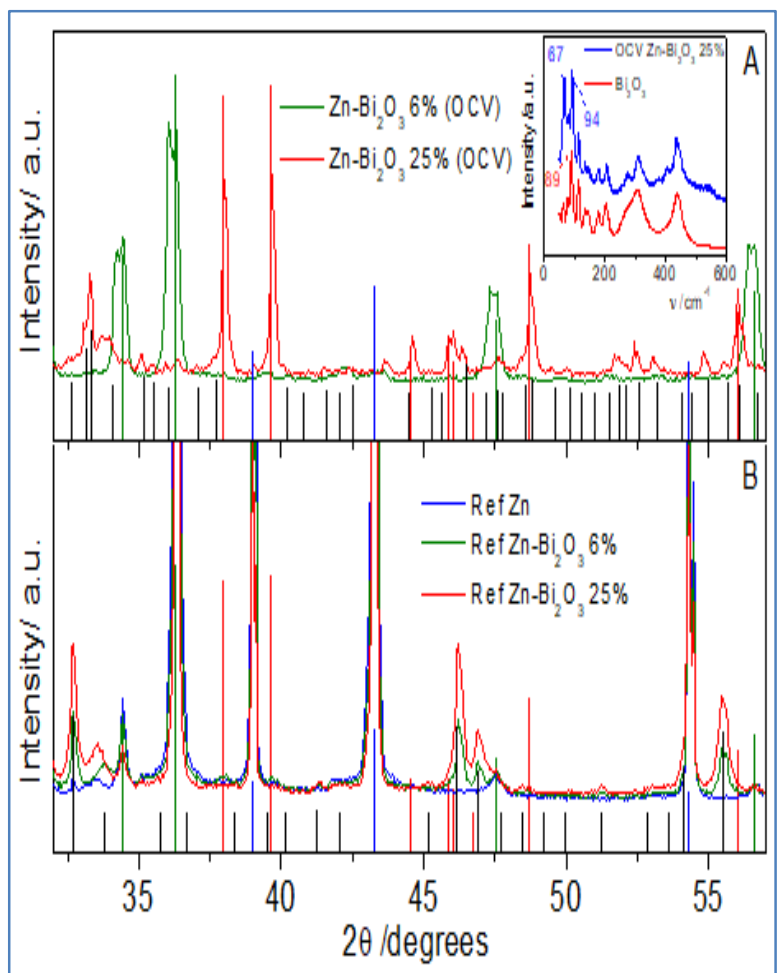

Figura 6.2-4: A) Difractogramas de XRD convencional de $\mathrm{Zn}-\mathrm{Bi}_{2} \mathrm{O}_{3} 6 \%$ y $25 \%$ después de 24 horas a OCV en solución de $6 \mathrm{M} \mathrm{KOH.} \mathrm{B)}$ Difractogramas de XRD convencional de muestras de $\mathrm{Zn}$ y $\mathrm{Zn}-\mathrm{Bi}_{2} \mathrm{O}_{3}$ con diferente cantidad de $\mathrm{Bi}_{2} \mathrm{O}_{3}$. Las líneas verticales muestran los mismos PDF mostrados en la Figura 6.2-2, excepto en $A$, donde el PDF- 01$072-0398$ se muestra para $\mathrm{Bi}_{2} \mathrm{O}_{3}: \mathrm{Zn}$ (azul), $\mathrm{ZnO}$ (verde), $\mathrm{Bi}_{2} \mathrm{O}_{3}$ (negro) y $\mathrm{Bi}$ (rojo). Recuadro: Espectros Raman de $\mathrm{Bi}_{2} \mathrm{O}_{3}$ prístino y $\mathrm{Zn}_{-} \mathrm{Bi}_{2} \mathrm{O}_{3} 25 \%$ sometido a un proceso $\mathrm{OCV}$ de $24 \mathrm{~h}$.

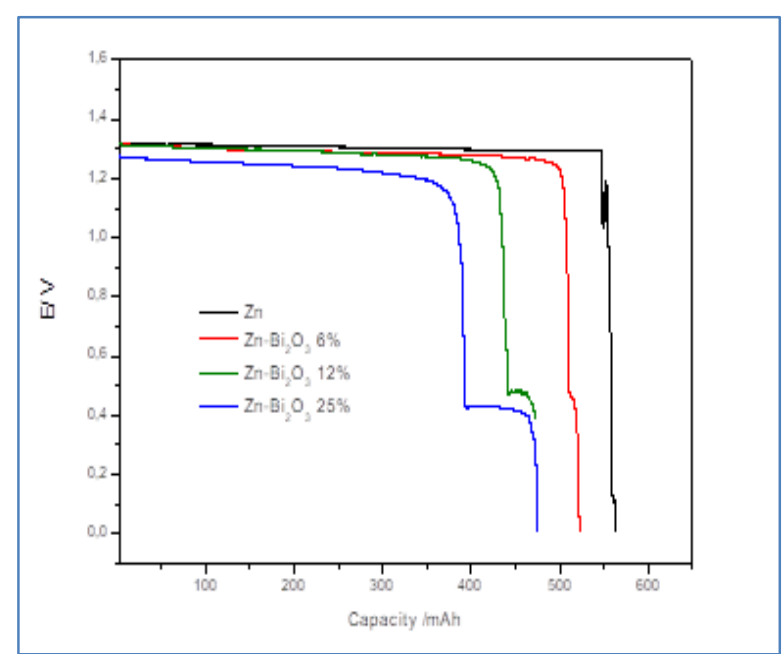

Figura 6.2-5: Curvas de descarga obtenidas para baterías de Zn-aire utilizando $\mathrm{Zn}$ puro o $\mathrm{Zn}-\mathrm{Bi}_{2} \mathrm{O}_{3} 6 \%, 12 \%$ y $25 \%$, como electrodos negativos.

\begin{tabular}{ccccccc}
\hline $\begin{array}{c}\mathrm{Bi}_{2} 0_{3} / \\
\text { wt.\% }\end{array}$ & $\begin{array}{c}\mathrm{m}_{\mathrm{el}} \\
/ \mathrm{g}\end{array}$ & $\begin{array}{c}\mathrm{m}_{\mathrm{Bi2} 203} \\
/ \mathrm{g}\end{array}$ & $\begin{array}{c}\mathrm{m}_{\mathrm{Zn}} \\
/ \mathrm{g}\end{array}$ & T.C. $/ \mathrm{mAh}$ & $\begin{array}{c}\text { E. C. } \\
/ \mathrm{mAh}\end{array}$ & $\begin{array}{c}\text { Zn Yield } \\
/ \text { wt. \% }\end{array}$ \\
\hline 0 & 0.881 & 0.000 & 0.881 & 722.6 & 559.0 & $77.3 \pm 0.1$ \\
6 & 0.897 & 0.054 & 0.843 & 672.8 & 509.0 & $73.5 \pm 1.9$ \\
12 & 0.910 & 0.109 & 0.801 & 619.0 & 437.0 & $74.0 \pm 1.0$ \\
25 & 0.901 & 0.225 & 0.676 & 476.4 & 390.0 & $84.3 \pm 3.0$ \\
\hline
\end{tabular}

Tabla 6.2-1: Composiciones de electrodos, capacidades de las baterías y rendimientos de Zn.

Además, a mayores cantidades de $\mathrm{Bi}_{2} \mathrm{O}_{3}$, este comportamiento apunta a la formación de un depósito masivo de Bi metálico, que parece impedir la deposición de $\mathrm{ZnO}$ en el electrodo.

Después de realizar las mediciones de OCV, cada una de las baterías de Zn-aire que utilizan $\mathrm{Zn}$ puro o diferentes electrodos de $\mathrm{Zn}-\mathrm{Bi}_{2} \mathrm{O}_{3}$ se descargaron completamente a una corriente constante de $-20 \mathrm{~mA}$, como se muestra en la Figura 6.2-5. Como se recoge en la Tabla 6.2-1, se mantuvo una masa constante del electrodo de $0.895 \pm 0.015 \mathrm{mg}$ para todas las muestras. Por consiguiente, cuanto mayor es el peso de $\mathrm{Bi}_{2} \mathrm{O}_{3}$, menor es la cantidad de zinc en el electrodo y, por lo tanto, los valores de 
capacidad obtenidos disminuyen con la menor cantidad de masa de $\mathrm{Zn}$ incluida en el electrodo negativo.

Además, se ha calculado el rendimiento de oxidación de Zn, Tabla 6.2-1. Los rendimientos de $\mathrm{Zn}$ para $\mathrm{Zn}-\mathrm{Bi}_{2} \mathrm{O}_{3}$ al $6 \%$ y al $12 \%$ son un poco inferiores al valor obtenido para los electrodos de $\mathrm{Zn}$ puro. Sin embargo, el rendimiento del $\mathrm{Zn}-\mathrm{Bi}_{2} \mathrm{O}_{3}$ $25 \%$ es mayor, alcanzando el $84.3 \pm 3.0 \%$ (este valor se ha obtenido teniendo en cuenta la cantidad de $\mathrm{Zn}$ gastada en la reducción de $\mathrm{Bi}^{3+}$ a Bi metálico). Este resultado indica que las reacciones secundarias que usan una fracción de Zn durante la descarga, como la de evolución del $\mathrm{H}_{2}$, se reduce debido a la presencia del Bi metálico en el electrodo negativo.

Cuatro tipos de electrodos basados en $\mathrm{Zn}$ que contienen diferentes cantidades de $\mathrm{Bi}_{2} \mathrm{O}_{3}$ han sido analizados in-operando por $X R D$ con radiación syncrotron durante el proceso de descarga de una batería alcalina real de Zn-aire.

Los difractogramas XRD obtenidos utilizando $\mathrm{Zn}$ puro como electrodo negativo se muestran en las Figura 6.2-6A y B. Como se puede ver, sólo se observan picos de $\mathrm{Zn}$ antes de iniciar la descarga (curva $\mathrm{t}=0$ ), que luego reducen sus intensidades durante el proceso de descarga. Además, cuando comienza la descarga, aparecen picos de $\mathrm{ZnO}$ debido a la oxidación de $\mathrm{Zn}$ a $\mathrm{Zn}^{2+}$ y la intensidad de los picos de $\mathrm{ZnO}$ aumenta a medida que avanza la descarga (6.2-6B).

Por otro lado, los difractogramas XRD de sincrotrón registrado para los electrodos negativos de $\mathrm{Zn}-\mathrm{Bi}_{2} \mathrm{O}_{3}$ muestran cambios evidentes debido a la presencia de $\mathrm{Bi}_{2} \mathrm{O}_{3}$ dentro del electrodo. Las Figuras 6.2-6A, D y E muestran los difractogramas de sincrotrón in-operando de un electrodo $\mathrm{Zn}-\mathrm{Bi}_{2} \mathrm{O}_{3}$ 6\% actuando como electrodo negativo, obtenidos durante la descarga de la batería de Zn-aire. Cabe señalar que en las mediciones de XRD del sincrotrón, la celda electroquímica se coloca en el goniómetro antes de la alineación de los rayos X. Por lo tanto, antes de iniciar la medición de la descarga, los electrodos ya están sumergidos en una solución de $6 \mathrm{M}$ $\mathrm{KOH}$ antes del proceso de descarga y la reacción (1) tendrá lugar. Es por esto, que se observan picos de Bi metálico desde el inicio de la medida. 


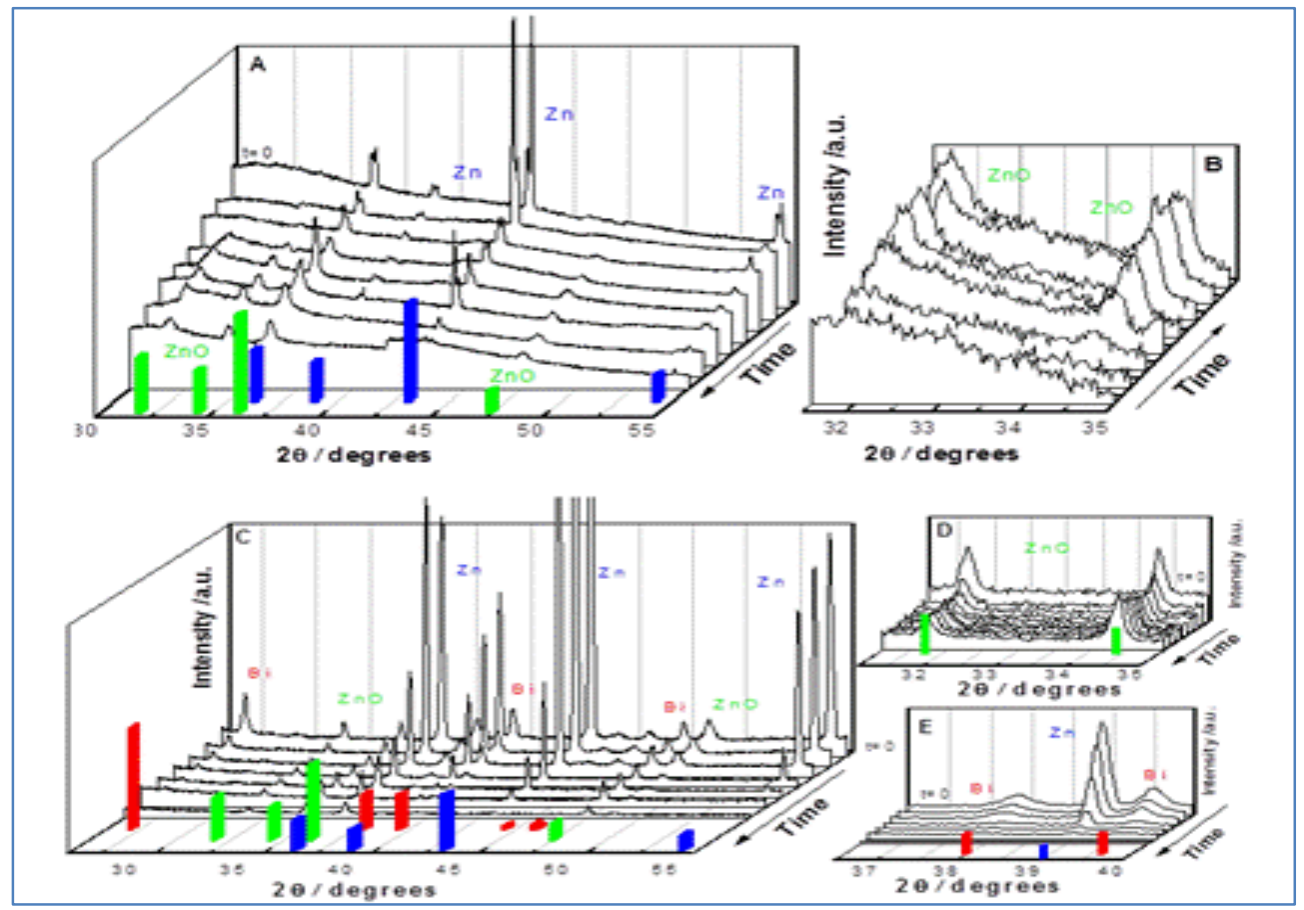

Figura 6.2-6: Difractogramas de XRD in-operando durante la descarga en diferentes rangos de electrodos de $\mathrm{Zn}$ puro $(\mathrm{A}$ y $\mathrm{B})$ y $\mathrm{Zn}-\mathrm{Bi}_{2} \mathrm{O}_{3} 6 \%(C, D$ y $E)$.

Coincidiendo con el difractograma XRD del electrodo negativo de Zn puro, observamos en la Figura 6.2-6C y D los picos correspondientes a Zn y ZnO. Además, también se observan nuevos picos debidos al Bi metálico desde el principio, aunque la intensidad de estos picos disminuye a medida que avanza la descarga, hasta desaparecer completamente al final de la misma (Figura 6.2-6C y E). Sin embargo, como era de esperar, los picos de $\mathrm{Bi}_{2} \mathrm{O}_{3}$ no aparecen en ningún difractograma, lo que confirma que los cationes $\mathrm{Bi}^{3+}$ se redujeron a Bi metálico.

Además, los picos de Zn disminuyen a medida que avanza la descarga, hasta ser completamente eliminados al final de la misma descarga, confirmando así que el Zn se oxidó a $\mathrm{Zn}^{2+}$. Finalmente, con respecto a los picos de $\mathrm{ZnO}$, éstos observan desde el principio hasta el final del proceso (Figura 6.2-6D).

Por el contrario, cuando se utilizan electrodos negativos con mayor cantidad de $\mathrm{Bi}_{2} \mathrm{O}_{3}$ (12\% o 25\%), se aprecian cambios importantes en los difractogramas de XRD con respecto a los resultados obtenidos para $\mathrm{Zn}-\mathrm{Bi}_{2} \mathrm{O}_{3}$ 6\% (Figura 6.2-7). Los difractogramas de sincrotrón XRD de un electrodo negativo al $12 \%$ de $\mathrm{Zn}-\mathrm{Bi}_{2} \mathrm{O}_{3}$, 
muestran de nuevo la disminución de los picos de $\mathrm{Zn}$ con el progreso de la descarga,

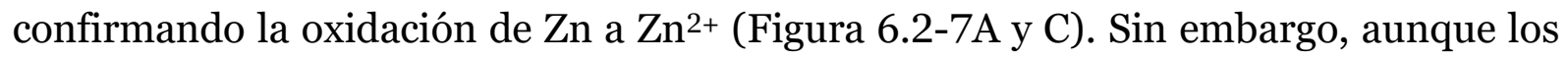
picos de Bi metálico aparecen de nuevo desde el principio, en este caso, estos picos aumentan en lugar de disminuir durante el proceso de descarga hasta alcanzar un estado estable (Figura 6.2-7A y C). Además, tampoco se observan picos de $\mathrm{Bi}_{2} \mathrm{O}_{3}$, lo que confirma la reducción de $\mathrm{Bi}^{3+}$ a Bi. Sorprendentemente, los picos de $\mathrm{ZnO}$ no se observan en ningún difractograma de XRD registrado para un electrodo negativo de $\mathrm{Zn}-\mathrm{Bi}_{2} \mathrm{O}_{3}$ al 12\% (Figura 6.2-7A y B).

$\mathrm{El}$ mismo comportamiento se encuentra para un electrodo negativo de $\mathrm{Zn}-\mathrm{Bi}_{2} \mathrm{O}_{3}$ al 25 \%: disminución de los picos de Zn, aumento de los picos de Bi metálicos desde el principio y en ningún caso se observan picos de $\mathrm{Bi}_{2} \mathrm{O}_{3}$ ni de $\mathrm{ZnO}$ durante la descarga completa (Figura 6.2-7D, E y F).

Ciertamente, la ausencia de picos de ZnO en los difractogramas XRD de sincrotrón es inesperada. La oxidación de $\mathrm{Zn}$ a $\mathrm{Zn}^{2+}$ se confirma por la disminución de los picos de Zn observados por las mediciones de XRD y por la curva de descarga obtenida simultáneamente con la adquisición de difractogramas de XRD de sincrotrón in-operando. En este sentido, normalmente se acepta que la oxidación del $\mathrm{Zn}$ como electrodo negativo de una pila alcalina acuosa sigue el siguiente mecanismo:

$$
\begin{aligned}
& \mathrm{Zn} \rightarrow \mathrm{Zn}^{2+}+2 \mathrm{e}^{-} \\
& \mathrm{Zn}^{2+}+4 \mathrm{OH}^{-} \leftrightarrows \mathrm{Zn}(\mathrm{OH})_{4}^{\overline{\bar{t}}}+2 e^{-} \\
& \mathrm{Zn}(\mathrm{OH})_{4}^{\overline{4}} \leftrightarrows \mathrm{ZnO}+\mathrm{H}_{2} \mathrm{O}+2 \mathrm{OH}^{-}
\end{aligned}
$$

Las reacciones (3) y (4) proceden hasta que la solubilidad del ión zincato, $\mathrm{Zn}(\mathrm{OH})_{4}^{2-}$, alcanza el punto de saturación en el electrolito alcalino. En este momento, el $\mathrm{ZnO}$ se deposita en el electrodo proporcionando cambios de forma y pasivando el electrodo negativo.

Podemos considerar que el punto de saturación de $\mathbf{Z n}(\mathbf{O H})_{4}{ }^{2-}$ no se alcanza durante las mediciones de XRD. Sin embargo, el ZnO sólo se observa para electrodos $\sin \mathrm{Bi}_{2} \mathrm{O}_{3}$ o con baja cantidad de $\mathrm{Bi}_{2} \mathrm{O}_{3}$. Por lo tanto, la ausencia de picos de $\mathrm{ZnO}$ cuando 
se incluyen mayores cantidades de $\mathrm{Bi}_{2} \mathrm{O}_{3}$ en el electrodo negativo tiene que estar relacionada con la formación de un depósito masivo de Bi metálico en el electrodo.

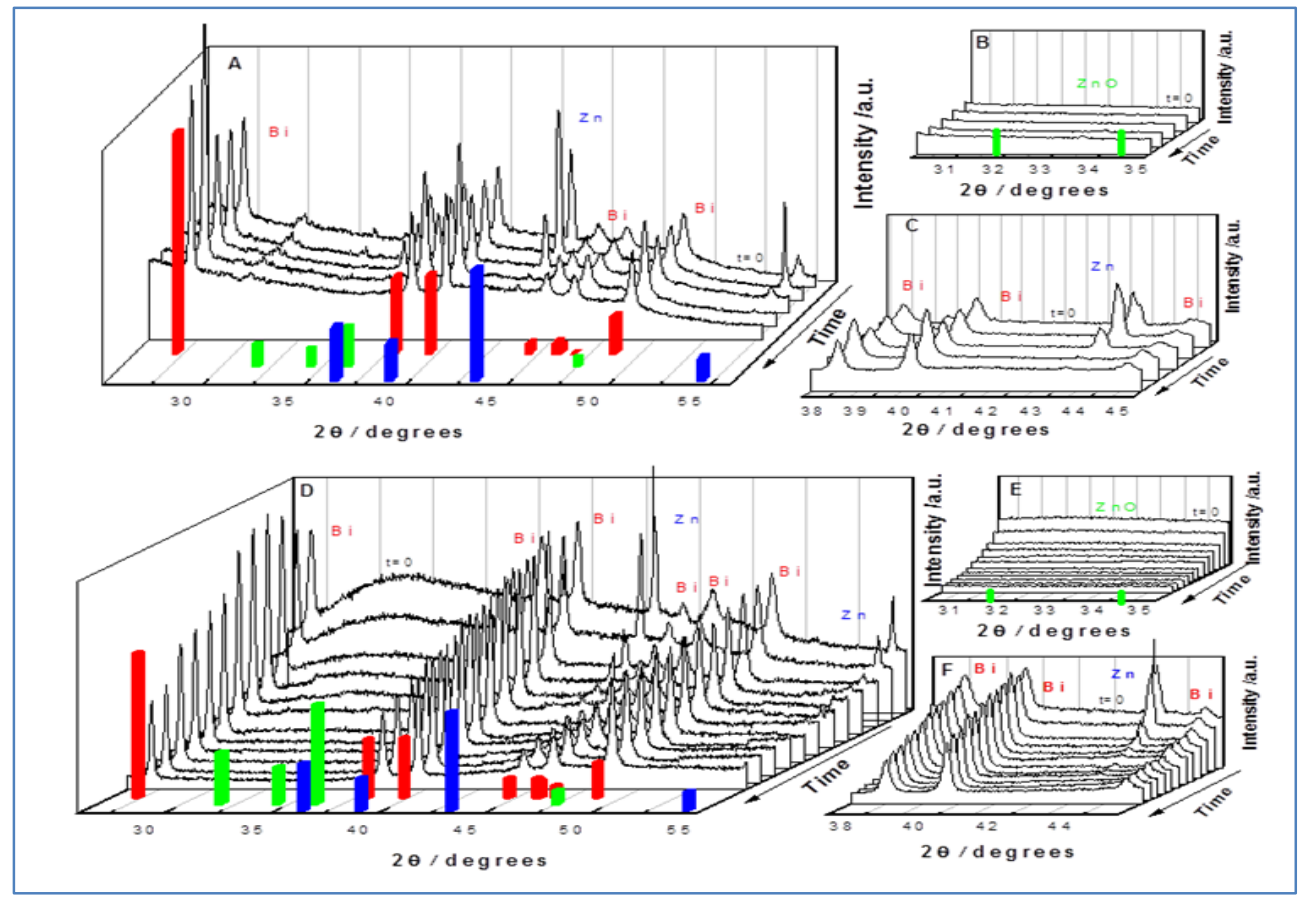

Figura 6.2-7: Difractogramas de XRD in-operando durante la descarga de electrodos negativos de $\left.\mathrm{Zn}-\mathrm{Bi}_{2} \mathrm{O}_{3} 12 \%, A\right), B$ ) y C) y $\mathrm{Zn}-\mathrm{Bi}_{2} \mathrm{O}_{3} 25 \%$, D), E) y F).

Con el objetivo de aclarar este resultado, hemos realizado un estudio adicional SEM de los electrodos de $\mathrm{Zn}-\mathrm{Bi}_{2} \mathrm{O}_{3}$. La Figura 6.2-8 muestra micrografías SEM y análisis elemental EDX realizados para los electrodos de $\mathrm{Zn}-\mathrm{Bi}_{2} \mathrm{O}_{3}$ en diferentes estados de descarga: muestras puras, después de un proceso OCV de 24 horas y después de una descarga hasta $1.0 \mathrm{~V}$ como potencial de corte. Este potencial corresponde al inicio del "colapso" de la batería, evitando así la posibilidad de reoxidación de Bi metálico a $\mathrm{Bi}^{3+}$.

Los electrodos sin sumergir en $\mathrm{KOH}$ se analizan en la Figura 6.2-8A-D: 8A y 8C muestran $\mathrm{Zn}-\mathrm{Bi}_{2} \mathrm{O}_{3} 6 \%$ y $\mathrm{Zn}-\mathrm{Bi}_{2} \mathrm{O}_{3}$ 25\%, 6.2-8B muestra el espectro EDX de ambos electrodos, confirmando la presencia de $\mathrm{Zn}$, Bi y O, y 6.2-8D muestra el análisis elemental de la región de $\mathrm{Zn}-\mathrm{Bi}_{2} \mathrm{O}_{3} 25 \%$ incluida en la Figura 6.2-8D, que muestra la distribución de $\mathrm{Bi}_{2} \mathrm{O}_{3}$ y $\mathrm{Zn}$ en el electrodo. Las figuras $8 \mathrm{E}-\mathrm{G}$ muestran diferentes rangos de aumento del electrodo $\mathrm{Zn}-\mathrm{Bi}_{2} \mathrm{O}_{3} 6 \%$ sometido a una prueba OCV de 24 horas. Como se puede ver, se observan cambios importantes con respecto a los electrodos recién preparados, y se encuentran dos estructuras diferentes. Mientras que las formaciones 
de "microflores" dominan la mayor parte de la superficie, también se observan pequeñas zonas más planas. Con el fin de dilucidar por qué se forman las diferentes regiones morfológicas hemos realizado análisis EDX, en dos puntos superficiales diferentes, tal y como se ilustra en la Figura 8F. Las mediciones EDX (Figura 8H) muestran que la región en forma de "microflor" tiene un pico de Zn más alto con respecto al $\mathrm{Bi}$, mientras que la región más plana produce un pico de Bi más intenso comparado con el pico de Zn. Por lo tanto, y considerando los cambios morfológicos observados desde los electrodos recién preparados hasta los sometidos a OCV, la región más plana parece una acumulación bidimensional de Bi metálico.

Sabiendo que las estructuras en "microflores" de $\mathrm{ZnO}$, similares a las obtenidas por nosotros, han sido frecuentemente reportadas en la bibliografía y que el análisis EDX en la Figura 8H indica que las zonas en forma de flor contienen principalmente $\mathrm{Zn}$, se puede inferir que se forma una capa de $\mathrm{ZnO}$ después del tratamiento OCV de un electrodo de $\mathrm{Zn}-\mathrm{Bi}_{2} \mathrm{O}_{3}$ al 6\%. Además, esta hipótesis está de acuerdo con los resultados obtenidos por las mediciones con radiación sincrotrón (Figura 6.2-2 y Figura 6.2-6C y D) y las mediciones de XRD convencionales (Figura 6.2-4). Además, la aparición de un pico de $\mathrm{K}$ apunta a la participación de los cationes $\mathrm{K}^{+}$en el proceso global.

Por otro lado, cuando un $\mathrm{Zn}-\mathrm{Bi}_{2} \mathrm{O}_{3}$ al $25 \%$ se somete a un proceso de OCV, la morfología resultante del electrodo cambia claramente de la obtenida para el $\mathrm{Zn}-\mathrm{Bi}_{2} \mathrm{O}_{3}$ al 6\%. La figura $8 \mathrm{I}$ muestra la imagen de la superficie de un $\mathrm{Zn}-\mathrm{Bi}_{2} \mathrm{O}_{3} 25 \%$ después de OCV, donde se observan formaciones de microcristales en la superficie del electrodo. Las mediciones EDX puntuales realizadas en un microcristal y en la superficie (Figura 6.2-8J) confirman que los microcristales están compuestos esencialmente por $\mathrm{Bi}$, mientras que la superficie contiene principalmente $\mathrm{Zn}$ pero no Bi. Este aspecto es confirmado por el análisis elemental incluido en la Figura 8K, que indica que se forman microcristales de Bi metálico sobre la superficie de $\mathrm{Zn}$. En este punto, teniendo en cuenta los difractogramas de XRD sincrotrón y de XRD convencional, podemos considerar que los microcristales están compuestos por Bi metálico, que se han formado en la superficie del Zn durante el proceso OCV a partir de la reducción de cationes $\mathrm{Bi}^{3+}$. Este aspecto también está de acuerdo con los 
cambios superficiales observados en las imágenes SEM, ya que es muy improbable que el $\mathrm{Bi}_{2} \mathrm{O}_{3}$ sea reestructurado para formar los microcristales obtenidos.
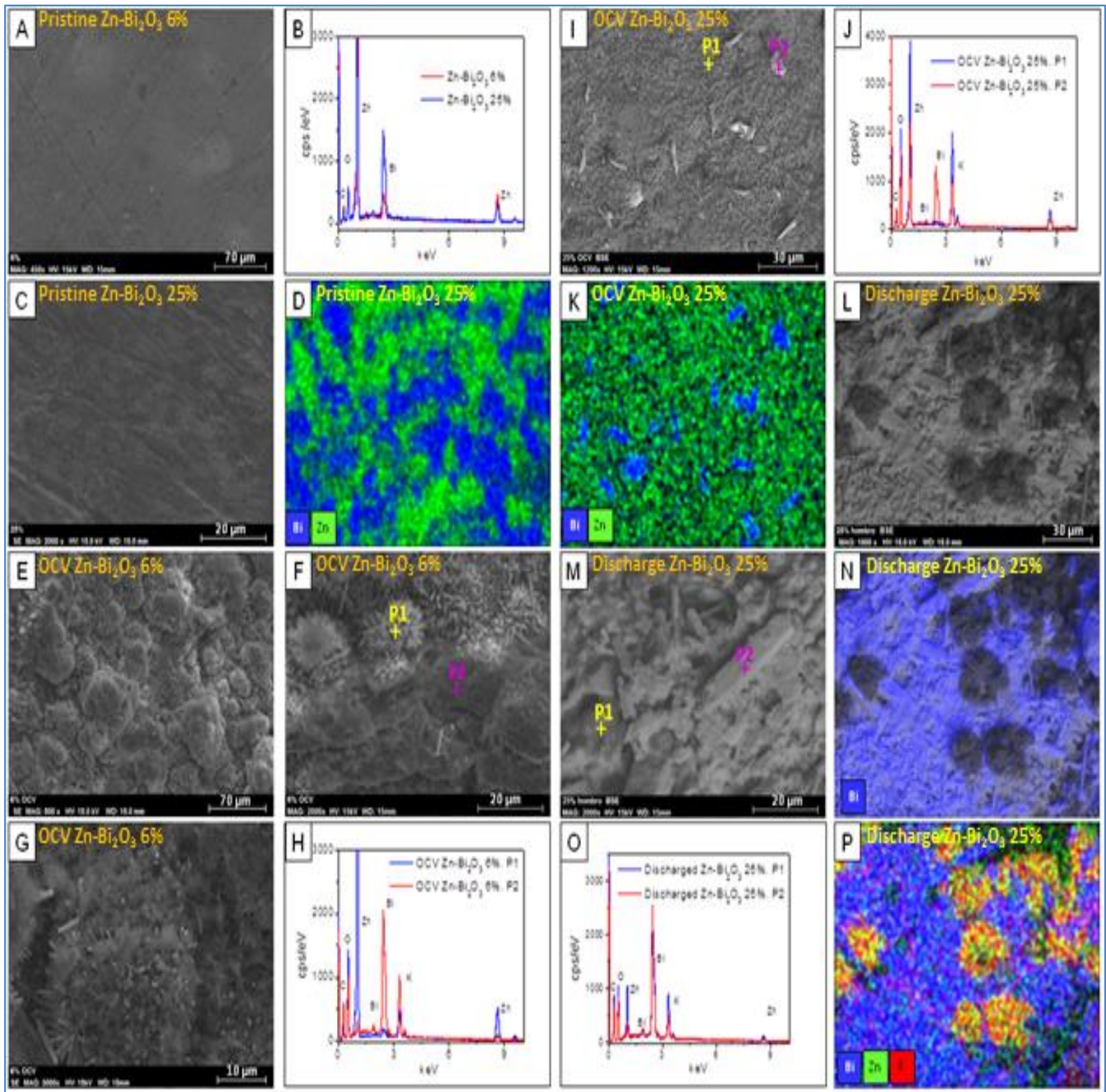

Figura 6.2-8: Imágenes SEM y mediciones $\mathrm{EDX}$ de electrodos de $\mathrm{Zn}$-Bi2 $\mathrm{O}_{3} 6 \%$ y $25 \%$ en diferentes estados de carga, tal y como indican las etiquetas. P1 y P2 en F, I y M indican los puntos en los que se han realizado análisis $E D X y$ sus espectros se muestran en $H, J$ y $O$, respectivamente. D y $K$ corresponden a las imágenes $S E M C$ e I, respectivamente. $Y$ los mapeos $N$ y $P$ corresponden a la imagen SEM L.

Finalmente, cuando un electrodo $\mathrm{Zn}-\mathrm{Bi}_{2} \mathrm{O}_{3}$ al 25\% es descargado hasta un potencial de corte de $1.0 \mathrm{~V}$, las imágenes SEM muestran nuevos cambios en la superficie. En este caso, la formación de Bi metálico parece extenderse masivamente 
(Figura 6.2-8M). Las mediciones EDX realizadas en dos puntos de este electrodo confirman la existencia de una gran cantidad de Bi respecto al Zn, aunque las zonas de sombra parecen contener más Zn. Nótese que en este electrodo no se observan en absoluto las "microflores", lo que confirma que el $\mathrm{ZnO}$ no se forma en la superficie, como ya se ha concluido a partir de los difractogramas XRD.

Además, cuando se captura una imagen más grande de este electrodo, se observan zonas oscuras más altas con estructuras fibrosas (Figura 6.2-8L). Prestando atención a la imagen SEM 8L y a los análisis elementales $8 \mathrm{~N}$ y $8 \mathrm{P}$, podemos concluir que el Bi metálico se dispersa sobre una gran superficie del electrodo, aunque en las estructuras oscuras fibrosas no se observa.

El análisis elemental 8P muestra claramente que las formaciones oscuras están compuestas principalmente de $\mathrm{K}$ y $\mathrm{Zn}$. Una vez más encontramos los cationes $\mathrm{K}^{+}$de las soluciones de $\mathrm{KOH}$, que tienen que participar en las reacciones redox que ocurren durante los procesos de OCV y descarga. En este caso, podemos plantear la hipótesis de que las formaciones oscuras pueden deberse a la deposición de especies $\mathrm{K}-\mathrm{Zn}-\mathrm{OH}$, como $\mathrm{K}_{2} \mathrm{Zn}(\mathrm{OH})_{4}$.

\subsection{Conclusiones.}

En este artículo hemos demostrado mediante análisis de difracción XRD de sincrotrón y otras mediciones electroquímicas y espectroscópicas que se genera un depósito de $\mathrm{Bi}$ metálico en el electrodo negativo de $\mathrm{Zn}-\mathrm{Bi}_{2} \mathrm{O}_{3}$, debido a la reducción espontánea de $\mathrm{Bi}^{3+}$ a Bi metálico proporcionada por la oxidación simultánea de $\mathrm{Zn}$ a $\mathrm{Zn}^{2+}$. Además, la formación de Bi metálico continúa durante la descarga de la batería. El uso de una pequeña cantidad de $\mathrm{Bi}_{2} \mathrm{O}_{3}$ en el electrodo negativo inicial forma un depósito metálico inestable de Bi junto a una capa de $\mathrm{ZnO}$. Sin embargo, el uso de cantidades mayores de $\mathrm{Bi}_{2} \mathrm{O}_{3}$ en los electrodos negativos iniciales proporciona un depósito masivo de Bi metálico estable. En este caso, el depósito de Bi metálico parece evitar la precipitación de $\mathrm{ZnO}$ en el electrodo. Además, la película metálica estable de Bi en el electrodo negativo puede proporcionar ventajas adicionales para las baterías reversibles basadas en $\mathrm{Zn}$, como la reducción de la evolución de $\mathrm{H}_{2}$, la mejora de la conductividad del electrodo y la disminución de la formación dendrítica de Zn. 
Structural Modifications and Ionic Transport of PVA-KOH Hydrogels Applied in Zn/Air Batteries.

Santos, F.; Tafur, J. P.; Abad, J.; Fernández, A. J.. J. Electroanal. Chem. 2019, 850, 113380. https://doi.org/10.1016/j.jelechem.2019.113380.

"I'm not sure if I was the first man in space or the last dog." 



\section{RESUMEN}

Una serie de geles poliméricos a base de alcohol vinílico (PVA) dopados con solución de $\mathrm{KOH}$ han sido sintetizados por el método "solution casting method" en ausencia de otros aditivos y reticulantes. La inmersión de estas membranas en una solución de 12M KOH provoca la entrada de una mayor cantidad de $\mathrm{KOH}$ y agua dentro de la matriz polimérica. Las mediciones XRD, TGA, XPS y ATR-FTIR confirman la reestructuración de las cadenas de PVA dependiendo de la cantidad de $\mathrm{KOH}$ y agua dentro de la membrana. Este hecho está de acuerdo con la mejora de la conductividad iónica, la disminución de la energía de activación y el aumento de la intensidad de los picos en los ensayos de voltametría cíclica. Además, estas membranas de PVA-KOH han sido probadas en baterías de Zn/PVA-KOH/aire confirmando la importancia de la cantidad de KOH y agua dentro del electrolito polimérico. Finalmente, las mediciones XRD y EDX demuestran el confinamiento de $\mathrm{Zn}^{++}$cerca del electrodo de $\mathrm{Zn}$ haciendo imprescindible el movimiento de aniones $\mathrm{OH}^{-}$dentro de la membrana, como única especie iónica causante del transporte de la carga a través de la membrana. Este hecho, junto con los resultados espectroscópicos y eléctricos nos permite discutir la mejora del transporte aniónico dentro de las membranas basado en el mecanismo de Grotthuss.

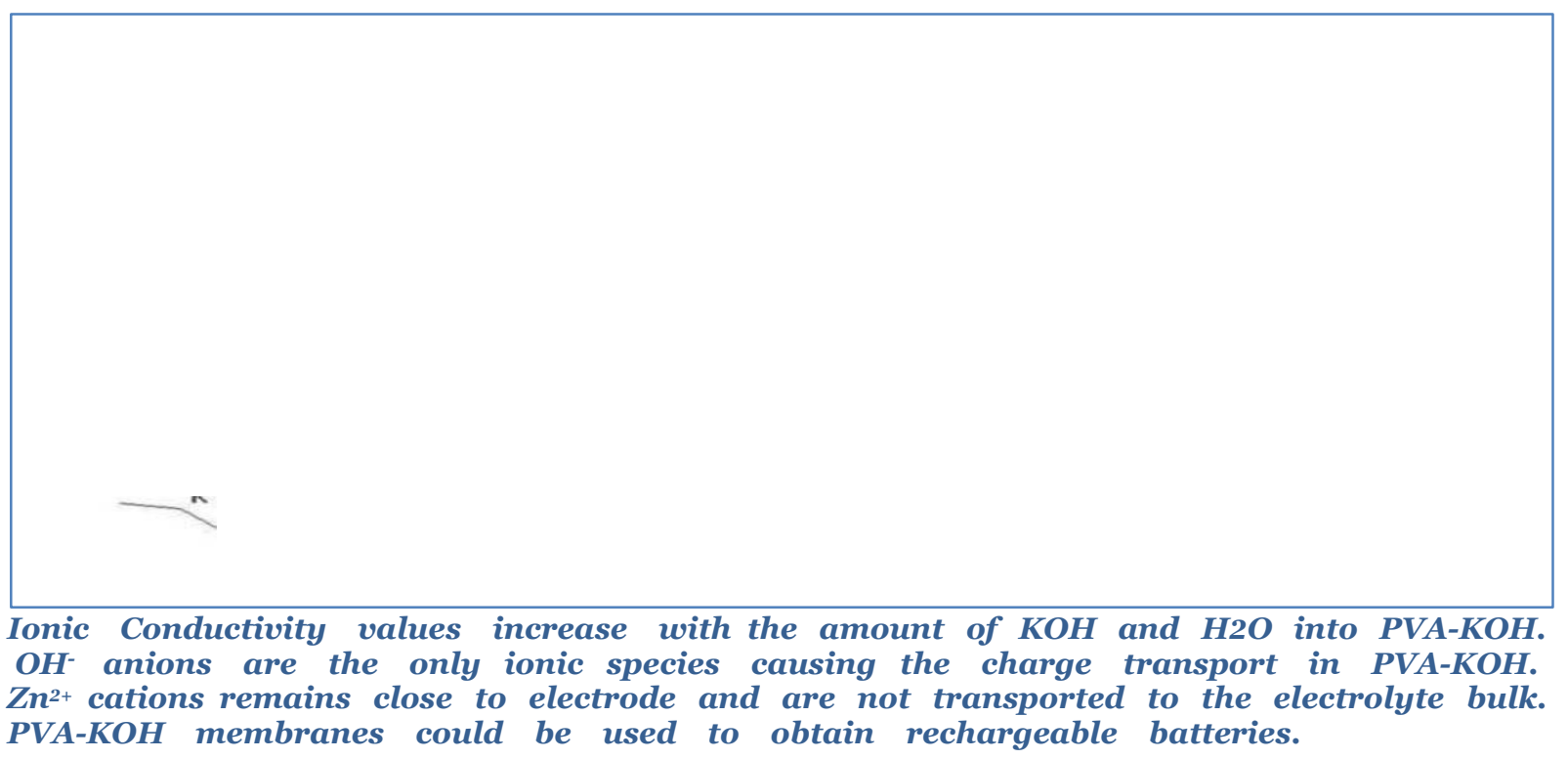




\subsection{Introducción}

En los capítulos 4 y 5 hemos descrito y analizado electrolitos de geles poliméricos basados en Líquidos Iónicos (IL-GPEs). Sin embargo, es sabido que los de electrolitos alcalinos son los que ofrecen unas mejores propiedades en las baterías de zinc. Este es el motivo por el que nos hemos propuesto sintetizar otros tipos de GPEs en los que podamos introducir disoluciones de KOH en su interior. Para ello, debemos usar un polímero que sea compatible con una disolución acuosa, como es el alcohol Polivinílico (PVA), el cual es un polímero semicristalino hidrófilo, fácil de preparar, no tóxico y barato.

El PVA dopado con hidróxido de potasio (KOH) ha sido estudiado extensamente, pero apenas se ha estudiado en baterías de zinc-aire. La adición de $\mathrm{KOH}$ aumenta el carácter amorfo de la membrana y disminuye la estabilidad de la película de PVA. Además, la conductividad iónica está influenciada por la cantidad de moléculas de $\mathrm{KOH}$ y $\mathrm{H}_{2} \mathrm{O}$ dentro de la membrana. Para películas de PVA-KOH se han registrado valores de conductividad iónica de hasta $4.7 \times 10^{-1} \mathrm{~S} \mathrm{~cm}^{-1}$.

En este capítulo se han preparado y analizado diferentes membranas PVA-KOH añadiendo distintas cantidades de KOH 6 M a una disolución acuosa de PVA. La Tabla 7.1-1 muestra el peso inicial de los componentes utilizados en cada GPE preparada. Las membranas PVA-KOH 10, PVA-KOH 30 y PVA-KOH 50 se obtuvieron agregando $10 \mathrm{ml}, 30 \mathrm{ml}$ o $50 \mathrm{ml}$ de solución de $\mathrm{KOH} 6 \mathrm{M}$ a la solución de PVA, respectivamente. Además, la membrana PVA-KOH 30 sw. representa una membrana de PVA-KOH 30, que una vez preparada, fue sumergida en una solución de KOH 12 M durante 24 horas con el consiguiente aumento de peso y volumen.

\begin{tabular}{ccccc}
\hline MEMBRANE & mPVA /g & mKOH /g & Ea $/ \mathbf{e V}$ & $\boldsymbol{\sigma} / \mathbf{S c m}^{-1}$ \\
\hline PVA PURO & 4 & 0 & - & $\approx 10^{-10}$ \\
PVA-KOH 10 & 4 & 3.36 & 0.18 & 0.012 \\
PVA-KOH 30 & 4 & 10.10 & 0.15 & 0.14 \\
PVA-KOH 50 & 4 & 16.83 & 0.21 & 0.16 \\
PVA-KOH 30 sw. & 4 & $10.10+\chi$ & 0.16 & 0.34
\end{tabular}

Tabla 7.1-1: Diversos valores experimentales para diferentes membranas de PVA-KOH. 


\subsection{Resultados.}

Es bien sabido que las propiedades químicas y físicas de las membranas hidrofílicas se ven afectadas por el contenido de agua. Las membranas de PVA aumentan su volumen por absorción de agua, pero también pueden perder agua en función de la temperatura ambiente y la humedad relativa. Este hecho es un inconveniente importante para su aplicación en dispositivos como las baterías de zincaire.

Para comprobar los cambios con el tiempo del contenido de agua en la membrana, hemos estudiado cómo se modifica el peso de ésta con el tiempo de almacenamiento a temperatura ambiente. La Figura 7.2-1A muestra los cambios de peso y de conductividad de una membrana PVA-KOH 30 durante 25 días. Como se puede observar, la membrana sufre un rápido proceso de deshidratación durante las primeras 72 horas, pero posteriormente, la pérdida de agua se ralentiza hasta que alcanza un estado estable.

Del mismo modo, se han controlado los cambios de peso de las membranas PVA-KOH 30 sw. sumergida 24 horas en una solución de KOH 12 M. En este caso, observamos un comportamiento de peso y conductividad iónica, casi estable desde el inicio y durante los 20 días en que se tomaron medidas (Figura 7.2-1B). Obsérvese que las mediciones de la membrana sw. comienza cuando se extrae la membrana de la solución de $\mathrm{KOH} 12$ M, es decir, después de 24 horas de inmersión en esta solución.

El aumento de volumen de los hidrogeles se puede determinar por diferentes métodos. Hemos calculado el índice de aumento de volumen, swelling ratio por sus siglas en inglés (SR) siguiendo la siguiente ecuación:

$$
S R=100 \times \frac{m_{e}-m_{d}}{m_{d}}
$$

donde $\mathrm{m}_{\mathrm{d}} \mathrm{y} \mathrm{m}_{\mathrm{e}}$ son peso de muestra antes y después del aumento de volumen, respectivamente. El tiempo de inmersión en $\mathrm{KOH} 12 \mathrm{M}$ fue siempre de 24h. La Tabla 7.2-1 muestra los valores para cinco membranas de PVA-KOH 30. Siempre se obtuvo un valor de SR de $34 \pm 2 \%$. 


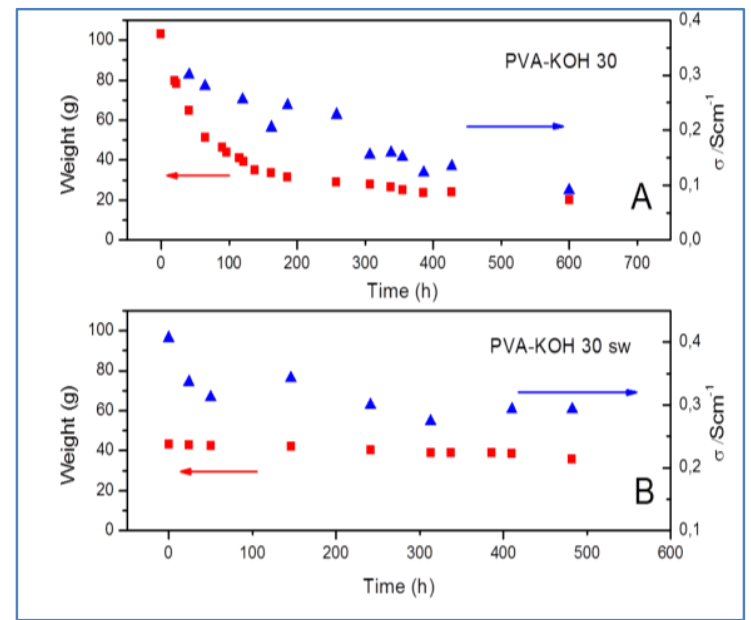

Figura 7.2-1: Peso y conductividad iónica de las membranas con el tiempo de almacenamiento a temperatura ambiente. A) Membrana PVA-KOH 30 y B) Membrana PVA-КОН 30 sw..

\begin{tabular}{cccc}
\hline Muestra & $\begin{array}{c}\text { Peso } \\
\text { inicial } \\
/ \mathbf{g}\end{array}$ & $\begin{array}{c}\text { Peso } \\
\text { después de } \\
\text { sumergir } / \mathbf{g}\end{array}$ & $\begin{array}{c}\text { Aumento } \\
\text { de peso \%. }\end{array}$ \\
\hline $\mathbf{A}$ & 0.93 & 1.23 & 32.26 \\
$\mathbf{B}$ & 0.75 & 1.00 & 33.33 \\
$\mathbf{C}$ & 0.76 & 1.02 & 34.21 \\
$\mathbf{D}$ & 0.73 & 0.99 & 35.62 \\
$\mathbf{E}$ & 0.78 & 1.03 & 32.05 \\
\hline
\end{tabular}

Tabla 7.2-1: Valores para diferentes membranas de PVA-KOH-30 después de su inmersión durante 24 horas en $\mathrm{KOH} 12 \mathrm{M}$.

La caracterización de los estos hidrogeles se realizó utilizando diferentes técnicas. La Figura 7.2-3 muestra los espectros XRD de las membranas de PVA puro y PVA-KOH con diferentes cantidades de KOH. Además, se muestra una membrana que ha sido sumergida en KOH 12M PVA-KOH 30 sw.

El PVA puro muestra un pico intenso en $2 \theta=20^{\circ}$ y un pico secundario a $40.5^{\circ}$. Estos picos indican un cierto grado de fase cristalina en el PVA puro, que puede asociarse con la alineación de las cadenas de polímeros debido a los puentes de hidrogeno formados entre los grupos $\mathrm{OH}$ de las cadenas de PVA. Una vez que la solución de $\mathrm{KOH}$ es incorporada dentro de la matriz polimérica, los picos son más bajos y más anchos, indicando un aumento de los dominios amorfos en la estructura de PVA. Estos cambios tienen que estar motivados por la retención de $\mathrm{KOH}$ y moléculas de agua dentro del polímero.

Siguiendo con la caracterización, como puede verse en la Figura 7.2-2A para una membrana de PVA KOH 30, los picos XPS observados en 292.5 y 295.3 eV, asignados a $2 p_{3 / 2}$ y K2$p_{1 / 2}$, demuestran la presencia de $\mathrm{K}$ dentro del PVA-KOH. El análisis del nivel C1s muestra un pico principal a $284.8 \mathrm{eV}$ atribuido a las especies de $\mathrm{CH}_{2}$ de las cadenas poliméricas, dos pequeños componentes a 286.5 y $287.8 \mathrm{eV}$ son asignados a las especies de $\mathrm{C}-\mathrm{OH}$ y $\mathrm{C}=\mathrm{O}$ respectivamente, y un pico más pronunciado a $289.3 \mathrm{eV}$ 
se atribuye a las especies de carboxilato - COO. Además, también se observa un componente de baja energía de enlace a $282.7 \mathrm{eV}$. Este componente indica la interacción entre un metal (K) y el carbono.

Por otro lado, la región O1s se muestra en la Figura 7.2-2B El pico principal a $531.0 \mathrm{eV}$ ha sido asignado a las especies $-\mathrm{OH}, \mathrm{C}=\mathrm{O}$, y $\mathrm{H}_{2} \mathrm{O}$, sin poder distinguir entre ellas. El pico a $532.7 \mathrm{eV}$ puede asignarse al oxígeno de enlace simple en el grupo de carboxilato - $\mathrm{COO}$, ya que este átomo de oxígeno presenta una energía de enlace mayor que los átomos de oxígeno presentes en los grupos - $\mathrm{OH}, \mathrm{C}=\mathrm{O}$ y $\mathrm{H}_{2} \mathrm{O}$. Por último, el componente de menor energía de enlace observado en $528.9 \mathrm{eV}$ debe asignarse a la interacción entre $\mathrm{O}$ y un metal, en este caso K-O.

Las curvas termogravimétricas, Figura 7.2-4, muestran que el PVA puro presenta una pérdida de peso del $10 \%$, que se atribuye al agua libre que queda en la membrana. Una segunda pérdida de peso se produce rápidamente a $310{ }^{\circ} \mathrm{C}$ e implica dos procesos: la eliminación de los grupos acetato de cadenas laterales y los grupos $\mathrm{OH}$ para producir dienos. A unos $420^{\circ} \mathrm{C}$ se observa un tercer paso que se ha asignado a la rotura de la cadena de carbonos. Al final, sólo queda un 5\% del peso inicial del PVA puro.

Con respecto a las membranas de PVA-KOH, todas ellas tienen una pérdida de masa de alrededor de $100{ }^{\circ} \mathrm{C}$. Sin embargo, esta pérdida será mayor ya que la cantidad de agua es mayor por la cantidad de solución de $\mathrm{KOH}$ utilizada durante el proceso de síntesis. Se observa una segunda pérdida de peso a unos $200^{\circ} \mathrm{C}$, que corresponderá a la eliminación de grupos $\mathrm{OH}$ y cadenas laterales. Finalmente, la tercera pérdida de peso, correspondiente a la rotura de la cadena de carbono, se observa alrededor de $\operatorname{los} 430-440^{\circ} \mathrm{C}$.

Debe tenerse en cuenta que, mientras que los valores observados para la primera y la tercera etapa son cercanos para todas las membranas, la segunda etapa de las membranas de PVA-KOH se obtiene aproximadamente a $110^{\circ} \mathrm{C}$ menos que la temperatura obtenida para el PVA puro. 
Estos resultados nos indican que, la estabilidad térmica del sistema de PVA disminuye una vez que el $\mathrm{KOH}-\mathrm{H}_{2} \mathrm{O}$ se incorpora a la membrana, lo cual debe impedir de alguna manera la interacción entre los grupos $\mathrm{OH}^{-}$de las cadenas de polímeros cercanas, haciendo que la nueva estructura del polímero sea más débil. Esto está de acuerdo con el mayor contenido en agua de las membranas de PVA-KOH, ya que las moléculas de agua debilitan los enlaces de hidrógeno entre las cadenas de polímeros y conducen a un aumento del volumen libre.

Estos resultados concuerdan con la pérdida de cristalinidad observada en los espectros de XRD cuando se incorpora $\mathrm{KOH}$ a las membranas de PVA: un GPE más amorfo tiene menor estabilidad.

Por otra parte, la introducción de la solución de $\mathrm{KOH}$ dentro de las membranas afecta claramente las bandas observadas en el espectro ATR-FTIR (Figura 7.2-5). Las bandas características del PVA puro pueden observarse en el espectro ATR-FTIR mostrado en la Figura 7.2-5. Las bandas a 1243, 1084, 945 y $1732-1710 \mathrm{~cm}^{-1} \mathrm{se}$ atribuyen respectivamente a los modos $v(\mathrm{C}-\mathrm{O}-\mathrm{C}), \mathrm{v}(\mathrm{C}-\mathrm{O}), \mathrm{v}(\mathrm{C}-\mathrm{C}-\mathrm{O})$ y $v(\mathrm{C}-\mathrm{C}-\mathrm{O})$ debido a los grupos acetato que permanecen en la estructura de PVA desde su proceso de fabricación. La presencia de estas bandas es razonable, ya que en el PVA utilizado (hidrolizado parcialmente) se incluyen un $12 \%$ de grupos acetato, tal y como declarado en la hoja de datos del producto.

Por el contrario, cuando la disolución de KOH se incorpora al PVA, se encuentran varios cambios significativos. La introducción de moléculas de agua dentro del polímero junto con el $\mathrm{KOH}$ se demuestra por la banda de $1640 \mathrm{~cm}^{-1}$, que aparece en todos los espectros de las membranas de PVA-KOH, coincidiendo con el pico observado en el espectro de la solución de KOH. Además, las bandas de 945, 1245 y $1732-1710 \mathrm{~cm}^{-1}$, asignadas a grupos de acetato, desaparecen. Este comportamiento puede estar relacionado con la hidrólisis de grupos acetato por grupos $\mathrm{OH}^{-}$del $\mathrm{KOH}$. Sin embargo, en este caso, los picos debidos a los grupos de acetato deben observarse en los espectros ATR-FTIR aunque se hayan separado de las cadenas de PVA.

Además, los cambios observados en los espectros ATR-FTIR apuntan a interacciones entre el $\mathrm{KOH}$ y las cadenas de PVA, como ya se dedujo de las mediciones 
XRD, XPS y TG. Dado que el átomo de oxígeno en los grupos $\mathrm{OH}$ y $\mathrm{C}=\mathrm{O}$ del PVA es un fuerte donante de electrones, con pares de electrones disponibles, los cationes $\mathrm{K}^{+} \mathrm{se}$ coordinarán con estos grupos formando complejos del tipo $\mathrm{C}=\mathrm{O}---\mathrm{K}^{+} \mathrm{o} \mathrm{C}-\mathrm{O}---\mathrm{K}^{+}$.

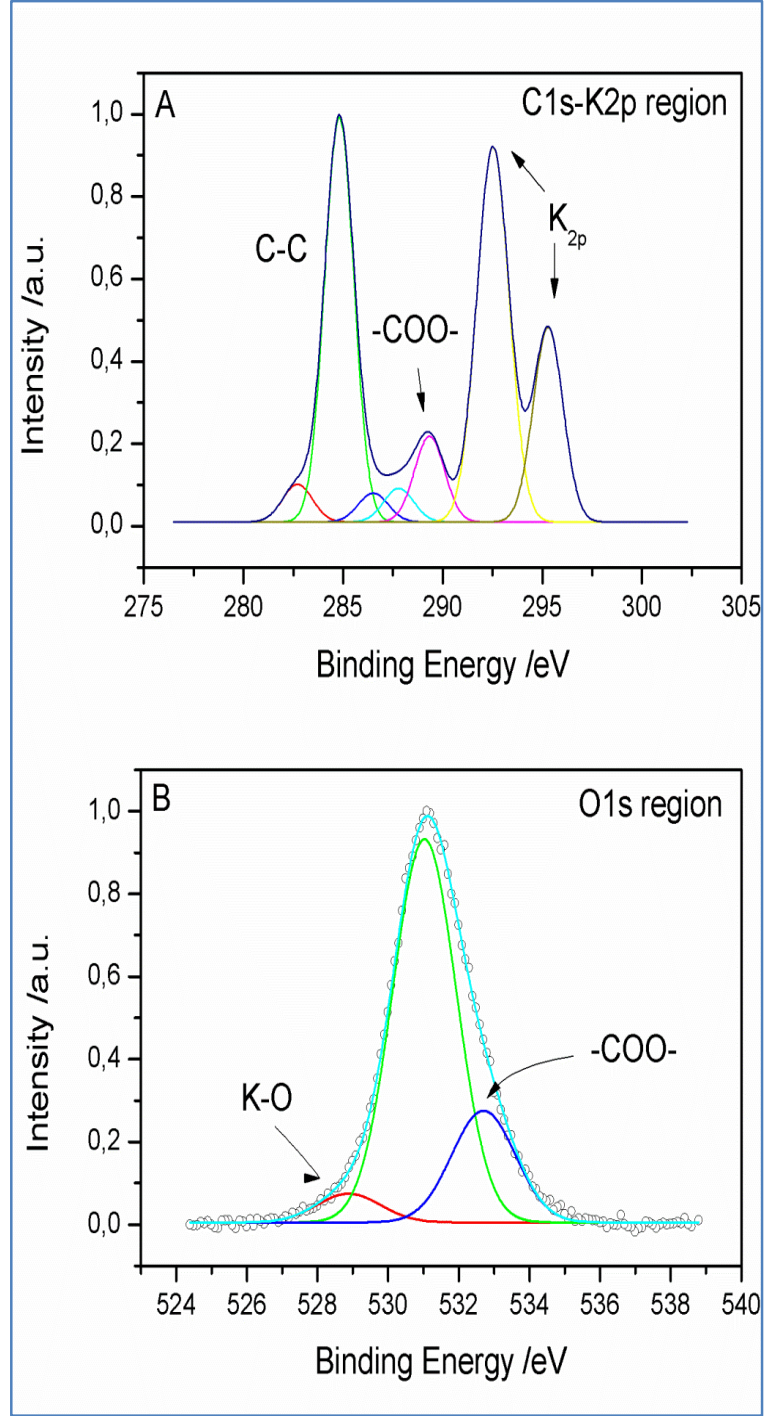

Figura 7.2-2: Espectros XPS de la membrana PVA- KOH 30. A) Región C1s y K2p. B) Región O1s.

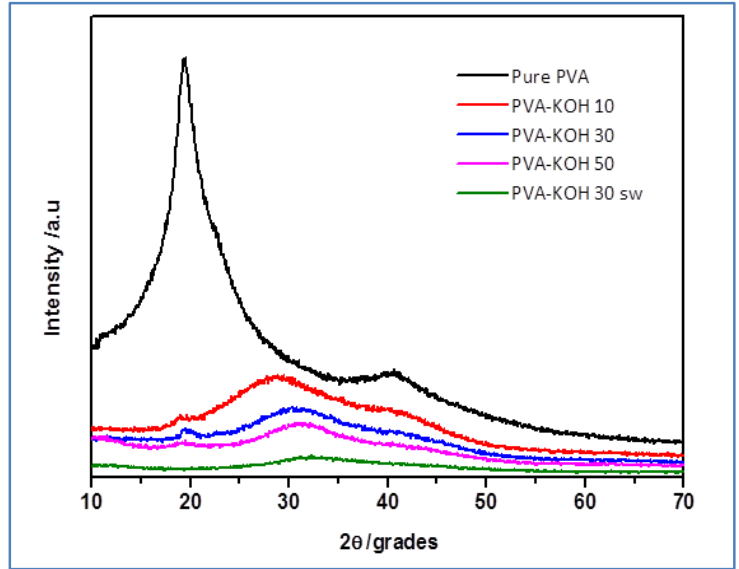

Figura 7.2-3: Difractogramas de XRD de las membranas preparadas.

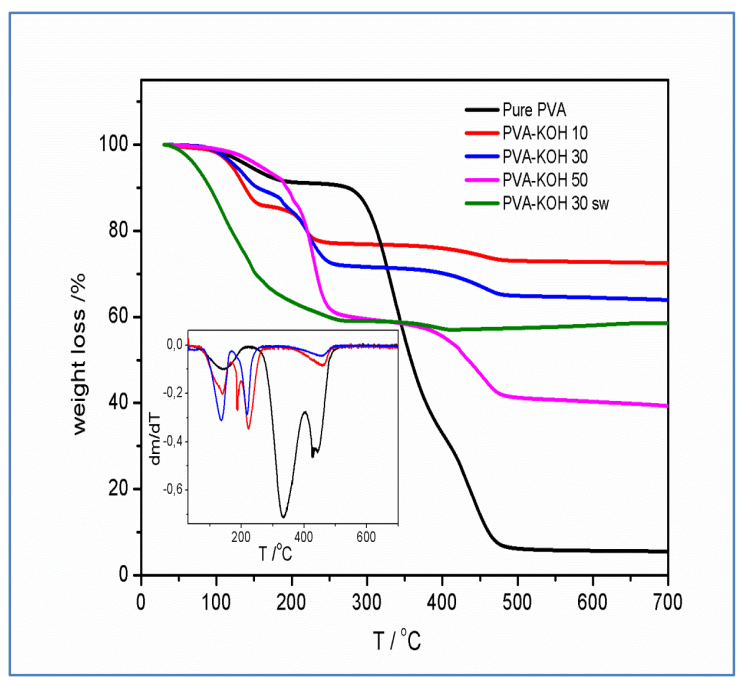

Figura 7.2-4: Curvas TG de las membranas preparadas. El recuadro muestra la derivada de las curvas.

Por otro lado, se observan importantes cambios espectrales en la región del "strecthing" del $\mathrm{OH}$ a $3000-3500 \mathrm{~cm}^{-1}$. Con frecuencia se han reportado en esta región picos más amplios y desplazados a un número de onda más bajo, lo que se ha interpretado como la existencia de una red de puentes de hidrógeno más intensos y en mayor cantidad. Por lo tanto, como se observa en la Figura 7.2-5, los GPEs de PVA- 
$\mathrm{KOH}$ muestran cambios hacia frecuencias más bajas y bandas de mayor anchura por la mayor cantidad de $\mathrm{KOH}$ y moléculas de agua incorporadas en el PVA.

Este resultado indica que, aunque la inclusión de la solución de $\mathrm{KOH}$ dentro de la matriz polimérica proporciona la ruptura de los enlaces por puentes de hidrogeno entre cadenas, se forma una mayor cantidad de puentes de hidrogeno por el aumento de las moléculas de $\mathrm{KOH}$ y $\mathrm{H}_{2} \mathrm{O}$ dentro del GPE.

Sorprendentemente, el espectro de PVA-KCl es muy similar al obtenido para el PVA puro, aunque se observa una intensa banda a $1640 \mathrm{~cm}^{-1}$. Hay que señalar que la banda de carbonilo de los grupos acetato se desplaza hasta $1712 \mathrm{~cm}^{-1} \mathrm{y}$ el modo v (CO) se desplaza hasta $1089 \mathrm{~cm}^{-1}$. Estos cambios pueden indicar una interacción C=O-- $\mathbf{K}^{+}$y C-O--- $\mathbf{K}^{+}$, aunque más débiles que los que aparecen en PVA-KOH. Este resultado confirma que los aniones $\mathrm{Cl}^{-}$tienen una pequeña influencia en las cadenas de PVA en comparación con los grupos hidroxilos del $\mathrm{KOH}$.

Finalmente, también hemos registrado un espectro ATR-FTIR de una membrana PVA-KOH 30 sw., obtenido por inmersión de una de PVA-KOH-30 en KOH $12 \mathrm{M}$ durante 24 horas. En este caso se observan los mismos picos obtenidos a partir de la membrana sin sumergir, excepto para las bandas anchas en $\approx 3300 \mathrm{~cm}^{-1}$, que tienen que estar relacionadas con la incorporación de una cantidad adicional de KOH y agua dentro de la membrana, como ya se ha deducido por mediciones de XRD y TG.

La Figura 7.2-6A muestra la variación de la conductividad iónica con la temperatura para los GPEs basados en PVA con diferente concentración de KOH. Las membranas obedecen al comportamiento de Arrhenius en un amplio rango de temperaturas, como lo confirman los datos ajustados a la ecuación:

$$
\sigma T=\sigma_{0} \exp \left(-E_{a} / k_{B} T\right)
$$

donde $\sigma_{0}$ es el factor preexponencial, Ea la energía de activación, $\mathrm{k}_{\mathrm{B}}$ la constante de Boltzmann y $\mathrm{T}$ la temperatura de ensayo. A partir de las pendientes de la Figura 7.2 $6 \mathrm{~A}$ se pueden obtener los valores de energía de activación, que se muestran junto con los valores de conductividad a $20^{\circ} \mathrm{C}$ en la Tabla 7.1-1 para todas las membranas 
analizadas. El valor de conductividad más alto, $0.34 \mathrm{Scm}^{-1}$ a $20{ }^{\circ} \mathrm{C}$, se obtuvo para el hidrogel PVA-KOH 30 sw., confirmando la importancia de sumergir las membranas de PVA-KOH en una solución de 12M KOH.

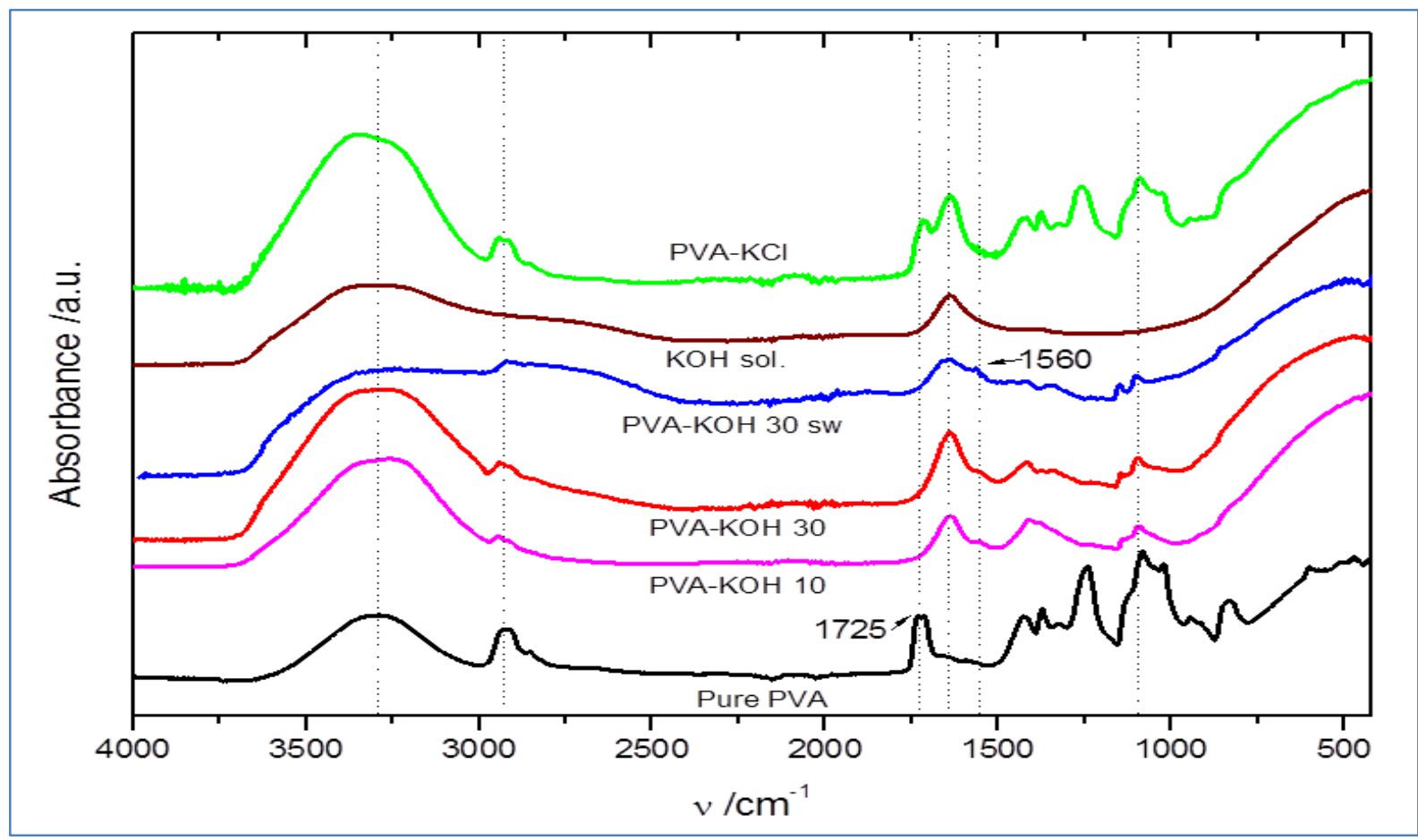

Figura 7.2-5: Espectros ATR-FTIR de las membranas de PVA Puro, PVA-KOH 30 y PVA-KOH 30 sw. Sumergida en KОН 12M durante $24 \mathrm{~h}$. Se incluyen espectros de la solución de 6M KOH y PVAKCl para comparar.

La dependencia de la temperatura de las membranas PVA-KOH 30 sw. también se incluye en la Figura 7.2-6. De nuevo, ésta también obedece al comportamiento de Arrhenius, pero los valores de conductividad aumentan notablemente con respecto a las no sumergidas. El aumento de los valores de conductividad de las membranas con aumento de peso (sw.) tiene que estar relacionado con la entrada de una cantidad adicional de $\mathrm{KOH}$ y agua cuando se sumergen en KOH 12M, como han confirmado las mediciones ATR-FTIR, TGA y XRD.

Para confirmar el transporte iónico de los GPEs, se realizó un estudio por voltametría cíclica (CV) utilizando una celda simétrica Zn/GPE/Zn. La Figura 7.2-6B muestra el comportamiento voltamperométrico de las membranas PVA-KOH 30 y PVA-KOH 30 sw. En esta figura se observa claramente un aumento de la densidad de 
corriente, el cual debe asociarse a la absorción de agua y $\mathrm{KOH}$ cuando las membranas son sumergidas en $\mathrm{KOH} 12 \mathrm{M}$

Además, el comportamiento cuasi-reversible de los procesos de oxidación/reducción se observa en la Figura 7.2-6B, donde se muestran 50 ciclos consecutivos de la membrana sumergida de PVA-KOH, confirmando un comportamiento muy estable con el ciclado.

Los resultados CV junto con la conductividad iónica y los valores de energía de activación confirman que estas membranas podrían ser usadas como electrolitos poliméricos en fase gel en baterías basadas en $\mathrm{Zn}$.

Con el objetivo de demostrar la utilidad de las membranas de PVA-KOH como electrolitos poliméricos, se han probado en baterías de Zn/PVA-KOH/aire utilizando una corriente de $-5 \mathrm{~mA}$ y una placa de $\mathrm{Zn}$ como ánodo. Como puede verse en la Figura 7.2-6C la membrana no sumergida proporciona un valor de capacidad de descarga muy bajo. Sin embargo, los valores de capacidad de descarga aumentan con el tiempo que la membrana fue sumergida en la solución de KOH 12M. Además, se ha probado una membrana de PVA-KOH 30 sw. en una batería de Zn/PVA-KOH/aire a temperatura ambiente, utilizando un ánodo de polvo de $\mathrm{Zn}$ en lugar de placas de $\mathrm{Zn}$. La Figura 7.2-6D muestra esta descarga a $-20 \mathrm{mAcm}^{-2}$, donde se obtuvieron capacidades de descarga de $\sim 300 \mathrm{mAhg}^{-1}$.

Por último, hemos confirmado que este tipo de membranas se pueden utilizar en baterías recargables. Membranas utilizadas en los procesos de descarga y descarga/carga han sido analizadas por XRD (Figura 7.2-7A). Como se muestra, sólo se observa $\mathrm{ZnO}$ después de un proceso de descarga y sólo aparecen picos de Zn Metal después de un proceso de descarga/carga, confirmando que el Zn metal se oxidó formando $\mathrm{ZnO}$ durante la descarga y que los cationes de $\mathrm{Zn}^{2+}$ se redujeron para obtener de nuevo $\mathrm{Zn}$ metal durante el proceso de carga.

Además, se registraron curvas de polarización usando valores de corriente entre 0 y $100 \mathrm{~mA}$ y una velocidad de barrido de $0.1 \mathrm{mAs}^{-1}$ (Figura 7.2-6E y F). Se llevaron a cabo tres barridos consecutivos después de un periodo de OCV. La Figura 
7.2-6E muestra las curvas de Potencial frente a la Intensidad, donde se observa que el mismo potencial fue obtenido en cada curva, $0.9 \mathrm{~V}$ para una corriente de $100 \mathrm{~mA}$. En la Figura 7.2-6F se incluyen las curvas de potencial frente al tiempo para los tres barridos realizados, como puede verse un mismo valor de $1.43 \mathrm{~V}$ fue obtenido tras cada barrido y un periodo de OCV de 16 minutos.

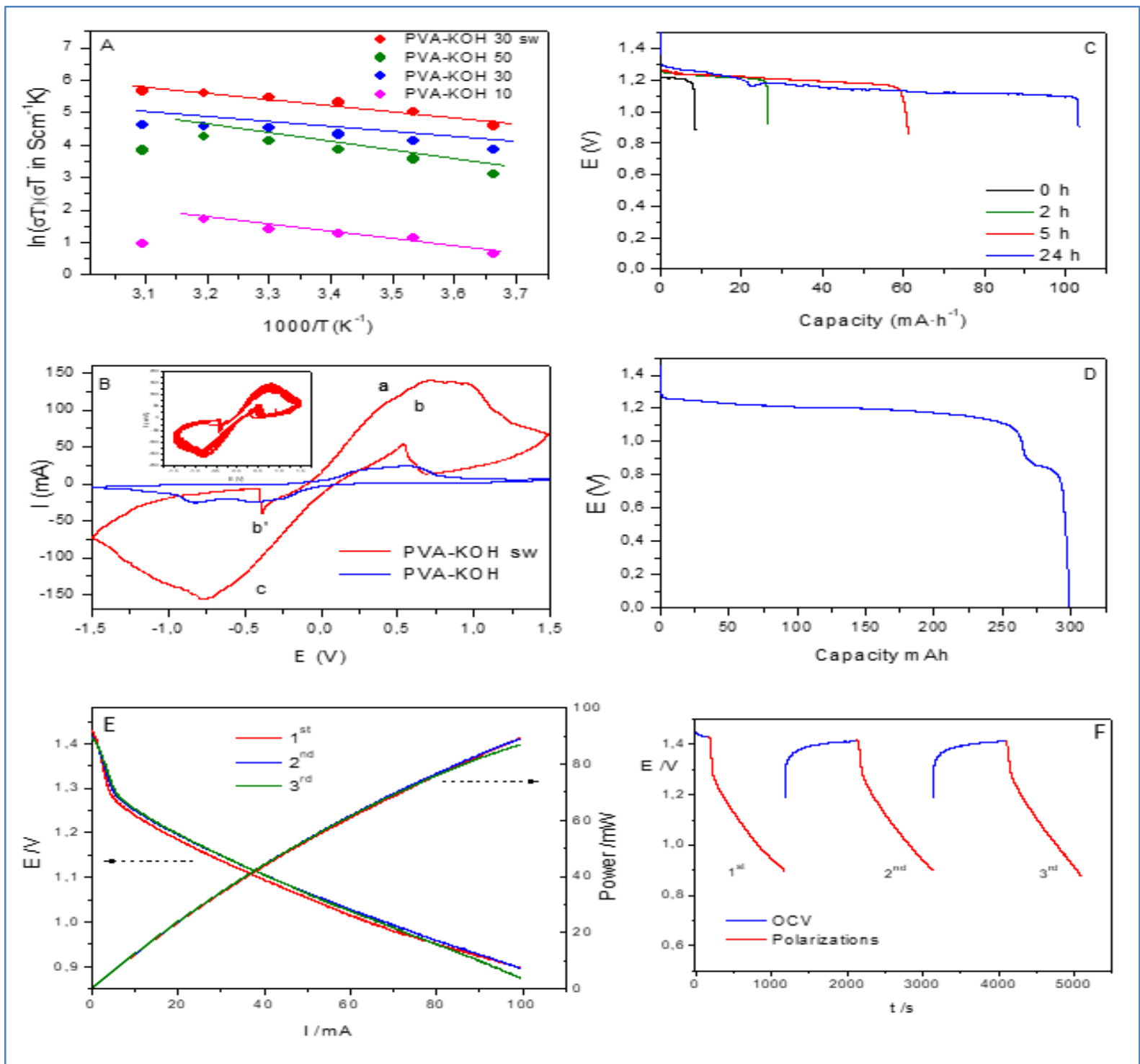

Figura 7.2-6: A) Valores de conductividad de las membranas basadas en PVA-KOH con la temperatura, indicando un comportamiento Arrhenius. B) Voltametría cíclica de PVA-KOH 30 y PVA-KOH 30 sw. Recuadro: 50 ciclos consecutivos de la membrana con PVA-KOH 30 sw. C) Curvas de descarga de las baterías de aire Zn/PVA-KOH 30/aire con el tiempo de inmersión de la membrana PVA-KOH 30 en solución de 12M KOH, utilizando una placa de Zn como ánodo. D) Curva de descarga de una batería Zn/PVA-KOH 30 sw. (sumergida 24 horas en KOH 12 M). E) Curvas de polarización de una batería Zn/PVA-KOH 30 sw./aire a una velocidad de 0.1 mAs ${ }^{-1}$. F) Potencial vs. tiempo durante las mediciones de polarización, incluyendo $\mathrm{OCV}$. 
Con el objetivo de confirmar si los cationes $\mathrm{Zn}^{2+}$ se mueven a través de la membrana hemos llevado a cabo medidas experimentales adicionales. La Figura 7.2-8 muestra una imagen SEM de la sección transversal de la membrana PVA-KOH 30 sw. utilizada durante una descarga en una batería de Zn/PVA-KOH/aire. Además, hemos realizado un análisis de la sección de la membrana mediante EDX de Zn, K y O, desde la superficie de la membrana que estuvo en contacto con el electrodo de $\mathrm{Zn}$ hasta alcanzar una profundidad de $3600 \mu \mathrm{m}$. Como se puede ver, la cantidad de O es estable a lo largo de la membrana. Sin embargo, K y Zn varían con la profundidad: La cantidad de $\mathrm{K}$ es mínima cerca del electrodo $\mathrm{Zn}(\mathrm{x}=0)$, pero a $\mathrm{x}=150 \mu \mathrm{m}$ aumenta rápidamente hasta alcanzar un valor estable en el seno del electrolito. Por el contrario, el Zn alcanza el máximo cerca del electrodo de $\mathrm{Zn}$. Este resultado confirma que el $\mathrm{ZnO}$ se forma cerca de la superficie del electrodo de $\mathbf{Z n}$ y que los cationes de $\mathrm{Zn}^{2+}$ no se transportan a lo largo del electrolito. Como se muestra en los difractogramas XRD realizados en el lado del PVA-KOH en contacto con el electrodo de $\mathrm{Zn}$, se observan picos de $\mathrm{ZnO}$ en la membrana de PVA-KOH después del proceso de descarga, pero sólo aparecen picos de Zn Metal para la membrana utilizada en un ciclo de descarga y carga (Figura 7.2-8).

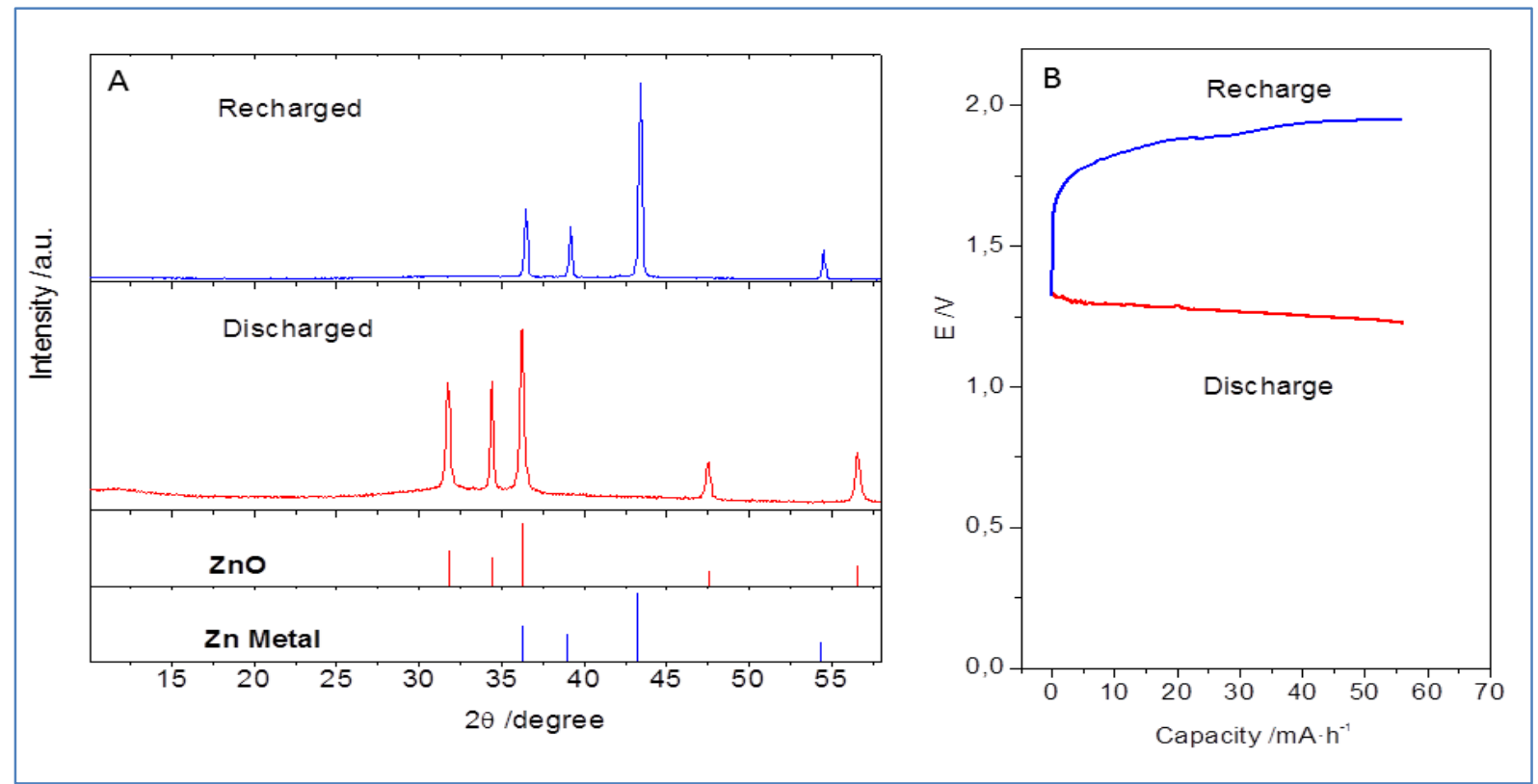

Figura 7.2-7: A) Difractogramas XRD de la membrana PVA-KOH utilizada en baterías de aire Zn/PVA-KOH 30 sw./air después de una descarga y un ciclo de descarga/carga de baterías Zn/PVA-KOH $30 \mathrm{sw}$./air. Las líneas verticales muestran las tarjetas de la base de datos ICDD de Zn[Card-00-004-0831] (azul) y ZnO[Card-00-036-1451] (rojo) B) Curvas de descarga y carga de una batería sw/air Zn/PVA-KOH 30. 
Este experimento nos confirma que el $\mathrm{Zn}^{2+}$ no participa en el intercambio iónico y que, por tanto, serán los aniones $\mathrm{OH}^{-}$los que contribuirán mayoritariamente a este transporte iónico. Además, en la bibliografía se han publicado valores de números de transporte aniónico, t-, cercanos a 1 para diversos electrolitos poliméricos alcalinos basados en PVA. Este resultado concuerda con las medidas realizadas por nosotros siguiendo el método de Evans.

Según lo expuesto anteriormente, se deduce que el transporte iónico es principalmente aniónico en nuestras membranas de PVA-KOH y, por lo tanto, podemos considerar al $\mathrm{OH}^{-}$como la única especie que contribuye al transporte iónico dentro de la membrana. En la literatura se han considerado varios mecanismos de transporte para participar en el transporte $\mathrm{OH}^{-}$a través de una membrana, como la difusión, la migración, la convección o el mecanismo Grotthuss. Aunque todos estos mecanismos pueden participar en el transporte del $\mathrm{OH}^{-}$, aunque son numerosos los autores que asumen que el $\mathrm{OH}^{-}$es transportado principalmente siguiendo el mecanismo de Grotthuss.

Se sabe que el movimiento del OH- puede ser impedido por una estructura cerrada del polímero, así como por una fuerte interacción entre el $\mathrm{OH}^{-}$y las cadenas poliméricas. Como hemos comentado, el transporte de $\mathrm{OH}^{-}$dentro de la membrana depende claramente de la cantidad de agua y de la concentración de $\mathrm{KOH}$ incluida en la membrana, así como de los tamaños de los poros formados en la estructura del polímero.

Es razonable pensar que unos poros más grandes facilitarán el movimiento iónico. Además, la cantidad de agua influye en el proceso de conductividad de varias maneras: 1) Una mayor absorción de agua aumentará los espacios entre las cadenas de polímero y disminuirá la fuerza de interacción de los grupos $\mathrm{OH}^{-}$entre las cadenas contiguas; 2) Se necesita suficiente cantidad de agua dentro de la matriz polimérica para formar una red de enlace por puentes de hidrogeno y para construir aniones hidroxilos con esferas de solvatacion estables; 3) Finalmente, las moléculas de agua en la matriz del polímero provocan la disminución de la fase cristalina en beneficio de regiones amorfas, mejorando los valores de conductividad de las membranas. 


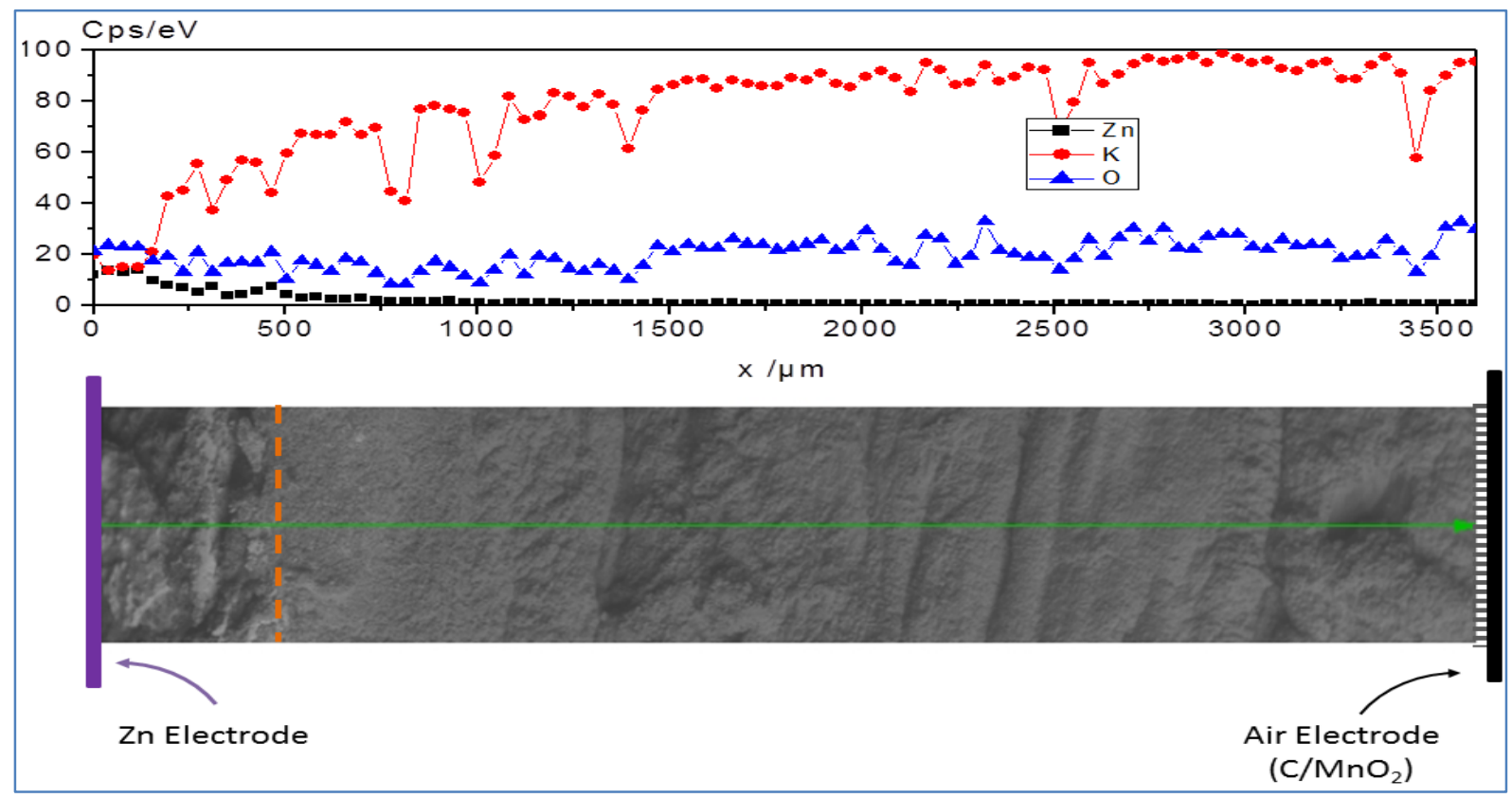

Figura 7.2-8: Análisis por imagen SEM y análisis EDX de la sección transversal de una membrana PVA-KOH 30 sw. utilizada durante una descarga en una batería de aire Zn/PVA-KOH/aire. Zn, K y $O$ se analizaron mediante $E D X$ desde la superficie de la membrana que estuvo en contacto con el electrodo de Zn hasta alcanzar una profundidad de 3600 $\mathrm{m}$.

Respecto a los polímeros de PVA-KOH sintetizados en este trabajo, hemos observado mediante mediciones de XRD que la inclusión de KOH y agua dentro de la matriz de PVA proporciona un aumento de las regiones amorfas del polímero, lo que ayudará a mejorar la conductividad iónica. Además, las mediciones ATR-FTIR y TG revelan interacciones entre las cadenas de PVA y el $\mathrm{KOH}$ y $\mathrm{H}_{2} \mathrm{O}$ incluidos en el polímero. Estas interacciones son más importantes cuando se incorpora una mayor cantidad de $\mathrm{KOH}$ y $\mathrm{H}_{2} \mathrm{O}$, lo que demuestra que la inmersión de las películas de PVA$\mathrm{KOH}$ en la solución de $\mathrm{KOH} 12 \mathrm{M}$, donde se absorben $\mathrm{KOH}$ y $\mathrm{H}_{2} \mathrm{O}$ adicionales, proporciona la reestructuración más importante de las cadenas de PVA.

Teniendo en cuenta los comentarios anteriores y nuestros resultados, podemos proponer que el mecanismo de Grotthuss contribuye significativamente o es el mecanismo principal para el transporte de aniones hidroxilo a través de los canales formados en la matriz PVA-KOH, aunque la difusión o migración no puede descartarse completamente.

El Esquema 7.2.1 representa la estructura de PVA sin $\mathrm{KOH}$ ni $\mathrm{H}_{2} \mathrm{O}$. En este caso, se forma una gran cantidad de enlaces de hidrógeno entre las cadenas de PVA cercanas, 
haciendo que esta estructura esté muy compacta, lo que impedirá el movimiento de los aniones. Por lo tanto, el valor de conductividad iónica de este polímero será muy bajo.

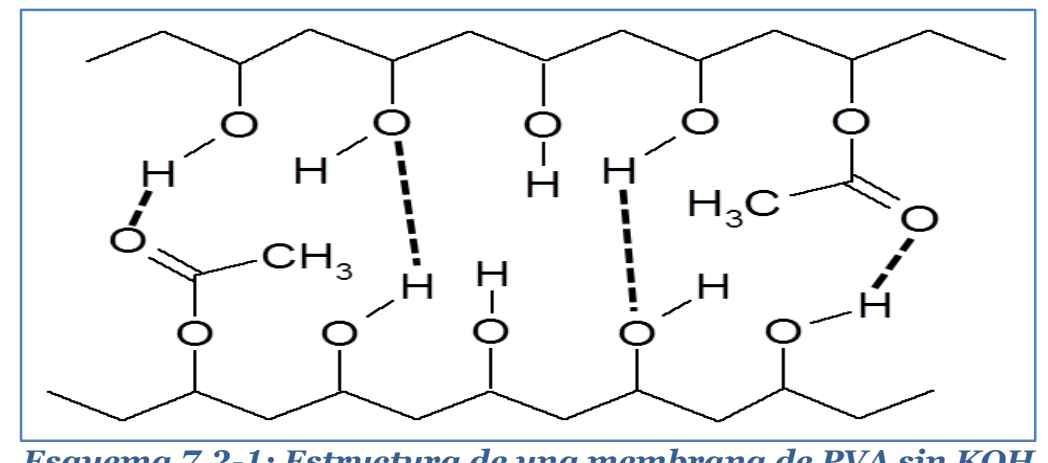

Esquema 7.2-1: Estructura de una membrana de PVA $\sin \mathrm{KOH}$.

Por el contrario, la presencia de $\mathrm{KOH}$ y $\mathrm{H}_{2} \mathrm{O}$ en los polímeros PVA-KOH rompe un gran número de enlaces de hidrogeno entre cadenas, las modificaciones observadas en la región de $3500 \mathrm{~cm}^{-1}$ en los espectros de ATR-FTIR revela que se forma una nueva red de enlaces de hidrogeno, probablemente incluyendo grupos $\mathrm{OH}^{-}$de las cadenas de PVA así como $\mathrm{OH}^{-}$de las moléculas $\mathrm{KOH}$ y $\mathrm{H}_{2} \mathrm{O}$.

Este proceso provoca la separación de las cadenas creando canales más amplios y facilitando el movimiento de los aniones $\mathrm{OH}^{-}$. Debe tenerse en cuenta que el mecanismo de Grotthuss necesita suficiente cantidad de moléculas de $\mathrm{H}_{2} \mathrm{O}$ para formar la esfera de solvatación de los aniones $\mathrm{OH}^{-}$.

Los Esquemas 7.2-2 y 3 muestran el mecanismo de Grotthuss que ocurre dentro de una membrana PVA-KOH 30 y otra PVA-KOH 30 sumergida en $\mathrm{KOH} 12 \mathrm{M}$, respectivamente. Ambos esquemas muestran un transporte de $\mathrm{OH}^{-}$similar a través de los canales de PVA. Sin embargo, en el Esquema 2 la separación entre las cadenas de PVA y la cantidad de $\mathrm{KOH}$ y $\mathrm{H}_{2} \mathrm{O}$ dentro de la matriz polimérica será menor que la observada en el Esquema 3. Así, en las membranas no sumergidas, Esquema 7.2-2, un menor espacio entre cadenas de PVA hará que el movimiento de $\mathrm{OH}^{-}$sea difícil y, probablemente, la mayoría de los aniones de $\mathrm{OH}^{-}$crearán la esfera de solvatación formando puentes de hidrogeno con los grupos $\mathrm{OH}^{-}$de las cadenas de PVA y las moléculas de $\mathrm{H}_{2} \mathrm{O}$. Este hecho influirá en el transporte de $\mathrm{OH}^{-}$dentro de la membrana, 
reduciendo el número de transporte de $\mathrm{OH}^{-}$y el valor de conductividad iónica con respecto a las membranas de PVA-KOH sumergidas (PVA-KOH sw.).

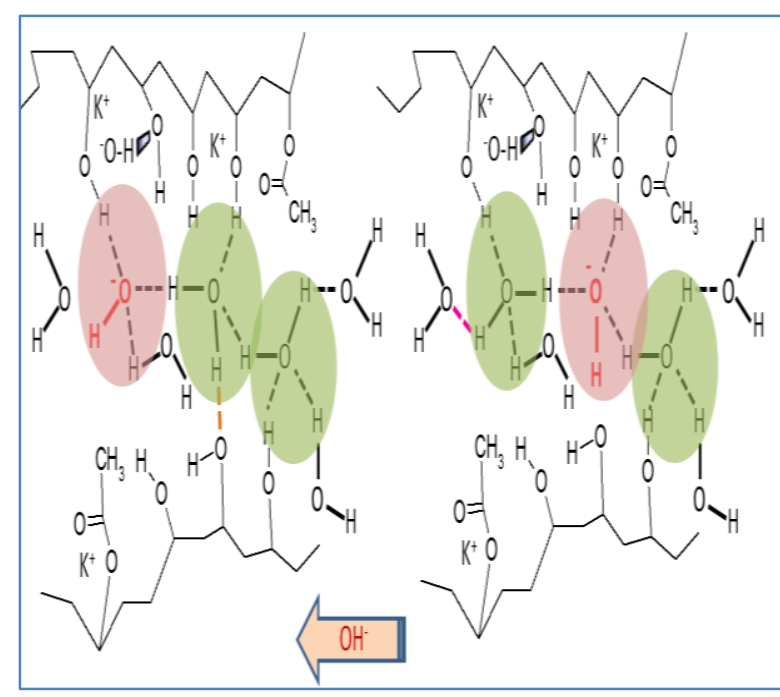

Esquema 7.2-2: Transporte de $\mathrm{OH}$ - siguiendo un mecanismo Grotthuss en una membrana PVA-КОН 30. La flecha indica la dirección de transporte. Durante el transporte $\mathrm{OH}$-, se rompe un enlace por puente de hidrogeno (rosa) y se forma uno nuevo enlace (naranja)

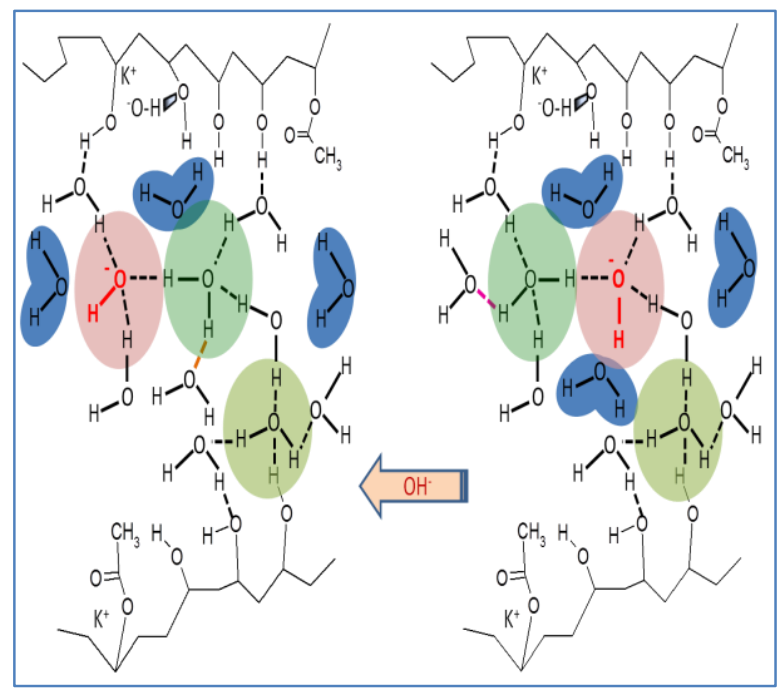

Esquema 7.2-3: $\mathrm{OH}$ - transporte siguiendo un mecanismo de Grotthuss en una membrana PVA- KOH 30 sw. La flecha indica la dirección de transporte $\mathrm{OH}$-. Durante el transporte $\mathrm{OH}$-, se rompe un enlace por puente de hidrogeno (rosa) y se forma uno nuevo (naranja).

Sin embargo, las membranas de PVA-KOH sumergidas en solución de KOH 12 M, presentarán una estructura con un mayor espacio entre cadenas (Esquema 7.2-3). En este caso, un mayor número de aniones $\mathrm{OH}^{-}$será capaz de desarrollar esferas de solvatación completas sólo con moléculas de $\mathrm{H}_{2} \mathrm{O}$ sin formar puentes de hidrogeno con grupos del PVA. Esta situación permitirá un transporte más rápido de los aniones $\mathrm{OH}^{-}$a través de los canales poliméricos. Además, en esta situación, se obtendrán valores de conductividad iónica y número de transporte aniónico más altos, como lo han demostrado nuestros resultados.

\subsection{CONCLUSIONES}

Se han obtenido diferentes membranas de PVA puro y PVA-KOH por el método "solution casting method", estas se han analizado mediante diversas técnicas experimentales y además aplicadas como electrolito polimérico en baterías de Zn/PVA$\mathrm{KOH} /$ aire. Las técnicas XRD, ATR-FTIR y TGA han confirmado la reestructuración de las cadenas de PVA cuando se incluyó una solución acuosa de $\mathrm{KOH}$ en la membrana. 
Además, estas membranas aumentan su peso en una solución acuosa de KOH $12 \mathrm{M}$, se incorpora una mayor cantidad de moléculas de $\mathrm{KOH}$ y $\mathrm{H}_{2} \mathrm{O}$ a la membrana, lo que provoca los cambios en la estructura del polímero.

Las membranas de PVA-KOH sumergidas en una solución acuosa de KOH 12M mejora las propiedades de transporte iónico: se obtuvo una conductividad iónica de $0.34 \mathrm{Scm}^{-1}$ y una energía de activación de $0.16 \mathrm{eV}$ a temperatura ambiente. Además, se produjo un incremento de las intensidades máximas de los picos anódicos y catódicos en los ensayos de voltametría cíclica y mayores valores de capacidad en las baterías de Zn/PVA-KOH/aire.

La mejora de este comportamiento de transporte iónico se ha explicado en base al aumento de los canales entre cadenas de PVA, una matriz polimérica más amorfa y la formación de una nueva red de enlaces por puentes de hidrogeno, todo ello motivado por el aumento de $\mathrm{KOH}$ y $\mathrm{H}_{2} \mathrm{O}$ dentro de las membranas. Finalmente, el número de aniones $\mathrm{OH}^{-}$transportados y el confinamiento de $\mathrm{Zn}^{2+}$ cerca de la superficie del electrodo de $\mathrm{Zn}$ hacen necesario el transporte de los aniones $\mathrm{OH}^{-}$a través de la membrana como principal especie iónica causante de conductividad, lo que puede explicarse por un mecanismo de Grotthuss. 



\section{Conclusiones y Perspectivas Futuras.}

"Science is truth for life, watch religion fall obsolete..." 



\subsection{Conclusiones.}

El objetivo principal del presente trabajo fue la mejora o perfeccionamiento del funcionamiento de una batería de zinc aire actuando sobre los distintos componentes funcionales de la misma. Tal y como se mencionó en este trabajo, el objetivo principal puede ser desgajado en varios objetivos parciales.

En la primera parte de este trabajo, Capitulo (IV), se ha sintetizado y caracterizado un electrolito polimérico compuesto de PVdF-HFP, liquido iónico y una sal de zinc, el cual fue probado como electrolito de una batería de $\mathrm{Zn} / \mathrm{MnO}_{2}$. Este electrolito polimérico, ha sido fabricado de forma sencilla por el método "solution casting method". Se ha variado el tipo de líquido iónico contenido en el gel pero se ha mantenido siempre el mismo tipo de sal, triflato de zinc $\left(\mathrm{ZnTf}_{2}\right)$. Se ha demostrado que los electrolitos de gel polimérico (GPE) pueden ser utilizados en baterías sustituyendo al electrólito líquido.

Más concretamente, hemos observado que el líquido iónico ejerce poca o ninguna influencia cuando la concentración de la sal de triflato de zinc añadida al GPE es suficientemente elevada. Sin embargo se ha constatado que la conductividad de estos electrolitos poliméricos es muy pobre cuando no se añade liquido iónico, con lo que se hace imprescindible el uso de líquidos iónicos si deseamos obtener un valor de conductividad más elevado.

Por otro lado, se ha observado que el disolvente utilizado en el proceso de síntesis del electrolito polimérico da lugar a cambios estructurales, resultando en fases distintas dependiendo del disolvente. Usando THF se obtiene principalmente la fase $\alpha$, mientras que el uso de NMP origina una fase $\beta$. Además la retención de disolvente dentro del GPE se ha puesto de manifiesto por medidas de ATR-FTIR y se ha confirmado que la interacción de los grupos carbonilos del NMP con los cationes $\mathrm{Zn}^{2+}$ es fundamental para favorecer el transporte catiónico dentro de la membrana.

Por último los ensayos realizados a una batería de $\mathrm{Zn} / \mathrm{GPE} / \mathrm{MnO}_{2}$. han demostrado de nuevo, que no existe un comportamiento dependiente del líquido 
iónico, siendo la concentración de sal de zinc añadida, la que determina el rendimiento de estas baterías.

En el segundo artículo (Capítulo V) resultado de este trabajo, se procedió a estudiar otro componente de las baterías de zinc usando el mismo sistema que en el artículo previo, $\mathrm{Zn} / \mathrm{IL}-\mathrm{GPE} / \mathrm{MnO}_{2}$. En este caso, nos centramos en analizar la reacción de oxidación y reducción que se produce en el electrodo negativo cuando se lleva a cabo un proceso de descarga y uno carga, respectivamente.

El electrodo negativo de las baterías de zinc suele ser zinc en polvo, aunque no necesariamente, como se ha expuesto en esta memoria. Sin embargo, el problema subyacente y común a todas las morfologías del zinc que se usan para formar el electrodo negativo, entre otros, es la formación de una capa pasivante de ZnO. Este mecanismo no está aún definido claramente.

Por ello, se han estudiado electrodos de zinc a diferentes estados de carga y descarga por medio de spectroscopía fotoelectrónica de alta energía (HAXPES), XRD con radiación sincrotrón así como XPS convencional. Al ser HAXPES una técnica más energética hemos podido estudiar niveles más internos del Zinc, concretamente el nivel 1s. También se han utilizado las líneas Auger inducidas por los rayos X para estudiar los estados de oxidación. En todos los casos se ha detectado la oxidación del $\mathrm{Zn}_{\text {a } \mathrm{Zn}^{2+}}$ durante la descarga y el proceso inverso durante el proceso de carga, pero esta técnica no nos ha permitido inferir las especies químicas presentes. En cambio, la técnica XRD con radiación sincrotrón ha confirmado la presencia de $\mathrm{Zn}(\mathrm{OH})_{2}$ en estados intermedios de carga y descarga, junto al $\mathrm{ZnO}$, el cual es la única especia presente cuando se realizan descargas más profundas

Por medio de Refinamiento Rietveld comparativo entre los patrones XRD teóricos y experimentales se ha determinado la concordancia de los mismos con solo un área de pico no definida de un $0.3 \%$ lo que nos demuestra la exactitud en la identificación de fases presentes.

Además, estas mismas técnicas han constatado la entrada al electrodo negativo de aniones triflato y de disolvente (NMP) acompañando a los iones $\mathrm{Zn}^{2+}$. Este resultado 
concuerda con las medidas de ATR-FTIR, las cuales confirmaron la interacción entre los cationes $\mathrm{Zn}^{2+}$ y el grupo carbonilo del NMP.

Finalmente se ha propuesto un mecanismo para las reacciones que tienen lugar durante los procesos de oxidación y reducción en el electrodo negativo. Según éste, durante la descarga, se propone la formación de $\mathrm{Zn}(\mathrm{OH})_{2}$ como especie intermedia antes de la obtención de la película pasiva de ZnO. Además, durante la carga, la reducción de $\mathrm{ZnO}$ a $\mathrm{Zn}$ metal se realiza a través de la formación de $\mathrm{Zn}(\mathrm{OH})_{2}$. Sin embargo, no se puede descartar un proceso simultáneo de $\mathrm{Zn}$ a $\mathrm{ZnO}$ y de $\mathrm{ZnO}$ a $\mathrm{Zn}$ directamente.

En el Capítulo VI, se ha estudiado como afecta la adición de distintas cantidades de óxido de bismuto al electrodo negativo de una batería de zinc-aire. Se han usado

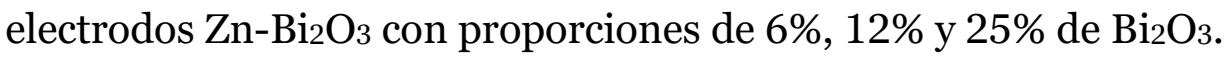

Hemos demostrado mediante análisis XRD con radiación de sincrotrón y otras mediciones electroquímicas y espectroscópicas que sobre el electrodo negativo se genera un depósito de $\mathrm{Bi}$ metálico, debido a la reducción espontánea de $\mathrm{Bi}^{3+}$ a $\mathrm{Bi}$ metálico proporcionada por la oxidación simultánea de $\mathrm{Zn}$ a $\mathrm{Zn}^{2+}$. La reacción espontánea se produce en el medio alcalino antes de la descarga, a circuito abierto y continúa durante la descarga de la batería. El uso de una pequeña cantidad de $\mathrm{Bi}_{2} \mathrm{O}_{3}$ en el electrodo negativo inicial forma un depósito metálico inestable de Bi junto a una capa de $\mathrm{ZnO}$. Sin embargo, el uso de cantidades mayores de $\mathrm{Bi}_{2} \mathrm{O}_{3}$ en los electrodos negativos iniciales proporciona un depósito masivo de Bi metálico estable. En este caso, el depósito de Bi metálico parece evitar la precipitación de $\mathrm{ZnO}$ en el electrodo ya que no se ha observado la presencia de $\mathrm{ZnO}$ en estos casos.

$\mathrm{Al}$ contrario de los electrolito poliméricos usados en los capítulos IV y V, los cuales estaban formados de PVdF-HFP, con líquidos iónicos y sal de triflato de zinc con disolvente orgánico, en el capítulo VII se ha estudiado un electrolito polimérico compuesto de PVA y KOH de base acuosa. La principal característica del PVA dopado con $\mathrm{KOH}$ es que puede formar un hidrogel, el cual es susceptible de aumentar su volumen y peso absorbiendo cantidades extras de electrolito líquido sin poner en 
peligro su estabilidad estructural, pero variando de manera acusada algunas características interesantes para su uso en dispositivos electroquímicos.

Así, se ha visto por XRD que se crean estructuras más amorfas dependiendo tanto del $\mathrm{KOH}$ añadido inicialmente como al sumergir el gel en disolución acuosa de $\mathrm{KOH}$ concentrado (12M). Por medio de XPS se ha demostrado la interacción del potasio dentro de la matriz polimérica con los grupos acetatos residuales debido al proceso de fabricación del PVA. Se considera que los grupos acetatos residuales procedentes del proceso de fabricación son modificados por los aniones hidroxilo por lo que el espectro ATR-FTIR registrado, se modifica de manera considerable respecto al espectro de la estructura inicial de PVA sin $\mathrm{KOH}$. Los espectros de ATR-FTIR demuestran además, la inclusión de agua y $\mathrm{KOH}$ en el gel lo que produce el ensanchamiento de la banda de "stretching" a 3000-3500 cm-1. Este ensanchamiento se vuelve a producir cuando los geles se sumergen en $\mathrm{KOH}$ 12M absorbiendo una cantidad adicional de agua y $\mathrm{KOH}$. El papel fundamental de los aniones hidroxilo se puso de manifiesto comparando el comportamiento de las membranas sintetizadas usando $\mathrm{KCl}$ en vez de $\mathrm{KOH}$. En este caso la estructura inicial del PVA se mantiene, cosa que no ocurre cuando se usa $\mathrm{KOH}$.

La inclusión adicional de agua y $\mathrm{KOH}$ cuando estos hidrogeles son sumergidos en $\mathrm{KOH} 12 \mathrm{M}$, provoca un aumento de la conductividad pero no de la misma forma que lo produciría una cantidad equivalente de $\mathrm{KOH}$ durante el proceso de síntesis. Este aumento de la conductividad se puso de manifiesto mediante VC obteniendo un aumento considerable de las intensidades corriente.

Se ha comprobado mediante EDX de una sección transversal de un gel polimérico utilizada en una descarga de una batería que los cationes $\mathrm{Zn}^{2+}$ no contribuyen en el transporte de carga pues permanecen muy cerca del electrodo negativo. Por lo tanto el transporte es fundamentalmente aniónico.

La reestructuración que se produce en estos hidrogeles cuando son sumergidos en $\mathrm{KOH}$, aumento de volumen y peso, junto con el aumento de la conductividad nos induce a pensar que el transporte de $\mathrm{OH}^{-}$se ve muy favorecido por la creación de canales dentro del gel polimérico los cuales permiten que haya menos interacciones de 
las cadenas poliméricas entre sí, con ruptura de puentes de hidrogeno, y formación de nuevos puentes de hidrogeno entre las moléculas de agua y los grupos $\mathrm{OH}$-de las cadenas poliméricas y de la disolución. En esta situación estos grupos $\mathrm{OH}^{-}$van a estar solvatados con más moléculas de agua. Por tanto, cuanto mayor es la cantidad de agua en el interior del electrolito, se va a facilitar el transporte de los grupos $\mathrm{OH}^{-} \mathrm{y}$, así, aumentará la conductividad del electrolito, como se ha observado experimentalmente. Este transporte aniónico ha sido explicado siguiendo un mecanismo tipo Grotthus.

Finalmente se ha probado el rendimiento del gel en una batería de zinc-aire obteniendo un voltaje de trabajo de $1.2 \mathrm{~V}$ a una intensidad de descarga de $20 \mathrm{mAcm}^{-2}$, lo que demuestra que este tipo de hidrogeles pueden ser utilizados en estos dispositivos. La capacidad obtenida en la descarga, 300mAh entra dentro de lo esperado debido a la poca eficiencia del ánodo de zinc en polvo cuando, este no se ha modificado o nanoestructurado ni se ha dopado o aditivado para alcanzar mayores eficiencias.

\subsection{Perspectivas futuras.}

El último componente fundamental de las baterías de metal-aire es el electrodo de aire. Tal y como se mostró en el Capítulo II, el electrodo de aire contiene un catalizador para facilitar la reacción de reducción del oxígeno del aire. Sobre este componente se comenzó a trabajar en la último periodo de trabajo de esta tesis, pero aún no ha fructificado en forma de artículo científico aunque si en forma de comunicación a congreso de electroquímica.

Un objetivo de una futurible investigación sobre este componente sería obtener un electrodo bifuncional, es decir, que sea activo para ambas reacciones, reducción del oxígeno del aire y evolución de oxígeno; sin embargo, cualquier mejora en la ORR, podría ser utilizada actualmente en baterías de zinc-aire primarias comerciales.

Los catalizadores para las reacciones de reducción y evolución del oxígeno son factores clave para las nuevas tecnologías energéticas, como las pilas de combustible, la separación de agua, etc. A pesar de los tremendos esfuerzos realizados, el desarrollo 
de catalizadores de reducción de oxígeno con alta actividad y bajo coste sigue siendo un gran reto para los científicos.

Tradicionalmente, los catalizadores basados en Pt son considerados como los más eficientes para la reacción de reducción de oxígeno (ORR). Desafortunadamente, la escasa rentabilidad, el alto costo y la lenta actividad catalítica de reducción de oxígeno limitaron las aplicaciones a gran escala de los catalizadores basados en Pt. Para eliminar la dependencia de los catalizadores basados en Pt, se están realizando grandes esfuerzos en el desarrollo de catalizadores sin metales preciosos.

Los óxidos metálicos de transición son una de las alternativas más prometedoras. De hecho el óxido de manganeso $\mathrm{MnO}_{2}$. es el óxido preferido actualmente como catalizador en electrodos de aire usado en baterías de zinc aire comerciales. $\mathrm{El} \mathrm{Cr}_{2} \mathrm{O}_{3}$ es químicamente estable e insoluble tanto en medio ácido como alcalino. Pero la conductividad del el $\mathrm{Cr}_{2} \mathrm{O}_{3}$ es bastante débil, lo que inhibe su aplicación en campos de investigación electroquímica. Muy recientemente, se ha demostrado que la combinación de tales óxidos con formas alotrópicas de carbono (grafito, grafeno y óxido de grafeno) y sus derivados, da a lugar a una familia de materiales compuestos (composites) con aplicaciones muy prometedoras (actividad fotocatalítica, catalizadores en baterías o células solares). Soportando $\mathrm{Cr}_{2} \mathrm{O}_{3}$ sobre materiales carbonosos como el grafeno, se pretende aumentar esta conductividad electrónica.

En nuestro laboratorio se han investigado materiales nano- $\mathrm{Cr}_{2} \mathrm{O}_{3}$ soportados en grafeno, GO y grafito. Estos composites mostraron actividad catalítica para la ORR usando la técnica RDE “rotating disc electrodo”. Esta línea de trabajo se seguirá usando con otros materiales disponibles, ya en nuestro laboratorio, a base de materiales carbonosos nanoestructurados.

Por otro lado, el óxido de bismuto es un material interesante desde el punto de vista electroquímico. Se ha usado como aditivo, material activo en sensores, fotocatalizador, etc., con la única debilidad de su baja densidad energética en lo que respecta a su uso en baterías. 
Su baja conductividad electrónica como la mayoría de óxidos, se ha podido mejorar simplemente añadiendo el óxido a un soporte metálico y con esta disposición se ha podido comprobar la reversibilidad del óxido de bismuto usado como cátodo durante el desarrollo de baterías recargables. Esta línea de trabajo ya ha producido una comunicación a un congreso de electroquímica.

Baterías de óxido de bismuto como material activo se han fabricado y probado tanto con electrolitos líquidos como con electrolitos poliméricos en medio alcalino, mostrando rendimientos culómbicos por encima del 90\%, lo cual es un acicate para seguir esta línea de investigación.

También se ha observado una diferencia de potencial entre el "plateau" de descarga con la de carga de alrededor de $100 \mathrm{mV}$, lo cual es prometedor. Aun teniendo el hándicap de la baja densidad energética gravimétrica, debemos tener en cuenta que las baterías de plomo con su baja densidad energética se siguen utilizando en sistemas de almacenamiento de energía estacionario, estamos convencidos que el óxido de bismuto será utilizado como material activo en sistemas de almacenamiento electroquímico. 


\subsection{Conclusions.}

The main objective of the present work was the improvement of the operation of a zinc-air battery working on its different functional components. As mentioned in this paper, the main objective can be broken down into several sub-objectives.

In the first part of this work, Chapter (IV), we have worked on the electrolyte of a $\mathrm{Zn} / \mathrm{MnO}_{2}$. battery. The polymeric gel electrolyte composed of PVdF-HFP as matrix, has been manufactured in a very straightforward way by the "solution casting method". The type of ionic liquid contained in the gel has been changed but the same type of salt has always been used, zinc triflate (ZnTf2). It has been shown that polymer gel electrolytes (GPE) can be used in batteries replacing the liquid electrolyte.

More specifically, we have observed that the ionic liquid exerts little or no influence when the concentration of zinc triflate salt added to the GPE is high enough to mask this influence. However, it has been found that the conductivity of these polymeric electrolytes is very poor when no ionic liquid is added, making the use of ionic liquids essential if a higher conductivity value is to be obtained.

On the other hand, it has been observed that the solvent used in the polymer electrolyte synthesis process results in structural changes, giving rise to different phases within the PVdF-HFP depending on the solvent. Using THF we obtained mainly the phase $\alpha$, and this one with a more defined crystalline structure according to the XRD results. However, when NMP is used, the phase obtained is likely to be the $\beta$ phase. Solvent retention within the GPE has also been evidenced by ATR-FTIR measurements and the interaction of NMP carbonyl groups with $\mathrm{Zn}^{2+}$ cations has been confirmed.

After the electrochemical study of this polymeric gel, it has been used in a Zinc/GPE/ $\mathrm{MnO}_{2}$. battery. Likewise, it has been shown that no behaviour could be ascribed to be ionic liquid dependant, being the triflate salt concentration determining the performance of these polymeric electrolytes.

In the second article (Chapter V) resulting from this work, another zinc battery component was studied using the same system as in the previous article, $\mathrm{Zn} / \mathrm{GPE} / \mathrm{MnO}_{2}$. 
The negative electrode of zinc batteries is usually zinc powder, although not necessarily, as discussed in this paper. However, the underlying problem common to all kind of zinc morphologies used to form the negative electrode, among others, is the formation of a passivating layer of $\mathrm{ZnO}$. This mechanism is not clearly defined.

Thus, zinc electrodes at different states of charge have been studied by means of high energy photoelectronic spectroscopy (HAXPES) and XRD with synchrotron radiation as well as conventional XPS. Since HAXPES is a more energetic technique, we have been able to study more internal levels of the Zinc, specifically level 1s. X-rayinduced Auger lines have also been used to study oxidation states. In all cases the oxidation of $\mathrm{Zn}$ to $\mathrm{Zn}^{2+}$ during discharge and the inverse process during the charging process has been ratified, but we have not been able to find out what zinc-containing chemical species were present. In a second phase, and employing XRD with synchrotron radiation, the presence of $\mathrm{Zn}(\mathrm{OH})_{2}$ is confirmed in intermediate states of charge and discharge, and only $\mathrm{ZnO}$ was present when deeper discharges were carried out.

Rietveld Refinement has determined the concordance between the theoretical and experimental XRD patterns with only an undefined peak area of $0.3 \%$, which stands out the accuracy in the identification of phases present.

During the recharge, the entrance of triflate anions and NMP solvent accompanying the $\mathrm{Zn}^{2+}$ ions to the negative electrode have been recorded. Also, studying ATR-FTIR records, we have observed the chemical interaction between $\mathrm{Zn}^{2+}$ and NMP's carbonyl groups, shifting of the band.

Finally, a mechanism for the reactions that take place during the oxidation and reduction processes in the negative electrode has been proposed. Besides, the formation of the species $\mathrm{ZnO}$ and $\mathrm{Zn}(\mathrm{OH})_{2}$ has been justified by the presence of water, either, contained in the commercial ionic liquid or absorbed by the GPE from the atmosphere. Accordingly, the water present inside the GPE was calculated, by DSC, to be sufficient to obtain all the species containing oxygen and hydrogen.

In Chapter VI, it has been studied, how the addition of different amounts of bismuth oxide affects, the negative electrode performance in a zinc-air battery. 


\section{CAPÍTULO VIII. Conclusiones y Perspectivas Futuras.}

We have demonstrated by synchrotron XRD diffraction analysis and other electrochemical and spectroscopic measurements that a metallic Bi deposit is generated on the positive electrode of $\mathrm{Zn}-\mathrm{Bi}_{2} \mathrm{O}_{3}$, due to the spontaneous reduction from $\mathrm{Bi}^{3+}$ to metallic $\mathrm{Bi}$ coupled with the simultaneous oxidation of $\mathrm{Zn}$ to $\mathrm{Zn}^{2+}$. This spontaneous reaction occurs in the alkaline medium even at OCV period and continues during the battery discharge. The use of a small amount of $\mathrm{Bi}_{2} \mathrm{O}_{3}$ on the initial negative electrode forms an unstable metal $\mathrm{Bi}$ deposit together with a layer of $\mathrm{ZnO}$. However, the use of larger amounts of $\mathrm{Bi}_{2} \mathrm{O}$ in the initial negative electrode provides a massive deposit of stable metallic Bi. In this case, the deposition of metallic Bi seems to avoid the precipitation of $\mathrm{ZnO}$ in the electrode since the presence of $\mathrm{ZnO}$ has not been observed.

Whereas in Chapters IV and V polymeric electrolytes formed from PVdF-HFP, with ionic liquids and zinc triflate salt with an organic solvent have been used, in this chapter, we have studied a polymeric electrolyte composed of PVA and $\mathrm{KOH}$ in an aqueous base. The main characteristic of $\mathrm{KOH}$-doped PVA is that it can form a hydrogel, which is prone to increase its volume and weight by absorbing extra amounts of liquid electrolyte without jeopardizing its structural stability but changing sharply interesting characteristics related to its suitability to be used in electrochemical devices.

Thus, according to XRD results, more amorphous structures are created depending on both, the initially added $\mathrm{KOH}$ and by submerging the gel in an aqueous solution of concentrated $\mathrm{KOH}(12 \mathrm{M})$. By XPS, the interaction of potassium, within the polymeric matrix, with the residual acetate groups due to the PVA manufacturing process has been demonstrated. Residual acetate groups from the manufacturing process are modified in some way, hydrolysis is a plausible possibility, by hydroxyl anions as they are labile groups. Therefore, the ATR-FTIR recorded once the $\mathrm{KOH}$ is added is considerably different to the one recorded when PVA doesn't contain $\mathrm{KOH}$.

ATR-FTIR demonstrates the inclusion of water and $\mathrm{KOH}$ in the gel which causes the broadening of the stretching band at 3000-3500 $\mathrm{cm}^{-1}$. This broadening occurs to a greater extent when the gels are immersed in $\mathrm{KOH} 12 \mathrm{M}$ absorbing an additional amount of water and $\mathrm{KOH}$. The fundamental role of hydroxyl anions was demonstrated 
by comparing the behaviour of membranes using $\mathrm{KCl}$ instead of $\mathrm{KOH}$. In this case, the initial structure of the PVA is maintained, which does not occur when $\mathrm{KOH}$ is used.

The additional incoming of water and $\mathrm{KOH}$ when these hydrogels are submerged in $\mathrm{KOH} 12 \mathrm{M}$ causes an increase in conductivity but not in the way that an equivalent amount of $\mathrm{KOH}$ would produce during the synthesis process. Besides, adding an extra amount of $\mathrm{KOH}$ during the synthesis would produce a structural deterioration of the hydrogels. The increase in conductivity was evidenced by VC obtaining higher currents.

It was proven by EDX of a cross-section of a polymeric gel used in a battery discharge that the $\mathrm{Zn}^{2+}$ cations do not contribute to the charge transport as they remain very close to the negative electrode. Therefore transport is fundamentally anionic

The rearrangement that occurs in these hydrogels when they are submerged in $\mathrm{KOH}$, with volume and weight increasing, along with higher conductivity values leads us to think that the transport of $\mathrm{OH}$ - is greatly favoured by the creation of wider channels inside the polymeric gel. This wider channels will allow fewer inter polymeric chain interactions, and new hydrogen bonds between water molecules and $\mathrm{OH}$ groups, belonging to both polymeric chains and solution, will be created. Thus, these $\mathrm{OH}$ - groups are going to be solvated with more water molecules.

Once these $\mathrm{OH}$ - groups are sufficiently solvated, the Grotthus mechanism can be proposed as the main transport mechanism, but we cannot rule out another transport mechanism. The amount of water is, therefore, fundamental to obtain good conductivity values.

Finally, the performance of the gel in a zinc-air battery was tested, demonstrating that it can be used in these devices with a working voltage of $1.2 \mathrm{~V}$ and a discharge intensity of $20 \mathrm{mAcm}^{-2}$. The capacity obtained in the discharge is within expectations due to the low efficiency of the powdered zinc anode, when it has not been modified or nanostructured or doped to achieve greater efficiencies. 


\subsection{Future perspectives.}

The last fundamental component of metal-air batteries is the air electrode. As shown in Chapter II, the air electrode contains a catalyst to facilitate the oxygen reduction reaction of the air. Work on this component began in the last period of this thesis, but it has not yet fructified in the form of a scientific article but in a communication to an electrochemistry congress.

The ultimate goal would be to obtain a bifunctional electrode, i.e. one that is active for both air oxygen reduction and oxygen evolution reactions, however any improvement, in the ORR, could currently be used in commercial primary zinc-air batteries.

Catalysts for oxygen reduction and evolution reactions are key factors for new energy technologies such as fuel cells, water separation, etc. Despite tremendous efforts, the development of low-cost, high activity oxygen reduction catalysts remains a major challenge for scientists.

Traditionally, Pt-based catalysts are considered the most efficient ones for oxygen reduction reaction (ORR). Unfortunately, low profit, high cost and slow catalytic oxygen reduction activity limited the large-scale applications of Pt-based catalysts. To eliminate the dependence on Pt-based catalysts for oxygen reduction, major efforts are being made to develop catalysts without precious metals.

Transition metal oxides are one of the most promising alternatives. As a matter of fact , manganese oxide $\left(\mathrm{MnO}_{2}\right.$.) is currently the preferred oxide as a catalyst in air electrodes used in commercial air zinc batteries. $\mathrm{Cr}_{2} \mathrm{O}_{3}$ is chemically stable and insoluble in both acidic and alkaline media., but the conductivity of $\mathrm{Cr}_{2} \mathrm{O}_{3}$ is quite weak, which inhibits its application. Very recently, it has been demonstrated that the combination of such oxides with allotropic forms of carbon (graphene, graphite and graphite oxide) and their derivatives, gives rise to a family of composite materials with very promising applications (photocatalytic activity, catalysts in batteries or solar cells). By supporting $\mathrm{Cr}_{2} \mathrm{O}_{3}$ on carbonaceous materials, it is intended to increase this electronic conductivity. 
In our laboratory, we have already worked with nano- $\mathrm{Cr}_{2} \mathrm{O}_{3}$ materials supported in graphene, GO and graphite. These composites showed catalytic activity for ORR using the RDE technique "rotating disc electrode". On the other hand, this line of research will continue in our lab using other materials already available in our laboratory, based on nanostructured carbonaceous materials, such as aerogels, carbonaceous inks, etc.

Bismuth oxide, on the other hand, is an interesting material from an electrochemical point of view which is widely used as additive, active material in sensors, photocatalyst, etc. Its only weakness, due to its low gravimetric energy density, is a concern regarding its use in batteries. Anyway, we have to recall that lead is still in use as active material in stationary electrochemical storage systems, being even heavier than bismuth, so could be bismuth in a short term a replacement for lead.

Its low electronic conductivity, like most oxides, has been improved by simply adding the oxide to a metal support and with this arrangement, the reversibility of the bismuth oxide used as a cathode has already been verified by ourselves during the development of rechargeable batteries. This line of work has already produced a communication to an electrochemistry congress.

Bismuth oxide batteries as active material have been built and tested with both, liquid electrolytes and polymeric electrolytes in an alkaline medium, showing coulombic yields above $90 \%$, which is an incentive to follow this line of research. 

Anexo I. Índice de Tablas. 



\section{CAPÍTULO I. Introducción y Panorama General.}

Tabla 1.1-1: Características de las baterías metal-aire. 10

\section{CAPITULO II. Revisión Teórica y Bibliográfica.}

Tabla 2.1-1: Principales propiedades del zinc utilizado en aplicaciones de baterías. 28

Tabla 2.1-2: Propiedades relevantes de una disolución de $\mathrm{KOH} 35 \%$ en peso de $\mathrm{KOH}$.................... 31

Tabla 2.3-1: Polímeros más comunes utilizado para fabricar GPEs y SPEs. .................................... 39

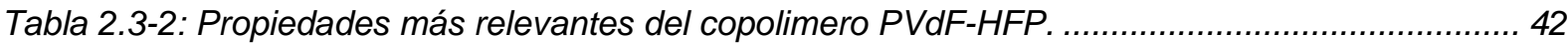

Tabla 2.3-3. Algunas de las propiedades físicas de los disolventes orgánicos más utilizados en el campo de investigación de los GPEs. 46

Tabla 2.3-4: Propiedades físicas y químicas más relevantes del PVA .............................................. 50

Tabla 2.5-1: Potenciales de electrodo termodinámicas de reducción electroquímica del $\mathrm{O}_{2}$............... 54

\section{CAPÍTULO III. Metodología Experimental.}

Tabla 3.2-1: Materiales utilizados en este trabajo.

Tabla 3.2-2: Composición de todos los GPES sintetizados y nomenclaturas utilizadas. IL representa los diferentes líquidos iónicos: EMIM TFSI (ET), BMIM TF (BTF) Y EMIM TF (ETF). En todos los casos se emplearon 3,6 g de NMP. También se incluye el polímero PVDF-HFP. 75

\section{CAPÍTULO IV. Influence of the Ionic Liquid Type on the Gel Polymer Electrolytes Properties.}

Tabla 4.1-1: Composición de todos los GPEs sintetizados y nomenclaturas utilizadas. IL representa los diferentes líquidos iónicos: EMIM TFSI (ET), BMIM Tf (BTf) y EMIM Tf (ETf). En todos los casos se emplearon 3,6 g de NMP. También se incluye el polímero PVdF-HFP. 105

Tabla 4.2-1: Temperatura de transición vitrea, Tg, conductividad iónica, $\sigma$, energía de activación, E, y números de transporte catiónico, $t_{+}$, para los electrolitos poliméricos estudiados. $\sigma$ y valores $t_{+}$ obtenidos a $30{ }^{\circ} \mathrm{C}$.

CAPÍTULO V. A Synchrotron X-Ray Diffraction and Hard x-Ray Photoelectron Spectroscopy Study of $\mathrm{Zn}$ Negative Electrodes at Different Charge and Discharge States of $\mathrm{Zn} / \mathrm{MnO2}$ Batteries Using an Ionic Liquid-Based Gel Polymer Electrolyte.

Tabla 5.2-1: Cantidades relativas de las diferentes especies en los electrodos negativos analizados obtenidas por el ajuste de datos de Rietveld. 
CAPÍTULO VI. In Situ Synchrotron X-Ray Diffraction Study of Zn/Bi2O3 Electrodes Prior to and during Discharge of Zn-Air Batteries: Influence on ZnO Deposition.

Tabla 6.2-1: Composiciones de electrodos, capacidades de las baterías y rendimientos de Zn...... 143

CAPÍTULO VII. Structural Modifications and lonic Transport of PVA-KOH Hydrogels Applied in Zn / Air Batteries.

Tabla 7.1-1: Diversos valores experimentales para diferentes membranas de PVA-KOH. 154

Tabla 7.2-1: Valores para diferentes membranas de PVA-KOH-30 después de su inmersión durante 24 horas en $\mathrm{KOH} 12 \mathrm{M}$. 156 
Anexo II. Índice de figuras. 



\section{Anexo II. Índice de figuras}

\section{CAPÍTULO I. Introducción y Panorama General.}

Figura 1.1-1: Emisión total de gases de efecto invernadero en EE.UU. en 2016.

Figura 1.1-2: Aumento previsto del consumo de energía en el sector del transporte. Tomado de la referencia 3.

Figura 1.1-3: Generación global de electricidad en la propuesta 2DS, izquierda. \% de energía renovable en la generación de electricidad por regiones, derecha.

Figura 1.1-4: Posicionamiento de diversas tecnologías de almacenamiento de energía según su potencia nominal y tiempos de descarga.

Figura 1.1-5: Ingresos de las empresas de la industria de semiconductores afiliadas a la WSTS (World semiconductor trade statistics). Tomado de la referencia 12.

Figura 1.1-6: Densidad de energía específica teórica de varios sistemas de baterías, incluyendo los tipos representativos de sistemas de baterías metal-aire, litio-aire y zinc-aire. Tomado de Jülich Forchung Zentrum. 9

Figura 1.1-7: Baterías para sistemas de tracción de vehículos eléctricos. Referencia 24.................. 10

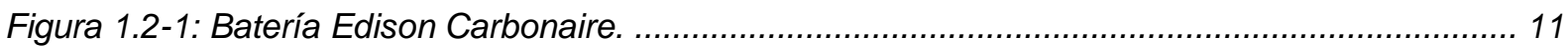

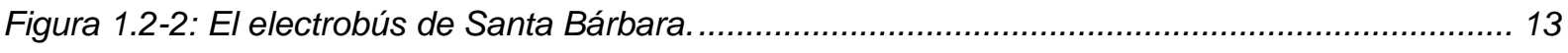

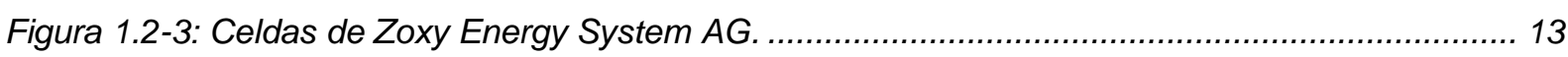

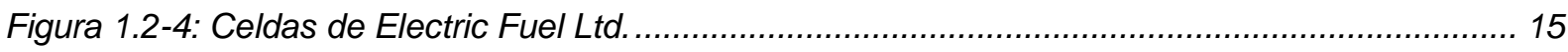

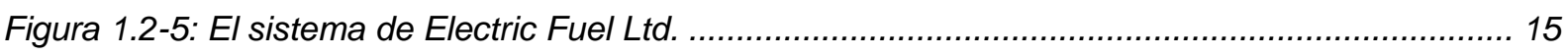

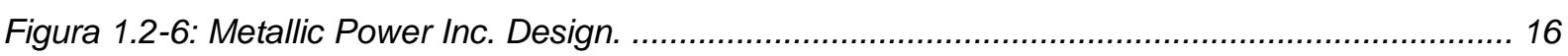

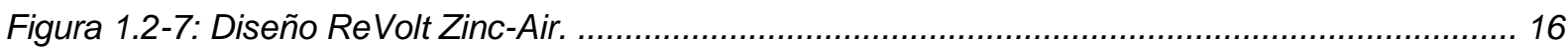

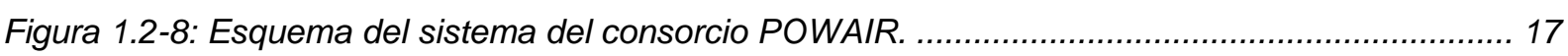

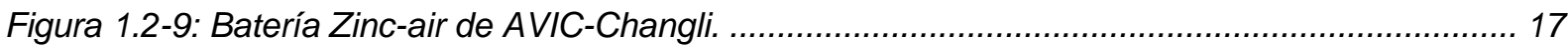

\section{CAPITULO II. Revisión Teórica y Bibliográfica.}

Figura 2.1-1: Esquema de una pila de botón de zinc-aire comercial. Tomado de la referencia dos.... 27 Figura 2.1-2: Diferentes morfologías de zinc producidos por diferentes métodos. Reproducido de11.29 Figura 2.1-3: Conductividad de disoluciones de $\mathrm{KOH}$ a distintas concentraciones y solubilidad del ZnO en las mismas disoluciones 17.

Figura 2.1-4: Vista esquemática de un electrodo de difusión de gas, a la izquierda. Componentes de un Electrodo de aire E4B suministrado por Electric Fuel Ltd., a la derecha. 32

Figura 2.2-1: Vista esquemática de las reacciónes químicas implicadas en una batería de zinc-aire. El zinc se oxida en el ánodo para formar ZnO vía zincato. El oxígeno permea a través del electrodo de aire y se reduce para formar aniones hidroxilo. El CO2 presente en el aire también se disuelve en el electrolito para formar carbonato.

Figura 2.2-2: Representación esquemática de un límite de tres fases entre las partículas catalíticas. 36 
Figura 2.3-1: SPE electrolito polimérico sólido, izquierda, GPE, gel polimérico, centro, polielectrolito, derecha.

Figura 2.3-2: Cationes y aniones más comunes en la formación de los líquidos iónicos (ILs). Tomado

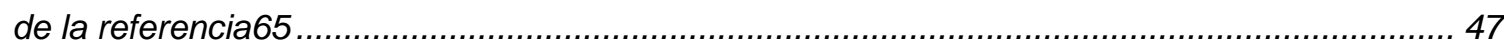

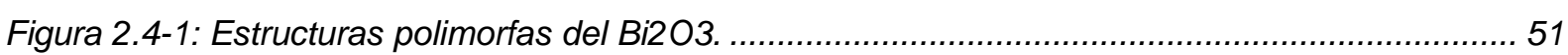

Figura 2.5-1: Modelos para la adsorción de oxígeno en una superficie de metal y caminos de reacción

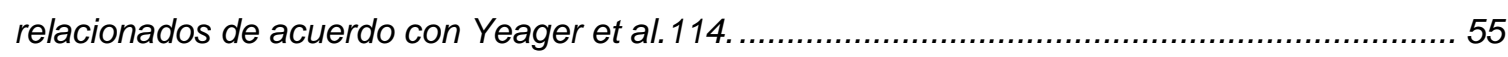

Figura 2.5-2: Actividad de catalizadores metálicos en función de la energía de enlace. ..................... 57

\section{CAPÍTULO III. Metodología Experimental.}

Figura 3.2-1: A) Proceso esquemático para la fabricación de membranas usando el método "solution casting method". B) Desecador termostático. C) y D) Membranas de PVdF-HFP-ZnTf2 y PVA-

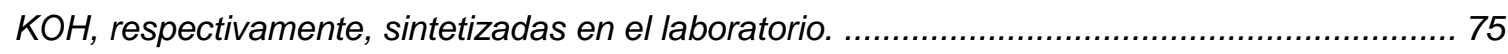

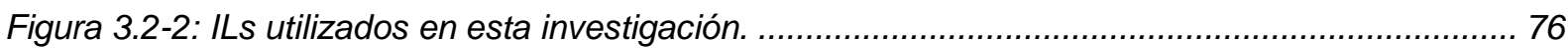

Figura 3.2-3: Esquema del proceso de fabricación de un electrodo de aire a escala de laboratorio con catalizador de $\mathrm{MnO2}$, parte superior. Imagen de un electrodo de aire fabricado en el laboratorio, parte inferior.

Figura 3.2-4: Prensa hidráulica donde se realizaron los cátodos por prensado de la mezcla de los componentes.

Figura 3.2-5: Batería con GPE completamente montada (izquierda). Los componentes de la misma batería (derecha).

Figura 3.2-6: Vista esquemática de la celda electroquímica utilizada para electrolitos líquidos (izquierda). Componentes de la celda (centro).Batería completamente montada (derecha). .... 79

Figura 3.3-1: Configuración básica $S E M^{4}$ (izquierda) y equipo de microscopia electrónico de barrido en el Servicio de Apoyo a la Investigación Tecnológica utilizada en esta investigación, derecha. .. 80

Figura 3.3-2: Diagrama de la interacción física entre la muestra y el haz de electrones. del HelmholtzZentrum Dresden-Rossendor.

Figura 3.3-3: Esquema de funcionamiento XRD; Ecuación de Bragg y explicación geométrica para la difracción de la radiación $X$.

Figura 3.3-4: Bruker D8 Advance (Bruker AXS GmbH (izquierda) y el esquema básico de difracción de rayos $X$ óptica de un difractómetro (derecha).

Figura 3.3-5: Componente básico de una instalación de radiación de sincrotrón. Tomado del sitio web del ESRF.

Figura 3.3-6: Dispositivo de inserción tipo ondulador (izquierda), "tipo de lombriz" (centro) e imán de flexión (derecha).

Figura 3.3-7: Vista esquemática de principio de funcionamiento de XPS (izquierda) y la configuración HAXPES utilizado en SpLine rama B (derecha). 
Figura 3.3-8: Estructura esquemática de los espectrómetros de IR. A: espectrómetro dispersivo, la resolución espectral se logra por una rejilla como elemento dispersivo. B: espectrómetro de $F T$ IR: la información espectral se genera por el interferómetro Michelson, registrado como un interferograma y convertido en un espectro por transformación de Fourier. 88

Figura 3.3-9: Representación esquemática del campo evanescente (izquierda). La intensidad del campo disminuye exponencialmente al aumentar la distancia desde la superficie. Equipo FTIRATR utilizado en esta investigación (derecha).

Figura 3.3-10: Vista esquemática de un "heat flux" DSC (izquierda). Equipo de DSC utilizado en esta investigación (derecha). 90

Figura 3.3-11: Estructura esquemática de un sistema horizontal (izquierda). Equipo de TGA utilizado en esta investigación (derecha).

Figura 3.4-1: Potenciostato VSP de cinco canales usado en este trabajo (izquierda). Esquemas de configuración de electrodos (derecha).

Figura 3.4-2: Forma gráfica típica de CV para diferentes sistemas electroquímicos y señal de entrada (recuadro).

Figura 3.4-3: Fórmulas espectroscopia de impedancia (izquierda). Representación en plano complejo de la impedancia (derecha). .95

Figura 3.4-4: Gráfico típico de Nyquist (izquierda). Diagrama de Bode (derecha)............................. 96

Figura 3.4-5: Esquema del proceso de una carga y descarga galvanostatica. 97

\section{CAPÍTULO IV. Influence of the Ionic Liquid Type on the Gel Polymer Electrolytes Properties.}

Figura 4.2-1: Difractogramas XRD: PVdF-HFP (THF), PVdF-HFP (NMP) y BTf-ZnTf2 GPE 1,3 y 4. 106 Figura 4.2-2: Espectros ATR-FTIR de GPEs analizados en el rango de frecuencia de $1580-1730 \mathrm{~cm}-1$ para (A) BTf-ZnTf2.-GPEs; y (B) ETf-ZnTf2-GPEs. Insertos: Espectros ATR-FTIR de disolvente NMP, IL puro, ZnTf2 GPE y PVdF-HFP (NMP). 107

Figura 4.2-3. Espectros ATR-FTIR de GPEs analizados en el rango de frecuencia de 1000-1080 cm-1 para (A) BTf-ZnTf2.-GPEs; y (B) ETf-ZnTf2-GPEs. Insertos: Espectros ATR-FTIR de disolvente

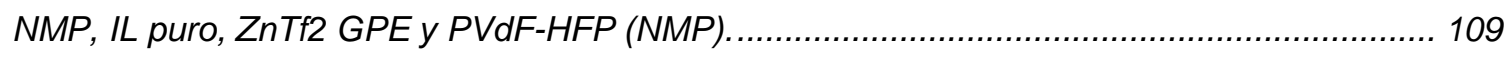

Figura 4.2-4: Gráficos DSC de (A) BTf-ZnTf2-GPEs; (B) BTf-ZnTf2-GPEs. .................................. 111

Figura 4.2-5: : Gráficos VTF de (A) GPEs BTf-ZnTf2; y (B) GPEs BTf-ZnTf2 ............................. 111

Figura 4.2-6: Numero de transporte catiónico y aniónico para IL-ZnTf2 GPEs vs masa de ZnTf2.... 112 Figura 4.2-7: Voltametría cíclica de las celdas Zn/GPE/Zn para BTf-ZnTf2 GPE 4, ETf-ZnTf2 GPE 4 y ET-ZnTf2 GPE 4. Recuadro: 20 ciclos consecutivos de ETf-ZnTf2 GPE 4 y BTf-ZnTf2 GPE 4 comparado con ZnTf2-GPE 4. Velocidad de barrido $=20 \mathrm{mV} / \mathrm{s}$. 112

Figura 4.2-8: Primeros ciclos de descarga de una celda Zn/GPE/MnO2 a $1 \mathrm{mAcm}-2$ para BTf- ZnTf2 GPE 6, ETf-ZnTf2 GPE 6 y ET-ZnTf2 GPE 6. El voltaje de corte a $0.4 \mathrm{~V}$. 114 
Figura 4.2-9: $\sigma$ total, aniónico, $\sigma$ - y catiónico, $\sigma+$ para los tres IL-GPEs sin sal. Recuadro: Número de transporte aniónico y catiónico para el mismo IL-GPE libre de sal.

Figura 4.2-10: Deconvolución de picos ATR-FTIR en el rango 3000-3240 frente a la masa de ZnTf2.

La leyenda indica ILs.

Figura 4.2-11: Espectros ATR-FTIR en el rango $3000-3240 \mathrm{~cm}-1$ para (A) ILs puras; (B) IL-GPEs sin sal; $y$ (C) IL-ZnTf2 GPEs 4. La leyenda indica los nombres de IL. 115

\section{CAPÍTULO V. A Synchrotron X-Ray Diffraction and Hard x-Ray Photoelectron Spectroscopy Study of $\mathrm{Zn}$ Negative Electrodes at Different Charge and Discharge States of $\mathrm{Zn} / \mathrm{MnO2}$ Batteries Using an Ionic Liquid-Based Gel Polymer Electrolyte.}

Figura 5.1-1: Curvas de descarga (A) y carga (B) obtenidas para baterías Zn/IL-GPE/MnO2. Se muestran las tensiones de corte alcanzadas durante los procesos de descargas y las cargas se realizaron hasta alcanzar la misma capacidad de carga q se descargó previamente.

Figura 5.2-1: a) Espectros HAXPES Zn 2p3/2, b) Espectros XPS Zn 2p3/2 de una fuente convencional y c) Espectros HAXPES Zn 1s. La línea negra corresponde a la lámina prístina de Zn, la línea roja al ánodo de $Z n$ descargado y la línea verde al electrodo de $Z n$ recargado. 123

Figura 5.2-2: a) Espectros HAXPES para la línea Zn LMM, b) Espectros XPS para la línea Zn LMM y c) Espectros HAXPES para la línea Zn KLL. La línea negra corresponde a la lámina prístina de $Z n$, la línea roja al ánodo de Zn descargado y la línea verde al electrodo de Zn recargado..... 125

Figura 5.2-3: a) Espectros HAXPES O 1s y b) Espectros XPS O 1s de una fuente de laboratorio. La línea negra corresponde a la lámina prístina de Zn, la línea roja al ánodo de Zn descargado y la línea verde al electrodo de $Z n$ recargado.

Figura 5.2-4: HAXPES a) $F$ 1s y b) Espectros $S$ 1s para electrodos de Zn cargados y descargados. Las líneas roja y verde corresponden a los electrodos de $\mathrm{Zn}$ descargados y recargados, respectivamente.

Figura 5.2-5: Difractogramas de rayos $X$ de lámina prístina de $Z n$ (azul), y los ánodos de $Z n$ descargados hasta 1.1 (magenta), 0.8 (verde) y $0.4 \mathrm{~V}$ (rojo), denominados como D-1.1, D-0.8 y $D-0.4$, respectivamente. Los picos se asignan a $\mathrm{Zn}, \mathrm{ZnO}$ y $\mathrm{Zn}(\mathrm{OH}) 2$ con los símbolos que se identifican en la leyenda. El recuadro muestra el tamaño de cristalito del $\mathrm{ZnO}$ en los tres estados de descarga. 128

Figura 5.2-6: Difractogramas de rayos $X$ de los electrodos de $Z n$ descargados hasta 1.1, 0.8 y $0.4 \mathrm{~V}$ y luego recargados hasta obtener la misma capacidad descargada, denominada C-1.1 (azul marino), C-0.8 (verde) y C-0.4 (rojo), respectivamente. Los picos se asignan a $\mathrm{Zn}, \mathrm{ZnO}, \mathrm{Zn}(\mathrm{OH}) 2$ y ZnTf2 con los símbolos que se identifican en la leyenda. El recuadro muestra los tres difractogramas de rayos $X$ en la región de 4-12 grados. 128 
Figura 5.2-7: Comparación entre espectros de rayos $X$ experimentales (puntos azules) y los obtenidos por los refinamientos de Rietveld (líneas rojas). $\lambda=1.12701 \AA$.

Figura 5.2-8: Espectros ATR-FTIR de a) SO3 y b) $\mathrm{C}=\mathrm{O}$ regiones del grupo de electrodos negativos de Zn cargados y descargados. Se han incluido como referencia los espectros BMIMTF y NMP. c) Espectros ATR-FTIR de la región del grupo OH del GPE basado en BMIMTf. El líquido iónico BMIMTf se muestra como referencia. 132

Figura 5.2-9: a) Curva TGA de GPE basado en BMIMTF. B) Curva derivada del análisis de TGA. Los recuadros muestran la región de temperatura donde se evapora el agua. 132

Figura 5.3-1: Mecanismo propuesto para la formación y destrucción de especies de $Z n$ en el electrodo negativo durante los procesos de descarga y carga.

\section{CAPÍTULO VI. In Situ Synchrotron X-Ray Diffraction Study of Zn/Bi2O3 Electrodes Prior to and during Discharge of $\mathrm{Zn}$-Air Batteries: Influence on ZnO Deposition.}

Figura 6.2-1: Celda Electroquímica situada en el portamuestras del difractómetro de rayos $X$ en la línea de haz BM-25 del sincrotrón ESRF. B) Esquema de la celda electroquímica utilizada en las mediciones de XRD del sincrotrón. C) Configuración de la misma celda electroquímica donde ambos electrodos estaban orientados el uno hacia el otro para realizar descargas convencionales y mediciones de OCV. 139

Figura 6.2-2: A) Difractogramas $X R D$ de sincrotrón de muestras de referencia de $\mathrm{Bi2O}$ y $\mathrm{Zn}$-Bi2O3 comparados con un $\mathrm{Zn}$-Bi2O3 6\% sumergido en solución de $\mathrm{KOH}$ antes de iniciar la descarga de la batería. B) Difractogramas XRD de sincrotrón de muestras de Zn-Bi2O3 con diferentes cantidades de Bi2O3 (6\%, 12\% y 25\%) sumergidas en solución de $\mathrm{KOH}$ antes de iniciar la descarga de la batería.

Figura 6.2-3: Evolución del voltaje a circuito abierto (OCV) registradas para los electrodos negativos $\mathrm{Zn}$-Bi2O3 en tres rangos de tiempo diferentes. Se ha incluido la curva OCV de Bi2O3 puro para comparar. Electrolito: $6 \mathrm{M} \mathrm{KOH}$ en agua.

Figura 6.2-4: A) Difractogramas de XRD convencional de Zn-Bi2O3 6\% y 25\% después de 24 horas a OCV en solución de $6 \mathrm{M} \mathrm{KOH}$. B) Difractogramas de XRD convencionales de muestras de Zn y $\mathrm{Zn}$-Bi2O3 con diferente cantidad de Bi2O3. Las líneas verticales muestran los mismos PDF mostrados en la Figura 6.2-2, excepto en A, donde el PDF- 01-072-0398 se muestra para Bi2O3: $\mathrm{Zn}$ (azul), $\mathrm{ZnO}$ (verde), Bi2O3 (negro) y Bi (rojo). Recuadro: Espectros Raman de Bi2O3 prístino y un $\mathrm{Zn}$-Bi2O3 25\% sometido a un proceso OCV de $24 \mathrm{~h}$.

Figura 6.2-5: Curvas de descarga obtenidas para baterías de $\mathrm{Zn}$-aire utilizando $\mathrm{Zn}$ puro o $\mathrm{Zn}$-Bi2O3 $6 \%, 12 \%$ y $25 \%$, como electrodos negativos. 143

Figura 6.2-6: Difractogramas de XRD in-operando durante la descarga en diferentes rangos de electrodos de $Z n$ puro ( $A$ y B) y Zn-Bi2O3 6\% (C, D y E). 145 
Figura 6.2-7: Difractogramas de XRD in-operando durante la descarga de electrodos negativos de $\mathrm{Zn}$ Bi2O3 12\%, A), B) y C) y Zn-Bi2O3 25\%, D), E) y F).

Figura 6.2-8: Imágenes SEM y mediciones EDX de electrodos de Zn-Bi2O3 6\% y 25\% en diferentes estados de carga, tal y como indican las etiquetas. P1 y P2 en F, I y M indican los puntos en los que se han realizado análisis EDX y sus espectros se muestran en $\mathrm{H}, J$ y $O$, respectivamente. $D$ y K corresponden a las imágenes SEM C e I, respectivamente. Y los mapeos $N$ y $P$ corresponden a la imagen SEM $L$.

\section{CAPÍTULO VII. Structural Modifications and lonic Transport of PVA-KOH Hydrogels Applied in Zn / Air Batteries.}

Figura 7.2-1: Peso y conductividad iónica de las membranas con el tiempo de almacenamiento a temperatura ambiente. A) Membrana PVA-KOH 30 y B) Membrana PVA-KOH 30 sw. 156

Figura 7.2-2: Espectros XPS de la membrana PVA- KOH 30. A)Región C1s y K2p. B) Región O1s. 159

Figura 7.2-3: Difractogramas de XRD de las membranas preparadas. 159

Figura 7.2-4: Curvas TG de las membranas.. El recuadro muestra la derivada de las curvas. 159

Figura 7.2-5: Espectros ATR-FTIR de las membranas de PVA Puro, PVA-KOH 30 y PVA-KOH 30 sw.

Sumergida en $\mathrm{KOH} 12 \mathrm{M}$ durante $24 \mathrm{~h}$. Se incluyen espectros de la solución de $6 \mathrm{M} \mathrm{KOH} \mathrm{y} \mathrm{PVA-}$ $\mathrm{KCl}$ para comparar. 161

Figura 7.2-6: A) Valores de conductividad de las membranas basadas en PVA-KOH con la temperatura, indicando un comportamiento Arrhenius. B) Voltametría cíclica de PVA-KOH 30 y PVA-KOH 30 sw. Recuadro: 50 ciclos consecutivos de la membrana con PVA-KOH $30 \mathrm{sw}$. C) Curvas de descarga de las baterías de aire $\mathrm{Zn} / \mathrm{PVA}-\mathrm{KOH} 30 /$ aire con el tiempo de inmersión de la membrana PVA-KOH 30 en solución de $12 \mathrm{M} \mathrm{KOH}$, utilizando una placa de Zn como ánodo. D) Curva de descarga de una batería Zn/PVA-KOH 30 sw. (sumergida 24 horas en $\mathrm{KOH} 12 \mathrm{M}$ ). E) Curvas de polarización de una batería $\mathrm{Zn} / \mathrm{PVA}-\mathrm{KOH} 30 \mathrm{sw}$ /aire a una velocidad de $0.1 \mathrm{mAs}-1$. F) Potencial vs. tiempo durante las mediciones de polarización, incluyendo OCV. 163

Figura 7.2-7: A) Difractogramas XRD de la membrana PVA-KOH utilizada en baterías de aire Zn/PVA$\mathrm{KOH} 30$ sw./air después de una descarga y un ciclo de descarga/carga de baterías $\mathrm{Zn} / \mathrm{PVA}-\mathrm{KOH}$ $30 \mathrm{sw}$ /air. Las líneas verticales muestran las tarjetas de la base de datos ICDD de Zn[Card-00004-0831] (azul) y ZnO[Card-00-036-1451] (rojo) B) Curvas de descarga y carga de una batería sw/air Zn/PVA-KOH 30 . 164

Figura 7.2-8: Análisis de imaOgen SEM y análisis EDX de la sección transversal de una membrana PVA-KOH $30 \mathrm{sw}$. utilizada durante una descarga en una batería de aire $\mathrm{Zn} / \mathrm{PVA}-\mathrm{KOH} / \mathrm{aire}$. Zn, K y $O$ se analizaron mediante EDX desde la superficie de la membrana que estuvo en contacto con el electrodo de Zn hasta alcanzar una profundidad de $3600 \mu \mathrm{m}$............................................. 166

Esquema 7.2-1: Estructura de una membrana de PVA $\sin \mathrm{KOH}$.............................................. 167 


\section{Anexo II. Índice de figuras}

Esquema 7.2-2: Transporte de $\mathrm{OH}$ - siguiendo un mecanismo Grotthuss en una membrana PVA-KOH

30. La flecha indica la dirección de transporte. Durante el transporte $\mathrm{OH}$-, se rompe un enlace por puente de hidrogeno (rosa) y se forma uno nuevo enlace (naranja).... 168

Esquema 7.2-3: $\mathrm{OH}$ - transporte siguiendo un mecanismo de Grotthuss en una membrana PVA- KOH $30 \mathrm{sw}$. La flecha indica la dirección de transporte $\mathrm{OH}$ - Durante el transporte $\mathrm{OH}$-, se rompe un enlace por puente de hidrogeno (rosa) y se forma uno nuevo (naranja). 168 

ANEXO III. Publicaciones. 

Parte de los resultados presentados en este documento ya se han publicado debido a su relevancia en revistas "peer reviewed" y también como documentos de congresos en forma de poster o comunicaciones orales.

\section{Artículos publicados.}

(1) Influence of the Ionic Liquid Type on the Gel Polymer Electrolytes Properties. Tafur, J. P.; Santos, F.; Fernández Romero, A. J.. Membranes $\begin{array}{lllll}\text { (Basel). } & \text { 2015, } & \text { 752-771. }\end{array}$ https://doi.org/10.3390/membranes5040752.

(2) Cálculo de la Energía de Activación de Electrolitos Poliméricos-tipo Gel mediante medidas de la constante dieléctrica. Santos, F.; Tafur, J.P.; Fernández Romero, A.J.. Anuario de Jóvenes Investigadores, 2016,9, 148150. ISSN 2444-2968.

(3) A Synchrotron X-Ray Diffraction and Hard x-Ray Photoelectron Spectroscopy Study of Zn Negative Electrodes at Different Charge and Discharge States of $\mathrm{Zn} / \mathrm{MnO} 2$ Batteries Using an Ionic Liquid-Based Gel Polymer Electrolyte. Abad, J.; Santos, F.; Tafur, J. P.; Urbina, A.; Román, E.; González-Martínez, J. F.; Rubio-Zuazo, J.; Castro, G. R.; Fernández Romero, A. J. J. Power Sources 2017, 363, 199-208. https://doi.org/10.1016/j.jpowsour.2017.07.082.

(4) In Situ Synchrotron X-Ray Diffraction Study of $\mathrm{Zn} / \mathrm{Bi}_{2} \mathrm{O}_{3}$ Electrodes Prior to and during Discharge of $\mathrm{Zn}$-Air Batteries: Influence on $\mathrm{ZnO}$ Deposition. Santos, F.; Abad, J.; Vila, M.; Castro, G. R.; Urbina, A.; Fernández Romero, A. J. Electrochim. Acta 2018, 281, 133-141. https://doi.org/10.1016/j.electacta.2018.05.138.

(5) Structural Modifications and Ionic Transport of PVA-KOH Hydrogels Applied in Zn / Air Batteries. Santos, F.; Tafur, J. P.; Abad, J.; Fernández, A. J.. J. Electroanal. Chem. 2019, 850, 113380. https://doi.org/10.1016/j.jelechem.2019.113380. 


\section{Poster presentados.}

(1) Análisis Superficial mediante DRX (sincrotrón) del electrodo de Zn en distintos estados de carga de una batería Zn/IL-GPE/MnO2. F. Santos, J.P. Tafur, J. Abad, A. Urbina, J. Rubio-Zuazo, G.R. Castro, A.J. F. Romero. XXXVII reunión del grupo 1de electroquímica de la real sociedad española de química. Alicante, 17-20 de julio de 2016.

(2) Proceso de descarga en dos etapas de una batería de $\mathrm{Zn} / \mathrm{IL}-\mathrm{GPE} / \mathrm{MnO}_{2}$. F. Santos, J.P. Tafur, J. Abad, E. Román, A.J. Fernández Romero. XXXVII reunión del grupo 1de electroquímica de la real sociedad española de química. Alicante, 17-20 de julio de 2016.

(3) In situ videoelectrochemistry of $\mathrm{Zn}+\mathrm{Bi}_{2} \mathrm{O}_{3}$ anodes in $\mathrm{Zn}$-air batteries. F.

Vicente, F. Santos, J.J. García-Jareño, A.J. Fernández Romero, J. Agrisuelas. XXXIX Reunión del Grupo de Electroquímica de la Real Sociedad Española de Química y III Simposio E3 del Mediterráneo. Madrid, 2-5 Julio 2018.

(4) Ionic transport study of PVA-KOH Hydrogels to be applied in Zn/air batteries. Antonio J. Fernández, José Abad, Florencio Santos, Juan P. Tafur. 25th Topical Meeting of the International Society of Electrochemistry. Toledo 12-15 Mayo 2019.

(5) Synchrotron XRD in Operando Study of Zn/PVA/Air Battery. José Abad, Rosalía Cid, José Pérez, German R. Castro, Florencio Santos, Antonio Urbina. Antonio J. Fernández. 25th Topical Meeting of the International Society of Electrochemistry. Toledo 12-15 Mayo 2019.

(6) In Operando High Resolution X-ray diffraction (HR-XRD) Analysis of Battery Electrode Surfaces. J. Abad, R. E. López-Vicente, C. Toledo, F. Santos, J. Rubio-Zuazo, G. R. Castro, M. Vila, R. Cid, J. Padilla, A. Urbina, A. J. Fernández Romero. SpLineMeeting 2019.Madrid 30-31 Mayo 2019.

(7) Síntesis y caracterización de electrolitos poliméricos PVA/VA-VEOVA para su aplicación en baterías de Zn. Edwin Reyez, Antonio Díaz Barrios, Florencio Santos, Antonio J. Fernández Romero, Juan P. Tafur. XL Reunión del Grupo de Electroquímica de la Real Sociedad Española de Química y XX Encontro Ibérico de Electroquímica. Huelva, 9-12 Julio 2019. 


\section{Comunicaciones orales.}

(1) Efecto del $\mathrm{Bi}_{2} \mathrm{O}_{3}$ sobre la superficie del ánodo durante la descarga de baterías Zn/aire. Estudio de XRD "in situ" con radiación sincrotrón. Florencio Santos, José Abad, María Vila, Germán R. Castro, Antonio J. Fernández Romero. XXXVIII Reunión del Grupo de Electroquímica de la Real Sociedad Española de Química y XIX Encontro Ibérico de Electroquímica. Vitoria, 5-7 Julio 2017.

(2) Caracterización de Hidrogeles para su aplicación en baterías de Zn/aire. Florencio Santos, Juan P. Tafur, Antonio J. Fernández Romero. . XXXVIII Reunión del Grupo de Electroquímica de la Real Sociedad Española de Química y XIX Encontro Ibérico de Electroquímica. Vitoria, 5-7 Julio 2017.

(3) Análisis Espectroscópico y Electroquímico de Geles de PVA-KOH usados como electrolitos poliméricos en baterías de Zn/aire. Juan P. Tafur Guisao, Florencio Santos, Javier Padilla, Antonio J Fernández Romero. XXIII Congreso de la Sociedad Iberoamericana de Electroquímica. Cusco (Perú) 38 Junio 2018.

(4) Chromium (III) oxide as catalyst in air electrodes to be applied in zinc-air batteries. F. Santos, P. Almodóvar, C. Díaz-Guerra, A.J. Fernández Romero. XXXIX Reunión del Grupo de Electroquímica de la Real Sociedad Española de Química y III Simposio E3 del Mediterráneo. Madrid, 2-5 Julio 2018.

(5) Study of electrode-gel poymer electrolyte interfase in Zn-based batteries. F. Santos, J. P. Tafur, J. Abad, A. Urbina, R. Cid, J. Rubio-Zuazo, G.R. Castro, A.J. Fernández Romero. XXXIX Reunión del Grupo de Electroquímica de la Real Sociedad Española de Química y III Simposio E3 del Mediterráneo. Madrid, 2-5 Julio 2018.

(6) Environmental and Economical Requirements for a Sustainable Zn/air battery. 25th Topical Meeting of the International Society of Electrochemistry. 3rd Workshop of the E3TECH Spanish Excellence Network Toledo 12-15 Mayo 2019.

(7) Theoretical and Experimental Study of Chromium (III) Oxide-Based Materials as Catalysts for ORR. Florencio Santos, Paloma Almodóvar, Carlos 
Díaz-Guerra, Antonio J. Fernández Romero, Joaquín González, Ángela Molina. 25th Topical Meeting of the International Society of Electrochemistry. Toledo 12-15 Mayo 2019.

(8) Bismuth oxide $\left(\mathrm{Bi}_{2} \mathrm{O}_{3}\right)$ as a rechargeable and high stability positive electrode for alkaline zinc batteries. F. Santos, S. Lorca, J. Abad, J.P. Tafur, A. Urbina, A. J. Fernández Romero. XL Reunión del Grupo de Electroquímica de la Real Sociedad Española de Química y XX Encontro Ibérico de Electroquímica. Huelva, 9-12 Julio 2019. 
ANEXO IV. Abreviaturas. 



\section{Abreviaturas.}

AES

AN

BMIMTf $_{2}$

CE

DMF

DSC

EC

EDX

EIS

EMIN-TFSI

EP

FWHM

GPE

HAXPES

IL

$\mathrm{LiClO}_{4}$

$\mathrm{MnO}_{2}$

NMP

$\mathrm{OCV}$

PC

PAN

PEG

PEGME

PEO

PMMA

PVA
Auger electron Spectroscopy

Acetonitrile

1-Butyl-3-methylimidazolium trifluoromethanesulfonate

Counter electrode

$\mathrm{N}, \mathrm{N}$-dimethyl formamide

Differential Scanning Calorimetry

Ethylene carbonate

Energy dispersive X-Ray

Electrochemical Impedance Spectroscopy

1-Ethyl-3-methylimidazolium bis(trifluoromethylsulfonyl)imide

Electrode polarization

Full Width at Half Maximum

Gel Polymer Electrolyte

Hard X-ray Photo-Electron Spectroscopy

Ionic liquid

Lithium perchlorate

Manganese dioxide

N-methyl-2-pyrrolidone

Open Circuit Voltage

Propylene carbonate

Poly(acrylonitrile)

Polyethylene glycol

Polyethylene glycol methyl ether

Poly(ethylene oxide)

Poly(methyl methacrylate)

Poly(vinyl alcohol) 


\begin{tabular}{|c|c|}
\hline PVdF & Poly(vinylidene fluoride) \\
\hline PVdF-HFP & Poly(vinylidene fluoride-co-hexafluoropropylene) \\
\hline PVP & Poly(vinyl pyrrolidine) \\
\hline $\mathrm{Scm}^{-1}$ & Siemens per centimetre \\
\hline SEM & Scanning Electron Microscopy \\
\hline SPE & Solid polymer electrolyte \\
\hline THF & Tetrahydrofuran \\
\hline VTF & Vogel Fulcher Tamman \\
\hline XRD & X-Ray Diffraction \\
\hline XPS & X-Rays Photo-Electron Spectroscopy \\
\hline $\mathrm{ZnTf}_{2}$ & Triflato de zinc \\
\hline $\mathrm{Ea}$ & Activation energy (kJ mol-1) \\
\hline $\mathrm{P}$ & Power density $\left(\mathrm{kW} \mathrm{kg}^{-1}\right)$ \\
\hline $\mathrm{T}_{\mathrm{b}}$ & Boiling temperature $\left({ }^{\circ} \mathrm{C}\right)$ \\
\hline $\mathrm{T}_{\mathrm{g}}$ & Glass transition temperature $\left({ }^{\circ} \mathrm{C}\right)$ \\
\hline $\mathrm{T}_{\mathrm{m}}$ & Melting temperature $\left({ }^{\circ} \mathrm{C}\right)$ \\
\hline $\mathrm{Z}$ & Impedance $(\Omega)$ \\
\hline $\mathrm{Z}^{\prime}$ & Real part of impedance $(\Omega)$ \\
\hline $\mathrm{Z}^{\prime \prime}$ & Imaginary part of impedance $(\Omega)$ \\
\hline$\eta$ & Dynamic viscosity $(\mathrm{cP}$ or $\mathrm{mPa} \cdot \mathrm{s})$ \\
\hline$\eta$ & Overvoltage \\
\hline
\end{tabular}


$\sigma$

$\theta$

$2 \theta$

$\varepsilon$

Ionic conductivity $\left(\mathrm{S} \mathrm{cm}^{-1}\right)$

Phase angle $\left(^{\circ}\right)$

Diffraction angle $\left(^{\circ}\right)$

Dielectric constant 

ANEXO V. Índices de impacto. 

Tafur, J. P.; Santos, F.; Fernández Romero, A. J.. Membranes (Basel). 2015, 5, (4), 752-771. https://doi.org/10.3390/membranes5040752.

\section{Scopus Preview}

\section{Source details}

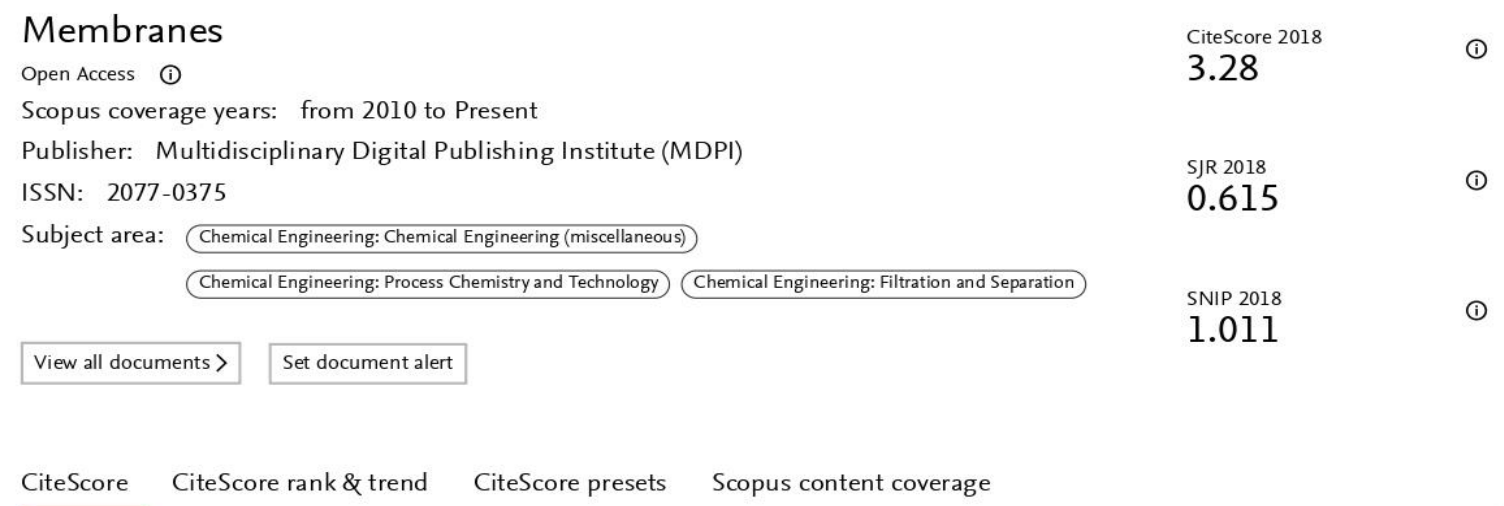

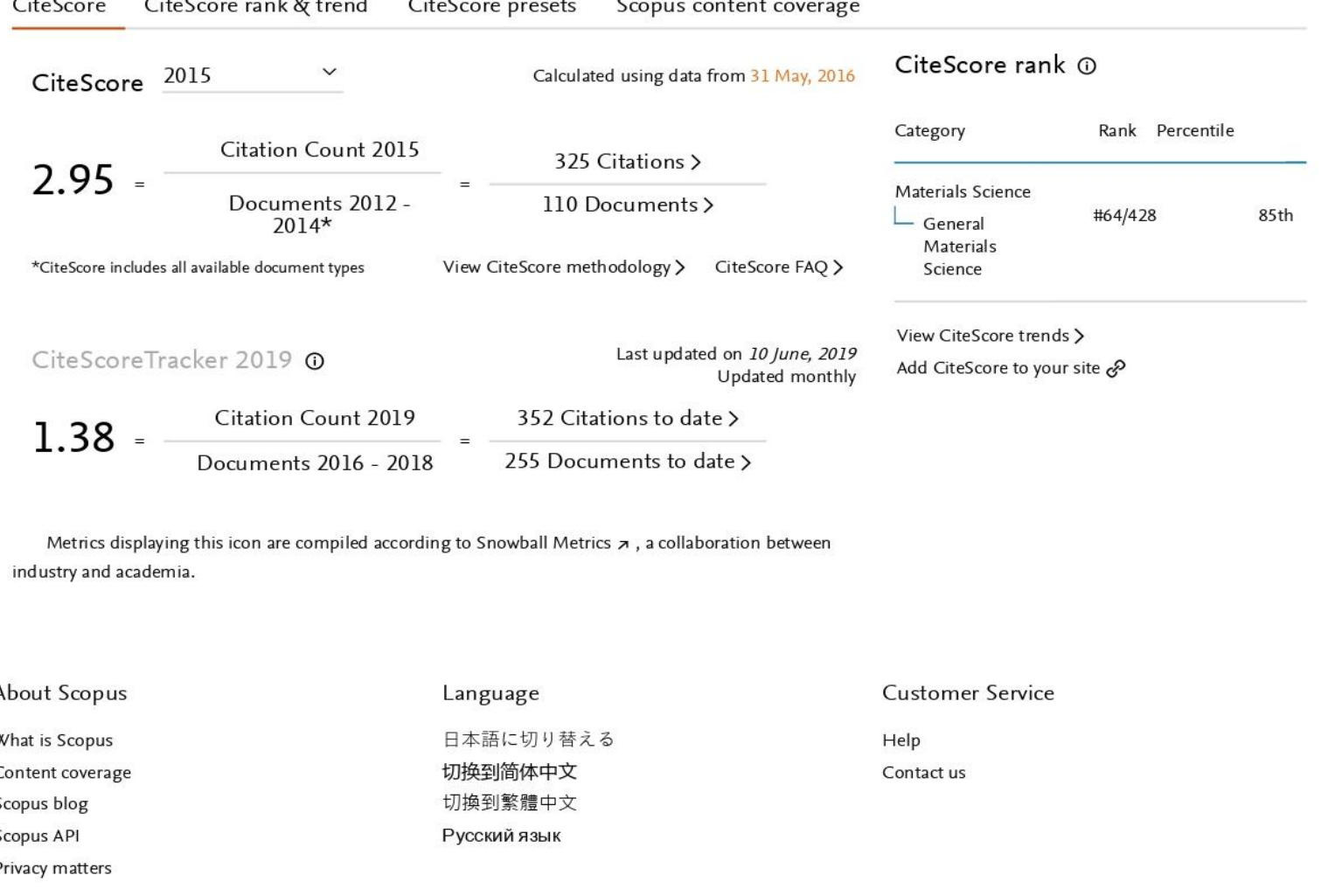

ELSEVIER Terms and conditions $\pi$ Privacy policy $\pi$

Copyright (c) Elsevier B.V x. All rights reserved. Scopus $\circledast$ is a registered trademark of Elsevier B.V.

We use cookies to help provide and enhance our service and tailor content. By continuing, you agree to the 
Abad, J.; Santos, F.; Tafur, J. P.; Urbina, A.; Román, E.; González-Martínez, J. F.; Rubio-Zuazo, J.; Castro, G. R.; Fernández Romero, A. J. J. Power Sources 2017, 363, 199-208. https://doi.org/10.1016/j.jpowsour.2017.07.082.

InCites Journal Citation Reports Page 3 of $17 \quad$ Clarivate

Journal Impact Factor Calculation

2017 Journal Impact Factor $=\frac{25,042}{3,606}=6.945$

How is Journal Impact Factor Calculated?

ل $\mid F=\frac{\text { Citations in } 2017 \text { to items published in } 2015(\mathbf{1 4 , 1 2 3})+2016}{(\mathbf{1 0 , 9 1 9 )}}=\frac{25,042}{3,606}$
InCites Journal Citation Reports
Page 7 of 17

Box plot

\section{Category Box Plot 2017}

Category Box Plot

The category box plot depicts the distribution of Impact Factors for all journals in the category. The horizontal line that forms the top of the box is the 75th percentile (Q1). The horizontal line that forms the bottom is the 25th percentile (Q3). The horizontal line that

intersects the box is the median Impact Factor for the category.

Horizontal lines above and below the box, called whiskers, represent maximum and minimum values

The top whisker is the smaller of the following two values:

the maximum Impact Factor (

The bottom whisker is the larger of the following two values.

The bottom whisker is the larger

Box Plots are provided for the current JCR year for each of the categories in which the journal is indexed

J POWER SOURCES, IF: 6.945
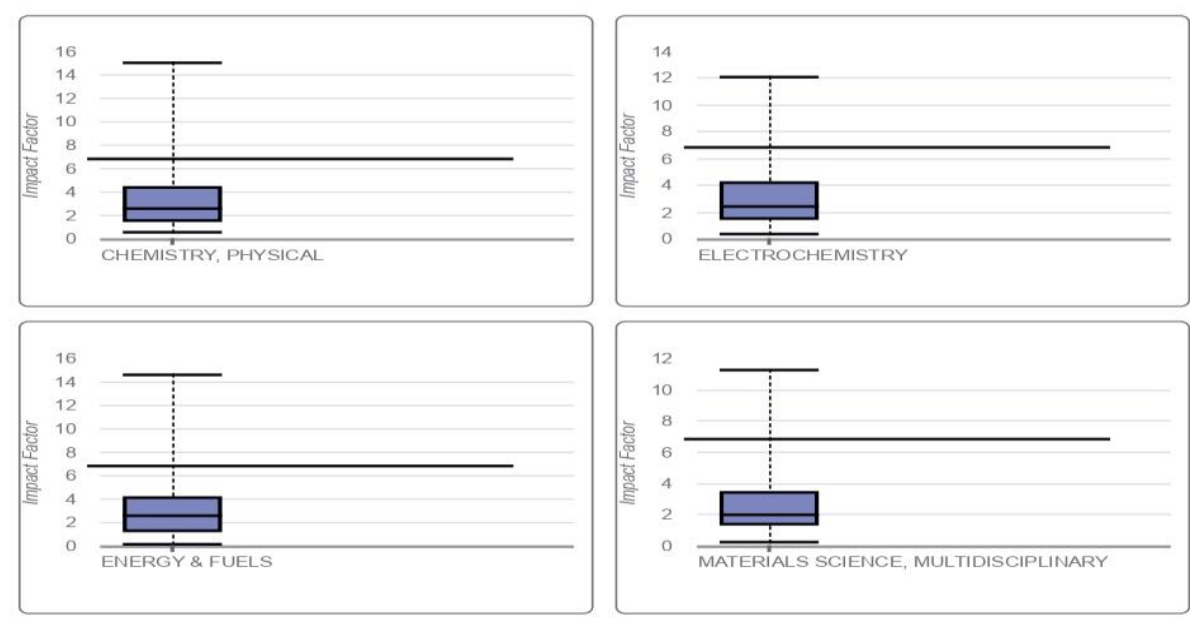
Santos, F.; Abad, J.; Vila, M.; Castro, G. R.; Urbina, A.; Fernández Romero, A. J.
Electrochim.
Acta
2018,
281 ,
$133-141$.

https://doi.org/10.1016/j.electacta.2018.05.138.

8/7/2019

InCites Joumal Citation Reports
InCites Journal Citation Reports
Page 3 of 17
1) Clarivate

Journal Impact Factor Calculation

2018 Journal Impact Factor $=\frac{24,745}{4,597}=5.383$

How is Journal Impact Factor Calculated?

$\sqrt{1}=\frac{\text { Citations in } 2018 \text { to items published in } 2016(\mathbf{1 4 , 0 4 0 )}+\mathbf{2 0 1 7}}{(\mathbf{1 0 , 7 0 5 )}}=\frac{24,745}{\text { Number of citable items in } 2016(\mathbf{2 , 4 5 3 )}+\mathbf{2 0 1 7}(\mathbf{2 , 1 4 4 )}}=\frac{24,597}{4}$

InCites Journal Citation Reports Page 7 of $17 \quad$ Clarivate

Box plot

Category Box Plot 2018

Category Box Plot

The category box plot depicts the distribution of Impact Factors for all journals in the category. The horizontal line that forms the top of the box is the 75th percentile (Q1). The horizontal line that forms the bottom is the 25th percentile (Q3). The horizontal line that intersects the box is the median Impact Factor for the category.

Horizontal lines above and below the box, called whiskers, represent maximum and minimum values

The top whisker is the smaller of the following two values:

the maximum Impact Factor (IF)

Q1 IF + 3.5(Q1 IF - Q3 IF)

The bottom whisker is the larger of the following two values:

the minimum Impact Factor (IF)

Q1 IF - 3.5(Q1 IF - Q3 IF)

Box Plots are provided for the current JCR year for each of the categories in which the journal is indexed.

ELECTROCHIM ACTA, IF : 5.383

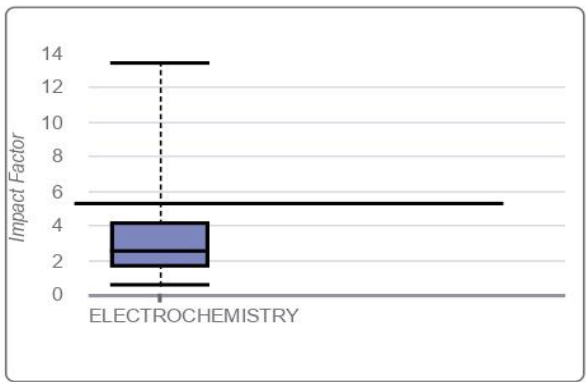


Santos, F.; Tafur, J. P.; Abad, J.; Fernández, A. J.. J. Electroanal. Chem. 2019, 850, 113380. https://doi.org/10.1016/j.jelechem.2019.113380.

\begin{tabular}{|c|c|c|}
\hline InCites & Journal Citation Reports & 10 Clarivate \\
\hline \multicolumn{3}{|c|}{ Journal Impact Factor Calculation } \\
\hline \multicolumn{3}{|c|}{2018 Journal Impact Factor $=\frac{4,052}{1,259}=3.218$} \\
\hline \multicolumn{3}{|c|}{ How is Journal Impact Factor Calculated? } \\
\hline \multirow{2}{*}{ J|F } & $\begin{array}{c}\text { Citations in } 2018 \text { to items published in } 2016(2,064)+2017 \\
(1,988)\end{array}$ & 4,052 \\
\hline & Number of citable items in $2016(607)+2017(652)$ & 1,259 \\
\hline
\end{tabular}

The category box plot depicts the distribution of Impact Factors for all journals in the category. The horizontal line that torms the top of the box is the 75th percentle (Q1). The horizontal line that forms the bottom is the 25th percentlie (Q3). The horzontal line that intersects the box is the median Impact Factor for the category.

Horizontal lines above and below the box, called whiskers, represent maximum and minimum values.

The top whisker is the smaller of the following two values:

the maximum Impact Factor (IF)

Q1 IF +3.5(Q1 IF - Q3 IF)

The bottom whisker is the larger of the following two values:

the minimum Impset Factor (IF)

Q1 IF-3.5(Q1 IF-Q3 IF)

Box Plots are provided for the current JCR year tor each of the categories in which the journal is indexed

J ELECTROANAL CHEM, IF: 3.218

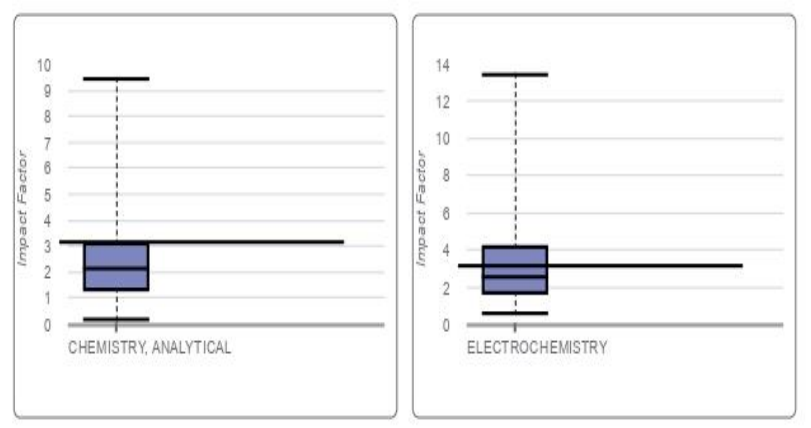


ANEXO VI. Notificaciones de Aceptación. 

Influence of the lonic Liquid Type on the Gel Polymer Electrolytes Properties. Tafur, J. P.; Santos, F.; Fernández Romero, A. J.. Membranes (Basel). 2015, 5, (4), 752-771. https://doi.org/10.3390/membranes5040752

Financial Assistant

*MDPI AG* - Multidisci CH-4057 Basel, Switz; Tel. +41616837734 Fax +41613028918

E-mail Accounting: billi

E-mail: strasser@mdp http:I/www.mdpi.com/ 
Synchrotron X-Ray Diffraction and Hard x-Ray Photoelectron Spectroscopy Study of $\mathrm{Zn}$ Negative Electrodes at Different Charge and Discharge States of $\mathrm{Zn} / \mathrm{MnO} 2$ Batteries Using an lonic Liquid-Based Gel Polymer Electrolyte. Abad, J.; Santos, F.; Tafur, J. P.; Urbina, A.; Román, E.; González-Martínez, J. F.; Rubio-Zuazo, J.; Castro, G. R.; Fernández Romero, A. J. J. Power Sources 2017, 363, 199-208. https://doi.org/10.1016/j.jpowsour.2017.07.082.

\section{View Letter}

Close

$\begin{array}{ll}\text { Date: } & \text { Jul } 23,2017 \\ \text { To: } & \text { "Fernández Romero Antonio J." antonioj.fernandez@upct.es } \\ \text { From: } & \text { "Journal of Power Sources (ELS)" eesserver@eesmail.elsevier.com } \\ \text { Reply To: } & \text { "Journal of Power Sources (ELS)" power@elsevier.com } \\ \text { Subject: } & \text { POWER-D-17-01643R2 - Final Decision }\end{array}$

MS. NO.: POWER-D-17-01648R2

Title: A synchrotron $x$-ray diffraction and hard $x$-ray photoelectron spectroscopy study of $Z n$ negative electrodes at different charge and discharge states of $\mathrm{Zn} / \mathrm{MnO} 2$ batteries using an lonic liquid-based gel polymer electrolyte

Corresponding Author: Dr. Fernández Romero Antonio J.

All Authors: José Abad; Florencio Santos; Juan P. Tafur; Antonio Urbina; Elisa Román; Juan Francisco González-Martínez; Juan Rubio-Zuazo; Germán R. Castro; Fernández Romero Antonio J., PhD

Dear Dr. Antonio J.,

I am pleased to inform you that your manuscript referenced above has been accepted for publication in Journal of Power Sources.

Your accepted manuscript will now be transferred to our production department and work will begin on creation of the proof. If we need any additional information to create the proof, we will let you know. If not, you will be contacted again in the next few days with a request to approve the proof and to complete a number of online forms that are required for publication.

In due course you will receive a copyright transfer form and galley proofs of your paper from Elsevier. Please deal with these quickly in order that publication may be expedited. You will also receive a manuscript number which you may use to track the progress of your paper, online, via the Elsevier Author Gateway

http://www.elsevier.com/trackarticle

Elsevier aims to publish your manuscript online, on ScienceDirect (http://www.sciencedirect.com) as quickly as possible. Typically online publication will take place within 8 weeks of your article being accepted for publication. For guidelines on how to track your manuscript in EES please go the following address:

http://help.elsevier.com/app/answers/detail/p/7923/a id/89

When your paper is published on ScienceDirect, you want to make sure it gets the attention it deserves. To help you get your message across, El style presentatlons that aros she to create an Audiosilides presentation shortly. For more information and examples, please visit http://www.elsevier.com/audloslides.

Thank you for your contribution to the Journal of Power Sources.

With kind regards,

Yong-yao Xia, Dr.

Editor

Journal of Power Sources, Editorial Office

E-mail: power@elsevier.com

Comments from the Editors and Revlewers: 
In Situ Synchrotron X-Ray Diffraction Study of $\mathrm{Zn} / \mathrm{Bi}_{2} \mathrm{O}_{3}$ Electrodes Prior to and during Discharge of Zn-Air Batteries: Influence on ZnO Deposition. Santos, F.; Abad, J.; Vila, M.; Castro, G. R.; Urbina, A.; Fernández Romero, A. J. Electrochim. Acta 2018, 281, 133-141. https://doi.org/10.1016/i.electacta.2018.05.138.

\section{View Letter}

Close

$\begin{array}{ll}\text { Date: } & \text { May 22, } 2018 \\ \text { To: } & \text { "Fernández Romero Antonio J." antonioj.fernandez@upct.es } \\ \text { From: } & \text { Shi-Gang SUN eesserver@eesmail.elsevier.com } \\ \text { Reply To: } & \text { Shi-Gang SUN sgsun@xmu.edu.cn } \\ \text { Subject: } & \text { Electrochimica Acta - Your Submission (EA18-0356R2) }\end{array}$

Ms. Ref. No.: EA18-0356R2

Title: In situ synchrotron $\mathrm{x}$-ray diffraction study of $\mathrm{Zn} / \mathrm{Bi} 2 \mathrm{O} 3$ electrodes prior to and during discharge of $\mathrm{Zn}$-air batteries: Influence on $\mathrm{ZnO}$ deposition

Electrochimica Acta

Dear Dr. Antonio J.,

I am pleased to inform you that the revised version of your paper "In situ synchrotron x-ray diffraction study of $\mathrm{Zn} / \mathrm{Bi} 2 \mathrm{O} 3$ electrodes prior to and during discharge of $\mathrm{Zn}$-air batteries: Influence on $\mathrm{ZnO}$ deposition" has been accepted for publication in Electrochimica Acta without further modifications. The manuscript will now go to the Production Department of Elsevier for technical editing. You will receive the proofs from Elsevier in due course.

When your paper is published on ScienceDirect, you want to make sure it gets the attention it deserves. To help you get your message across, Elsevier has developed a new, free service called Audioslides: brief, webcaststyle presentations that are shown (publicly available) next to your published article. This format gives you the opportunity to explain your research in your own words and attract interest. You will receive an invitation email to create an AudioSlides presentation shortly. For more information and examples, please visit http://www.elsevier.com/audioslides.

Your accepted manuscript will now be transferred to our productlon department and work will begin on creation of the proof. If we need any additional information to create the proof, we will let you know. If not, you will be contacted again in the next few days with a request to approve the proof and to complete a number of online forms that are required for publication.

Thank you for submitting your work to this Journal.

With kind regards,

Shi-Gang SUN, Ph.D

Associate Editor

Electrochimica Acta

Note

I wish to inform you that if one or more authors of this paper are aged less than 30 on January 1 st of the year of the award (i.e. the year following the publication year), they are eligible for the ORONZIO AND NICCOLO DE NORA FOUNDATION YOUNG AUTHOR PRIZE. The rules of this award may be found in the web site of the International Society of Electrochemistry (http://www. ise-online.org/awards/index.php). Applications can be submitted once a year, generally from February 1st to May 1st. A call for applications is published in the ISE web site and in ISE pages of some issues of Electrochimica Acta.

Did you know you can get a free publication certificate, and lots of other services related to your accepted paper, via the Elsevier WebShop? For more information go to:

http://webshop.elsevier.com/myarticleservices/publication-recognition/

Comments from Editor and Reviewers:

Reviewer \#1: I have reviewed the revised manuscript as requested. During the previous revision the authors addressed many of my concerns. The remaining concerns were minor and they appear to be addressed in the current manuscript. My only concerm is that the English could still use some editing, but I leave this to the editor. 
Structural Modifications and lonic Transport of PVA-KOH Hydrogels Applied in Zn / Air Batteries. Santos, F.; Tafur, J. P.; Abad, J.; Fernández, A. J.. J. Electroanal. Chem. 2019, 850, 113380. https://doi.org/10.1016/j.jelechem.2019.113380.

\section{View Letter}

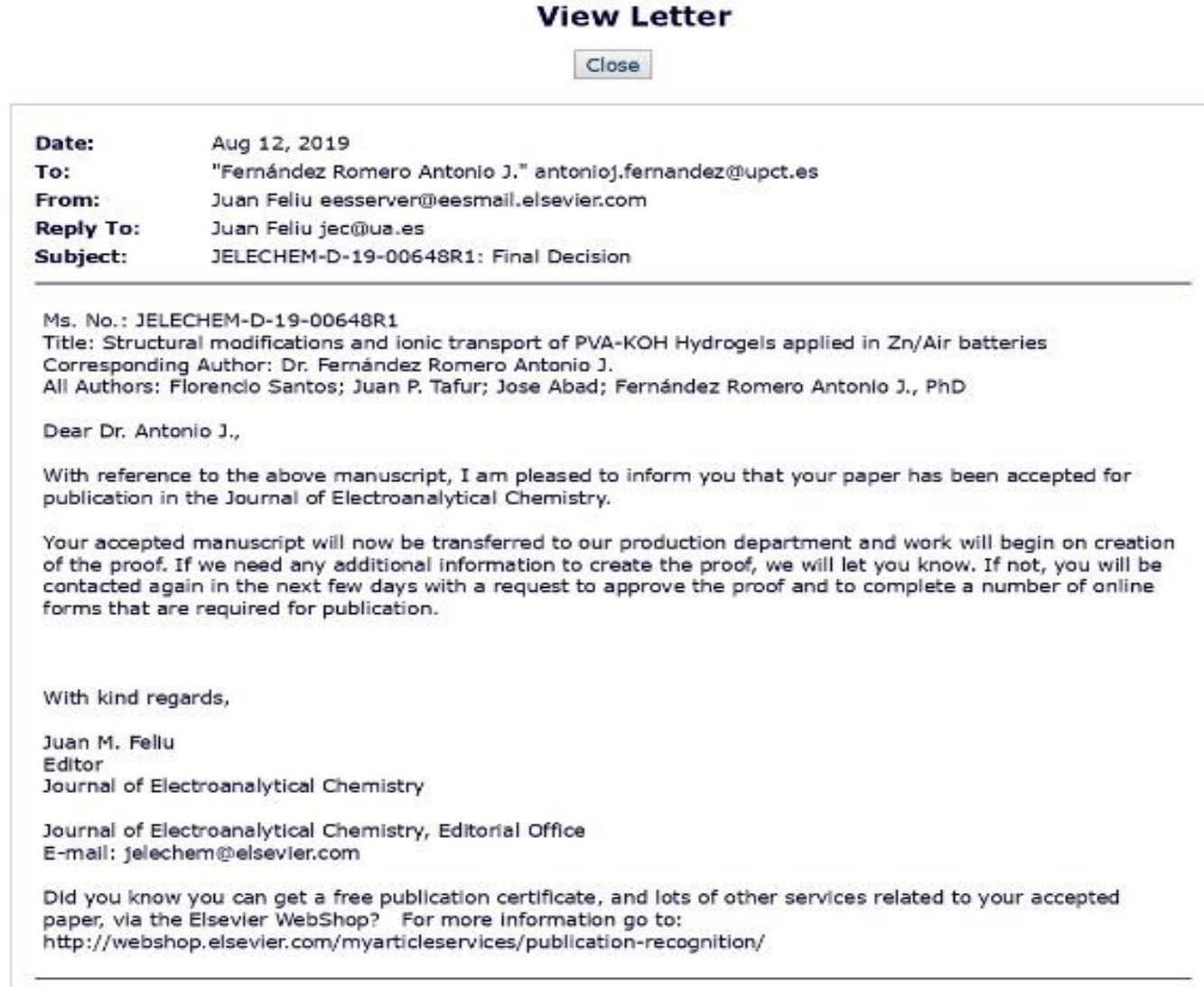


ANEXO VII. Artículos Impresos. 

Article

\title{
Influence of the Ionic Liquid Type on the Gel Polymer Electrolytes Properties
}

\author{
Juan P. Tafur, Florencio Santos and Antonio J. Fernández Romero * \\ Grupo de Materiales Avanzados para la Producción y Almacenamiento de Energía (MAPA), \\ Campus de Alfonso XIII, Universidad Politécnica de Cartagena, Cartagena 30203, Murcia, Spain; \\ E-Mails: tafur8652@gmail.com (J.P.T.); fsantoscutillas@gmail.com(F.S.) \\ * Author to whom correspondence should be addressed; E-Mail: antonioj.fernandez@upct.es; \\ Tel.: +34-968-325-580; Fax: +34-968-325-931.
}

Academic Editor: Bruno Scrosati

Received: 30 September 2015 / Accepted: 17 November 2015 / Published: 19 November 2015

\begin{abstract}
Gel Polymer Electrolytes (GPEs) composed by $\mathrm{ZnTf}_{2}$ salt, poly(vinylidene fluoride-co-hexafluoropropylene) (PVdF-HFP), and different ionic liquids are synthesized using n-methyl-2-pyrrolidone (NMP) as solvent. Three different imidazolium-based ionic liquids containing diverse cations and anions have been explored. Structural and electrical properties of the GPEs varying the $\mathrm{ZnTf}_{2}$ concentration are analyzed by ATR-FTIR, DSC, TG, and cyclic voltammetry. Free salt IL-GPEs present distinct behavior because they are influenced by the different IL cations and anions composition. However, inclusion of $\mathrm{ZnTf}_{2}$ salt inside the polymers provide GPEs with very similar characteristics, pointing out that ionic transport properties are principally caused by $\mathrm{Zn}^{2+}$ and triflate movement. Whatever the IL used, the presence of NMP solvent inside the polymer's matrix turns out to be a key factor for improving the $\mathrm{Zn}^{2+}$ transport inside the GPE due to the interaction between $\mathrm{Zn}^{2+}$ cations and carbonyl groups of the NMP. High values of ionic conductivity, low activation energy values, and good voltammetric reversibility obtained regardless of the ionic liquid used enable these GPEs to be applied in $\mathrm{Zn}$ batteries. Capacities of 110-120 $\mathrm{mAh} \cdot \mathrm{g}^{-1}$ have been obtained for $\mathrm{Zn} / \mathrm{IL}-\mathrm{GPE} / \mathrm{MnO}_{2}$ batteries discharged at $-1 \mathrm{~mA} \cdot \mathrm{cm}^{-2}$.
\end{abstract}

Keywords: ionic liquid-based Gel Polymer Electrolytes; ionic conductivity; cation transport number; zinc batteries 


\section{Introduction}

Gel polymer electrolytes (GPEs) are materials which are neither solids nor liquids, but hold both the cohesive properties of solids and the diffusive character of liquids. Hence, these electrolytes have become relevant due to their use as excellent substitutes of the liquid electrolytes or as separators in ionic devices including batteries, supercapacitors, fuel cells, etc. [1,2]. GPEs can be prepared by trapping liquid electrolytes into different polymer hosts. In this case, the salt provides free-mobile ions which take part in the conduction process, the plasticizing solvent is one of the key factors to take into account the increased conductivity in GPE by ions solvating, and the polymer provides mechanical stability. Hence, the morphology and properties of GPEs will depend on the type and amount of polymer host, salt, and solvent present in the polymer matrix [1-8]. Among the host materials used in GPEs, PVdF-HFP has been widely employed because this is a copolymer with enough crystallinity to maintain a mechanical stability and it is amorphous enough to contain liquid electrolytes [6]. Moreover, due to its high dielectric constant, $\varepsilon=8.4$, PVDF-HFP could be the right host to solvate more salt, contributing to enhancing the electrical conductivity of the polymer electrolyte [9].

Different organic solvent plasticizers, such as dimethyl carbonate (DMC), propylene carbonate (PC), and ethylene carbonate (EC), have been extensively used with a wide range of ILs and salts. Plasticizers improve the flexibility of the polymer matrix when added, i.e., promoting amorphicity due to its high dielectric constants; $\mathrm{EC}=90.5$ and $\mathrm{PC}=60.6[10]$.

Moreover, the interaction between solvent $\mathrm{C}=\mathrm{O}$ groups and salt cations improves the cation transport inside the membrane [11-14]. Recently, our group has reported an interaction between $\mathrm{Zn}^{2+}$ cations and $\mathrm{C}=\mathrm{O}$ groups of the NMP solvent inside the IL-based GPEs, which has been proven to be fundamental to increase the $\mathrm{Zn}^{2+}$ cation transport inside the GPE [14]. Carbonyl groups of NMP, as well as those on plasticizers such as EC and PC, are able to reduce the $\mathrm{Zn}^{2+}$ coordination with anions in the GPE, avoiding or reducing the cluster formation. Thus, cationic transport is favored and, hence, higher cationic conductivity results [15].

In addition, inclusion of ionic liquids (ILs) instead of classical salt solutions has helped to improve the properties of the GPEs for supercapacitors and battery applications [3,4,11-14,16-25]. Their use is justified by important attributes, including a wide electrochemical window, high ionic conductivity, high thermal stability, non-volatility, non-flammability, etc. Furthermore, systems composed by a host, IL, and salt have been announced as relevant to battery technology, where it may lead to enhanced $\mathrm{Li}^{+}$, $\mathrm{Na}^{+}$, or $\mathrm{Zn}^{2+}$ transfer between the electrodes [3,14,24-29].

The main aim of this paper is to investigate new GPEs based on $\mathrm{ZnTf}_{2}$ and different ILs to be used in $\mathrm{Zn}$ batteries. These GPEs have been synthesized using NMP as solvent as it plays an important role enhancing cation transport numbers. However, the inclusion of an IL inside this kind of GPE has also been demonstrated as important to obtain a good polymer electrolyte. Therefore, in this work we have studied the influence of ILs, containing different types of cation and anions, on the electrical and structural properties of these GPEs. We have synthesized GPEs based on PVDF-HFP and $\mathrm{ZnTf}_{2}$ salt using three different ionic liquids (Table 1). These GPEs have been studied using several spectroscopic and electrochemical techniques in order to find out whether ion transport is modified or not, depending on the anions and cations type forming the ILs, as well as the extent of this modification. 
Table 1. Composition of all GPEs synthesized and the nomenclatures used. IL designs the different ionic liquids: EMIM TFSI (ET), BMIM Tf (BTf), and EMIM Tf (ETf). In all cases $3.6 \mathrm{~g}$ of NMP was employed. PVdF-HFP polymer is also included.

\begin{tabular}{cccc}
\hline GPE name & PVdF-HFP/g & $\mathbf{I L} / \mathbf{g}$ & $\mathbf{Z n T f}_{2} / \mathbf{g}$ \\
\hline PVdF-HFP & 0.5 & 0 & 0 \\
IL-GPE & 0.5 & 0.445 & 0 \\
ZnTf $_{2}$ GPE & 0.5 & 0 & 0.255 \\
$\mathrm{IL}-Z n T f_{2}$ GPE 1 & 0.5 & 0.445 & 0.127 \\
IL-ZnTf $_{2}$ GPE 2 & 0.5 & 0.445 & 0.255 \\
IL-ZnTf $_{2}$ GPE 3 & 0.5 & 0.445 & 0.382 \\
IL-ZnTf $_{2}$ GPE 4 & 0.5 & 0.445 & 0.509 \\
IL-ZnTf $_{2}$ GPE 5 & 0.5 & 0.445 & 0.636 \\
IL-ZnTf $_{2}$ GPE 6 & 0.5 & 0.445 & 0.763 \\
\hline
\end{tabular}

\section{Results and Discussion}

\subsection{Structural Characterization of the Gel Polymer Electrolytes}

\subsubsection{XRD}

The X-ray diffraction spectroscopy (XRD) is a useful tool to distinguish the different crystalline phases of PVdF-HFP [3,6,14,30-34]. All phases show a big peak at approximately $20^{\circ}$. Both $\alpha$ and $\gamma$ phases have a second peak at $\sim 18^{\circ}$, whereas the $\beta$ phase has a broader single line in the same region. However, there is a clear change in the PVDF-HFP spectra when the film is synthesized using THF or NMP as it has been previously reported [14]. This result indicates that NMP modifies the PVdF-HFP structure, which may be related with interactions between NMP molecules and PVdF-HFP chains. Retention of NMP molecules inside the polymer has been confirmed by different ways, as it will be described below. Incorporation of $\mathrm{IL}$ and $\mathrm{ZnTf}_{2}$ salt into the GPE produced even wider and lower intensity peaks indicating a more amorphous structure, which can be caused by $\mathrm{IL}$ and $\mathrm{ZnTf}_{2}$ blended with the PVdF-HFP polymer. Figure 1 shows the XRD spectra of PVdF-HFP membrane with BMIM $\mathrm{Tf} \mathrm{IL}$ at different concentrations of $\mathrm{ZnTf}_{2}$, which are very similar to those found for EMIM Tf-based GPEs and those reported previously for EMIM TFSI-based GPEs [14]. 


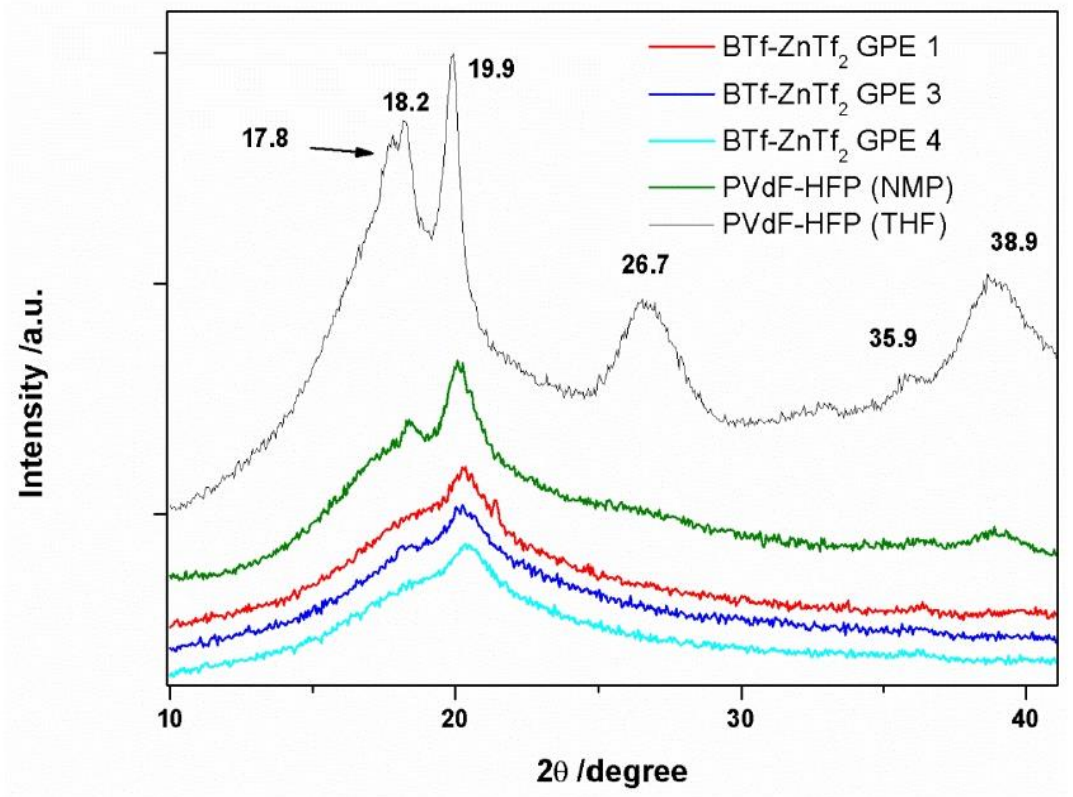

Figure 1. XRD spectra of PVdF-HFP (THF), PVdF-HFP (NMP), and BTf-ZnTf GPE 1,3 , and 4 .

\subsubsection{ATR-FTIR Spectroscopy}

ATR-FTIR spectra of PVdF-HFP films prepared using THF and NMP as solvents have been recorded. Once again there is a clear variation in the spectra. The spectrum of the PVdF-HFP film synthesized using THF shows bands assigned to the formation of a type $\alpha$ phase. However, when NMP is used as solvent, a different structure was obtained with bands attributed to a phase $\beta$ of PVdF-HFP [3,6,14,30-34]. This has been comprehensively studied in reference 14 .

NMP characteristic bands can be observed in the ATR-FTIR spectrum of the PVdF-HFP(NMP) [14], among them there is an intense band at $\sim 1667 \mathrm{~cm}^{-1}$, which has been attributed to the carbonyl group (Figure 2). These bands indicate that NMP molecules remain inside the polymeric matrix. Although the resulting position of the reflection can be influenced by many factors in such a complex system as this one, it is clear that the incorporation of NMP inside the polymer electrolyte increases the amorphous structure of the membrane, as it has been demonstrated by XRD spectra. Addition of IL and $\mathrm{ZnTf}_{2}$ salt to the PVdF-HFP prepared with NMP produced spectra with similar morphology, confirming that polar and amorphous structures were obtained [14].

NMP characteristic carbonyl band appearing at $\sim 1667 \mathrm{~cm}^{-1}$ is shifted to minor wavenumber values, $\sim 1637 \mathrm{~cm}^{-1}$, once $\mathrm{ZnTf}_{2}$ salt is incorporated into the membrane. Additionally, a rising intensity has been observed with the $\mathrm{ZnTf}_{2}$ concentration. This process is observed for ETf and BTf-based GPEs, coinciding with the behavior reported previously for ET-based GPEs [14]. Moreover, as can be seen in the insets in Figure 2, no shifts were observed when only ILs, without $\mathrm{ZnTf}_{2}$ salt, was incorporated inside the PVdF-HFP polymer. This fact suggests that the peak shifts are due to interaction between 
$\mathrm{Zn}^{2+}$ cations and the $\mathrm{C}=\mathrm{O}$ groups of the NMP molecules. The $\sim 1637 \mathrm{~cm}^{-1}$ band intensity was raised with the salt concentration, indicating that a higher quantity of $\mathrm{Zn}^{2+}$ cations interact with $\mathrm{C}=\mathrm{O}$ groups of NMP until it reaches a maximum value (Figure 2). Similar observations have been explained as a consequence of the strong interaction between a EC plasticizer and lithium or zinc salts $[12-14,35]$.

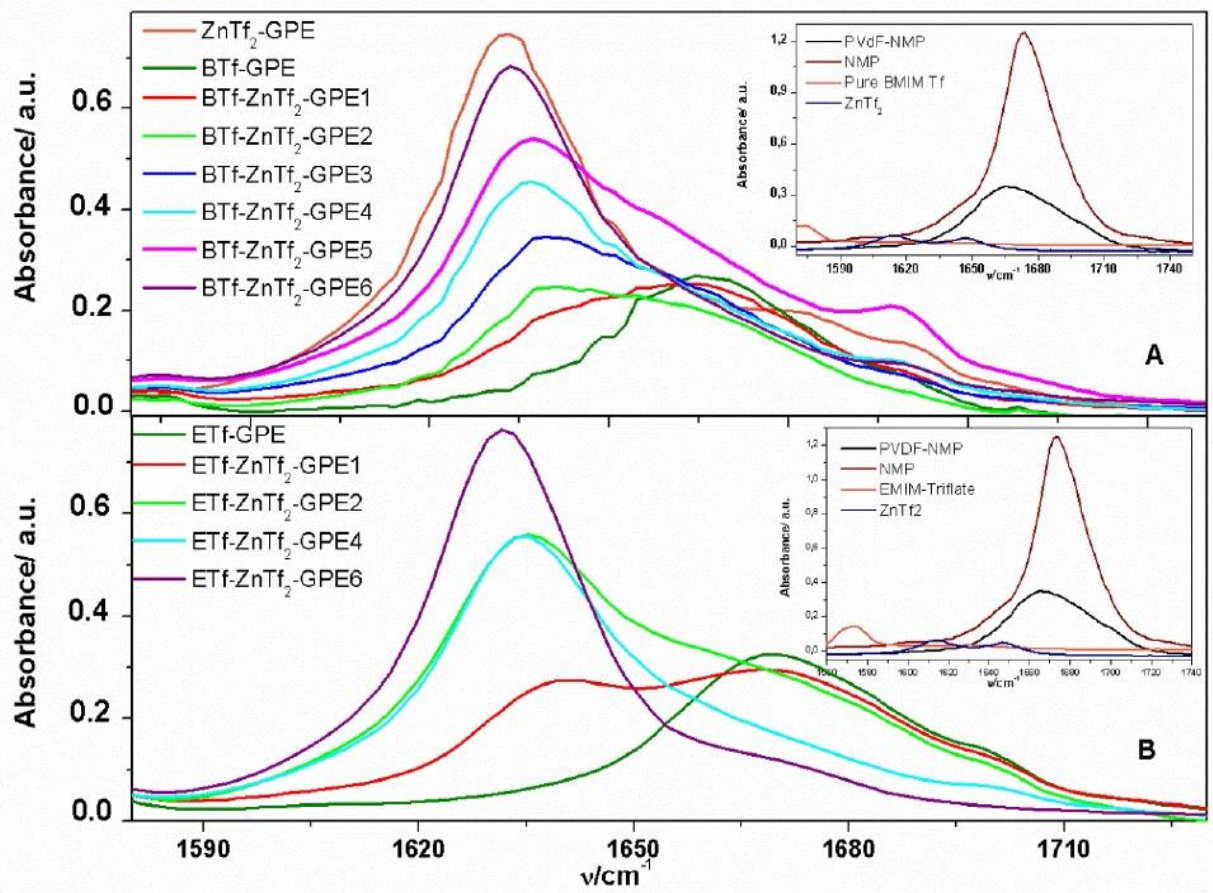

Figure 2. ATR-FTIR spectra of GPEs analyzed in the $1580-1730 \mathrm{~cm}^{-1}$ frequency range for (A) BTf-ZnTf 2 -GPEs; and (B) ETf-ZnTf 2 -GPEs. Insets: ATR-FTIR spectra of NMP solvent, pure IL, $\mathrm{ZnTf}_{2}$ GPE, and PVdF-HFP (NMP).

$\mathrm{ZnTf}_{2}$ has high dissociation ability due to the strong electron-withdrawing $\mathrm{SO}_{2} \mathrm{CF}_{3}$ groups and also has a low tendency to form ion-pairs [36]. Moreover, the high dielectric constant of PVdF-HFP $(\varepsilon=8.4)$ helps dissociating the salt and, hence, fostering high free ion concentration in the gel. This fact, together with a $\mathrm{Zn}^{2+}$-NMP interaction, should produce a strong dissociation of the $\mathrm{ZnTf}_{2}$, resulting in a great amount of free $\mathrm{Tf}$ anions. With the aim to confirm if $\mathrm{Tf}$ anions are free or forming ion pairs inside the GPE, we have analyzed the $1000-1080 \mathrm{~cm}^{-1}$ wavenumber range, where bands associated with free triflate anions $\left(1030 \mathrm{~cm}^{-1}\right)$, ion-pairs $\left(\sim 1042 \mathrm{~cm}^{-1}\right)$, and higher aggregates $\left(\sim 1055 \mathrm{~cm}^{-1}\right)$ formed by the triflate anions have been reported previously [35,37].

Figure 3 shows the $1000-1080 \mathrm{~cm}^{-1}$ range of the ATR-FTIR spectra obtained for ETf and BTf-based GPEs. As can be seen, only an intense band is obtained at $\sim 1030 \mathrm{~cm}^{-1}$, indicating that free triflate anions are present for all IL-based GPEs. Furthermore, the peak intensity increases with the amount of salt added, which is indicative of the amount of free triflate anions increasing with the salt 
concentration. Moreover, this peak does not shift, confirming that a similar triflate interaction resulted for all GPEs prepared.

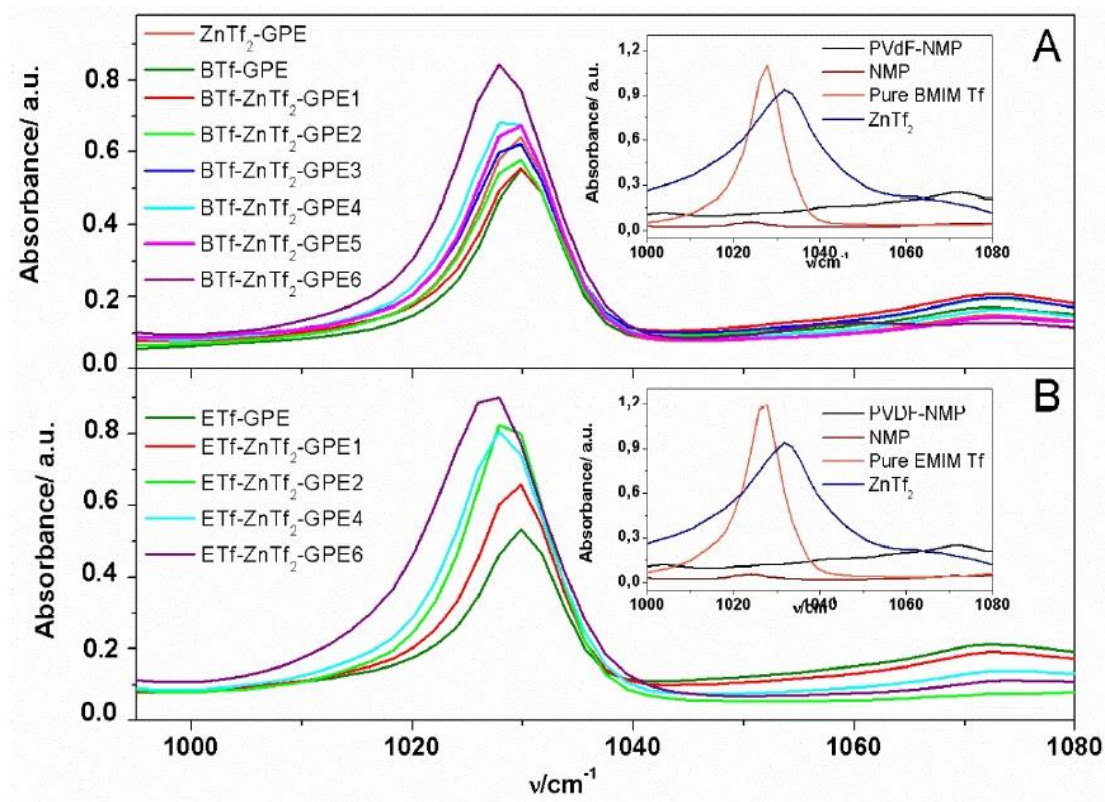

Figure 3. ATR-FTIR spectra of GPEs analyzed in the $1000-1080 \mathrm{~cm}^{-1}$ frequency range for

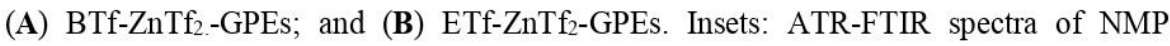
solvent, pure IL, $\mathrm{ZnTf}_{2}$ GPE, and PVdF-HFP (NMP).

Regarding the other two triflate anion characteristic bands, due to ion-pairs $\left(\sim 1042 \mathrm{~cm}^{-1}\right)$ and higher aggregates $\left(\sim 1055 \mathrm{~cm}^{-1}\right)$ formation, they have not been detected. This behavior is in agreement with that observed previously for ET-based GPEs [14].

\subsubsection{Thermal Analysis}

DSC analysis provides information on important parameters as glass temperature, melting point, and thermal stability of the GPEs. These parameters will affect the properties of the electrolyte material when operating in a battery. We have carried out a DSC study of the three different IL-based GPEs.

Glass transition temperature ( $\mathrm{Tg}$ ) is one of the most important parameters of the amorphous phase and it has been measured for all synthesized GPEs (Table 2). When only IL was added to the PVdF-HFP the resulting films produced the lowest $\mathrm{Tg}$ values, $\sim-80^{\circ} \mathrm{C}$, for the three IL-GPEs studied. However, inclusion of $\mathrm{ZnTf}_{2}$ without $\mathrm{IL}$ inside the GPEs provided the highest $\mathrm{Tg}$ value, $\sim-30{ }^{\circ} \mathrm{C}$. Incorporation of $\mathrm{IL}$ and $\mathrm{ZnTf}_{2}$ together into the GPEs exhibited $\mathrm{Tg}$ intermediate values, ranging between -67 and $-50{ }^{\circ} \mathrm{C}$, which were shifted from lower to higher temperature with the increasing of the salt concentration. This result can be explained as due to that polymer chains movements are being hindered by the inclusion of a higher amount of salt. Additionally, Tg values are very similar for all GPEs analyzed, indicating that the degree of the hindrance should be similar regardless the IL type 
included in the GPE. This leads us to think that the interaction between polymer matrix and ILs are similar when enough amount of salt is added.

Table 2. Glass transition temperature, $\mathrm{T}_{\mathrm{g}}$, ionic conductivity, $\sigma$, activation energy, $\mathrm{E}$, and cationic transport number, $t_{+}$, values for the gel polymer electrolytes studied. $\sigma$ and $t_{+}$ values obtained at $30^{\circ} \mathrm{C}$.

\begin{tabular}{|c|c|c|c|c|c|c|}
\hline GPE name & EMIM TFSI & EMIM Tf & BMIM Tf & EMIM TFSI & EMIIM Tf & BMIM Tf \\
\hline Sample & \multicolumn{6}{|c|}{$\sigma\left(\mathrm{S} \mathrm{cm}^{-1}\right) \cdot 10^{-3}$} \\
\hline IL-GPE & -81.6 & -79.3 & -78.8 & 1.98 & 7.07 & 5.2 \\
\hline $\mathrm{IL}-\mathrm{ZnTf}_{2}$ GPE 1 & -67.5 & -64.8 & -56.3 & 3.82 & 7.05 & 1.93 \\
\hline IL-ZnTf ${ }_{2}$ GPE 2 & -58.5 & -63.2 & -56.3 & 3.73 & 4.62 & 2.68 \\
\hline $\mathrm{IL}-\mathrm{ZnTf}_{2}$ GPE 3 & -57.3 & - & -55.3 & 3.05 & - & 2.99 \\
\hline IL-ZnTf $f_{2}$ GPE 4 & -56.9 & -61.1 & -54.5 & 2.2 & 1.96 & 2.21 \\
\hline IL-ZnTf ${ }_{2}$ GPE 5 & -53.3 & - & -53.8 & 1.54 & - & 2.57 \\
\hline IL-ZnTf ${ }_{2}$ GPE 6 & -49.4 & -51.3 & -51.1 & 1.88 & 1.09 & 1.88 \\
\hline GPE name & EMIM TFSI & EMIM Tf & BMIM Tf & EMIM TFSI & EMIM Tf & BMIM Tf \\
\hline Sample & \multicolumn{3}{|c|}{$t_{+}$} & \multicolumn{3}{|c|}{$E_{a}(e V)$} \\
\hline IL-GPE & 0.098 & 0.42 & 0.19 & 0.041 & 0.024 & 0.03 \\
\hline IL-ZnTf ${ }_{2}$ GPE 1 & 0.296 & - & 0.42 & 0.027 & 0.026 & 0.026 \\
\hline IL-ZnTf ${ }_{2}$ GPE 2 & 0.42 & 0.53 & 0.56 & 0.026 & 0.028 & 0.025 \\
\hline IL-ZnTf $f_{2}$ GPE 3 & 0.428 & - & 0.52 & 0.028 & - & 0.028 \\
\hline IL-ZnTf ${ }_{2}$ GPE 4 & 0.578 & 0.52 & 0.56 & 0.03 & 0.037 & 0.033 \\
\hline IL-ZnTf $f_{2}$ GPE 5 & 0.544 & - & - & 0.032 & - & 0.033 \\
\hline IL-ZnTf ${ }_{2}$ GPE 6 & 0.575 & 0.52 & 0.48 & 0.027 & 0.038 & 0.031 \\
\hline
\end{tabular}

In addition, endothermic peaks (Figure 4) related to the melting temperatures ( $\mathrm{Tm}$ ) have been

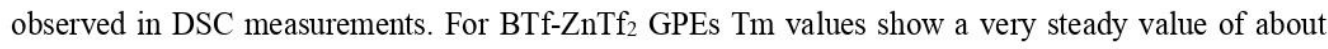
$110^{\circ} \mathrm{C}$ with a small trend to lower temperatures. A similar behavior is observed for ET-ZnTf $\mathrm{GPEs}_{2}$ with $\mathrm{Tm}$ values also about $110^{\circ} \mathrm{C}$ and same trend to lower temperatures.

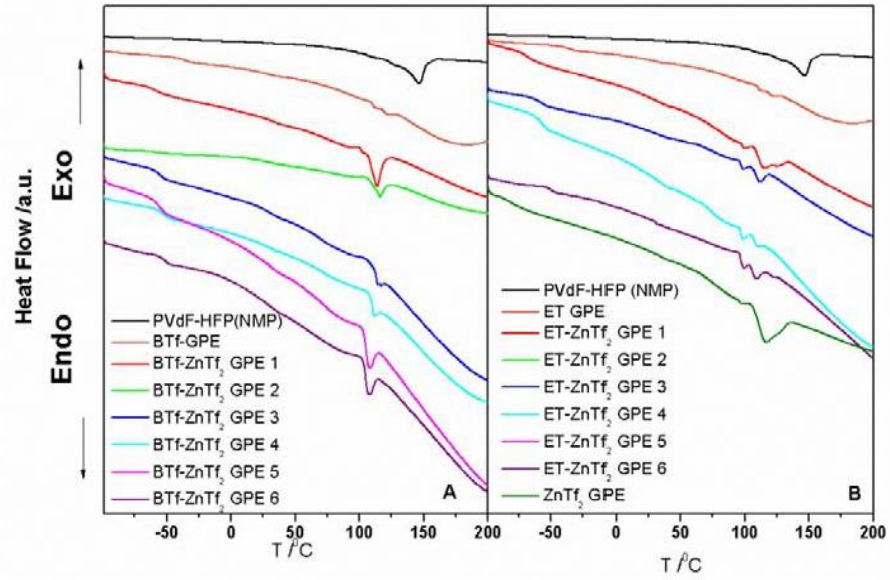

Figure 4. DSC plots of (A) BTf-ZnTf $f_{2}$ GPEs; (B) BTf-ZnTf $f_{2}$ GPEs. 
Hence, $\mathrm{Tg}$ values shifting indicated that a large amount of the amorphous phase being present in the GPEs with the salt concentration, but it also suggest some restrictions in the flexibility imposed on the polymer chains [6]. From DSC analysis we can deduce that the type of anion or cation included in the IL does not induce important changes in the polymer matrix properties. Thus, the GPE's behavior is mainly due to the polymer matrix, salt, and solvent interactions. Moreover, DSC curves demonstrate a stable thermal behavior in a wide range of temperatures, over $130{ }^{\circ} \mathrm{C}$, which is vast enough to the application of these GPEs in batteries.

\subsection{Electrical and Electrochemical Properties}

\subsubsection{Temperature Dependence of Ionic Conductivity}

Figure 5 shows the variation of ionic conductivity with the temperature for ETf and BTf-based GPEs with different concentration of $\mathrm{ZnTf}_{2}$. All the plots obey the Vogel-Tammen-Fulcher (VTF) behavior throughout the temperature range under study, as it has been frequently observed for IL-based GPEs, and they are fitted to the equation:

$$
\sigma=\mathrm{AT}^{-1 / 2} \exp \left(-\frac{\mathrm{E}_{a}}{\mathrm{k}_{\mathrm{B}}\left(\mathrm{T}-\mathrm{T}_{0}\right)}\right)
$$

where $\mathrm{A}$ is the pre-exponential factor; $\mathrm{E}_{\mathrm{a}}$ the activation energy; $\mathrm{k}_{\mathrm{B}}$ the Boltzmann constant; $\mathrm{T}$ the testing temperature and $\mathrm{T}_{0}$ the equilibrium glass transition temperature. VTF behavior has been largely reported for IL-based polymer electrolytes [3,4,14,16,20,21,26].

From slopes in Figure 5 the activation energy values can be obtained, which are presented together with conductivity values for all ETf, BTf, and ET-based GPEs in Table 2. Ea values for all GPEs ranged between 0.024 and $0.038 \mathrm{eV}$, and no relevant changes were observed for all GPEs, except for ET free $\mathrm{ZnTf}_{2}$ which have a maximum value of $0.041 \mathrm{eV}$.

Table 2 displays that all ionic conductivities obtained at $30^{\circ} \mathrm{C}$ for the GPEs studied have similar values, ranging between $1.09 \times 10^{-3}$ and $7.07 \times 10^{-3} \mathrm{~S} \cdot \mathrm{cm}^{-1}$. However, note that $\mathrm{ZnTf}_{2}$ salt free GPEs provide very different values of the ionic conductivity: very low value for the ET-GPE, $1.5 \times 10^{-3} \mathrm{~S} \cdot \mathrm{cm}^{-1}$, intermediate value, $5.3 \times 10^{-3} \mathrm{~S} \cdot \mathrm{cm}^{-1}$, for BTf-GPE and the highest value, $7.07 \times 10^{-3} \mathrm{~S} \cdot \mathrm{cm}^{-1}$, for ETf-GPE.

$\mathrm{ZnTf}_{2}$ addition produces different behavior for the three IL type GPEs. ETf-GPEs' conductivity always decrease with the salt concentration, for ET-GPEs, the conductivity values increase initially with low salt quantity and, after that decrease, an addition of ZnTf to BTf-GPEs decrease the conductivity with respect to the salt-free GPE, but similar values are obtained in the whole concentration range.

From IL- $\mathrm{ZnTf}_{2}$ GPE 3 onwards we have obtained very similar conductivity values for each IL under same salt concentration, indicating clearly no significant variation or influence exerted by the IL anions or cations. 


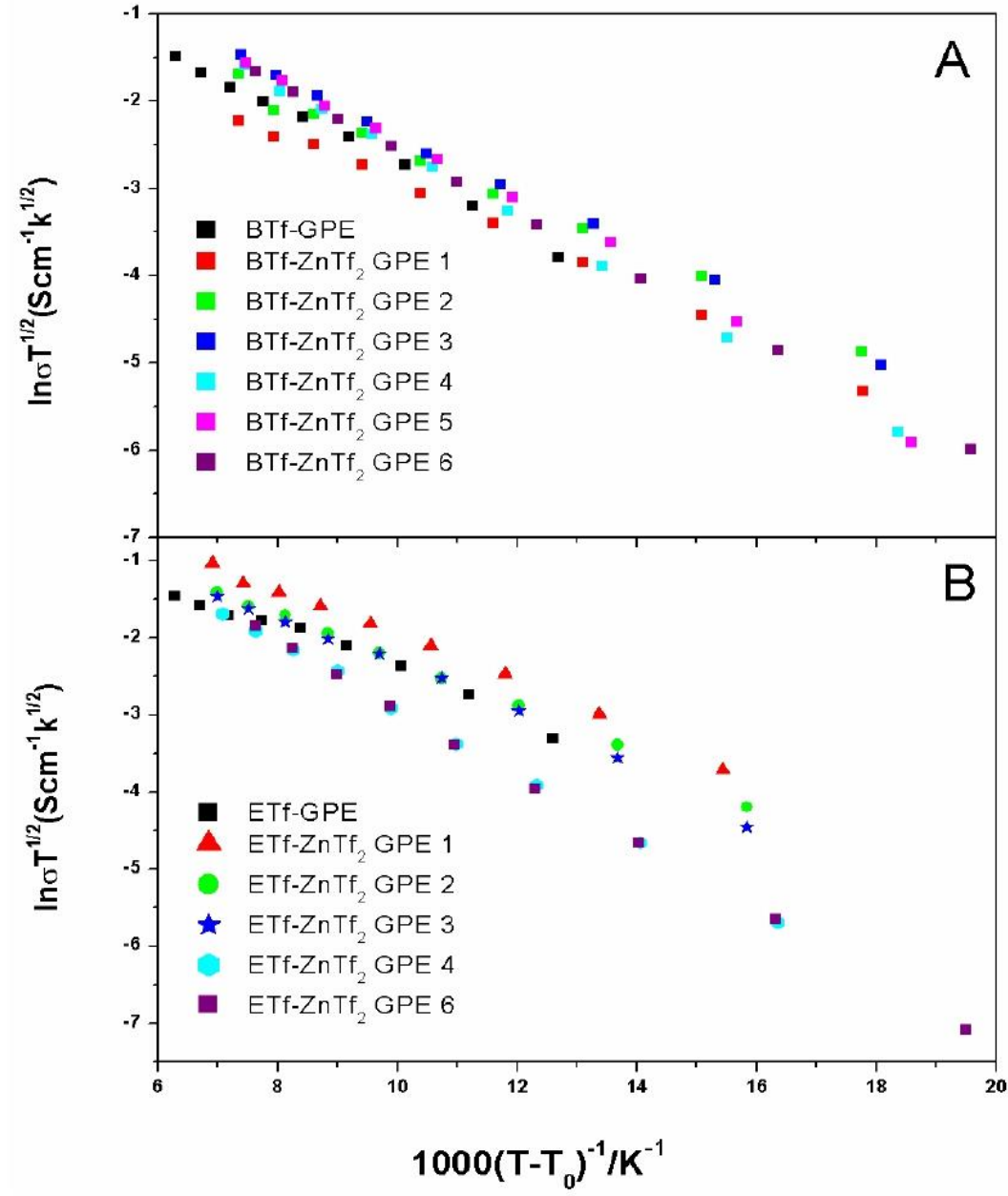

Figure 5. VTF plots of (A) BTf-ZnTf $f_{2}$ GPEs; and (B) BTf-ZnTf $f_{2}$ GPEs.

\subsubsection{Transport Number}

The total ionic transport number (tion) was evaluated by the polarization technique [38], and values $>0.98$ were always obtained for the three IL-based GPEs under study, which indicates that the total conductivity was predominantly ionic. We have also determined the cationic transport numbers $\left(t_{+}\right)$using the Evans method [14,22,23,39-41], because $t_{+}$values are a key factor in the optimization of electrolytes for zinc batteries. Figure 6 and Table 2 show the $t+$ values for the GPEs studied. Even if this method carries a certain degree of uncertainty, reproducible values were obtained within an acceptable error range. Three measurements were carried out to obtain each $t+$ value. Additionally, t- values are depicted in Figure 6. 


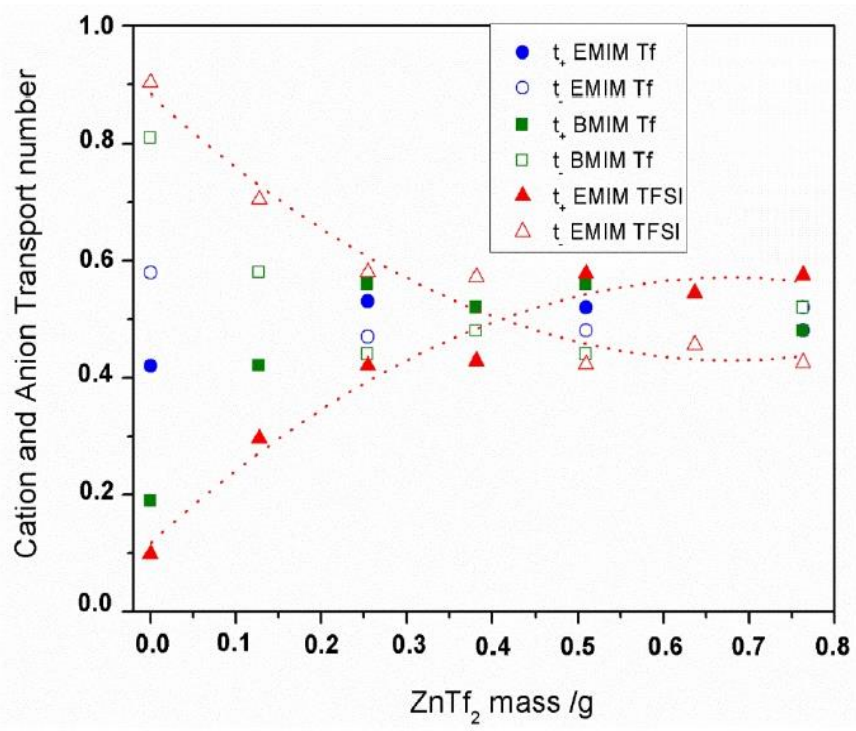

Figure 6. Cation and anion transport number for IL-ZnTf 2 GPEs vs mass of $\mathrm{ZnTf}_{2}$ used. The legend indicates the IL names.

We have analyzed how the transport cation number values are affected by varying the amount of salt inside the membrane. Figure 6 shows $t+$ and $t$ - values for the three-type IL-based GPEs. A similar tendency has been obtained for three kind IL-GPEs. As can be seen, at low salt concentrations into GPEs $t$ - values are always higher than $t_{+}$. However, $t+$ increases with the salt concentration inside the membrane for all GPEs, making $t+$ higher than $t$ - for higher salt concentration GPEs.

Since $\mathrm{EMIM}^{+}$and $\mathrm{BMIM}^{+}$are bulky cations, mobility should be very low, and therefore the conductivity in these films will be predominantly anionic when salt have not been added yet to the system. Addition of $\mathrm{ZnTf}_{2}$ salt inside the GPEs provided higher $\mathrm{t}+$ values with salt concentrations until it reaches a maximum value $c a .0 .55 \pm 0.05$ for the three IL-based GPEs. These $t+$ values indicate that cation mobility increased when $\mathrm{ZnTf}_{2}$ salt was incorporated into the GPE, due mainly to $\mathrm{Zn}^{2+}$ takes over. Knowing that the $\mathrm{EMIM}^{+}$is a bulky cations and $\mathrm{BMIM}^{+}$, even bulkier, mobility has to be very low due to great volume, as it was commented previously. Thus, we can consider that the cation transport values were due mainly to $\mathrm{Zn}^{2+}$ cations. Similar $\mathrm{t}+$ values for the $\mathrm{Zn}^{2+}$ transport have been reported in the literature by different authors for several polymer electrolytes $[4,14,41,42]$. To this point, we have to consider the interaction between the $\mathrm{Zn}$ cations and carbonyl groups of the NMP molecules, as it was deduced from ATR-FTIR measurements. Recently, we have reported that $\sim 1636$ $\mathrm{cm}^{-1}$ peak intensity versus salt mass plot has a very similar tendency as the one obtained for $\mathrm{t}+$ values, for ET- ZnTf 2 GEP. Similar tendencies have been obtained for ETf- and BTf-based GPEs. Thus, we can deduce that the higher cationic transport numbers obtained for the GPEs with higher salt concentrations are a consequence of $\mathrm{Zn}^{2+}$ cations are solvated by NMP solvent, favoring the cation transport inside the GPE regardless the IL included in the GPE [14]. 


\subsubsection{Cyclic Voltammetry}

In order to confirm $\mathrm{Zn}^{2+}$ conduction into the GPEs, a cyclic voltammetric study was carried out using a $\mathrm{Zn} / \mathrm{GPE} / \mathrm{Zn}$ symmetric cell. Figure 7 shows the comparison of the voltammograms registered for three GPE types. No relevant differences were observed for all GPEs indicating that IL cation and anion types do not affect the general voltammetric behavior. We obtained similar density current values, $c a$. $15 \mathrm{~mA} \cdot \mathrm{cm}^{-2}$, and $\Delta \mathrm{E}$ for the $\mathrm{IL}-\mathrm{ZnTf}_{2} \mathrm{GPE} 4$. These current values are much higher than those obtained by us for similar GPEs using THF instead of NMP as solvent [3], confirming again the importance of the NMP molecules inside the membranes. Furthermore, reversibility of this system has been verified by the peaks stability observed when several consecutive cycles were registered for the GPEs (Inset in Figure 7 shows 20 consecutive voltammetric cycles for ETf-ZnTf $2_{2}$ GPE 4 and BTf-ZnTf 2 GPE 4). Additionally, voltammograms corresponding to the $\mathrm{ZnTf}_{2}$-free IL-based membranes show that there is essentially no current for these GPEs [14]. No current was either obtained for IL-free membrane voltammograms, confirming that only $\mathrm{ZnTf}_{2}$ inside the polymer was not enough to produce good transport results. Finally, these voltammograms indicate that $\mathrm{Zn}^{2+}$ ions are indeed mobile in the GPEs and $\mathrm{Zn}$ is capable of dissolution into and deposition from the membranes, which is essential for their potential application in Zinc batteries $[3,14,26]$. Therefore, these results demonstrate that these membranes composed by PVdF-HFP, ZnTf 2 , and different ILs, such as EMIM Tf, BMIM Tf, or EMIM TFSI, may be used in Zinc-based batteries as GPEs [14,24].

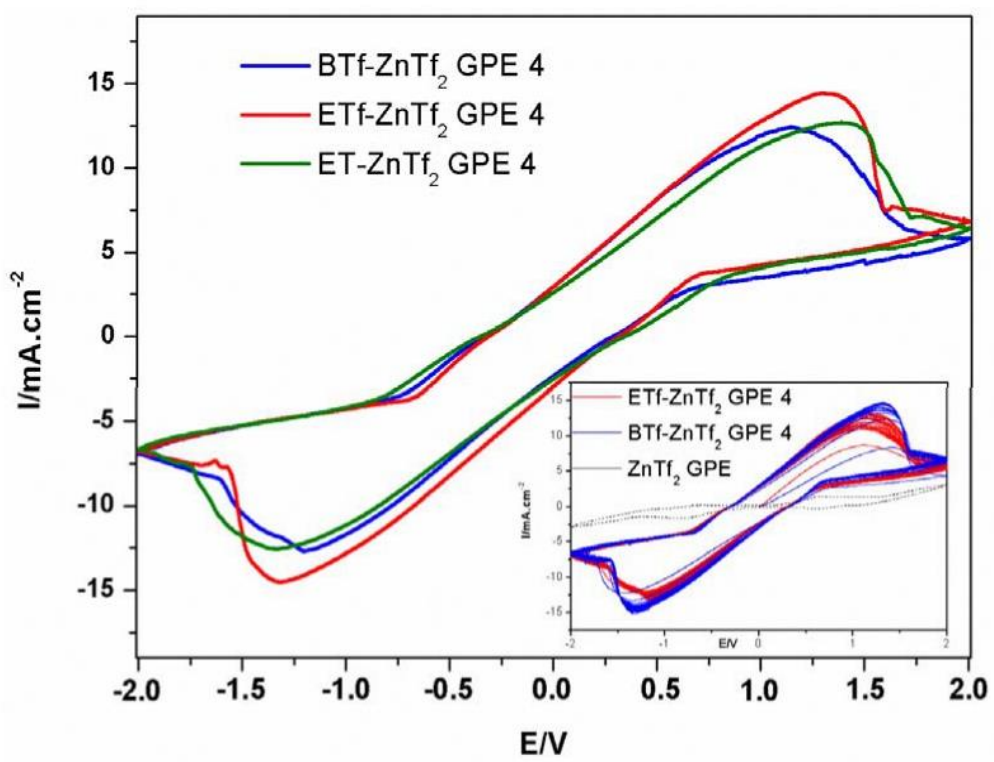

Figure 7. Cyclic voltammograms of $\mathrm{Zn} / \mathrm{GPE} / \mathrm{Zn}$ symmetric cells for $\mathrm{BTf}-\mathrm{ZnTf}_{2}$ GPE 4,

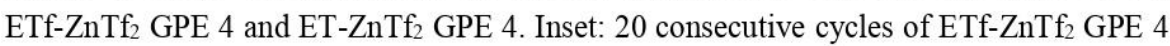
and BTf-ZnTf $f_{2}$ GPE 4 compared with $\mathrm{ZnTf}_{2}-\mathrm{GPE}$ voltammogram. Scan rate $=20 \mathrm{mV} / \mathrm{s}$. 


\subsection{4. $\mathrm{Zn} / \mathrm{GPE} / \mathrm{MnO}_{2}$ Batteries}

Finally, three $\mathrm{ZnTf}_{2}$-GPEs containing different ILs have been tested in a $\mathrm{Zn} / \mathrm{GPE} / \mathrm{MnO}_{2}$ battery at room temperature. Figure 8 shows the first discharge curve carried out at $-1 \mathrm{~mA} \cdot \mathrm{cm}^{-2}$ to $0.4 \mathrm{~V}$ of the cut-off cell voltage, obtaining similar discharges capacities of $110-120 \mathrm{mAh} \cdot \mathrm{g}^{-1}$. Once again no significant changes were found for different IL-based GPEs, confirming that IL type does no influence the GPE behavior.

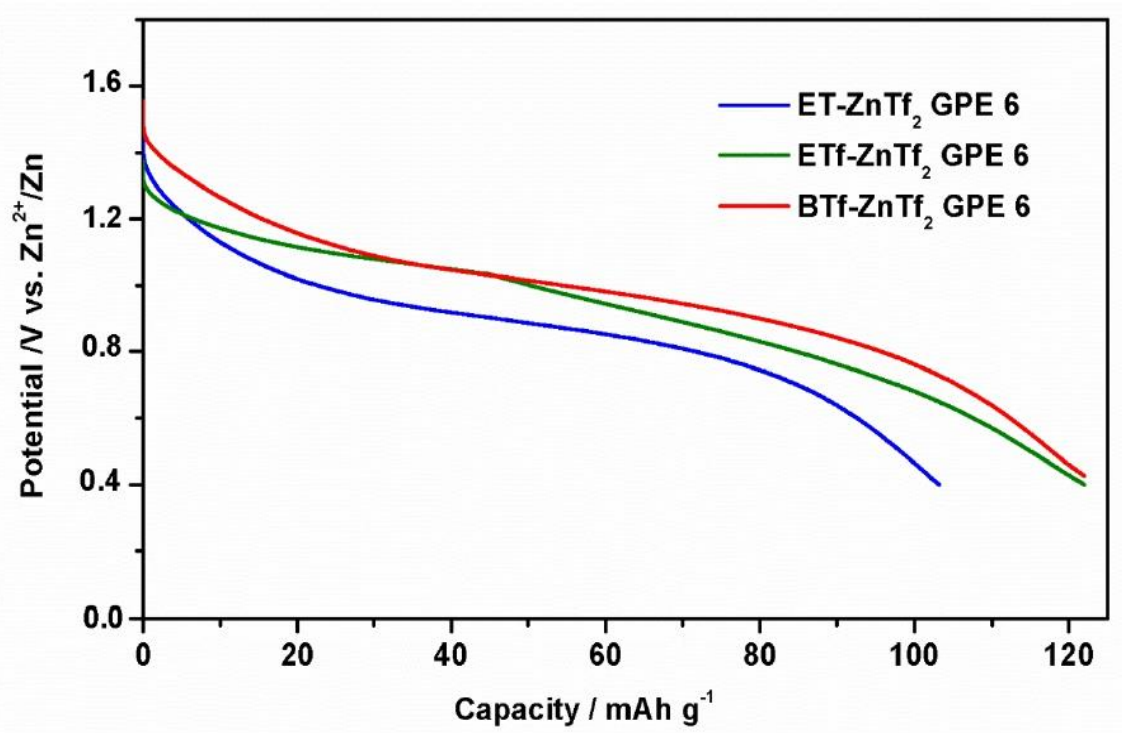

Figure 8. First discharge curves of a $\mathrm{Zn} / \mathrm{GPE} / \mathrm{MnO}_{2}$ cell at $1 \mathrm{~mA} \cdot \mathrm{cm}^{-2}$ for BTf- $\mathrm{ZnTf} f_{2}$

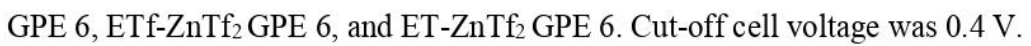

\subsection{Conductivity and ATR-FTIR Analysis of the IL-Based GPEs with and without ZnTf2}

The results presented in this work point to a similar electrical and structural behavior for all IL-ZnTf $f_{2}$ GPEs synthesized, although three different ionic liquids were used. The three type GPEs show, when including an enough amount of $\mathrm{ZnTf}_{2}$ salt, similar ionic conductivity, activation energies, transport number, and $\mathrm{Tg}$ values. Furthermore, the voltammograms and discharge curves obtained for the GPEs synthesized with the same amount of $\mathrm{ZnTf}_{2}$ but changing the ionic liquid, present a very close behavior. In this sense, we wonder why the different cations and anions of the ionic liquids used have not affected the general behavior of the GPEs.

With the aim to clarify this point, we have paid attention to the conductivity values obtained for the three salt-free GPEs (Figure 9). As can be seen, different conductivity values are obtained depending on the IL added, higher conductivity resulted in order ETf-GPE $>$ BTf-GPE $>$ ET-GPE. The ionic conductivity is very low for the ET-GPE, which contains $\mathrm{TFSI}^{-}$anions; however, it is higher for ETf-GPE and BTf-GPE, both of them including $\mathrm{Tf}^{-}$anions. This behavior seems to indicate that $\mathrm{TFSI}^{-}$ 
anion affects clearly the ionic conductivity of the ET-GPE, probably due to the interaction between $\mathrm{TFSI}^{-}$and $\mathrm{EMIM}^{+}$, which will be very different to that resulting between $\mathrm{BMIM}^{+}$or $\mathrm{EMIM}^{+}$with $\mathrm{Tf}^{-}$.

To explain this behavior, additional analyses have been carried out. The conductivity, $\sigma$, can be expressed by $[38,42]$ :

$$
\sigma=\sum n_{i} Z_{i} e \mu_{i}
$$

where $n_{i}$ is the density of charge carriers of species $i$; $Z_{i e}$ the charge on these species and $u_{i}$ is the ionic mobility of species $i$. Ignoring the sign of the charge number $Z_{i}$, we can write, for all 1:1 electrolytes:

$$
\sigma=e\left(n^{+} \mu^{+}+n^{-} \mu^{-}\right)
$$

From this equation and considering the transport number measured for these GPEs, we can obtain the anionic, $\sigma_{-}$, and cationic, $\sigma_{+}$, conductivities as [22]:

$$
\begin{aligned}
& \sigma_{+}=\sigma t_{+} \\
& \sigma_{-}=\sigma t_{-}
\end{aligned}
$$

Unfortunately, when more of two kinds of ions are including inside the GPEs, this model cannot be applied. Thus, to calculate the anionic, $\sigma_{-}$, and cationic, $\sigma_{+}$, conductivities for the GPEs containing IL and $\mathrm{ZnTf}_{2}$ we would have to know the charge carrier numbers and ion mobility values for all ionic species included in the GPE.

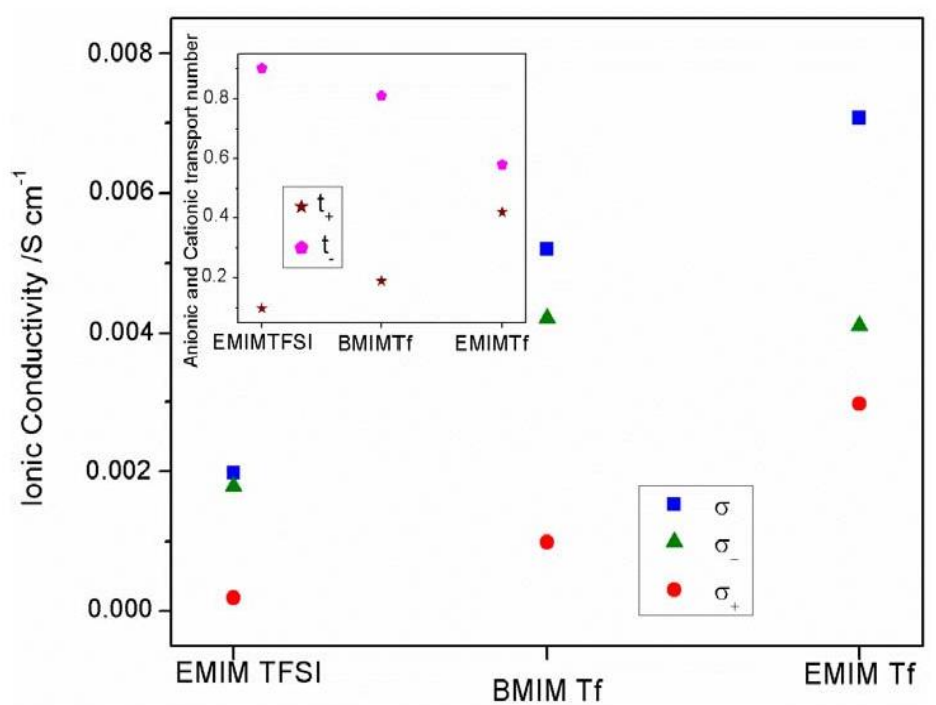

Figure 9. Total, $\sigma$, anionic, $\sigma_{-}$, and cationic, $\sigma_{+}$conductivities for the three salt free IL-GPEs. Inset: Anionic and cationic transport number for the same salt free IL-GPEs.

Figure 9 shows the total, anionic and cationic conductivities for the three salt-free GPEs. As can be seen, for all GPEs, $\sigma_{-}$is always higher than $\sigma_{+}$, indicating that ion transport is mainly anionic. This result is in agreement with the $t_{+}$and $t$ - plot, inset in Figure 9. Furthermore, TFSI ${ }^{-}$conductivity is lower than $\mathrm{Tf}^{-}$conductivity observed for ETf and BTf GPEs. 
This behavior may be explained in base of the different cationic-anionic interactions occurring in each GPE. In this sense, since the three ILs used in this work have an imidazolium cation, we have analyzed the $3000-3240 \mathrm{~cm}^{-1}$ region obtained by ATR-FTIR, where $\mathrm{C}-\mathrm{H}$ imidazolium bands are presented.

In Figure 10, 3000-3240 $\mathrm{cm}^{-1}$ ATR-FTIR wavenumber range obtained for the three different ILs-based GPEs are compared. This figure includes the three salt free GPEs and IL-ZnTf 2 GPE 4 membrane spectra. Additionally, ATR-FTIR spectra of pure ILs are included for comparison purposes. Figure 10A shows that pure EMIM TFSI bands have a shift with respect the other pure ILs. This shift is also observed for the salt free ET-GPE (Figure 10B). However, once the salt is included in the GPEs this shifting disappears (Figure 10C). The last result indicates that in these GPEs the IL cations will present very similar interaction with the corresponding anions.

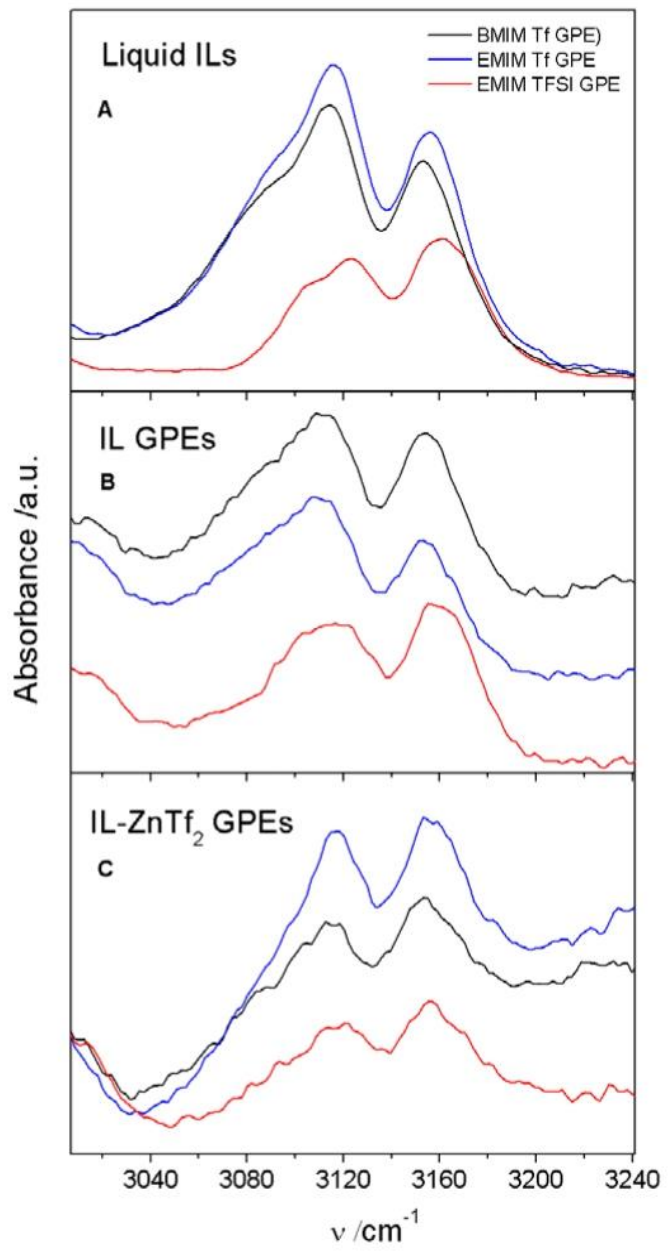

Figure 10. ATR-FTIR spectra at $3000-3240 \mathrm{~cm}^{-1}$ frequency range for (A) pure ILs; (B) salt free IL-GPEs; and (C) IL- ZnTf 2 GPEs 4. The legend indicates the IL names. 
In order to highlight the magnitude of this shifting, we have carried out the deconvolution of ATR-FTIR bands and four peaks were obtained for all GPEs and pure ILs. Figure 11 displays the frequencies of the four ATR-FTIR bands for pure ILs and for all GPEs synthesized. This figure shows that no shifting is observed neither for the two highest frequency bands $\left(\sim 3165\right.$ and $\left.\sim 3155 \mathrm{~cm}^{-1}\right)$ regardless the IL used, nor for pure ILs. Furthermore, both bands show similar and steady values for all GPEs throughout the whole salt concentration range. However, the other two bands $\left(\sim 3115\right.$ and $\left.\sim 3090 \mathrm{~cm}^{-1}\right)$ are shifted to higher frequencies for pure EMIM TFSI IL and for free salt or low salt contain ET-GPEs. However, the rising of salt inside the GPEs produces that ET based GPEs show similar peak frequencies to those obtained for ETf and BTf-based GPEs. This result points to similar cation-anion interactions when enough concentration of $\mathrm{ZnTf}_{2}$ is added to the GPE.

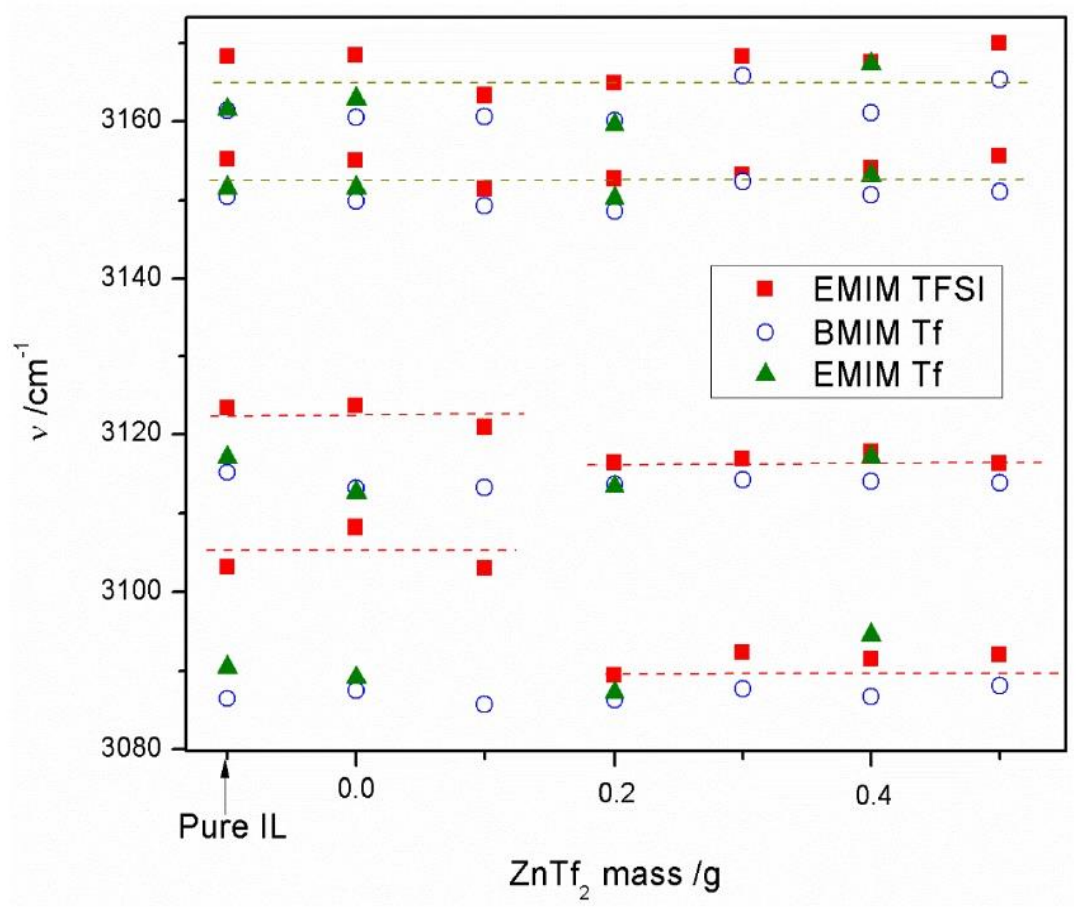

Figure 11. Deconvoluted peak wavenumbers from ATR-FTIR 3000-3240 range vs. mass of $\mathrm{ZnTf}_{2}$. The legend indicates ILs.

\section{Experimental Section}

99\% 1-Ethyl-3-methylimidazolium bis(trifluoromethylsulfonyl)imide (EMIM TFSI), 99\% 1-Butyl3-methylimidazolium trifluoromethanesulfonate (BMIM Tf), and 99\% 1-Ethyl-3-methylimidazolium trifluoromethanesulfonate (EMIM Tf) were purchased from IOLITEC. The co-polymer poly(vinylidene fluoride-cohexafluoropropylene) (PVdF-HFP), tetrahydrofuran (THF), n-methyl-2-pyrrolidone (NMP), and zinc trifluoromethanesulfonate $\left(\mathrm{ZnTf}_{2}\right)$ were obtained from Sigma-Aldrich (St. Louis, MO, USA). 
GPEs were prepared using a solution cast method reported previously [14]. Table 1 shows the weight of the components used in each prepared GPE.

$\mathrm{X}$-ray diffraction patterns of the synthesized polymers were recorded using a Bruker (Billerica, MA, USA) D8-Advance Powder Diffractometer. ATR-FTIR spectra were obtained using a Thermo Nicolet 5700 Infrared Spectrometer (Thermo Fisher Scientific, Waltham, MA, USA) in the wave number range from 400 to $4000 \mathrm{~cm}^{-1}$. Ionic conductivity was determined from AC impedance measurements using a Biologic VSP Modular five-channel potensiostat/galvanostat in the frequency range from $100 \mathrm{kHz}$ to $40 \mathrm{mHz}$. The temperature was set by a Julabo F25 thermostat (Julabo GMBH Seelbach, Germany) in the range from 278 to $353 \mathrm{~K}$. The cell arrangement consisted of two platinum electrodes, which acted as blocking electrodes.

Ionic conductivity, $\sigma$, was calculated from the equation:

$$
\sigma=\frac{l}{R_{b} A}
$$

where $l$ is the thickness of the sample; $R_{b}$ the bulk resistance; and $A$ the electrode/electrolyte contact area. The cationic transport number $\left(\mathrm{t}_{+}\right)$was evaluated using the Evans method [22,23,] AC impedance measurements were registered prior and after a DC polarization on the $\mathrm{Zn} / \mathrm{GPE} / \mathrm{Zn}$ cell. To polarize the cell a DC voltage $(\Delta \mathrm{V}=0.05 \mathrm{~V})$ was applied. $\mathrm{t}+$ values were obtained from the next equation:

$$
t_{+}=\frac{I_{s}\left(\Delta V-R_{0} I_{0}\right)}{I_{0}\left(\Delta V-R_{s} I_{s}\right)}
$$

where $I_{0}$ and $I_{s}$ are the initial and final currents and $R_{0}$ and $R_{s}$ are the cell resistances before and after polarization, respectively. Cyclic voltammetry was carried out using symmetric $\mathrm{Zn} / \mathrm{GPE} / \mathrm{Zn}$ cells.

GPEs were sandwiched between Pt and Pt electrodes ( $\mathrm{Zn} / \mathrm{GPE} / \mathrm{Pt}$ cell) or two $\mathrm{Zn}$ discs ( $\mathrm{Zn}$ (GPE/Zn cell). The contact area was always $0.5 \mathrm{~cm}^{2}$ and stainless steel current collectors were used. $\mathrm{Zn}$ discs (99.999\%) and Pt plates (99.97\%) used in these cells were purchased from Goodfellow (Huntingdon, England).

Galvanostatic charge/discharges were performed at $1 \mathrm{~mA} / \mathrm{cm}^{2}$ using a Biologic VSP Modular five-channel potensiostat/galvanostat. Cathode materials were prepared mixing $\mathrm{MnO}_{2}(80 \%)$, carbon black (15\%), and PVdF (5\%) in $5 \mathrm{~mL}$ of THF. The slurry was stirred at room temperature for $1 \mathrm{~h}$. After that, the slurry was dried in the oven at $80^{\circ} \mathrm{C}$ for $1 \mathrm{~h}$ and finally was compacted at a pressure of 10 tons $\cdot \mathrm{cm}^{-2}$. Thus, circular discs of diameter $12 \mathrm{~mm}$ were obtained. The specific capacity was calculated using the equation:

$$
C=\frac{I \times t}{m}
$$

where $I$ is the current constant intensity applied during the discharge process; $t$ is the discharging time before to reach $0.4 \mathrm{~V}$; and $m$ is the total $\mathrm{MnO}_{2}$ active mass added in the cathode.

\section{Conclusions}

In view of the results we can postulate that a different structural and electrical GPEs behavior will be obtained when no salt or low salt concentration is included in the membrane, depending on the 
IL type used. However, when an enough amount of $\mathrm{ZnTf}_{2}$ salt is introduced in the GPE, very similar behavior resulted regardless the IL used. This result points to that the $\mathrm{Zn}^{2+}$ and $\mathrm{Tf}^{-}$ion transport is predominant at high salt concentrations inside the GPEs. Additionally, when enough amount of $\mathrm{ZnTf}_{2}$ is included in the GPEs high cation transport number values were obtained, which has to be related with the NMP- $\mathrm{Zn}^{2+}$ interaction [14]. This fact makes $\mathrm{Zn}^{2+}$ the most important charge carrier in all GPEs regardless IL used. Thus, once again it is confirmed the relevance of the NMP presence inside the membrane to improve the conductivity properties of these GPEs.

In spite of this, inclusion of ILs inside the membranes is necessary to obtain GPEs with good electrical characteristics as it is demonstrated by the poor results obtained for IL-free GPEs in conductivities and VC measurements. A low ionic conductivity value of $1.1 \times 10^{-3} \mathrm{~S} \cdot \mathrm{cm}^{-1}$ at $30{ }^{\circ} \mathrm{C}$ was obtained for IL free $\mathrm{ZnTf}_{2}$ GPE 2. Additionally, the inset in Figure 7 shows that VC peaks obtained for an IL free $\mathrm{ZnTf}_{2}$ GPE 2 are very smaller than those observed for BTf and ETf $\mathrm{ZnTf}_{2}$ GPEs. Consequently, ILs have an important role in the conductivity process inside the GPEs. Thus, though the inclusion of NMP is fundamental to raise the cation transport number, high-quality GPEs were only obtained when NMP, IL, and $\mathrm{ZnTf}_{2}$ were included into the polymer matrix.

\section{Acknowledgments}

The authors thank the financial support from the Spanish Ministerio de Economía y Competitividad (Ref. ENE2013-48816-C5-3-R).

\section{Author Contributions}

Antonio J. Fernández Romero is the corresponding author and he has been in charge of revisions, guidance, realized the data analyses and wrote the paper. Juan P. Tafur has been in charge of article's experimental part as well as figures making and data manipulation. Florencio Santos has been dedicated to writing, figures editing, literature review and data analyses and manipulation.

\section{Conflicts of Interest}

The authors declare no conflict of interest.

\section{References}

1. Scrosati, B. Applications of Electroactive Polymers; Chapman and Hall: London, UK, 1993.

2. Stephan, A.M. Review on gel polymer electrolytes for lithium batteries. Eur. Polym. J. 2006, 42, 21-42.

3. Tafur, J.P.; Fernandez Romero, A.J. Electrical and spectroscopic characterization of PVdF-HFP and TFSI-Ionic liquids-based gel polymer electrolyte membranes. Influence of $\mathrm{ZnTf}_{2}$ salt. J. Membr. Sci. 2014, 469, 499-506.

4. Kumar, G.G.; Sampath, S. Electrochemical characterization of poly(vinylidenefluoride)-zinc triflate gel polymer electrolyte and its application in solid-state zinc batteries. Solid State Ionics 2003, 160, 289-300. 
5. Song, J.Y.; Wang Y.Y.; Wan, C.C. Review of gel-type polymer electrolytes for lithium-ion batteries. J. Power Sources 1999, 77, 183-197.

6. Abbrent, S.; Plestil, J.; Hlavata, D.; Lindgren, J.; Tegenfeldt, J.; Wendsjö, A. Crystallinity and morphology of PVdF-HFP-based gel electrolytes. Polymer 2001, 42, 1407-1416.

7. Sekhon, S.S. Conductivity behaviour of polymer gel electrolytes: Role of polymer. Bull. Mater. Sci. 2003, 26, 321-328.

8. Zhao, Y.; Zhang, Y.; Gosselink, D.; Doan, T.N.L.; Sadhu, M.; Cheang, H.-J.; Chen, P. Polymer electrolytes for lithium/sulfur batteries. Membranes 2012, 2, 553-564.

9. Ataollahi, N.; Ahmad, A.; Hamzah, H.; Rahman, M.Y.A.; Mohamed, N.S. Preparation and characterization of PVDF-HFP/MG49 based polymer blend electrolyte. Int. J. Electrochem. Sci. 2012, 7, 6693-6703.

10. Chernyak, Y. Dielectric constant, dipole moment, and solubility parameters of some cyclic acid esters. J. Chem. Eng. Data 2006, 51, 416-418.

11. Kim, C.S.; Oh, S.M. Importance of donor number in determining solvating ability of polymers and transport properties in gel-type polymer electrolytes. Electrochim. Acta 2000, 45, 2101-2109.

12. Wang, Z.; Huang, B.; Huang, H.; Xue, R.; Chen, L.; Wang, F. A Vibrational spectroscopic study on the interaction between lithium salt and ethylene carbonate plasticizer for PAN-based electrolytes. J. Electrochem. Soc. 1996, 143, 1510-1514.

13. Wang, Z.; Huang, B.; Huang, H.; Xue, R.; Chen, L.; Wang, F. Infrared spectroscopic study of the interaction between lithium salt $\mathrm{LiClO}_{4}$ and the plasticizer ethylene carbonate in the polyacrylonitrile-based electrolyte. Solid State Ionics 1996, 85, 143-148.

14. Fernandez Romero, A.J; Tafur, J.P. Interaction between $\mathrm{Zn}^{2+}$ cations and n-methyl-2-pyrrolidone in ionic liquid-based gel polymer electrolytes for $\mathrm{Zn} /$ batteries. Electrochim. Acta 2015, 176, 1447-1453.

15. Deshpande, A.; Kariyawasam, L.; Dutta, P.; Banerjee, S. Enhancement of lithium ion mobility in ionic liquid electrolytes in presence of additives. J. Phys. Chem. C 2013, 117, 25343-25351.

16. Ye, H.; Huang, J.; Xu, J.J.; Khalfan, A.; Greenbaum. S.G. Li ion conducting polymer gel electrolytes based on ionic liquid/PVDF-HFP blends. J. Electrochem. Soc. 2007, 154, A1048-A1057.

17. Nath, A.K.; Kumar, A. Ionic transport properties of PVDF-HFP-MMT intercalated nanocomposite electrolytes based on ionic liquid, 1-butyl-3-methylimidazolium bromide. Ionics 2013, 19, 1393-1403.

18. Koo, T.; Somers, A.; Torriero, A.A.J.; MacFarlane, D.R.; Howlett, P.C.; Forsyth, M. Discharge behaviour and interfacial properties of a magnesium battery incorporating trihexyl(tetradecyl)phosphonium based ionic liquid electrolytes. Electrochim. Acta 2013, 87, 701-708.

19. Shin, J.H.; Henderson, W.A.; Passerini, S. Ionic liquids to the rescue? Overcoming the ionic conductivity limitations of polymer electrolytes. Electrochem. Commun. 2003, 5, 1016.

20. Kim, G.T.; Appetecchi, G.B.; Alessandrini, F.; Passerini, S. Solvent-free, PYR1ATFSI ionic liquid-based ternary polymer electrolyte systems. J. Power Sources 2007, 171, 861-869.

21. Kim, G.; Appetecchi, G.B.; Carewska, M.; Joost, M.; Balducci, A.; Winter, M.; Passerini, S. UV cross-linked, lithium-conducting ternary polymer electrolytes containing ionic liquids. J. Power Sources 2010, 195, 6130-6137. 
22. Libo, L.; Jiajia, W.; Peixia, Y.; Shaowen, G.; Heng, W.; Xiuchun, Y.; Xuwei, M.; Shuo, Y.; Baohua, W. Preparation and characterization of gel polymer electrolytes containing $\mathrm{N}$-butyl- $\mathrm{N}$ methylpyrrolidinium bis(trifluoromethanesulfonyl) imide ionic liquid for lithium ion batteries. Electrochim. Acta 2013, 88, 147-156.

23. Yang, P.; Liu, L.; Li, L.; Hou, J.; Xu, Y.; Ren, X.; An, M.; Li, N. Gel polymer electrolyte based on polyvinylidenefluoride-co-hexafluoropropylene and ionic liquid for lithium ion battery. Electrochim. Acta 2014, 115, 454-460.

24. Tafur, J.P.; Abad, J.; Román, E.; Fernández Romero, A.J. Charge storage mechanism of $\mathrm{MnO}_{2}$ cathodes in $\mathrm{Zn} / \mathrm{MnO}_{2}$ batteries using ionic liquid-based gel polymer electrolytes. Electrochem. Commun. 2015, 60, 190-194.

25. Singh, P.K.; Sabin K.C.; Chen, X. Ionic liquid-solid polymer electrolyte blends for supercapacitor applications. Polym. Bull. 2015, doi:10.1007/s00289-015-1484-3.

26. Xu, J.J.; Ye, H.; Huang, J. Novel zinc ion conducting polymer gel electrolytes based on ionic liquids. Electrochem. Commun. 2005, 7, 1309-1317.

27. Ho C.C.; Evans, J.W.; Wright, P.K. Direct write dispenser printing of a zinc microbattery with an ionic liquid gel electrolyte. J. Micromech. Microeng. 2010, 20, doi:10.1088/0960-1317/20/10/104009.

28. Stolwijk, N.A.; Kösters, J.; Wiencierz, M.; Schönhoff, M. On the extraction of ion association data and transference numbers from ionic diffusivity and conductivity data in polymer electrolytes. Electrochim. Acta 2013, 102, 451-458.

29. Zhang, R.; Chen, Y.; Montazami, R. Ionic liquid-doped gel polymer electrolyte for flexible lithium-ion polymer batteries. Materials 2015, 8, 2735-2748.

30. Esterly, D.M.; Love, B.J. Phase transformation to $\beta$-poly(vinylidene fluoride) by milling. J. Polym. Sci. Part B Polym. Phys. 2004, 42, 91-97.

31. Du, C.H.; Zhu, B.K.; Xu, Y.Y. Preparation and properties PVDF based $\mathrm{BATIO}_{3}$ containing nanocomposites. J. Mater. Sci. 2006, 41, 417-421.

32. Vijayakumar, R.P.; Khakhar, D.V.; Misra, A. Phase transformation and enhancement of toughness in polyvinylidene fluoride by onium salts. J. Polym. Sci. Part B: Polym. Phys. 2011, 49, 1339-1344.

33. Bormashenko, Y.; Pogreb, R.; Stanevsky, O.; Bormashenko, E. Vibrational spectrum of PVDF and its interpretation. Polym. Test. 2004, 23, 791-796.

34. Boccaccio, T.; Bottino, A.; Capannelli, G.; Piaggio, P. Characterization of PVDF Membranes by vibrational spectroscopy. J. Membr. Sci. 2002, 210, 315-329.

35. Kumar, G.G.; Sampath, S. Spectroscopic characterization of a gel polymer electrolyte of zinc triflate and polyacrylonitrile. Polymer 2004, 45, 2889-2895.

36. Kataria, S.; Kumar, V.; Kumar, R. Development of ion conducting polymer gel electrolyte membranes based on polymer PVDF-HFP, BMIMTFSI ionic liquid and the Li-salt with improved electrical, thermal and structural properties. J. Mater. Chem. C 2015, 3, 7305-7318.

37. MacFarlane, D.R.; Meakin, P.; Bishop, A.; McNaughton, D.; Rosalie, J.M.; Forsyth, M. Ftir study of ion-pairing effects in plasticized polymer electrolytes. Electrochim. Acta 1995, 40, 2333-2337.

38. Renard, H.L; Marsa, B. Ionic properties of non-aqueous liquid and PVDF-based gel electrolytes containing a cesium thiolate/disulfide redox couple. Electrochim. Acta 2003, 48, 831-844. 
39. Evans, J.; Vincent C.A.; Bruce, P.G. Electrochemical measurement of transference numbers in polymer electrolytes. Polymer 1987, 28, 2324-2328.

40. Bruce, P.G; Evans, J.; Vincent C.A. Conductivity and transference number measurements on polymer electrolytes. Solid State Ionics 1988, 28, 918-922.

41. Plancha, M.J.; Rangel, C.M.; Sequeira, C.A.C.; Lumiar, P. Cation mobility in poly(ethylene oxide) solid electrolytes. J. Electroanal. Chem. 1998, 442, 91-97.

42. Chen, H.W; Lin, T.P.; Chang, F.C. Ionic conductivity enhancement of the plasticized PMMA/ $\mathrm{LiClO}_{4}$ polymer nano composite electrolyte containing clay. Polymer 2002, 43, 5281-5288.

(C) 2015 by the authors; licensee MDPI, Basel, Switzerland. This article is an open access article distributed under the terms and conditions of the Creative Commons Attribution license (http://creativecommons.org/licenses/by/4.0/). 
Journal of Power Sources $\mathrm{xxx}(2017) \mathrm{xxx}-\mathrm{xxx}$

A synchrotron $\mathrm{x}$-ray diffraction and hard $\mathrm{x}$-ray photoelectron spectroscopy study of $\mathrm{Zn}$ negative electrodes at different charge and discharge states of $\mathrm{Zn} / \mathrm{MnO}_{2}$ batteries using an ionic liquid-based gel polymer electrolyte

José Abad ${ }^{\mathrm{a}}$, Florencio Santos ${ }^{\mathrm{a}}$, Juan P. Tafur ${ }^{\mathrm{a}, \mathrm{b}}$, Antonio Urbina ${ }^{\mathrm{c}}$, Elisa Román ${ }^{\mathrm{d}}$, J.F. González-Martínez ${ }^{\mathrm{e}}$ J. Rubio-Zuazo ${ }^{\mathrm{d}, \mathrm{f}}$, G.R. Castro ${ }^{\mathrm{d}, \mathrm{f}}$, Antonio J. Fernández Romero ${ }^{\mathrm{a}, *}$

${ }^{a}$ Grupo de Materiales Avanzados para la Producción y Almacenamiento de Energia, Universidad Politécnica de Cartagena, Aulario II, Campus de Alfonso XIII, 30203 , Cartagena, Spain

${ }^{6}$ Facultad de Ingenieria en Ciencias Aplicadas, Universidad Técnica del Norte, Ibarra, Ecuador

' Departamento de Electrónica, Tecnologia de Computadoras y Proyectos, Universidad Politécnica de Cartagena, Plaza del Hospital 1, 30202, Cartagena, Spain

d Instituto de Ciencia de Materiales de Madrid (ICMM), Consejo Superior de Investigaciones Cientificas (CSIC), C/Sor Juana Inés de la Cruz 3, 28049, Madrid, Spain

'Instituto de Investigación en Óptica y Nanofisica, Universidad de Murcia, Spain

${ }^{f}$ SpLine Spanish CRG Beamline at the ESRF, Grenoble, France

ARTICLE INFO

Article history:

Received 7 April 2017

Received in revised form 19 July 201

Accepted 23 July 2017

Available online $\mathrm{xxx}$

Keywords:

Ionic liquid-based gel polymer electrolytes HAXPES

HAXP

XPS

Zinc batteries

\section{Introduction}

Zinc-based batteries are extensively commercialized due to their several advantages [1]. However, the zinc electrode problems such as anode passivation, dendritic growth, $\mathrm{H}_{2}$ evolution and shape changes have not been solved until now [1,2], creating a barrier to the commercialization of rechargeable $\mathrm{Zn}$-based batteries.

In this sense, use of Ionic Liquid (IL) can prevent dendritic formation during the $\mathrm{Zn}$ deposition and diminish $\mathrm{H}_{2}$ evolution, as well as other positive effects [3-6]. Therefore, IL-based Gel Polymer Electrolytes (IL-GPE) in $\mathrm{Zn}$ batteries have attracted much attention during the last decade in order to improve this type of batteries [7-11]. Thus, several research groups have used $I L$ electrolytes with the aim of making $\mathrm{Zn}$ /air batteries reversible.

The accomplishment of rechargeable batteries makes necessary an additional effort to understand the reactions occurring in the $\mathrm{Zn} / \mathrm{elec}$ trolyte interface during the discharging and recharging processes.

At the negative electrode in aqueous alkaline batteries, it is broadly accepted that the $\mathrm{Zn}$ is oxidized to $\mathrm{Zn}^{2+}$ by the following

" Corresponding author

Email address: antonioj.fernandez@upct.es (A.J. Fernández Romero) mechanism $[1,12]$

$\mathrm{Zn} \rightarrow \mathrm{Zn}^{2+}+2 \mathrm{e}^{-}$

$\mathrm{Zn}^{2+}+4 \mathrm{OH}^{-} \rightarrow \mathrm{Zn}(\mathrm{OH})_{4}{ }^{2-}$

$\mathrm{Zn}(\mathrm{OH})_{4}{ }^{2-} \rightarrow \mathrm{ZnO}+2 \mathrm{OH}^{-}+\mathrm{H}_{2} \mathrm{O}$

Reactions ( 1 and 2 ) proceed until the solubility of the zincate ion, $\mathrm{Zn}(\mathrm{OH})_{4}{ }^{2-}$, reaches the saturation point in the alkaline electrolyte. Then, $\mathrm{ZnO}$ is deposited on the electrode forming a poorly conductive film, which causes shape changes and the passivation of the negative electrode.

However, the process of formation of $\mathrm{ZnO}$ is not clear, and there are several authors that have proposed a mechanism where $\mathrm{Zn}(\mathrm{OH})_{2}$ or other $\mathrm{Zn}-\mathrm{OH}$ compounds are formed as intermediate products before the $\mathrm{ZnO}$ deposition occurs [12-16].

Obviously, when pure IL-based electrolytes are used, $\mathrm{ZnO}$ and $\mathrm{Zn}(\mathrm{OH})_{2}$ cannot be formed because there is no water in the medium. Nevertheless, small additions of water in the electrolyte may cause 
the formation of a metallic oxide film, in addition to improve the $\mathrm{Zn}^{2+} / \mathrm{Zn}$ redox reversibility, the diffusion coefficient of $\mathrm{Zn}$ species and the ionic conductivity of the IL electrolytes, among other positive effects [3-6,17].

Clarifying the processes occurring in the $\mathrm{Zn}$ electrode during the charging and discharging is essential to overcome these problems and to make this type of batteries reversible.

$\mathrm{X}$-Ray Diffraction (XRD) and X-Ray Photoelectron Spectroscopy (XPS) techniques have been frequently used to study the restructuration of the electrodes during the charging and discharging processes of different kind of batteries $[5,14,18,19]$. Moreover, the use of Hard X-Ray Photoelectron Spectroscopy (HAXPES) technique enables the study of bulk and buried interfaces up to a depth of several tens of nanometres in order to investigate these mechanisms [20-23].

Until now, only few articles have studied the mechanism of $\mathrm{Zn}$ anode oxidation and deposition during the discharge and charge of $\mathrm{Zn}$-based batteries that use an $\mathrm{IL}$-based GPE. In this work we have used synchrotron XRD and HAXPES, as well as conventional XPS techniques to analyze the restructuration of $\mathrm{Zn}$ electrode produced during discharging and recharging processes of a $\mathrm{Zn} / \mathrm{IL}-\mathrm{GPE} / \mathrm{MnO}_{2}$ battery.

\section{Experimental}

1-Buthyl-3-methylimidazolium trifluoromethanesulfonate, $99 \%$ (BMIMTf) was purchased from IOLITEC. The co-polymer poly(vinylidene fluoride-co-hexafluoropropylene) (PVdF-HFP), tetrahydrofuran (THF), n-methyl-2-pyrrolidone (NMP) and zinc trifluoromethanesulfonate $\left(\mathrm{ZnTf}_{2}\right)$ were obtained from Sigma-Aldrich.

HAXPES and XRD measurements were carried out at the BM- 25 SpLine beamline at the ESRF, Grenoble, France [24]. The experimental set-up in which the experiments have been performed is devoted to the combination of XRD and HAXPES [24]. This experimental setup is composed of a robust $2 \mathrm{~S}+3 \mathrm{D}$ diffractometer [25] which houses an UHV system and a high electron kinetic energy analyzer, capable to work from a few eV up to $15 \mathrm{keV}$ (details about the electron analyzer can be found in Refs. [26-28]. The large sample-analyzer distance $(50 \mathrm{~mm})$ allows the simultaneous accomplishment of photoemission and diffraction experiments. The detection geometry and consequently the counting rate can be optimized without changing neither the sample position nor the incoming beam impact point, i.e., without disturbing the diffraction geometry conditions, where that the electron analyzer is mounted on a 3-axis motorized table so that the analyzer focal point position can be adjusted on the sample.

Conventional XPS spectra were recorded using a hemispherical analyzer. Non-monochromatized $\mathrm{Mg} \mathrm{K}_{\alpha}(1253.6 \mathrm{eV}) \mathrm{X}$-rays were used. The data are analyzed after removal the $\mathrm{Mg} \mathrm{K}_{\alpha}$ satellite lines, subtraction of a Shirley type background and charge referenced to adventitious $\mathrm{C}$ 1s peak at $284.8 \mathrm{eV}$.

Synchrotron-based XRD difractograms have been collected using an excitation energy of $11 \mathrm{keV}$ and an incident wavelength of 1.12701 $\AA$. Rietveld refinement of the X-ray diffraction (XRD) data was performed to quantify relative amounts of phases present in the negative electrode (using Match 3.4.2. software). Although the Rietveld refinement was carried out maintaining $\lambda=1.12701 \AA$, the rest of the XRD patterns were converted to Copper $\mathrm{K}-\alpha(\lambda=1.54178 \AA)$.

Galvanostatic Charge/Discharges were carried out using a Biologic VSP Modular 5 channels potensiostat/galvanostat. Cathode materials were prepared as it has been reported previously $[10,11]$. Specific capacities and current densities were calculated in base on the cathode active material, that is, the initial weight of the active $\mathrm{MnO}_{2}$ in the cathode. $\mathrm{Zn}$ foils with purity of $99.9 \%$ were supplied by
Española del Zinc S.A. Every piece of Zinc foil was polished before use with sand paper of different grain sizes, in order to remove any zinc oxide that may be present on the foil.

GPEs were synthesized using a solution cast method: PVdF-HFP $(0.5 \mathrm{~g})$, BMIMTf $(0.445 \mathrm{~g})$ and $\mathrm{ZnTf}_{2}(0.763 \mathrm{~g})$ were dissolved in NMP $(3,6 \mathrm{~g}) .12 \mathrm{~mm}$ disks were cut from the membrane obtained to be used in the battery tests. Details about the synthesis and characterization of this kind of GPEs are provided in Refs. [10,11,18].

$\mathrm{Zn} / \mathrm{GPE} / \mathrm{MnO}_{2}$ cells were prepared sandwiching GPEs between a $\mathrm{Zn}$ foil and a $\mathrm{MnO}_{2}$ electrode. The contact area was always $\approx 1.1 \mathrm{~cm}^{2}$ and $\mathrm{Ni}$ mesh was used as current collector for the two electrodes. The whole system was then put in a sample holder to carry out the Galvanostatic Charge/Discharges. After completion, the cells were packed and labeled properly. The $\mathrm{Zn}$ foils were separated from the GPEs just before to start the different measurements. $\mathrm{Zn}$ samples were not washed to avoid dissolving the species formed on the electrode during the redox processes.

Thermogravimetric analysis (TGA) was used to measure the water content of the GPEs. TGA was run on 10-20 mg samples in a Mettler Toledo TGA/DSC $1 \mathrm{HT}$. The samples were heated at $\mathrm{N}_{2}$ atmosphere from $30^{\circ} \mathrm{C}$ to $600^{\circ} \mathrm{C}$ at $10^{\circ} \mathrm{C} / \mathrm{min}$. Besides, ATR-FTIR spectra were obtained using a Thermo Nicolet 5700 Infrared Spectrometer in the wave number range from $400 \mathrm{~cm}^{-1}$ to $4000 \mathrm{~cm}^{-1}$.

\subsection{Discharge and charge method}

In this work, Charge/Discharge measurements of $\mathrm{Zn} / \mathrm{IL}-\mathrm{GPE} /$ $\mathrm{MnO}_{2}$ batteries have been carried out in ambient air at specific current of $6.25 \mathrm{~m} \mathrm{~g} \mathrm{~g}^{-1}$. However, these batteries have been tested previously at a current range between 6.25 and $2000 \mathrm{~mA} \mathrm{~g}^{-1}$. A specific capacity of $125 \mathrm{mAh} \mathrm{g}^{-1}$ resulted for $6.25 \mathrm{~mA} \mathrm{~g}^{-1}$, while $78 \mathrm{mAh} \mathrm{g}^{-1}$ was obtained for $2000 \mathrm{~mA} \mathrm{~g}^{-1}$ [18]. These values are comparable to those obtained previously for different $\mathrm{Zn} / \mathrm{MnO}_{2}$ batteries $[29,30]$.

In this paper several $\mathrm{Zn}$ foils used as negative electrodes in $\mathrm{Zn} /$ IL-GPE/ $\mathrm{MnO}_{2}$ batteries have been analyzed. These electrodes have been discharged and recharged at different states of charge. Fig. 1a shows the discharge curves obtained until a cut off voltage of $1.1 \mathrm{~V}$ (blue), $0.8 \mathrm{~V}$ (green) and $0.4 \mathrm{~V}$ (blue). Hereafter, these discharge processes will be designed by D-1.1 V, D- $0.8 \mathrm{~V}$ and D- $0.4 \mathrm{~V}$, respectively. With respect to the charge processes, each charge of the batteries was carried out after a previous discharge. Fig. 1b shows the charge curves together with the previous discharge ones carried out until reaching $1.1 \mathrm{~V}$ (red), $0.8 \mathrm{~V}$ (green) and $0.4 \mathrm{~V}$ (blue). The charging processes were carried out to reach a charging capacity similar to that obtained in the previous discharge with cut off potentials of $1.1 \mathrm{~V}, 0.8 \mathrm{~V}$ or $0.4 \mathrm{~V}$, respectively. As in the discharges, hereafter the recharge processes will be named C-1.1, C-0.8 and C-0.4 for designing the processes reaching $1.1 \mathrm{~V}, 0.8 \mathrm{~V}$ and $0.4 \mathrm{~V}$, respectively, during the previous discharges.

Furthermore, to obtain a similar initial state, all batteries were previously discharged until $1.1 \mathrm{~V}$, and then recharged until reaching the same discharged capacity. Finally, each battery was discharged, or discharged and charged, at the required potential, as it has been described before.

\section{Results and discussion}

\subsection{HAXPES and conventional XPS measurements}

Due to the high X-ray flux used in HAXPES charging problems have been observed. For this reason the $\mathrm{Zn} 2 \mathrm{p}_{3,2}$ line has been aligned to a binding energy of $1022.2 \mathrm{eV}$. Fig. 2 shows the HAXPES Zn $2 \mathrm{p}_{3 / 2}$ 


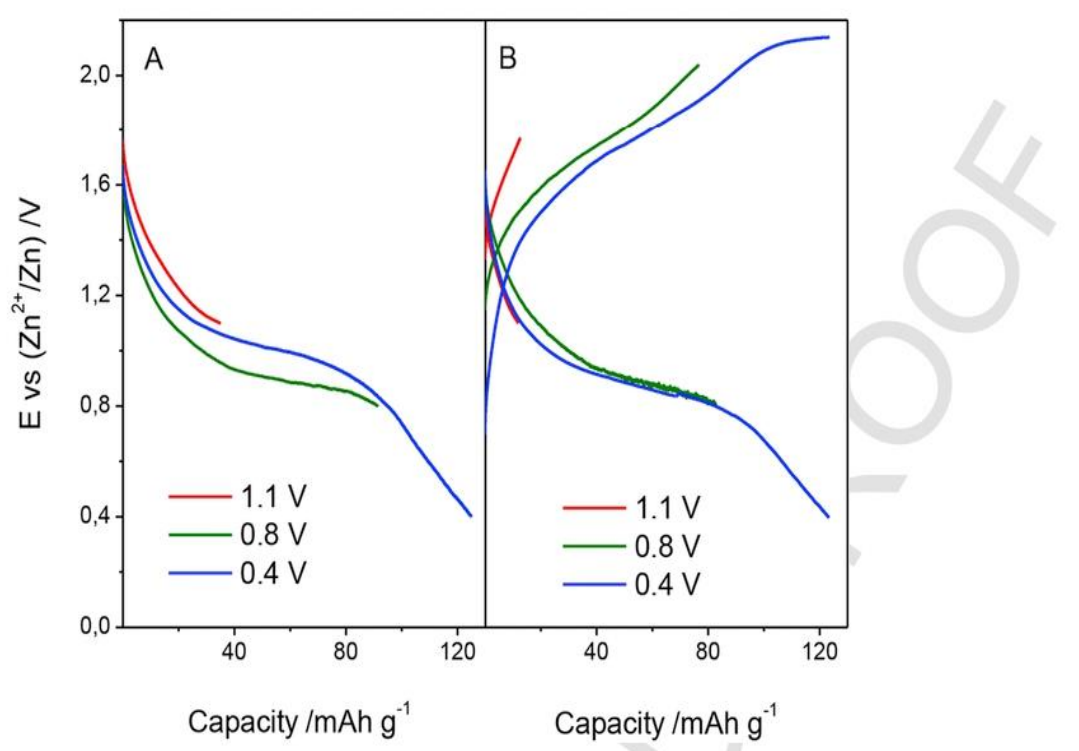

Fig. 1. Discharge (A) and charge (B) curves obtained for $\mathrm{Zn} / \mathrm{IL}-\mathrm{GPE} / \mathrm{MnO}_{2}$ batteries. The legend shows the cut off voltages reached during the discharge processes. In figure b, the charges were carried out until reaching a charging capacity similar to that obtained in the previous discharges.

(Fig. 2a) and $\mathrm{Zn} 1 \mathrm{~s}$ spectra (Fig. 2c) of the $\mathrm{Zn}$ electrodes at various states of charge: i) non-used $\mathrm{Zn}$ plate, ii) discharged until $0.4 \mathrm{~V}$ and iii) recharged completely. The binding energy (BE) of $\mathrm{Zn} 2 \mathrm{p}_{3 / 2}$ peak $(1022.2 \mathrm{eV})$ for non-used plate is assigned to the presence of metallic $\mathrm{Zn}$. Unfortunately, the $\mathrm{Zn} 2 \mathrm{p}$ lines are not very sensitive to the chemical environment $[31,32]$. Therefore, it is not possible to distinguish clearly the $\mathrm{Zn}$ chemical state between $\mathrm{ZnO}$ and metallic $\mathrm{Zn}$ since the differences are about a few hundred millivolts. Interestingly, after the discharge process (red line), this peak is split in two components $(1022.2 \mathrm{eV}$ and $1026.8 \mathrm{eV})$. The emergence of the second peak at $1026.8 \mathrm{eV}$ can be attributed to $\mathrm{Zn}^{2+}$. Although the observed shift of $4.6 \mathrm{eV}$ is large for the $\mathrm{Zn}^{2+} 2 \mathrm{p}_{32}$ line, this shift is due to the accumulation of a significant net of positive charge at the nonconductive regions of the surface, therefore increasing the $\mathrm{BE}$ of the photoelectrons [33]. Moreover, this second peak is not observed after a complete recharge (blue line). Only the peak at $1022.2 \mathrm{eV}$ remains, coinciding with the initial state and indicating that $\mathrm{Zn}^{2+}$ species were reduced to metallic $\mathrm{Zn}$. Another evidence pointing to the assignation of this peak to the $\mathrm{Zn}^{2+} 2 \mathrm{p}_{3 / 2}$ line is the $4 \mathrm{eV}$ obtained for the full width half maximum (FWHM), which is higher than the FWHM of the $\mathrm{Zn}$ metallic of $3.5 \mathrm{eV}$ [34]. Complementary conclusions can be deduced from XPS laboratory source. Since the X-Ray flux is lower than the one produced at a synchrotron source, the charging problems are minor and the alignment of the peaks is straightforward. Besides, the depth probed by a conventional source is lower than the HAXPES, therefore XPS is more sensitive to the processes occurring at the surface. The $\mathrm{Zn}$ plate and the recharge electrode peaks are centered at $1022.2 \mathrm{eV}$, while the discharged anode peak is located at $1022.1 \mathrm{eV}$ (Fig. 2b). Besides the latter (red line) shows a shoulder at low BE about $2 \mathrm{eV}$. This asymmetric shape of the $\mathrm{Zn} 2 \mathrm{p}_{3 / 2}$ has been reported previously in zinc oxide polymer interfaces and it has been assigned to $\mathrm{Zn}-\mathrm{O}-\mathrm{C}$ bonds [35]. This assumption is in agreement with the $\mathrm{C}$ $1 \mathrm{~s}$ spectra (not shown) where a shoulder appears, which corresponds with $\mathrm{Zn}-\mathrm{O}-\mathrm{C}$ bonds, at lower $\mathrm{BE}$ than the main peak corresponding to carbon contamination. Consequently, the presence of $\mathrm{Zn}-\mathrm{O}-\mathrm{C}$ species on the top surface is plausible in view of the results of XPS.

The high photon energy $11 \mathrm{keV}$ used in HAXPES allows us to measure the $\mathrm{Zn}$ 1s core level located at $9659.8 \mathrm{eV}$ in BE (Fig. 2c), which to our knowledge has not been published until now. It is interesting to note that after discharge process (red line) a shoulder at about $4.6 \mathrm{eV}$ is observed at higher $\mathrm{BE}$, which may be due to the charging effects. This finding is in agreement with the HAXPES $\mathrm{Zn} 2 \mathrm{p}_{3 / 2}$ results, indicating that some $\mathrm{Zn}$ species have been oxidized for the discharged battery. Moreover, this shoulder disappears for the charged electrode recovering the oxidation state of the $\mathrm{Zn}$ pristine foil.

$\mathrm{X}$-ray-induced Zn LMM Auger lines have been normally used to study the $\mathrm{Zn}$ oxidation states [33]. However, due to the high photon flux on the sample the peaks shift because of sample charging. For this reason the $\mathrm{Zn} \mathrm{LMM}$ and $\mathrm{Zn} \mathrm{KLL}$ peaks have been aligned to $992.0 \mathrm{eV}$ and $7526.4 \mathrm{eV}$, respectively. In Fig. 3a the $\mathrm{Zn}$ LMM Auger line is showed for $11 \mathrm{keV}$ photon energy for the three charging states. Similar spectra are obtained for non-used $\mathrm{Zn}$ plate (black line) and the recharged one (green line). However, discharged $\mathrm{Zn}$ anode (red line) shows a shoulder at $986.4 \mathrm{eV}$, which could be an indication of the formation of $\mathrm{Zn}^{2+}$ cations.

For comparison, the $\mathrm{Zn}$ LMM Auger line measured with a conventional X-ray source is shown in Fig. 3b. The shape of the $\mathrm{Zn}$ LMM line for the $\mathrm{Zn}$ plate and the recharged $\mathrm{Zn}$ electrode are quite similar, however their $\mathrm{KE} 987.3 \mathrm{eV}$ and $986.6 \mathrm{eV}$, respectively, is much lower that the value reported in the literature for metallic $\mathrm{Zn}$ (992-993 eV KE) [33]. The $\mathrm{Zn}$ LMM line for the discharged $\mathrm{Zn}$ anode (red line) presents a different line shape and the main peak is located at $986.9 \mathrm{eV}$ of $\mathrm{KE}$. This value is consistent with the presence of $\mathrm{Zn}^{2+}$ cations (987-989 eV KE) [33]. Traditionally, the Auger parameter $(\alpha)$ has been used to determine the oxidation state of $\mathrm{Zn}$. If we consider the Auger parameter plus the photon energy $\left(\alpha^{\prime}=\alpha+h v\right)$, we obtain the values of $2009.5,2009.0$, and 2008.8 for the $\mathrm{Zn}$ plate, discharged $\mathrm{Zn}$ anode and charged $\mathrm{Zn}$ electrode, respectively. Hence, 

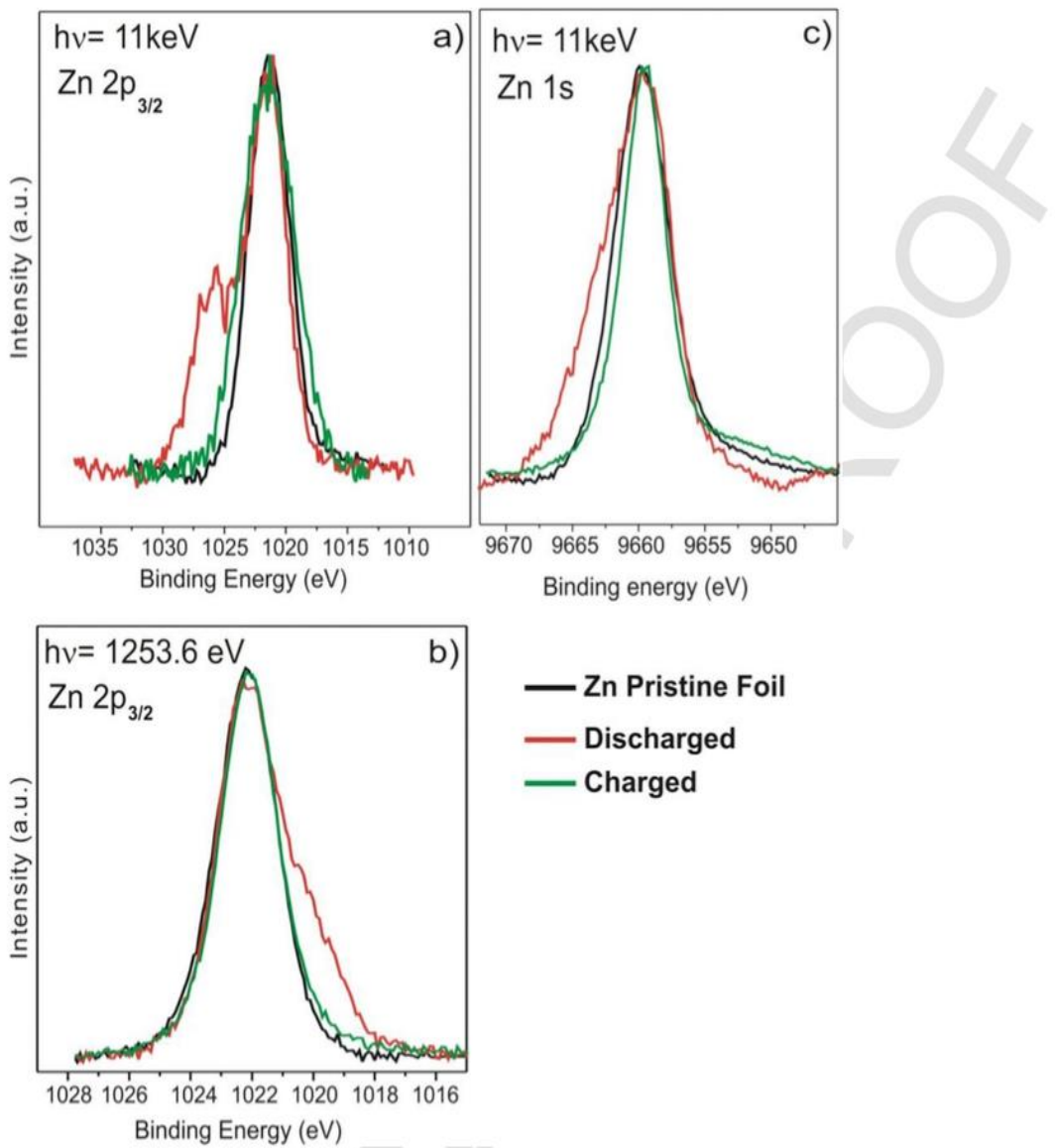

\section{- Zn Pristine Foil \\ - Discharged \\ - Charged}

Fig. 2. a) HAXPES $\mathrm{Zn} 2 \mathrm{p}_{32}$ spectra, b) XPS $\mathrm{Zn} 2 \mathrm{p}_{3 / 2}$ spectra from a laboratory source and c) HAXPES $\mathrm{Zn}$ 1s spectra. The black line corresponds to $\mathrm{Zn}$ pristine foil, the red line to discharged $\mathrm{Zn}$ anode and the green line to recharged $\mathrm{Zn}$ electrode. (For interpretation of the references to colour in this figure legend, the reader is referred to the web version of this article.)

in view of these results it is not possible to assign an oxidation state to $\mathrm{Zn}$ with the $\alpha$ parameter, due to the similar values of the discharged and charged electrodes.

The high photon energy allows us to study the $\mathrm{Zn} \mathrm{KLL} \mathrm{Auger}$ region, which to our knowledge has not been published previously. Fig. 3c shows $\mathrm{Zn} \mathrm{KLL}$ region for the three samples. The spectrum of the non-used $\mathrm{Zn}$ plate (black line) shows a peak at $7526.4 \mathrm{eV}$ with a shoulder at $7532.5 \mathrm{eV}$. For the discharged anode (red line), noticeable changes were observed, the shoulder at $7532.5 \mathrm{eV}$ disappeared and a new shoulder appeared at lower $\mathrm{KE}, 7521.1 \mathrm{eV}$. This behavior could be associated with the oxidation of $\mathrm{Zn}$ to $\mathrm{Zn}^{2+}$. Moreover, when the $\mathrm{Zn}$ electrode was recharged the shoulder at $7521.1 \mathrm{eV}$ disappeared and the $7532.5 \mathrm{eV}$ shoulder became visible again, indicating that the electrode recovers the initial state.

Thus, from the study of the $\mathrm{Zn}$ lines, we have shown experimentally that during the discharging process $\mathrm{Zn}$ was oxidized to $\mathrm{Zn}^{2+}$ and it was reduced during the recharge. However, we cannot know which $\mathrm{Zn}^{2+}$ species were formed and destroyed during discharging and charging processes. In this sense, analysis of the $\mathrm{O} 1 \mathrm{~s}$ region is more sensitive to the chemical environment and can help us in the determination of the $\mathrm{Zn}$ oxidation state.

Fig. 4 shows the $O 1$ s peak for the HAXPES technique (Fig. 4a) and for conventional XPS (Fig. 4b). In Fig. 4a the non-used Zn plate (black line) shows a peak at $532 \mathrm{eV}$, corresponding to contamination products absorbed on the plate. When the $\mathrm{Zn}$ anode is discharged (red line) the $\mathrm{O} 1 \mathrm{~s}$ peak is observed at lower binding energy, $530 \mathrm{eV}$. This peak is assigned to the presence of metal-O bond, pointing to the formation of $\mathrm{Zn}-\mathrm{O}$ bonds during the discharge. In addition, a component at $535 \mathrm{eV}$ was observed. However, for $\mathrm{Zn}$ recharged electrode (green line), the peak corresponding to $\mathrm{Zn}-\mathrm{O}$ bond disappears, indicating that $\mathrm{Zn}^{2+}$ was reduced to $\mathrm{Zn}$ metal. This spectrum shows also a high intensity peak at $535 \mathrm{eV}$ with a shoulder at $531 \mathrm{eV}$. The most intense peak at $535 \mathrm{eV}$ could be assigned to $\mathrm{S}=\mathrm{O}$ and $\mathrm{C}=\mathrm{O}$ bonds corresponding to Triflate anions and NMP molecules. This peak is more intense for the $\mathrm{Zn}$ recharged electrode than that observed for the discharged anode, which could indicate that Triflate and solvent molecules ingress massively in the anode accompanying the $\mathrm{Zn}^{2+}$ cations movement to the electrode during recharging process. 

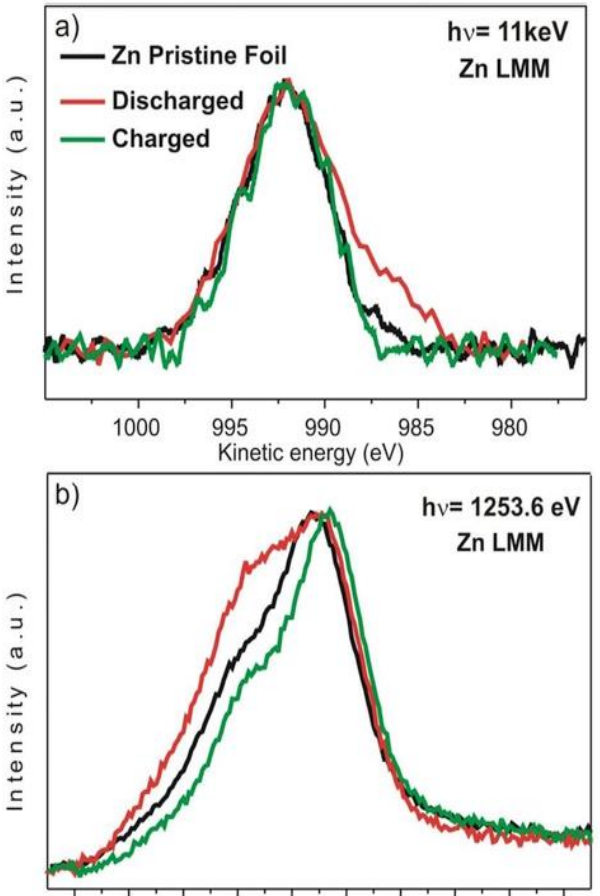

$\begin{array}{llllllllll}996 & 994 & 992 & 990 & 988 & 986 & 984 & 982 & 980 & 978\end{array}$ Kinetic energy (eV)

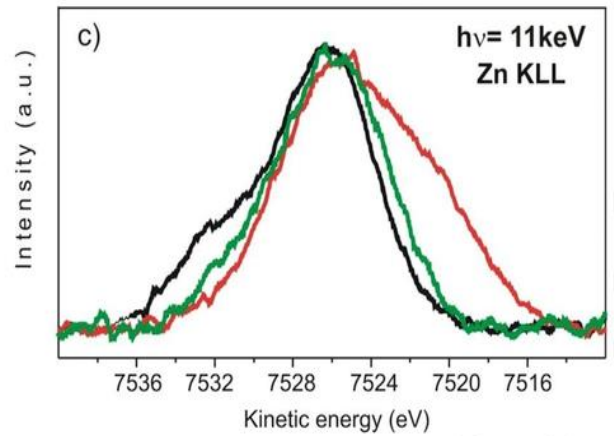

Fig. 3. a) HAXPES spectra for Zn LMM Auger line, b) XPS spectra for Zn LMM Auger line and c) HAXPES spectra for $\mathrm{Zn} \mathrm{KLL}$ Auger line. The black line corresponds to $\mathrm{Zn}$ pristin (For hered referred to the web version of this article )

Fig. $4 \mathrm{~b}$ shows the $\mathrm{O} 1 \mathrm{~s}$ region measured with conventional XPS The $\mathrm{Zn}$ pristine plate (black line) presents a peak located at $532 \mathrm{eV}$ in agreement with HAXPES results related with the contamination on the $\mathrm{Zn}$ surface. For the discharged $\mathrm{Zn}$ anode (red line) a shoulder appears at lower $\mathrm{BE}, 530 \mathrm{eV}$, corresponding with the $\mathrm{Zn}-\mathrm{O}$ bond. After the recharging process (green line) the shoulder at lower BE disappears and only remains the peak at $532 \mathrm{eV}$ in a clear indication that the $\mathrm{Zn}$ oxide species have been reduced after the recharging process.

It is important to note that the differences between the spectra measured by HAXPES and XPS are mainly due to different information depth of these two techniques. It is possible to obtain reliable in-
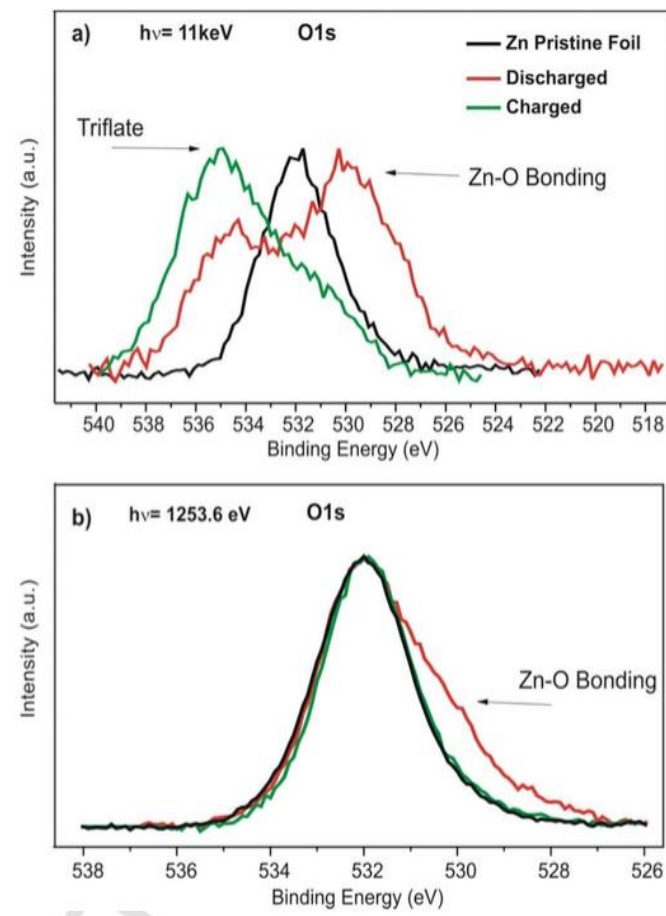

Fig. 4. a) HAXPES $O 1 s$ spectra and b) XPS $O 1 s$ spectra from a laboratory source. The black line corresponds to $\mathrm{Zn}$ pristine foil, the red line to discharged $\mathrm{Zn}$ anode and the green line to recharged $\mathrm{Zn}$ electrode. (For interpretation of the references to colour in this figure legend, the reader is referred to the web version of this article.)

formation for the conventional source $(\mathrm{O} 1 \mathrm{~s} \mathrm{KE}=723.6 \mathrm{eV})$ until depths of around $4.2 \mathrm{~nm}$, while for the synchrotron source (O $1 \mathrm{~s}$ $\mathrm{KE}=10462 \mathrm{eV}$ ), the depth is around $22.6 \mathrm{~nm}[36,37]$. Therefore, XPS is more sensitive to surface contamination than HAXPES.

Existence of Triflate anions inside the negative electrode is demonstrated analyzing $\mathrm{F}$ 1s and $\mathrm{S} 1 \mathrm{~s}$ regions. Fig. S1a of the supplementary material shows the F 1s region, where a peak at $684 \mathrm{eV}$ for both discharged and recharged negative electrodes is observed; the peak corresponding to the recharged electrode has been found three times more intense than that obtained for the discharged one. Similar result was observed when the S 1s was measured (Fig. S1b) resulting in a peak about three times more intense for recharged electrode than the peak for discharged one.

These results support the existence of Triflate anions inside the negative electrode, and a massive entrance of Triflate anions accompanying $\mathrm{Zn}^{2+}$ ingress in the anode during the recharging process.

\subsection{XRD measurements}

XPS and HAXPES measurements confirm the oxidation of $\mathrm{Zn}$ to $\mathrm{Zn}^{2+}$ during the discharging process and their reduction during the recharging. Furthermore, we can speculate that $\mathrm{Zn}-\mathrm{O}$ bonds are formed during the discharging process, but we cannot know which $\mathrm{Zn}$ species are formed and dissolved during the redox processes.

In order to elucidate which $\mathrm{Zn}$ species are formed during discharging and recharging, we have carried out simultaneously HAXPES and XRD measurements. Synchrotron radiation allows us to ob- 
tain very well defined peaks in X-Ray difractograms, such as those shown in Figs. 5 and 6 .

Fig. 5 shows the X-ray difractograms registered for a $\mathrm{Zn}$ pristine foil, and the $\mathrm{Zn}$ anodes discharged until $1.1 \mathrm{~V}, 0.8 \mathrm{~V}$ and $0.4 \mathrm{~V}$ $\mathrm{Zn}$ foil difractogram shows four peaks at $36.77,39.41,43.68$ and $54.86^{\circ}$, which are attributed to $(002),(100),(101)$ and $(102)$ characteristic crystallographic planes corresponding to metallic $\mathrm{Zn}$. This result is in agreement with experimental data cited in the Internationa Center for Diffraction Data (ICDD) database (Card-00-004-0831) Difractograms observed for discharged anodes are more complex as new peaks appear together to those assigned to metallic $\mathrm{Zn}$. Peaks at $32.12,34.79$ and $47.98^{\circ}$ can be attributed to (100), (002) and (102) crystallographic planes of $\mathrm{ZnO}$, in agreement with ICDD database (Card-00-036-1451). In addition, a peak at $36.46^{\circ}$ is found, which

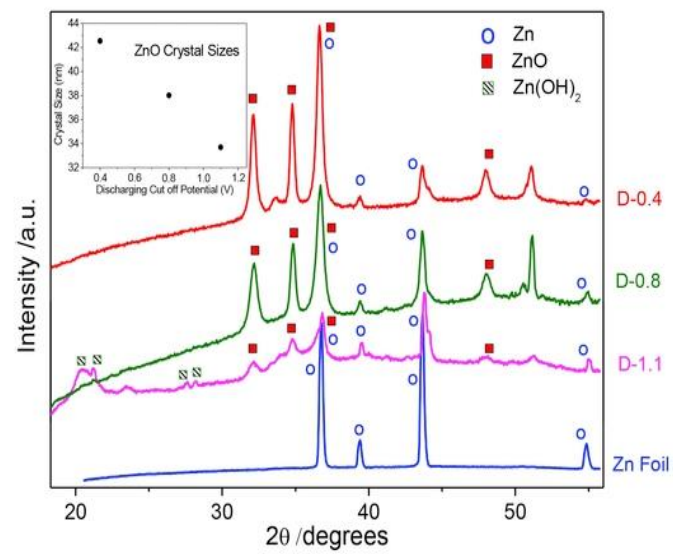

Fig. 5. $\mathrm{X}$-ray difractograms of $\mathrm{Zn}$ pristine foil (blue), and the $\mathrm{Zn}$ anodes discharged until 1.1 (magenta), 0.8 (green) and $0.4 \mathrm{~V}$ (red), named as D-1.1, D-0.8 and D-0.4, respectively. The peaks are assigned to $\mathrm{Zn}, \mathrm{ZnO}$ and $\mathrm{Zn}(\mathrm{OH})_{2}$ with symbols as it is identifie in the legend. The inset shows the crystallite size of $\mathrm{ZnO}$ formed at the three states of discharge. $\lambda=1.54178 \AA$. (For interpretation of the references to colour in this figure legend, the reader is referred to the web version of this article.)

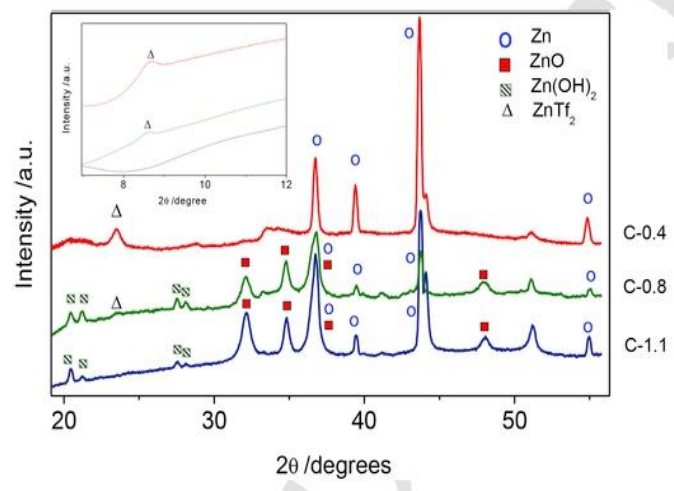

Fig. 6. X-ray difractograms of the $\mathrm{Zn}$ electrodes discharged until 1.1, 0.8 and $0.4 \mathrm{~V}$ and then recharged until obtain the same capacity discharged, named as C-1.1 (marine blue), $C-0.8$ (ren) and $C-0.4$ (red), respectively. The perks are assigned to $\mathrm{Zn}, \mathrm{ZnO}$, Z (OH) $\mathrm{Zn}(\mathrm{OH})_{2}$, and $\mathrm{ZnTF}_{2} \mathrm{xith}$ (t) reterences to colour in this figure legend, the reader is referred to the web version of this article.) corresponds to (101) plane of $\mathrm{ZnO}$, but it may overlap the metallic $\mathrm{Zn}$ peak observed at $36.76^{\circ}$. Finally, a peak at $51.10^{\circ}$ due to the adhesive $\mathrm{Cu}$ film used to support the samples is observed.

As can be seen, when carrying out a deeper discharge process, the intensity of $\mathrm{Zn}$ peaks diminish with respect to $\mathrm{ZnO}$ peaks. This result could indicate that during the discharging process $\mathrm{Zn}$ was oxidized to $\mathrm{Zn}^{2+}$ forming $\mathrm{ZnO}$. Crystallite sizes of nano-sized particles of $\mathrm{ZnO}$ have been estimated for different SOC electrodes from $\mathrm{ZnO}(002)$ diffraction peak, according to Scherrer equation [38].

$$
d_{c}=\frac{K \lambda}{\beta \cos \theta}
$$

where $d_{c}$ is the crystallite size, $\mathrm{K}(0.89)$ is the shape factor, $\lambda$ the $\mathrm{X}$-ray wavelength, $\beta$ the FWHM of the (002) peak, and $\theta$ is the diffraction angle. Inset in Fig. 5 shows the crystallite sizes measured for D-1.1, D- 0.8 and D-0.4. An increasing of crystallite sizes with the increment of the discharge deep was observed, from $33.7 \mathrm{~nm}$ for D-1.1 to $42.5 \mathrm{~nm}$ for D-0.4.

Regarding the charging process, Fig. 6 shows difractograms obtained for anodes discharged until $1.1,0.8$ and $0.4 \mathrm{~V}$ and then recharged to reach a similar capacity as discharged, which are named C-1.1, C-0.8 and C-0.4. As can be seen, difractograms C-1.1 and C-0.8 show the peaks corresponding to $\mathrm{ZnO}$, although all $\mathrm{ZnO}$ peaks diminish for C-0.8 with respect to C-1.1. However, peaks corresponding to $\mathrm{ZnO}$ disappeared totally when the battery was recharged completely, thus curve $\mathrm{C}-0.4$ displays only the peaks corresponding to metallic $\mathrm{Zn}$.

These results seem to indicate that a $\mathrm{ZnO}$ film is formed directly during the discharging and it is eliminated when the $\mathrm{Zn}$ electrode is recharged. However, attention must be paid in curves C- 0.8 and C-1.1, which show four additional peaks at 20.46,21.21, 27.53, and $28.11^{\circ}$. These peaks can be assigned to the formation of $\mathrm{Zn}(\mathrm{OH})_{2}$, according to ICDD database (Card - 04-012-2300) and [39]. However, these peaks were not present in curve $\mathrm{C}-0.4$, pointing to that $\mathrm{Zn}(\mathrm{OH})_{2}$ film was destroyed, such as $\mathrm{ZnO}$ film, when an entire recharge was carried out.

These peaks have also been observed during the discharging in curve $\mathrm{D}-1.1$, indicating that $\mathrm{Zn}(\mathrm{OH})_{2}$ was also formed during the discharging process. However, $\mathrm{Zn}(\mathrm{OH})_{2}$ film disappeared when cut off potentials of $0.8 \mathrm{~V}$ and $0.4 \mathrm{~V}$ were reached. Difractograms of D-0.8 and D- 0.4 only present the peaks corresponding to $\mathrm{ZnO}$ and metallic $\mathrm{Zn}$.

With the aim of quantifying the relative amounts of each phase formed during discharging and charging processes a Rietveld refinement have been carried out. Fig. 7 compares experimental and calculate data. As can be seen, a good agreement has been obtained for the six difractograms analyzed. An unidentified peak area maximum of $0.3 \%$ (see Table SI in the supplementary material) was obtained for all the fittings that have been carried out. Table 1 shows the relative amounts of each specie for all discharged and charged negative electrodes. Note that a $\mathrm{Cu}$ contribution from the adhesive film used to support the samples has been included in the treatments.

From Table 1, different facts can be extracted: i) it is demonstrated that a total discharge produces only $\mathrm{ZnO}$, although a low amount of $\mathrm{Zn}$ appeared; ii) when the recharge process is complete, only $\mathrm{Zn}$ was observed, with a small quantity of $\mathrm{ZnTf}_{2}$; and iii) $\mathrm{Zn}(\mathrm{OH})_{2}$ appears only in intermediate states of charging and discharging, always together to $\mathrm{ZnO}$.

Apparition of $\mathrm{Zn}(\mathrm{OH})_{2}$ peaks in the intermediate states of charge during both of charging and discharging processes, and their elimina- 

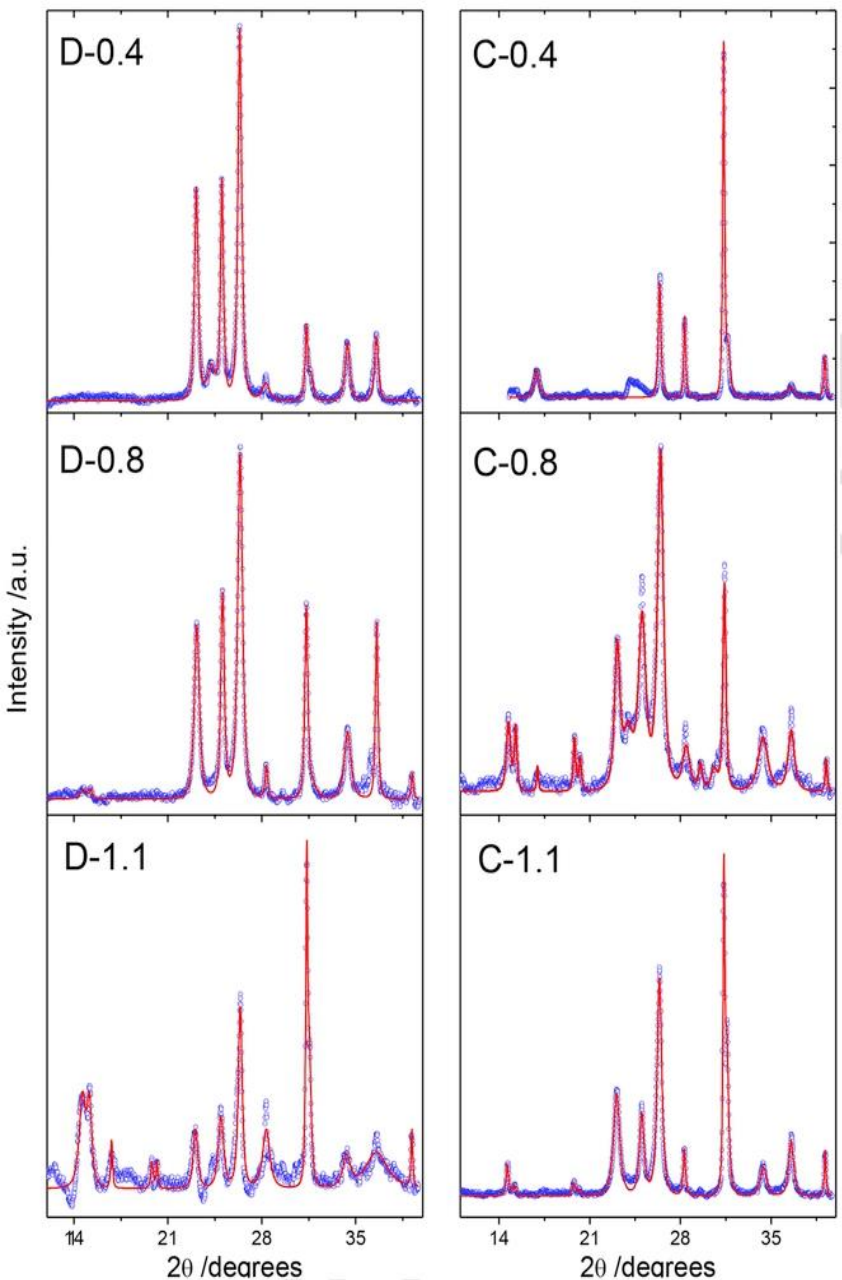

Fig. 7. Comparison between experimental X-ray spectra (blue points) and those obtained by Rietveld refinements (red lines). $\lambda=1.12701 \AA$ (For interpretation of the references to colour in this figure legend, the reader is referred to the web version of this article.)

Table 1

Relative amounts of different species in the negative electrodes analyzed as obtained by Rietveld data fitting

\begin{tabular}{lllllll}
\hline & $\begin{array}{l}\mathrm{D}-1.1 \\
/ \%\end{array}$ & $\mathrm{D}-0.8 / \%$ & $\mathrm{D}-0.4 / \%$ & $\mathrm{C}-1.1 \%$ & $\mathrm{C}-0.8 / \%$ & $\mathrm{C}-0.4 / \%$ \\
\hline $\mathrm{Zn}$ & 48.8 & 23.2 & 9.6 & 35.4 & 15.7 & 73.7 \\
$\mathrm{ZnO}$ & 23.0 & 67.3 & 85.0 & 40.4 & 47.3 & 0 \\
$\mathrm{Zn}(\mathrm{OH})_{2}$ & 11.5 & 0 & 0 & 8.4 & 21.1 & 0 \\
$\mathrm{ZnTF}$ & 0 & 0 & 0 & 0 & 9.4 & 18.2 \\
$\mathrm{Cu}$ & 16.8 & 9.4 & 5.4 & 15.9 & 6.6 & 8.0 \\
\hline
\end{tabular}

tion when the discharge and the charge were carried out completely may be associated with the formation of a pre-passive film of $\mathrm{Zn}(\mathrm{OH})_{2}$. According to various researchers $[16,40]$, during discharging a pre-passive film of $\mathrm{Zn}(\mathrm{OH})_{2}$ could be formed at higher potentials, which changes into a passive $\mathrm{ZnO}$ film when more cathodic po- tentials were reached. Thus, in the totally discharged anode only $\mathrm{ZnO}$ species were found.

During recharging, this process is inverted since in the early recharge the $\mathrm{ZnO}$ passive film is changed into $\mathrm{Zn}(\mathrm{OH})_{2}$, previous to $\mathrm{Zn}^{2+}$ reduction to $\mathrm{Zn}$. Hence, at high states of recharge both $\mathrm{ZnO}$ and $\mathrm{Zn}(\mathrm{OH})_{2}$ films are completely eliminated and only metallic $\mathrm{Zn}$ resulted. Although formation of $\mathrm{Zn}(\mathrm{OH})_{2}$ as intermediate species has been found, direct formation of $\mathrm{ZnO}$ during discharging and their reduction to $\mathrm{Zn}$ during recharging cannot be excluded.

At this point, we recall that HAXPES pointed out to a massive entrance of Triflate anions during the recharge process. In this sense, we have to pay attention to the two peaks observed in $\mathrm{C}-0.4$ difractogram at $2 \theta$ values of 8.5 and $24.5^{\circ}$ (Fig. 6). These peaks can be assigned to the presence of $\mathrm{ZnTf}_{2}$ inside the recharged negative electrode, in agreement with ICDD database (Card - 04-014-0963) and [41]. Therefore, this result confirms the entrance of $\mathrm{ZnTf}_{2}$, probably solvated with NMP inside the $\mathrm{Zn}$ electrode during the recharging 
process. From Rietveld data fitting, $\mathrm{ZnTf}_{2}$ appeared for C-0.8 (9.4\%) and $\mathrm{C}-0.4(18.2 \%)$, indicating that if the recharge process is longer, the amount of $\mathrm{ZnTf}_{2}$ penetrates in the negative electrode is higher.

The entrance of $\mathrm{ZnTf}_{2}$ and NMP during the recharge process is further demonstrated by ATR-FTIR spectroscopy. In the $995-1055 \mathrm{~cm}^{-1}$ region (Fig. 8a) a band at $\sim 1027 \mathrm{~cm}^{1}$ is observed, which corresponds to $\mathrm{SO}_{3}$ group of Triflate anions [9-11]. Once again, the peak corresponding to the totally charged electrode (C-0.4) is nearly four times more intense than the peak corresponding to the discharged one (D-0.4). This fact indicates a higher amount of Triflate in the recharged $\mathrm{Zn}$ electrode, in agreement with a massive entrance of $\mathrm{ZnTf}_{2}$ during the charging process. Besides, a $\sim 1027 \mathrm{~cm}$. ${ }^{1}$ peak for C-0.8 (middle state of charge) shows an intermediate intensity, while this peak for $\mathrm{D}-0.8$ is very similar to that obtained for $\mathrm{D}-0.4$, indicating that for whatever discharging capacity an analogous amount of Triflate anions enters the negative electrode.

Moreover, a band corresponding to $\mathrm{C}=\mathrm{O}$ group of NMP is observed in $1530-1810 \mathrm{~cm}^{-1}$ region (Fig. $8 \mathrm{~b}$ ). As can be seen, this band is shifted to lower frequency with respect to pure NMP, indicating an interaction of this group with $\mathrm{Zn}^{2+}$ cations, as it was reported by our group in previous works $[10,11]$. Once again, electrode $C-0.4$ shows the maximum intensity, followed by $\mathrm{C}-0.8$, and both of them having higher intensities than those observed for D- 0.4 and D- 0.8 . This fact points to a high uptake of NMP molecules inside the negative electrode accompanying Triflate anions during the recharging processes.

\subsection{Water content inside the gel polymer electrolyte}

In this kind of batteries an IL-based electrolyte has been used However, formation of $\mathrm{ZnO}$ and $\mathrm{Zn}(\mathrm{OH})_{2}$ needs a source of hydrogen and oxygen. Knowing that the experiments were carried out in ambient atmosphere, the most reasonable source of water molecules present in the medium should be those absorbed from the air by the ionic liquid-based GPEs. In this sense, it is important to note that BMIMTf ionic liquid has been previously reported to be miscible with water. Although the water content of commercial BMIMTf is $450 \mathrm{ppm}$, as reported by supplier, it can absorb water circa of wt 5\% [42]
With the aim to clarify the existence of water inside the GPE, two additional experiments have been carried out. Firstly, we have recorded an ATR-FTIR spectrum of BMIMTf-based GPE shown in Fig. 8c. In this spectrum, the peak corresponding to $\mathrm{OH}$ groups can be seen in the $3200-3700 \mathrm{~cm}^{-1}$ region. Furthermore, it is confirmed that water is present in this type of GPEs. Other peaks are assigned to aliphatic chains $\left(\sim 2900 \mathrm{~cm}^{1}\right)$ and imidazolium groups $\left(\sim 3100 \mathrm{~cm} .{ }^{1}\right)$, as can be seen in the BMIMTf ionic liquid spectrum.

On the other hand, we have carried out a termogravimetric analysis (TGA) of the BMIMTf-based GPE, shown in Fig. 2S of the supplementary material. The TGA curve (Fig. 2Sa) reveals an initial weight loss between $50^{\circ} \mathrm{C}$ to $171{ }^{\circ} \mathrm{C}$, pointed out by inflexion in the curve. Hence, at $171^{\circ} \mathrm{C}$ a $7.1 \%$ of total weight is lost, which corresponds to the amount of evaporated water [43]

Derivative curve for IL-based GPE is also showed in Fig. 2Sb. In this case, a peak is observed at $143.6{ }^{\circ} \mathrm{C}$, which is associated with water loss. Integration of this peak provides a $6.9 \%$ total area, which is very close to that obtained from TGA curve in Fig. 2Sa.

With the aim to probe if this water quantity is enough to form the total $\mathrm{ZnO}$ and $\mathrm{Zn}(\mathrm{OH})_{2}$ species obtained during the discharging processes we have carried out the following estimation:

The weight of the GPE used in D-0.4 discharge, where the highest capacity resulted, was equal to $0.37 \mathrm{~g}$. $6.9 \%$ of this mass is water and it corresponds to $14.2 \cdot 10^{-4} \mathrm{~mol}$ of water inside the GPE. On the other hand, the total $\mathrm{Zn}^{2+}$ produced during a complete discharge of $120 \mathrm{mAh}$ $\mathrm{g}^{-1}$ (see D-0.4 curve in Fig. 1) represents $2.64 \cdot 10^{-4} \mathrm{~mol}$. In order to get a mol of $\mathrm{ZnO}$, only one mol of water is needed, but in order to get a mol of $\mathrm{Zn}(\mathrm{OH})_{2}$ two moles of water are necessary. Furthermore, supposing that only $\mathrm{Zn}(\mathrm{OH})_{2}$ is formed, we will need $5.28 \cdot 10^{-4} \mathrm{~mol}$ of water. As we have detected $14.2 \cdot 10^{-4} \mathrm{~mol}$ of water inside the GPE, we can conclude that we have 2.7 as many water molecules as we need if only $\mathrm{Zn}(\mathrm{OH})_{2}$ was formed. Hence, we have got enough water to produce all $\mathrm{ZnO}$ and $\mathrm{Zn}(\mathrm{OH})_{2}$ species obtained during discharge and charge processes carried out in the experiments.
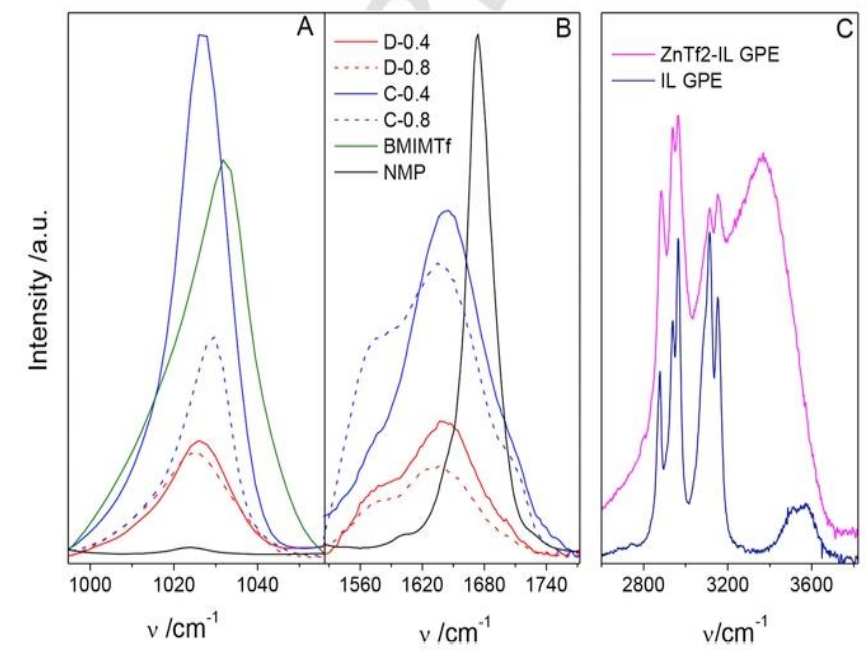

Fig. 8. ATR-FTIR spectra of a) $\mathrm{SO}_{3}$ and b) $\mathrm{C}=0$ group regions of $\mathrm{Zn}$ negative electrodes charged and discharged. BMIMTf and NMP spectra have been included as reference. c) ATR-FTIR spectra of $\mathrm{OH}$ group region of BMIMTf-based GPE. BMIMTf ionic liquid is shown as reference. 


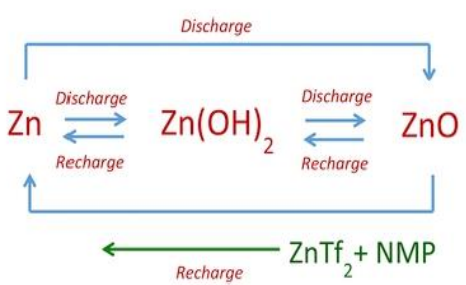

Scheme 1. Mechanism proposed for $\mathrm{Zn}$ species formation and destruction onto the negative electrode during the discharging and charging processes.

\section{Conclusions}

Discharged and recharged negative electrodes in a $\mathrm{Zn} / \mathrm{IL}-\mathrm{GPE}$ $\mathrm{MnO}_{2}$ battery have been studied by HAXPES, synchrotron XRD and conventional XPS. During discharging process, $\mathrm{Zn}(\mathrm{OH})_{2}$ formation in intermediate states of charge has been evidenced previously to $\mathrm{ZnO}$ film development. During the charge, $\mathrm{ZnO}$ passive film is changed to form a $\mathrm{Zn}(\mathrm{OH})_{2}$ film, which will be destructed at the same time that $\mathrm{Zn}^{2+}$ is reduced to metallic $\mathrm{Zn}$. Although in these kind of batteries an $\mathrm{IL}$-based electrolyte free of water has been used, $\mathrm{H}_{2} \mathrm{O}$ vapour molecules have to penetrate inside the electrolyte during the discharging and recharging processes, making possible the formation of $\mathrm{ZnO}$ and $\mathrm{Zn}(\mathrm{OH})_{2}$ species. Existence of water molecules inside the GPE has been demonstrated by TGA and ATR-FTIR measurements.

Moreover, HAXPES, XRD, and ATR-FTIR measurements demonstrate that the motion of $\mathrm{Zn}^{2+}$ cations to the negative electrode is accompanied by Triflate anions and NMP molecules from the electrolyte during the charging process. Consequently, we propose the following mechanism for discharging and charging processes:

During discharging, a $\mathrm{ZnO}$ passive film was formed directly or forming a pre-passive $\mathrm{Zn}(\mathrm{OH})_{2}$ film. Conversely, during charging process, a ZnO passive film was destructed by forming directly metallic $\mathrm{Zn}$ or by forming previously a $\mathrm{Zn}(\mathrm{OH})_{2}$ film. Moreover, entrance of Triflate anions and NMP molecules will occur during the charging process. Scheme 1

The proposed two reversible paths included in the scheme are compulsory because we have observed $\mathrm{ZnO}$ and $\mathrm{Zn}(\mathrm{OH})_{2}$ species in intermediate states, but only $\mathrm{ZnO}$ was obtained during a complete discharge and only $\mathrm{Zn}$ appeared in a total recharge. Hence, it is clear that $\mathrm{Zn}-\mathrm{ZnO}$ conversion through $\mathrm{Zn}(\mathrm{OH})_{2}$ formation exists, nevertheless we can not discard a direct conversion $\mathrm{Zn}-\mathrm{ZnO}$. In order to solve this question an "in situ" XRD study should be carried out during discharging and recharging processes.

\section{Acknowledgements}

The authors thank the financial support from the Spanish Ministerio de Economía y Competitividad (Ref. ENE2013-48816-C5-3-R and ENE2016-79282-C5-5-R) including FEDER funds and provision of synchrotron radiation facilities at ESRF BM25B line.

\section{Appendix A. Supplementary data}

Supplementary data related to this article can be found at http://dx doi.org/10.1016/j.jpowsour.2017.07.082.

\section{References}

[1] D. Linden, T B. Reddy Handbook of Batteries, fourth edMcGraw-Hill, 20011.
[2] H. Kim, G. Jeong, Y.-U. Kim, J.-H. Kim, C.-M. Park, H.J. Sohn, Chem. Soc Rev. 42 (2013) 9011

[3] M. Xu, D.G. Ivey, Z. Xie, W. Qu, Electrochim. Acta 89 (2013) 756-762.

[4] T.J. Simons, A. A.J. Torriero, P.C. Howlett, D.R. MacFarlane, M. Forsyth, Electrochem. Commun. 18 (2012) 119-122.

[5] Z. Liu, T. Cui, G. Pulletikurthi, A. Lahiri, T. Carstens, M. Olschewski, F. Endres, Angew. Chem. Int. Ed. 55 (2016)2889-2893.

[6] M. Xu, D. G. Ivey, Z. Xie, W. Qu, E. Dy, Electrochim. Acta 97 (2013) 289-295.

[7] J.J. Xu, H Ye, J. Huang, Electrochem Commun. 7 (2005) 1309-1317.

[8] T.E. Sutto, T.T. Duncan, T.C. Wong, K. McGrady, Electrochim Acta 56 (2011) 3375-3379.

[9] JP. Tafur, A.J. Fernandez Romero, J. Membr. Sci. 469 (2014) 499-506.

[10] JP. Tafur Guisao, A.J. Fernandez Romero, Electrochim. Acta 176 (2015) $1447-1453$.

[11] JP. Tafur, F. Santos, A.J. Fernández Romero, Membranes 5 (2015) 752-771.

[12] J.-S. Lee, S.T. Kim, R. Cao, N.-S. Choi, M. Liu, K T. Lee, J. Cho, Adv. Energy Mater 1 (2011) 34-50.

[13] M. Cai, S.M. Park, J. Electrochem. Soc. 143 (1996) 2125-2131.

[14] A.A. Mohamad, J. Power Sources 159 (2006) 752-757.

[15] R. Shivkumar, G.P. Kalaignan, T. Vasudevan, J. Power Sources 75 (1998) 90-100.

[16] A.R. Mainar, O. Leonet, M. Bengoechea, I. Boyano, I. Meatza, A. Kvasha, A Guerfi, J.A. Blázquez, Int. J. Energy Res. 40 (2016) 1032-1049.

[17] G. Cohn, A. Altberg, DD. Macdonald, Y. Ein-Eli, Electrochim. Acta 58 (2011), 1611611 (IL and water).

[18] J.P. Tafur, J. Abad, E. Román, A.J. Fernández Romero, Electrochem. Commin 60 (2015) 190-194.

[19] J.W. Gallaway, A.M. Gaikwad, B. Hertzberg, C.K. Erdonmez, Y.-C.K. Chen-Wiegart, L.A. Sviridov, K. Evans-Lutterodt, J. Wang, S. Banerjee, D.A. Steingart, J. Electrochem. Soc. 161 (2014) A275-A284

[20] T. Hishida, M. Kobata, E. Ikenaga, T. Sugiyama, K. Ohbayashi, K. Kobayashi, M. Okawa, T. Saitoh, Jpn. J. Appl. Phys. 54 (2015) 083201.

[21] J. Rubio-Zuazo, GR Castro, J. Electron Spectrosc. Relat. Phenom. 190 (2013) 205-209.

[22] J. Rubio-Zuazoa, E. Martinez, P. Batude, L. Clavelier, A. Chabli, G.R. Castro, Appl. Surf. Sci. 257 (2011) 3007-3013

[23] J. Rubio-Zuazo, GR. Castro, Rev. Adv. Mater. Sci. 15 (2007) 79-86

[24] GR. Castro, J. Synchrotron Radiat. 5 (1998) 657.

[25] E. Vlieg, J. Appl. Cryst. 31 (1998) 198-203.

[26] J. Rubio-Zuazo, GR. Castro, Nucl. Instrum. Methods Phys. Res. A 547 (2005) $64-72$

[2][8] J. Rubio-Zuazo, GR. Castro, J. Phys. Conf. Ser. 100 (2008) 012042.

J. Rubio-Zuazo, et al., J. Electron Spectrosc. Relat. Phenom. 180 (2010) 27-33, 33].

[29] D. Xu, B. Li, C. Wei, Y.-B. He, H. Du, X Chu, X. Qin, Q-H. Yang, F. Kang Preparation and characterization of $\mathrm{MnO} 2$ /acid-treated CNT nanocomposites for energy storage with Zinc ions, Electrochim. Acta 133 (2014) 254-261.

[30] Y. Yin, C. Liu, S. Fan, A new type of secondary hybrid battery showing excellent performances, Nano En. 12 (2015) 486-493.

[31] B.R. Strohmeier, D.M. Hercules, J. Catal. 86 (1984) 266

[32] G. Schon, J. Electron Spectrosc. 2 (1973) 75

[33] CD. Wagner, W.M. Riggs, L.E. Davis, J.F. Moulder, GE. Muilenberg (Eds.), Handbook of X-Ray Photoelectron Spectroscopy, 1st. ed., Perkin-Elmer Corp., Handb 1979 .

[34] M.C. Biesinger, L.W.M. Lau, A.R. Gerson, R.StC. Smart, Appl. Surf. Sci. $257(2010) 887$.

[35] S.B. Amor, M. Jacquet, P. Fioux, M. Nardin, Appl. Surf. Sci. 255 (2009) 5052-5061.

[36] J. Rubio-Zuazo, GR. Castro, J. Electron Spectrosc. Relat. Phenom. 184 (2011) 384-390Crossref.

[37] S. Tanuma, C.J. Powell, D.R. Penn, Surf. Interface. Anal. 43 (2011) 689-713.

[38] F. Moser, F. Fourgeot, R. Rouget, O. Crosnier, T. Brousse, Electrochim. Acta $109(2013) 110-116$.

[39] P. Li, Z P. Xu, M.A. Hampton, D.T. Vu, L. Huang, V. Rudolph, A V. Nguyen, J. Phys. Chem. C 116 (2012) 10325-10332.

[40] M. Cai, S.-M. Park, J. Electrochem. Soc. 143 (1996) 2125-2131.

[41] R. Dinnebier, N. Sofina, L. Hildebrandt, M. Jansen, Acta Cryst. B62 (2006) 467-473.

[42] Y. Cao, Y. Chen, X. Sun, Z. Zhang, T. Mu, Phys. Chem Chem. Phys. 14 (2012) $12252-12262$

[43] S.O. Han, L. T. Drzal, Eur. Polym J. 39 (2003) 1791-1799. 

Electrochimica Acta xxx (2018) xxx-xxx

\begin{tabular}{lc|}
\hline & Contents lists available at ScienceDirect \\
ELSEVIER & Electrochimica Acta \\
\hline
\end{tabular}

In situ synchrotron x-ray diffraction study of $\mathrm{Zn} / \mathrm{Bi}_{2} \mathrm{O}_{3}$ electrodes prior to and during discharge of $\mathrm{Zn}$-air batteries: Influence on $\mathrm{ZnO}$ deposition

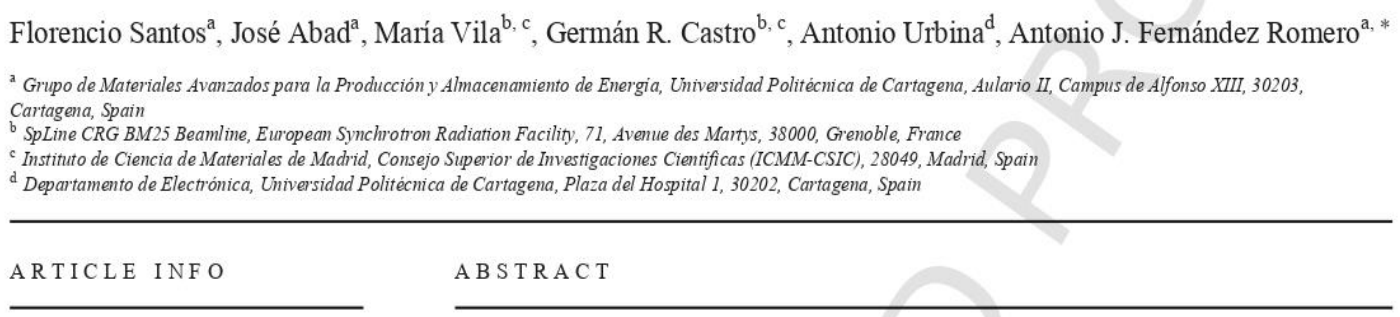

Article history:

Received 16 January 2018

Received in revised form 17 May 2018

Accepted 22 May 2018

Available online $\mathrm{xxx}$

Keywords:

In situ measurements

$\mathrm{Zn}-\mathrm{Bi}_{2} \mathrm{O}_{3}$

Synchrotron XRD

Zinc/air batteries

Zinc negative electrode

$\mathrm{Zn}$-based electrodes containing different amount of $\mathrm{Bi}_{2} \mathrm{O}_{3}$ have been analyzed by synchrotron XRD during the discharging process of a real $\mathrm{Zn} /$ air battery. $\mathrm{Bi}_{2} \mathrm{O}_{3}$ is clearly detected for pristine $\mathrm{Zn}_{-}-\mathrm{Bi}_{2} \mathrm{O}_{3}$ based electrodes. However, immersion of $\mathrm{Zn}-\mathrm{Bi}_{2} \mathrm{O}_{3}$ electrodes in $6 \mathrm{M} \mathrm{KOH}$ solution before starting the discharge results in the disappearance of $\mathrm{Bi}_{2} \mathrm{O}_{3} \mathrm{XRD}$ signature in the pattern and the appearance of new peaks indicating the presence of metallic $\mathrm{Bi}$, regardless of the amount of $\mathrm{Bi}_{2} \mathrm{O}_{3}$ initially included in the $\mathrm{Zn}_{-} \mathrm{Bi}_{2} \mathrm{O}_{3}$ electrodes. This behavior together with Open Circuit Voltage measurements points to a spontaneous reduction of $\mathrm{Bi}^{3+}$ to metallic $\mathrm{Bi}$ by the oxidation of $\mathrm{Zn}$ to $\mathrm{Zn}^{2+}$. Irrespective of the amount of $\mathrm{Bi}_{2} \mathrm{O}_{3}$ present in the negative electrodes, $\mathrm{Zn}$ $\mathrm{XRD}$ peaks diminish as the discharge proceeds. However, the initial amount of $\mathrm{Bi}_{2} \mathrm{O}_{3}$ clearly affect to $\mathrm{ZnO}$ and $\mathrm{Bi}$ metal XRD peaks. $\mathrm{ZnO}$ peaks are observed only for electrodes without $\mathrm{Bi}_{2} \mathrm{O}_{3}$ or those containing $6 \%$ of $\mathrm{Bi}_{2} \mathrm{O}_{3}$. Conversely, $\mathrm{ZnO}$ peaks do not appear in the XRD patterns obtained for higher quantities of $\mathrm{Bi}_{2} \mathrm{O}_{3}$ electrodes. Besides, in this case metallic Bi peaks are observed during all discharging processes, indicating that Bi remained in the electrode. Finally, SEM and EDX studies support these conclusions

(c) 2018 .

\section{Introduction}

Among the metal-air batteries, $\mathrm{Zn}$-air technology is considered nowadays the most promising material for commercial energy storage applications, since it has several advantages, such as low cost, safety, good material availability or use of aqueous electrolyte $[1,4]$. However, zinc electrodes pose several problems such as anode passivation, dendritic growth, $\mathrm{H}_{2}$ evolution and shape changes, which have not been solved until now $[1,6]$. These facts have not allowed the fabrication of rechargeable $\mathrm{Zn}$-based batteries with acceptable properties to be commercialized.

With the aim of solving the drawbacks arising from the use of $\mathrm{Zn}$, different solutions have been proposed, such as use of ionic liquid or gel polymeric electrolytes; increasing of zinc electrode surface area; or employment of different additives incorporated either to the electrode or the electrolyte solution [1-9]. In this sense, different pure metals, metal oxides and hydroxides or organic compounds, such as surfactants, have been tested as additives in order to improve the performance of Zn-based batteries.

Among the additives used in $\mathrm{Zn}$-based batteries, bismuth species have attracted a great deal of attention in the last decades. $\mathrm{Bi}_{2} \mathrm{O}_{3}$ or

" Corresponding author

Email address: antonioj.fernandez@upct.es (A.J. Fernández Romero) other Bi-based compounds have been incorporated directly to the negative electrode or added to the electrolyte so as to improve cycling stability, suppress dendritic growth, decrease hydrogen evolution and enhance the discharge capacity of zinc-based electrodes [5,6,10-16]. Besides, metallic Bi powder has been included in pasted zinc electrodes enhancing electronic conductivity, zinc utilization and discharge performance, as well as decreasing $\mathrm{H}_{2}$ evolution and electrode corrosion $[17,18]$.

X. Wei et al. [19] analyzed the electrochemical behavior of Ag, $\mathrm{Bi}, \mathrm{Cu}, \mathrm{Fe}, \mathrm{Ni}$ and $\mathrm{Sn}$ substrates on zinc deposition over battery cycling by cyclic voltammetry and impedance spectroscopy. These authors concluded that $\mathrm{Bi}$ and $\mathrm{Cu}$ are the best choice for zinc anode substrate. Among other properties, Bi substrate was declared as the metal with the highest hydrogen overvoltage, which is indicative of the lowest hydrogen evolution.

On the other hand, Shin et al. [11] analyzed $\mathrm{Zn}-\mathrm{Ag}$ rechargeable printed batteries with $\mathrm{Zn}-\mathrm{Bi}_{2} \mathrm{O}_{3}$-based electrodes. They used a gel electrolyte containing poly acrylic acid (PAA), $6 \mathrm{M} \mathrm{KOH}$ and $1 \mathrm{M}$ $\mathrm{LiOH}$. Although they could observe the formation of metallic $\mathrm{Bi}$ when the $\mathrm{Zn}-\mathrm{Bi}_{2} \mathrm{O}_{3}$ based electrodes were soaked in the electrolyte, they hypothesized that a new phase with $\left[\mathrm{BiO}_{4}\right]$ local bonding, such as $\mathrm{Bi}_{38} \mathrm{ZnO}_{58}$, could be created. These authors concluded that the benefit of adding $\mathrm{Bi}_{2} \mathrm{O}_{3}$ is not due to an improvement of the conductivity but to the fact that it provides additional surfaces for the deposition of $\mathrm{ZnO}$. 
Until now, in situ measurements have been scarcely used to analyze the reaction mechanism occurring in the $\mathrm{Zn}$-based electrodes doped with $\mathrm{Bi}_{2} \mathrm{O}_{3}$. Moser et al. [10] studied by conventional in situ $\mathrm{XRD}$ measurements the structural changes occurring in a $\mathrm{ZnO}-\mathrm{Bi}_{2} \mathrm{O}_{3}$ electrode in a rechargeable $\mathrm{Zn}-\mathrm{Ni}$ battery and evidenced the creation of a secondary electronic network of conductive metallic bismuth. Besides, Gallaway et al. [16] carried out an in situ synchrotron study of $\mathrm{Zn}$ plating using $\mathrm{Bi}_{2} \mathrm{O}_{3}$ as additive in a flowing cell. They observed that $\mathrm{Bi}_{2} \mathrm{O}_{3}$ added to zincate solution planarizes $\mathrm{Zn}$ layers during cycling.

In this work we have analyzed $\mathrm{Zn}$-based electrodes, composed of $\mathrm{Zn}$ and $\mathrm{Bi}_{2} \mathrm{O}_{3}$ powders, by In-situ Synchrotron XRD during the discharge of a real $\mathrm{Zn}$-air battery. Synchrotron radiation allows us to obtain well defined peaks in X-Ray patterns [20] though the X-rays have to pass through a relatively broad electrolyte layer. Besides, we have studied the spontaneous reduction of $\mathrm{Bi}_{2} \mathrm{O}_{3}$ to metallic $\mathrm{Bi}$, provided by the oxidation of a part of metallic $\mathrm{Zn}$ to $\mathrm{Zn}^{2+}$. Consequently, we observe metallic $\mathrm{Bi}$ deposited inside the $\mathrm{Zn}$ electrode since the beginning of the discharge process, without any current passing. Conversely, in previous investigations $\mathrm{Bi}_{2} \mathrm{O}_{3}$ has been added to the electrolyte solution or incorporated to the electrode forming a paste with $\mathrm{ZnO}$ to be used as negative electrode in a $\mathrm{Zn}$-based battery. Therefore, before discharge, the battery has to be subject to a first charge, where $\mathrm{Bi}_{2} \mathrm{O}_{3}$ is reduced to metallic $\mathrm{Bi}$ prior to the reduction of $\mathrm{ZnO}$ to metallic $\mathrm{Zn}$.

Finally, additional measurements, such as open circuit voltage (OCV), ex-situ XRD and Raman and Scanning Electronic Microscopy (SEM) Images, elemental maps and Energy Dispersive X-Ray (EDX) have confirmed the spontaneous metallic Bi formation prior to discharge as well as the in situ synchrotron $\mathrm{XRD}$ results.

\section{Experimental}

$\mathrm{Zn}$ powder $98.8 \%$ and $\mathrm{Bi}_{2} \mathrm{O}_{3}$ powder $99.5 \%$ were supplied by Goodfellow and Alfa Aesar companies respectively. $\mathrm{KOH} 90 \%$ was used as received from Sigma-Aldrich.

In situ XRD measurements were performed by means of High Resolution X-ray diffraction (HR-XRD) in BM25B - SpLine beamline at the European Synchrotron Radiation Facility (ESRF) [21,22] The end station is composed of a six circle multipurpose diffractometer. The ESRF synchrotron source has a high flux of photons and a tunable energy which allows performing diffraction experiments on samples with low diffraction signal. A photon energy of $20 \mathrm{keV}$ $(\lambda=0.6199 \AA)$ was used during the experiments. In this work, all XRD patterns have been converted to Copper $\mathrm{K}-\alpha(\lambda=1.5418 \AA)$. In situ measurements were registered while battery was discharged using a Biologic VSP Modular 5 channels potentiostat/galvanostat.

A homemade electrochemical cell was used to carry out the in situ synchrotron XRD measurements (Fig. 1A shows the cell located in the synchrotron XRD BM25 beamline sample holder). Anode materials were prepared compacting appropriate quantities of $\mathrm{Zn}$ and/or $\mathrm{Bi}_{2} \mathrm{O}_{3}$ powders at a pressure of 10 tons $\mathrm{cm}^{-2}$. In this work, $12 \mathrm{~mm}$ disks of pure $\mathrm{Zn}, \mathrm{Zn}-\mathrm{Bi}_{2} \mathrm{O}_{3} 6 \%, \mathrm{Zn}-\mathrm{Bi}_{2} \mathrm{O}_{3} 12 \%, \mathrm{Zn}-\mathrm{Bi}_{2} \mathrm{O}_{3} 25 \%$ and pure $\mathrm{Bi}_{2} \mathrm{O}_{3}$ have been prepared by press (Table 1 ).

For in situ measurements, Zn-based electrodes were supported onto $\mathrm{Cu}$ disks, which acted as collectors and they were then attached to a screw used to raise the electrode surface in order to minimize the beam path (both incident and reflected beams) in the solution. Therefore a small incident angle can be used, as it is shown in the scheme in Fig. 1B. A commercial EP4 electrode supplied by Electric Fuel Ltd. was used as air cathode, which was located in the opposite side of the cell. Besides, the electrochemical cell was closed with polypropylene film to prevent liquid leakage.

A $6 \mathrm{M} \mathrm{KOH}$ aqueous solution was used as electrolyte. This electrolyte concentration was chosen to provide a solution with the maximum value of ionic conductivity $[5,23]$.

Horizontal and vertical cell arrangements have been tested to carry out the in situ synchrotron XRD measurements. After different tests we chose the vertical arrangement because higher capacities and flatter discharge curves were obtained, even with higher discharge currents.

Conventional Galvanostatic Discharges and OCV measurements were carried out using a Biologic VSP Modular 5 channels potentiostat/galvanostat. The electrochemical cell used for these discharges was the same as that used in the synchrotron XRD measurements and it was also used in vertical arrangement. However, in these measurements, negative and positive electrodes were facing each other and separated by $1 \mathrm{~cm}$. In this case, polypropylene film was not needed to seal the cell, as it is shown in the scheme in Fig. 1C

SEM coupled with EDX analysis was carried out using a Hitachi S-3500N scanning electron microscope (Hitachi High-Technologies Corporation, Tokyo, Japan). Samples were mounted on carbon stubs using carbon tape, the morphology of the surface was imaged at different magnifications, using $70 \mathrm{~Pa}$ chamber pressure for back-scat-
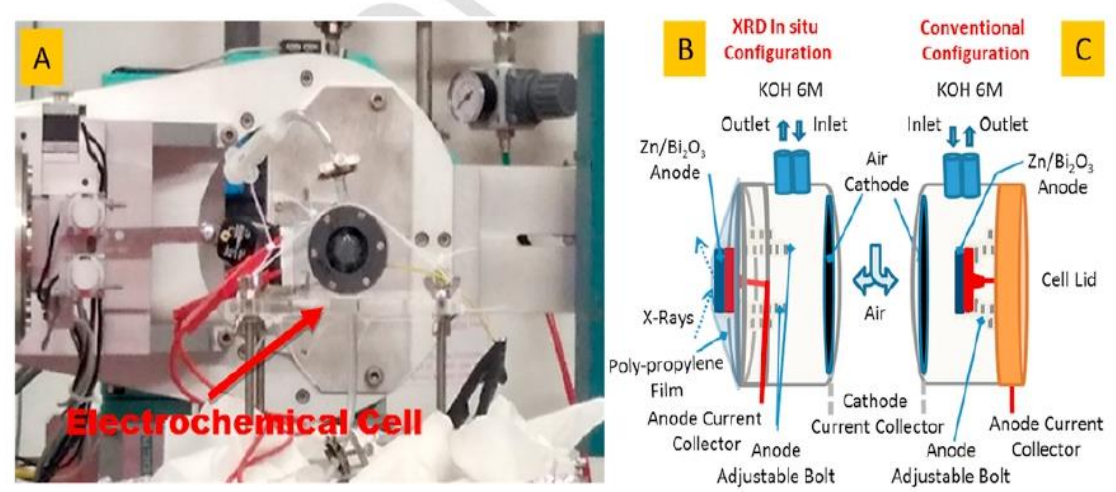

Fig. 1. A) Electrochemical cell located on the sample holder of the X-ray diffractometer at BM-25 beamline of the ESRF synchrotron. B) Scheme of the electrochemical cell used in the synchrotron XRD measurements. C) Configuration of the same electrochemical cell where both electrodes were facing each other to carry out conventional discharges and OCV measurements. 
Table 1

Electrode compositions, $\mathrm{Zn} /$ air battery capacities and $\mathrm{Zn}$ yields.

\begin{tabular}{lllllll}
\hline $\mathrm{Bi}_{2} \mathrm{O}_{3} / \mathrm{wt} . \%$ & $\mathrm{~m}_{\mathrm{e}} / \mathrm{g}$ & $\mathrm{m}_{\mathrm{Bi} 203} / \mathrm{g}$ & $\mathrm{m}_{\mathrm{Zn}} / \mathrm{g}$ & T. C. $/ \mathrm{mAh}$ & $\mathrm{E} . \mathrm{C} . / \mathrm{mAh}$ & $\mathrm{Zn} \mathrm{Yield} / \mathrm{wt} . \%$
\end{tabular}

\begin{tabular}{lllllll}
\hline 0 & 0.881 & 0.000 & 0.881 & 722.6 & 559.0 & $77.3 \pm 0.1$
\end{tabular}

$\begin{array}{lllllll}6 & 0.897 & 0.054 & 0.843 & 672.8 & 509.0 & 73.5 \pm 1.9\end{array}$

$\begin{array}{lllllll}12 & 0.910 & 0.109 & 0.801 & 619.0 & 437.0 & 74.0 \pm 1.0\end{array}$

$\begin{array}{lllllll}25 & 0901 & 0.225 & 0.676 & 4764 & 3900 & 843 \pm 3.0\end{array}$

$\mathrm{m}_{\mathrm{el}} \mathrm{m}_{\mathrm{Bi} 2 \mathrm{O}_{3}}$ and $\mathrm{m}_{\mathrm{Zn}}$ are the total electrode, $\mathrm{Bi}_{2} \mathrm{O}_{3}$ and $\mathrm{Zn}$ weights, respectively, T.C. and E.C. are the Theoretical and Experimental Capacities. T. C. values have been calculated taking into account the amount of $\mathrm{Zn}$ spent in the reduction of $\mathrm{Bi}^{3+}$ to metallic $\mathrm{B}$ $\mathrm{Zn}$ Yield values are calculated from three different experimental discharges for each electrode composition. Other values correspond to discharges shown in Fig. 5A.

tered electrons (BSE) or $<1 \mathrm{~Pa}$ for secondary electrons (SE). Microanalysis were done with a XFlash 5010 Bruker AXS Microanalysis, with a resolution of $129 \mathrm{eV}$.

Conventional diffraction patterns were collected using a computer-controlled Bruker D8 Advance laboratory diffractometer, operated in the reflection Bragg-Brentano geometry and configured in the $\theta / \theta$ mode to maintain a horizontal sample position at all times. The data were collected at room temperature, using $\mathrm{Cu}-\mathrm{K} \alpha(\lambda=1.5418 \AA)$.

RAMAN spectra were obtained at room temperature in a HORIBA Scientific's XplRa PLUS Raman microscope. The samples were excited by a $532 \mathrm{~nm}$ laser and a $100 \times$ objective was utilized. A charge coupled device detector was used to collect the scattered light dispersed by a 2400 lines $\mathrm{mm}^{-1}$ grating.

\section{Results and discussion}

\subsection{Measurements canied out before discharging processes}

In situ XRD synchrotron patterns of different negative electrodes have been obtained prior to starting the $\mathrm{Zn} /$ air battery discharge. Fig. 2 compares the patterns obtained for pure $\mathrm{Bi}_{2} \mathrm{O}_{3}$ and $\mathrm{Zn}-\mathrm{Bi}_{2} \mathrm{O}_{3}$ reference samples with $\mathrm{Zn}-\mathrm{Bi}_{2} \mathrm{O}_{3}$ samples containing $6 \%, 12 \%$ and $25 \%$ of $\mathrm{Bi}_{2} \mathrm{O}_{3}$, which were immersed in $\mathrm{KOH}$ electrolyte (without applying any voltage). Moreover, a pattern of $\mathrm{Bi}_{2} \mathrm{O}_{3}$ powder obtained by a conventional XRD diffractometer was included in Fig. $2 \mathrm{~B}$.

As it can be seen, pure $\mathrm{Bi}_{2} \mathrm{O}_{3}$ disk and $\mathrm{Bi}_{2} \mathrm{O}_{3}$ powder patterns are in agreement with the $\mathrm{Bi}_{2} \mathrm{O}_{3}$ Card-04-015-6851 of the experimental data cited in the International Center for Diffraction Data (ICDD) database (black lines). Besides, dry $\mathrm{Zn}-\mathrm{Bi}_{2} \mathrm{O}_{3}$ sample maintains the bands related to $\mathrm{Bi}_{2} \mathrm{O}_{3}$ together with those due to metallic $\mathrm{Zn}$ (blue lines correspond to the $\mathrm{Zn}$ Card-00-004-0831). Conversely, when $\mathrm{Zn}-\mathrm{Bi}_{2} \mathrm{O}_{3}(6 \%)$ sample was immersed in $6 \mathrm{M} \mathrm{KOH}$ solution evident changes have been observed. $\mathrm{Bi}_{2} \mathrm{O}_{3}$ peaks at $27.9^{\circ}, 31.7^{\circ}, 32.7^{\circ}$ and $46.1^{\circ}$ disappear and new bands at $27.2^{\circ}, 38.0^{\circ}, 39.6^{\circ}, 44.6^{\circ}, 46.0^{\circ}$ and $48.7^{\circ}$ appear. These new bands can be assigned to metallic $\mathrm{Bi}$, agreeing with Card-04-006-7762 (red lines). Besides, bands at $31.7^{\circ}$, $34.4^{\circ}$ and $47.6^{\circ}$ are ascribed to $\mathrm{ZnO}$ formation (green lines represent Card-00-036-1451, confirming that part of $\mathrm{Zn}$ has been oxidized to $\mathrm{Zn}^{2+}$ ).

Similar results have been reported previously during the charging of $\mathrm{ZnO}-\mathrm{Bi}_{2} \mathrm{O}_{3}$ negative electrodes in $\mathrm{Zn}$-based batteries. These authors pointed to the formation of a metallic $\mathrm{Bi}$ film through the reduction of $\mathrm{Bi}^{3+}$ of $\mathrm{Bi}_{2} \mathrm{O}_{3}$ before the reduction of $\mathrm{ZnO}$ [10-15]. The following reaction for the reduction of bismuth oxide was proposed

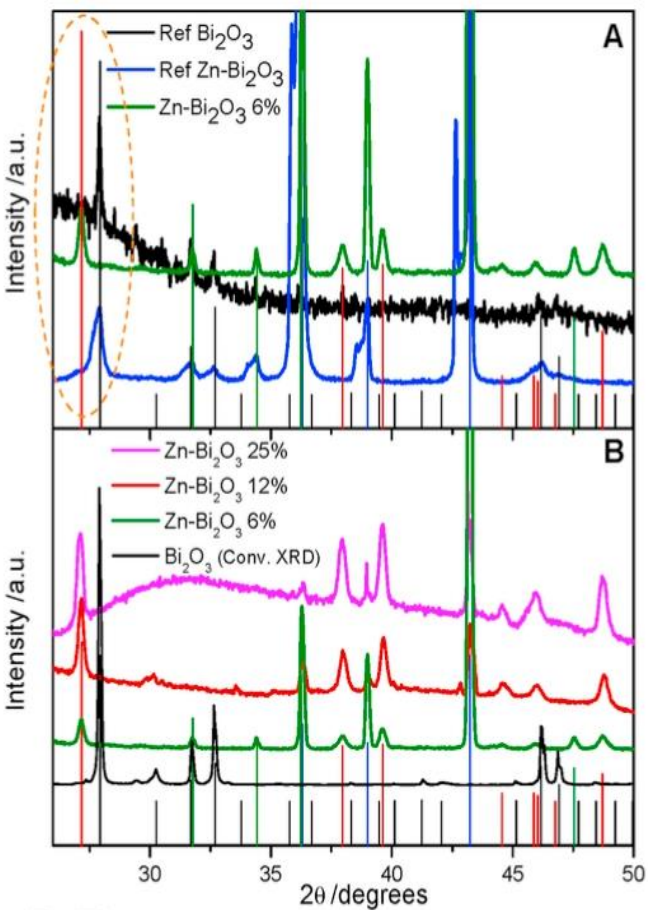

Fig. 2. A) Synchrotron XRD patterns of $\mathrm{Bi}_{2} \mathrm{O}_{3}$ and $\mathrm{Zn}-\mathrm{Bi}_{2} \mathrm{O}_{3}$ reference samples compared with a $\mathrm{Zn}-\mathrm{Bi}_{2} \mathrm{O}_{3} 6 \%$ immersed in $\mathrm{KOH}$ solution before starting the battery discharge. B) Synchrotron XRD patterns of $\mathrm{Zn}-\mathrm{Bi}_{2} \mathrm{O}_{3}$ samples with different amount of $\mathrm{Bi}_{2} \mathrm{O}_{3}(6 \%, 12 \%$ and $25 \%)$ immersed in $\mathrm{KOH}$ solution before starting the battery discharge. Besides, a conventional XRD pattern of $\mathrm{Bi}_{2} \mathrm{O}_{3}$ powder has been included to compare Vertical lines show the ICDD datase ards of $\mathrm{Zn}$ [Card-00-004-0831] to compare. Vertial limes show the ICDD database cards of $Z$ [Card-00-004-0831] (blue), $\mathrm{ZnO}$ [Card-00-036-1451] (green), $\mathrm{B}_{2} \mathrm{O}_{3}$ [Card-04-015-6851] (black) and $\mathrm{B}$ [Card-04-006-7762] (red). (For interpretation of the references to colour in this figure
legend, the reader is referred to the Web version of this article.) $[10,13,15]$,

$\mathrm{Bi}_{2} \mathrm{O}_{3}+3 \mathrm{H}_{2} \mathrm{O}+6 \mathrm{e}^{-} \rightarrow 2 \mathrm{Bi}+6 \mathrm{OH}^{-} \mathrm{E}^{0}=-0,46 \mathrm{~V}$ (vs. SHE)

However, in our case, we observe metallic Bi peaks, though our electrodes are composed of $\mathrm{Bi}_{2} \mathrm{O}_{3}$ and metallic $\mathrm{Zn}$, instead of $\mathrm{ZnO}$, even though no voltage was applied before detecting metallic $\mathrm{Bi}$. Therefore, this result suggests that reduction of $\mathrm{Bi}^{3+}$ has to be provided by simultaneous oxidation of $\mathrm{Zn}$ to $\mathrm{Zn}^{2+}$. Normal redox potential of $\mathrm{Zn}^{2+} / \mathrm{Zn}$ is negative enough to reduce $\mathrm{Bi}^{3+}$ to $\mathrm{Bi}$, and thus, this result may indicate a spontaneous redox process where the following global reaction may be proposed:

$\mathrm{Bi}_{2} \mathrm{O}_{3}+3 \mathrm{Zn}+3 \mathrm{H}_{2} \mathrm{O} \rightarrow 2 \mathrm{Bi}+3 \mathrm{Zn}^{2+}+6 \mathrm{OH}^{-}$

Besides, in this reaction $\mathrm{Bi}^{3+}$ intermediate species could be formed, occurring probably as water soluble hydrocomplexes $[24,25]$. Therefore, species as $\mathrm{Bi}(\mathrm{OH})^{2+}$ or $\mathrm{Bi}(\mathrm{OH})_{2}{ }^{+}$will be formed prior to the reduction of $\mathrm{Bi}^{3+}$ to metallic $\mathrm{Bi}$ by $\mathrm{Zn}$ oxidation. Besides, participation of $\mathrm{K}^{+}$cations in the global reaction could be taken into consideration. 
On the other hand, when $\mathrm{Zn}-\mathrm{Bi}_{2} \mathrm{O}_{3}$ electrodes with higher amount of $\mathrm{Bi}_{2} \mathrm{O}_{3}(12 \%$ and $25 \%)$ are immersed in the $6 \mathrm{M} \mathrm{KOH}$ solution, once again metallic $\mathrm{Bi}$ peaks appear while $\mathrm{Bi}_{2} \mathrm{O}_{3}$ ones disappear. However, a clear change with respect to $\mathrm{Zn}-\mathrm{Bi}_{2} \mathrm{O}_{3} 6 \%$ is observed (Fig. 2B): $\mathrm{ZnO}$ peaks are never observed in the XRD patterns of the electrodes with $12 \%$ and $25 \%$ of $\mathrm{Bi}_{2} \mathrm{O}_{3}$.

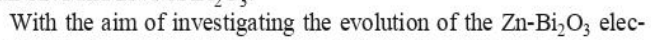
trodes when they are immersed in a $6 \mathrm{M} \mathrm{KOH}$ solution, we have performed a series of open circuit voltage (OCV) measurements. For that purpose, we have used the $\mathrm{Zn} /$ air cell described in the experimental section and Fig. 1C, but we started recording the voltage before adding the $\mathrm{KOH}$ solution. As a consequence, we can observe the potential evolution from the beginning, as it is shown in Fig. 3.

$\mathrm{OCV}$ measurements were registered during $24 \mathrm{~h}$ for $\mathrm{Zn}$ pure and the three composition $\mathrm{Zn}-\mathrm{Bi}_{2} \mathrm{O}_{3}$ electrodes. For all experiments, sharp increases of potential are observed immediately after incorporation of the solution to the cell and a stable potential close to $1.5 \mathrm{~V}$ was reached and maintained until the end of the measurement (Fig. 3C). However, paying attention to the change of potential, a real instantaneous increase is clear only for pure $\mathrm{Zn}$ electrode. Conversely, for all the samples containing $\mathrm{Bi}_{2} \mathrm{O}_{3}$, after the initial increase, the potential drops and a well defined peak appears, as it can be observed in Fig. 3B. Subsequently to this peak formation, the potential rose slowly, sometimes with erratic behaviour, until reaching a stable potential close to $1.5 \mathrm{~V}$. Moreover, as it can be seen in Fig. 3A, the time span necessary to reach the stable potential is longer when the amount of $\mathrm{Bi}_{2} \mathrm{O}_{3}$ is higher inside the negative electrode.

These OCV measurements are in agreement with the global redox reaction (2). When a pure $\mathrm{Zn}$ negative electrode is used, the steady potential is reached immediately. However the presence of $\mathrm{Bi}_{2} \mathrm{O}_{3}$ slowed down this process due to the oxidation of metallic $\mathrm{Zn}$ to $\mathrm{Zn}^{2+}$, thus reducing $\mathrm{Bi}^{3+}$ to metallic $\mathrm{Bi}$. While this spontaneous process is occurring there is no steady $\mathrm{Zn}$ surface in contact with the electrolyte and therefore a stable $\mathrm{Zn} /$ air OCV potential is not reached. Besides, this redox process will be longer when a higher amount of $\mathrm{Bi}^{3+}$ is included in the electrode. Note that the pure $\mathrm{Bi}_{2} \mathrm{O}_{3} /$ air pair presents an $\mathrm{OCV}$ value around $0.75 \mathrm{~V}$. Furthermore while $\mathrm{Bi}_{2} \mathrm{O}_{3}$ does not react completely an intermediate $\mathrm{OCV}$ value is obtained, ranging between $1.5 \mathrm{~V}$, due to pure $\mathrm{Zn}$, and $0.75 \mathrm{~V}$, due to pure $\mathrm{Bi}_{2} \mathrm{O}_{3}$. Finally, once the process is completed, the $\mathrm{Zn}$ /air $\mathrm{OCV}$ potential at $1.5 \mathrm{~V}$ is stabilized.

In addition, OCV curves shown in Fig. 3 are in agreement with the chronopotentiometry experiments carried out by McBreen and

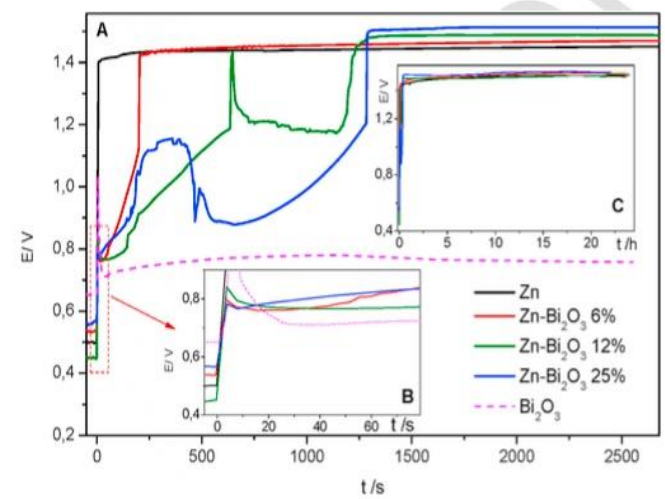

Fig. 3. Open circuit voltage $(\mathrm{OCV})$ curves registered for $\mathrm{Zn}$ and $\mathrm{Zn}-\mathrm{Bi}_{2} \mathrm{O}_{3}$ negative elec trodes at three different time ranges. OCV curve of pure $\mathrm{Bi}_{2} \mathrm{O}_{3}$ has been included for comparison. Electrolyte: $6 \mathrm{M} \mathrm{KOH}$ water solution.
Gannon with $\mathrm{ZnO}$ electrodes including 2 and $10 \mathrm{wt} \%$ of $\mathrm{Bi}_{2} \mathrm{O}_{3}$ [12], though we have used $\mathrm{Zn}-\mathrm{Bi}_{2} \mathrm{O}_{3}$ electrodes instead of $\mathrm{ZnO}-\mathrm{Bi}_{2} \mathrm{O}_{3}$ ones. These authors observed higher transition times for larger $\mathrm{Bi}_{2} \mathrm{O}_{3}$ amounts, which were explained as due to the reduction of $\mathrm{Bi}_{2} \mathrm{O}_{3}$ to metallic Bi prior to metallic $\mathrm{Zn}$ deposition. The same explanation was provided recently by Moser at al. [10], who found similar transition times at the beginning of the first charge of a $\mathrm{Zn}-\mathrm{Ni}$ battery, where $\mathrm{ZnO}$ with $9.5 \mathrm{wt} \% \mathrm{Bi}_{2} \mathrm{O}_{3}$ was used as negative electrode.

On the other hand, in order to verify the presence of metallic $\mathrm{Bi}$ after the OCV, we have carried out additional measurements by Raman spectroscopy. The Raman spectra of a pristine $\mathrm{Bi}_{2} \mathrm{O}_{3}$ sample and a $\mathrm{Zn}-\mathrm{Bi}_{2} \mathrm{O}_{3} 25 \%$ after $24 \mathrm{~h}$ OCV process are shown in the inset of Fig. 4. Pristine $\mathrm{Bi}_{2} \mathrm{O}_{3}$ spectrum shows the typical bands assigned to $\mathrm{Bi}_{2} \mathrm{O}_{3}$. However, after $\mathrm{OCV}, \mathrm{Zn}-\mathrm{Bi}_{2} \mathrm{O}_{3}$ Raman spectrum shows two high intensity peaks at 67 and $94 \mathrm{~cm}^{-1}$, which have been assigned frequently to the formation of metallic $\mathrm{Bi}[26,27]$.

Besides, we have carried out a series of ex-situ XRD measurements in a conventional XRD diffractometer. The XRD patterns of pristine $\mathrm{Zn}, \mathrm{Zn}-\mathrm{Bi}_{2} \mathrm{O}_{3} 6 \%$ and $\mathrm{Zn}-\mathrm{Bi}_{2} \mathrm{O}_{3} 25 \%$ electrodes is shown in Fig. 4, where it is compared to patterns of $\mathrm{Zn}-\mathrm{Bi}_{2} \mathrm{O}_{3} 6 \%$ and $25 \%$ electrodes subject to OCV tests during $24 \mathrm{~h}$ in $6 \mathrm{M} \mathrm{KOH}$ solution. As it can be seen, the patterns of all pristine electrodes show $\mathrm{Zn}$ and $\mathrm{ZnO}$ peaks, while those including $\mathrm{Bi}_{2} \mathrm{O}_{3}$ display also the peaks assigned to $\mathrm{Bi}_{2} \mathrm{O}_{3}$, but none of those attributed to metallic $\mathrm{Bi}$. Thus, this result is consistent with those obtained by synchrotron XRD for $\mathrm{Zn}$ and $\mathrm{Zn}-\mathrm{Bi}_{2} \mathrm{O}_{3}$ reference electrodes.

With respect to $\mathrm{Zn}-\mathrm{Bi}_{2} \mathrm{O}_{3}$ electrodes subject to OCV processes, once again a different behavior is observed for the electrode containing $\mathrm{Bi}_{2} \mathrm{O}_{3} 6 \%$ with respect to that containing $25 \%$ (Fig. $4 \mathrm{~A}$ ). The $\mathrm{Zn}-\mathrm{Bi}_{2} \mathrm{O}_{3} 6 \%$ pattern presents only the $\mathrm{ZnO}$ peaks, but peaks due to $\mathrm{Zn}, \mathrm{Bi}_{2} \mathrm{O}_{3}$ or metallic $\mathrm{Bi}$ are not observed. However, $\mathrm{Zn}-\mathrm{Bi}_{2} \mathrm{O}_{3}$ $25 \%$ pattern mainly shows peaks corresponding to metallic $\mathrm{Bi}$ and some small peaks corresponding to $\mathrm{Bi}_{2} \mathrm{O}_{3}$, nevertheless $\mathrm{ZnO}$ peaks do not appear in this pattern (Note that the $\mathrm{Bi}_{2} \mathrm{O}_{3}$ card 01-072-0398 corresponding to a monoclinic instead of a tetragonal structure was $\begin{array}{lll}\text { used } & \text { Fig. }\end{array}$

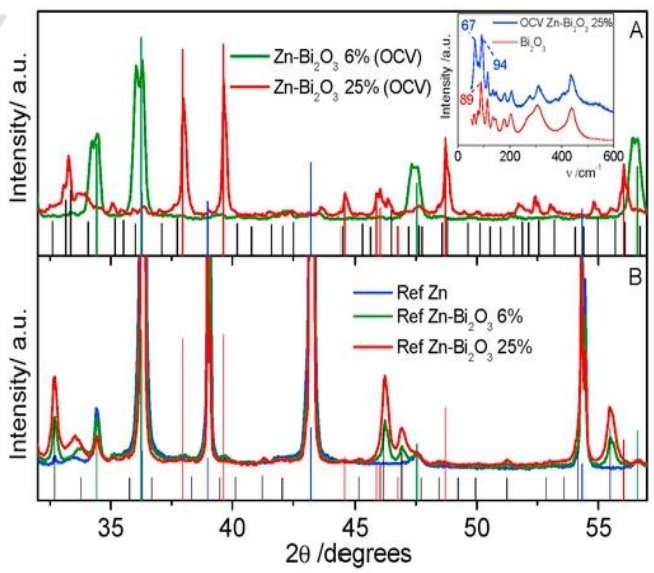

Fig. 4. A) Conventional XRD patterns of $\mathrm{Zn}-\mathrm{Bi}_{2} \mathrm{O}_{3} 6 \%$ and $25 \%$ after $24 \mathrm{~h}$ OCV process in $6 \mathrm{M} \mathrm{KOH}$ solution. B) Conventional XRD patterns of pristine $\mathrm{Zn}$ and $\mathrm{Zn}-\mathrm{Bi}_{2} \mathrm{O}_{3}$ samples with different amounts of $\mathrm{Bi}_{2} \mathrm{O}_{3}$. Vertical lines show the same ICDD database cards shown in Fig. 2, except in Fig. 4A, where card 01-072-0398 is shown for $\mathrm{Bi}_{2} \mathrm{O}_{3}: \mathrm{Zn}$ (blue), $\mathrm{ZnO}$ (green), $\mathrm{Bi}_{2} \mathrm{O}_{3}$ (black) and $\mathrm{Bi}$ (red). Inset: Raman spectra of pristine $\mathrm{Bi}_{2} \mathrm{O}_{3}$ and a $\mathrm{Zn}-\mathrm{Bi}_{2} \mathrm{O}_{3} 25 \%$ subject to a $24 \mathrm{~h} \mathrm{OCV}$ process. (For interpretation of the references to colour in this figure legend, the reader is referred to the Web version of this article.) 
indicating that the remaining $\mathrm{Bi}_{2} \mathrm{O}_{3}$ underwent a phase transition during the OCV treatment). Again, this result confirms that $\mathrm{ZnO}$ peaks are only observed when a lower quantity of $\mathrm{Bi}_{2} \mathrm{O}_{3}$ was added, as it was already found by in situ synchrotron XRD. Furthermore, at higher quantities of $\mathrm{Bi}_{2} \mathrm{O}_{3}$, this behavior points to the formation of a massive deposit of metallic $\mathrm{Bi}$, what seems to prevent the $\mathrm{ZnO}$ deposition onto the electrode. Consequently, at higher $\mathrm{Bi}_{2} \mathrm{O}_{3}$ content electrodes, $\mathrm{Zn}^{2+}$ cations obtained during the $\mathrm{Zn}$ negative electrode oxidation have to form $\mathrm{Zn}(\mathrm{OH})_{4}{ }^{2-}$ species, which are soluble in the bulk solution and in this case $\mathrm{ZnO}$ is not deposited.

\subsection{Analysis of $\mathrm{Zn}-\mathrm{Bi}_{2} \mathrm{O}_{3}$ electrodes during discharging processes}

\subsection{1. $\mathrm{Zn}-\mathrm{Bi}_{2} \mathrm{O}_{3}$ /air battery discharge curves}

After carrying out the OCV measurements as those displayed in Fig. 3, each of the $\mathrm{Zn}$ /air batteries using pure $\mathrm{Zn}$ or different $\mathrm{Zn}-\mathrm{Bi}_{2} \mathrm{O}$ as negative electrodes were discharged completely at a constant current of $-20 \mathrm{~mA}$. All discharge curves are shown in Fig. $5 \mathrm{~A}$ and their capacity values, considering a cut off potential of $0.8 \mathrm{~V}$, are include in Table 1. As shown in Table 1, a constant electrode mass of $0,895 \pm 0,015 \mathrm{mg}$ was kept for all the samples. Consequently, the
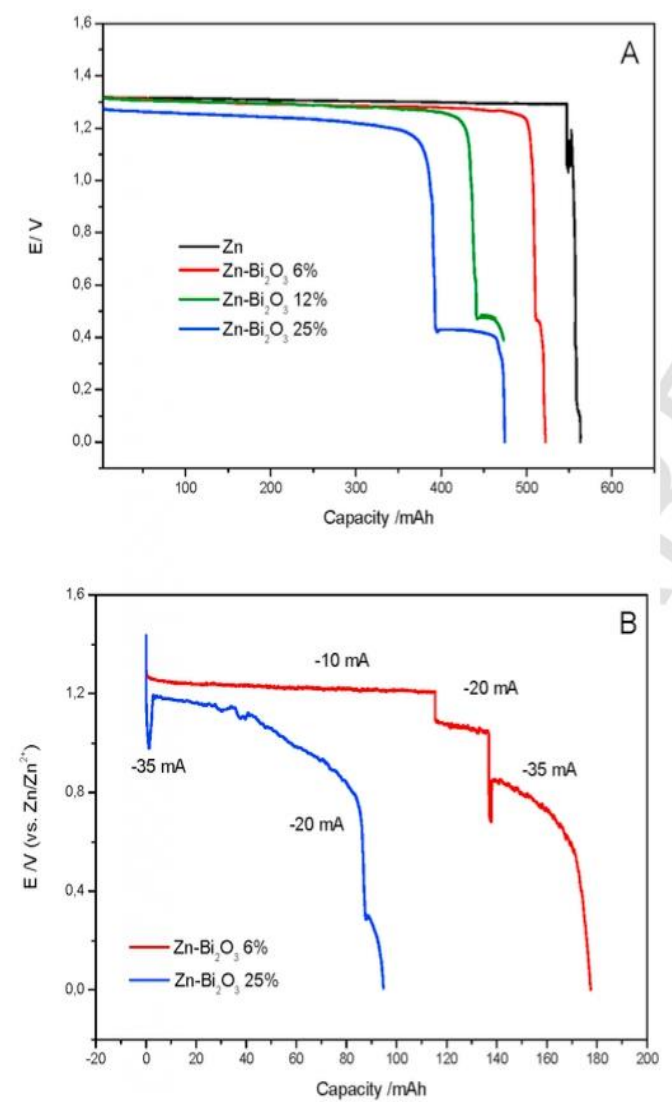

Fig. 5. A) Discharge curves obtained for $\mathrm{Zn} /$ air batteries using pure $\mathrm{Zn}$ or $\mathrm{Zn}-\mathrm{Bi}_{2} \mathrm{O}_{3} 6 \%$ $12 \%$ and $25 \%$, as negative electrodes. B) Discharge curves registered during in situ synchrotron XRD measurements for $\mathrm{Bi}_{2} \mathrm{O}_{3} 6 \%$ and $25 \%$. Numbers indicate the discharging current. higher the $\mathrm{Bi}_{2} \mathrm{O}_{3}$ weight, the lower the amount of zinc in the electrode. Thus, the capacity values obtained diminished with the minor amount of $\mathrm{Zn}$ mass included in the negative electrode.

Besides, we have calculated the $\mathrm{Zn}$ oxidation yield, with respect to the initial $\mathrm{Zn}$ mass, for all $\mathrm{Zn}$ /air batteries tested. For a pure $\mathrm{Zn}$ anode a yield of $77.3 \pm 0.1 \%$ was obtained, which is a common value reported for $\mathrm{Zn}$ alkaline batteries [28]. On the other hand, according to reaction (2) a fraction of $\mathrm{Zn}$ mass is employed to reduce the $\mathrm{Bi}^{3+}$ cations to $\mathrm{Bi}$. Thus, we have considered the quantity of $\mathrm{Zn}$ necessary to reduce all $\mathrm{Bi}^{3+}$ contained inside the different electrodes to calculate the theoretical capacities and, consequently, the $\mathrm{Zn}$ yields. As can be seen in Table 1, the $\mathrm{Zn}$ yields calculated for $\mathrm{Zn}-\mathrm{Bi}_{2} \mathrm{O}_{3} 6 \%$ and $12 \%$ are a bit lower than the value obtained for pure $\mathrm{Zn}$ electrodes. However, the yield for $\mathrm{Zn}-\mathrm{Bi}_{2} \mathrm{O}_{3} 25 \%$ is higher, reaching the $84.3 \pm 3.0 \%$ (Note that this value has been obtained taking into account the amount of $\mathrm{Zn}$ spent in the reduction of $\mathrm{Bi}^{3+}$ to metallic $\mathrm{Bi}$ ). This result seems to indicate that secondary reactions spending a fraction of $\mathrm{Zn}$ during the discharge process, such as $\mathrm{H}_{2}$ evolution, may be reduced due to the presence of a metallic $\mathrm{Bi}$ deposit on the negative electrode.

3.2.2. In situ $X R D$ synchrotron $\mathrm{Zn}-\mathrm{Bi}_{2} \mathrm{O}_{3}$ /air measurements

Four types of $\mathrm{Zn}$-based electrodes containing different amounts of $\mathrm{Bi}_{2} \mathrm{O}_{3}$ have been analyzed by in situ synchrotron XRD during the discharging process of a real alkaline $\mathrm{Zn}$ /air battery. Discharge curves registered during the synchrotron $\mathrm{XRD}$ measurements using $\mathrm{Zn}-\mathrm{Bi}_{2} \mathrm{O}_{3}$ $6 \%$ and $25 \%$ electrodes are shown in Fig. $5 \mathrm{~B}$. It should be noted that capacities obtained during synchrotron XRD measurements are lower than those shown in Fig. 5A, which were registered in the same cell but with the electrodes facing each other, as it has been mentioned before (see schemes in Fig. 1). In these measurements, a synchrotron $\mathrm{XRD}$ pattern was registered each $31 \mathrm{~min}$ during the total discharging processes.

Synchrotron XRD patterns obtained using a pure $\mathrm{Zn}$ disk as negative electrode are shown in Fig. 6A and b. As it can be seen, only $\mathrm{Zn}$ peaks are observed before starting the discharge ( $t=0$ curve), which then reduce their intensities during the discharging process. Besides, when the discharge starts, $\mathrm{ZnO}$ peaks appear due to $\mathrm{Zn}$ oxidation to $\mathrm{Zn}^{2+}$ and the intensity of the $\mathrm{ZnO}$ peaks increases as the discharge progresses (Fig. 6B).

On the other hand, synchrotron XRD patterns registered for $\mathrm{Zn}-\mathrm{Bi}_{2} \mathrm{O}_{3}$ negative electrodes show evident changes due to the presence of $\mathrm{Bi}_{2} \mathrm{O}_{3}$ inside the electrode, which provides metallic $\mathrm{Bi}$ from the moment it is introduced in the $\mathrm{KOH}$ solution. Fig. $6 \mathrm{C}, \mathrm{D}$ and $\mathrm{E}$ display the in situ synchrotron patterns of a $\mathrm{Zn}-\mathrm{Bi}_{2} \mathrm{O}_{3} 6 \%$ acting as negative electrode, obtained during the discharge of the $\mathrm{Zn} /$ air battery. It should be noted that in the synchrotron XRD measurements, the electrochemical cell is placed in the sample chamber prior to the X-ray alignment. Therefore, before starting the discharge measurement, the electrodes are already immersed in $6 \mathrm{M} \mathrm{KOH}$ solution, i.e. previous to the discharge process. Consequently, the $\mathrm{Zn}-\mathrm{Bi}_{2} \mathrm{O}_{3}$ negative electrode undergoes the same process as that observed in OCV curves of Fig. 3 and thus, these electrodes will be subject to the reaction (2) prior to applying current.

As it was observed for the XRD pattern of the pure $\mathrm{Zn}$ negative electrode, we find in Fig. $6 \mathrm{C}$ and $\mathrm{D}$ the peaks corresponding to $\mathrm{Zn}$ and $\mathrm{ZnO}$. However, new peaks due to metallic $\mathrm{Bi}$ are also observed from the beginning, though the intensity of these peaks decreases as the discharge progresses, until disappearing completely at the end of the discharge (Fig. $6 \mathrm{C}$ and $\mathrm{E}$ ). Nevertheless, $\mathrm{Bi}_{2} \mathrm{O}_{3}$ peaks do not appear in any pattern, confirming that $\mathrm{Bi}^{3+}$ cations were reduced to metallic $\mathrm{Bi}$. 

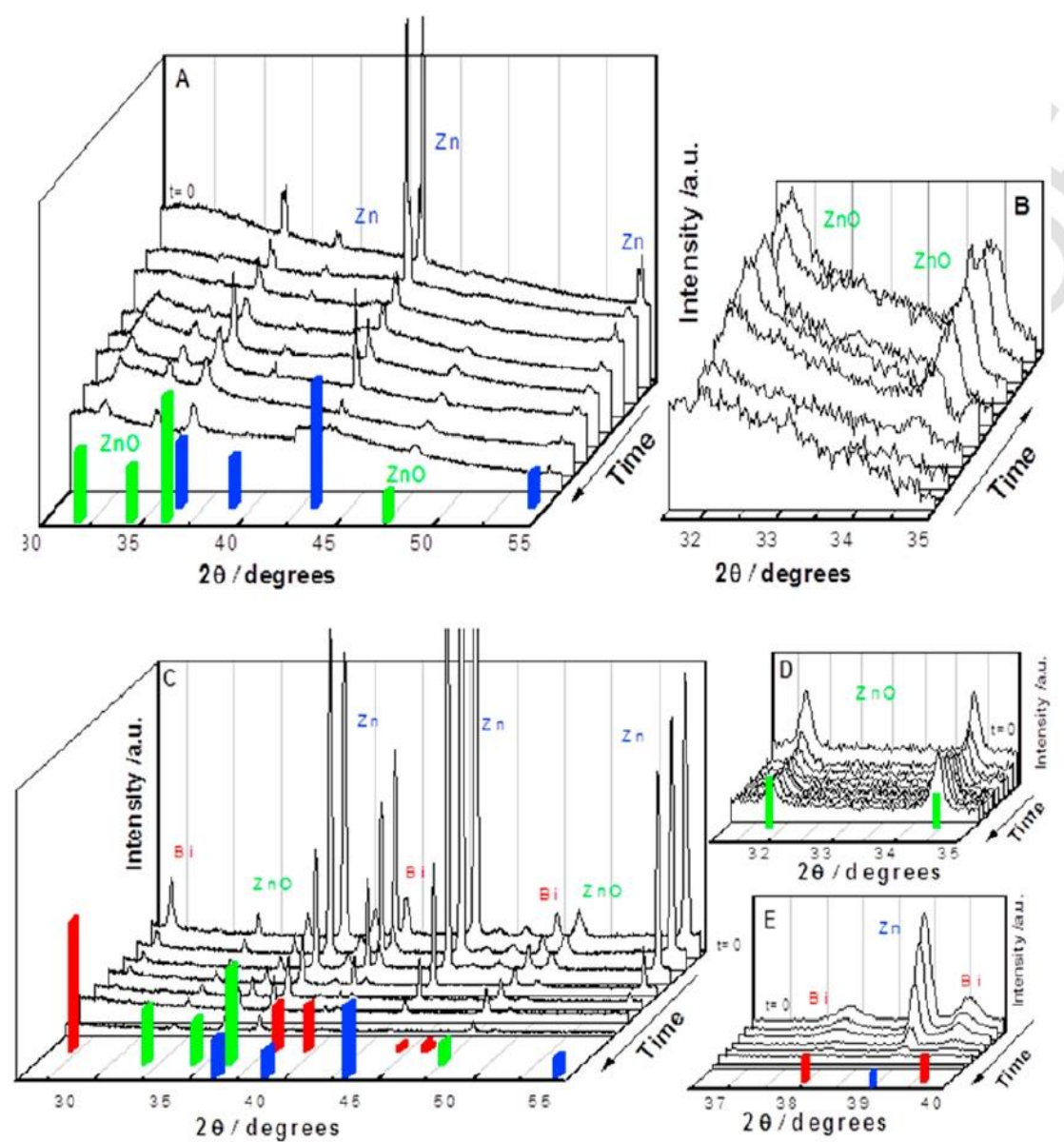

Fig. 6. In situ XRD patterns during the discharge at different $2 \theta$ ranges of pure $\mathrm{Zn}(\mathrm{A}$ and $\mathrm{B})$ and $\mathrm{Zn}-\mathrm{Bi}_{2} \mathrm{O}_{3} 6 \%(C, D$ and $\mathrm{E})$ negative electrodes.

In addition, $\mathrm{Zn}$ peaks diminish as the discharge progresses, until being completely eliminated at the end of the discharge. Thus, this confirms that $\mathrm{Zn}$ was oxidized to $\mathrm{Zn}^{2+}$. Finally, with respect to $\mathrm{ZnO}$ peaks, they are observed from the beginning until the end of the process (Fig. 6D).

Conversely, when negative electrodes with higher amount of $\mathrm{Bi}_{2} \mathrm{O}_{3}$ $(12 \%$ or $25 \%)$ are used, evident changes are found in the XRD patterns with respect to the results obtained for $\mathrm{Zn}-\mathrm{Bi}_{2} \mathrm{O}_{3} 6 \%$ (Fig. 7). Synchrotron XRD patterns of a $\mathrm{Zn}-\mathrm{Bi}_{2} \mathrm{O}_{3} \quad 12 \%$ negative electrode, show again the decrease in $\mathrm{Zn}$ peaks with the discharge progress, confirming the oxidation of $\mathrm{Zn}$ to $\mathrm{Zn}^{2+}$ (Fig. 7A and C). Although the metallic Bi peaks appear once again from the beginning, these peaks show an increase instead of decrease in this case. This increase is shown during the discharge process until they reach a stable state (Fig. 7A and C). In addition, $\mathrm{Bi}_{2} \mathrm{O}_{3}$ peaks are not observed either, confirming the reduction of $\mathrm{Bi}^{3+}$ to $\mathrm{Bi}$. Surprisingly, $\mathrm{ZnO}$ peaks are not observed in any $\mathrm{XRD}$ patterns registered for a $\mathrm{Zn}-\mathrm{Bi}_{2} \mathrm{O}_{3} \quad 12 \%$ negative electrode (Fig. 7A and B).

The same behavior is found for a $\mathrm{Zn}-\mathrm{Bi}_{2} \mathrm{O}_{3} 25 \%$ negative electrode: decrease in $\mathrm{Zn}$ peaks, increase in metallic $\mathrm{Bi}$ peaks from the beginning and neither $\mathrm{Bi}_{2} \mathrm{O}_{3}$ nor $\mathrm{ZnO}$ peaks are ever observed during the full discharge (Fig. 7D-F).

Certainly, the absence of $\mathrm{ZnO}$ peaks in synchrotron $\mathrm{XRD}$ patterns is unexpected. Oxidation of $\mathrm{Zn}$ to $\mathrm{Zn}^{2+}$ is confirmed by a decrease in of $\mathrm{Zn}$ peaks observed by XRD measurements and by the discharge curve obtained simultaneously to the acquisition of in situ synchrotron XRD patterns (Fig. 5B). In this sense, it is normally accepted that oxidation of $\mathrm{Zn}$ as the negative electrode of an aqueous alkaline battery follows the next mechanism $[4,6,20]$,

$$
\mathrm{Zn} \rightarrow \mathrm{Zn}^{2+}+2 \mathrm{e}^{-}
$$

$\mathrm{Zn}^{2+}+4 \mathrm{OH}^{-} \rightarrow \mathrm{Zn}(\mathrm{OH})_{4}^{2-}$

$$
\mathrm{Zn}(\mathrm{OH})_{4}^{2-} \rightarrow \mathrm{ZnO}+2 \mathrm{OH}^{-}+\mathrm{H}_{2} \mathrm{O}
$$



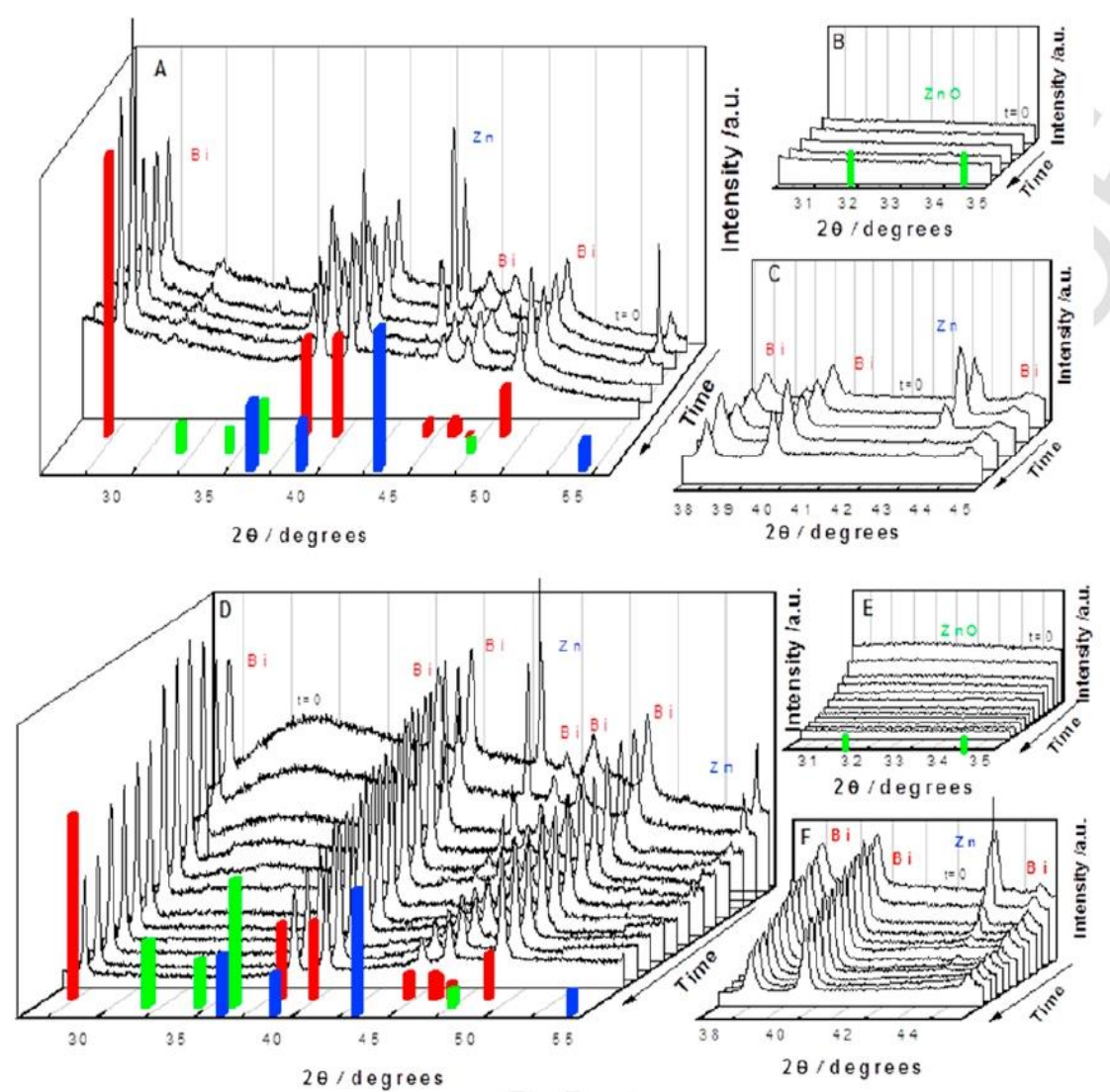

Fig. 7. In situ XRD patterns during the discharge at different $2 \theta$ ranges of $\left.\left.\mathrm{Zn}_{-}-\mathrm{Bi}_{2} \mathrm{O}_{3} 12 \%, A\right), \mathrm{B}\right)$ and $\mathrm{C}$ ) and $\left.\left.\mathrm{Zn}-\mathrm{Bi}_{2} \mathrm{O}_{3} 25 \%, \mathrm{D}\right), \mathrm{E}\right)$ and $\mathrm{F}$ ) negative electrodes.

Reactions (3) and (4) proceed until the solubility of the zincate ion, $\mathrm{Zn}(\mathrm{OH})_{4}{ }^{2-}$, reaches the saturation point in the alkaline electrolyte. At this moment, $\mathrm{ZnO}$ is deposited on the electrode providing shape changes and passivating the negative electrode.

We may consider that the saturation point of $\mathrm{Zn}(\mathrm{OH})_{4}{ }^{2-}$ is not reached during the XRD measurements. However, $\mathrm{ZnO}$ is only observed for electrodes without $\mathrm{Bi}_{2} \mathrm{O}_{3}$ or when a low quantity of $\mathrm{Bi}_{2} \mathrm{O}_{3}$ was used. Hence, the absence of $\mathrm{ZnO}$ peaks when higher amounts of $\mathrm{Bi}_{2} \mathrm{O}_{3}$ are included in the negative electrode has to be related with the formation of a massive deposit of metallic $\mathrm{Bi}$ onto the electrode.

3.2.3. SEM, elemental map and EDX measurements

With the aim of clarifying this result, we have carried out an additional SEM study of $\mathrm{Zn}-\mathrm{Bi}_{2} \mathrm{O}_{3}$ electrodes. Fig. 8 shows SEM micrographs, elemental maps and EDX measurements carried out for $\mathrm{Zn}-\mathrm{Bi}_{2} \mathrm{O}_{3}$ electrodes at different states of discharge: pristine, after $24 \mathrm{~h} \mathrm{OCV}$ process and after a discharge until $1.0 \mathrm{~V}$ cut off potential This potential corresponds to the beginning of the battery potential collapse, thus we avoid the possibility of reoxidation of metallic $\mathrm{Bi}$ to $\mathrm{Bi}^{3+}$.

Pristine electrodes are analyzed in Fig. 8A-D: A and C show the pristine $\mathrm{Zn}-\mathrm{Bi}_{2} \mathrm{O}_{3} 6 \%$ and $\mathrm{Zn}-\mathrm{Bi}_{2} \mathrm{O}_{3} 25 \%$, $8 \mathrm{~B}$ displays the EDX spectra of both electrodes, confirming the presence of $\mathrm{Zn}, \mathrm{Bi}$ and $\mathrm{O}$, and
$8 \mathrm{D}$ shows the elemental map of the $\mathrm{Zn}-\mathrm{Bi}_{2} \mathrm{O}_{3} 25 \%$ region included in Fig. $8 \mathrm{C}$, which displays the distribution of $\mathrm{Bi}_{2} \mathrm{O}_{3}$ and $\mathrm{Zn}$ in the pristine electrode. Fig. $8 \mathrm{E}-\mathrm{G}$ show different magnification ranges of the $\mathrm{Zn}-\mathrm{Bi}_{2} \mathrm{O}_{3} 6 \%$ electrode subject to a $24 \mathrm{~h} \mathrm{OCV}$ test. As it can be seen, important changes are observed with respect to pristine electrodes, and two different structures are found. While micro-flower formations dominate the majority of the surface, small flatter zones are also observed. In order to elucidate why different morphology regions are formed, we have carried out EDX analyses in two different surface points, as it is illustrated in Fig. 8F. EDX measurements (Fig. 8H) show that the micro-flower-shape region has a higher $\mathrm{Zn}$ peak than that of $\mathrm{Bi}$, while the flatter region produces a more intense $\mathrm{Bi}$ peak compared with $\mathrm{Zn}$ peak. Therefore, and considering the morphology changes observed from the pristine to OCV subjected electrodes, the flatter region seems to be a two-dimensional accumulation of metallic Bi.

However, considering that micro-flower structures of $\mathrm{ZnO}$, similar to those obtained by us, have been frequently reported in the bibliography $[29,30]$ and that the EDX analysis in Fig. $8 \mathrm{H}$ indicates that the flower-shape zones contain mainly $\mathrm{Zn}$, it can be inferred that a $\mathrm{ZnO}$ layer is formed after the OCV treatment of a $\mathrm{Zn}-\mathrm{Bi}_{2} \mathrm{O}_{3} 6 \%$ electrode. Besides, this hypothesis is in agreement with the results obtained by synchrotron (Figs. 2 and $6 \mathrm{C}$ and D) and conventional (Fig. 4) XRD 

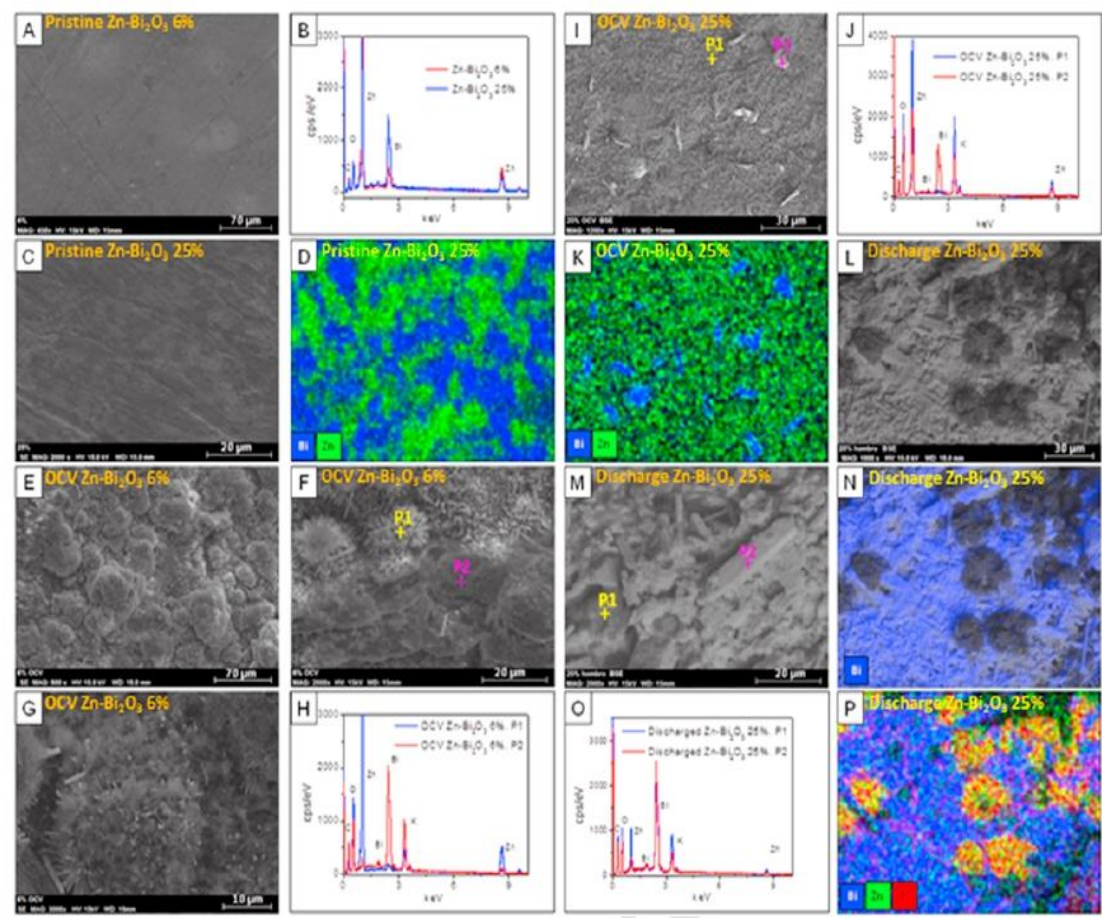

Fig. 8. SEM secondary electron images, elemental maps and $\mathrm{EDX}$ spectra of $\mathrm{Zn}-\mathrm{Bi}_{2} \mathrm{O}_{3} 6 \%$ and $25 \%$ electrodes at different states of charge, as the labels indicate. $\mathrm{P} 1$ and $\mathrm{P} 2$ in $\mathrm{F}$, $\mathrm{I}$ and $\mathrm{M}$ indicate points where EDX analyses have been carried out and their spectra are shown in $\mathrm{H}, \mathrm{J}$ and $\mathrm{O}$, respectively. Maps in $\mathrm{D}$ and $\mathrm{K}$ correspond to SEM images $\mathrm{C}$ and $\mathrm{I}$ respectively. Maps in N and P correspond to SEM image L.

measurements. Moreover, the appearance of a $\mathrm{K}$ peak points to the participation of $\mathrm{K}^{+}$cations in the global process.

On the other hand, when a $\mathrm{Zn}-\mathrm{Bi}_{2} \mathrm{O}_{3} 25 \%$ is subject to an $\mathrm{OCr}$ process, the resultant morphology of the electrode changes clearly from the one obtained for $\mathrm{Zn}-\mathrm{Bi}_{2} \mathrm{O}_{3} 6 \%$ electrode. Fig. 8I shows the surface image of a $\mathrm{Zn}-\mathrm{Bi}_{2} \mathrm{O}_{3} 25 \%$ after $\mathrm{OCV}$, where micro-crystals formations are observed on the electrode surface. Point EDX measurements carried out on a micro-crystal and on the bulk surface (Fig. $8 \mathrm{~J})$ confirm that the micro-crystals are composed essentially of $\mathrm{Bi}$ while the bulk surface contains mainly $\mathrm{Zn}$ but no $\mathrm{Bi}$. This aspect is confirmed by the elemental map included in Fig. $8 \mathrm{~K}$, indicating that metallic Bi micro-crystals are formed onto $\mathrm{Zn}$ surface. At this point, taking into account the synchrotron and conventional XRD patterns, we can consider that the micro-crystals are composed of metallic $\mathrm{Bi}$, which have been formed on the $\mathrm{Zn}$ surface during the $\mathrm{OCV}$ proces from the $\mathrm{Bi}^{3+}$ cations reduction. This aspect is also in agreement with the surface changes observed in SEM images, since it is very unlikely that $\mathrm{Bi}_{2} \mathrm{O}_{3}$ is restructured to form the micro-crystals obtained.

Finally, when a $\mathrm{Zn}-\mathrm{Bi}_{2} \mathrm{O}_{3} 25 \%$ electrode is discharged until a $1.0 \mathrm{~V}$ cut off potential, SEM images demonstrate new surface changes. In this case, metallic Bi formation seems to extend massively (Fig. 8M). EDX measurements carried out in two points of this electrode confirm the existence of a great quantity of $\mathrm{Bi}$ with respect to $\mathrm{Zn}$, although shadow zones seem to contain a greater amount of $\mathrm{Zn}$. Note that in this electrode micro-flower shapes are not observed at all, confirming that $\mathrm{ZnO}$ is not formed onto the surface, as it has already been concluded from XRD patterns.
In addition, when an enlarged image of this electrode is captured, higher dark zones with fibrous structures are observed (Fig. 8L). Paying attention to the SEM image in Fig. 8L and the elemental maps in Fig. $8 \mathrm{~N}$ and $\mathrm{P}$, we can conclude that metallic $\mathrm{Bi}$ is dispersed throughout a significant amount of the surface area of the electrode, although in the fibrous dark structures $\mathrm{Bi}$ is not observed.

The elemental map P clearly shows that the dark formations are composed mainly of $\mathrm{K}$ and $\mathrm{Zn}$. Once again we find $\mathrm{K}^{+}$cations from the $\mathrm{KOH}$ solutions, which have to participate in the redox reactions, occurring during the $\mathrm{OCV}$ and discharge processes. In this case, we can hypothesize that dark formations can be due to deposition of $\mathrm{K}-\mathrm{Zn}-\mathrm{OH}$ species, such as $\mathrm{K}_{2} \mathrm{Zn}(\mathrm{OH})_{4}[28,31]$. However, neither synchrotron nor conventional XRD patterns present any peaks corresponding to these species. Consequently, for this hypothesis to be confirmed, this point should be studied in depth.

\section{Conclusions}

In this article we have demonstrated that a deposit of metallic $\mathrm{Bi}$ is generated in situ onto the negative electrode from $\mathrm{Zn}-\mathrm{Bi}_{2} \mathrm{O}_{3}$ electrodes by using synchrotron XRD diffraction analysis and other electrochemical and spectroscopic measurements. This is due to a spontaneous reduction of $\mathrm{Bi}^{3+}$ to metallic $\mathrm{Bi}$ provided by simultaneous oxidation of $\mathrm{Zn}$ to $\mathrm{Zn}^{2+}$. Besides, formation of metallic $\mathrm{Bi}$ continues during the battery discharge. Use of a small quantity of $\mathrm{Bi}_{2} \mathrm{O}_{3}$ in the initial negative electrode forms some unstable metallic $\mathrm{Bi}$ deposit together with a $\mathrm{ZnO}$ layer. However, use of higher quantities of $\mathrm{Bi}_{2} \mathrm{O}_{3}$ in the initial negative electrodes provides a massive deposit of stable 
metallic Bi. In this case, metallic $\mathrm{Bi}$ deposit seems to avoid the $\mathrm{ZnO}$ precipitation onto the electrode. Furthermore, the stable metallic $\mathrm{Bi}$ film in the negative electrode may provide additional advantages for reversible $\mathrm{Zn}$-based batteries, such as reduction in $\mathrm{H}_{2}$ evolution, improvement of electrode conductivity and decrease in $\mathrm{Zn}$ dendritic formation.

\section{Acknowledgements}

The authors thank the financial support from the Spanish MINECO and AEI/FEDER/UE project (Ref. ENE2016-79282-C5-5-R), and ESRF and ICMM-CSIC by provision of beam time at BM25B line. A.U. thanks F. Séneca (Región de Murcia, Spain; Ref 19882-GERM-15). Besides, Juan Albaladejo is acknowledged for the manufacture of the electrochemical cell.

\section{References}

[1] D. Linden, T B. Reddy, Handbook of Batteries, fourth ed.McGraw-Hill, 2011

[2] H. Kim, G. Jeong, Y.-U. Kim, J.-H. Kim, C.-M. Park, H.-J. Sohn, Metallic anodes for next generation secondary batteries, Chem. Soc. Rev. 42 (2013) 9011, https://doi.org $/ 10.1039 / \mathrm{c} 3 \mathrm{cs} 60177 \mathrm{c}$

[3] M. Xu, D.G. Ivey, Z. Xie, W. Qu, Rechargeable Zn-air batteries: progress in electrolyte development and cell configuration advancement, J. Power Sources 283 (2015) 358-371, https://doi. org/10.1016/j.jpowsour.2015.02.114.

[4] J.S. Lee, S.T. Kim, R. Cao, N.S. Choi, M. Liu, K.T. Lee, J. Cho, Metal-air batteries with high energy density. $\mathrm{Li}$-air versus $\mathrm{Zn}$-air, $\mathrm{Adv}$. Energy Mater 1 (2011) 34-50, https://doi. org/10.1002/aenm 201000010

[5] A.R Mainar, O. Leonet, M. Bengoechea, I. Boyano, I. De Meatza, A. Kvasha, A. Guerfi, J. Alberto Blázquez, Alkaline aqueous electrolytes for secondary A. Guerfi, J. Alberto Blazzquez, Alkaline aqueous electrolytes for secondary zinc-air batteries: an over

[6] A.R. Mainar, L.C. Colmenares, J.A. Blázquez, I. Urdampilleta, A brief overviev of secondary zinc anode development: the key of improving zinc-based energy storage systems, Int. J. Energy Res. (2017) https://doi.org/10.1002/er.3822

[7] J.P. Tafur, A.J. Fernández Romero, Electrical and spectroscopic characterization of PVdF-HFP and TFSI-ionic liquids-based gel polymer electrolyte membranes Influence of ZnTf2 salt, J. Membr. Sci. 469 (2014) 499-506, https://doi.org/10. 1016/j.memsci.2014.07.007.

[8] J.P. Tafur Guisao, AJ. Fernandez Romero, Interaction between $\mathrm{Zn} 2+$ cations and n-methyl-2-pyrrolidone in ionic liquid-based Gel Polymer Electrolytes for Zn batteries, Electrochim. Acta 176 (2015) 1447-1453, https://doi.org $/ 10.1016$ $\mathrm{Zn}$ batteries, Electroch
electacta. 2015.07 .132$.

[9] Z. Liu, T. Cui, G. Pulletikurthi, A. Lahiri, T. Carstens, M. Olschewski, F. Endres, Dendrite-free nanocrystalline zinc electrodeposition from an ionic liquic containing nickel triflate for rechargeable $\mathrm{Zn}$-Based batteries, Angew. Chem. In Ed. 55 (2016) 2889-2893, https://doi.org/10.1002/anie.201509364.

[10] F. Moser, F. Fourgeot, R. Rouget, O. Crosnier, T. Brousse, In situ X-ray diffraction investigation of zinc based electrode in Ni-Zn secondary batteries, Electrochim. Acta 109 (2013) 110-116, https://doi.org/10.1016/j.electacta.2013.07 023

[11] J. Shin J-M. You, J.Z. Lee, R. Kumar, L. Yin, J. Wang, Y. Shirley Meng, Deposition of $\mathrm{ZnO}$ on bismuth species towards a rechargeable $\mathrm{Zn}$-based aqueous position of ZnO on bismuth spectes towards a rechargeable Zn-based aqueous
battery, Phys. Chem. Chem. Phys. 18 (2016) 26376-26382, https://doi.org/10. 1039/C6CP04566A

[12] J. McBreen, E. Gannon, Bismuth oxide as an additive in pasted zinc electrodes, J. Power Sources 15 (1985) 169-177, https://doi. org/10.1016/ 0378-7753(85)80070-7

[13] Y.F. Yuan, Y. Li, S. Tao, F.C. Ye, J.L. Yang, S.Y. Guo, J.P. Tu, Preparation and electrochemical performance of nanosized Bi compounds-modified $\mathrm{ZnO}$ for $\mathrm{Zn}$ Ni secondary cell, Electrochim. Acta 54 (2009) 6617-6621, https://doi.org/10 1016/j.electacta.2009.06.063
[14] YF. Yuan, L.Q. Yu, H.M. Wu, JL. Yang, Y.B. Chen, S.Y. Guo, J.P. Tu, Electrochemical performances of $\mathrm{Bi}$ based compound film-coated $\mathrm{ZnO}$ as anodic materials of Ni-Zn secondary batteries, Electrochim. Acta 56 (2011) 4378-4383, https://doi.org/10.1016/j.electacta.2011.01.006

[15] O. Pyper, B. Hahn, R. Schöllhorn, Electrochemical solid-solid conversion of bismuth oxide to bismuth metal, J. Mater. Chem. 7 (1997) $465-469$, https://doi org $/ 10.1039 / \mathrm{A} 605939 \mathrm{~B}$.

[16] J.W. Gallaway, A.M. Gaikwad, B. Hertzberg, C.K. Erdonmez, Y.-C.K Chen-Wiegart, L.A. Sviridov, K. Evans-Lutterodt, J. Wang, S. Banerjee, D.A.
Steingart, An in situ synchrotron study of zinc anode planarization by a bismuth Steingart, An in situ synchrotron study of zinc anode planarization by a bismuth
additive, J. Electrochem. Soc. 161 (2013) A275-A284, https://doi org $/ 10.1149 / 2$. additive,

[17] C. Zhang, J.M. Wang, L. Zhang, J.Q. Zhang, C.N. Cao, Study of the performance of secondary alkaline pasted zinc electrodes, J. Appl. Electrochem 31 (2001) 1049-1054, https://doi.org/10.1023/A:1017923924121.

[18] YN. Jo, HS. Kim, K. Prasanna, P.R. Ilango, W. Lee, S.W. Eom, C.W. Lee, Effect of additives on electrochemical and corrosion behavior of gel type electrodes for Zn-air system. Ind. Eng. Chem. Res. 53 (2014) 17370-17375, https:// doi.org/10.1021/ie5027315.

[19] X. Wei, D. Desai, G.G. Yadav, D.E. Turney, A. Couzis, S. Banerjee, Impact of anode substrates on electrodeposited zinc over cycling in zinc-anode rechargeable alkaline batteries, Electrochim Acta 212 (2016) 603-613, https://doi. org/ able alkaline batteries, Electroch

[20] J. Abad, F. Santos, J.P. Tafur, A. Urbina, E. Román, JF. Gonzàlez-Martinez, J. Rubio-Zuazo, G.R. Castro, A.J. Fernández Romero, A synchrotron x-ray diffraction and hard $\mathrm{x}$-ray photoelectron spectroscopy study of $\mathrm{Zn}$ negative electrodes at different charge and discharge states of $\mathrm{Zn} / \mathrm{MnO} 2$ batteries using an ionic liquid-based gel polymer electrolyte, J. Power Sources 363 (2017) 199-208, https:// doi. org/10.1016/j.jpowsour 2017.07.082

[21] GR. Castro, Optical design of the general-purpose Spanish X-ray beamline for absorption and diffraction, J. Synchrotron Radiat. 5 (1998) 657-660, https://doi. org $/ 10.1107 /$ S0909049597019079.

[22] J Rubio-Zuazo, P. Ferrer, A. López, A Gutiérrez-León, I da Silva, G.R. Castro, The multipurpose X-ray diffraction end-station of the BM25B-SpLine synchrotron beamline at the ESRF, Nucl. Instrum. Meth. Phys. Res. Sect. A Accel. Spectrom. Detect. Assoc. Equip 716 (2013) 23-28, https.//doi.org/10.1016/j.nima 2013.03.019

[23] R.J. Gilliam, J.W. Graydon, D.W. Kirk, S.J. Thorpe, A review of specific conductivities of potassium hydroxide solutions for various concentrations and ten peratures, Int. J. Hydrogen Energy 32 (2007) 359-364, https://doi.org/10.1016/j. ijhydene 2006.10.062

[24] I. Svancara, P. Kotzian, M. Bartos, K. Vytras, Groove electrodes: a new alternative of using carbon pastes in electroanalysis, Electrochem Commun. 7 (2005) 657-662, hitps://doi org $/ 10.1016 /$ jelecom 2005.04 .017 .

[25] T.P. Gujar, V.R. Shinde, C.D. Lokhande, S.H. Han, Electrosynthesis of $\mathrm{Bi}_{2} \mathrm{O}_{3}$ thin films and their use in electrochemical supercapacitors, J. Power Sources thin films and their use in electrochemical supercapacitors, J. Power Sour
161 (2006) $1479-1485$, https://doi org $/ 10.1016$ / j jpowsour. 2006.05.036.

[26] S. Onari, M. Miura, K. Matsuishi, Raman spectroscopic studies on bismuth nanoparticles prepared by laser ablation technique, Appl. Surf. Sci. 197 (2002) 615-618, https://doi.org/10.1016/S0169-4332(02)00410-5

[27] JA. Steele, R.A Lewis, In situ micro-Raman studies of laser-induced bismuth oxidation reveals metastability of $\beta$-Bi_2O_3 microislands, Opt. Mater. Express 4 (2014) 2133, https://oi.org/10.1364/OME. 4.002133

[28] C.Y. Jung, T.H. Kim, W.J. Kim, S.C. Yi, Computational analysis of the zinc utilization in the primary zinc-air batteries, Energy 102 (2016) 694-704, https://doi. org $/ 10.1016 /$ jenergy 2016.02 .084 .

[29] R. Wahab, S.G. Ansari, Y.S. Kim. H.K. Seo, G.S. Kim, G. Khang, H.S. Shin, Low temperature solution synthesis and char acterization of $\mathrm{ZnO}$ nano-flowers, Mater. Res. Bull. 42 (2007) 1640-1648, https://doi.org/10.1016/j.materresbull. 2006.11.035.

[30] Y. . Yuan, J.P. Tu, H.M. Wu, Y.Z. Yang, D.Q. Shi, X.B. Zhao, Electrochemical performance and morphology evolution of nanosized $\mathrm{ZnO}$ as anode material of Ni-Zn batteries, Electrochim. Acta 51 (2006) 3632-3636, https://doi.org/10. 1016/j.electacta. 2005.10 .017

[31] M. Geng, D. O. Northwood, Development of advanced rechargeable NiMH and $\mathrm{Ni} / \mathrm{Zn}$ batteries, Int. J. Hydrogen Energy 28 (2003) 633-636, https://doi.org/10 1016/S0360-3199(02)00137-4. 

Journal of Electroanalytical Chemistry $\mathrm{xxx}(\mathrm{xxxx}) \mathrm{xxx}-\mathrm{xxx}$

Contents lists available at ScienceDirect

Journal of Electroanalytical Chemistry

\section{Structural modifications and ionic transport of PVA-KOH hydrogels applied in Zn/Air batteries}

Florencio Santos ${ }^{\mathrm{a}}$, Juan P. Tafur ${ }^{\mathrm{a}, \mathrm{b}}$, José. Abad ${ }^{\mathrm{a}}$, Antonio J. Fernández Romero ${ }^{\mathrm{a}, *}$

a Grpo de Materiales Avanzados para la Producción y Almacenamiento de Energía, Universidad Politécnica de Cartagena, Aulario II, Campus de Alfonso XIII, 30203 Cartagena, Spain ${ }^{b}$ School of Chemical Science and Engineering. Yachay Tech University, Yachay City of Knowledge, 100650 Urcuqui, Bcuador

\section{ARTICLE INFO}

\section{Keywords:}

Polymer electrolyte

Ionic conductivity

PVA

Grothuss mechanisn

Zinc/Air battery

\section{A B S T R A C T}

A series of Poly (vinyl alcohol) (PVA)-based gel polymer electrolytes doped with $\mathrm{KOH}$ solution have been synthesized by a cast method in absence of other additives and crosslinkers. Immersion of these membranes in $12 \mathrm{M}$ $\mathrm{KOH}$ solution causes the entrance of a higher amount of $\mathrm{KOH}$ and water inside the polymeric matrix. XRD, TGA, XPS and ATR-FTIR measurements confirm PVA chains restructure depending on the amount of $\mathrm{KOH}$ and water inside the membrane. This fact is in agreement with the improvement of the ionic conductivity, diminishing of activation energy and increasing of peaks intensities in cyclic voltammograms. Besides, these PVA-KOH membranes have been tested in $\mathrm{Zn} / \mathrm{PVA}-\mathrm{KOH} /$ Air batteries confirming the importance of the amount of $\mathrm{KOH}$ and water inside the gel polymer electrolyte. Finally, XRD and EDX measurements demonstrate the confinement of $\mathrm{Zn}^{++}$close to $\mathrm{Zn}$ electrode during the test of $\mathrm{Zn} /$ Air batteries, making necessary the movement of $\mathrm{OH}^{-}$anions inside the membrane, as the only ionic species causing the charge transport through the membrane. This fact, together with spectroscopic and electrical results allows us to discuss the improvement of the anionic transport inside the membranes based on the Grotthuss mechanism.

\section{Introduction}

Gel polymer electrolytes (GPEs) are materials which are neithe solids nor liquids but hold both the cohesive properties of solids and the diffusive character of liquids. Hence, these electrolytes have become relevant due to their use as excellent substitutes of the liquid electrolyte or as separators in ionic devices including batteries, super-capacitors, fuel cells, and others [1-4]. GPEs can be prepared by trapping liquid electrolytes into different polymer hosts. In this case, the salt provide free-mobile ions which take part in the conduction process; the plasticizing solvent allows to increase the conductivity values in GPEs due to the ions solvating, and the polymer provides mechanical stability. Hence, the morphology and properties of GPEs will depend on the type and the amount of polymer host, salt and solvent present in the polymer matrix [3-19].

The use of a GPE in a battery needs to fulfil some requirements, such as high ionic conductivity and good mechanical and electrochemical stabilities at a wide temperature range [11]. There are numerous previous studies using different polymer as host material, including polyethylene oxide ( $\mathrm{PEO}$ ), polyacrylonitrile (PAN), polymethyl- methacrylate (PMMA) and, poly (vinylidene fluoride-co-hexafluoropropylene) (PVdF-HFP) to name but a few, which have been tested in different battery types [11-19]. However, among biodegradable synthetic polymer, polyvinyl alcohol (PVA) is a promising candidate material to become the polymer host due to its ability to provide good optical, mechanical and electrochemical properties. PVA is also a semi-crystalline polymer with high hydrophilicity, easy to prepare, non-toxic and cheap material.

PVA doped with potassium hydroxide $(\mathrm{KOH})$ has been studied extensively and received much attention due to their wide application in electrochemical devices such as super-capacitors, anion exchange membranes for fuel cells and Zinc alkaline batteries [4-10].

$\mathrm{KOH}$ is incorporated to the PVA to provide free ions mobiles inside the membrane. However, the addition of $\mathrm{KOH}$ raises the amorphous character of polymer chains and diminishes the thermal stability of the PVA film [9]. Besides, the ionic conductivity of PVA-KOH polymer is highly influenced by the amount of $\mathrm{KOH}$ and $\mathrm{H}_{2} \mathrm{O}$ molecules inside the membrane $[9,20,21]$. Ionic conductivity values of $4.710^{-2} \mathrm{Scm}^{-1}$ have been reported for PVA-KOH films [9].

\footnotetext{
- Corresponding author.

Email address: antonioj.fernandez@upct.es (A.J. Fernández Romero)
} 
In addition, with the aim to improve their electrochemical and mechanical properties, PVA has been blended with others materials, such as polymers, crosslinking agents or chemically inert materials. $[5,6,22-28]$. For instance, ionic conductivity values of $2.210^{-1} \mathrm{Scm}^{-1}$ have been reached for a PVA-KOH polymer cross-linked with poly (ethylene glycol) diglycidyl ether (PEGDGE) [27].

In this work, new results obtained for PVA-KOH hydrogels by several experimental techniques, such as XRD, TGA, XPS and ATR-FTIR, have demonstrated the polymer structural changes occurred in the polymer electrolyte depending on the amount of $\mathrm{KOH}$ and $\mathrm{H}_{2} \mathrm{O}$ molecules added to the PVA. Besides, AC Impedance spectroscopy, cyclic voltammetry and Galvanostatic Discharge tests have evidenced the improvement of the ionic transport along the membrane depending on the amount of $\mathrm{KOH}$ and water in the film. Finally, XRD and EDX measurements demonstrate the confinement of $\mathrm{Zn}^{2+}$ close to $\mathrm{Zn}$ electrode during the test of $\mathrm{Zn}$ /Air batteries, making necessary the movement of $\mathrm{OH}^{-}$anions inside the membrane, as the only ionic species causing the charge transport through the membrane. This fact, together with spectroscopi and electrical results allows us to discuss the improvement of the anionic transport inside the membranes based on the Grotthuss mechanism.

\section{Material and methods}

PVA MOWIOL 18-88 (MW 130.000), PVA 20-98 (MW 125.000), $\mathrm{KCl}(>99 \%), \mathrm{NaOH}(>97 \%)$ and $\mathrm{KOH}(85 \%)$ were obtained from Sigma-Aldrich., Millipore water with resistivity of $>18 \mathrm{M} \Omega \mathrm{cm}$ was always used.

The preparation of the GPEs was carried out following the solution casting method. Briefly, PVA was dissolved in deionized water at $90^{\circ} \mathrm{C}$ under severe stirring for two hours until a clear solution was obtained. Once the solution was cold, different volumes of $\mathrm{KOH} 6 \mathrm{M}$ were dropwise added maintaining the stirring. The resulting liquid was the poured into a Petri dish and let to cast in controlled atmosphere to avoid the presence of carbon dioxide. After that, the membranes were kept in a desiccator until required for use. Specimens of $12 \mathrm{~mm}$ diameter were punched immediately before being tested in batteries and conductivity measurements.

Besides, PVA-KOH soaked membranes were obtained starting from specimens of PVA-KOH gels dried for 10 days, which subsequently were immersed in $\mathrm{KOH} 12 \mathrm{M}$ for $24 \mathrm{~h}$ prior to be used in any test. The soak step was also carried out in absence of $\mathrm{CO}_{2}$ into an atmosphere controlled desiccator. Before any test, all specimens soaked or not, were rinsed with plenty of water to remove the rest of $\mathrm{KOH}$ from the membrane surface.

Table 1 shows the initial weight of the components used in each prepared GPE. Membranes PVA-KOH 10, PVA-KOH 30 and PVA-KOH 50 have been obtained adding $10 \mathrm{ml}, 30 \mathrm{ml}$ or $50 \mathrm{ml}$ of $6 \mathrm{M} \mathrm{KOH}$ solution to the PVA solution, respectively. Besides, membrane PVA-KOH 30 swollen (designed by PVA-KOH $30 \mathrm{sw}$ ) stand for a PVA-KOH $30 \mathrm{mem}-$ brane, which was immersed in a $12 \mathrm{M} \mathrm{KOH}$ solution for $24 \mathrm{~h}$.

Table 1

Initial weights of PVA and $\mathrm{KOH}$ used to prepare the membranes and activation energy, $\mathrm{E}_{a}$ and ionic conductivity values, $\sigma$, obtained for each membrane.

\begin{tabular}{lllll}
\hline Membrane & $\mathrm{m}_{\mathrm{PVA}} / \mathrm{g}$ & $\mathrm{m}_{\mathrm{KOH}} / \mathrm{g}$ & $\mathrm{E}_{\mathrm{a}} / \mathrm{eV}$ & $\sigma / \mathrm{Scm}^{-1}$ \\
\hline PVA Pure & 4 & 0 & - & $\approx 10^{-10}[33]$ \\
PVA-KOH 10 & 4 & 3.36 & 0,18 & 0.012 \\
PVA-KOH 30 & 4 & 10.10 & 0.15 & 0.14 \\
PVA-KOH 50 & 4 & 16.83 & 0.21 & 0.16 \\
PVA-KOH 30 sw & 4 & $10.10+\chi$ & 0.16 & 0.34 \\
\hline
\end{tabular}

$\chi$ is the additional amount of $\mathrm{KOH}$ incorporated into the membrane during the immersion of the membrane in $12 \mathrm{M} \mathrm{KOH}$ solution. Ionic conductivity values have been obtained at $\mathrm{T}=20^{\circ} \mathrm{C}$
X-ray diffraction patterns were collected using a computer-controlled Bruker D8 Advance laboratory diffractometer, operated in the reflection Bragg-Brentano geometry and configured in the $\theta / \theta$ mode to maintain a horizontal sample position at all times. The data were collected at room temperature, using $\mathrm{Cu}-\mathrm{K} \alpha(\lambda=1.5418 \AA)$.

XPS spectra were recorded using a hemispherical analyzer. Non-monochromatized $\mathrm{Mg} \mathrm{K} \mathrm{K}_{\alpha}(1253.6 \mathrm{eV})$ X-rays were used. The data are analyzed after removing the $\mathrm{Mg} \mathrm{K}$ satellite lines, as well as subtracting a Shirley type background and charge referenced to $\mathrm{CH}_{2}$ species of $\mathrm{C}$ 1 s peak at $284.8 \mathrm{eV}$. Peak fitting of $\mathrm{C}$ ls and $\mathrm{O} 1 \mathrm{~s}$ were performed using Gaussian line-shapes with a fixed FWHM of $1.8 \mathrm{eV}$ and $2.1 \mathrm{eV}$, respectively.

SEM coupled with EDX analysis was carried out using a Hitachi S-3500 N scanning electron microscope (Hitachi High-Technologies Corporation, Tokyo, Japan), using $70 \mathrm{~Pa}$ chamber pressure for back-scattered electrons (BSE) or $<1 \mathrm{~Pa}$ for secondary electrons (SE). Microanalysis was done with a XFlash 5010 Bruker AXS Microanalysis, with a resolution of $129 \mathrm{eV}$.

ATR-FTIR spectra were obtained using a Thermo Nicolet $5700 \mathrm{In}$ frared Spectrometer in the wave number range from $400 \mathrm{~cm}^{-1}$ to $4000 \mathrm{~cm}^{-1}$. Thermo-gravimetry analysis was done on samples of 5-10mg using a Mettler-Toledo TGA/DSC $1 \mathrm{HT}$ up to $700^{\circ} \mathrm{C}$, at a heating rate of $10^{\circ} \mathrm{C} / \mathrm{min}$ and under $\mathrm{N}_{2}$ atmosphere. Cyclic voltammetry was carried out using symmetric $\mathrm{Zn} / \mathrm{GPE} / \mathrm{Zn}$ cells by means of a Biologic VSP Modular 5 channels potentiostat/galvanostat

Ionic conductivity was determined from AC impedance measurements using the same potentiostat/galvanostat in the frequency range from $100 \mathrm{kHz}$ to $40 \mathrm{mHz}$. The temperature was set by a Julabo F25 thermostat in the range from 278 to $343 \mathrm{~K}$. Two platinum electrodes of $1 \mathrm{~cm}^{2}$ area were used, which acted as blocking electrodes.

Ionic conductivity, $\sigma$, was calculated from the equation:

$\sigma=l / R_{b} A$

Galvanostatic Discharges were performed at 20mA using a Biologic VSP Modular 5 channels potentiostat/galvanostat. The contact area was always $1.1 \mathrm{~cm}^{2}$ and stainless steel current collectors were used. The cathode used in the experiments was the Air E4B electrode supplied by Electric Fuel Ltd. Zn powder (98.7\%) and Zn plates (99.97\%) used as anode in these cells were purchased from Goodfellow and Española del Zinc S.A., respectively.

Polarization curves were carried out with a current scan technique included in EC-Lab® software of the Biologic VSP potentiostat/galvanostat. The intensity changed from 0 to $100 \mathrm{~mA}$ at $0.1 \mathrm{mAs}-1$ scan rate. Before performance a current scan the battery was maintained at open circuit voltage (OCV). Three consecutive current scans were registered.

\subsection{Membrane weight change}

It is well known that the chemical and physical properties of the hydrophilic membranes are affected by the water content. $[9,20,21] \mathrm{Be}-$ sides, PVA membranes undergo swelling but they can also lose water as a function of ambient temperature and relative humidity. This fact is an important drawback for their application in devices such as Zinc/Air batteries [29].

In order to check the changes with the time of the membrane water content, we have studied how membranes weight is modified with storage time at ambient temperature. Fig. 1A shows the weight changes of a PVA-KOH 30 membrane for 25 days. As it can be seen, the membrane suffers a quick dehydration process during the first $72 \mathrm{~h}$, but, after that, the loss of water slows down until it reaches a steady state. Fig. 1A displays also the ionic conductivity changes occurring to a PVA-KOH membrane maintained at room ambient temperature. As can 

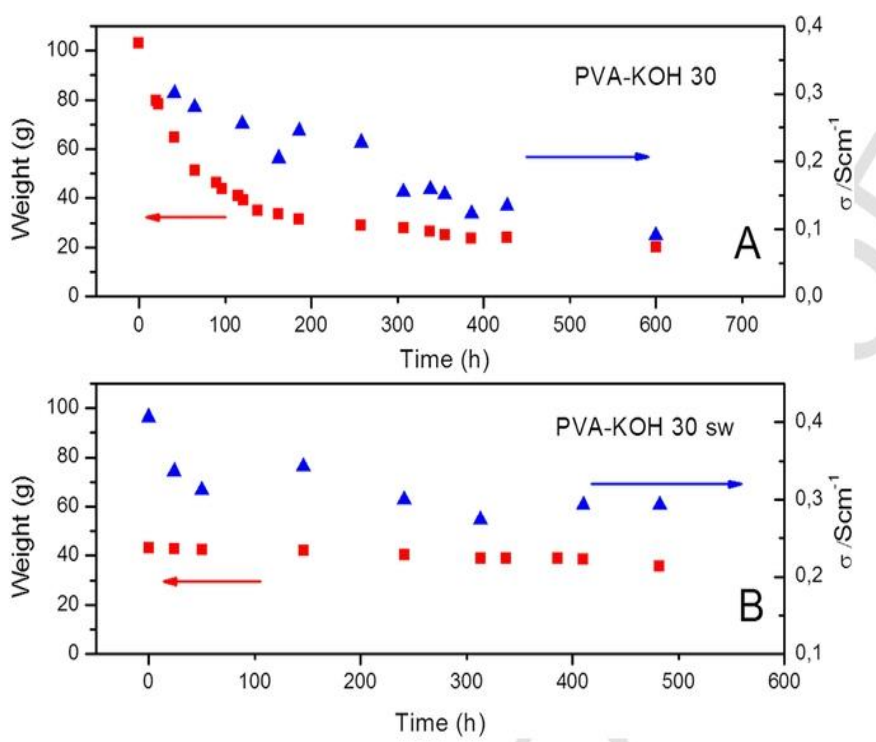

Fig. 1. Membranes weight and ionic conductivity values changes with the storage time at ambient temperature. A) For a PVA-KOH 30 membrane and B) For a PVA-KOH 30 swollen membrane.

be seen, ionic conductivity values tend to a constant as it was observed for membrane weights.

With the aim of keeping reproducible conditions as much as possible for the experiments where water content could play a critical role, membranes were always used after storage for 10 days at ambient temperature, assuring in this way steady water content.

Besides, we have monitored the weight changes of PVA-KOH 30 soaked membranes, which were stored 10 days at ambient temperature and then left soaking for $24 \mathrm{~h}$ in a $12 \mathrm{M} \mathrm{KOH}$ solution. In this case, we observe a quasi-steady weight and ionic conductivity behavior for 20 days, from the beginning (Fig. 1B). Note that measurements for soaked membrane start when the hydrogel was pulled out of the $12 \mathrm{M}$ $\mathrm{KOH}$ solution, that is after $24 \mathrm{~h}$ immersed in this solution.

On the other hand, when a dry hydrophilic polymer, such as PVA, is dipped in water the interaction between water molecules and polymer chains provides an expansion of the polymer until reaching an equilibrium swelling level. The swelling behavior of hydrogels can be ascertained by different methods. We have calculated the swelling ratio (SR) following the next equation [5]:

$S R=100 \times \frac{\mathrm{m}_{\mathrm{e}}-\mathrm{m}_{\mathrm{d}}}{\mathrm{m}_{\mathrm{d}}}$

where $m_{d}$ and $m_{e}$ are weights of samples before and after swelling, respectively. The immersion time in $\mathrm{KOH} 12 \mathrm{M}$ was always $24 \mathrm{~h}$. Table 2 shows the swelling values for five PVA-KOH 30 membranes. A SR value of $34 \pm 2 \%$ was always obtained.

\section{Table 2}

Swelling ratios for different PVA-KOH-30 membranes after their immersion for $24 \mathrm{~h}$ in $\mathrm{KOH} 12 \mathrm{M}$.

\begin{tabular}{llll}
\hline Sample & Initial weight/g & Weight after soaking/g & Swelling ratio/\% \\
\hline A & 0.93 & 1.23 & 32.26 \\
B & 0.75 & 1.00 & 33.33 \\
C & 0.76 & 1.02 & 34.21 \\
D & 0.73 & 0.99 & 35.62 \\
B & 0.78 & 1.03 & 32.05 \\
\hline
\end{tabular}

\section{Results and discussion}

3.1. Structural characterization of the gel polymer electrolytes

3.1.1. $X R D$

The X-ray diffractometry (XRD) is a useful tool to distinguish the different crystalline phases of PVA-KOH hydrogels [30,31]. Fig. 2 shows the XRD spectra of pure PVA as well as PVA-KOH membranes at different concentrations of $\mathrm{KOH}$, which are very similar to those previously reported [30]. Besides, a PVA-KOH 30 swollen membrane is displayed.

The pure PVA pattern shows a big peak at $2 \theta=20^{\circ}$ and a secondary peak at $40.5^{\circ}$. These peaks indicate a certain extent of crystalline phase in pure PVA, which can be associated with polymer chains alignment due to H-bonds formed between $\mathrm{OH}$ groups of packed PVA chains. However, once the $\mathrm{KOH}$ solution is incorporated inside the polymer matrix, lower intensity and wider peaks are found in the XRD patterns, indicating an increase of the amorphous domains in the PVA structure [32]. Note that the PVA-KOH 30 sw membrane presents the lower intensity peaks.

These changes have to be provided by the retention of $\mathrm{KOH}$ and water molecules inside the polymer, which will be related to interactions between $\mathrm{KOH}, \mathrm{H}_{2} \mathrm{O}$ molecules and PVA chains.

\subsubsection{XPS measurements}

As can be seen in Fig. 3A for a PVA KOH 30 membrane, XPS peaks observed at 292.5 and $295.3 \mathrm{eV}$ assigned to $\mathrm{K} 2 \mathrm{p}_{3 / 2}$ and $\mathrm{K} 2 \mathrm{p}_{1 / 2}$ demonstrate the presence of $\mathrm{K}$ inside the PVA-KOH GPE. Besides, C1s region is shown in this figure. The analysis of C1s core level shows a main peak at $284.8 \mathrm{eV}$ attributed to $\mathrm{CH}_{2}$ species of the polymeric chains, two small components at 286.5 and $287.8 \mathrm{eV}$ assigned to $\mathrm{C}-\mathrm{OH}$ [33] and carbonyl $\mathrm{C}=\mathrm{O}$ species, respectively, and a more pronounced peak at $289.3 \mathrm{eV}$ attributed to carboxylate - $\mathrm{COO}$ species [34]. The presence of this peak confirms the existence of acetate groups inside the polymer, which is expected because the PVA used in this work is not fully hydrolyzed, containing up to $12 \%$ acetate groups, as manufacturer 


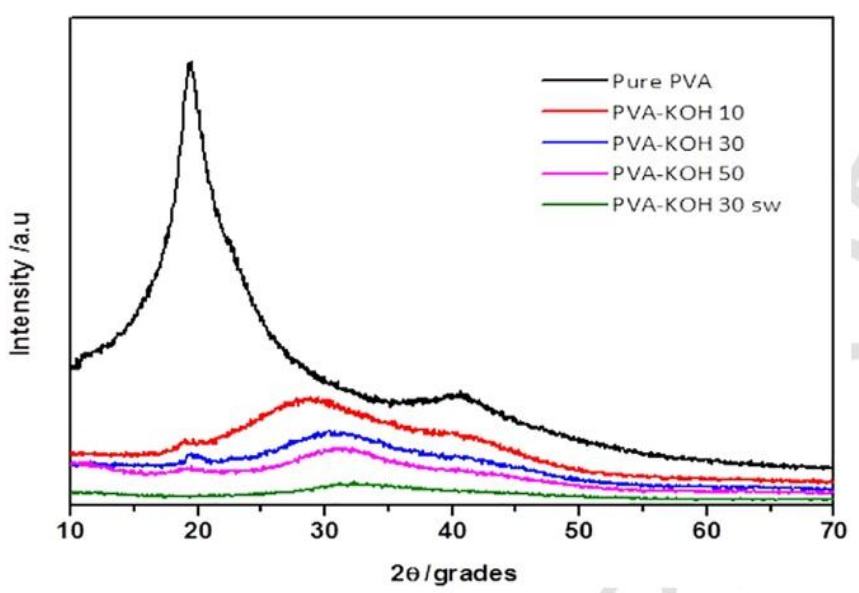

Fig. 2. XRD patterns of the prepared membranes.
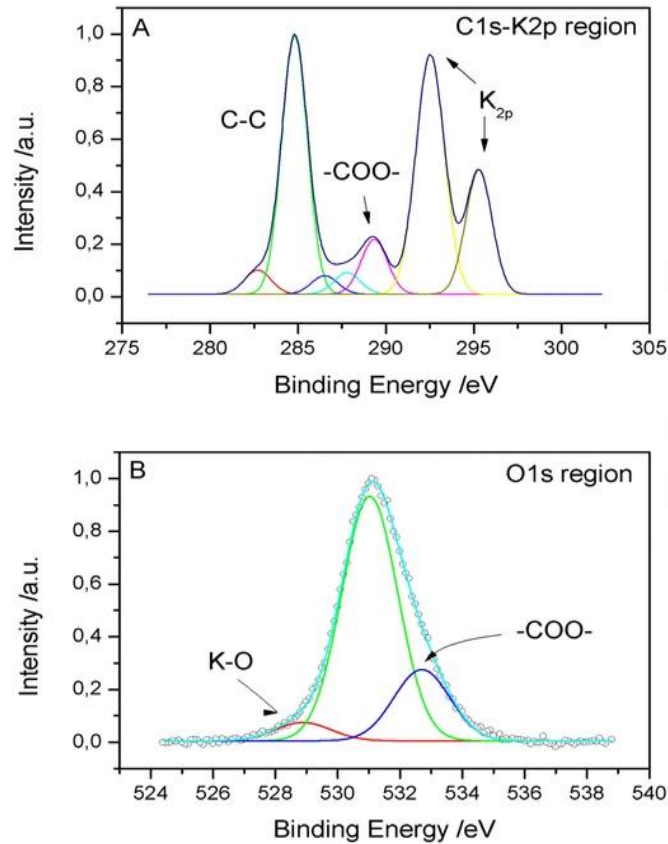

Fig. 3. XPS spectra of PVA-KOH 30 membrane. A) Cls and K2p region. B) Ols region.

datasheet indicates. Besides, a low binding energy component is also observed at $282.7 \mathrm{eV}$. This component indicates the interaction between a metal $(\mathrm{K})$ and the carbon.

On the other hand, the O1s region obtained for the PVA-KOH GPE is displayed in Fig. 3B. Deconvolution of the O 1s spectra is complex due to the small differences in $\mathrm{O}$ ls binding energy for $-\mathrm{OH}, \mathrm{C}=\mathrm{O}$, and C-O-C species, together with the broadness of the peaks [35]. O1s experimental peak has been fitted with three components at 528.9, 531.0 and $532.7 \mathrm{eV}$.

The main peak at $531.0 \mathrm{eV}$ has been assigned to $-\mathrm{OH}, \mathrm{C}=\mathrm{O}$, and $\mathrm{H}_{2} \mathrm{O}$ species, without being able to distinguish between them. The peak at $532.7 \mathrm{eV}$ can be assigned to the single bonded oxygen in the carboxylate-COO group, since this oxygen atom presents higher binding energy than the oxygen atoms present in the $-\mathrm{OH}, \mathrm{C}=\mathrm{O}$, and $\mathrm{H}_{2} \mathrm{O}$ groups. [35]. Finally, the lower binding energy component observed at $528.9 \mathrm{eV}$ has to be assigned to the interaction between $\mathrm{O}$ and a Metal (M-O). In this case, as only $\mathrm{K}$ metal is inside the polymer, this peak points to a $\mathrm{K}-\mathrm{O}$ interaction and taking into account the low binding energy shoulder of the $\mathrm{C} 1 \mathrm{~s}$ orbital, it is interesting to note the presence of $\mathrm{K}$ bonded to $\mathrm{C}$ and $\mathrm{O}$. The presence of Metal-C-O complexes has been already reported in the literature for evaporated Aluminum on PVA [36].

\subsubsection{Thermogravimetric analysis}

Fig. 4 compares the thermos-gravimetric curves of pure PVA with PVA-KOH gel electrolytes. Initially, pure PVA presents a $10 \%$ weight loss, which is attributed to free water remaining in the membrane. A second weight loss proceeds quickly with onset at $310^{\circ} \mathrm{C}$ and it involves two processes: elimination of side chains acetate groups and $\mathrm{OH}$ groups to produce polyenes [37,38]. At around $420^{\circ} \mathrm{C}$ a third step is observed which has been assigned to PVA backbone breaking $[37,38]$. These three steps are clearly identified in the TGA derivative curve

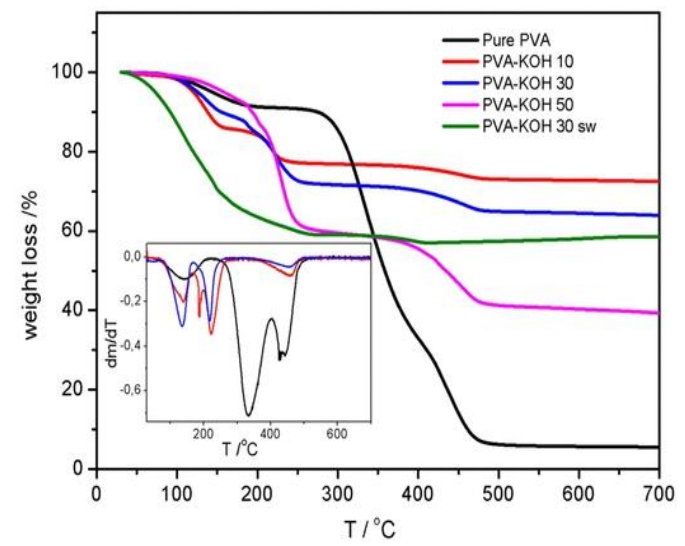

Fig. 4. TG curves of the prepared membranes. Inset shows the differentiated TG curves of PVA-KOH membranes. 
(inset in Fig. 4). At the end, only a 5\% of initial weight of pure PVA remains.

With respect to PVA-KOH membranes, all of them have a mass loss at around $100^{\circ} \mathrm{C}$. However, the amount of water is higher with the quantity of $\mathrm{KOH}$ solution used during the synthesis process. A second weight loss is observed at around $200^{\circ} \mathrm{C}$, which will correspond to $\mathrm{OH}$ groups and side chains elimination. Finally, the third weight loss, corresponding to PVA backbone breaking, is observed at around $430-440^{\circ} \mathrm{C}$ $[37,38]$.

It should be noted that while the onsets observed for the first and the third steps are close for all membranes, the onset obtained for the second step for PVA-KOH membranes occur at $110^{\circ} \mathrm{C}$ lower than the temperature obtained for pure PVA. Furthermore, the inclusion of $\mathrm{KOH}$ and water inside the membrane only affects the second step, which is related to the removal of $\mathrm{OH}$ groups and side chains of PVA. This fact indicates that $\mathrm{KOH}-\mathrm{H}_{2} \mathrm{O}$ included in the membrane interact with $\mathrm{OH}$ and carbonyl groups of the PVA chains. Thus, the thermal stability of the PVA system is diminished once the $\mathrm{KOH}-\mathrm{H}_{2} \mathrm{O}$ is incorporated to the gel [9]: it must disrupt somehow the interaction between $\mathrm{OH}$ groups of nearby polymer chains, making the new polymer structure weaker. This result is in agreement with the $\mathrm{KOH}$ interaction with PVA chains deduced from ATR-FTIR spectra, as it will be commented below. It is known that at higher water contents, water molecules weaken the hydrogen bonds between polymer chains and it leads to an increase in free volume [39].

This argument is again supported by the PVA-KOH 30 soaked membrane TGA results shown in Fig. 4, where the second step occurred at an even lower temperature. As can be seen, this curve is very different from those obtained from non-swollen membranes, pointing to a great structural change. At $100^{\circ} \mathrm{C}$ there is a weight loss of $27 \%$, indicating that this membrane presents a higher amount of water. At $150^{\circ} \mathrm{C}$, a change of slope is observed, which corresponds to $\mathrm{OH}$ and acetate groups elimination, confirming that membrane stability clearly decreases. Besides, a small step is observed near $400^{\circ} \mathrm{C}$. These results are in agreement with the crystallinity loss observed in XRD spectra when $\mathrm{KOH}$ is incorporated to PVA membranes: a more amorphous GPE has lower stability.

Finally, we have paid attention to the residue remaining at $700^{\circ} \mathrm{C}$ for each membrane analyzed. For pure PVA membrane only $5 \%$ of the total weight remains, while those membranes including $\mathrm{KOH}$ present higher weight rest at $700^{\circ} \mathrm{C}$, which increases with the amount of $\mathrm{KOH}$ incorporated inside the membrane. This rest material should be related to the amount of potassium, which could form $\mathrm{K}_{2} \mathrm{O}$ compound at these high temperatures, as it has been proposed before [40].

With respect to the PVA-KOH 30 swollen membrane, the residue remaining at $700{ }^{\circ} \mathrm{C}$ is $58.3 \%$, which is lower than the percentage obtained for a similar non-swollen membrane, $63.9 \%$. This apparent contradiction is explained considering the initial weight of both membranes and the swelling percentage for the PVA-KOH soaked membrane. Table 2 presents the initial and after swollen weight measured for 5 different samples of PVA-KOH 30 membranes. As can be seen, a $34 \pm 2 \%$ swelling ratio has been always obtained. Considering the sample weights used in TGA analysis and the percentages remaining at $700^{\circ} \mathrm{C}$, we can calculate that non-swollen membranes hold $0.49 \mathrm{~g}$ of $\mathrm{K}$ compounds, while the swollen ones hold $0.59 \mathrm{~g}$. From this calculation, we can conclude that during the swollen process more $\mathrm{KOH}$, together with water molecules, has penetrated in the membrane from the $\mathrm{KOH}$ $12 \mathrm{M}$ solution.

\subsubsection{ATR-FTIR spectroscopy}

In agreement with the XRD and TG results, introduction of $\mathrm{KOH}$ solution inside the membranes affects clearly the bands observed in the ATR-FTIR spectra (Fig. 5).

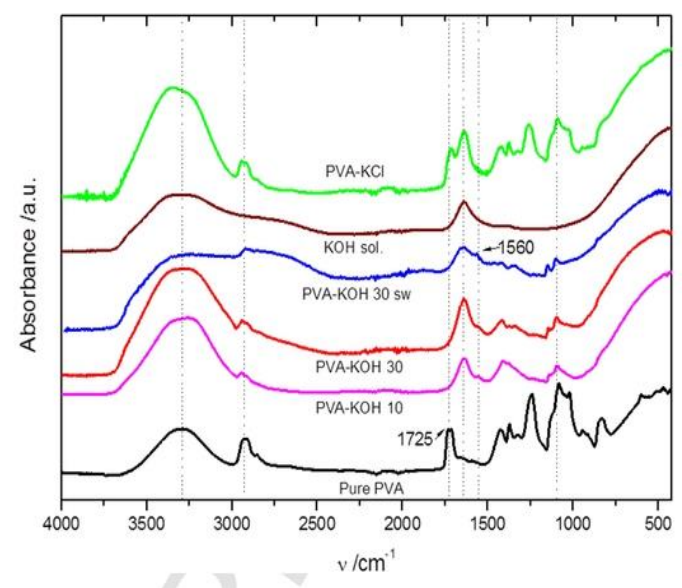

Fig. 5. ATR-FTIR spectra of the PVA Pure and PVA-KOH membranes. PVA-KOH sw denotes a PVA-KOH 30 membrane swollen in $12 \mathrm{M} \mathrm{KOH}$ for $24 \mathrm{~h}$. Spectra of $6 \mathrm{M} \mathrm{KOH}$ solution and PVA-KCl 30 are included to compare.

The pure PVA characteristic bands [41,42] can be observed in the ATR-FTIR spectrum shown in Fig. 5. Among them, bands at 1243, 1084, 945 and $1732-1710 \mathrm{~cm}^{-1}$ are attributed respectively to $\nu$ (C-O-C), $\nu$ (C -O), $v(\mathrm{C}-\mathrm{C}-\mathrm{O})$ and $v(\mathrm{C}=\mathrm{O})$ modes due to the acetate groups remaining in the PVA structure from its manufacturing process. As it has been mentioned before, the presence of these bands is reasonable since $12 \%$ acetate groups are included in the PVA used, as the manufacturer datasheet indicates.

Conversely, when $\mathrm{KOH}$ is incorporated to PVA, several changes are found. Introduction of water molecules inside the polymer together with $\mathrm{KOH}$ is demonstrated by the $1640 \mathrm{~cm}^{-1}$ band, which appears in all spectra of PVA-KOH membranes, in agreement with $\mathrm{KOH}$ solution spectrum, included in Fig. 5. Besides, bands at 945, 1245 and $1732-1710 \mathrm{~cm}^{-1}$ assigned to acetate groups disappear. This behavior may be related to the hydrolysis of acetyl groups by $\mathrm{OH}^{-}$groups of the $\mathrm{KOH}$. However, in this case, peaks due to acetate groups should be observed in ATR-FTIR spectra although they were cleavaged from the PVA chains. On the other hand, XPS measurements have demonstrate the presence of C= O groups, which are due to acetate groups. In addition, several articles have reported the shift, diminution and/or disappearing of $\sim 1740 \mathrm{~cm}^{-1}$ band of $\mathrm{C}=\mathrm{O}$ groups, as a result of the interactions with cations or due to crosslinking of the PVA chains. [43-46]

Furthermore, the changes observed in the ATR-FTIR spectra point to interactions between $\mathrm{KOH}$ and PVA chains, as it was already deduced from XRD, XPS and TG measurements. Since oxygen atom in $\mathrm{OH}$ and $\mathrm{C}$ $=0$ groups of the PVA is a strong electron donor due to it has lone pairs of electrons available, $\mathrm{K}^{+}$cations will be coordinated with these groups forming complex such as $\mathrm{C}=\mathrm{O} \cdots \mathrm{K}^{+}$or $\mathrm{C}-\mathrm{O} \cdots \mathrm{K}^{+}$These type of interactions has already been proposed for PVA doped with $\mathrm{Mg}^{2+}$ or $\mathrm{Cd}^{2+}$ salts $[37,38]$. XPS measurements confirm also this aspect (Fig. 3).

This interaction can be also checked out analyzing the $1084 \mathrm{~cm}^{-1}$ band observed for Pure PVA and assigned to $\nu(\mathrm{C}-\mathrm{O})$. When $\mathrm{KOH}$ is incorporate to the membrane, this band diminishes their intensity and shifts at 1094, 1097 and $1099 \mathrm{~cm}^{-1}$ for PVA-KOH 10, 30 and 50 GPEs, confirming the $\mathrm{C}-\mathrm{O} \cdots \mathrm{K}^{+}$interaction. In addition, a new peak observed at $1560 \mathrm{~cm}^{-1}$ appears in all GPEs doped with $\mathrm{KOH}$, which can be assigned to carbonyl groups. A similar result has been already reported by J. Oiao et al. [5,46], who observed that introduction of $\mathrm{KOH}$ inside PVA-based membrane provided disappearance of the $\mathrm{C}=\mathrm{O}$ peak observed at $1718 \mathrm{~cm}^{-1}$ while a new characteristic band centered at $1571 \mathrm{~cm}^{-1}$ appeared. These authors attributed this behavior to a dis- 
proportionation reaction of the "free" - $\mathrm{CHO}$ groups of the glutaralde hyde (GA) included in the membrane and assigned the $1571 \mathrm{~cm}^{-1}$ peak to the stretching vibration of the potassium carboxylate $[\mathrm{C}=\mathrm{O}(-\mathrm{O}-\mathrm{K})$ ] formed. However, in this work we have not ever used GA as crosslinking agent. Thus, we can associate the band observed at $1560 \mathrm{~cm}^{-1}$ to the interaction between the acetate groups of the PVA and cations $\mathrm{K}^{+}$

On the other hand, important spectral changes are observed in the fundamental $\mathrm{OH}$ stretching region at $3000-3500 \mathrm{~cm}^{-1}$. It has been frequently reported broader peaks and shifted to a lower wave number in this region when a higher quantity and stronger H-bonding are formed [47]. Hence, as it is observed in Fig. 5, PVA-KOH GPEs show shifts to lower frequencies and more broadness bands with the higher amount of $\mathrm{KOH}$ incorporated into the PVA. This result indicates that, though the inclusion of $\mathrm{KOH}$ solution inside the polymeric matrix provides the rupture of the inter chains $\mathrm{H}$-bonds, a higher amount of $\mathrm{H}$-bridges is formed with the increasing of $\mathrm{KOH}$ and $\mathrm{H}_{2} \mathrm{O}$ molecules inside the GPE. Furthermore, a new H-bond network will be formed by PVA OH groups, water molecules and hydroxyl groups of KOH.

Fig. 5 also shows the spectrum of a PVA GPE doped with $\mathrm{KCl}$, compared with those obtained for KOH-PVA 30 and Pure PVA. Surprisingly, the PVA-KCl spectrum is very similar to the one obtained for Pure PVA, although an intense $1640 \mathrm{~cm}^{-1}$ band is observed and the $\mathrm{OH}$ stretching band (in $3000-3500 \mathrm{~cm}^{-1}$ region) is more intense than the one obtained in pure PVA spectrum. Both facts can be explained by a higher amoun of water molecules inside the PVA-KCl GPE. Besides, in this case all the pure PVA bands are observed in this spectrum with minimal intensity changes and shifted slightly. Among them, it has to be noted that the carbonyl band of acetyl groups is shifted until $1712 \mathrm{~cm}^{-1}$ and v (C-O) mode is shifted to $1089 \mathrm{~cm}^{-1}$. These shifts may indicate $\mathrm{C}=\mathrm{O} \cdots \mathrm{K}+$ and $\mathrm{C}-\mathrm{O} \cdots \mathrm{K}^{+}$interaction, though weaker than those appearing in PVA-KOH. This result confirms that $\mathrm{Cl}^{-}$anions have a small influence on the PVA chains compared with the hydroxyl groups of $\mathrm{KOH}$.

Finally, we have also recorded an ATR-FTIR spectrum of a PVA-KOH $30 \mathrm{sw}$ membrane, obtained by soaking a PVA-KOH-30 in KOH $12 \mathrm{M}$ for $24 \mathrm{~h}$ (Fig. 5A). We found that the spectrum obtained does not show significant changes with respect to non-swollen membrane spectra. The same peaks obtained from the non-swollen membrane are observed in this case, except for wider bands at $\approx 3300 \mathrm{~cm}^{-1}$, which has to be related to the incorporation of an additional amount of $\mathrm{KOH}$ and water inside the membrane, as it has already been deduced by XRD and TG measure ments. Besides, $1560 \mathrm{~cm}^{-1}$ appeared and the $\mathrm{v}(\mathrm{C}-\mathrm{O})$ mode was shifted to $1102 \mathrm{~cm}^{-1}$.

\subsection{Electrical and electrochemical properties}

\subsubsection{Temperature dependence of ionic conductivity}

Fig. 6A shows the variation of ionic conductivity with the temperature for PVA based GPEs with different concentration of $\mathrm{KOH}$. All plot obey Arrhenius behavior throughout a wide temperature range, as it is confirmed by data fitted to the equation:

$$
T=\sigma_{0} \exp \left(-E_{a} / k_{B} T\right)
$$

where $\sigma_{0}$ is the pre-exponential factor, $E_{a}$ the activation energy, $k_{B}$ the Boltzmann constant and $\mathrm{T}$ the testing temperature. From slope in Fig. 6A the activation energy values can be obtained, which are shown together with conductivity values at $20^{\circ} \mathrm{C}$ for all membranes in Table 1. Lower $\mathrm{E}_{a}$ values of $0.15 \pm 0.01$ were obtained for PVA-KOH 30 and PVA-KOH 30 sw membranes, with respect to PVA-KOH 10 and PVA-KOH 50. As can be seen in this Figure and Table 1, similar ionic conductivity values of $0.15 \pm 0.01 \mathrm{Scm}^{-1}$ at $20^{\circ} \mathrm{C}$ were obtained for PVA-KOH 30 and 50 GPEs, which are much higher than those resulted for PVA-KOH-10 membrane, $0.012 \mathrm{Scm}^{-1}$. However, the highest tivity value, $0.34 \mathrm{Scm}^{-1}$ at $20^{\circ} \mathrm{C}$, was obtained for PVA-KOH $30 \mathrm{sw}$ hydrogel, confirming the relevance of soaking the PVA-KOH membranes in $12 \mathrm{M} \mathrm{KOH}$ solution.

Temperature dependence of PVA-KOH 30 sw membranes is also included in Fig. 6A. As can be seen, the soaking of the membrane in $\mathrm{KOH}$ obeys again Arrhenius behavior, but conductivity values notably increase with respect to those not soaked. Increase of conductivity values of swollen membranes has to be related with the entrance of an additional amount of $\mathrm{KOH}$ and water during the swollen process, as it has been confirmed by ATR-FTIR, TGA and XRD measurements.

\subsubsection{Cyclic voltammetry}

In order to confirm the ionic transport into the GPEs, a cyclic voltammetric (CV) study was carried out using a $\mathrm{Zn} / \mathrm{GPE} / \mathrm{Zn}$ symmetric cell. Fig. 6B shows the voltammetric behavior of PVA-KOH 30 and PVA-KOH $30 \mathrm{sw}$ membranes. A huge increase of the current density is observed, which has to be associated with the effect of water and $\mathrm{KOH}$ uptake during the soaking process.

As can be seen, a quasi-reversible behavior is obtained for oxidation/ reduction processes, with a and c peaks charges very closed. Besides, in the cathodic sweep a low anodic peak, b, is observed. This peak has been reported before, and it was assigned to the further oxidation of $\mathrm{Zn}$ after the dissolution of the passive film formed on the $\mathrm{Zn}$ electrode surface, which come off during the cathodic scan [48]. These authors use a convectional three electrode cell, with Pt as counter-electrode, and observed the peak b only in the cathodic branch of the voltammogram. However, we have used a $\mathrm{Zn} / \mathrm{PVA}-\mathrm{KOH} / \mathrm{Zn}$ cell and this is the reason why we found this peak type, $\mathrm{b}$ and $\mathrm{b}$ ', in both voltammetric branches.

Besides, the quasi-reversible behavior of the oxidation/reduction processes is demonstrated in the inset of Fig. 6B, where 50 consecutive cycles of the PVA-KOH soaked membrane are shown, confirming a very steady behavior with the cycling. This result corroborates the usefulness of this membrane type in rechargeable batteries.

CV results together with ionic conductivity and activation energy values confirm that these membranes should be good candidates to be used as gel polymer electrolytes in $\mathrm{Zn}$-based batteries.

\subsection{3. $\mathrm{Zn} / \mathrm{GPE} /$ Air batteries}

Electrochemical performance of $\mathrm{Zn} / \mathrm{PVA}$-KOH/Air batteries has been examined carried out by galvanostatic discharge profiles and polarization curves. With the aim of proving the usefulness of PVA-KOH membranes as polymer electrolytes, we have tested $\mathrm{Zn} / \mathrm{PVA}-\mathrm{KOH} /$ Air batteries at $-5 \mathrm{~mA}$ discharge current, using a $\mathrm{Zn}$ plate as anode. As can be seen in Fig. 6C, non-soaked membrane provides a very low discharge capacity value, $7 \mathrm{mAh}$. However, discharge capacity values increase with the time the membrane was soaked in the $12 \mathrm{M} \mathrm{KOH}$ solution. Discharge capacities of $110 \mathrm{mAh}$ were obtained for a PVA-KOH membrane soaked in $12 \mathrm{M} \mathrm{KOH}$ for $24 \mathrm{~h}$

Besides, a soaked PVA-KOH 30 membrane has been tested in a $\mathrm{Zn} /$ PVA-KOH/Air battery at room temperature, using a $\mathrm{Zn}$ powder anode instead of $\mathrm{Zn}$ plates. Fig. 6D shows the first discharge and charge curves carried out at $-20 \mathrm{mAcm}^{-2}$, where discharge capacities of $\sim 300 \mathrm{mAhg}^{-1}$ were obtained.

Additionally, polarization curves were accomplished from 0 to $100 \mathrm{~mA}$ at $0.1 \mathrm{mAs}-1$ current scan rate (Fig. $6 \mathrm{E}$ and F). Three consecutive scans were canied out after an open circuit voltage (OCV) period. Fig. $6 \mathrm{E}$ shows the repeatability of the potential versus intensity curves, obtained after OCV periods, where the same potential of $0.9 \mathrm{~V}$ at $100 \mathrm{~mA}$ was reaching in the three curves. Fig. $6 \mathrm{~F}$ displays the potential versus time of the complete polarization measurement, where a OCV initial value of $1.43 \mathrm{~V}$ was obtained. As can be seen, after each polarization curve and a OCV period of $16 \mathrm{~min}$ this potential value was reached again, confirming the repeatability of the discharge curves. 

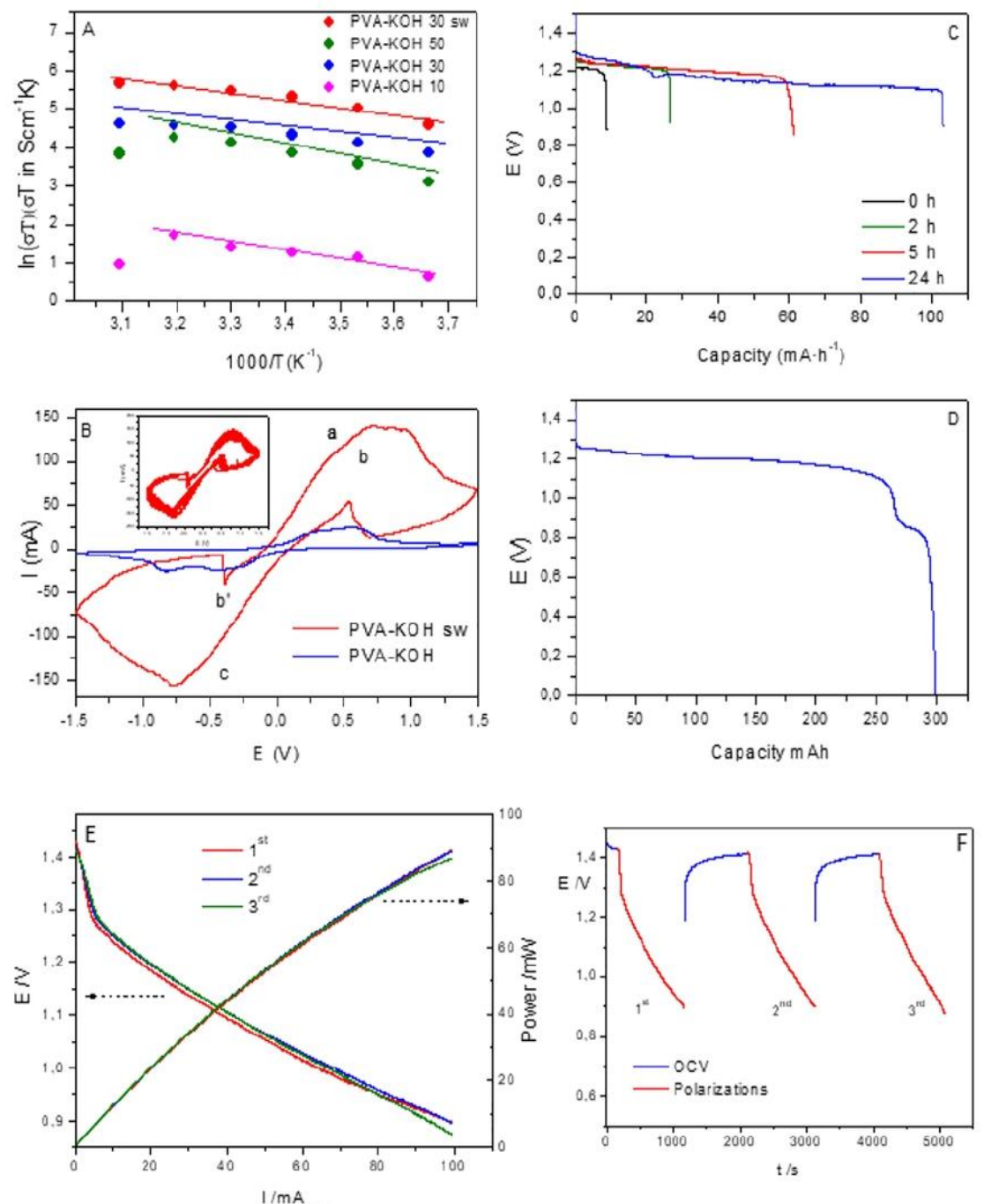

Fig. 6. A) Conductivity values of the PVA-KOH based membranes with the temperature, indicating an Arrhenius behavior. B) Cyclic Voltammograms of PVA-KOH 30 and PVA-KOH 30 swollen membranes. Inset: 50 consecutive cycles of the swollen membrane. C) Discharge curves of Zn/PVA-KOH 30/Air batteries with the immersion time of the PVA-KOH 30 membrane in $12 \mathrm{M} \mathrm{KOH}$ solution, using a $\mathrm{Zn}$ plate as anode. D) Discharge curve of a $\mathrm{Zn} / \mathrm{PVA}-\mathrm{KOH} 30 \mathrm{sw} / \mathrm{Air}$, using Zn powder as anode. In this case, the PVA-KOH membrane was immersed $24 \mathrm{~h}$ in $12 \mathrm{M} \mathrm{KOH}$ solution. E) Polarization curves of a Zn/PVA-KOH 30 sw/Air battery at $0.1 \mathrm{mAs} \mathrm{s}^{-1}$ scan rate. Three consecutive polarization curves were carried out after a OCV period. $\mathrm{F}$ ) in $12 \mathrm{M} \mathrm{KOH}$ solution. E) Polarization curves of a $\mathrm{Zn} / \mathrm{PVA}-\mathrm{KOH} 30 \mathrm{sw} / \mathrm{Air}$ battery at $0.1 \mathrm{mAs}^{-1} \mathrm{scan}$
Potential versus time during the polarization measurements, including $\mathrm{OCV}$ and polarization curves.

Finally, we have confirmed that this kind of membranes can be used in rechargeable batteries. Two membranes used in discharge and discharge/charge processes have been analyzed by XRD (Fig. 7A). As it is shown, only $\mathrm{ZnO}$ is observed after a discharge process and only Zn Metal peaks appeared after a discharge/charge process, confirming that $\mathrm{Zn}$ Metal was oxidized forming $\mathrm{ZnO}$ during discharge and all $\mathrm{Zn}^{2+}$ cations were reduced to obtain again $\mathrm{Zn}$ Metal during the charge process. Note that the XRD analyses shown in Fig. 7 were carried out to PVA-KOH membranes, not to $\mathrm{Zn}$ electrodes. Fig. 7B shows the discharge and charge curves.

\section{3. $\mathrm{OH}^{-}$transport inside the PVA-KOH membranes}

The alkaline PVA-based polymer electrolytes have shown ionic transport properties of anionic exchange membranes (AEM) with negative transport numbers, $\mathrm{t}$, close to 1 . Thus, $\mathrm{C}-\mathrm{C}$ Yang et al. [28] re-

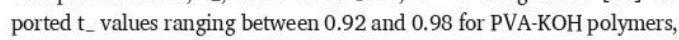
depending on the intensity applied and solution concentration used to carry out the $t_{-}$measurements by Hittorf's method. Besides, when tetraethyl-ammonium-chloride (TEAC) was incorporated to PVA-based membrane, $t$. values of 0.99 were reached.

In this sense, we have obtained similar t_ values following an Evans method [11,17], but we have used two $\mathrm{Zn}$ electrode to obtain the anionic transfer number of PVA-KOH membranes. A $0.99 \mathrm{t}$ _ value was ob- 

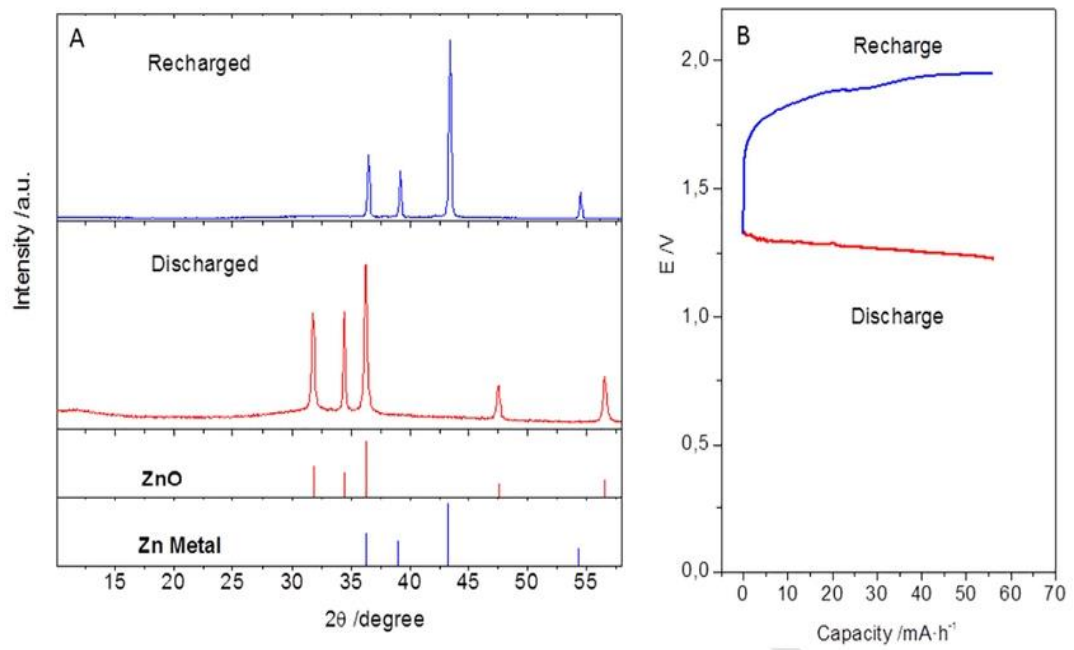

Fig. 7. A) XRD patterns of PVA-KOH membrane used in Zn/PVA-KOH 30 sw/Air batteries after a Discharge and a Discharge/Charge cycle curves of Zn/PVA-KOH 30/Air batteries. Vertical lines show the ICDD database cards of Zn [Card-00-004-0831] (blue) and ZnO [Card-00-036-1451] (red) B) Discharge and Charge curves of a Zn/PVA-KOH 30 sw/Air battery. (For interpretation of the references to colour in this figure legend, the reader is referred to the web version of this article.)

tained for PVA-KOH membranes soaked in KOH $12 \mathrm{M}$ solution, confirming the $\mathrm{OH}^{-}$anions as the only ionic species moving through the membrane.

With the aim to confirm if $\mathrm{Zn}^{2+}$ cations are moved through the membrane, we have carried out additional experimental measures. Fig. 8 shows a SEM image of the cross section of the PVA-KOH 30 membrane used during a discharge in a Zn/PVA-KOH/Air battery. Besides, we have carried out a EDX line profile analysis of $\mathrm{Zn}, \mathrm{K}$, and $\mathrm{O}$ from the membrane sufface that was in contact with $\mathrm{Zn}$ electrode until reaching $3600 \mu \mathrm{m}$ in depth. As can be seen, $\mathrm{O}$ amount is stable all along the membrane. However, $\mathrm{K}$ and $\mathrm{Zn}$ varies with the depth: $\mathrm{K}$ quantity is minimum near the $\mathrm{Zn}$ electrode $(\mathrm{x}=0)$, but at $\mathrm{x}=150 \mu \mathrm{m}$ increase quickly until reaching a stable valor in the electrolyte bulk.
Conversely, $\mathrm{Zn}$ is maximum close to $\mathrm{Zn}$ electrode, between $\mathrm{x}=0$ and $\mathrm{x}=100 \mu \mathrm{m}$, after that it goes down slowly until $\mathrm{x}=500 \mu \mathrm{m}$, where the amount of $\mathrm{Zn}^{2+}$ is zero. It should be noted that $\mathrm{Zn}$ atoms are confined to $0-500 \mu \mathrm{m}$ zone and, beyond that $\mathrm{Zn}$ is not observed. Paying attention to the SEM image, a change of the membrane structure is clearly observed near $500 \mu \mathrm{m}$ (this interface is marked with an orange line in the image). This result confirms that $\mathrm{ZnO}$ is formed close to $\mathrm{Zn}$ electrode surface and $\mathrm{Zn}^{2+}$ cations are not transported to the electrolyte bulk. As it is shown in XRD difractograms carried out on the PVA-KOH side in contact with the $\mathrm{Zn}$ electrode, $\mathrm{ZnO}$ peaks are observed in the PVA-KOH membrane after discharging process, but only Zn Metal peaks appear for the membrane used in a discharge and charge cycle (Fig. 7), confirming that this battery can be recharged.
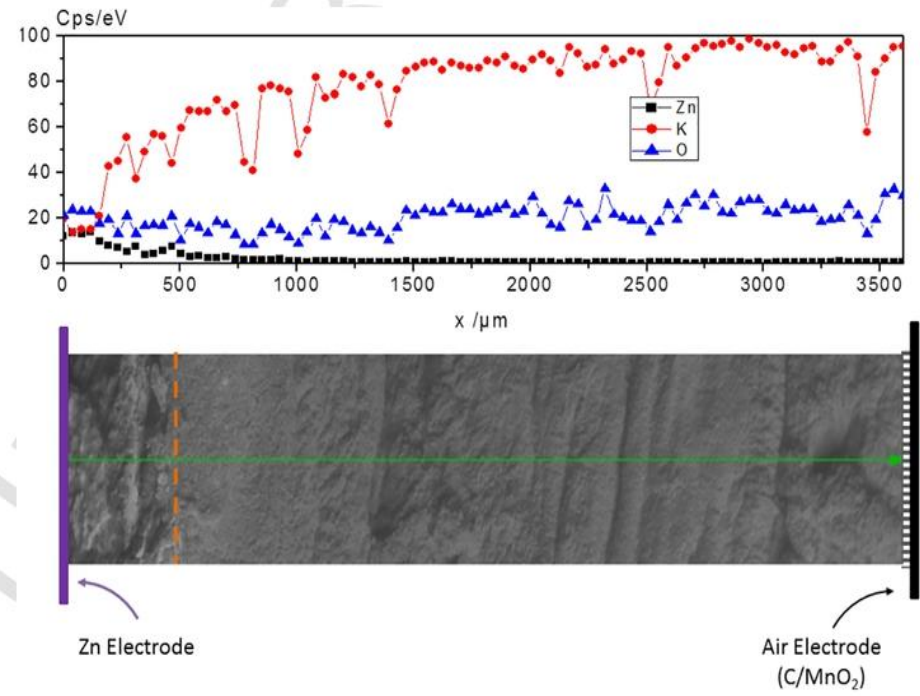

Fig. 8. SEM image and EDX line profile analysis of the cross section of a PVA-KOH 30 sw membrane used during a discharge in a Zn/PVA-KOH/Air battery. Zn, K, and O atoms were analyzed by EDX line profile from the membrane surface that was in contact with $\mathrm{Zn}$ electrode until reaching $3600 \mu \mathrm{m}$ in depth. 
Furthermore, the ionic transport is mainly anionic in our PVA-KOH membranes and thus, we can consider the $\mathrm{OH}^{-}$as the only species contributing to the ionic transport inside the membrane.

Several transport mechanisms have been considered to participate in the $\mathrm{OH}^{-}$transport through a membrane, such as diffusion, migration, convection or the Grotthuss mechanism. Although all of these mechanisms can participate in the $\mathrm{OH}^{-}$transport, several authors assume $\mathrm{OH}^{-}$is transported mainly following the Grotthuss mechanism at higher membrane water contains $[6,21,49]$.

On the other hand, it is known that $\mathrm{OH}^{-}$movement can be impeded by a closed structure of the polymer, as well as a strong interaction between $\mathrm{OH}^{-}$and the polymer chains. It has been reported that $\mathrm{OH}^{-}$transport inside the membrane clearly depends on the amount of water and $\mathrm{KOH}$ concentration included in the membrane and the pore sizes formed in the polymer structure [19-21]. It is reasonable to think that greater pores will make easier the ionic movement, as it has been confirmed be fore. Besides, water amount influences the conductivity process in several ways: 1) A higher water uptake will increase the pore spaces be tween polymer chains and will decrease the strength of interaction of $\mathrm{OH}^{-}$with the polymer chains. 2) Enough quantity of water inside the polymeric matrix is necessary to form an H-bonds network and to build up hydroxyl anions with stable solvation shells. 3) Finally, water mole cules coming in the polymer matrix provide the decreasing of the crystalline phase to the benefit of the amorphous regions, enhancing the conductivity values of PVA-based membranes [6,21].

Regarding the PVA-KOH polymers synthesized in this work, we have observed by XRD measurements that the inclusion of $\mathrm{KOH}$ and water inside the PVA matrix provides an increase of the polymer amor-

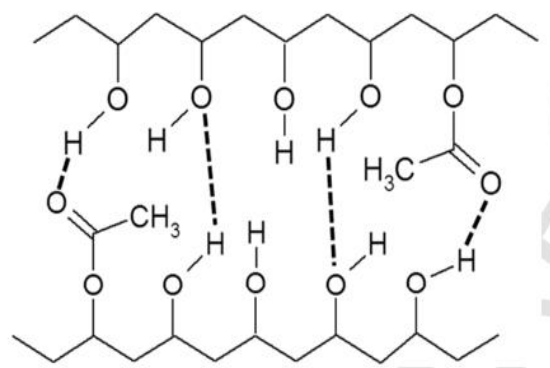

Scheme 1. Structure of a PVA membrane without $\mathrm{KOH}$.

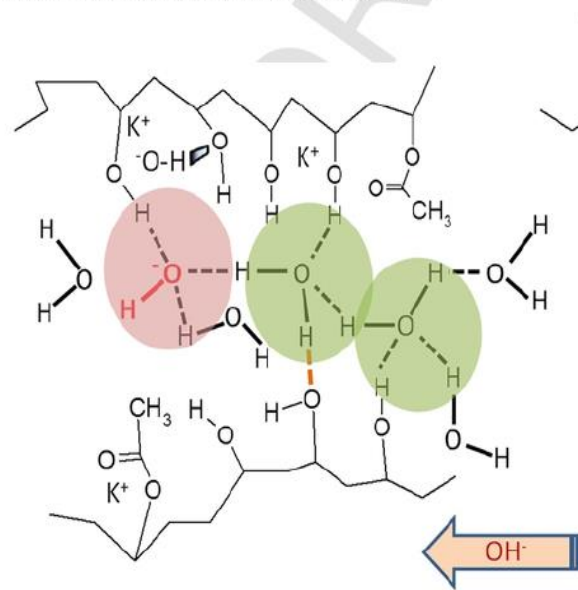

phous regions, which will help to enhance the ionic conductivity. In addition, ATR-FTIR and TG measurements reveal interactions between PVA chains and the $\mathrm{KOH}$ and $\mathrm{H}_{2} \mathrm{O}$ included in the polymer. These interactions are more important when a higher amount of $\mathrm{KOH}$ and $\mathrm{H}_{2} \mathrm{O}$ are incorporated proving that immersion of PVA-KOH films in $\mathrm{KOH} 12 \mathrm{M}$ solution, where additional $\mathrm{KOH}$ and $\mathrm{H}_{2} \mathrm{O}$ are up-taken, provides the more important restructuration of the PVA chains.

Taking into account the above comments and our results, we can propose that the Grotthuss mechanism significantly contributes to or is the central mechanism for hydroxyl anion transport through PVA-KOH canals, though diffusion or migration cannot be completely discarded.

Furthermore, we propose here a tentative mechanism for the $\mathrm{OH}-$ transport inside the PVA-KOH membranes based on the Grotthuss theory.

Scheme 1 represents the PVA structure without $\mathrm{KOH}$ and $\mathrm{H}_{2} \mathrm{O}$. In this case, a great deal of Hydrogen bonds is formed between nearby PVA chains, making this structure very packed, which will prevent the ion movement. Thus, the ionic conductivity value of this polymer will be very low, as it is well known.

Conversely, the presence of $\mathrm{KOH}$ and $\mathrm{H}_{2} \mathrm{O}$ in the PVA-KOH polymers breaks a great number of inter-chain $\mathrm{H}$-bonds, though the modification of $3500 \mathrm{~cm}^{-1}$ reveals that a new $\mathrm{H}$-Bond network is formed, probably including $\mathrm{OH}$ groups of the PVA chains, $\mathrm{OH}^{-}$from the $\mathrm{KOH}$ and $\mathrm{H}_{2} \mathrm{O}$ molecules. This process causes separation of the chains creating wider channels and making easier the movement of the $\mathrm{OH}^{-}$anions. It should be noted that Grotthuss mechanism needs enough amount of $\mathrm{H}_{2} \mathrm{O}$ molecules to form the solvation shell of the $\mathrm{OH}^{-}$anions $[6,21,49]$. In this mechanism, $\mathrm{OH}^{-}$solvated by four $\mathrm{H}_{2} \mathrm{O}$ molecules, $\mathrm{OH}^{-}-\left(\mathrm{H}_{2} \mathrm{O}\right)_{4}$, are considered as inactive $\mathrm{OH}^{-}$anions. They are transformed to active $\mathrm{OH}^{-}-\left(\mathrm{H}_{2} \mathrm{O}\right)_{3}$ solvation state, breaking an $\mathrm{H}$-bond in the first solvation shell. In this state, the $\mathrm{OH}$ hydrogen forms an $\mathrm{H}$-bond with another $\mathrm{H}_{2} \mathrm{O}$ molecule, providing that the initial $\mathrm{OH}^{-}$anion is now changed to an $\mathrm{H}_{2} \mathrm{O}$ molecule tetrahedrally solvated, this is, a water molecule with an ideal bulk solvation pattern [6,21].

Schemes 2 and 3 show the Grotthuss mechanism occurring inside the PVA-KOH and PVA-KOH soaked in KOH $12 \mathrm{M}$, respectively. Both schemes show a similar $\mathrm{OH}^{-}$transport through the PVA canals. However, in Scheme 2 the separation between PVA chains and the amount of $\mathrm{KOH}$ and $\mathrm{H}_{2} \mathrm{O}$ inside the polymeric matrix will be lower than the one observed in Scheme 3. Thus, in non-soaked membranes, Scheme 2, a minor space inter PVA chains will cause that $\mathrm{OH}^{-}$movement will be difficult and, probably the most of $\mathrm{OH}^{-}$anions will create the solvation shell forming $\mathrm{H}$-bonds with $\mathrm{OH}$ groups of the PVA chains and $\mathrm{H}_{2} \mathrm{O}$ molecules. This fact will influence the $\mathrm{OH}^{-}$transport inside the membrane,

Scheme 2. $\mathrm{OH}^{-}$transport following a Grothuss Mechanism in a PVA-KOH 30 membrane. The arrow shows the $\mathrm{OH}^{-}$transport direction. During the $\mathrm{OH}^{-}$transport, a $\mathrm{H}-$ bond (pink) is broken and a new $\mathrm{H}$-bond (orange) is formed. 

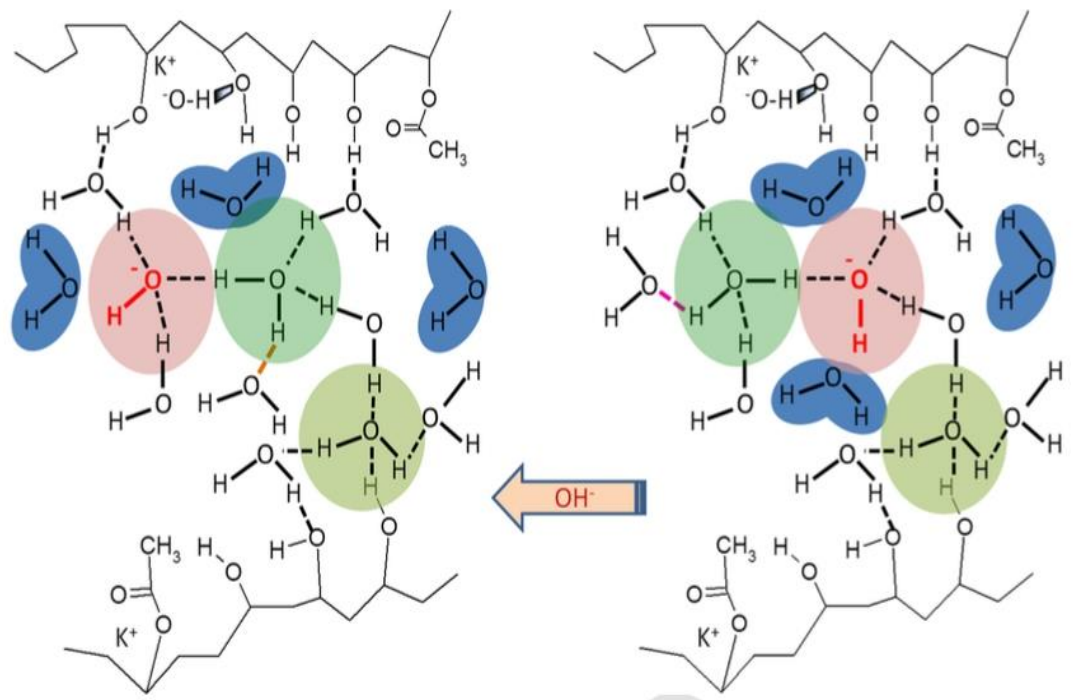

Scheme 3. $\mathrm{OH}^{-}$transport following a Grothuss Mechanism in a PVA-KOH 30 swollen membrane. The arrow shows the $\mathrm{OH}^{-}$transport direction. During the $\mathrm{OH}^{-}$transport, a H-bond (pink) is broken and a new H-bond (orange) is formed.

reducing the $\mathrm{OH}^{-}$transport number and the ionic conductivity value with respect to soaked PVA-KOH membranes.

However, PVA-KOH membranes soaked in $\mathrm{KOH} 12 \mathrm{M}$ solution, where a great deal of $\mathrm{KOH}$ and $\mathrm{H}_{2} \mathrm{O}$ molecules were up-taken, will present a structure with a higher inter-chain space (Scheme 3 ). In this case, a higher number of $\mathrm{OH}^{-}$anions will be able to develop complete solvation shells only with $\mathrm{H}_{2} \mathrm{O}$ molecules without forming some $\mathrm{H}$-bond with PVA OH groups. This situation will allow a faster transport of the $\mathrm{OH}^{-}$anions through the polymeric canals. Furthermore, in this situation, higher ionic conductivity and anionic transport number values will be obtained, as it has been demonstrated by our results.

\section{Conclusions}

Different pure PVA and PVA-KOH membranes have been obtained by a solution cast method and they have been analyzed by several experimental techniques and applied as a polymer electrolyte in $\mathrm{Zn} /$ PVA-KOH/Air batteries. XRD, ATR-FTIR and TGA techniques have confirmed the restructuration of the PVA chains when $\mathrm{KOH}$ aqueous solution was included in the membrane. Besides, when these membranes are swollen in $12 \mathrm{M} \mathrm{KOH}$ aqueous solution a higher quantity of $\mathrm{KOH}$ and $\mathrm{H}_{2} \mathrm{O}$ molecules are incorporated into the membrane, enhancing the polymer structure changes.

Soaking the KOH-PVA membranes in $12 \mathrm{M} \mathrm{KOH}$ aqueous solution improves the ionic transport properties: ionic conductivity of 0.34 $\mathrm{Scm}^{-1}$ and energy activation of $0.16 \mathrm{eV}$ at room temperature were obtained. Besides, an increment of peak intensities of the voltammograms and larger capacity values in Zn/PVA-KOH/Air batteries resulted.

The improvement of this ionic transport behavior has been explained in the basis of the increase of the PVA inter-chains canals, a higher degree of amorphosity in the host polymer and the formation of a H-bond network, all of that motivated by the rise of $\mathrm{KOH}$ and $\mathrm{H}_{2} \mathrm{O}$ inside the membranes. Finally, transport number of $\mathrm{OH}^{-}$anions and the confinement of $\mathrm{Zn}^{2+}$ close to $\mathrm{Zn}$ electrode surface make necessary the $\mathrm{OH}^{-}$anions transport through the membrane as the only ionic species causing conductivity, which may be explained by a Grotthuss mechanism.

\section{Acknowledgements}

The authors thank the financial support from Spanish Ministerio de Economía y Competitividad and AEI/FEDER/UE (Spain, Refs. ENE2016-79282-C5-5-R) and Fundación Séneca (Región de Murcia, Spain; Ref: 20985/PI/18).

\section{References}

[1] B. Scrosati, Applications of Electroactive Polymers, 3rd ed.Chapman and Hall, London, 1993

[2] A.M. Stephan, Review on gel polymer electrolytes for lithium batteries, Eur. Polym. J. 42 (2006) 21-42, https://doi.org/10.1016/j.eurpolymj.2005.09.017. [3] N.A. Choudhury, S. Sampath, A.K. Shukla, Hydrogel-polymer electrolytes for elec-
trochemical capacitors: an overview, Energy Environ. Sci. 2 (2009) 55-67, https:// trochemical capacitors: an ov
doi.org/10.1039/B811217G.

[4] H. Inoue, in: G. Kreysa, K. Ota, R.F. Savinell (Eds.), Hydrogel Electrolyte. In Encyclopedia of Applied Electrochemistry, Springer NY, 2014, pp. 1035-1039, https:// doi.org/10.1007/978-1-4419-6996-5_515.

[5] J. Fu, J. Qiao, H. Lv, J. Ma, X.-Z. Yuan, H. Wang, Alkali doped poly (vinyl alcohol) (PVA) for anion-exchange membrane fuel cells-ionic conductivity, chemical stability and FT-IR characterizations, ECS Trans. 25 (2010) 15-23, https://doi.org/10. $1149 / 1.3315169$

[6] G. Merle, M. Wessling, K. Nijmeijer, Anion exchange membranes for alkaline fue cells: a review, J. Membr. Sci. 377 (2011) 1-35, https://doi.org/10.1016/j. memsci. 2011.04.043.

[7] Z.S. Mahmud, N.H.M. Zaki, R.H.Y. Subban, A.M.M. Ali, M.Z.A. Yahya, MG49-KOH-PC alkaline gel polymer electrolytes membrane for supercapacitors, IEEE Colloquium on Humanities, Science and Engineering (CHUSER), Kota Kinabalu 2012 (2012) 621-626, https://doi.org/10.1109/CHUSER.2012.6504387.

[8] B. Li, X. Lu, J. Yuan, Y. Zhu, L. Li, Alkaline poly (vinyl alcohol)/poly (acrylic acid) polymer electrolyte membrane for Ni-MH battery application, Ionics 21 (2014) 141-148, https://doi.org/10.1007/s11581-014-1145-9.

[9] C.C. Yang, S.J. Lin, Preparation of composite alkaline polymer electrolyte, Mater C.C. Yang, S.J. Lin, Preparation of composite alkaline polymer electrolyte, $M$

[10] P.B. Bhargav, V.M. Mohan, A.K. Sharma, V.V.R.N. Rao, Structural and electrical properties of pure and $\mathrm{NaBr}$ doped poly (vinyl alcohol) (PVA) polymer electrolyte properties of pure and $\mathrm{NaBr}$ doped poly (vinyl alcohol) (PVA) polymer electrolyte
films for solid state battery applications, Ionics 13 (2007) 441-446, https://doi. films for solid state battery applica
org/10.1007/s1 1581-007-0130-y.

[11] J.P.T. Guisao, A.J. Fernández Romero, Interaction between $\mathrm{Zn} 2+$ cations and $\mathrm{N}$-methyl-2-pyrrolidone in ionic liquid-based gel polymer electrolytes for $\mathrm{Zn}$ batteries, Electrochim. Acta 176 (2015) 1447-1453, https://doi.org/10.1016/j.electacta. 2015.07.132

[12] B. Scrosati, C.A. Vincent, Polymer electrolytes: the key to lithium polymer batteries, MRS Bull. 25 (2000) 28-30, https://doi.org/10.1557/mrs2000.15. 
[13] S.-H. Wang, P.-L. Kuo, C.-T. Hsieh, H. Teng, Design of poly (acrylonitrile)-based gel electrolytes for high-performance lithium ion batteries, ACS Appl. Mater. Interfaces 6 (2014) 19360-19370, https://doi.org/10.1021/am505448a.

[14] W. Li, Y. Pang, J. Liu, G. Liu, Y. Wang, Y. Xia, A PEO-based gel polymer electrolyte for lithium ion batteries, RSC Adv. 7 (2017) 23494-23501, https://doi.org/10. 1039/C7RA02603J.

[15] J.P. Tafur, A.J. Fernández Romero, Electrical and spectroscopic characterization of PVdF-HFP and TFSI-ionic liquids-based gel polymer electrolyte membranes. Influence of ZnTf2 salt, J. Membr. Sci. 469 (2014) 499-506, https://doi.org/10.1016/ j. memsci.2014.07.007.

[16] J. Abad, F. Santos, J.P. Tafur, A. Urbina, E. Román, J.F. González-Martínez, J. Rubio-Zuazo, G.R. Castro, A.J. Fermández Romero, A synchrotron X-ray diffraction and hard X-ray photoelectron spectroscopy study of Zn negative electrodes at different charge and discharge states of $\mathrm{Zn} / \mathrm{MnO} 2$ batteries using an ionic liquid-based gel polymer electrolyte, J. Power Sources 363 (2017) 199-208, https:// doi.org/10.1016/j.jpowsour. 2017.07.082

[17] J.P. Tafur, F. Santos, A.J. Fernández Romero, Influence of the ionic liquid type on the gel polymer electrolytes properties, Membranes 5 (2015) 752-771, https://doi org $/ 10.3390 /$ membranes 5040752

[18] T.-Y. Wu, W.-B. Li, C.-W. Kuo, C.-F. Chou, J.-W. Liao, H.-R. Chen, C.-G. Tseng, Study of poly (methyl methacrylate)-based gel electrolyte for electrochromic device, Int. J. Electrochem. Sci. 8 (2013) 10720-10732

[19] J.P. Tafur, J. Abad, E. Román, A.J. Fernández Romero, Charge storage mechanisn of $\mathrm{MnO}_{2}$ cathodes in $\mathrm{Zn} / \mathrm{MnO}_{2}$ batteries using ionic liquid-based gel polymer electrolytes, Electrochem. Commun. 60 (2015) 190-194, https://doi.org/10.1016/j. elecom. 2015.09.011

[20] A. Lewandowski, K. Skorupska, J. Malinska, Novel poly (vinyl alcohol)-KOH-H2O alkaline polymer electrolyte, Solid State Ionics 133 (2000) 265-271, https://doi. org/10.1016/S0167-2738(00)00733-5.

[21] K.N. Grew, W.K.S. Chiu, A dusty fluid model for predicting hydroxyl anion conductivity in alkaline anion exchange membranes, J. Electrochem. Soc. 157 (2010) B327-B337, https://doi. org/10.1149/1.3273200

[22] W.H. Philipp, L.C. Hsu, Three Methods for In Situ Cross-Linking of PolyvinylAlcohol Films for Application as Ion-Conducting Membranes in Potassium Hydroxide Electrolyte. NASA Tech. Pap., No. 1407, 1979 .

[23] K.C.S. Figueiredo, T.L.M. Alves, C.P. Borges, Poly (vinyl alcohol) films crosslinked by glutaraldehyde under mild conditions, J. Appl. Polym. Sci. 111 (2009) by glutaraldehyde under mild conditions, J. App/.

[24] A.K. Sonker, K. Rathore, R.K. Nagarale, V. Verma, Crosslinking of polyvinyl alcohol (PVA) and effect of crosslinker shape (aliphatic and aromatic) thereof, $J$. Polym. Environ. 26 (2018) 1782-1794, https://doi.org/10.1007/s10924-0171077-3.

[25] X. Liu, Q. Chen, L. Lv, X. Feng, X. Meng, Preparation of transparent PVA/TiO2 nanocomposite films with enhanced visible-light photocatalytic activity, Catal Commun. 58 (2015) 30-33, https://doi.org/10.1016/j.catcom.2014.08.032

[26] S. Sugumaran, C.S. Bellan, M. Nadimuthu, Characterization of composite PVA-Al2O3 thin films prepared by dip coating method. Iran, Polym. J. 24 (2015) 63-74, https://doi.org/10.1007/s13726-014-0300-5.

[27] G. Merle, S.S. Hosseiny, M. Wessling, K. Nijmeijer, New cross-linked PVA based polymer electrolyte membranes for alkaline fuel cells, J. Membr. Sci. $409-410$ (2012) 191-199, https://doi.org/10.1016/j.memsci.2012.03.056.

[28] C.C. Yang, S.J. Lin, G.M. Wu, Study of ionic transport properties of alkaline poly (vinyl) alcohol-based polymer electrolytes, Mater. Chem. Phys. 92 (2005) 251-255, https://doi.org/10.1016/j.matchemphys.2005.01.022.

[29] Y. Li, H. Dai, Recent advances in zinc-air batteries, Chem. Soc. Rev. 43 (2014) 5257-5275, https://doi.org/10.1039/C4CS00015C.

[30] A.A. Mohamad, N.S. Mohamed, M.Z.A. Yahya, R. Othman, S. Ramesh, Y. Alias, A. Arof, Ionic conductivity studies of poly (vinyl alcohol) alkaline solid polymer elec trolyte and its use in nickel-zinc cells, Solid State Ionics 156 (2003) 171-177, https://doi.org/10.1016/S0167-2738(02)00617-3.
[31] C.C. Yang, Chemical composition and XRD analyses for alkaline composite PVA polymer electrolyte, Mater. Lett. 58 (2004) 33-38, https://doi.org/10.1016/ S0167-577X(03)00409-9.

[32] C.C. Yang, Study of alkaline nanocomposite polymer electrolytes based on PVA-ZrO2-KOH, Mater. Sci. Eng., B 131 (2006) 256-262, https://doi.org/10.1016/ j.mseb.2006.04.036

[33] P. Louette, F. Bodino, J.J. Pireaux, Poly (vinyl alcohol) (PVA) XPS reference core level and energy loss spectra, Surf. Sci. Spectra 12 (2005) 106, https://doi.org/10. $1116 / 11.20050922$

[34] S. Akhter, K. Allan, D. Buchanan, J.A. Cook, A. Campion and J.M. White, XPS and IR study of X-ray induced degradation of PVA polymer film, Appl. Surf. Sci.. 35 (1988-89) 241-258. doi.https://doi.org/10.1016/0169-4332(88)90053-0.

[35] D.T. Clark, B.J. Cromarty, A. Dilks, A theoretical investigation of molecular core binding and relaxation energies in a series of oxygen-containing organic molecule of interest in the study of surface oxidation of polymers, J. Poly

[36] P. Stoyanov, S. Akhtert, J.M. White, XPS study of metal/polymer interaction evaP. Stoyanov, S. Akhtert, J.M. White, XPS study of metal/polymer interaction eva-
porated aluminum on polyvinyl alcohol polymer, Surf. Interface Anal. 15 (1990) porated aluminum on polyvinyl alcohol polymer, $S$
$509-515$, https://doi.org $/ 10.1002 /$ sia.740150903.

[37] J.W. Gilman, D.L. Vanderhart, T. Kashiwagi, Thermal decomposition chemistry of poly (vinyl alcohol), Fire Polym. II Mater. Test Hazard Prev. 599 (1995) 161-185, https://doi.org/10.1021/bk-1995-0599.ch011.

[38] I. Restrepo, C. Medina, V. Meruane, A. Akbari-Fakhrabadi, P. Flores, S. Rodriguez-Llamazares, The effect of molecular weight and hydrolysis degree of poly (vinyl alcohol)(PVA) on the thermal and mechanical properties of poly (lactic acid)/PVA blends, Polimeros 28 (2018) 169-177, https://doi.org/10.1590/01041428.03117.

[39] R. Zelkó, G. Szakonyi, The effect of water on the solid state characteristics of pharmaceutical excipients: molecular mechanisms, measurement techniques, and quaity aspects of final dosage form, Int. J. Pharm. Investig. 2 (2012) 18, https://doi. org/10.4103/2230-973X.96922

[40] C.A. Strydom, A.C. Collins, J.R. Bunt, The influence of various potassium compound additions on the plasticity of a high-swelling south African coal under pyrolyzing conditions, J. Anal. Appl. Pyrolysis 112 (2015) 221-229, https://doi.org/ 10.1016/j.jaap.2015.01.023

[41] J.E. Mark, Physical Properties of Polymers Handbook, Springer-Verlag Ed, New York, 2007, (https://doi.org/10.107/978-0-387-59002-5).

[42] Clariant GmbH. Mowiol Polyvinyl Alcohol, 1999.

[43] V.C. Costa, H.S. Costa, W.L. Vasconcelos, M.D.M. Pereira, R.L. Oréfice, H.S. Mansur, Preparation of hybrid biomaterials for bone tissue engineering, Mater

[44] R.F. Bhajantri, V. Ravindrachary, A. Harisha, V. Crasta, S.P. Nayak, B. Poojary, Microstructural studies on BaCl2 doped poly (vinyl alcohol), Polymer 47 (2006) crostructural studies on BaCl2 doped poly (vinyl alcohol), Poly

[45] B.M. Baraker, B. Lobo, Spectroscopic analysis of CdCl2 doped PVA-PVP blend films, Can. J. Phys. 95 (2017) 738-747, https://doi.org/10.1139/cjp-2016-0848.

[46] J. Qiao, J. Fu, R. Lin, J. Ma, J. Liu, Alkaline solid polymer electrolyte membrane based on structurally modified PVA/PVP with improved alkali stability, Polymer 51 (2010) 4850-4859, https://doi.org/10.1016/j.polymer.2010.08.018.

[47] M. Reichenbächer, J. Popp, Challenges in Molecular Structure Determination. V1brational Spectroscopy, Springer, Ed, 2012108, https://doi.org/10.1007/978-3642-24390-5.

[48] M. Cai, S.-M. Park, Spectroelectrochemical studies on dissolution and passivation of zinc electrodes in alkaline solutions, J. Electrochem. Soc. 143 (1996) 2125-2131.

[49] M.E. Tuckerman, D. Marx, M. Parinello, The nature and transport mechanism of hydrated hydroxide ions in aqueous solution, Nature 417 (2002) 925-929, https:// doi.org/10.1038/nature00797. 